La educación musical en el franquismo 



\section{CAPÍTULO 1. INTRODUCCIÓN}

\subsection{PRESENTACIÓN DEL TEMA}

Cuando se pregunta a la gente de mi generación sobre sus impresiones y recuerdos de la educación musical que recibieron siendo niños, la mayor parte de la gente responde afirmando que "sencillamente no recibieron educación musical de ningún tipo".

Esta afirmación tan rotunda y negativa me llevó a preguntarme e interesarme por las que de verdad han sido las circunstancias que rodearon a la educación musical entre los años 1940 y 1975 . Porque sin ninguna duda hoy somos los herederos directos de aquella generación, porque nuestra consideración general hacia el hecho musical desde el punto de vista social y educativo están estrechamente ligados a la formación que en su día recibimos, y porque las secuelas y las aportaciones de aquellos años condicionan la forma de ver la educación musical por parte de los que hoy son los dirigentes desde las estructuras de poder educativo (consejerías de educación de las diferentes comunidades autónomas, ministerio de educación ...)

El objetivo de esta tesis es profundizar en el conocimiento de los condicionantes históricos, en la formación recibida, la organización de la información musical, la formación del profesorado que iba a impartir los conocimientos, los procesos de cambio en los planes de estudio y la introducción de los métodos pedagógicos utilizados.

Pero, por encima de todo, deseo ser capaz de echar un vistazo atrás a la historia más reciente para comprender el porqué de la situación actual de la educación musical en España. No pretende ser sólo una visión historicista de cómo fueron las cosas en el pasado, sino analizar las causas y consecuencias para poder aplicar algunas de las conclusiones en la educación musical que queremos para el momento presente y también para el futuro. 


\section{La educación musical en el franquismo}

La educación musical es una de las materias que más han cambiado en el planteamiento del currículo en los últimos 50 años. Y esta tesis pretende analizar y ayudarnos a comprender mejor el cómo y el porqué de este cambio.

La música como forma de expresión artística es una necesidad social de primer orden que se produce de forma instintiva en todas las culturas humanas. Simplemente, desde que fuimos capaces de emitir sonidos, fuimos capaces de hacer música. Hoy en día incluso, se plantea cada vez con más interés la pregunta de si los animales realizan música con finalidades no sólo informativocomunicativas (el sonido como hecho puramente lingüístico), sino con una intencionalidad estética de disfrute ${ }^{1}$.

La forma en la que percibimos la belleza, la intencionalidad artística, la necesidad de expresión del individuo y de comunicar los sentimientos individuales de forma comprensiva al resto de la sociedad son la base del lenguaje artístico.

Pero, igualmente, las sociedades condicionan las formas de expresión adecuadas en cada momento y dan prioridad a determinados aspectos en detrimento de otros a la hora de transmitir las formas de expresión.

Es decir, que la música y la forma de enseñarla están condicionadas por ambos elementos, el individual y el colectivo, ya que como todo lenguaje incorpora la capacidad creativa e innovadora del individuo, pero necesita al mismo tiempo de la expansión y conocimiento del código lingüístico para poder ser comprendido por los demás.

En una época tan ideologizada como fue el franquismo

"la concepción que los individuos y, en su caso, las instituciones, poseen acerca de las
finalidades y las misiones que la educación puede o debe cumplir en el seno de la
sociedad, están latentes en todo el hecho educativo, y tienen una trascendencia
cardinal, por cuanto interpretan absolutamente todo el proceso, condicionándolo y
determinándolo en toda su expresión, al tiempo que, subsidiariamente, implican la

${ }^{1}$ PUNSET, J osep María. “¿Por qué cantan los pájaros”, en Redes. TVE 
difusión de diferentes modelos de sociedad, de individuo y de identidad personal y cultural" ${ }^{2}$.

No es casualidad que toda una generación perciba que no ha recibido educación musical como tal, cuando sin embargo hay constancia de

"todo un proceso de adoctrinamiento conscientemente premeditado y explícito al servicio de un proyecto ideológico" ${ }^{3}$.

El aprendizaje imitativo, la conformación del repertorio homogeneizado, la falta de profundidad en los conocimientos y en los procedimientos analíticos que permitan la configuración de ideas personales y propias, conllevan a posteriori el rechazo o el abandono de los aprendizajes que hoy calificaríamos de "no significativos" para el alumnado.

Pero aún más, la desconexión con respecto al aprendizaje del lenguaje musical, es desde mi punto de vista el elemento que más condiciona la calificación negativa con respecto a la educación musical. Al no haberse producido la iniciación al lenguaje musical (más tarde veremos algunas de las causas históricas que han producido este desfase) hay una profunda incomprensión de los elementos que ya en la época eran percibidos como una auténtica educación musical: ser capaces de leer una partitura o de transcribir la producción propia.

A ello se añade una rémora histórica en el aprendizaje de la música en este país: la diferenciación entre la música profesional y la educación musical para todos, como muy sabiamente planteaba Federico Sopeña ${ }^{4}$ :

"es necesario diferenciar en dos diversas formas de enseñanza que "socialmente" importan, porque de la primera, del profesional de la música, depende una gran parte

\footnotetext{
${ }^{2}$ HERRERO SUAREZ, Henar. (2002) Educación no formal y adoctrinamiento infantil en la "España Azul". Flechas y Pelayos (1938-45). Tesis doctoral no publicada leída en la Universidad de Valladolid. Vol. I, pag 22.

${ }^{3}$ IBÁÑEZ MARTíN, J. (1981) Introducción al concepto de adoctrinamiento. En Revista Española de pedagogía, no 153, pag. 90-97

${ }^{4}$ SOPEÑA, Federico. (1964). Las dos enseñanzas de la música. En Páginas de la revista de educación, no 39
} 


\section{La educación musical en el franquismo}

del espectáculo, y hoy ya puede hablarse de "política del espectáculo"- casi ministerio en algunas partes- con su importancia social y, además, con todo un aparejo administrativo donde el música tiene todavía más palabra que puesto; de la otra enseñanza depende algo que es distinto y mayor que el "adorno", pues por una parte , puede formar una minoría importante de aficionados y, más al fondo, un capítulo esencial en el refinamiento de la sensibilidad."

Es muy significativo de la percepción social de la educación musical - que aun siendo Sopeña quien habla y que ya estamos a bien mediados el franquismo todavía se refiera a la educación musical para todos como "clases de adorno", aunque más adelante se va a referir a la enseñanza en el sistema educativo general de la escuela primaria y el bachillerato.

Y es que, ni siquiera en la actualidad tenemos claro todavía la separación y diferenciación de objetivos que queremos perseguir y - a pesar de que la ley de conservatorios actual es muy clara en cuanto a sus intenciones de profesionalización - los resultados reales no se ajustan a los principios establecidos.

Aún hay mucha confusión hoy en día sobre los objetivos del lenguaje musical en la escuela (por ejemplo: lectura melódica en clave de sol y en todo caso introducción a los bajos armónicos en clave de fa en educación secundaria) y los del conservatorio (en el mismo caso: lectura en todas las claves con el objeto de realizar transporte a primera vista, lectura de partitura orquestal con instrumentos transpositores), todo ello confundido con la antigua denominación de "solfeo" que abarcaba otros muchos aspectos (entonación, fraseo, capacidad tonal, modal y atonal, etc...).

Otra de las grandes cuestiones que llama la atención es la homogeneidad del repertorio y la conformación del "cancionero" aprendido por toda una generación. Y ese cancionero, o al menos una parte de él, sigue siendo lo que consideramos el bloque de canciones infantiles tradicionales. No importa de qué parte de España provengamos, hay todo un bloque común de tipo folklórico que reconoce nuestra generación, sin saber de dónde ni cómo nos ha llegado, 
pero evidentemente no puede estar condicionado por la regionalidad de nuestros ancestros, sino que es común a todo el territorio. No obstante lo percibimos como tradicional, y es lógico pues nos ha llegado a través de transmisión oral, pero ha sido manipulado para conformar una percepción ideológica del estado.

La conformación de un cancionero ideológico no sólo se refiere pues a los ejemplos más claros y extremos: los himnos, sino que se extiende también a la fórmula para percibir el estado como una entidad única capaz de integrar de forma bastante equitativa a todas las zonas del estado, incluyendo - aunque en pequeñas cantidades - las peculiaridades lingüísticas zonales y regionales (algunas de las cuales hoy consideramos idiomas: catalán, gallego, vasco, pero también otros como el bable).

El adoctrinamiento implica además la consciencia y la intencionalidad en la aplicación de esta selección de repertorio para ofrecer una imagen del país, fomentar los sentimientos patrióticos y religiosos, intentar recuperar y mantener la tradición y la identidad nacional (hoy hablaríamos en el mismo sentido de las identidades nacionales). Y ello ligado a las edades más tempranas de formación y a la exaltación de determinados valores, todo ello asociado a la aceptación social en el grupo y bajo una capa de "diversión" como era el caso de los campamentos.

Hay también una singular diferenciación en la forma de tratar la educación musical desde el punto de vista del género ${ }^{5}$, ya desde el planteamiento de los objetivos educativos, pasando por la selección de diferentes repertorios y en general a la concepción general de por qué y para qué se desea inculcar una educación diferente a los hombres y a las mujeres.

Este hecho llevó a desarrollar en la Sección Femenina una auténtica sección dedicada a la música, a su enseñanza, a la publicación y difusión de melodías, a la selección de repertorios. Su labor es enorme, aunque no deja de estar

\footnotetext{
${ }^{5}$ LABAJ O, J. (1998) La educación musical de la sección femenina. En MANCHADO, M Música y mujeres: género y poder. Madrid: Horas y horas
} 


\section{La educación musical en el franquismo}

condicionada tanto por los elementos ideológicos que la caracterizan como grupo de transmisión ideológica de la Falange, sino además cambiante, fiel reflejo de las transformaciones que va sufriendo la sociedad española y sobre todo el cambio legislativo educativo que supone la introducción de la reforma de Villar Palasí. Por eso, una gran parte de los documentos de este trabajo se refieren a documentos analizados en el Archivo General de la Administración correspondientes a la regiduría de música de la Sección Femenina.

Pero a diferencia de otros estudios, éste no pretende centrarse únicamente en la Sección Femenina, sino abarcar en su conjunto la educación musical no profesionalizada, incluyendo también el trabajo - mucho más de adoctrinamiento que de enseñanza - del Frente de Juventudes. Este tratamiento completo es vital para comprender por qué en nuestro país la "música es aún un asunto de mujeres", y la creencia absolutamente trasnochada (pero muy real a la hora de encontrar tenores y bajos en los coros, o simplemente comprobar estadísticamente la proporción de colaboración en actividades culturales de la población) de que la necesidad y conveniencia de cultivarse culturalmente sea más propia de un sexo que de otro. La educación franquista partía de esta idea, formó a una generación entera en ella y aún hoy, especialmente en los ambientes rurales o alejados de los núcleos grandes de población y con mayor oferta cultural, es una palpable realidad.

El análisis de la educación musical no profesionalizada en su conjunto es capaz de aportar algunos datos esclarecedores del comportamiento cultural de la sociedad actual y ése es el auténtico centro de interés al realizar este trabajo más desde un punto de vista analítico que descriptivo, más desde un punto de vista crítico que meramente historicista.

Este trabajo pretende, pues, encontrar y debatir las razones por las que, a diferencia de otros países, somos un país realmente retrasado musicalmente, poco consumidor de música de cualquier tipo (como muy bien saben en las casas discográficas, los distribuidores comerciales y los organizadores de conciertos tanto de música culta como de tipo popular). 


\section{Capítulo 1. Introducción}

Debemos ser capaces de recapacitar y crear una sociedad en la que los individuos puedan expresarse libre, individual y colectivamente, sin necesidad de maestros ni directores que seleccionen el repertorio, donde ser músico sea una profesión respetada e igual a cualquier otra y donde los gustos personales no estén condicionados por una escasa oferta comercial, sino que todos puedan tener acceso a cualquier tipo de música, libres de juicios de valor.

La música no es un instrumento de aprendizaje solamente (claro que nos sirve para aprender idiomas, matemáticas e incluso las ideas que nos quieran vender), sino una materia que nos enseña a expresarnos por nosotros mismos, como el lenguaje que es.

Y para ello necesitamos conocer en profundidad cómo ha sido en el pasado, porque nuestras ideas colectivas aún están muy ligadas a la forma en que fue transmitida en la época franquista. Necesitamos conocer y reflexionar para cambiar, porque si no, la educación musical que hacemos en el presente seguirá sin cambiar lo fundamental: la actitud que tenemos como sociedad ante el hecho musical y la comprensión de por qué es necesario y enriquecedor aprenderlo.

\subsection{FUENTES}

He trabajado con fuentes muy diversas, que he ido recopilando a lo largo del período de investigación.

\subsubsection{Legislativas}

Por una parte, el trabajo se inicia a partir de la consulta de los textos legales correspondientes al sistema educativo y a la presencia de la música en los mismos. En este sentido las fuentes provienen principalmente de dos archivos:

\section{BIBLIOTECA DEL MINISTERIO DE EDUCACIÓN Y CIENCIA}

Es uno de los primeros archivos consultados. Sus fondos, especialmente sobre temas legislativos de tipo educativo, han sido fundamentales para la elaboración de este trabajo de investigación, ya que además de los Boletines 


\section{La educación musical en el franquismo}

del Estado, se pueden consultar los Boletines del Ministerio de Educación y Ciencia en los que aparecen normativas de rango menor.

BIBLIOTECA PÚBLICA DE LA FACULTAD DE DERECHO DE LA UNIVERSIDAD DE VALLADOLID

Debido a la cercanía y accesibilidad, una gran parte de los documentos legislativos fueron consultados en sus fondos de Boletines Oficiales del Estado y el Aranzadi como colección legislativa.

LA TESIS DOCTORAL La música en España durante el franquismo a través de la legislación (1936-1951) de Gemma Zalduondo ${ }^{6}$ ha sido un documento imprescindible para la consecución de los datos y documentos legislativos hasta 1951 relativos a esta investigación.

\subsubsection{Documentales}

Una vez conocida la estructura del sistema educativo general, una gran parte de la documentación en la que sustenta sus tesis este trabajo provienen de otras dos fuentes directas: la documentación de Sección Femenina y de Frente de Juventudes

\section{EL ARCHIVO GENERAL DE LA ADMINISTRACIÓN}

En Alcalá de Henares. Es realmente de donde proviene la mayor parte de la documentación propiamente referida al Frente de Juventudes y a la Sección de Música de la Sección Femenina.

En este archivo se guardan hoy en día una gran cantidad de las cajas de documentos de las delegaciones nacionales de ambas entidades. En su mayor parte se encuentran tal como fueron traídas de ambas sedes, por lo que se observa una cierta ordenación en las de Sección Femenina bastante más cuidada que en los documentos referidos a Frente de Juventudes - donde prácticamente la única clasificación interior corresponde a la datación anual de los mismos, sin subsecciones departamentales - lo que dificultó y retrasó notablemente su lectura.

\footnotetext{
${ }^{6}$ Pérez Zalduondo, G (2002) La música en España durante el franquismo a través de la legislación (1936-1951) Universidad de Granada
} 
Así, mientras los documentos de la Sección Femenina consultados estaban en cajas que explicitaban que pertenecían a la consejería de Música e incluso detallaban por bloques los contenidos (cajas de la Escuela Nacional de música, cajas de la sección de Folklore, cajas de la revista Consigna, los documentos relativos al Frente de Juventudes estaban totalmente mezclados, de tal forma que para leer cualquier referente a música había que leer la caja entera sobre campamentos, actividades deportivas, visitas políticas e institucionales y todo tipo de documentación irrelevante para este estudio, hasta encontrar algún documento que hiciera referencia a la educación musical. No obstante, de la lectura de ambos se puede colegir el diferente estilo con el que trabajaban ambas entidades, de qué forma colaboraban para realizar determinadas actividades, así como las diferencia de tratamiento que unas y otros daban al hecho musical, y ello en sí mismo es uno de los estudios relevantes de este trabajo.

Los fondos consultados han sido los siguientes

\begin{tabular}{|c|c|c|}
\hline 51.10 & Cajas 1-12 & 23/24.604 Grupo 4, no 1 \\
\hline 69 & & 21 poyete derecho \\
\hline 51.14 & Cajas 26 y 27 & Grupo $15, \mathrm{n}=5$ \\
\hline 51.19 & Cajas 1-235 & 23/21.308, grupo 3, no 12 \\
\hline 51.20 & Cajas 1-12 & $23 / 28.401$, grupo $7, n=3$ \\
\hline 51.21 & Cajas 1-53 & $23 / 28.302$, grupo $7, n=8$ \\
\hline 51.31 & Cajas $165-168$ y 177 & 23/31.306-31.507, grupo 1 no 2 \\
\hline 51.34 & Paquetes $64-103$ & $23 / 32.308$, grupo 13, no 6 \\
\hline 51.34 & Paquetes 42-61 & 23/32.405, grupo 13 , no 7 \\
\hline 51.41 & Cajas 650-655 & $23 / 25.302-25.405$, grupo 2 , no 6 \\
\hline 51.43 & Cajas 503-513 & 23/34.509-34.708, grupo 2, no 3 \\
\hline 51.48 & Cajas 419-434 & 23/34.405-34.407, grupo 2, no 2 \\
\hline 51.22 & Cajas 1-129 & $23 / 27.408$, grupo $6, n=9$ \\
\hline
\end{tabular}




\begin{tabular}{|l|l|l|}
\hline 51.23 & Cajas 1-207 & 23/27.704, grupo 7, no 1 \\
\hline 51.23 & Cajas 1-72 & 23/32.205, grupo 13, no 1 \\
\hline 51.33 & Cajas 1-54 & 23/31.201, grupo 1, no 2 \\
\hline 51.34 & Cajas 208-222 & 23/31.507, grupo 1, no 3 \\
\hline 51.41 & Fichero 79, mod. 23 & Fotografías Sección Femenina \\
\hline 51.39 & Paquete 291 & 21/21.307, grupo 3, no 9 \\
\hline 51.40 & Cajas 1-140 & 23/20.706-21.307, grupo 3, no 7 \\
\hline 51.42 & Cajas 528-590 & 23/25.201-25.302, grupo 2, no 5 \\
\hline 51.42 & Anexo 1. Fotografías & Módulo 23. Fichero 54 \\
\hline
\end{tabular}

\subsubsection{Publicaciones}

En este sentido hay varios tipos de publicaciones diferentes cuyo estudio detenido y en algunas ocasiones analítico y exhaustivo ha sido la base para las conclusiones sobre la educación musical en el período franquista.

Desde el punto de vista institucional destacan por su importancia dos publicaciones:

Normas relacionadas con el departamento de música de la Regiduría Central de cultura (1954) de I Delegación Nacional de la Sección Femenina de FET y de las JONS

Orientaciones pedagógicas para los planes y programas de estudios de la Educación General Básica (1971) del Ministerio de Educación y Ciencia

Por mucha importancia que tuvieran las intenciones ideológicas e institucionales que hay detrás del proceso educativo, las publicaciones musicales o con contenido musical son las que finalmente llegaban a los educadores, y por tanto son el fiel reflejo de lo que realmente se enseñaba a la población.

La selección del material incluido en las publicaciones de diverso tipo nunca es casual, sino que supone una intencionalidad evidente ya que ha pasado por 
varios procesos antes de llegar a la edición: autorizaciones de las autoridades pertinentes, encargo de recogida de determinadas canciones en el ámbito popular rural, armonizaciones y arreglos en algunos casos, criba y selección de los elementos que se incluyen en la publicación... y desde luego, censura.

Las publicaciones musicales reflejan claramente lo que se deseaba que fuera aprendido: los himnos más importantes (en el que es relevante incluso su orden de aparición), las canciones religiosas predominantes, la aparición de todas las regiones que conforman el territorio nacional y su equilibrio, la categorización por su funcionalidad: nanas, villancicos, cantos de juego 0 corros, danzas, canciones de campamento.

Desde luego, también hay que tener en cuenta el papel que juega la culturización de la población, especialmente a través de la enseñanza de la historia de la música y su presencia en las publicaciones, escolares o de divulgación en los centros vinculados a las instituciones (por ejemplo los Centros Medina de la Sección Femenina).

Entre ellas, conviene destacar por su especial importancia:

\begin{tabular}{|l|}
\hline Sección femenina \\
\hline Cancionero de Sección Femenina (1943) \\
\hline Mil Canciones españolas \\
\hline Villancicos y canciones religiosas de navidad (1956) \\
\hline Revista Consigna para maestras \\
\hline Canciones infantiles (1964) \\
\hline Canciones populares para escolares (1960, 1965y 1969) \\
\hline Cancionero popular español (1968) \\
\hline Iniciación. Educación musical preescolar (1975) \\
\hline Historia de la música de Rafael Benedito (1955) \\
\hline
\end{tabular}


La educación musical en el franquismo

\begin{tabular}{|l|}
\hline Frente de J uventudes \\
\hline Cancionero falangista (1945) \\
\hline Cancionero Juvenil de Manuel Rodríguez (1947) \\
\hline Cancionero de juventudes de José de Arriaca (1967) \\
\hline Cancionero del Frente de juventudes (1963) Ed. Doncel \\
\hline Edición digital de España es mi canción \\
\hline Marchas y montañismo (1943) \\
\hline Manual de campamentos (1948) \\
\hline El frente de juventudes en la escuela (1960)
\end{tabular}

Otras publicaciones de campamentos de Frente de Juventudes y publicaciones menores de Sección Femenina

Otras publicaciones escolares en las que aparecen canciones o música, muchas de las cuales provienen del fondo personal que he ido consiguiendo a través de donaciones de amigos, compra en librerías especializadas en libros antiguos, préstamo de instituciones y particulares, y la consulta de dos fondos especializados en libros educativos, entre los que destacan muy especialmente:

Música y canto / y // (1960) para bachillerato y magisterio

Boletines no 5 y 7 de la Inspección de enseñanza primaria de Valladolid (1956) Tratado de música para las escuelas del magisterio (1940)de Soler y Arnaudas

Formación musical / y // (1960) de Matilde Murcia para magisterio

ARCHIVO DEL CENTRO CULTURAL DE BERLANGA DE DUERO dirigido por el Dr. Agustín Escolano Benito

COLECCIÓN DE LIBROS ESCOLARES ANTIGUOS del profesor de Educación Secundaria Manuel Cabornero en Geria (Valladolid) 


\section{Capítulo 1. Introducción}

\subsubsection{Entrevistas y testimonios personales}

Se realizaron varias entrevistas a personas que vivieron personal y directamente la educación musical en esta etapa. La más importante de ellas es sin duda la entrevista realizada a la Catedrático de la Escuela Universitaria del profesorado de Valladolid Dña. Florentina López.

Además se han recogido numerosos testimonios personales, algunos solicitados y otros simplemente aportados de forma voluntaria y no premeditada por diversos informantes al conocer que se estaba realizando este estudio

\subsubsection{Bibliográficas}

Estamos asistiendo a una auténtica explosión de estudios sobre el período franquista desde el punto de vista educativo, ya que somos herederos directos de ella, por lo que muchos estudiosos piensan que debemos mirar al pasado inmediato para poder mejorar el presente educativo.

Han sido especialmente interesantes por su especificidad sobre educación musical las aportaciones de las tesis doctorales no publicadas de Antonia Luengo $^{7}$ y Manuel Parra Celaya ${ }^{8}$

También tienen un especial espacio en este trabajo los estudios dedicados a la enseñanza no formal y a la transmisión ideológica y el adoctrinamiento ideológico.

\subsection{METODOLOGÍA}

He tratado de combinar varios tipos de metodología para ser capaz de obtener una visión lo más completa posible de la realidad de la enseñanza musical no profesionalizada a lo largo del franquismo.

\subsubsection{Bibliografía inicial}

Los estudios sobre historia de la educación musical son bastante recientes y vienen a encuadrarse metodológicamente hablando en el campo de la

\footnotetext{
${ }^{7}$ LUENGO SOJ O, A. (1996) Sección Femenina. Actividad musical. Tesis doctoral no publicada. Universidad de Barcelona. Barcelona

8 PARRA CELAYA, M. (1989) La pedagogía del Frente de Juventudes. Tesis doctoral no publicada. Universidad de Barcelona. Barcelona.
} 


\section{La educación musical en el franquismo}

antropología musical, en la que se interrelacionan los aspectos historiográficos y las relaciones sociales entre la cultura y la sociedad.

Partiendo del esquema de Levi-Strauss ${ }^{9}$ (1974) , J. Martí ${ }^{\mathbf{1 0}}$ (1992) establece para la etnografía musical tres niveles: un nivel más descriptivo, de recogida de datos en el campo (etnografía), un segundo nivel de sistematización, clasificación y síntesis de los datos (etnología) y un tercer nivel de elaboración teórica, reflexión general y filosófica sobre el fenómeno y su relación humana (antropología). En el presente trabajo se han utilizado los tres niveles para estudiar la documentación que conservamos sobre la educación musical de la época.

Como propone Merriam $^{\mathbf{1 1}}$ (1964) la antropología musical tiene que adentrarse en el estudio de los significados culturales asociados a la música. En una concepción de que "la cultura es un comportamiento adquirido" y que "el proceso de aprendizaje se relaciona con los ideales y los valores culturales", es necesario prestar especial atención al aprendizaje musical en la enculturación, la socialización y la escolarización. En su taxonomía sobre los usos de la música, destaca en relación a nuestro trabajo la función 2: como institución social (organización social, instrucción, estructuras políticas, cantos educativos,; 3: como estructuración del hombre en el universo, especialmente en el apartado de la transmisión de las creencias religiosas a través del canto; y en la función 5 que se ocupa del lenguaje y los textos de las canciones.

Los estudios de Hargreaves y North $^{\mathbf{1 2}}$ se adentran en la psicología social de la música.

Por su parte, es esencial la aportación de Bruner $^{\mathbf{1 3}}$, y la FolK. psychology de introducir el estudio de la actividad docente como herramienta para la transmisión y construcción del conocimiento y la transmisión cultural en la sociedad, incorporando la idea de un conexión entre la cultura escolar (formal)

\footnotetext{
${ }^{9}$ LEVI-STRAUSS , C (1995). Antropología estructural (2o reimp) Barcelona: Paidós (Versión original en francés: Anthropologie structurale. París: Plon, 1974)

${ }^{10}$ MARTí, J. (1992) Hacia una antropología de la música. Anuario Musical 47,195-225

${ }^{11}$ MERRIAM, A.P. (1964) The Anthropology of Music. Chicago: Northwestern University Press

12 HARGREAVES, D.J. y NORTH, A.C. (Eds) (1997) The Social Psychology of Music. Oxford: Oxford University Press

${ }^{13}$ BRUNER, J. (1997) La educación, puerta de la cultura. Madrid: Visor
} 
y la cultura en general (informal) a modo de bucle de retroalimentación. Las

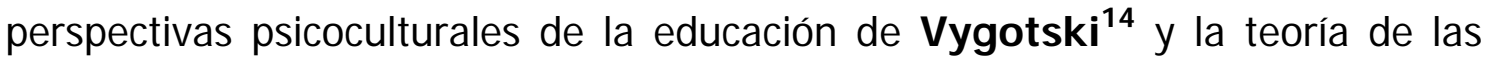
"inteligencias múltiples" de Gardner ${ }^{15}$ nos llevan a un concepto de análisis globalizador de la cultura y a su importantísimo papel en la trasmisión por medio de la educación. En palabras de Geertz ${ }^{\mathbf{1 6}}$ "la educación no es una isla, sino una parte del continente de la cultura".

Desde el punto de vista paradigmático de la investigación recogidos por Latorre $^{\mathbf{1 7}}$ et alt., este trabajo utiliza preferente los enfoques de tipo interpretativo y sociocrítico. El primero tiene como finalidad de la investigación comprender e interpretar la realidad y los significados de las percepciones, intenciones y acciones y el segundo identificar el potencial de cambio y analizar la realidad. Las relaciones que se han establecido entre el investigador y el objeto de investigación, dependiendo de las herramientas metodológicas utilizadas es en unos casos positivista (neutralidad e independencia), sobre todo en las partes analíticas y en otras interpretativa, es decir, que se ven afectadas por las experiencias del investigador y los sujetos informantes. El tipo de conocimiento al que se llega es fundamentalmente inductivo, relativo a un contexto determinado.

El método utilizado es fundamentalmente la investigación narrativa, etnográfica, el estudio de casos y la fundamentación teórica, según los planteamientos de I barretxe $\mathbf{~}^{\mathbf{1 8}}$

Las principales técnicas utilizadas han sido el análisis documental, la entrevista en profundidad, la conexión relacional de los elementos analizados para obtener conclusiones del tercer nivel antropológico (ver Martí): Nivel de elaboración

\footnotetext{
${ }^{14}$ VYGOTSKI, L.S. (1979) El desarrollo de los procesos psicológicos superiores. Barcelona: Crítica

${ }^{15}$ GARDNER, H. (1997) Arte, mente y cerebro. Una aproximación cognitiva a la creatividad. Barcelona: Paidós

${ }^{16}$ GEERTZ, C. (1989) La interpretación de las culturas (2º reimp.) Barcelona: Gedisa (Versión original en inglés: The interpretation of Cultures. Nueva Cork: Basic Books, 1973)

${ }^{17}$ LATORRE, , A., DEL RINCÓN, D. y ARNAL, J. (1996) Bases metodológicas de la investigación educativa. Barcelona: Graó

${ }^{18}$ IBARRETXE, G (2006) El conocimiento científico en investigación musical, en DíAZ, M. (coord) Introducción a la investigación en educación musical.<Madrid: Enclave creativa
} 


\section{La educación musical en el franquismo}

teórica, reflexión general y filosófica sobre el fenómeno estudiado y su relación con la condición humana.

En conclusión, la metodología utilizada, combina rasgos cuantitativos y empírico-analíticos en el análisis del apartado documental, y metodología cualitativa para llegar a unas conclusiones de carácter principalmente interpretativo.

La combinación de paradigmas e integración metodológica se ajusta a las tesis de diversidad complementaria expuestas por Walter y Evers $^{\mathbf{1 9}}$ según la cual diversos tipos paradigmáticos se apoyan y complementan en el proceso de investigación, a pesar de tener una base distinta desde el punto de vista ontológico y epistemiológico. La estrategia de la complementación propuesta por Bericat $^{\mathbf{2 0}}$ permite la cohabitación de métodos cualitativos y cuantitativos, aplicados a diferentes parcelas de la realidad investigada, en función de obtener una síntesis interpretativa que integre los resultados obtenidos por ambos.

Aplicando la terminología de Sabarriego y Bisquerra ${ }^{21}$, la elección de las diversas metodologías y los procedimientos técnicos para aplicarlas, ha sido hecha en función de las necesidades que planteaban los diversos materiales documentales, combinando métodos descriptivos, correlaciónales y explicativos causales.

\subsubsection{Herramientas metodológicas}

\subsection{2.a Historiografía}

Hay una gran cantidad de documentación historiográfica sobre el franquismo desde el punto de vista político. El uso de la bibliografía de tipo historiográfico ha permitido elaborar un contexto socio-político en el que encuadrar la investigación.

\footnotetext{
${ }^{19}$ WALKER, J.C. y EVERS, C.W. (1988) The espistemological unity or educational research. En J.P. KEEVES (Ed, Educational Resarch, Methodology and Measurement: An Internacional Handbook (pp 28-36). Oxford:Pergamon

${ }^{20}$ BERICAT, E. (1998) La integración de los métodos cuantitativo y cualitativo en la investigación social. Barcelona: Ariel

${ }^{21}$ SABARIEGO, M. y BISQUERRA, R. (2004) El proceso de investigación. En BISQUERRA, R. (Coord.) Metodología de la Investigación Educativa. Madrid: La Muralla
} 
Inicialmente era absolutamente necesario profundizar en el conocimiento del franquismo desde un punto de vista histórico. Para ello han sido utilizados como referente básico las monografías de Payne $^{22}$ y Preston $^{23}$, así como los textos de Tuñón de Lara $^{24}$, Biescas ${ }^{25}$, Sueiro y Díaz $^{26}$, Tamames $^{27}$ y de la Cierva $^{28}$.

Desde el punto de vista del conocimiento sobre la vida cultural durante el período franquista han sido de especial interés los textos de $\mathbf{A b e l l a}^{29}, \mathbf{C i r i c i}^{\mathbf{3 0}}$, Abellán $^{31}$ y Castellet $^{32}$.

En lo referente al fascismo como corriente de pensamiento y en especial a su plasmación en las asociaciones de Falange Española de las FET y de las JONS cobran especial relevancia los estudios de Tannenbaum ${ }^{33}$, Ellwood ${ }^{34}$, Chueca $^{35}$, Sáez Marín ${ }^{36}$, Gallego ${ }^{37}$, González Gallego ${ }^{38}$ y Richmond ${ }^{39}$.

\footnotetext{
22 PAYNE, S. (1967). La España de Franco. Nueva Cork: Cromwell

23 PRESTON, P (1994), Franco, caudillo de España. Barcelona: Grijalbo

${ }^{24}$ TUÑ́́N DE LARA, M. (1977). Ideología y sociedad en la España contemporánea. Por un análisis del franquismo. Madrid: Edicusa

${ }^{25}$ TUÑÓN DE LARA, M. y BIESCAS, J. A. (1980) Historia de España, tomo X. España bajo la dictadura franquista. Barcelona: Labor

${ }^{26}$ SUEI RO, D. y DÍAZ, B.(1986) Historia del franquismo. Madrid: Sarpe

${ }^{27}$ TAMAMES, R. (1977) . La era de Franco. Madrid: Alianza Universidad

${ }^{28}$ CIERVA, R. de la (1978) Historia del franquismo. Barcelona: Planeta.

Francisco Franco. Biografía histórica. Barcelona: Planeta

${ }^{29}$ ABELLA, R. (1975) Por el imperio hacia Dios. Barcelona: Planeta -------- (1996) La vida cotidiana bajo el régimen de Franco. Madrid: Temas de Hoy

${ }^{30} \mathrm{CIRICI}$ PELLICER, A. (1977) La estética del franquismo. Barcelona: Gustavo Gili

${ }^{31}$ ABELLÁN, J.L. (1971) La cultura en España. Madrid: Cuadernos para el diálogo

${ }^{32}$ CASTELLET, J. M. et alt (1977). La cultura bajo el franquismo. Barcelona: Ediciones de bolsillo

${ }^{33}$ TANNENBAUM, E. (1975) La experiencia fascista. Sociedad y cultura en Italia. Madrid: Alianza Universitaria

${ }^{34}$ ELLWOOD, S. (1987) Spanish fascism in the Franco Era: falange Española de las JONS 193675. Basingstoke: MacMillan (1984) Prietas las filas. Historia de la Falange Española 1933-1983. Barcelona:

Grijalbo
}

${ }^{35}$ CHUECA RODRÍGUEZ, R. (1978) El boletín de los seminarios de formación del Frente de J uventudes en VARIOS: Las fuentes ideológicas de un régimen (España 1939-45). Zaragoza: Libros Pórtico.

estudio sobre FET-JONS. Madrid: Centro de Investigaciones Sociológicas (1983) El fascismo en los comienzos del régimen de Franco. Un Contemporánea. Salamanca, vol V, 4 (1987), pag. 87-104

${ }^{36}$ SÁEZ MARÍ N, J. (1988). El Frente de Juventudes: política de juventud en la España de la postguerra 1937-1960. Madrid: Siglo XXI

${ }^{37}$ GALLEGO MÉNDEZ, M (1983). Mujer, falange y franquismo. Madrid: Taurus

38 GONZÁLEZ GALLEGO, I. (1988). Falange y educación. Zaragoza, 1936-1940. En Historia de la Educación, 7. pag (203-230) 
Respecto a la educación durante el franquismo me resultó extremadamente útil la selección bibliográfica de trabajos publicados a partir de 1975 que realiza José María Hernández Díaz $^{\mathbf{4 0}}$, así como los trabajos fundamentales de Cámara Villar ${ }^{41}$, Carbonel $^{42}$ y Palop $^{43}$.

Está apareciendo recientemente bastante bibliografía sobre la diferenciación de género en la enseñanza y en concreto sobre la enseñanza de las mujeres durante el período franquista. Tal vez el iniciador de esta proliferación fue el libro de Beneria ${ }^{44}$. Posteriormente, las aportaciones del libro de María Inmaculada Pastor ${ }^{45}$, publicado por el Instituto de la mujer, supusieron el impulso definitivo para los estudios sobre la educación no formal de las mujeres a través de la Sección Femenina, labor continuada por Ortolá Noguera ${ }^{46}$ y las ya antes citadas Gallego Méndez y Kathleen Richmond. En lo que respecta a la educación musical propiamente dicha y los estudios de género, hay que destacar los estudios de $\mathbf{G r e e n}^{\mathbf{4 7}}$ y Manchado $^{\mathbf{4 8}}$ y la tesis doctoral de Luengo ${ }^{49}$

\footnotetext{
${ }^{39}$ RICHMOND, K. (2004) Las mujeres en el fascismo español. La Sección femenina de la falange 1934-1959. Madrid: Alianza Ensayo

${ }^{40}$ HERNÁNDEZ DíAZ, J. M. (1989) Franquismo y educación. Selección bibliográfica de trabajos publicados desde 1975 en Revista Historia de la Educación vol. 8. Salamanca.(pp. 335-342)

${ }^{41}$ CÁMARA VILLAR, G. (1984) Nacional-catolicismo y escuela. La socialización política del franquismo (1936-1951). Granada: Hesperia

(1984) El adoctrinamiento político en la escuela del franquismo: nacional-catolicismo y textos escolares, 1936-51. En Infancia y sociedad en España. Granada: Hesperia. (pp. 351 y ss).

${ }^{42}$ CARBONELL, J. (1976) Cuatro décadas de educación franquista: Marco legal y política educativa. En Cuadernos de pedagogía, suplemento nำ3, (pp. 24-29).

${ }^{43}$ PALOP, P. (1976) Límites ideológicos de la pedagogía franquista. En Endecha pedagógica. Oviedo ( pp. 5-8).

${ }^{44}$ BENERIA, L.(1977) Mujer, economía y patriarcado durante la España franquista. Barcelona: Anagrama

${ }^{45}$ PASTOR, M.I. (1984). La educación femenina en la posguerra (1939-45) El caso de Mallorca. Madrid: Ministerio de Cultura

${ }^{46}$ ORTOLÁ NOGUERA, A. (1994) El castillo de La Mota en medina del Campo. Valladolid: Junta de Castilla y León

${ }^{47}$ GREEN, L. (2001) Música, género y educación

${ }^{48}$ MANCHADO TORRES, M (1998). Música y mujeres: género y poder. Madrid: Horas y horas

${ }^{49}$ LUENGO SOJO, A (1996) Sección Femenina. Actividad musical. Tesis doctoral no publicada leída en la Universidad de Barcelona.
} 
En lo que se refiere al Frente de Juventudes y su participación en la educación hay tres publicaciones fundamentales al respecto: los estudios de Sáez Marín $^{50}$ y de Cruz Orozco ${ }^{51}$ y una tesis doctoral de Parra Celaya ${ }^{52}$

\subsection{2.b Legales}

Los textos legislativos de las dos leyes de Educación, los Boletines Oficiales del Estado y las directrices del Ministerio de Educación y Ciencia son documentos fundamentales en este trabajo de investigación, ya que es a partir de ellos de donde se obtienen los marcos legales en los que se desarrolla toda la formación del profesorado que va a impartir música y los que condicionan la política educativa del país.

Las dos leyes de Educación de la etapa franquista son un reflejo de los condicionantes políticos del momento, la primera claramente influenciada por la guerra civil recién terminada y la segunda por un momento de crecimiento económico y apertura política del régimen.

Conocer el entorno histórico y político, por tanto, es fundamental para encuadrar la enseñanza de la música y la forma en que se llevó a cabo.

\subsection{2.c Recensión, búsqueda y selección de documentación original de Falange}

La búsqueda y revisión de los textos relacionados con la educación musical en la época franquista ha ocupado una parte importante de esta investigación.

Al delegar la ley parte de la formación de los maestros en el ámbito musical en otras instituciones de carácter ideológico: Frente de Juventudes y Sección Femenina, ha habido que rastrear a través de los inmensos fondos del Archivo General de la Administración.

La mayor parte del material utilizado era hasta la fecha absolutamente desconocido o simplemente ignorado, guardado cuidadosamente entre la gran

\footnotetext{
${ }^{50}$ SÁEZ MARÍN, J. (1988) El Frente de Juventudes. Política de juventud en la España de la postguerra (1937-1960). Madrid: Siglo XXI

${ }^{51}$ CRUZ OROZCO, J. I. (2001) El yunque azul. Frente de Juventudes y sistema educativo. Madrid: Alianza

52 PARRA CELAYA, M. (1989) La pedagogía del Frente de Juventudes. Tesis no publicada leída en la Universidad de Barcelona.
} 


\section{La educación musical en el franquismo}

cantidad de fondos documentales sin clasificar, por lo que son innovadores y aportan nuevas perspectivas "desde dentro" del papel que ambas organizaciones jugaron en la formación de profesorado y en la divulgación de la música entre los niños y en general en la sociedad española, los medios a través de los que llevaron a cabo esta labor y la utilización que se hizo de este medio para la transmisión ideológica y el adoctrinamiento.

\subsection{2.d El análisis musical del repertorio}

El análisis musical nos permite

- comprender mejor los criterios de selección utilizados

- valorar el grado de adecuación a los fines perseguidos

- realizar hipótesis sobre la incidencia en la pervivencia de algunos elementos del folklore

- observar la predominancia e incidencia de ciertas características musicales: uso de determinados compases, peculiaridades rítmicas, principales intervalos iniciales de entonación, modalidades y tonalidades más difundidas.

Dada la gran cantidad de repertorio analizado y recogido en esta investigación, así como la importancia de su difusión a través de los canales ideológicos (son, sin duda, los cancioneros más importantes de la época franquista) nos permiten realizar hipótesis sobre su incidencia en la memoria musical desde el punto de vista educativo hasta conformar el "mundo sonoro" considerado como educación musical en el período histórico que nos ocupa (es decir, dejando a un lado la música de transmisión comercial o popular, así como el mundo de la formación profesionalizada y de la música culta).

\subsection{2.e Percepción de la educación musical en la sociedad}

La educación musical de los niños en ámbitos no profesionales está estrechamente vinculada a la forma de entender la escuela y su papel en la vida cotidiana de la sociedad española.

La complementariedad de la educación a través de canales no formales (campamentos, círculos medina, círculos J osé Antonio) y su vinculación a otras 


\section{Capítulo 1. Introducción}

instituciones altamente ideologizadas incide una vez más en la importancia de la formación paralela en la sociedad real.

La idea que hoy tenemos de formación musical abarca mucho más allá de lo que como individuos percibimos, incluyendo los repertorios que se han asentado a lo largo de una generación. La no percepción de la misma como una actividad consciente y voluntaria nos lleva a conclusiones sobre un proceso de adoctrinamiento generalizado.

El hecho de que no haya transcurrido aún mucho tiempo y podamos disfrutar de testimonios de personas vivas que vivieron de primera mano la experiencia de este tipo de educación musical es una enorme ventaja, sin duda, para la realización de esta investigación, ya que los propios interesados pueden hablar de cómo la percibieron y cómo pueden analizarla por sí mismos desde la perspectiva actual. Incluso nos permiten elaborar algunas hipótesis sobre su pervivencia o fracaso a medio y largo plazo.

\subsection{ESTADO DE LA CUESTIÓN}

\subsubsection{La investigación en educación musical}

La investigación en educación musical en España está condicionada por la historia reciente: se ha comenzado a investigar en profundidad desde la aparición de la titulación de maestro especialista en Educación Musical (LOE 1990).De hecho, la opinión generalizada es que anteriormente a esta etapa no había educación musical como tal en las escuelas o era realizada de forma extraescolar e irregular.

Esto último es cierto, pero ello no impide que se deba analizar sistemáticamente, porque es el antecedente inmediato de la situación a la que ahora asistimos y, en muchos casos, directa sucesora de ella.

Si la historia de la educación en España es un campo de investigación con una tradición ya asentada, las didácticas específicas no han tenido tanta suerte. Y la última en incorporarse ha sido prácticamente la educación musical. 


\section{La educación musical en el franquismo}

¿Por qué? ¿Acaso no suscita el suficiente interés para los investigadores?. Por el contrario, estoy convencida de que muchos colegas sentimos que hay un enorme campo abierto a la investigación en este tema, es más bien la inmensidad del mismo lo que nos asusta. Más de cuarenta años de sistema educativo, que no cambia legalmente hasta mucho después de la muerte de Franco y cuyos condicionantes arrastramos de manera inconsciente.

En todo caso, la historia de la educación musical a nivel mundial también es bastante reciente. Aunque los grandes métodos pedagógicos de educación musical tienen su nacimiento en el siglo XIX, la generalización como parte de un sistema educativo - con rango más o menos complementario u obligatorio según la tradición musical de los diferentes países europeos - se produce de manera progresiva a lo largo de toda la primera y convulsa (por las dos guerras mundiales que asolan el centro del continente y sus aliados) mitad del siglo XX.

De esta práctica a la iniciación de una reflexión analítica e investigadora sobre la historia de su nacimiento y divulgación, las formas de llevarla a cabo, la formación de los profesores que la imparten, las condiciones sociales que la rodean, su relación con las instituciones de poder (políticas y educativas), y de la observación y conclusiones sobre los resultados obtenidos en la población (infantil y adulta) todavía hay un largo trecho temporal, sin duda necesario para obtener datos fiables, métodos de investigación y personal formado.

Pero en realidad, lo que más ha condicionado que este proceso se llevara a cabo con bastante retraso, son los cambios que ha sufrido la educación y el concepto educativo a lo largo de la última mitad del siglo XX. En este último período han aparecido nuevas perspectivas de investigación educativa que nos permiten analizar desde innovadpres puntos de vista el fenómeno de la educación musical. Entre ellos, quiero hacer especial hincapié en las aportaciones que la sociología de la educación y los aspectos de educación no formal han tenido en la forma de plantear el presente estudio. 
La sociología de la educación musical como campo de investigación se ha empezado a desarrollar a partir de 1950. Tal como se recoge en elNew handbook of Research on music teaching and learning "l3 "la sociología de de educación musical creció exponencialmente a partir de 1990, lo que llevó a ampliar la metodología y campos de estudio y a incrementarse de manera dramática las publicaciones sobre el tema". A este respecto destacan las publicaciones teóricas básicas de Bernstein ${ }^{54}$, Bordieu ${ }^{55}$, Collins ${ }^{56}$, Freyre y Giroux ${ }^{57}$. En el estudio del papel sociológico que juegan los profesores de música en la escuela es especialmente destacable el trabajo de White ${ }^{\mathbf{5 8}}$ sobre el papel social de los profesores de música en la escuela en Estados Unidos. Siguiendo sus pasos, son también fundamentales los trabajos de $\mathbf{S m a l l}^{\mathbf{5 9}}$, Benner $^{60}$, Cox $^{61}$, Green $^{62}$, Humphreys ${ }^{63}$ y Rideout ${ }^{64}$.

Destaca también dentro de los estudios que relacionan sociología y educación la enorme importancia que está adquiriendo en los últimos años la diferencia de género, es decir, la educación diferenciada de niños y niñas. Este campo de investigación cobra mucho significado en el presente estudio, ya que la formación musical durante el franquismo se vio especialmente asociada a una profunda diferenciación de género. Desde el punto de vista específico, son muy

\footnotetext{
${ }^{53}$ COLWELL, Richard y RICHARDSON, Carol (Eds.) (2002): The new handbook of resarch on music teaching and learning New York: Oxford University Press

${ }^{54}$ BERNSTEIN,B. (1981) Studien zur sprachlichen sozialisation .Frankfurt: Ullstein

${ }^{55}$ BORDIEU, P (1979) Distinction: A social critique of the judgement of taste. Cambridge, MA: Harvard University Press

${ }^{56}$ COOLINS, R. (1971) Functional and conflict theoires of educational stratification. American Sociological Review, 36 (6)

${ }^{57}$ GIROUX, H (1981).: /deology, culture and the process of schooling. Filadelfia: Temple University Press,

${ }^{58}$ WHITE, H. G (1964). The professional role and status of the school music techer in American society. Tesis doctoral , Universidad de Kansas: Lawrence

${ }^{59}$ SMALL, C.(1977) Music, society, education. Londres: Calder

${ }^{60}$ BENNER, C.H.(1974) Implications or social change for music education. En ISME Yearbook 11,1974

${ }^{61}$ COX, P.H.(1994) The professional socialization of Arkansas music teachers as musicians and educators, Tesis doctoral en la Universidad de North Texas, Denton.

${ }^{62}$ GREEN, L. (1999) Research in the sociology of music education: some introductory comment. En Music Education Research, 1, (pp.159-170)

${ }^{63}$ HUMPHREYS, J.T. (1997) Expanding the horizons of music education history and sociology.

En Quarterly Journal of music teaching and learning, 7, (pp. 5-19)

${ }^{64}$ RIDEOUT, R.R. (2000) On the sociology of music education. School of music de la

Universidad de Oklahoma.
} 
relevantes los estudios de Green $^{65}$, Giroux ${ }^{66}$, Lamb $^{67}$, McCarthy $^{68}$ y McClary ${ }^{69}$.

En los últimos años en España se están llevando a cabo una serie de estudios sobre todas las actividades educativas ligadas al Franquismo. No es de extrañar, ya que somos herederos directos de sus formas y contenidos pedagógicos que nos fueron presentados en la niñez como esquemas válidos y fundamentales para comprender el mundo.

La elevada carga ideológica de muchos de esos contenidos y la forma de presentarlos a la juventud ha sido aún más patente si cabe en las áreas de conocimiento vinculadas más estrechamente a Frente de Juventudes y Sección Femenina: Educación física, Educación política, Manualidades y Música.

El personal que los impartía a nivel escolar y de educación secundaria estaba normalmente estrechamente vinculado y había recibido a su vez la formación en ambas instituciones.

\subsubsection{La formación de los músicos}

En lo que a la música se refiere, es curioso, ya que el sistema de formación profesionalizado en el área se realizaba a través de los conservatorios. Pero este personal especializado se centró en la enseñanza de la música como actividad profesional en los propios conservatorios, sin entrar al mundillo educativo general, excepto en el caso de la educación superior (el personal de música de las escuelas Normales primero, y de las Escuelas Universitarias de

${ }^{65}$ GREEN, L. (1993) Music, gender and education: a report on some exploratory research. En British Journal or Music Education, 10, (pp. 219-254)

(1994) Gender, musical meaning and education. En Philosophy of Music Education Review, 2,( pp. 99-105)

${ }^{66}$ GIROUX, H. (1991) Postmodernism, feminism, and cultural politics: Redrawing educational bounderies. Albany State University of New Cork Press

${ }^{67}$ LAMB, R. (1990) Possibilities or/for feminist music criticism in music education. En British Journal of Music Education, 10, (pp. 169-180). 1990

-----(1994) Feminism as critique in philosophy of music education. En Philosophy of Music Education Review,2, (pp. 59-74)

${ }^{68}$ MCCARTHY, M.(1996) Wheels within wheels: feminism, gender and multicultural music education, a response to Green and Lamb. En Critical reflections on music education:

Proceedings of the second international symposium on the philosophy of music education, (pp. 264-272).Canadian Music Education Research Center, University of Toronto

${ }^{69}$ MCCLARY, S.(1991) Feminine endings: music, gender and sexuality, Minneapolis: University of Minnesota Press 


\section{Capítulo 1. Introducción}

Magisterio después, eran titulados de conservatorio dedicados a la enseñanza no profesionalizada).

Los conservatorios de música, tras una larga y cruenta batalla inicial para conseguir un cierto reconocimiento oficial de sus estudios profesionales, dejaron en manos de otros la educación musical general. Incluso hoy pervive la pugna y la incomprensión en lo que respecta a la colaboración entre ambos ámbitos educativos, con desconfianzas fundamentales entre el sistema de enseñanzas artísticas y el sistema general de enseñanza. Estas batallas abarcan todo tipo de cuestiones, desde el desprecio y el desentendimiento de unas y otras, hasta la pugna por el reconocimiento de titulaciones, la capacidad para impartir enseñanzas, la diferenciación de los centros a los que se tiene acceso.. Pese a todos los buenos intentos de la administración y de las actuales leyes de educación en crear sistemas paralelos e intercomunicados estamos lejos de conseguir que ello sea una realidad generalizada, aún hoy en día.

\subsubsection{La formación de los maestros}

La formación paralela del personal dirigida a edades escolares y de secundaria era impartida en las Escuelas Normales y luego complementada con las instrucciones recibidas en los cursillos de formación de Frente de Juventudes y Sección Femenina, que le daban un carácter de uso pedagógico notablemente diferente al recibido en la formación anterior.

Se están realizando numerosos estudios sobre el peso específico de la formación de los maestros durante el franquismo, de la carga ideológica de la misma y de su función de transmisores del nuevo orden establecido, de su función social como pilar de la comunidad - especialmente en el ámbito rural, donde el maestro era junto con el médico, el sacerdote y el alcalde, la representación del poder establecido y veladores de la estabilidad y el bien social ${ }^{70}$.

La formación de los maestros y los profesores ha cambiado mucho en las dos leyes de Educación del Franquismo. Y sin embargo, no podemos hablar de profesores especialistas en música hasta el año 1983, con las primeras

\footnotetext{
${ }^{70}$ Crónicas de un pueblo. Televisión Española
} 


\section{La educación musical en el franquismo}

oposiciones de música de Educación Secundaria, y hasta la reforma de la LOU con los primeros maestros especialistas en educación musical.

\subsubsection{Sección Femenina y Frente de Juventudes}

La educación no formal, sin embargo, en el caso de la educación musical alcanza además un peso específico, ya que era completada a través de cursillos realizados en las instituciones de transmisión ideológica más poderosas del momento con su origen en Falange Española de las FET y de las JONS: Frente de Juventudes y Sección Femenina.

Ambas instituciones tenían sistemas pedagógicos absolutamente diferentes a la hora de enfocar la educación y ello conlleva una profunda disparidad de tipo sexual en la formación educativa de los niños y las niñas, sobre la que se está haciendo mucho hincapié en nuestros días. El sexismo diferenciador en la educación franquista, la educación de las mujeres muy especialmente, está siendo objeto de constantes estudios desde los años 80 , ya que es muy evidente su papel y muy contrastante con la rápida revolución que supuso la incorporación de la mujer al trabajo en España de forma generalizada ya en la última etapa del régimen franquista y en constante crecimiento desde entonces hasta la práctica generalizada en nuestros días.

Su tarea educativa para formar mujeres-madre para el Estado, preparadas para transformar la realidad desde el entorno de sus hogares y su vida cotidiana, cuya tarea fundamental era el bienestar de la familia como eje de construcción social y en la que era relegada a tareas de limpieza, cocina, mantenimiento, salubridad, y sobre todo la posición de inferioridad con respecto al marido, son temas de constante exposición en todos los ámbitos sociales, por su tremendo contraste con la situación social de la mujer en la actualidad, muy pocos años después. Sobre ello se escriben innumerables textos todos los días, no sólo ensayos rigurosos, sino constantes alusiones en todo tipo de publicaciones.

Sin embargo, la tarea cultural de Sección Femenina no suele ser objeto de trabajo, probablemente por el menor interés general en esta temática. La educación cultural de las mujeres, como la de los hombres, parece tener menor 
interés que la formación tecnocrática, científica, económica o de cualquier otro tipo.

Tampoco Frente de Juventudes, la institución dedicada a la formación de los hombres, ha sido demasiado tratada últimamente. Excepto los primeros años después de la guerra civil, en la que estuvo ligada a la formación de las élites del partido falangista, se dedicó a la formación de los jóvenes, tanto en edad infantil como juvenil desde un punto de vista educativo no formal y sus actividades se vincularon más a la educación física por el hecho de ser realizadas habitualmente en campamentos alejados del entorno familiar. Pero en realidad, en estos campamentos y convivencias grupales era donde se formaban premilitar e ideológicamente. Allí aprendían, además de a realizar marchas interminables por las montañas otras muchas actividades: cocina, autosuficiencia, supervivencia, gimnasia y salud, relación social... y música, desde luego. La mayoría de los trabajos sobre Frente de Juventudes se centra en la formación de élites políticas, pero su tarea de formación con los jóvenes fue mucho más allá, aunque al parecer menos apreciada. Y tal vez, en la población general, dejó una huella menos consciente, aunque no por ello menos importante.

\subsubsection{La educación no formal}

En los últimos años estamos asistiendo a un nuevo enfoque sobre la educación que ha ampliado los horizontes de los estudios sobre el tema.

El término educación no formal se empieza a utilizar ampliamente a partir de la Conferencia Internacional sobre la crisis mundial de la Educación (Williamsburg, Virginia, USA, 1967)

A partir de las aportaciones de Coombs (1972), Ahmed (1975). y La Belle (1980), se ha debatido mucho sobre las nomenclaturas de educación formal, no formal e informal.

La intencionalidad ha sido uno de los criterios más utilizados para explicar las diferencias entre una educación informal ( a lo largo de toda la vida) o una 


\section{La educación musical en el franquismo}

educación formal y no formal, según Scribner y Cole ${ }^{71}$. Ambas, formal y no formal, son procesos educativos organizados, coordinados y y sistematizados.

Para Trilla ${ }^{\mathbf{7 2}}$ la educación formal estaría delimitada " a lo que se inscribe en los ciclos organizados y avalados por el estado que certifica y que lo acredita ante el gobierno correspondiente para proseguir con otro cilo educativo 0 terminal".

Quintana (1991) por su parte distingue entre educación reglada y no reglada, es decir fuera del ámbito escolar, aunque no por ello menos sitemática.

La educación no formal es, pues "la modalidad educativa que comprende todas las prácticas y procesos que se desprenden de la participación de las personas en grupos sociales estructurados, deliberadamente educativos, pero cuya estructura institucional no certifica para los ciclos escolarizados avalados por el estado.

La educación no formal es atendida por organizaciones en dos niveles: aquellas cuyo propósito básico es el cambio social a través de acciones de alimentación, producción o salud, y aquellas otras cuyo propósito básico es eminentemente educativo, pero que conforman un abanico de posibilidades y prácticas concretas que hace difícil generalizar características básicas a su alrededor. La pedagogía del ocio, educación del tiempo libre (...) y animación cultural (...) son prácticas educativas que en algún momento y otro tocan los niveles de la educación no formal"m33.

La educación no formal y no reglada, recibida fuera de la escuela, pero presente en la conformación del universo del individuo, especialmente durante la infancia y la adolescencia, ha adquirido gran importancia en la forma de

\footnotetext{
${ }^{71}$ SCRIBNER, S y COLE, M. Cognitive Consequences of formal and informal Education. En Science, 182,(pp. 553-559)

72 TRILLA, J. (1986) La educación informal. Barcelona: PPU TRILLA, J. (1992) La educación no formal. Definición, conceptos básicos y ámbitos de aplicación. En SARRAMONA J. (Ed.) La educación no formal. CEAC, Barcelona, (pp. 9-50) TRILLA J. et alt. (1993) La educación fuera de la escuela: ámbitos no formales y educación social. Barcelona: Ariel ${ }^{73}$ En http://www. conocimientosweb. net/portal/article660.htm/
} 


\section{Capítulo 1. Introducción}

abordar la formación especialmente en los ámbitos culturales, como destaca Vila ${ }^{\mathbf{7 4}}$, al decir que

“las prácticas educativas ocupan una parte muy importante de la actividad humana. En el acerbo popular, a veces, la educación queda limitada a la escuela, y por tanto, a las prácticas educativas escolares. Sin embargo, si entendemos la educación como el centro de la apropiación cultural, parece claro que se extiende más allá de la escuela. Así, la familia, los medios de comunicación, los grupos de amigos, las instituciones culturales, etc, ejercen una notable influencia educativa, de modo que nociones como educación permanente, animación socio-cultural (...) forman ya parte del bagaje de nuestras sociedades y se configuran como prácticas educativas de pleno derecho".

Este tipo de educación, que podía recibirse de forma muy organizada y establecida - casi tanto como la educación escolar normalizada - o de forma más informal y desestructurada, ha abierto nuevas puertas a la investigación educativa en el período franquista, ya que los procesos de transmisión ideológica y de adoctrinamiento de los regímenes totalitarios las utilizan como auténticos ejes para la transmisión de la propaganda y la creación de universos conceptuales que funcionan excepcionalmente bien en entornos infantiles y juveniles.

El análisis de los cómic de propaganda ${ }^{75}$ es un gran ejemplo que me ha inspirado para realizar mis propios análisis sobre las canciones en general, y muy especialmente de los himnos falangistas.

Al incluir la educación no formal como parte del análisis del hecho educativo del momento, también se puede incluir la labor de difusión cultural y dentro de ella el papel jugado por los círculos Medina y los Conciertos para la juventud.

La importante presencia y esfuerzos dedicados a la conservación del folklore y su difusión de manera artificial entre la población por medio de los Coros y Danzas nos hablan de la enorme importancia de este tipo de educación no formal y de su generalización por todo el territorio nacional.

\footnotetext{
${ }^{74}$ VILA, I.(1998) Familia, escuela y comunidad. Barcelona: ICE

${ }^{75}$ HERRERO SUÁREZ, Henar. Un yugo para los flechas.
} 


\subsubsection{Conclusiones sobre el estado de la cuestión}

Aunque se están produciendo una gran cantidad de estudios sobre la educación durante el franquismo y, además, se están viendo enriquecidos por la inclusión de formas de educación no formal hasta ahora no demasiado presentes en los estudios anteriores, la verdad es que la música es uno de los aspectos menos estudiados.

¿Por qué?

- En primer lugar deberíamos preguntarnos si la educación cultural en España ha tenido y tiene una consideración específica similar a otros ámbitos (científicos, económicos, sociales). Tal vez a ello se deba en parte ser siempre menos estudiado o recabar menos interés que las otras parcelas de la formación educativa.

- En segundo lugar, la educación musical en España todavía afronta grandes debates y disputas sobre su propia identidad. Las luchas entre "las dos educaciones musicales", la profesional y la generalizada a toda la población aún están en desarrollo y chocan frecuentemente en sus intereses y realidades cotidianas.

- En tercer lugar, hasta ahora la educación musical en España no abarcaba aquellas formas inconscientes de aprendizaje realizadas en ámbitos no formales educativos, pero ellas son las que han condicionado la mayor parte del repertorio aprendido.

- En cuarto lugar, porque la educación musical en España está cambiando constantemente y aunque aún no hemos llegado a unas leyes de mínimos claras a las que atenernos todos los profesionales con rigor en los diferentes niveles educativos, al menos hemos estabilizado a los profesionales que la imparten, su formación y sus condiciones de trabajo. Pero ello no quiere decir que sea definitivo, ya que se aprecia una cierta precariedad en su presencia formativa y en la propia presencia de la enseñanza musical en el sistema (se pierde la asignatura en el segundo año de ESO en la Comunidad de Castilla y León, con lo que se quiebra su continuidad en el sistema educativo regular, por 
ejemplo), siempre pendiente de vaivenes políticos, y con demasiado poco tiempo de aplicación regularizada real (apenas 15 años a nivel escolar y 25 en Secundaria)

- En quinto lugar, porque la educación musical en España es todavía objeto de poca investigación. No figura en los proyectos de I+D, ni en los programas de investigación a no ser que utilice las TIC (Técnicas de información y comunicación). La mejora en la enseñanza musical se realiza sobre todo por esfuerzos personales a partir del conocimiento de las técnicas pedagógicas de finales del siglo XIX y principios del siglo $\mathrm{XX}$, que son las más difundidas en nuestro país (Orff, Kodaly, Ward, Willems..), pero realmente hace falta una gran renovación. $Y$ esta renovación no está impulsada por el apoyo a la investigación en los temas de educación musical, que no es considerada como un objetivo prioritario, por parte de las instancias de la comunidad educativa.

- En sexto y último lugar, porque el estudio de la historia de la educación musical es una práctica iniciada muy recientemente. Su objetivo no es sólo el conocer el pasado educativo, sino ser capaz de analizar y proponer mejoras en la forma de educar musicalmente en el presente, así como de realizar propuestas aplicables para la educación musical en un futuro próximo

\subsection{OBJETIVOS E HIPÓTESIS}

Este trabajo se plantea diferentes tareas que pretender ofrecernos una visión general de la educación musical durante el franquismo a partir de varios enfoques complementarios.

\subsubsection{Objetivos}

- Identificar la educación musical en sus diversos niveles, diferenciando la educación profesional de la educación musical no profesionalizada y destinada a toda la población. 


\section{La educación musical en el franquismo}

- Para ello se utilizará tanto el contexto formal: la escuela, como el contexto no formal: los campamentos, las publicaciones de cancioneros, la documentación existente en el AGA sobre la labor de divulgación musical: conciertos, conferencias, fondos discográficos, cursillos de formación, festivales.

- Profundizar en el conocimiento de la formación del profesorado que impartía estas actividades musicales.

- Analizar los documentos que han pervivido de este pasado musical, llegando a conclusiones sobre los procedimientos de selección de repertorio y capacidad de divulgación del mismo.

- Catalogar las actividades de educación musical realizadas durante la etapa franquista y valorar su difusión entre la población.

\subsubsection{Hipótesis de trabajo}

- Razones para que la mayor parte de los receptores de dicha actividad no sea percibida por los receptores como una auténtica educción musical

- Identificar los rasgos que definen la educación musical y que pueden estar relacionados con elementos de adoctrinamiento y transmisión ideológica

- Identificar los rasgos de educación diferenciada en género a través de la educación musical

- Ser capaces de establecer una progresión temporal y una evolución en la forma de plantear la educación musical a lo largo de los 40 años de duración del franquismo relacionada con la evolución legal del sistema educativo en España.

- A través del análisis del repertorio, establecer qué rasgos musicales han tenido prioridad. 


\section{Capítulo 1. Introducción}

- Observar cuáles de esos rasgos pedagógicos aún perviven en la actualidad y hacer propuestas para corregirlos y mejorar la educación musical en el presente y el futuro inmediato.

- Valorar aquellos rasgos valiosos de la educación musical y reconocer la labor realizada en el pasado y que nos ha permitido llegar a la situación actual. 


\section{CAPÍTULO 2. EL MARCO LEGAL}

Conocer a fondo el marco legal en el que se desarrolló la educación musical durante el período franquista es fundamental, ya que es a partir de las leyes de educación como se desarrolla y configura la educación musical desde el punto de vista institucional.

Es la plasmación de cómo ve el Estado su función educativa en lo que a la música se refiere, la atención que le presta, la forma en que se va a formalizar, la planificación global, la creación de los medios disponibles para llevarla a cabo y, sobre todo, la visión de la presencia y el reconocimiento oficial de cómo se deben realizar estos estudios.

\subsection{LOS CONSERVATORIOS}

\subsection{1 ¿Por qué hablar de los Conservatorios?}

Aunque los Conservatorios son los centros en los que se realiza la educación musical profesionalizada - y por lo tanto no son el objetivo de este estudio - es inevitable hacer alusión al marco formal y los cambios que se realizan en él para entender el conjunto de la educación musical durante este período en España.

Ello se debe a una de las hipótesis de trabajo en las que se basa esta investigación, y es que los Conservatorios no han sido sólo centros de formación profesionalizada estrictamente, sino también centros de formación y divulgación musical.

Este fenómeno puede llegar a extenderse a alguno de los niveles en nuestros propios días, ya que los estudios de nivel elemental aún están dedicados además de a la formación inicial de estudios profesionales - a la formación de aficionados y a la introducción instrumental. Esta concepción de la formación musical es la que provee a los Conservatorios del mayor número de sus estudiantes, ya que el abandono a lo largo de los estudios es bastante numeroso. 


\section{La educación musical en el franquismo}

La dedicación horaria necesaria para la formación musical más elevada no era excesiva durante el período de 1940 a 1975 y se podían realizar los estudios de forma libre, por lo que, aunque extensos en el tiempo (entre 6 y 10 años de duración), eran compatibilizados por numerosos estudiantes que no deseaban tener una formación o ejercer una actividad profesional.

Estas consideraciones eran especialmente significativas en el caso de una educación diferenciada sexualmente por el género, ya que como veremos, la formación musical no profesionalizada era un objetivo apreciado en la educación de las mujeres, pero no así su actividad profesional (de hecho, la presencia femenina en la orquesta nacional era francamente mínima y tampoco era mayoritaria su presencia en la docencia - aunque ésta era mucho mayor -). De hecho, para un alto porcentaje de la población femenina que terminaba sus estudios de conservatorio, dicha formación de alto nivel era mayoritariamente un complemento bien visto en sus habilidades.

Los conservatorios no han tenido consideración de estudios regularizados dentro del sistema educativo a lo largo de todo el período franquista, sino de estudios especiales, y aún hoy arrastramos algunos restos de este tipo de pasado: así, el título superior de conservatorios ha sido recientemente validado como titulación de rango universitario capacitadota para realizar los cursos de doctorado; o, en un caso aún más sangrante, los estudios de grado medio aún no han conseguido una validez dentro del sistema educativo general.

Conocer en cualquier caso, aunque sea de manera general, el marco legal en el que se encuadran los estudios profesionales, es necesario para comprender la relación entre las "dos enseñanzas de la música" a las que hace alusión Federico Sopeña ${ }^{\mathbf{7 6}}$. Verdaderamente, en la época franquista, no se puede emprender un estudio de la formación no profesionalizada sin tener en cuenta la formación de los conservatorios.

\subsubsection{Las leyes que afectan a los Conservatorios}

En un primer momento inmediatamente después de la guerra civil, asistimos a una auténtica batalla de los conservatorios que ya existían hasta el momento

${ }^{76}$ SOPEÑA, Federico (1964). Op. Cit. 
por conseguir la calificación y el reconocimiento de sus estudios y titulaciones, basándose en el Decreto de 16 de junio de 1905 (Gaceta del 17 de junio) sobre la concesión de validez académica oficial de las enseñanzas de conservatorios de música municipales y provinciales.

Es patente, pues, el enorme interés que tienen los centros de estudios profesionales en obtener el reconocimiento oficial y del más alto rango para los estudios que imparten, ya que hasta el momento sólo tenía carácter de Conservatorio Superior el Real Conservatorio de Madrid.

Ello conlleva un primer momento de confusión y se produce un intento de cambio significativo en los estudios musicales de los conservatorios.

Primero se concedió validez académica a los estudios de Grado Superior que se cursaban en el Conservatorio Municipal de San Sebastián (Orden 15 de abril de 1939 BOE 19 de abril) e inmediatamente se constituye la comisión para reorganizar dichos estudios (Orden 10 de junio de 1939, BOE 25 de junio)..

Este reconocimiento de validez académica (que en ningún caso se explicita con referencia a otras titulaciones), conlleva la inmediata creación de otra comisión para reorganizar los estudios del Conservatorio Nacional de Música y Declamación de Madrid (Orden 19de junio de 1939, BOE 26 de junio), al que siguen los de Zaragoza (Orden 19 de junio de 1939, BOE 30 de junio) y Cádiz (Orden 25 de agosto de 1939, BOE 7 de septiembre).

Pero dada la premura por empezar el curso, todas estas comisiones se disuelven y se constituye una única comisión formada exclusivamente por catedráticos del Conservatorio de Madrid (Orden 16 de septiembre de 1939, BOE 27 de septiembre). Ello supone la clarísima opción por una centralización absoluta por parte del estado.

\subsection{2.a Decreto de 15 de junio de 1942}

Esta reorganización culmina en el Decreto de 15 de junio de 1942 (BOE de 4 de julio) por el que se reorganizan los conservatorios y que deroga la legislación anterior (Real Decreto de 16 de junio de 1905). Las intenciones centralizadoras que asume el estado, la restricción de la validad de los títulos y 


\section{La educación musical en el franquismo}

la regulación de los planes de estudio a nivel estatal, se hacen patentes en el texto del decreto, así como las vinculaciones ideológicas que hay en toda legislación de esta época inicial del franquismo y que se plasman en el lenguaje empleado en las consideraciones previas.

“Es preocupación primordial del Gobierno el resurgimiento de la cultura y del arte patrios y la educación de la sensibilidad pública con una sólida formación espiritual y artística, mediante una enseñanza bien organizada. Para contribuir a tales fines es preciso abordar de una vez y a fondo el problema de la educación musical, del arte dramático y de las danzas artísticas y folklóricas, tal como en los conservatorios oficiales ha de plantearse.

Estas enseñanzas no han tenido, en nuestra Patria, a pesar de laudables intentos, un plan orgánico y bien determinado. El único centro docente regulado por el Estado fue el Real Conservatorio de Madrid (...) Surgieron después en varias iniciativas por iniciativa privada las más de las veces, centros de enseñanza musical y de declamación, que si bien obedecían a un buen deseo, no se hallaban debidamente fiscalizados por el Estado, ni siguieron en sus planes aquellas normas de orientación obligadas en establecimientos de esta naturaleza.

El Real Decreto de 16 de junio de 1905 ha servido desde entonces de norma para la creación de conservatorios de tipo diferente, sin plan fijo unitario ni verdaderamente pedagógico. Es, pues, urgente la reforma, que será el punto básico de partida para la reorganización de todos los Conservatorios españoles"

Efectivamente, el decreto 15/06/42 establece:

- Los tipos de Conservatorios: Elementales, profesionales y Superior

- Qué categoría tienen los conservatorios reconocida:

1. Superior: Sólo el Conservatorio Nacional de Música y Declamación de Madrid

2. Profesionales: Córdoba, Málaga, Murcia, Sevilla, Valencia, Bilbao, Zaragoza, Tenerife y Coruña, que tienen "dotaciones generales 0 especiales en la Ley económica.

3. Los conservatorios subvencionados o con validez académica de Cádiz, Salamanca, Oviedo, Baleares, Ceuta, San Sebastián, Santander, Vitoria y Valladolid, conservarán su situación hasta entonces (conservatorios elementales) 


\section{Capítulo 2. El marco legal}

4. La Escuela Municipal de Música de Barcelona obtiene la categoría de Conservatorio Profesional (siempre que se sujete a las condiciones establecidas en el decreto)

5. El conservatorio del Liceo de Barcelona es considerado conservatorio elemental (siempre que se sujete a las condiciones establecidas en el decreto)

- Las enseñanzas que se pueden cursar en cada tipo de conservatorio

- Por qué miembros debe estar formado el equipo directivo de cada tipo de conservatorio

- Se diferencian los cuerpos de profesores según el tipo de conservatorios

1. Catedráticos numerarios, Profesores especiales y auxiliares numerarios para el Conservatorio de Superior de Madrid y conservatorios profesionales.

2. En los conservatorios elementales sólo puede haber profesores especiales y auxiliares.

- El acceso al cuerpo de Catedráticos Numerarios y Profesores Especiales se realiza mediante concurso-oposición en Madrid ante un tribunal nombrado por el Ministerio de Educación Nacional.

- El acceso al cuerpo de profesores auxiliares se realiza por concursooposición en los conservatorios respectivos. Y explicita que "los profesores especiales y auxiliares, percibirán sus haberes en concepto de sueldo o gratificación"

- Se crea una Inspección General de Conservatorios

Esta es la primera gran ley reguladora de los estudios, titulaciones, profesorado concernientes a los conservatorios de la época franquista. Hasta su posterior reforma en 1966, es el marco regulador de los estudios de música en los conservatorios. J erarquiza, centraliza y unifica los cuerpos de profesorado y los tipos de enseñanza. 
En 1944, y tras "un estudio más detenido de la cuestión" se transforma la crea un nuevo Conservatorio Superior de Música y Declamación en Barcelona. Y las funciones docentes se separan (Decreto 26 de enero de 1944, BOE 16 de febrero):

- La Escuela Municipal de Música y el Conservatorio del Liceo asumen la docencia musical

- El Instituto del Teatro de la Diputación de Barcelona asume las enseñanzas de declamación y danza.

También en este año empiezan a transformarse la calificación de otros conservatorios y pasan de ser conservatorios elementales a conservatorios profesionales los de San Sebastián (Decreto 29 de abril de 1944, BOE 7 de mayo).

Este ejemplo se extiende poco a poco a otras ciudades, y así van consiguiendo el reconocimiento como Conservatorios profesionales los de Ganada (Decreto de 14 de mayo de 1948, BOE 23 de mayo), Pamplona (Decreto 20 de abril de 1951, BOE 4 de mayo, aunque parece que no se crea definitivamente hasta el Decreto de 21 de agosto de 1956 , BOE 20 de septiembre), Valladolid (Decreto 10 de febrero de 1956, BOE 20 de febrero) y Oviedo (Decreto 21 de febrero de 1958, BOE 6 de marzo).

Se crean también varios conservatorios elementales como los de Santiago de Compostela - se le concede el grado de conservatorio elemental a la Escuela de música de los Amigos del País - (Decreto 9 de enero de 1953, BOE 2 de febrero), Albacete (Decreto 12 de febrero de 1954, BOE 23 de febrero), Tarragona - se le concede el grado de conservatorio elemental al Instituto Musical de F.E.T. y de las J.O.N.S. - (Decreto 28 de mayo de 1954, BOE 8 de junio), Gerona (Decreto 6 de octubre de 1955, BOE 8 de agosto), Pontevedra y Vigo (Decreto 14 de junio de 1957, BOE 17 de julio), Tarrasa (Decreto 21 de febrero de 1958, BOE 5 marzo), Las Palmas, Lérida y Sabadell (Decreto de 21 de febrero de 1958, BOE 6 de marzo), Jaén (Decreto 9 de mayo de 1958, BOE 11 de junio), León (Decreto 24 de 
septiembre de 1958, BOE 15 de octubre), Manresa (Decreto 26 de febrero de 1959, $B O E 7$ de marzo), el de Orense (Decreto 3 de diciembre de 1959, BOE 15 de diciembre).

Tras esta regularización, muchas otras provincias consiguen tener nuevos conservatorios y escuelas de música en muchos casos promovidos y fuertemente ligados a las instituciones locales: diputaciones y ayuntamientos y a veces a algunas instituciones musicales (la banda, hermandades y cofradías, sociedades particulares). De esta manera, una gran parte del personal docente de los conservatorios es contratado por la administración local, y en algunos casos incorporados a la administración local por medio de concursos internos y oposiciones, convirtiéndose en funcionarios del ayuntamiento o la diputación respectiva. Dichas instituciones eran también las encargadas de conseguir las dotaciones económicas, locales e inmuebles en los que impartir los estudios, material musical y docente, contratación y pago de personal docente y administrativo, y en algunos casos, de supervisar el plan de estudios y la incorporación de nuevas especialidades. De esta manera, se generaliza por todo el país una red de conservatorios con dependencia local unificados por el plan de estudios propuesto por la ley, pero con gran diversificación de medios, aplicación del plan de estudios y sin una validación de las titulaciones obtenidas dentro del sistema general educativo: se trataba de una titulación profesional si se llegaba al grado medio que capacitaba para el ejercicio de la profesión (en cualquier caso, incluso hoy, el acceso a las orquestas se realiza mediante pruebas en las que hay que tocar y no en relación con la consecución de un título académico). La auténtica validez del título académico, pues, se refiere sobre todo a la capacitación de personal docente para los propios conservatorios y otras instituciones educativas.

\subsection{2.b Decreto de 10 de septiembre de 1966}

Los años 60 suponen una revolución económica y también cultural para el país. En 1966 se introduce una nueva ley de conservatorios que - al igual que su homóloga del sistema educativo general (Ley General de Educación de Villar 


\section{La educación musical en el franquismo}

Palasí, 1970) - intenta adaptar la educación musical profesionalizada a los nuevos tiempos y solucionar la necesidad de reconocimiento de las titulaciones, iniciando el proceso de integración dentro del sistema general educativo.

El Decreto de 10 de septiembre de 1966 (BOE de 24 de octubre) introduce la Reglamentación General de los Conservatorios de Música que ha regido la vida musical académica hasta la entrada en vigor de la LOGSE.

Su introducción ideológica nos habla de "la preocupación del Estado español por el resurgimiento de la cultura y del arte patrios y la educación de la sensibilidad pública con una sólida formación espiritual y artística" y de la necesidad de "armonizarnos con las modernas orientaciones en la organización de las enseñanzas de la música (...) en relación a las fórmulas frecuentes en los estudios de música de los conservatorios extranjeros"

Este interés por la apertura a lo que se está haciendo en otros centros de música europeos habla por sí solo del ambiente aperturista y el cambio ideológico que se pretende en la segunda mitad del franquismo. No obstante, seguimos con la idea de vincular la formación espiritual y las enseñanzas artísticas como leit motiv constante a lo largo del período histórico que nos concierne..

El texto legal se concentra en varios puntos:

- Clasificación de conservatorios oficiales en Estatales / No estatales

1. Los estatales son aquellos creados con dicha calificación y sostenidos con fondos públicos por el Estado.

Su profesorado tiene que ingresar en los cuerpos correspondientes mediante Concurso-oposición, en Madrid, ante un tribunal nombrado por el MEC. Hay tres categorías de profesorado: Catedráticos, Profesores Especiales y Profesores Auxiliares

Son los siguientes:

Conservatorio Superior de Madrid

Conservatorios Profesionales de Córdoba, Málaga, Murcia, Sevilla y Valencia 


\section{Capítulo 2. El marco legal}

1. Los no estatales son aquellos creados y sostenidos por corporaciones locales (provincias y municipios) u otras entidades públicas.

Se reconoce en el propio decreto que su creación era una "necesidad imperiosa al no existir centros estatales nada más que en seis capitales de provincia, y cómo el decreto de 16 de junio de 1905 abrió una vía de la cual han surgido la mayor parte de los conservatorios con validez académica oficial de sus enseñanzas". Se alaba la "organización y prestigio verdaderamente ejemplares" de algunos de ellos, y se reconoce la "vida precaria por falta de los medios económicos para su sostenimiento" de otros. E incluso se explicita con toda claridad la conveniencia de que se establezcan nuevos centros de este tipo ya que "satisfacen adecuadamente una necesidad social, sin carga económica para el Estado"

El profesorado es contratado por las entidades locales y sólo en el caso de provisión de plazas en propiedad accede por oposición o concurso-oposición libre, convocado por la entidad de la que dependa el centro, ante un tribunal constituido por tres miembros de los cuerpos de conservatorios del estado y otros dos vocales propuestos por el director del propio conservatorio. Su régimen jurídico es el propio de la entidad de la que dependen.

En el momento de promulgarse el decreto eran conservatorios no estatales de estudios de validez reconocida los siguientes:

Conservatorio Superior de Barcelona

Conservatorios Profesionales de Alicante, Bilbao, Coruña, Granada, Oviedo, Pamplona, San Sebastián, Santa Cruz de Tenerife, Valladolid y Zaragoza.

Conservatorios Elementales de Albacete, Baleares, Burgos, Cádiz, Cartagena, Cuta, Gerona, Jaén, Jerez de la Frontera, Las Palmas, León, Lérida, Logroño, Manresa, Orense, Pontevedra, Sabadell, Salamanca, Santander, Santiago de Compostela, Tarragona, Tarrasa, Vigo y Vitoria.

2. Conservatorios de música no oficiales. Hay dos tipos: autorizados y reconocidos, que se rigen por el Reglamente General de Centro no 


\section{La educación musical en el franquismo}

oficiales de enseñanzas artísticas. El decreto no explicita nada en cuanto a sus estudios, títulos, cualificación del profesorado y los ignora totalmente, haciendo constar su existencia sólo en el artículo cuarto de la ley.

Se siguen mantenido los tres grados de titulaciones y de tipos de conservatorios: Superiores, profesionales y elementales. Los estudios conducentes a estas titulaciones sólo pueden ser cursados en conservatorios del grado correspondiente.

Los títulos de profesor superior son expedidos únicamente por el Ministerio de Educación y Ciencia, y los demás títulos y diplomas (instrumentista o cantante) son expedidos por los propios conservatorios con la firma de su director y secretario.

Explicita así mismo las funciones profesionales para las que capacita cada una de las titulaciones. El título de Profesor Superior es obligatorio para la enseñanza como Profesor Especial o Catedrático en los conservatorios superiores y profesionales. El título de Profesor capacita para ejercer la enseñanza musical en centros públicos y privados, para ser profesor de conservatorios elementales y para ser Auxiliar en conservatorios profesionales y superiores. El diploma de instrumentista o cantante capacita para ingresar en entidades de tipo profesional musical y sindical. El diploma elemental se exigirá para desempeñar funciones directamente relacionadas con la música en bibliotecas y discotecas. En principio, dicha distribución supone que se "acentúa debidamente su significación haciéndolos obligatorios para el ejercicio de determinadas actividades profesionales"

La Reglamentación introduce algunas novedades:

- Además de la enseñanza profesional, los conservatorios "serán autorizados a tener una sección de enseñanza no profesional como formación cultural complementaria, de menor rigor, y sin valor académico. Los programas de ésta serán de menor contenido y profundidad. Con ello se pretende "dar estado legal a una tradicional 
realidad nacional a la vez que se acepta una fórmula muy frecuente en los estudios de música de los conservatorios extranjeros"

- Todos los conservatorios deberán organizar cursos preliminares de canto coral, independientes del Solfeo y la Teoría de la música, destinados

"a despertar en los alumnos el interés por la música, practicando canciones populares correctamente armonizadas a dos y tres voces y obras sencillas de autores eminentes".

- Permite a los conservatorios organizar cursillos intensivos o cursos especiales con profesores invitados, nacionales o extranjeros

- La Inspección del Estado sobre toda clase de conservatorios, será ejercida por el Ministerio de Educación y Ciencia a través de la Inspección General de conservatorios o de inspectores extraordinarios nombrados para casos especiales. La inspección no sólo fiscalizará sino que "impulsará la renovación y perfeccionamiento de los métodos educativos"

- Finalmente, deroga las leyes anteriores de 1905 y 1942, y el decreto de 11 de marzo de 1952 por el que se habían separado los cuerpos de Conservatorios de Música y los de Declamación, conservando en vigor la parte relativa a las Escuelas de Arte dramático.

\subsection{LAS LEYES DE EDUCACIÓN}

El franquismo fue plenamente consciente en su deseo de cambiar el sistema educativo y las interesantes - pero breves en su aplicación temporal innovaciones que había introducido la izquierda durante la república: modernización del sistema de financiación y estatalización de la enseñanza, la aplicación de una filosofía social y pedagógica derivada del Krausismo con gran influencia de la Institución Libre de Enseñanza, la pretensión de hacer de la instrucción el factor principal de la promoción social en base exclusiva al mérito y no a las clases sociales establecidas, su extensión e importancia como elemento del cambio social, la neutralización ideológica y el laicismo (apartando 


\section{La educación musical en el franquismo}

a las congregaciones religiosas de la enseñanza a través del artículo 30 de la Ley de Congregaciones religiosas).

Después de la guerra civil se embarca en una profunda reforma del sistema con una fuerte carga ideológica que justificara la contienda y que transmitiera una serie de valores muy diferentes a los que se habían divulgado durante la época de la república.

\subsubsection{La educación musical en las escuelas primarias}

La educación musical a la que se refiere siempre el sistema educativo consiste fundamentalmente en el canto. Esta atención a la canción como elemento central de la educación musical aparecía ya en la época republicana y tiene desde el primer momento mucho que ver con la mejora del manejo y control de la voz (sistema respiratorio, dicción, entonación). Pero el franquismo va a hacer de ella un instrumento de transmisión ideológica de primer orden a través de la selección y obligatoriedad de aprendizaje de determinados repertorios en todo el estado.

En una primera etapa, efectivamente la educación musical del país se realiza a través del canto, del aprendizaje y repetición de las canciones seleccionadas hasta configurar un repertorio unificado en todo el territorio español de los llamados "cantos patrióticos", mediante procedimientos fundamentalmente imitativos.

El canto grupal y monódico es la forma fundamental de interpretación musical escolar. Para ello es necesario el buen ejemplo vocal del maestro, para quien la principal dificultad consciente suele ser la inseguridad en la entonación.

La actividad coral es una actividad básica e intuitiva que realizan todos los niños por imitación, por lo que en sí misma no significa un proceso de especial dificultad, pero en el franquismo fue una actividad obligatoria, dirigida y utilizada para la transmisión de otro tipo de conceptos ideológicos, unos más conscientes que otros. La obligatoriedad de cantar en las escuelas se realizaba no siempre de manera vinculada a las actividades educativas, sino en otras actividades (cantar determinados repertorios al entrar en formación a las aulas, 
cantos en las actividades de carácter religioso, himnos ideológicos asociados a la formación política en los actos de carácter oficial).

\subsection{1.a. Hasta la ley de Educación Primaria de 1945}

Desde el año 1857 en que se publica la Ley de Instrucción Pública o Ley Moyano no se dictaron Leyes Generales de Educación hasta la ley de Educación Primaria de 1945, y los cambios que se introdujeron fueron modificaciones por medio de decretos, entre los que destacan la Reforma de Romanones (1901) y las llevadas a cabo en 1923 y 1931 (Dictadura de Primo de rivera y la 2a República respectivamente). No por falta de interés, seguramente, sino por falta de tiempo material para llevar a cabo una transformación profunda como es siempre un cambio legislativo a nivel de educación general y su aplicación en todo el país. Dado lo convulso de la situación política del primer tercio del siglo XX en España, que finalmente desembocó en una guerra civil, era casi imposible obtener el consenso político necesario para la elaboración de una reforma legislativa de tal magnitud.

Se libraron en este período auténticas batallas ideológicas desde el punto de vista del concepto de educación y su aplicación. La legislatura de izquierdas durante la república intentó llevar a cabo un cambio de tal significación que el propio Manuel Azaña, a la altura de la crisis de 1933, y preguntándose sobre las razones que pudieran explicar la caída del régimen decía - según recoge Ramos Oliveira ${ }^{77}$ :

"Cada vez que repaso los anales del Parlamento Constituyente y quiero discernir dónde se jugó el porvenir de la política republicana y dónde se atravesó la cuestión capital que ha servido para torcer el rumbo de la política, mi pensamiento y mi memoria van inexorablemente a la Ley de Congregaciones Religiosas, al artículo 26 de la Constitución, a la política laica, a la neutralidad de la escuela, a todo lo que se ha derivado de bienes, de esperanzas y de rigores de justicia del principio asentado en la Constitución de la República, contra lo cual se hanb desarrollado todas las maniobras visibles e invisibles que han sido capaces de suscitar una reacción contra nosotros para ver si nos hacía naufragar y, por último, confesémoslo, nos ha hecho naufragar y hemos naufragado"

${ }^{77}$ RAMOS OLIVEIRA, A. Historia de España, Tomo III. México: Compañía General de Ediciones 


\title{
La educación musical en el franquismo
}

La cuestión educativa, la concepción de la escuela y su papel como elemento de estructuración de la sociedad fue vital e incluso uno de los ejes desencadenantes de la extrapolación de la sociedad española y de la propia guerra civil. Los intereses (económicos e ideológicos) que se hallaban en juego, coletean por la historia contemporánea de nuestra país desde entonces como uno de los más importantes elementos de conflicto social y político.

La educación musical no es ni mucho menos de interés para el enfrentamiento (siempre se le ha dado un carácter secundario dentro de la educación española) pero su concepción posterior y la forma en que se va a organizar después de la guerra sí se ve afectada claramente por las dos grandes tomas de postura enfrentadas que entran en conflicto: la escuela estatal por un lado y la escuela religiosa por otro, y en su lucha por la hegemonía educativa.

Ello no quiere decir que no esté presente la educación musical, ya que era obligatoria en las escuelas, pero según Oriol $^{\mathbf{7 8}}$ (2005)

"la música en la Educación Primaria y Secundaria sólo se contemplaba mediante la enseñanza de canciones populares y patrióticas".

Tenemos pocas referencias específicas a la educación musical en las escuelas anteriores a la publicación de la Ley de Educación Primaria de 1945, pero de esas pocas reseñas se pueden sacar algunas conclusiones.

1940 fue el año de la creación mediante la Orden de 27 de abril de 1940 (BOE de 1 de mayo) de la Comisaría General de Música dentro de la Dirección General de Bellas Artes ante

\begin{abstract}
"la urgencia por reanudar e intensificar la vida musical española, dificultada durante los años gloriosos de lucha y liberación, y el deseo del nuevo Estado de conceder a la música toda la atención que merece, tanto por lo que sustantivamente significa dentro de las Bellas Artes, como por su alto e insustituible valor educativo en la formación espiritual y en la disciplina de la nueva juventud española".
\end{abstract}

De hecho en su artículo 1 o expone que se crea dicha comisaría para

\footnotetext{
${ }^{78}$ ORIOL, N (2005) La música en las enseñanzas de régimen general en España y su evolución en el siglo XX y comienzos del XXI. En Revista electrónica Europea de Música en la Educación LEEME. 16. Universidad de la Rioja y Rediris CSIC. http://musica.rediris.es . Parte de este artículo fue publicado como "La formación del profesorado de música en la Enseñanza General" en Revista Música y Educación, Año XII, oo 37.
} 
estudiar y proponer a la superioridad resoluciones sobre todo lo referente a la educación y cultura musical de nuestra patria.

Dicha primera Comisaría General estaba formada por el Padre Nemesio Otaño, Joaquín Turina y Antonio José Cubiles. No obstante, al año siguiente, se remodelará en el Consejo Nacional de Música por la Orden de 3 de abril de 1941 (BOE de 8 de abril), del que forman parte el Padre Nemesio Otaño como presidente y José Cubiles, Victor Espinós, Facundo de la Viña, Jesús Guridi, Antonio Tovar, José Roda y el marqués de Bolarque. A su vez, la Comisaría General de la Música queda constituida por sólo dos miembros: J oaquín Turina como Comisario y Federico Sopeña como Secretario.

También en estos años se crea la Orquesta nacional por medio de la Orden de 12 de junio de 1940 (BOE de 20 de junio), su dotación de plantilla y remuneraciones en la Orden de 10 de marzo de 1941 (BOE de 16 de marzo) y se convocan oposiciones al cuerpo de directores de bandas de música en la Orden de 9 de julio de 1940 (BOE de 12 de julio).

Por el contrario, la vida musical más lúdica sufría una estricta regulación y censura a través del Consejo Nacional de Teatros y espectáculos y la suspensión de licencias de apertura para nuevos cabarets y dancings, así como la censura y apertura de expedientes a los que estaban en servicio.

Que se estaba enseñando música en los centros escolares era evidente, pero las reseñas que de ellos tenemos en la legislación anterior a 1945 y posterior a la guerra son escasas.

Tenemos constancia de que se enseñaba música en la escuela primaria porque en la Orden de 13 de marzo de 1941 (BOE de 22 de marzo) se regula el funcionamiento de las clases complementarias:

\footnotetext{
"Establecidas las clases complementarias en el mayor número posible de grupos escolares, según deseo de justicia de esta Dirección General de Primera Enseñanza y con la esperanza de ampliarlas cuando los presupuestos del Estado lo permitan, se tendrán en cuenta por los señores directores de las mismas las siguientes indicaciones: 1o Funcionarán durante los ocho meses de enero a mayo y de octubre a diciembre, todos inclusive. $2^{\circ}$ Se dedicará a las mismas, como mínimo, una hora alterna a cada clase, siempre fuera de las horas reglmentarias de la escuela, excepto la clase de
} 
Música y rítmica, que podrá darse dentro del horario escolar, cuando sean ejercicios de conjunto, si así se considera conveniente. 3o Los directores vienen obligados a presentar ante la Dirección general el horario destinado a cada clase, con el fin de que puedan ser visitadas oportunamente. 4ํㅡ Ha sido deseo de esta Dirección indicar que los señores directores desempeñen una clase, que ésta sirva de modelo en su funcionamiento y orientación, pudiendo, sin embargo, nombrar profesor que le sustituya, si así lo estima oportuno y sus obligaciones le impiden desempeñarla.50 Como orientación general se tendrá siempre en cuenta que estas clases son de FORMACIÓN ${ }^{79}$, eminentemente prácticas, y por lo que al presente año afecta, con tendencia a que las realizaciones en estas clases obtenidas puedan ser materia de una exposición escolar pública (..) 8o Esta Dirección General confía y espera del celo de los señores directores y maestros al encomendarles las clases complementarias"

La extensión en la cita se debe a que algunos de los aspectos que se reseñan en esta orden del BOE hacen patentes los serios problemas con los que se ha de enfrentar la educación musical: carácter complementario de los estudios, horario extraescolar excepto para la sesiones en grupo, falta de dotación presupuestaria, asignación dudosa del profesorado que tiene que impartirlas, confianza en la buena actitud al respecto de directores y maestros, y levísima alusión a la vigilancia de su cumplimiento por parte de la Inspección educativa.

En lo referente a la enseñanza secundaria y la presencia de la educación musical en las mismas es muy significativo el texto de la Orden de $\mathbf{3 0}$ de junio de 1941 (BOE de 14 de agosto) sobre la creación de Escuelas del Hogar en los Institutos Femeninos de Enseñanza Media, por la que se crean las plantillas de la siguiente manera:

"Directora, una maestra propietaria de escuela nacional, percibiendo su dotación con cargo al primer escalafón. Profesoras: Una de Economía doméstica, otra de Labores, otra de Corte, otra de Trabajos manuales, zurcido y repaso, una de música, un médico puericultor y una auxiliar secretaria", todas ellas con una dotación económica que en relación al profesorado de institutos resultaba superior a los otros docentes. Mediante el Artículo 2ํㅡ, además, especifica que “el nombramiento del personal será realizado por el Ministerio a propuesta de la Sección Femenina de Falange Española Tradicionalista y de las J.O.N.S"

${ }^{79}$ Las mayúsculas son del BOE original 


\section{Capítulo 2. El marco legal}

Aunque superficialmente esta orden parece tener un carácter menor, es de vital importancia, ya que la educación Secundaria será desde este momento regulada de esta manera: diferenciación de género en la enseñanza musical en la educación secundaria, favorable claramente a las mujeres y bajo instrucción del personal de Sección Femenina asignado a los centros de Enseñanzas Medias. La Orden hace alusión expresa a la obligación y dotación de estas plazas en los Institutos "Beatriz Galindo "e "Isabel la Católica" de la capital, y por ende, a su extensión a todo el territorio nacional.

Sabemos también que se impartía en las Escuelas de Magisterio (donde en principio seguía rigiendo el plan de estudios 1931) porque se hace alusión a la supresión de dos plazas en las Escuelas Femeninas y que su docencia será retomada por el docente en vigor en las masculinas (Sevilla y Murcia).

\subsection{1.b. Ley de Educación Primaria. 17 de junio de 1945 (BOE 18 de julio)}

Conforme a la retórica de los primeros años del régimen de Franco, la ley tiene una introducción larga de carácter ideológico en la que se explicitan algunas de las directrices de las líneas de pensamiento sobre las que se construye.

Para empezar, se considera a sí misma una renovación imprescindible después de la guerra civil al declarar:

\footnotetext{
"una nueva ley de educación primara, que por su propia esencia afecta tan hondamente a la sustancia espiritual de un pueblo y que por lo extenso de su aplicación y la intensidad y trascendencia de su contenido tan certeramente caía en la entraña íntima y en al zona vital de la nación, presupone unos (...) sólidos cimientos en los que hayan de estrecharse en firme soldadura la propia experiencia histórica y la ambición renovadora que la evolución de los tiempos reclama. España no puede afrontar una transformación que significa para el mañana después de su última victoria contra el materialismo ateo, la supervivencia de su ser histórico, la paz interior y el desenvolvimiento de su potencial espiritual, a través de la generaciones fecundas que hoy son la infancia, niñez y juventud, sin un anudamiento y enlace con la tradición pedagógica nacional."
}

En otras palabras, es una ley de vencedores, con afanes de justificación tradicionalista. 


\section{La educación musical en el franquismo}

La constante pugna interior entre la iglesia y el monopolio falangista dan origen a un tipo de vinculación estado-iglesia que se plasma en esta ley de educación en lo que llamamos nacional-catolicismo y cuya génesis y características tan bien analiza Cámara Villar ${ }^{\mathbf{8 0}}$ (1984). Según se desprende de su análisis, la época inmediatamente posterior a la guerra civil se caracteriza por

"el enfrentamiento entre dos concepciones básicas de la escuela definidas e inspirados por dos universos ideológicos opuestos y (...) es la dimensión que más determinaría la política educativa posterior a la sublevación militar, el apoyo prestado por la Iglesia y los sectores católicos a ésta y, en contrapartida, la gran influencia obtenida por éstos y las órdenes (religiosas) docentes sobre la educación nacional".

\section{Según Rubio Llorente ${ }^{81}$ (1974)}

"el sentido de una política educativa viene dado por la opción a favor de una u otra de las alternativas que se ofrecen respecto de las cuestiones básicas: valores y aptitudes que se pretenden inculcar e intensidad de ese adoctrinamiento; estructura del sistema educativo y apertura de sus distintos niveles a los diferentes estratos sociales, mayor 0 menor autonomía del sistema cultural, con primacía de los valores culturales o subordinación de éstos a los políticos o económicos"

En lo que respecta al sistema educativo fue patente en el primer franquismo la clara opción por la "catolización" de la escuela, la prioridad de la enseñanza privada de carácter religioso en la enseñanza secundaria y la depuración e intensificación de los procesos de adoctrinamiento en el cuerpo de maestros, especialmente grave en los últimos años de la guerra y finalmente institucionalizada en el período ministerial de Ibáñez Martín (1939-1951), bajo cuyo mandato se configura y promulga la ley general de Educación de 1945.

La auténtica batalla por el poder ideológico dentro de la educación que se libra entre la Iglesia y Falange se plasma en la propia sección introducción de la ley. Esta situación de inestabilidad repercutirá, desde nuestro punto de vista, decisivamente en el futuro de la educación musical en España, permitiendo una doble vía en la que se diluía la responsabilidad de la formación y la confusión con respecto a su propio carácter como materia y sus contenidos. Y llevó a la

\footnotetext{
${ }^{80}$ CÁMARA VILLAR, G (1984). Nacional catolicismo y escuela. La socialización política del Franquismo (1936-1951) Jaén, Hesperia.

${ }^{81}$ RUBIO LLORENTE, F. (1974) La política educativa. En La España de los años 70. Vol. III Madrid: Editorial Moneda y Crédito
} 


\section{Capítulo 2. El marco legal}

disgregación en sectores ideológicamente enemistados y competitivos entre sí de la introducción de la innovación pedagógica en la educación musical, lo que no hizo sino restarle fuerza y provocar la disparidad de criterios y formas de enseñar.

Así, tras desacreditar la educación de la etapa republicana, "la nueva ley invoca entre sus principios inspiradores como el primero y más fundamental, el religioso (...) que en armonía con la tradición ha de ser ante todo católica"

Y al mismo tiempo, "además, la escuela en nuestra patria ha de ser esencialmente española. $Y$ en este aspecto, la ley se inspira en el punto programático del Movimiento Nacional por el que se supedita la función docente a los intereses supremos de la Patria"

Entre sus objetivos destacan en el artículo 10 los apartados b).- "formar la voluntad, la conciencia y el carácter del niño en orden al cumplimiento de su deber y a su destino eterno" y c).-infundir en el espíritu del alumno el amor y la idea del servicio a la Patria, de acuerdo con los principios inspiradores del Movimiento

En el Capítulo IV, artículo 37, se clasifican las materias en tres tipos:

- Instrumentales (lectura interpretativa, escritura ortografía, redacción , dibujo y cálculo),

- Formativas, consideradas las "bases de la educación moral e intelectual" (primero formación religiosa, segundo la formación del espíritu nacional - incluidas la geografía y la historia, especialmente de España -, tercero formación intelectual -que incluye la lengua nacional y las matemáticas y cuanto la educación física.

- Complementarias, como la iniciación a las Ciencias de la naturaleza, las que tienen carácter artística (música, canto y dibujo) o utilitario (trabajos manuales, prácticas de taller y labores femeninas)

Así pues, como se puede apreciar, la educación musical sí estaba presente en la ley del 45 (al menos tanto como las ciencias naturales o las labores femeninas). 
En el artículo 38 de la ley, se especifica que los cuestionarios de "formación del espíritu nacional, educación física, iniciación para el hogar, canto y música serán redactados por los organismos competentes".

Es más, en el artículo 43 de la ley se hace alusión expresa a la extensión cultural en la escuela, calificándola como "misión de la escuela en la formación del ambiente cultural de la localidad que se completará con la utilización de práctica que hagan del maestro el propulsor entre el elemento popular de cuanto signifique cultura en todos los aspectos de la vida".

El Capítulo V de la ley, dedicado a las actividades complementarias de la escuela, especialmente en sus artículos 44 y 45 tienen una gran importancia para algunos de los postulados básicos a partir de los cuales se realiza este trabajo de investigación, pero serán analizados, como corresponde en principio a la formación extraescolar, en el apartado de la educación no formal.

Efectivamente, los Cuestionarios de Enseñanza Primaria fueron publicados en 1953 y más tarde revisados en la Orden de 8 de julio de 1965 (BOE 24 de septiembre)

\subsection{1.b.I. Cuestionarios de Enseñanza Secundaria de 1953}

La Ley de 26 de febrero de 1953 (BOE de 27 de febrero) sobre Ordenación de la Enseñanza Media recoge en el Capítulo II sobre el profesorado, en el artículo 45 que "podrá nombrarse profesorado especial en los centros oficiales para el desempeño de las clases de lenguas modernas, enseñanzas artísticas, trabajos manuales y de todas aquellas materias que puedan ser establecidas con carácter complementario. Disposiciones especiales determinarán la titulación exigible a este profesorado. El profesorado especial de formación del espíritu nacional y de educación física, así como el de enseñanza del hogar será designado de acuerdo con las Delegaciones Nacionales del Frente de Juventudes y de la Sección Femenina de las FET y de las JONS.

En la Orden de 3 de noviembre de 1953 (BOMEC de 19 de noviembre, 3 y 7 de diciembre de 1953 y 22 de febrero de 1954) sobre Reglamento 
General de los centros de Enseñanza Media y Profesional se contempla en el artículo 44 que "la educación de las alumnas será completada con las enseñanzas del hogar" en la que se contempla la Música y está asignada a Sección Femenina.

Igualmente, el en artículo 46 se expone que "la educación patriótica corresponde al profesor del Espíritu nacional(...) y habrá de abarcar c.Cantos nacionales y patrióticos.

En el artículo 50 se explicita que "la educación artística tratará de fomentar en los escolares el amor a las Bellas Artes, su sensibilidad estética y su urbanidad social. Serán sus medios (...) b.- La organización de coros y orfeones, rondallas y cuadros de declamación, c).- Veladas artísticas y sesiones musicales

Los cuestionarios correspondientes se publicaron en la Orden de $\mathbf{2 1}$ de enero de 1954 (BOMEC de 10 de febrero de 1954) y en él se especifica que las disciplinas a las que se refiere son Religión, Filosofía, Gramática española y lengua y literatura españolas, griego, latín, geografía e historia, matemáticas, física y química, ciencias naturales, música y dibujo, y sus orientaciones metodológicas.

La Música, que aparece sin más acompañantes ni epítetos como asignatura independiente, está presente en todos los cursos con el siguiente cuestionario.

Música

10 y $2^{\circ}$ cursos.

a.- Nociones del solfeo. Las indispensables, si no han sido ya adquiridas en la escuela preparatorio, para la lectura musical de las canciones que deban ser cantadas a coro.

b.- Lección coral. Estudio e interpretación en conjunto, a una o dos voces de las siguientes materias: canciones populares españolas, canciones populares extranjeras, canciones antiguas y viejos romances españoles, misas 


\section{La educación musical en el franquismo}

gregorianas, repertorio elemental latino gregoriano y popular religioso español

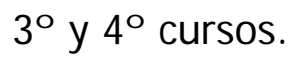

a.- Lección coral. Continuación de los cursos primero y segundo

b.- Introducción a al música. Audición de obras o fragmentos de difícil comprensión, con explicaciones y ambientación previa del profesor

5은 curso

a.- Primer curso de Historia de la música. Siglos XV al SVIII. Con ejemplos musicales

b.- Práctica coral. Continuación del repertorio de canciones populares y religiosas, y coro seleccionado de alumnos (aquí la ley no hace ninguna alusión a que esta sea una materia para alumnas o que haya diferencia en el tratamiento de sexos)

6응 curso

a.- Segundo curso de Historia de la Música. Siglos XIX y XX

b.- Práctica coral. I gual que en quinto curso.

Orientaciones metodológicas.

1. La práctica coral es indispensable para todos los alumnos, salvo aquellos que demuestren notoria incapacidad musical. Los Institutos Nacionales y Centros no oficiales reconocidos, crearán, además, un coro con alumnos seleccionados, bajo la dirección del profesor de música.

2. Para la "Introducción a la música" serán utilizados principalmente discos. Los centros deberán formar su discoteca propia. El profesor debe ilustrar los ejemplos musicales con concisas y amenas orientaciones verbales. 
3. Las características metodológicas de la "Historia de la Música" son muy similares a las de la "Historia del Arte" en general. Debe tenerse presente que las nociones teóricas e históricas carecen de valor si no van acompañadas del ejemplo sonoro que las convierte en historia viva. Para la Historia de la música, además de los discos y del empleo de magnetófonos, radio, etc, se podrá también acudir al complemento de conferencias ilustradas musicalmente en los centros y a la asistencia a conciertos fuera de los mismos.

Es curioso el desarrollo del cuestionario, pues introduce por primera vez la Música como una asignatura propia, sin añadidos, común para alumnos y alumnas y separadamente de las materias tradicionalmente asignadas al Frente de juventudes y Sección Femenina. De hecho, los cuestionarios de las otras asignaturas asignadas a las Escuelas de Hogar: Formación familiar y social, Labores, Corte, Higiene y Formación del espíritu nacional están desarrollados con posterioridad en la Orden de 8 de marzo de 1954 (BOMEC de 22 de marzo de 1954).

\subsection{1.b.II Cuestionarios de Enseñanza Primaria de la Orden Ministerial de 8 de julio de 1965 (BOE 24 de septiembre)}

La publicación de unos nuevos cuestionarios oficiales se hizo necesaria para adaptar los contenidos y la propia estructura de la ley en vigor a las necesidades socio-económicas y culturales de un país en vías de desarrollo. Son tal vez la muestra más clara desde el punto de vista legal de la transformación que estaba sufriendo la sociedad española y que culminará con la elaboración de una nueva ley general de educación en 1970 (sometida a largo debate en los dos años anteriores)

Es muy significativa la nueva redistribución del contenido en cinco sectores educativos que no se ajustan a la ley original:

- Técnicas instrumentales de la cultura (lectura, escritura, lengua extranjera y matemáticas

- Unidades didácticas básicas y realistas de Naturaleza y Vida social, que proporcionen al escolar primaria un conocimiento diferencial en 


\section{La educación musical en el franquismo}

estos saberes imprescindibles para su proyección en el mundo y en la vida

- Técnicas de expresión artística (dibujo, Música y manualizaciones), sobre cuya base pueda el escolar primario contemplar y crear los valores estéticos y artísticos y adquirir las destrezas operativas necesarias para la vida

- Materias de carácter especial (religión, educación cívico-social, prácticas de iniciación profesional, enseñanzas del hogar y educación física)

- Habituación

La Orden ministerial especifica que las técnicas instrumentales, las técnicas de expresión artística y las materias de carácter especial seguirán un desarrollo independiente a lo largo de los distintos cursos.

En la distribución semanal de materias por curso, la educación artística aparece contemplada con una dedicación de $\underline{2}$ horas y media a la semana en cada año, con presencia desde 1으 hasta 8을 curso.

Efectivamente, el cuestionario se desarrolla en las tres áreas de conocimiento asignadas a la Expresión artística: Dibujo, Música y canto y manualizaciones. En el área de Música y canto se especifican las actividades escolares que deben conducir al cultivo de:

a. El canto coral, con medio a educar la voz, el oído, el sentido del ritmo y la acción vocal conjuntada

b. La afición por la buena música mediante la audición de composiciones que, partiendo de lo folklórico, llevan hasta la música sinfónica

c. El conocimiento de los más destacados aspectos exigidos por una mínima cultura musical. Principalmente se busca despertar y cultivar la sensibilidad en relación con el arte musical por medio de una adecuada práctica del canto. Sin necesidad de llegar a constituir coros organizados - que sólo son posibles en 


\section{Capítulo 2. El marco legal}

determinadas escuelas - es evidente que la canción escolar bien llevada puede facilitar extraordinariamente la educación musical de los escolares

En cuanto a la distribución de los contenidos por cursos consta de la siguiente manera:

Curso 1ำ (6-7 años).- Canciones de temas populares de carácter infantil y melodía sencilla entonadas a coro, buscando principalmente el ritmo con ayuda de palmadas, instrumentos de percusión, etc. Conocidas composiciones regionales. Audición de discos con canciones infantiles

Curso 2ํ (7-8 años).- Canto coral con ejercicios individuales de entonación, tratando de conseguir la corrección melódica. Práctica de canto a media voz. Canciones folklóricas cantadas por los niños. Audición de música infantil y regional

Curso 3o (8-9 años).- Canciones variadas en las que se practiquen ejercicios rítmicos a tres y cuatro tiempos. Ejercicios de matización de intensidad. Distinción entre sonido y ruido. Audición de composiciones variadas grabadas en discos

Curso 4ํ (9-10 años).- Ejercicios de entonación, ritmo y matización mediante canciones sencillas. Distinción entre intensidad, tono y timbre de los sonidos. Audición de pequeños fragmentos de música selecta

Curso 5o (10-11 años).- Prácticas de canto coral exigiendo una relativa perfección. Iniciación al canto en dos voces. Audición de grabaciones incluyendo algunas composiciones líricas y clásicas

Curso 6o (11-12 años).- Interpretación coral de motivos folklóricos, líricos y clásicos, debidamente adaptados. Entonación de la escala musical diatónica. I dea del pentagrama y del nombre de las notas musicales. Noción de melodía y acompañamiento. Audición de discos con música selecta, regional y sinfónica

Curso 70 (12-13 años).- Canciones folklóricas, arreglos de música selecta para coros. A ser posible a dos voces y con adecuada matización. Terminología 


\section{La educación musical en el franquismo}

relativa a distintas agrupaciones musicales y a los instrumentos. Audición de discos con los tiempos más conocidos de algunas obras líricas y sinfónicas

Curso 8 (13-14 años).- Canto coral a dos voces en algunas composiciones de distintos géneros. Breves biografías de algunos músicos universales y nacionales. Audición de obras clásicas completas

Dada la extensión y desglose de los contenidos que había que explicar no puedo sino estar en desacuerdo cuando se afirma como lo hace Oriol (2005) que debido al carácter formativo complementario con que aparece la educación artística en la ley de 1945 ésta “quedaba supeditada a la buena voluntad o afición de algún maestro que quisiera enseñar algunas nociones de música 0 canciones en el contexto de sus clases".

Esta opinión está muy extendida, pero, como vemos, la ley contempla su presencia y desglosa los contenidos que se tienen que impartir, y la aprobación y comprobación de los mismos es asignada a la Inspección de Enseñanza Primaria.

Uno de los objetivos de esta investigación es, pues, llegar a analizar y a proponer los motivos por los que no llegó a buen término la educación musical en esta primera etapa del franquismo y a conocer mejor los cambios que supuso la aplicación de la nueva ley de 1970.

\subsection{1.c. Ley General de Educación y financiamiento de la Reforma Educativa de 4 de agosto de 1970 (BOE 6 de agosto).}

Se trata de una ley con un amplio espíritu de reforma para ajustar la educación a la nueva situación social y económica del país. Superadas las luchas por el poder entre los sectores católico conservador y la falange (con clara pérdida de esta última), asistimos a una profunda transformación social y política: Los fascismos han perdido la segunda guerra mundial y España entra en la órbita de influencia norteamericana en una nueva fase de aperturismo político internacional que reconfigura Europa en dos bloques hegemónicos y 
antagónicos que se enfrentan ideológica y políticamente en la llamada "guerra fría"(occidental proamericano y comunista prosoviético).

En este nuevo marco se elabora un amplio sistema de reforma que parte de la publicación en febrero de 1969 de un estudio previo sobre "La Educación en España: Bases para una política educativa" (Libro Blanco) que presenta las líneas generales de la reforma y sirve al mismo tiempo de consulta a la sociedad, otorgándole una participación previa sin precedentes, conscientes de la necesidad de un amplio consenso social para hacer posible su aplicación ${ }^{82}$.

La Ley General contempla los diferentes niveles de educación: Educación General Básica (EGB), la Educación Secundaria que se desglosa en Bachillerato Unificado y Curso de Orientación Universitaria (BUP y COU) y en Educación Profesional, y el tercer nivel correspondiente a la enseñanza universitaria superior.

\section{a).- La Educación General Básica (EGB)}

En la declaración de principios que supone siempre la sección introductoria de la ley, en el artículo 16 expone que la Educación General Básica se orientará a
la adquisición, desarrollo y utilización funcional de los hábitos y de las técnicas instrumentales de aprendizaje, al ejercicio de las capacidades de imaginación, observación y reflexión, a la adquisición de nociones y hábitos religiosos-morales, al desarrollo de aptitudes para la convivencia y para vigorizar el sentido de pertenencia a la comunidad local, nacional e internacional, a la iniciación en la apreciación y expresión estética y artística y al desarrollo del sentido cívico-social y de la capacidad físico- deportiva.

Este articulado se desglosa en las diferentes áreas de conocimiento, y la educación musical se incluye en la Educación General Básica junto con la Educación Física y deportiva en el "área de Expresión Dinámica"

Según consta en las Orientaciones pedagógicas para los planes y programas de estudios de la Educación General Básica (MEC), el área de expresión dinámica

\footnotetext{
${ }^{82}$ Ley General de Educación y disposiciones complementarias. Textos legales del Ministerio de Educación y Ciencia, pag. 38
} 
puede englobar la educación del movimiento, ritmo, expresión corporal, mimo, dramatización, juegos, gimnasia, deportes y música. Por su clara interrelación no es fácil ni conveniente separar los aspectos señalados al menos durante la primera etapa de la EGB, la diferenciación será progresiva y corresponderá más específicamente a la Segunda Etapa (...)El área de Expresión dinámica, por su propio carácter, exige una metodología esencialmente activa (...)

Por lo que se refiere a la educación musical, no se trata de dar un conocimiento teórico de los elementos musicales, sino de lograr unas vivencias y mediante ellas enriquecer la imaginación y toda la personalidad del alumno. No se puede señalar un solo método, sino que es conveniente conocer los existentes y llegar a un método personal adaptado a la situación concreta de aprendizaje. A título indicativo señalamos algunos de los más conocidos como el Ward, el sistema Orff Schulwerk y el de Zoltan Kodaly.

La canción tiene gran importancia y forma parte esencial del proceso educativo musical. Se debe iniciar con varios ejercicios de lenguaje, utilizando las palabras con su propio métrica. El canto se introducirá de modo graduado en cantidad y calidad: sencillas marchas, cantos populares y regionales hasta llegar a piezas de estructuras más complejas. El canto coral, en todas sus modalidades proporciona una actividad sumamente motivada e interesante.

La audición musical y el contacto con las grandes obras pueden formar parte del proceso de formación musical desde su iniciación, siempre teniendo en cuenta el nivel y los conocimientos culturales de los alumnos. Se les ejercitará en la distinción de voces e instrumentos de forma práctica e intuitiva, se favorecerá la asistencia a conciertos, se presentarán los autores situándolos en el momento cultural y artístico de su época.

La lectura y notación musical se enseñarán como medio de comprensión y perfeccionamiento del canto y para facilitar las composiciones creativas.

La metodología de esta área debe basarse en la espontaneidad, naturalidad y creatividad.

De hecho se proponen como objetivos específicos del área con respecto a la formación musical

- el desarrollo de la sensibilidad auditiva y artística

- El desarrollo de actitudes de apreciación musical

- Contacto con las grandes obras musical

- Habilidad para expresar ritmos conocidos

- Capacidad de componer temas musicales 


\section{Capítulo 2. El marco legal}

- Capacidad para distinguir y comparar voces, instrumentos y tipos de actividad musical

- Destreza en el manejo de algún instrumento musical

- Capacidad para interpretar temas musicales

- Capacidad de improvisación

En el desglose de contenidos consta

\begin{tabular}{|c|c|}
\hline \multicolumn{2}{|c|}{ Primera Etapa de EGB } \\
\hline 1er. Curso & $\begin{array}{l}\text { Reacción espontánea a la música oída. Reconocer sonidos producidos por } \\
\text { distintos medios. Interpretar el sentimiento y el ánimo a través de pantomimas } \\
\text { o movimientos rítmicos. Improvisar sencillos temas musicales. Utilizar las } \\
\text { palabras con su propia métrica. Participar en juegos cantados y canciones con } \\
\text { movimiento. Seguir los ritmos en los diferentes pasos (marchar, correr, saltar). } \\
\text { Reaccionar a los cambios de compás y tono. Participar interpretando } \\
\text { personalmente un movimiento rítmico iniciado espontáneamente ante un } \\
\text { estímulo natural o instrumental }\end{array}$ \\
\hline 20 Curso & $\begin{array}{l}\text { Usar instrumentos para acompañar movimientos y canciones. Combinar el } \\
\text { movimiento en el espacio con el tiempo del canto y de los inztrumentos. } \\
\text { Interpretar canciones a través de actividades rítmicas y dramáticas. Reconocer } \\
\text { melodías y canciones sencillas. Descubrir los pasos rítmicos al esculhar un } \\
\text { tema. Reconocer instrumentos corrientes por la vista y el sonido. Crear ritmos y } \\
\text { melodías }\end{array}$ \\
\hline 3er. Curso & $\begin{array}{l}\text { Conocer y expresar pasos rítmicos y danzas populares sencillas. Reconocer el } \\
\text { acento, compás, ritmo, valor de los eimpos en un canto o danza colectiva. } \\
\text { Utilizar los instrumentos de percusión para comprar canciones rítmicas y } \\
\text { dramatizaciones. Conocimiento de las formas elementales: lied-canción, rondó. } \\
\text { Principios de lectura musical. }\end{array}$ \\
\hline 40 Curso & $\begin{array}{l}\text { Dirigir sencillas melodías y composiciones. Identificar pasos rítmicos comunes a } \\
\text { partir de la escritura musical. Interpretar movimientos rítmicos para utilizarlos } \\
\text { en dramatización y canto. Entonación de canciones conocidas. Inventar } \\
\text { sencillas canciones. Iniciación a la flatua dulce }\end{array}$ \\
\hline 50 Curso & $\begin{array}{l}\text { Conocer nuevas formas de danzas y los pasos ritmos correspondientes. } \\
\text { Identificar ritmos básicos en la poesía y música popular. Interpretar nuevos } \\
\text { ritmos y canciones. Aprender los símbolos musicales de clave y metro. Cantar } \\
\text { en coro. I dentificar los instrumentos y reconocer el grupo al cual perteneces. }\end{array}$ \\
\hline
\end{tabular}


Postura correcta para el canto

\begin{tabular}{|l|l|}
\hline \multicolumn{2}{|l|}{ Segunda Etapa de EGB } \\
\hline 60 Curso & $\begin{array}{l}\text { Participar en canto coral a dos voces. Conocer algunos instrumentos distintos } \\
\text { de los de percusión. Participar en la formación de rondallas y agrupaciones } \\
\text { musicales instrumentales. Crear melodías sencillas e interpretarlas en grupo. } \\
\text { Capacidad para escuchar música de obras conocidas. Capacidad para escuchar } \\
\text { valorativamente música. Lectura musical en forma entonada y rítmica. } \\
\text { Conocimiento del vocabulario preciso de los instrumentos, agrupaciones } \\
\text { instrumentales, orquesta sinfónica, orquesta de cámara. Participar en danzas } \\
\text { populares y forlklóricas. Movimientos rítmicos racionalizados }\end{array}$ \\
\hline 70 Curso & $\begin{array}{l}\text { Participar en canto coral. Distinguir las cualidades del sonido. Expresar en } \\
\text { forma corporal los movimientos rítmicos. Capacidad para escuchar y } \\
\text { comprender varias formas musicales. Conocimiento y destreza para manejar } \\
\text { algún instrumento musical no sólo de percusión. Construir sencillos } \\
\text { instrumentos musiclaes. Participar en danzas folklóricas distintas de las de la } \\
\text { propia región }\end{array}$ \\
\hline 80 Curso & $\begin{array}{l}\text { Actuar en público participando en coros o bailes. Lectura y notación musical. } \\
\text { gpreciar valorativamente la cultura musical en otros pueblos. Conocimiento de } \\
\text { grandes figuras de la música, en relación con la cultura de su tiempo. Crear y } \\
\text { pequeñas orquestas. Utilizar la música como medio de recreación }\end{array}$ \\
\hline
\end{tabular}

Respecto al profesorado que debía impartir la música en la Segunda Etapa de $E G B$, el Decreto de 25 de mayo de 1972 (BOE de 7 de junio) explicita que “podrán impartir las enseñanzas correspondientes al sexto curso de EGB los maestros de Enseñanza Primaria que reúnan el requisito de poseer un título expedido por un Conservatorios de música, Escuela de canto, Instructores generales y maestros instructores de las Delegaciones de Frente de Juventudes y Sección Femenina", evidentemente para impartir las asignaturas vinculadas a las áreas de Expresión Dinámica.

Es más, el Ministerio crea cursillos de especialización para el profesorado de la Segunda Etapa de Educación General Básica (EGB) por medio de la Orden de 4 de mayo de 1973 (BOE de 17 de mayo), en el que se contempla 


\section{Capítulo 2. El marco legal}

en el apartado f). “Educación estética y pretecnológica en la que se establecen tres modalidades independientes de cursillos: a).- Música y dramatización, b) Expresión Plástica y c). Pretecnología. Dichos cursos fueron organizados por el MEC en toda España en los diferentes distritos universitarios a través de las Resoluciones de 7 de junio (BOE de 7 de julio) y de 11 de octubre (BOE de 6 de noviembre)

\section{b).- La música en el Bachillerato Unificado Polivalente (BUP)}

Por su parte, también es de destacar la presencia de la asignatura de Música en el nuevo Bachillerato Unificado Polivalente (BUP). El plan de estudios contempla tres categorías: de asignaturas

- materias comunes, que habrán de ser cursadas por todos los alumnos,

- materias optativas

- enseñanzas y actividades técnico-profesionales

Las materias comunes se imparten en diversas áreas:

- Lenguaje (Lengua y Literatura, latín, lengua extranjera)

- Formación estética, con especial atención a Dibujo y Música (Art. 25)

- Social y antropológica (geografía e historia, filosofía, formación política, social y económica)

- Formación religiosa

- Ciencias matemáticas y de la naturaleza (matemáticas, Ciencias Naturales, Física y Química)

- Educación Física y deportiva

\section{c.- La música en la educación superior (Universidades)}

Como se puede observar, la formación musical está presente en la ley en los dos niveles iniciales del proceso educativo. Lamentablemente, la música había desaparecido de la Universidad española con la supresión de la cátedra de 


\section{La educación musical en el franquismo}

Salamanca bajo el reinado de Isabel II, tras la muerte de Manuel Doyagüe. La incorporación de las Escuelas de Magisterio al sistema universitario por la ley de 1970 bajo la denominación de Escuelas Universitarias del Profesorado de

EGB, implican la vuelta de la música a la Universidad, y finalmente en la Orden de 8 de octubre de 1984 (BOE 17 de diciembre) se reintroduce el Título de Licenciado en Musicología para la Universidad de Oviedo, a la que seguirían muchas otras. Hasta entonces, la música en las facultades universitarias había permanecido presente como actividad extraescolar a través de la muy meritoria tarea de las "Cátedras de difusión cultural".

La presencia y el carácter de enseñanza obligatoria en la ley obligan a cualificar profesorado y a dotar plazas por oposición en la Enseñanza Secundaria. Pero, como veremos, hasta 1982 no se realizan las primeras oposiciones de profesorado especialista en música a nivel nacional. Ello no quiere decir que no estuviera presente, puesto que era de obligado cumplimiento. Pero entonces, ¿quiénes impartían la asignatura? El personal de Sección Femenina en los centros de Educación Secundaria femenina y diferentes tipos de profesionales en los masculinos. $Y$ esto es un resto de la relación ambigua que hasta el momento se había venido estableciendo entre el Ministerio y los órganos de Formación Juvenil del Movimiento que arrastran desde la ley de 1945 a nivel educativo, tanto para la enseñanza primaria como para la enseñanza secundaria.

La nueva ley introduce además aspectos importante en cuanto a la formación continuada del profesorado y la importancia de la innovación educativa, lo que permitirá a todos los niveles unas grandes posibilidades de cambio y la introducción de los sistemas pedagógicas de la educación musical europea en nuestro país a través de diferentes vías. Y a través de la creación y participación de los Institutos de Ciencias de la Educación (ICE) en la formación continua del profesorado se permite colaborar a todos los niveles educativos en actividades comunes de innovación metodológica en la educación musical: cursos en los que colabora el MEC, los maestros de primera y segunda etapa de EGB, los profesores de BUP y las Escuelas Universitarias de Formación del Profesorado 


\section{Capítulo 2. El marco legal}

\subsubsection{La educación no formal}

En los últimos 20 años se está prestando especial atención a los contenidos de aprendizaje realizados de forma no reglada, es decir, fuera del sistema escolar. Así se incorporan las lecturas infantiles, el cómic, el cine, la publicidad, los contenidos televisivos y radiofónicos y otras formas de divulgación masivas a los estudios sobre transmisión ideológica y de conocimientos.

En el caso de la educación musical de la población general, este contexto es especialmente significativo, ya que una gran parte de la transmisión musical se realiza de forma oral y fuera del ámbito escolar, pero no por ello de manera menos regularizada, dirigida, ideológica y estructurada. De hecho, los límites entre la educación formal y no formal en la ley del 45 (y su reformulación en 1967) en lo que se refiere a la educación musical, son poco claros y por ello una buena parte de la educación musical se realiza en ámbito extraescolar, pero de una manera totalmente organizada.

Las actividades lúdico-deportivas, muy especialmente los campamentos, son una de las actividades más importantes y con más cantidad de música regulada e impresa. Se crean cancioneros específicos para los campamentos, que se editan y son un fiel reflejo de los repertorios más extendidos entre la juventud durante el período franquista. Muchas de estas canciones, precisamente por ser aprendidas en un entorno lúdico y no ser asociadas a un proceso de aprendizaje puramente musical, son recordadas y permanecen en los repertorios de la generación - sin ser entendidas como parte de una educación musical - determinada ideológicamente para presentar una concepción del Estado y del entorno falangista.

La utilización de la canción por parte de las instituciones no es tan inocente, sino que la selección del repertorio se lleva a cabo de forma intencionada para realizar la transmisión de determinados principios e ideales, con la intención de crear estados de espíritu colectivo y de identificación grupal muy específicos. 


\section{La educación musical en el franquismo}

Además de la utilización de las canciones, las instituciones falangistas realizan una labor de divulgación cultural que también está tamizada por condicionantes ideológicos. Esta divulgación se realiza a través de varios canales:

- Publicaciones: como Consigna, la revista para maestras. También las publicaciones de folklore, historia de la música, cancioneros infantiles, religiosos, villancicos.

- Cursos de formación de profesores, que van desde el aprendizaje memorístico hasta la formación especializada en educación musical en los centros de pedagogía más reconocidos. Hay una gran variedad de grados en este tipo de formación que analizaremos detenidamente en este trabajo.

- Actividades lúdicas: festivales de coros y danzas, grupos de folklore, concursos de villancicos, animación cultural, campamentos

- Conciertos para niños

- Programas de radio y televisión para divulgación musical

- Formación en zonas rurales en las que también se incorporaban repertorios musicales

- Centros de animación cultural: Centros Medina y J osé Antonio en los que se crean discotecas y se imparten conferencias y audiciones de música culta.

Como se ve, hay una gran cantidad de posibilidades sociales en las que difundir la música de forma no reglada. Evidentemente, no en todas las zonas se realiza con la misma efectividad, interés o receptividad por parte de la población, ni son iguales las dotaciones en las grandes ciudades que en los centros de formación rural, por lo que las diferencias son notables.

\subsection{2.a La ley de Educación Primaria de 1945 y la educación no formal}

El Capítulo V de la ley, dedicado a las actividades complementarias de la escuela, especialmente en sus artículos 44 y 45 adquiere una gran 


\section{Capítulo 2. El marco legal}

importancia posterior ya que justifica la interacción de las instituciones del Movimiento como actividades a realizar dentro y fuera del recinto escolar.

Artículo 44. La función docente realizada en la escuela se complementará con actividades pedagógicas y sociales que tiendan a perfeccionar la formación de los alumnos 0 a prestarles ayudas por medio de instituciones de carácter complementario Artículo 45. Instituciones pedagógicas.- Se podrán organizar en la escuela aquellas instituciones que tengan por finalidad :(..)

b).- Las agrupaciones artísticas que organicen festivales con recitados, escenificaciones, conciertos, programas de radio y emisiones infantiles

e).- La asistencia a campamentos, albergues y marchas de alta montaña, ejercicios de deportes, masas corales y grupos de danzas se organizarán de acuerdos con las disposiciones vigentes

Cada una de estas actividades tendrá su desarrollo dentro de la escuela y en su gobierno podrán participar los propios escolares. Las actividades enumeradas en los apartados b) y e) se desenvolverán según la dirección del Frente de Juventudes y Sección Femenina, a cuya inspección quedarán sujetas. El desenvolvimiento próspero y continuado de cualquiera de ellas, acreditado en su caso por los organismos antes citados, servirá de mérito puntuable al maestro en los concursos profesionales y de recompensa para los discípulos

Estos artículos serán refrendados de nuevo en el Decreto de $\mathbf{2}$ de febrero

de 1967 (BOE 13 de febrero) que aprueba el texto refundido de la Ley de enseñanza primaria y especifica en su Título VII que se redactará un decreto específicamente para regularizar las relaciones entre el Movimiento y la educación primaria.

La vinculación de las actividades de formación complementaria de carácter musical llevadas a cabo dentro de la escuela a las instituciones del Movimiento ligadas a la formación juvenil por la ley abre las puertas a las teorías sobre su papel en la educación no formal. 
2.3 ESQUEMA RESUMEN DE LA LEGISLACIÓN SOBRE LA EDUCACIÓN MUSICAL DURANTE EL FRANQUISMO (19391975).

Conservatorios

Decreto 15 de junio de 1942

BOE 4 de julio de 1942

Decreto 10 de septiembre de 1966

BOE 24 de octubre de 1966

\begin{tabular}{|c|c|}
\hline le Fdur & (io) \\
\hline $\begin{array}{lll}\text { Ordenación } & \text { de } & \text { Educación } \\
\text { Secundaria } & & \\
\end{array}$ & $\begin{array}{l}26 \text { de febrero de } 1953 \text { (BOE } 27 \text { de } \\
\text { febrero) }\end{array}$ \\
\hline $\begin{array}{l}\text { Reglamento General de Centros de } \\
\text { Enseñanza. Media y Profesional }\end{array}$ & $\begin{array}{l}3 \text { de noviembre de } 1953 \text { (BOMEC } 19 \text { de } \\
\text { noviembre, } 4 \text { y } 7 \text { de diciembre de } 1953 \\
\text { y } 22 \text { de febrero de } 1954\end{array}$ \\
\hline $\begin{array}{l}\text { Cuestionarios de Enseñanza } \\
\text { Secundaria }\end{array}$ & 21 de enero de 1954 \\
\hline $\begin{array}{l}\text { Cuestionarios de Enseñanza } \\
\text { Primaria }\end{array}$ & $\begin{array}{l}21 \text { de enero de } 1954 \text { (BOMEC } 10 \text { de } \\
\text { febrero) }\end{array}$ \\
\hline Cuestionario de Enseñanza Primaria & $\begin{array}{l}8 \text { de julio de } 1965 \text { (BOE } 24 \text { de } \\
\text { septiembre) }\end{array}$ \\
\hline $\begin{array}{l}\text { Decreto Texto refundido de la Ley } \\
\text { de enseñanza Primaria }\end{array}$ & $\begin{array}{l}2 \text { de febrero de } 1967 \text { (BOE } 13 \text { de } \\
\text { febrero) }\end{array}$ \\
\hline
\end{tabular}

Ley General de Educación y Financiamiento de la Reforma Educativa de 4 de agosto de 1970 (BOE 6 de agosto)

- Decreto sobre profesorado de 25 de mayo de 1972 (BOE 7 de junio) música en la Segunda Etapa de EGB 
Capítulo 2. El marco legal

- Cursillos de especialización para el Orden de 4 de mayo de 1973 (BOE 17 profesorado de la Segunda Etapa de mayo) 


\section{CAPÍTULO 3. LA FORMACIÓN MUSICAL DE LOS MAESTROS}

\subsection{LA FORMACIÓN EN LAS ESCUELAS NORMALES}

\subsubsection{El marco legal de la formación de los maestros}

La formación de los maestros en las Escuelas de Magisterio ha sufrido a lo largo del siglo XX notables transformaciones, desde los requisitos y edades iniciales, la duración de los estudios, los planes de estudio, la regularización del profesorado e incluso el gran paso al configurarse como estudios universitarios en la ley de Villar Palasí (con anterioridad a 1970, tienen el rango de estudios de Enseñanza medias, al igual que las Escuelas de Comercio o los institutos de bachillerato)

Según los datos aportados por Alonso Medina y Rodríguez Cruz ${ }^{83}$ (1999) los requisitos iniciales fueron variando según los planes de estudios de la siguiente manera:

Plan de estudios de 1900. Título de maestro elemental (2 cursos). Se requería conocimientos de enseñanza primaria y prueba de acceso.

Plan de estudios de 1901. Título de maestro elemental ( 3 cursos). Se requería conocimientos de enseñanza primaria y prueba de acceso

Plan de estudios de 1903. Título de maestro elemental ( 2 cursos). Se requería conocimientos de enseñanza primaria y prueba de acceso.

Título de maestro superior (2 cursos). Sólo pudieron optar las maestras a partir de 1907

Plan de estudios de 1914. Título único de maestro (4 cursos). Se requería Conocimientos de enseñanza primaria y prueba de acceso

\footnotetext{
${ }^{83}$ ALONSO MEDINA, J y RODRÍGUEZ CRUZ, P. Evolución histórica de la formación musical de los maestros (1900-1967). En // Jornadas de historia local canaria: enseñanza y educación en Canarias., Boletín Millares Carlo, no 18; 1999
} 
En lo referente a la legislación educativa que regula la enseñanza de la música en las Escuelas Normales y su proyección en la enseñanza primaria antes de 1930, es destacable el artículo de López Casanova ${ }^{84}$ (2000).

Plan de estudios de 1931. Título de maestro (4 cursos, el último para una reválida y realizar las prácticas con sueldo de maestro interino). Se requería bachillerato y prueba de acceso. Supuso la fusión de las Escuelas de Maestros y Maestras (Orden de 30 de octubre de 1931) y toman el nombre de Escuelas Normales del Magisterio Primario. En este plan, que permaneció vigente hasta después de la guerra, se observa un claro predominio de las materias profesionales, metodológicas y de orientación psicopedagógicas, por medio de clases de metodología y las prácticas del último curso.

La guerra supone un período convulso tras el cual se produce una auténtica purga ideológica que diezmó al profesorado en activo del país. La mayoría fueron expedientados y apartados del servicio docente, cuando no incapacitados para ejercer la profesión durante los siguientes 40 años. Según el propio José María Pemartín (Jefe del Servicio Nacional de enseñanza Superior y Media entre febrero de 1938 y abril de 1939) más del un 75\% del personal oficial enseñante había "traicionado la causa nacional", lo que implicaba la depuración de cifras cercanas a las tres cuartas partes del personal docente del Ministerio de Instrucción Pública anterior y conllevaba las consiguientes dificultades para la atención de la nueva población escolar por el estado (carencia que fue muy oportunamente ocupada por las instituciones escolares religiosas).

Por ello, se acometió rápidamente una reforma de la ley de educación que permitiera controlar desde las publicaciones escolares a los contenidos que se iban a impartir e incluso la forma de impartirlos.

La necesidad inmediata de incorporar nuevos maestros y maestras favoreció un tipo de acceso rápido a la profesión por medio del llamado Maestro-bachiller a través del Decreto de 10 de febrero de 1940, con un curso muy corto de

${ }^{84}$ LÓPEZ CASANOVA, M.B. La música en el Magisterio de las Escuelas Normales y su proyección a la primera enseñanza desde 1837 a 1930. En Música y educación: Revista trimestral de pedagogía musical, año 15, № 49, 2002, pag 29-44 


\section{Capítulo 3. La formación musical de los maestros}

formación pedagógica y la realización de prácticas docentes en escuelas, tras obtener el título de bachillerato. Ello permitió dotar de maestros muy jóvenes a las escuelas del país, ya que hay que recordar que había centros educativos de tipo elemental a lo largo de todo el territorio nacional en cada núcleo rural. La

Orden de 7 de octubre de 1941 (BOE de 12 de octubre) dispone que

"los alumnos del Magisterio que en concepto de Bachiller hayan aprobado alguna asignatura con anterioridad al 1 de octubre del corriente,(...) se les autoriza para terminar la carrera por dicho plan".

En la Orden de 24 de septiembre de 1942 (BOE de 15 de octubre) se regula el curso no oficial para bachilleres y no bachilleres que plasma en la convocatoria de exámenes de ingreso en las Escuelas Normales del Magisterio Primario las siguientes condiciones:

\footnotetext{
Haber cumplido dentro del año actual la edad de 12 años y estar en buen estado de salud. Se pueden cursar los estudios de forma oficial y libre y los ejercicios constarán de un ejercicio de redacción, lectura, resolución de problemas sobre las cuatro operaciones aritméticas, preguntas sobre religión, geografía e historia de España, geometría, ciencias de la naturaleza y las alumnas además un ejercicio de costura como prueba de acceso. Para los que poseen el grado de bachiller podrán obtener el título de Maestro de Primera Enseñanza en el próximo curso 1942-43, previa la aprobación de las asignaturas de religión e historia sagrada, caligrafía 1 y 2, Música 1 y 2, religión y moral, pedagogía 1 y 2, historia de la pedagogía y prácticas de la enseñanza, Y además para las alumnas los tres cursos de labores y economía doméstica. Estos alumnos bachilleres harán sus estudios solamente por enseñanza no oficial.
}

En un primer momento hay una serie de promociones de maestros que se titulan de manera casi automática con el bachillerato y un curso de formación complementaria. En dicho complemento profesional, se les exige un cierto conocimiento del lenguaje musical, siempre destinado a la entonación y el canto monódico, formación que deben conseguir por sí mismos, ya que cursan los estudios de forma libre ( no presencial).

Los alumnos tenían que pasar una prueba de entonación de canciones sobre un repertorio predeterminado, que en algunos casos era memorizado. Debido a la extrema urgencia en obtener nuevos profesionales, el corto período de formación (sin existencia previa de otra formación musical en el sistema general 


\section{La educación musical en el franquismo}

de educación) no podía garantizar un aprendizaje real de los elementos del lenguaje musical

Desde el punto de vista legal, las primeras notas que aparecen son una tendencia a la amortización y reunificación de plazas en las Escuelas Normales. Es el caso de la plaza de profesora de música de Sevilla en la Escuela de Magisterio Femenina y que es absorbida por el titular de la masculina (Orden 18 de mayo de 1940, BOE de 6 de junio) y la de Murcia.

En 1942 se convalidan las asignaturas de música de obligatorio cumplimiento en las Escuelas Normales e Institutos de Enseñanza Media por asignaturas cursadas en los conservatorios de música cuyos estudios tengan validez oficial reconocida, con lo que se establece una correspondencia ambigua de los diferentes estudios (profesionales y no profesionales). La orden ministerial de 14 de agosto de 1942 (BOE de 29 de agosto) advierte de la ausencia de legislación anterior al respecto, pero alega que

"resultando que se repite con frecuencia el caso de alumnos que han terminado con brillante aprovechamiento sus estudios superiores musicales, no obstante lo cual han de someterse a examen ante otros centros sobre elementariedades cuyo conocimiento tienen sobradamente acreditado (...) y considerando la conveniencia de que se establezca, por modo general, la convalidación de las enseñanzas de música que se cursan en los centros en que estas materias ocupan un lugar secundario en los planes de estudio por aquellas otras análogas que constituyen la materia propia de las enseñanzas cursadas en los conservatorios"

Como se puede apreciar, en los primeros años de la posguerra, además de desear titulaciones rápidas dada la necesidad urgente de maestros, se confunden los tipos de formación a que conduce cada titulación, con lo que se supone del texto de la ley que para cursar estudios musicales reconocidos no era necesario disponer del título de bachiller $y$, además establece prioridades a favor de la importancia de la enseñanza en el conservatorio, lo que nos lleva a plantearnos cuáles eran los contenidos de la formación musical de los maestros, y la propia institucionalización de la idea de que la formación musical no es tanto una tarea escolar y docente como de los conservatorios. 


\section{Capítulo 3. La formación musical de los maestros}

En el proceso de reestructuración de los estudios del Magisterio, la Orden de 27 de noviembre de 1943 ( $B O E$ de 30 de noviembre), en la matrícula del segundo curso de las Escuelas de Magisterio hace constar la obligatoriedad de la asignatura de música con una dedicación horaria de 2 veces por semana (al igual que religión, lengua, geografía, historia y educación patriótica, matemáticas, ciencias de la naturaleza, dibujo y gimnasia). Igualmente, en la Orden de 16 de octubre de 1944 (BOE de 21 de octubre) se especifica para el tercer curso la asignatura de música con presencia dos horas a la semana.

La publicación de la Ley General de Educación Primaria de 1945 obliga a reestructurar la organización docente de las Escuelas de magisterio, con lo cual aparecen las normas y asignaturas para el primer curso en la Orden de $\mathbf{9}$ de octubre de 1945 (BOE de 11 de octubre), también llamado “Plan profesional" para su cumplimiento inmediato. Se introduce la pedagogía general ( 3 horas semanales y la psicología general ( 3 horas semanales) y la música pasa a estar bajo un epígrafe llamado "cursos prácticos de especialización" con una duración de 6 horas semanales, entre cuyas materias están comprendidas: idiomas, cantos escolares, enseñanzas artísticas y organizaciones postescolares. Los alumnos deberán escoger obligatoriamente dos de estos cursos prácticos y las alumnas uno (ya que el otro es obligatoriamente Enseñanza del Hogar).

En el Plan de Estudios que finalmente se formaliza en la Orden de $\mathbf{1 4}$ de octubre de 1946 (BOE de 19 de octubre), aunque sigue agrupada bajo el epígrafe de "cursos prácticos de especialización", aparece finalmente desglosada como música, especificada su obligatoriedad ( no a escoger entre varias) para ambos sexos y con presencia en los tres cursos en la Orden de 26 de octubre de 1946 (BOE de 26 de noviembre), con dos horas semanales en primer curso, y una hora semanal en segundo y tercer curso respectivamente.

De hecho, la Ley de 23 de diciembre de 1947 (BOE de 27 de diciembre) especifica que las dotaciones que figuran en el presupuesto en vigor de las Escuelas del Magisterio incluyen cincuenta profesores o profesoras de música. Cierto que todos ellos en la categoría de profesores especiales, al igual 


\section{La educación musical en el franquismo}

que los de francés y dibujo, con un sueldo muy inferior a los de profesores numerarios y adjuntos.

\section{En el Reglamento de Escuelas del Magisterio de 7 de julio de 1950}

(BOE de 7 de agosto) se exige ya el bachillerato elemental para el ingreso a todos los alumnos. Especifica que los estudios constarán de 3 cursos y una reválida, en los que aparece la Música en dos: Segundo curso con el epígrafe de música, elementos de solfeo y cantos religiosos, patrióticos y escolares y en tercer curso sólo con el epígrafe más general de música: cantos. Su presencia era de dos horas semanales en cada curso.

El llamado Plan de estudios de 1967, especificado en el decreto de 2 de febrero de 1967 (BOE de 13 de febrero), se establece finalmente como requisito para el acceso a los estudios profesionales del magisterio la posesión del título de bachiller superior, sin necesidad de otras pruebas de acceso. Los estudios se estructuran en dos cursos, con una prueba final de madurez y la realización de prácticas de enseñanza en un tercer año en colegios nacionales. Contempla la enseñanza de música en los dos cursos con una dedicación lectiva de dos horas semanales, pero precisando que se darán en sesiones de tarde (junto a dibujo, manualizaciones y enseñanzas del hogar y prácticas de enseñaza. Además, este plan de estudios, abría una puerta importantísima a la educación no formal, al contemplar que

“al final del primer curso, los alumnos realizarán los cursos de capacitación en las actividades de tiempo libre organizadas por acuerdo de la Dirección General de Enseñanza Primaria y las Delegaciones Nacionales de Цuventudes y Sección Femenina".

De hecho, el capítulo único del Título VII trata en al artículo 99 de la existencia de un

"decreto especial que determinará las relaciones de las distintas Delegaciones y Servicios del Movimiento con la Educación Primaria".

La disposición transitoria segunda de este decreto de 2 de febrero de 1967 establece que

“los actuales profesores especiales de dibujo, idiomas, música, labores y enseñanzas del hogar de las Escuelas Normales que hayan ingresado en su cargo por oposición y se hallen en posesión del título de Enseñanza Superior requerido para el desempeño de la 


\section{Capítulo 3. La formación musical de los maestros}

cátedra, pasarán a formar parte del cuerpo de Catedráticos con la antigüedad de la fecha de la oposición de cada uno"

\subsection{2 ¿Cuáles eran los contenidos musicales de la formación de los maestros?}

Los contenidos que se imparten para la preparación musical de los maestros antes de la guerra civil quedan configurados en la Orden de 15 de noviembre de 1910

1er. Curso.

Conocimiento de las notas, figuras, silencios, pentagrama, líneas adicionales, claves, compases de compasillo, $2 / 4$ y $3 / 4$, partes fuertes y débiles, escala diatónica mayor y menor, tonos y semitonos de que consta, puntillo, ligadura, calderón, síncopa, sostenido, bemol y becuadro, intervalos: conjunto y disjunto, mayores y menores, movimiento del compás o aires

Lecciones prácticas en las que se hace uso del tono de do mayor y la menor en clave de sol, de los compases de compasillo, 2/4 y 3/4, síncopas, puntillo y hasta las corcheas y semicorcheas con sus silencios

Canto escolar fácil a una sola voz

2 curso

Conocimiento de los tonos y modos mayores y menores hasta tres sostenidos y tres bemoles, alteraciones propias y accidentales, compás binario, 2/8, 6/8 y $12 / 8$

Apoyaturas y mordentes, doble puntillo, tresillos, seisillos, fusas y sus silencios, clasificación de los compases de combinación doble y triple.

Conocimiento de la clave de Fa en cuarta línea 


\section{La educación musical en el franquismo}

En las lecciones prácticas se hace uso de los tonos mayores y menores y de todas las combinaciones de medida hasta la fusa

Puede adiestrarse en los cantos escolares a dos voces.

Las diferentes reformas legales que se van haciendo, entre la que cabe destacar como la más novedosa la de 1931 no cuenta con unos cuestionarios de la asignatura publicados, con lo que el profesorado de las asignaturas de cada Escuela Normal iba confeccionándolos a medida que pasaban los cursos, valiéndose de los anteriores parámetros establecidos por los de 1910 y los libros en vigor. En el plan de Cultura General de la Orden de 24 de septiembre de 1942, los cuestionarios se fueron publicando una vez iniciado ya el curso.

La aplicación de la Ley de Educación de 1945 y la aparición del Plan Profesional (llamado así porque los alumnos tenían que seguir obligatoriamente un curso de especialización profesional en formación agrícola, industrial o mercantil además de las asignaturas propias del Magisterio), permite la aparición de unos cuestionarios nuevos en la Orden de 9 de octubre de 1946 (BOE de noviembre), en los que aparecen los siguientes contenidos:

\section{Primer curso: cantos escolares}

Conocimiento e interpretación práctica de los signos empleados en la escritura del lenguaje de la Música

Pentagramas, líneas y espacios adicionales

Clave de sol en segunda, compases, figuras, silencios, puntillos hasta la corchea inclusive, intervalos, aires principales, su significado, palabras y signos que modifiquen la expresión musical

Ejercicios de entonación y de medida 


\section{Capítulo 3. La formación musical de los maestros}

Canciones infantiles, religiosas, patrióticas, regionales y rítmicas a una o dos voces

Formación de coros

En el Plan de estudios de 1950, que reforma el anterior de 1945, los contenidos se desglosan en la Orden de 10 de julio de 1951 (BO del Ministerio de Educación nacional de 17 de septiembre) sobre cuestionario para el segundo curso de las Escuelas del magisterio, en dos partes, teórica y práctica.

\section{Segundo curso. Música: Elementos de solfeo y cantos religiosos, patrióticos y escolares ( 2 horas semanales)}

a.- Parte teórica

Música: definición razonada

Solfeo: Notas. Pentagrama y líneas adicionales. Claves. Figuras y silencios. Compases. Partes fuertes y débiles. Líneas divisorias y barras de conclusión. Signos de prolongación, de repetición y de retorno. Movimiento del compás o aires. Escala natural. Tonos y semitonos. Alteraciones. Intervalos. Tonalidad.

b.- Parte práctica

Clave de sol en segunda línea. Compases de compasillo, 2/4 y 3/4. Figuras y silencios desde la redonda hasta la corchea con puntillo y semicorchea, ligadura y calderón. Síncopas. Repeticiones, retornos y compases incompletos. Aires principales y sus modificativos más comunes. Sostenido, bemol y becuadro accidentales. Intervalos mayores y menores. Tonalidad de do mayor y la menor.

Canto. Definición. La voz humana. Sus registros. Emisión. Vocalización. Expresión. Aplicación del texto a la música. Estudio de canciones escolares unisonales: cantos religiosos, patrióticos e instructivos 
Los cuestionarios correspondientes al tercer curso se publican en la Orden de 20 de marzo de 1952 (BOMEC de 31 de marzo y 15 de septiembre de 1952)

\section{Tercer curso: Cantos. 2 horas semanales}

a.- Parte teórica

Música. Además de las materias estudiadas en el curso anterior comprenderá: Conocimiento de los tonos o escalas diatónicas mayores y menores (ampliación). Alteraciones propias. Armadura de las claves. Tonos relativos. Subdivisión de los compases. Valores irregulares. Notas de adorno

b.- Parte práctica

Clave de fa en cuarta línea. Compases: binarios, 3/8, 6/8, 9/8 y 12/8, doble puntillos, tresillos y seisillos, compases de subdivisión, todas las combinaciones de valores hasta la fusa y su silencio, apoyaturas y mordentes

Canto. Estudio de canciones unisonales y de dos o más voces. Cantos religiosos, patrióticos, instructivos y populares moralmente seleccionados.

Metodología. Procedimientos y formas didácticas más adecuadas a la enseñanza de los cantos corales de los niños

Es evidente que esta formación les proporcionaba a los futuros maestros sobre todo conocimientos de solfeo y teoría de la música, así como el aprendizaje de una serie de canciones de carácter marcadamente ideológico, tanto por su clasificación (religiosas, patrióticas) como por sus criterios de selección (populares moralmente adecuados). En ningún caso se habla en estos cuestionarios de metodología de la canción, excepto de forma generalizada y por el objetivo final: que sean aprendidos por los niños. Así que se le puede suponer como elemento principal la memorización, repetición e imitación, tal vez por partes analíticas en el mejor de los casos. 


\section{Capítulo 3. La formación musical de los maestros}

Este tipo de formación se ve muy claramente plasmada en los libros que sirven como método para estudiar dichos contenidos en las escuelas de magisterio. Tal es el caso del Tratado de música para las Escuelas de Magisterio de Soler Palmer y Arnaudas Larrode ${ }^{\mathbf{8 5}}$, obra aprobada por el Consejo Nacional de Educación y declarada de utilidad para las Escuelas Normales por la Dirección General de Primera Enseñanza en 27 de octubre de 1940 y Boletín oficial del Ministerio de Educación nacional de 27 de junio de 1955, según consta en su portada, cuyos contenidos siguen punto por punto los cuestionarios. Así el volumen segundo, destinado al segundo año, desglosa de la siguiente forma los contenidos:

Compás binario / Alteraciones propias.- Tono de sol mayor / Clave de Fa en cuarta./ Doble puntillo. Blanca y negra con doble puntillo / Tonos relativos: tono de mi menor / Compás de 3/8 / Tono de Fa mayor. Non molto, non troppo, non tanto y poco mosso / Tresillos / Tono de re menor. Piú animato, piú mosso / Seisillos / Tono de remenos. Presto y vivace / Notas de adorno. Apoyatura / Tono de si menor. Prestísimo y vivacísimo / Tono de si bemol mayor. Fusas y su silencio. Clasificación de los compases. Subdivisión de los de combinación doble / Tono de sol menor. Semicorcheas con puntillo y su silencio con puntillo / Tono de la mayor. Corchas y su silencio con doble puntillo / Mordentes simples / compás de 6/8 / Tono de fa sostenido menor. Mordentes dobles, mordentes rectos de 3 ó más notas. Subdivisión del 6/8 / Tono de mi bemol mayor. Compás de 9/8. Subdivisión / Tono de do menor. Compás de 12/8. Subdivisión / Armadura, conocimiento y cambio de tono / Mordentes circulares / Abreviaturas de los mordentes /

Curiosamente, añade como apéndice unas Breves instrucciones sobre la enseñanza de los cantos escolares a los niños. Y como trabajo propone una serie de piezas de canto escolar para dos voces, para el comienzo de los exámenes o reparto de premios.

Dado el enorme control que ejerció el estado sobre los libros para la educación, es un buen exponente para comprender cómo se realizaban las enseñanzas musicales en las Escuelas de magisterio desde la época del final de la guerra civil y durante la vigencia de la Ley de educación primaria de 1945,

\footnotetext{
${ }^{85}$ SOLER PALMER, M. y ARNAUDAS LARRODE, M. Tratado de música para las escuelas del magisterio.
} 


\section{La educación musical en el franquismo}

que seguía vigente aunque los planes de estudio de magisterio hubieran cambiado en otros aspectos (requisitos para el acceso, duración de los estudios) pero que en el caso de la Música no sufrieron modificaciones ni de nomenclatura ni de presencia en el currículo (siempre mantuvieron su existencia durante dos cursos escolares y con una dedicación docente de dos horas semanales)

\subsubsection{El plan 67}

Mención aparte merece el plan que surge en las escuelas primarias de la aplicación del Decreto de 2 de febrero de 1967 (BOE de 13 de febrero) por el que se aprueba el texto refundido de la Ley de Enseñanza Primaria, siendo ministro de Educación Manuel Lora Tamayo.

Este nuevo texto de la ley incorpora algunos rasgos muy significativos con respecto a la reforma educativa que se intenta realizar y que llegará a su plasmación final en la Ley General de Educación de Villar Palasí tres años más tarde. De entre ellas destacamos muy especialmente el artículo 64 a, por el que el acceso a los estudios profesionales del Magisterio será directo (sin prueba de acceso) y se requerirá estar en posesión del título de bachiller superior en cualquiera de sus modalidades. Ello supone una preparación evidente y necesaria para la transformación de las Escuelas Normales a su incorporación dentro del sistema universitario como Escuelas Universitarias de Formación del Profesorado.

El plan reformado de 1967, en el que la música sigue estando presente en los dos cursos (casi un 7\% del total del curriculum) con una presencia de dos horas a la semana, los contenidos del cuestionario presentan grandes novedades que nos hacen pensar en el profundo cambio que se está gestando a nivel educativo en las inmediaciones de la nueva ley de educación de 1970. Presentan una formación desglosada mucho más compleja, que centra su atención en un aprendizaje más práctico. Distinguen los cuestionarios una parte activa y una parte receptiva. Según Alonso Medina y Rodríguez Cruz (2005) plasma una "formación teórico-práctica del alumnado (...) que tiene por 


\section{Capítulo 3. La formación musical de los maestros}

objeto su aplicación en la educación del niño (...), aconsejando que las clases fueran vivas y participativas, apoyándose en el lenguaje musical como una consecuencia racional de todas aquellas sensaciones experimentadas de forma rítmica- sonora. Sin embargo, y desde la perspectiva actual extraña que aún no apareciera en el plan de estudios la denominación Didáctica de la música, cosa que ya ocurre con otras materias fundamentales, como Didáctica de las matemáticas, de las Ciencias naturales, de la lengua española y literatura, de la geografía e historia, de la física y química, o incluso, didáctica de la religión y didáctica de la Formación del espíritu nacional".

Dichos cuestionarios del plan 67 se organizan de la siguiente manera:

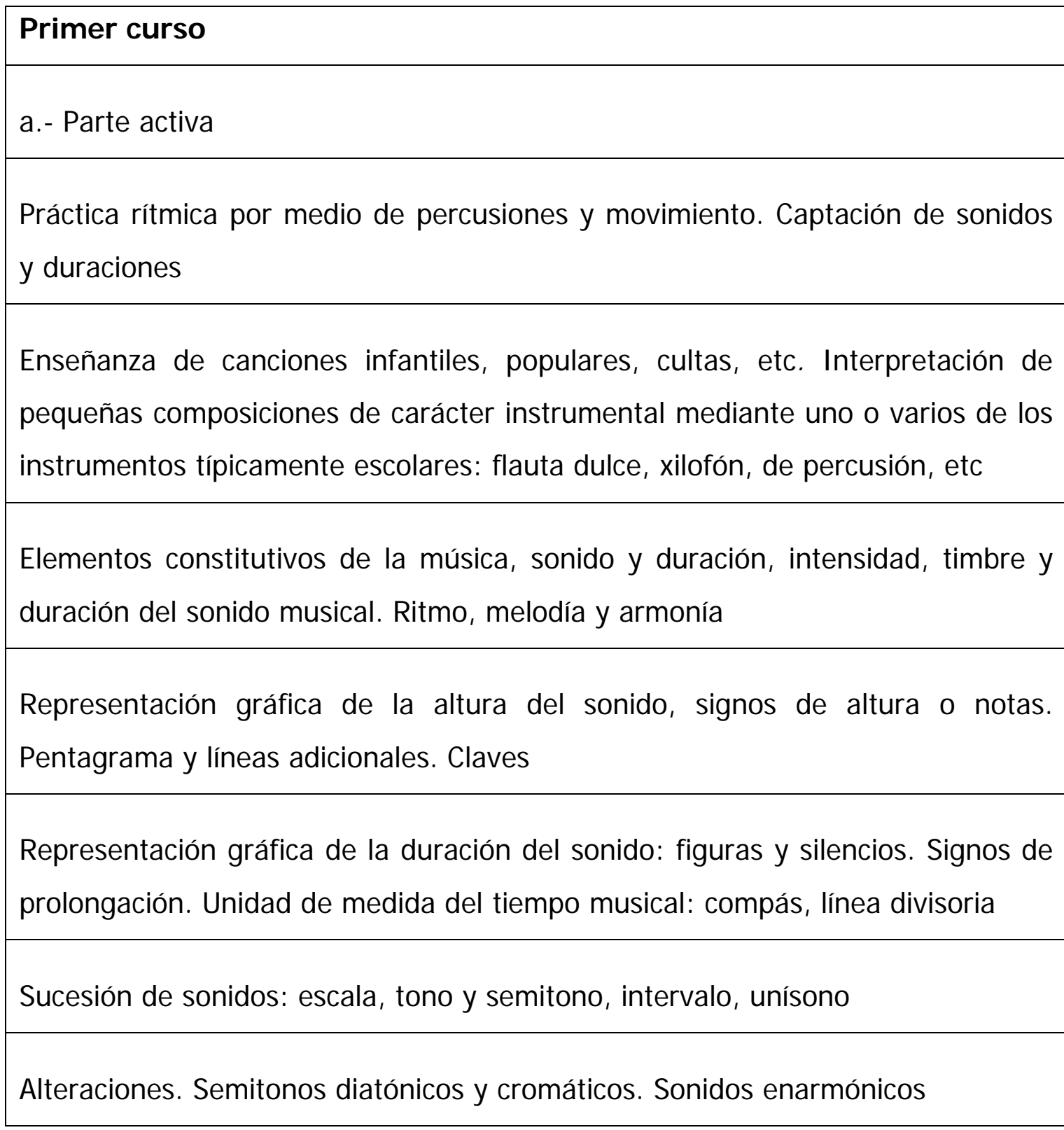



Ritmo. Partes del compás y sus fracciones, fuertes y débiles. Síncopa y contratiempo

Signos de repetición y abreviación

Expresión musical: Movimiento, carácter, matiz, acentuación, articulación y fraseo.

Durante este período se hará uso de la clave de sol, figura de notas y silencios hasta la semicorchea y los compases de $2 / 4,3 / 4$ y $4 / 4$.

b.- Parte receptiva

Audiciones comentadas, directas o a través de los medios audiovisuales de las obras más representativas de los grandes maestros, en las que el alumno logre conocer las características de la música vocal e instrumental y las formas musicales más cultivadas a través de la historia de la música

Música vocal: la voz humana como instrumento musical. Clasificación de las voces y sus registros. Características de las voces infantiles. Agrupaciones vocales. La música vocal a través de la historia: monodía y polifonía

Música instrumental: instrumentos musicales y su clasificación. Agrupaciones instrumentales musicales asequibles al niño. Evolución histórica de la música instrumental

Formas musicales. Fraseo y sintaxis musical. Géneros musicales. Consideración de estos aspectos en la m'suica adecuada a los diferentes grados escolares

Formas vocales más importantes: Canción, coral, motete, madrigal

Formas instrumentales más importantes: Danza, suite, sonata, concierto, poema sinfónico

Formas mixtas: melodía vocal acompañada, cantata, oratorio, teatro lírico 


\section{Capítulo 3. La formación musical de los maestros}

Características formales de la música apropiada al niño

\section{Segundo curso}

a.- Parte activa

Práctica de simultaneidades rítmicas por medio de percusiones y movimientos

Enseñanza de canciones infantiles, populares, cultas etc., a una, dos y más voces

Adiestramiento del alumno en la dirección de coros y agrupaciones instrumentales escolares, así como el modo de impartir la educación musical en la escuela

La selección de repertorio de música vocal e instrumental partirá en sentido progresivo de lo practicado en el curso anterior. Su consecuencia será el conocimiento del siguiente contenido:

Organización y relación de los sonidos musicales. Tonalidad. Modalidad

Principio físico armónico desde el punto de vista musical

Compases de subdivisión binaria, ternaria e irregular

Grupos de duración de sonido con valoración especial

Adornos melódicos

En la actividad práctica de este curso se hará uso de la clave de sol. Figuras de notas y silencios hasta el cuarto de tiempo. Compases de2/2, 3/8, 6/8 ,9/8, 12/8 y 5/8. Transposición de melodías sencillas

b. - Parte receptiva 
Audiciones comentadas, directa o a través de los medios audiovisuales, encaminadas a conocer con preferencia
a).- Las obras y compositores más representativos de la música española
b).- La música popular española. Sus características y principales formas

En este curso los comentarios de las audiciones, en determinadas ocasiones, estarán a cargo de los propios alumnos, previa orientación del profesor

Montaje musical en la escenificación de canciones, romances y cuentos. Juegos musicales. Teatro infantil

Orientación pedagógica, bibliográfica y discográfica para seleccionar convenientemente el repertorio de música más idóneo a utilizar por el maestro en la escuela primaria.

Efectivamente, estos cuestionarios para la formación de los estudios de Magisterio suponen un cambio radical con respecto a los anteriores. Estamos asistiendo al reflejo de una auténtica revolución pedagógica desde el punto de vista musical que se plasmará definitivamente en la ley de 1970 y que conduce hasta nuestros días.

Una orientación hacia la aplicación escolar de la música, la introducción de sistemas pedagógicos musicales, la preocupación por una formación práctica del profesorado, el desglose de contenidos en torno al lenguaje musical, la educación vocal, la audición e historia de la música culta y el folklore, la aparición de la interpretación musical con instrumentos escolares, la atención a la dirección coral y la introducción del movimiento y la dramatización en el ámbito escolar, son las características básicas de esta renovación que se plantea en la segunda mitad de los años 60 y que cambiará completamente la configuración de la educación musical en España. 


\section{Capítulo 3. La formación musical de los maestros}

No por ello dejan de existir los elementos teóricos y de lenguaje musical, tan necesarios. Porque ¿dónde si no podrían haberlos aprendido? En todo caso, en los conservatorios (pero en principio éstos tienen una orientación profesional que no necesariamente tenía que coincidir con la voluntad de los futuros maestros y exigía una dedicación para el dominio de algún instrumento de tipo clásico).

Como queda patente, la educación musical hasta ese momento en los colegios no incluía el dominio del lenguaje musical ni la formación instrumental básica. El bachillerato estaba más volcado en la historia de la música y los conocimientos más teóricos y reflexivos de las formas musicales o la clasificación y reconocimiento de los instrumentos sinfónicos. Luego, el único sitio donde se podía acceder a una formación en el lenguaje musical básico sin intención de profesionalizarse era en las Escuelas Normales del Magisterio.

Y a partir de este momento de finales de los años 60, vamos a asistir a una auténtica revolución, ya que dichos conocimientos van a estar cada vez más orientados al aprendizaje y a la puesta en práctica de la música en las escuelas primarias, haciendo llegar a todos los niños la práctica instrumental y no sólo al canto vocal.

\subsection{LA FORMACIÓN EN LAS ESCUELAS UNIVERSITARIAS DE FORMACIÓN DEL PROFESORADO}

Finalmente, la Ley General de Educación de 1970 impuso una nueva reforma del plan de estudios, dándoles rango de estudios universitarios y completa integración de las Escuelas Normales del Magisterio dentro de la Universidad bajo la denominación de Escuelas Universitarias.

Se crean dos grandes ramas de especialización: Educación Preescolar y Primaria, y dentro de esta última se realizan diversas especialidades (Ciencias, Filología) según las especificidades del segundo ciclo de EGB. 


\section{La educación musical en el franquismo}

Para crear profesorado que pudiera impartir la Segunda Etapa de la EGB, el MEC crea los cursillos de especialización, que se publican en la Orden de 4 de mayo de 1973 (BOE de 17 de mayo), dentro de los cuales está contemplada el área f).-de Educación estética y pretecnológica. Dentro de esta área se establecen tres modalidades independientes de cursillos: a) Música $\boldsymbol{y}$ dramatización, b) Expresión Plástica y c) pretecnología. Según especifica la Orden citada "los profesores se especializarán normalmente en una de dichas materias. Estos cursillos tendrán una duración de 100 horas más otras 50 horas dedicadas a trabajos de programación y aplicación práctica en el centro donde presten sus servicios".

Estos cursillos fueron organizados por el MEC en toda España a través de los diferentes distritos universitarios a través de las Resoluciones de $\mathbf{7}$ de junio de 1973 (BOE de 7 de julio) y 11 de octubre de 1973 (BOE de 6 de noviembre).

El contenido de estos cursillos para formar profesores de Segunda Etapa de EGB especializados en Música y dramatización están recogidos y desglosados en los cuestionarios de la Resolución de 29 de julio de 1972 (BOE de 29 de agosto de 1972) y especifican para la formación de dicho profesorado:

1. Elementos constitutivos de la música: altura, duración, intensidad y timbre

2. Modalidades de producción del sonido musical

3. Conocimiento y práctica de la lectura y escritura musical: elementos necesario: pentagrama, clave, figuras, notas.

4. Familias de instrumentos musicales

5. Práctica de los instrumentos de percusión

6. Técnica vocal y coral

7. Iniciación a la práctica de un instrumento melódico

8. Esquemas rítmicos y melódicos: "ostinatos rítmicos e improvisaciones melódicas"

9. Dirección de canto colectivo y canto coral 


\section{Capítulo 3. La formación musical de los maestros}

10. Expresión oral y expresión corporal individual y en grupo

11. Movimientos simples en compás binario y ternario

12. Técnicas de improvisación y dramatización

13. Creación de guiones y textos teatrales

14. Títeres y guiñol

15. Técnicas de la composición del lugar dramático

16. Coreografías simples lineales y simétricas

17. Montaje musical, teatral y de danzas sencillas

18. Repertorio e interpretación de canciones y textos

19. Las obras musicales universales en relación con los demás aspectos d ela cultura de su tiempo

20. Audición y comprensión musical

21. Literatura infantil, escenificación de romances y representación de obras musicales y teatrales

22. Léxico específico de las artes dinámicas

23. Estudio y utilización de la imaginación y experiencia de los alumnos

En el mismo sentido se transforman también los contenidos de la asignatura de Música en las Escuelas Universitarias del Profesorado de EGB, cambiando radicalmente sus contenidos en el llamado Plan 70.

Gran ejemplo del cambio que se realiza en la forma de entender la formación musical de los maestros para trasladarla posteriormente a las escuelas son las publicaciones o manuales para las Escuelas Universitarias que autoriza el Ministerio de Educación Nacional desde 1969.

Uno de los manuales más extendidos es Formación musical i y // de Matilde Murcia $^{86}$, Catedrático de Música de la Escuela Universitaria del Profesorado de EGB de Madrid y que tuvo una gran difusión en los años 70 y 80 por todas las

${ }^{86}$ MURCIA, M. (1979) Formación musical / y //. Gráficas Ajenjo: Madrid 


\section{La educación musical en el franquismo}

Escuelas Universitarias del país. En él se recogen, además de las consabidas lecciones solfeísticas para el aprendizaje de los elementos del lenguaje y la teoría de la música y las canciones populares e infantiles, otras secciones estructurales:

Ejercicios de prosodia y ritmo basados en los principios de la metodología Orff Schulwerk - principalmente utilizando elementos del lenguaje, percusión corporal y movimiento - , práctica de instrumentos: la flauta dulce y el instrumentario Orff (instrumentos de percusión afinada: placas) incluyendo instrumentaciones, una historia de la música y de las principales formas musicales, presentación de las características del folklore español por regiones ( con canciones e instrumentos), principios de armonía, composición e instrumentación, iniciación a la dirección coral e instrumental, dramatización y un apartado de didáctica de la música para la aplicación escolar desglosados los contenidos por cursos.

También adquieren gran difusión las publicaciones pedagógicas ligadas al método Orff, entre las que destacan fundamentalmente las de Sanuy y González Sarmiento ${ }^{87}$, Peris Lacasa ${ }^{88}$ y Angulo $^{89}$

\subsection{EL PROFESORADO DE MÚSICA DE LAS ESCUELAS DE MAGISTERIO Y ESCUELAS UNIVERSITARIAS DE FORMACIÓN DEL PROFESORADO}

La formación de los profesores de música de las Escuelas de Magisterio tiene que reunir dos requisitos fundamentales: el conocimiento de la realidad escolar infantil y la formación musical.

En cuanto a la primera, se conseguía mediante la formación como maestros en alguna Escuela de Magisterio y el ejercicio profesional en colegios de educación primaria.

La segunda, lógicamente, se conseguía en los únicos centros capaces de capacitar profesionalmente a los músicos: los conservatorios.

\footnotetext{
${ }^{87}$ SANUY, M. y GONZALEZ SARMIENTO, L.(1969). Orff-schulwerk. Música para niños (Versión original española basada en la obra de Carl ORFF y Gunild KEETMAN). Madrid: Unión musical española.

${ }^{88}$ PERIS LACASA, J.(1965) Música para niños. Madrid: Doncel

${ }^{89}$ ANGULO, M. (1968) Música y didáctica. Madrid: Editorial Magisterio Español
} 


\title{
Capítulo 3. La formación musical de los maestros
}

Como hemos visto, las asignaturas de música tenían el carácter de materias complementarias en el capítulo IV, artículo 37 de la Ley de 1945, junto con Ciencias de la Naturaleza, el dibujo, los trabajos manuales, las prácticas de taller y las labores femeninas

En la misma ley se establece en el artículo 65, sobre profesorado de las Escuelas del magisterio que

\begin{abstract}
“habrá de poseer preparación académica adecuada y la doble experiencia de la escuela primaria y de la escuela de magisterio. Conocimiento de la escuela española, que habrá experimentado viviéndola y regentándola por el tiempo mínimo de un año, o posesión del título de licenciado en la sección de Pedagogía de la Facultad de Filosofía y Letras. Este título será suficiente sin necesidad del de maestro. Oposición que seleccione a los mejor preparados y más aptos por sus dotes vocacionales y actuación mínima de un año en una escuela del Magisterio.
\end{abstract}

En el caso de las asignaturas especiales de ampliación serán desempeñadas por licenciados en otras Facultades de acuerdo con la naturaleza de la disciplina".

Este último apartado no es nada clarificador, puesto que el título de los conservatorios no obtuvo nunca calificación de licenciatura durante el franquismo. De hecho, es una larga historia que nos lleva hasta 1980 para el reconocimiento sólo de algunas titulaciones y únicamente a efectos docentes, y que se extiende hasta el 2005 en el reconocimiento necesario para cursar estudios universitarios de tercer ciclo.

En la clasificación del profesorado que se hace en dicho artículo 65, los profesores se dividen en 4 categorías: Numerarios, especiales, adjuntos y ayudantes de clases prácticas.

Los profesores de la asignatura de Música son Profesores especiales, ya que a este tipo pertenecen los de religión, los de las disciplinas que atiendan a la formación del espíritu nacional, complementarias y de especialización determinada. 


\section{La educación musical en el franquismo}

Los profesores adjuntos son profesores temporales en curso de completar los requisitos del apartado de formación (actuación mínima de una año en la escuela primaria, dirección de un centro, están cursando la especialidad de pedagogía o a falta de la oposición).

Los profesores ayudantes de clases prácticas son maestros nacionales que "en virtud de un procedimiento de selección regentan las escuelas anejas e incorporadas".

Sin embargo, los profesores numerarios (de las disciplinas fundamentales) y especiales (de las asignaturas complementarias) "habrán de ser designados mediante oposición, salvo el de religión que será designado por la jerarquía eclesiástica; los adjuntos y ayudantes se designarán en las condiciones reglamentarias".

Es decir, que en principio, y aunque deben reunir las mismas características, se hace una división en función del tipo de materias que van a impartir, entre profesores numerarios y especiales, ambos tras pasar por una oposición para incorporarse a la docencia. Esto establece diferencias severas tanto de categoría como retributivas. Así, por ejemplo en la Ley de $\mathbf{2 3}$ de diciembre de 1947 (BOE de 27 de diciembre) se hace una catalogación de la plantilla existente hasta el momento en las Escuelas de Magisterio en la que aparecen los siguientes datos:

Profesores numerarios

\begin{tabular}{|l|l|l|l|l|l|l|l|}
\hline 22 & 24 & 26 & 28 & 31 & 34 & 36 & 39 \\
\hline 21.000 & 20.000 & 18.000 & 16.000 & 14.000 & 12.000 & 11.000 & 10.000 \\
\hline
\end{tabular}

Profesoras numerarias

\begin{tabular}{|l|l|l|l|l|l|l|l|}
\hline 28 & 30 & 33 & 35 & 39 & 43 & 46 & 48 \\
\hline 21.000 & 20.000 & 18.000 & 16.000 & 14.000 & 12.000 & 11.000 & 10.000 \\
\hline
\end{tabular}




\section{Capítulo 3. La formación musical de los maestros}

Lo que implica un total de 240 profesores y 312 profesoras numerarias, con sueldos que oscilan entre las 10.000 y las 21.000 pesetas anuales.

Sin embargo, en el artículo dos de la misma, aparece una dotación de $\mathbf{5 0}$ profesores o profesoras de música (y tan sólo 35 de francés y 36 de dibujo), con un sueldo hasta el momento de 6.000 pesetas anuales, que se incrementan a 8.000 en esta referencia legal.

En conclusión, el profesorado especial de música en el año 1947 en las Escuelas de Magisterio representa un $9 \%$ del profesorado total. Si tenemos en cuenta que la carga lectiva representa aproximadamente entre un 7 y un $10 \%$ del currículo, parece bastante ajustado.

Pero el desajuste salarial teniendo en cuenta el acceso por oposición es más que notable, ya que en el cuerpo de profesores especiales no parece haber incrementos por antigüedad, y en cualquier caso se sitúan en torno a un $60 \%$ y un $80 \%$ de las percepciones mínimas al ingresar en el cuerpo de la otra categoría. Esta diferencia se empezará a subsanar con el artículo 124 del decreto de 7 de julio de 1950 (BOE de 7 agosto) en el que se contempla por primera vez que los profesores especiales percibirán el sueldo o gratificación consignados en los presupuestos del Estado, que será incrementado cada cinco años en 1.000 pesetas, mediante el sistema de quinquenios.

En las plantillas unificadas de Profesores de Escuelas de magisterio que aparecen en el BOE de $\mathbf{2 7}$ de diciembre de 1957 consta que el número total de profesores especiales de música (numerarios) a fecha del 1 de octubre de 1958 era de 54 profesores con unas percepciones económicas de $\mathbf{1 5 . 1 2 0}$ pesetas. Esta es la misma cantidad que perciben los profesores numerarios especiales de Francés, Dibujo y Caligrafía. No obstante, los profesores numerarios de otras asignaturas perciben entre 21.480 y 40.200 pesetas (según categoría y antigüedad). Y en el otro extremo del sistema, 


\section{La educación musical en el franquismo}

están los profesores de Educación Física, Formación política, labores del hogar y trabajos manuales, que perciben 7.560 pesetas como sueldo.

El Decreto de 7 de julio de 1950 (BOE de 7 de agosto) sobre el Reglamento de las Escuelas de magisterio regula el sistema de acceso a las plazas de profesorado. Así en el Capítulo XIII, artículo 111 especifica que

\footnotetext{
"el ingreso en el profesorado especial de labores, trabajos manuales, música, dibujo, idiomas y caligrafía se hará mediante oposición. Para tomar parte en ella deben poseer los aspirantes el título de maestro de Primera enseñanza y el título profesional correspondiente, siendo éste para los de Música los del conservatorio". El artículo 123 afirma que "todas las plazas vacantes de profesores especiales serán provistas alternativamente por turnos sucesivos de traslado y de oposición libre".
}

Los tribunales de oposición para proveer las plazas de profesores numerarios, especiales y adjuntos estaban constituidos de la misma forma, según el artículo 129: cinco miembros titulares y sus suplentes, de los cuales un presidente del Instituto de España, consejeros de Educación nacional o vocales del Consejo Superior de Investigaciones científicas, tres vocales profesores numerarios de las cátedras correspondientes a las que se oposita y un especialista titular

La oposición constaba de los siguientes ejercicios de carácter eliminatorio (artículo 132):

- Memoria o trabajo de investigación personal sobre un asunto pedagógico o sobre cuestiones de la práctica profesional y exposición de un plan completo de organización de las escuelas anejas, con todas sus clases e instituciones complementarias.

- Otros trabajos que considere dignos de ser tomados en consideración, así como los méritos profesionales que pueda justificar.

- Un trabajo escrito sobre finalidad, carácter y organización de las prácticas de los alumnos durante los años de la carrera del magisterio, con redacción del cuestionario o programa y explicación verbal, como máximo de media hora, de una de las lecciones de dicho programa 


\section{Capítulo 3. La formación musical de los maestros}

sacada a suerte por el opositor. El tiempo para la realización escrita de esta parte será no inferior a cuatro horas.

- Un ejercicio escrito sobre un tema de religión, otro de formación del espíritu nacional y otro sobre un plan de Educación física adaptado a las escuelas anejas del magisterio. Cuatro horas

- Ejercicio oral sobre un tema de organización escolar y metodología, otro sobre pedagogía fundamental e historia de la pedagogía y otro sobre instituciones complementarias de la escuela o de iniciación profesional. Las maestras además desarrollarán un tema de enseñanzas del hogar.

- Ejercicio práctico:

- Actuación del opositor por sorteo y sesiones completas en dos sección de la escuela aneja, previa la presentación del oportuno plan de trabajo al tribunal. Para las maestras, una sección será de párvulos y otra la que por suerte le corresponda.

- Visitas colectivas de los opositores a un grupo escolar correspondiente al sexo y exposición escrita de sus impresiones, deducciones acerca del régimen, procedimientos y organización de la escuela visitada. El tribunal determinará la duración de los ejercicios y, en todos los casos, los temas serán sacados a suerte entre los contenidos en el cuestionario que publique la Dirección general de enseñanza Primaria.

Las primeras oposiciones de cátedras de magisterio y las normas para la constitución de los tribunales que habrán de juzgarlas se plasma en la orden de 15 de diciembre de 1952 (BOE de 20 de diciembre)

El derecho de movilidad del profesorado queda configurado en la ley de 24 de abril de 1958 (BOE de 25 de abril) que responde a la necesidad de igualar las oportunidades de los aspirantes ante el concurso de traslado, especificando que la mitad de las plazas saldrán a concurso de traslado y la otra mitad a concurso oposición, y estableciendo que todas las cátedras de nueva creación serán provistas la primera vez necesariamente por oposición. Una de las grandes innovaciones que incorpora esta ley es que pretende regular de manera 


\section{La educación musical en el franquismo}

igualitaria los derechos a este respecto de los catedráticos y profesores de institutos de bachillerato, universidades, escuelas de comercio y escuelas de magisterio, al decir que "se ha estimado que todo este sistema de concursos y de resolución de los mismos puede aplicarse con unas mismas características tanto a las cátedras de universidad como a las de los Institutos Nacionales de Enseñanza Media y a las Escuelas de comercio, así como a las plazas de profesores numerarios de Escuelas del Magisterio. Esta tendencia hacia la unificación tiene especial interés no sólo porque da el mismo trato a todos estos concursos que se refieren a realidades semejante, sino también porque viene a ser como un ensayo para la unificación que en materia de oposiciones pudiera llevarse a cabo en el futuro, para estos distintos grados de la enseñanza".

Dado que el Decreto de 24 de septiembre de 1958 (BOE de 13 de octubre) se hacen extensibles las disposiciones anteriores sobre provisión de cátedras vacantes a las plazas de profesores especiales y adjuntos de las Escuelas de Magisterio, estamos asistiendo al primer rasgo legislativo de paridad.

Este acercamiento paulatino entre el dividido cuerpo de profesores numerarios y especiales culminará en .el Decreto de 2 de febrero de 1967 (BOE del 13 de febrero) por el que se aprueba el texto refundido de la ley de Enseñanza Primaria (en vigor la de 1945), que en su segunda disposición transitoria expone que

\footnotetext{
"los actuales profesores especiales de dibujo, idiomas, música, labores y enseñaza del hogar de las Escuelas Normales que hayan ingresado en su cargo por oposición y que se hallen en posesión del título de enseñanza superior requerido para el desempeño de la cátedra, pasarán a formar parte del cuerpo de catedráticos con la antigüedad de la fecha de la oposición de cada uno.
}

En lo que respecta a la educación Superior, la Ley de $\mathbf{1 9 7 0}$ supone también una regularización del profesorado de las Escuelas de Magisterio dentro del sistema general universitario, con lo que los catedráticos de música existentes desde las oposiciones convocadas en la orden de 27 de febrero de 1956 (BOE de 3 de abril) y la ley de 24 de abril de 1958 (BOE de 25 de abril) e 


\section{Capítulo 3. La formación musical de los maestros}

incorporados a las cátedras por el decreto de 2 de febrero de 1967 (BOE del 13 de febrero) se integran en el resto de cuerpos de funcionarios del Estado dentro del profesorado universitario tras una larga batalla por el reconocimientos de los derechos adquiridos debido a los problemas, ya antiguos, con la falta de reconocimiento en el sistema general educativo de las titulaciones específicas de los conservatorios.

\subsection{LA PEDAGOGÍA MUSICAL EN ESPAÑA}

Mientras en otros países europeos se estaba produciendo desde el último tercio del siglo XIX toda una nueva revolución en la enseñanza de la música, que la hacía accesible a toda la población y no sólo a los niños especialmente dotados con habilidades musicales o con deseo de transformarse en músicos profesionales, en España, la educación musical aún se centraba en los conservatorios o en todo caso en la educación de las clases más altas de la sociedad.

En todo caso, era un complemento cultural bien visto, especialmente en la formación de la sociedad femenina de alto rango. Muchas de ellas sabían cantar y tocar como aficionadas el piano, e incluso una buena parte de ellas cursaban estudios en el conservatorio para adquirir mayores habilidades interpretativas como instrumentistas, pero rara vez se dedicaban a la vida profesional concertística o formaban parte minoritaria de las orquestas. Se trataba sobre todo de un complemento cultural que revertía en la vida familiar o social como asistentes a conciertos o piezas de teatro musical (zarzuelas y óperas).

La formación de las alumnas en este tipo de educación musical se siguió realizando a lo largo de todo el franquismo, especialmente en las escuelas de las órdenes religiosas, poseedoras de pianos en sus residencias, como actividades extraescolares, voluntarias y no sistemáticamente programadas. 


\section{La educación musical en el franquismo}

Otra historia muy diferente era la de los coros, ya que existía una gran tradición coral, especialmente en algunas zonas del país. Las formaciones vocales siempre han tenido mucha importancia en el país y especialmente en torno a ellas se fueron gestando las principales innovaciones pedagógicas musicales en el entorno español

\subsubsection{La pedagogía musical en España hasta los años 60}

La necesidad de hacer llegar la música a todos los niños y no solamente a los especialmente dotados para ello, ha hecho surgir según Oriol (2005) "métodos que tratan de dulcificar la abstracción de dificultades que se derivan de establecer una progresión y continuidad a lo largo de todo el proceso educativo, no solamente basado en el desarrollo del lenguaje musical y sus diferentes aplicaciones técnicas, sino tendiendo a familiarizar al niño con la realidad musical, con los hechos musicales, por vía experimental y participativa y desde una perspectiva amplia y globalizadora"

Se realiza sobre todo en instituciones escolares de tipo religioso (exceptuando la actividad de Joan Llongueres). Esto es bastante lógico si tenemos en cuenta que dichos centros educativos tenían muchas más dotaciones económicas que los centros públicos, mayor libertad para impartir sus enseñanzas y contratar personal especializado para hacerlo, que en ellos la actividad coral ligada a la vida religiosa tenía una presencia claramente establecida y una gran tradición en la preparación de directores de coro (y por tanto interesados en la enseñanza musical de los niños), la capacidad de difusión a través de sus propios medios de formación del profesorado (en las escuelas del Magisterio de la iglesia) y sobre todo su preeminencia en la educación de un cierto nivel (educación secundaria, educación de las clases sociales más privilegiadas) como sostiene Cámara Villar (1984).

Entre las instituciones corales de una gran tradición musical destaca la Escolanía de Montserrat, como uno de los grandes centros de formación musical infantil. 


\section{Capítulo 3. La formación musical de los maestros}

Especial atención merece la labor realizada en ella por el Padre Ireneu

Segarra (1917- 2005), uno de los pioneros en la educación musical infantil. No sólo recibió la educación musical como niño en el coro de la propia escolanía con el Padre Anselm Ferrer y el Padre Angel Rodamilans, sino que profesó sus votos en agosto de 1934. Su formación musical externa al monasterio siguió su curso con clases de piano con Frank Marshall, de armonía y contrapunto con Joseph Barberá, de fuga y composición con Critòfol Taltabull, y sobre todo su estancia en París en 1952 para asistir a las clases de Nadia Boulanger (la gran gurú de la música de principios del siglo $\mathrm{XX}$, a cuyas clases asistieron desde Gershwin o Copland hasta Stravinski). Ya desde 1941 y sobre todo a partir de los años 50, supliendo al Padrid David Pujol, asumió la dirección de la escolanía. Establece contacto con otros coros extranjeros, especialmente con "Los niños cantores de Viena" y los "Domspatzen" de Ratisbona y empieza un periplo internacional de conciertos a partir de la peregrinación a Roma con motivo de la proclamación del dogma de la Asunción de la Virgen de Montserrat, que le llevan a ponerse en contacto con otras formas de enseñar la música y con un nuevo medio de difusión: la grabación discográfica. De su labor pedagógica, centrada en la educación de la voz, la lectura de textos vocales y métodos de canto, así como de su colaboración con el Dr. Jordi Perelló, nacieron dos elementos fundamentales en la pedagogía musical española, y sobre todo de gran difusión en la zona catalana: "Ĺa voz del niño cantor" (1963) y muy especialmente en Método de enseñanza musical "EI meu llibre de música", distribuido en ocho grados, dirigidos en las escuelas y que ha encontrado continuidad hasta nuestros días en la Escuela de Pedagogía Musical Ireneu Segarra..

Otro de los grandes pedagogos musicales de estos primeros años es Manuel Borqunyó (1886-1973). También de origen catalán, estudia como escolano en el monasterio de Montserrat con el Padre Guzmán, así como en el Conservatorio Municipal de Música de Barcelona con los profesores Nicolau, Pellicer y Lamotte de Grignon. Ligado a la actividad coral desde 1913, intenta crear un nuevo tipo de escuelas de música con financiación municipal en el 


\section{La educación musical en el franquismo}

Ateneo de I gualada, siguiendo modelos centroeuropeos en las que se ofreciera educación musical, sección coral y sección de conciertos por medio de bandas de música. A partir de 1930 emprende una activa campaña para solucionar la organización de la educación musical en la escuela, desarrollando una metodología ecléctica basada en su conocimiento de otros métodos europeos, ya que como miembro honorario del Instituto Español de musicología había asistido a los congresos de la "Internacional Society for Musical Education" de París (1937), Bruselas (1953) y de Moscú (1970). Su actitud crítica ante los métodos de París Galin-Chevé-Gedalge, Dalcroze, Ward, Orff o Kodaly le lleva a introducir elementos de todos ellos pero con moderación en una progresión educativa con tres etapas:

- Periodo de gestación (de 4 a 7 años), con predominancia de las prácticas motrices, marchas y danzas. Canciones populares y con gestos. Silencio y audición de pequeñas obras musicales. Es un período de aprendizaje mayoritariamente intuitivo

- Período de preparación (de 7 a 9 años) que pretende la familiarización con los elementos musicales por medio de ejercicios de respiración mesurada y de emisión y articulación de la voz. Iniciación al dictado. Entonación de canciones a dos voces.

- Periodo de realización (9 a 13 años) donde se integran todos los elementos de la música: sonido, ritmo, tonalidad y expresión en la práctica del solfeo.

Su metodología se apoya en una serie de analogías visuales como la fononimia, la representación virtual de los sonidos en la pizarra, la mano-pentagrama y la dactilorritmia de Guido d'Arezzo y la rítmica vocal a través de la guía vocal respiratoria. Considera que el elemento más importante de la educación musical de los niños en la escuela es el canto coral. También introduce la audición y hace especial hincapié en la importancia de la programación de los contenidos a enseñar y de la correcta adaptación de los métodos extranjeros cuando se quieren aplicar al sustrato nacional y las canciones populares del país. 


\section{Capítulo 3. La formación musical de los maestros}

A partir de 1942 se traslada hasta el fin de sus días a Tenerife donde realiza una gran labor a través de su actividad en el "Coro de Santa Cecilia", el "Instituto Municipal de Pedagogía," el Seminario Diocesano, el Colegio Alemán y otras muchas escuelas religiosas. También colaboró con Sección Femenina en su etapa de difusión de metodologías de educación musical.

Entre la comunidad de educadores religiosos se hizo muy famoso un método internacional que tuvo gran difusión: el de Lustine Ward (1879-1975) ${ }^{\mathbf{9 0}}$. Esta pedagoga americana basa su sistema de pedagogía musical para los niños en la antigua tradición coral de canto en la iglesia. Heredera también de algunas aportaciones de otras metodologías, utiliza la separación de los elementos musicales de ritmo y entonación en la enseñanza, la discriminación de alturas mediante el canto diario de patrones de entonación, un sistema numérico sustitutivo del solfeo de carácter principalmente modal y la relatividad de alturas con el do móvil. Además incorpora la quironimia para la dirección y memorización de entonaciones y el aprendizaje del ritmo mediante el movimiento.

El repertorio de aprendizaje se nutre de melodías clásicas, canciones del folklore europeo y sobre todo del canto gregoriano, introduciendo muchas de las aportaciones introducidas para su dirección e interpretación desde el monasterio de Solesmes ${ }^{91}$

Su obra fue publicada exhaustivamente por la Catholic Education Press desde1910 y su método se extendió por todo el mundo de influencia católica, especialmente a través de cursos de formación del profesorado, y especialmente en España a través de las aplicaciones de Rosa Mạ Font.

La otra gran iniciativa pedagógico musical que se inicia en esta etapa tiene también su origen en el contexto de la vida musical catalana, pero en este caso no está ligada a las instituciones religiosas. Se trata de la obra de \oan

\footnotetext{
${ }^{90}$ WARD, J. (1962) Método Ward. Bélgica: Desclée

${ }^{91}$ COMBE, P. (1987) Justine Ward and Solesmes Washington D.C: Catholic University of America Press
} 


\section{La educación musical en el franquismo}

Llonqueres (1880-1953), músico formado con Doménech Mas, el profesor Secarrant, aunque también formó parte de la escolanía de Sant Pere de les Puelles, tradición coral que seguiría como cantante en el Orfeó Catalá Más tarde sería alumnos de Enrique Granados y de Enric Morera.

Inicia su actividad en Terrasa en 1903 donde funda la Escola Municipal de Música, la Escuela Coral y la Escuela Vallparadís, donde aplicó por primera vez la metodología de la rítmica con el método Dalcroze aprendido en Ginebra. La obtención del diploma del método Dalcroze en Hellerau en 1912 le convierte en uno de los poquísimos músicos en tener acceso directo a uno de los grandes sistemas metodológicos de la época. Alumno predilecto de Jean Jacques Dalcroze, crea con el apoyo de Lluis Mollet y Francesc Pujol, el Instituto de Rítmica y plástica de Barcelona en el marco del Orfeó Catalá. Director de educación musical en las escuelas del Ayuntamiento de Barcelona y profesor de música en la escuela municipal de Vilajoana, introdujo en ellas la aplicación del método Dalcroze con niños discapacitados.

Dirigió también la educación musical en las Escuelas Blanquerna y fue profesor de rítmica en el Institut Esola de la Generalitat durante la república. En 1924 fundó y dirigió la Academia de Música de Barcelona.

La importancia que adquirió la pedagogía rítmica le puso en contacto con los grupos de coros y danzas (como el de Esbart Verdaguer, con el que colaboró intensamente) y con otras instituciones ligadas a la danza contemporánea y el ballet, como el Institut del Teatre.

Escribió más de cien canciones con gestualidad para niños y divulgó ampliamente las teorías pedagógicas de la euritmia de Dalcroze y de su aplicación en la enseñanza de la rítmica y la plástica en niños y adultos, así como a la formación de profesores de música en la metodología de la rítmica. Aunque apartado de la vida pública durante el franquismo, muchos de sus alumnos trabajaron sobre todo a través de la danza y de la expresión corporal con actividades ligadas al folklore y también a la educación física. Su libro "El 


\section{Capítulo 3. La formación musical de los maestros}

ritmo" ofrece, además de un perfil biográfico de Jacques Dalcroze, las bases filosóficas de su método y la importancia pedagógica de la educación rítmica en las escuelas de educación general.

A su muerte, en 1953, su hija Pilar reestablece los contactos con el Instituto Dalcroze de Ginebra y reanuda los cursos de formación musical a través de la creación del actual Institut Joan Llongueres. Desde 1964 la sustituyeron en la dirección sus hijas Nuria y Pilar junto a Ma Mercé Cardoner y Carme Viturí .

\subsubsection{La introducción de los métodos de pedagogía musical a partir de 1960}

Según Xoan María Carreira ${ }^{\mathbf{2 2}}$ a partir de 1957 se inició un período de transición del modelo fascista-autárquico al modelo autoritario-tecnocrático.

Los años 60 suponen el inicio de una época de aperturismo y modernización en todos los ámbitos de la sociedad española: políticamente nos abrimos hacia el entorno de influencia norteamericano, económicamente principalmente debido a las inversiones de capital extranjero, y sobre todo a un gran cambio cultural de la sociedad, caracterizado por la expansión urbana, la reducción de la tasa de analfabetismo, la presencia de la radio y la televisión y la expansión cultural, que culminará desde el punto de vista educativo en la Ley General de Educación de 1970.

Estas transformaciones también afectan y muy profundamente al mundo de la educación musical. El nuevo papel que juega la cultura en la educación y las acciones que emprende la sociedad civil, especialmente en el ámbito musical Sección Femenina, hacen que se empiecen a divulgar y poner en práctica los métodos pedagógicos musicales internacionales más importantes.

\footnotetext{
${ }^{92}$ CARREIRA, X. M. La música contemporánea en España durante los años 60 ( 1 y 2). En Mundo clásico. También en versión electrónica en http://www.mundoclasico.com
} 


\section{La educación musical en el franquismo}

Además de desarrollar el sistema Dalcroze (que ya se había introducido en Cataluña por la labor de Joan Llongueres) y de continuar difundiéndose el sistema Ward (especialmente con las adaptaciones hechas por Ma Rosa Font $^{93}$ en su obra pedagógica sobre la metodología del ritmo musical, que desde su labor como profesora en la Escuela de Música Sagrada de Madrid y Vic habían conseguido una gran divulgación entre el profesorado de los colegios de las órdenes religiosas), se introducen por fín en España las principales metodologías pedagógicas de educación musical que en esos momentos se llevaban ya poniendo en práctica desde principios de siglo en otros países europeos.

Este aperturismo se inicia fundamentalmente con las becas que Sección Femenina otorga a las dos hermanas Sanuy para ir a ampliar sus estudios en el Orff Institut en Salzburgo. Su aprovechamiento de los cursos seguidos no sólo se plasmó en la publicación de la adaptación del método (la aplicación del Orff a la escuela, el Orff schulwerk) al español, sino que abrió las puertas a que se realizaran una gran cantidad de cursos de formación e innumerables actividades de casi todos los métodos pedagógicos musicales en España.

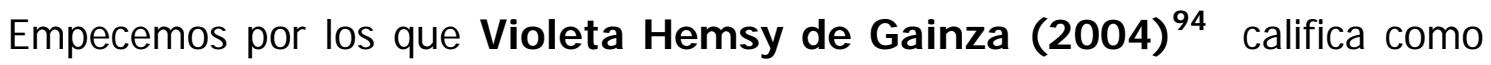
los métodos activos (que se desarrollan en torno a los años 1940-50) Entre ellos destaca la labor de Dalcroze ${ }^{95}$ y su Euritmia, la aportación de Edgar Willems ${ }^{96}$ al conocimiento de la psicología infantil y los trabajos de Maurice Martenot ${ }^{97}$. Las ideas de J ohn Dewey (filósofo y educador americano) sobre la "necesidad de democratizar la educación y hacer una educación para todos" se plasman no sólo en todas las reformas educativas posteriores, sino que

\footnotetext{
${ }^{93}$ FONT, R.M. (1972). Metodología del ritmo musical, 1 y 2.Valladolid: Lex nova y (1980) Metodología del ritmo musical. El ritmo en la educación preescolar. Madrid: Ediciones paulinas ${ }^{94}$ HEMSY DE GAINZA, V. (2004) La educación musical en el siglo XX. En Revista musical chilena, vol. 58, no 201, pag. 74-81. También en formato electróncio en http://www.scielo.cl y (2002) Didáctica de la música contemporánea en ela aula. En Pedagogía musical. Dos décadas de pensamiento y acción educativa .Buenos Aires: Lumen

${ }^{95}$ DALCROZE, E.J. (1967). Rythm, music and education (8 volúmenes). Londres: The Riversided Press

${ }_{96}$ WILLEMS, E. (1981) El valor humano de la educación musical. Buenos Aires: Eudeba.

${ }^{97}$ MARTENOT, M (1970) Principes fondamentaux de formation musicale et leur aplication. París: Magnard y Juegos musicales (5 discos). París: Pleïade
} 


\section{Capítulo 3. La formación musical de los maestros}

influencian claramente a J ames Mursell ${ }^{\mathbf{9 8}}$ que inicia su particular camino en la pedagogía musical en Norteamérica.

En la siguiente década, Hemsy de Gainza subraya la importancia de la divulgación de los que ella califica de métodos instrumentales, entre los que destaca los de Carl Orff, Zoltan Kodaly y Suzuki, el primero centrao en los conjuntos instrumentales y la introducción de la percusión afinada y no afinada en la escuela, el segundo que privilegia la educación vocal y el trabajo coral, haciendo especial hincapié en la importancia del folklore, y el último qu ese dedica a la enseñanza a través de un instrumento culto: el violín.

La siguiente generación según Hemsy de Gainza es la dedicada a los métodos creativos y se desarrolla fundamentalmente en los años 79. Sus principales representantes son George Self ${ }^{99}$ con su muy innovadora obra Sounds in class que introduce la composición contemporánea en el aula como elemento creativo de educación musical y Murray Schafer ${ }^{\mathbf{1 0 0}}$.

Todos estos métodos pedagógicos son conocidos y difundidos de manera prácticamente simultánea en nuestro país en los años 60 y 70. Cierto es que la educación musical estaba tomando un nuevo impulso en nuestro país con su nuevo posicionamiento dentro de la reforma educativa pero es verdad también que colaboraron otros factores a que esta difusión se produjera: con éxito:

- Era necesario formar al profesorado para que impartiera la asignatura de Educación dinámica y música en las escuelas e institutos.

- Había voluntad por parte de la política educativa de que se hiciera de manera metodológica y pedagógicamente innovadora

- Los profesores mostraban un gran interés y entusiasmo por estas nuevas propuestas en la forma de enseñar la música

\footnotetext{
${ }^{98}$ MURSELL, J. (1943) Music in american schools. Nueva York: Silver Burdett Company y (1948) The psicology of music. Nueva Yourk: Norton and Co.

${ }^{99}$ SELF, G. (1991) Nuevos sonidos en clase. Buenos Aires: Ricordi

100 SCHAFER, M. (1984) Cuando las palabras cantan. Buenos Aires: Ricordi; El compositor en el aula. Buenos Aires: Ricordi; (1985) Limpieza de oídos. Buenos Aires: Ricordi y (1986) El rinoceronte en el aula. Buenos Aires: Ricordi
} 


\section{La educación musical en el franquismo}

- La apertura política y la mejora de la situación económica permitía viajar a los ponentes y conceder becas para la formación a estudiantes avanzados

- Se destinan importantes partidas presupuestarias a la innovación educativa y a la formación del profesorado

- La editorial Ricordi Americana, en Buenos Aires, juega un papel importantísimo con la publicación en español de casi todas las metodologías, obras de referencia, composiciones y material musical escolar.

- La Sociedad Internacional de Educación Musical (ISME) jugó también un papel fundamental en la difusión por toda Europa y el continente americano de estas metodologías, otorgando su apoyo financiero y estructural a las instituciones educativas interesadas en la innovación y la introducción de otras formas de educación musical en las escuelas, especialmente bajo la presidencia de Zoltan Kodaly y Dimitri Kabalevski.

Veamos, aunque sea por encima, algunas de las importantes aportaciones metodológicas de estas grandes escuelas de pedagogía musical.

\section{Método Dalcroze. Emile Jacques Dalcroze (Viena 1865-Ginebra 1950)}

Músico y pedagogo suizo, su método se caracteriza por la utilización del principio de la euritmia, lo que permite adquirir el sentido musical por medio del ritmo corporal. Su análisis del movimiento bajo los principios de tensión/aflojamiento y contracción/descontracción son la base de la danza contemporánea. La búsqueda de la armonización interior a través del movimiento y de la expresión gestual son objetivos principales de su sistema de educación musical. Su obra fundamental, "El ritmo, la música y la educación" fue publicada en 1920 y obtuvo una gran divulgación sobre todo ligada a la expresión corporal.

El Instituto Dalcroze en Ginebra es el principal centro de difusión de su obra y sus enseñanzas. 


\section{Capítulo 3. La formación musical de los maestros}

En España, la difusión de su método se realiza aún hoy fundamentalmente a través del Institut Llongueres en Barcelona.

MétodoWillems. Edgar Willems (Bélgica 1890- 1978). Aunque nacido en Bélgica, la mayor parte de su labor pedagógica se desarrolla en Suiza. Comparte las teorías de Dalcroze sobre los beneficios de la educación eurítmica y el movimiento natural. Su trabajo se desarrolla sobre todo a partir de la comprensión de la psicología infantil y del desarrollo de las cualidades musicales innatas en él. Preconiza el equilibrio entre las bases educativas del ritmo, melodía y armonía, trabajados sobre todo a partir del ritmo corporal y la voz. Trabaja en profundidad la discriminación auditiva, la lectura relativa con do móvil y los elementos afectivos de la música.

Su obra más importante es "La educación musical de los más pequeños". El conjunto de su obra y las aportaciones posteriores de su escuela se ha realizado a través de la Asociación pro-Música y de las actuales asociaciones Willems. Su difusión en España ha sido realizada fundamentalmente por su colega y amigo Jacques Chapuis a través de numerosos cursos para profesores y músicos.

Método Martenot. Maurice Martenot (París 1898- Clichy 1980). Su interés por la investigación en el campo de las ondas sonoras y la música electrónica le llevó a diseñar uno de los primeros teclados electrónicos en los que se podían modificar parámetros musicales como timbre, altura, duración, ataque y armónicos. Su método supone el inicio de la música electrónica, de la manipulación del sonido y la experimentalidad. Aunque no está específicamente dirigido a los niños, sino a todos los que desean "jugar con el sonido", sus ideas tendrán suma importancia en la música contemporánea y en su introducción posterior en la escuela bajo el concepto de creatividad en el aula.

A partir de 1938 se interesa por la afinación intrazonal y la música de otras culturas. Su influencia en toda la música contemporánea y especialmente en la música electrónica es enorme. 


\section{La educación musical en el franquismo}

Método Ward. Justine Ward (1879-1975). Se basa en la importancia del canto y la entonación melódica, al que se añade la larga tradición religiosa del canto gregoriano. Su concepto rítmica de arsis y tesis, la utilización de la quironomía en la dirección y memoriación de las melodía, las aplicaciones de las innovaciones de Solesmes en la interpretación del canto gregoriano y el conocimiento de la música modal aplicados a la educación vocal de los niños y en especial a los coros infantiles son sus principales características. Fue un método muy difundido a lo largo del siglo XX en la educación vinculada a los organismos e instituciones religiosas.

En España se difundió especialmente a través de la adaptación del método y las aplicaciones escolares que realizó Ma Rosa Font y su gran labor como profesora en la Escuela de Música Sagrada de Madrid

\section{Método Kodaly. Zoltan Kodaly (Kecskemet, Hungría 1882-Budapest} 1967) Uno de los padres de la pedagogía musical centroeuropea, profesor de Bela Bartok y compositor de prestigio, su obra se basa en el estudio del patrimonio musical folklórico húngaro. Su deseo de llevarlo a la escuela y al conocimiento de todos los jóvenes del país le hace desarrollar un método pedagógico basado en la educación vocal y el canto, la fononimia o asociación de posturas de las manos a las notas, la altura relativa de los sonidos, el sistema modal y pentatónico (fundamental en las canciones populares centroeuropeas), y el aprendizaje del lenguaje rítmico a partir de las llamadas "sílabas rítmicas (ta, titi)". Su aplicación desde los años 40 en todo el estado húngaro a nivel escolar fue el detonador de la toma de conciencia de otros países con respecto a la importancia de la educación musical desde el punto de vista del sistema educativo.

Método Orff. Carl Orff (Munich 1895-1982) Funda en 1942 junto con Dorotea Günther la Gunterschule, en la qu ese trabaja conjuntamente gimnasia rítmica, danza clásica y educación musical. Crea en colaboración con Kart Maendler una serie de instrumentos de percusión adaptados para la escuela, divididos en sección no afinada e instrumentos de placas agrupadas por familias 


\section{Capítulo 3. La formación musical de los maestros}

y tesituras que sean de fácil utilización para los niños. Su obra se ha difundido sobre todo a través de la acción educativa del Orff Institut en Salzburgo (Austria) y sigue vigente en la actualidad.

La aplicación escolar de su obra, la llamada Orff Schulwerk se ha convertido en uno de los grandes elementos bibliográficos de práctica escolar en todo el mundo. Trabajando a partir de la célula rítmica de la lengua hablada y de los ritmos del lenguaje (prosodia, rima, recitado), introduce los elementos de percusión corporal, movimiento y percusión instrumental. Utiliza el eco rítmico y la imitación, la entonación de las canciones del folklore (fundamentalmente pentatónicas) y sobre todo a partir de un objetivo básico: la participación activa de los niños mediante la utilización efectiva de los elementos musicales.

Su difusión en España se realizó fundamentalmente a partir de la enseñanza recibida por Montserrat Sanuy en el Orff Institut y por los cursos en diversos lugares de España que contrató Sección Femenina con otro de los prestigiosos adaptadores de la aplicación escolar: Jos Wuytack, en los años 70.

\subsubsection{La pedagogía musical en España después de 1960}

A partir de la introducción y difusión mayoritaria en España de los principales métodos internacionales de pedagogía musical, se produce un auténtico movimiento renovador entre los profesionales dedicados a la educación musical en nuestro país.

En estos primeros años del aperturismo en España se producen cambios estructurales fundamentales respecto a la educación musical desde el propio sistema educativo que culminarán en la época democrática con la creación del profesorado especialista en música en las escuelas (LOGSE 1990).

Para empezar, surge lo que vamos a llamar la segunda generación de pedagogos musicales españoles del siglo XX, cuya labor se empieza a difundir a 


\section{La educación musical en el franquismo}

través de las instituciones establecidas (cursos y publicaciones en instituciones religiosas y civiles, Sección Femenina y los nuevos recursos de innovación educativa promovidos por el Ministerio de Educación e Institutos de Ciencias de la Educación (ICE).

Algunos siguen vinculados a la enseñanza en los colegios de las órdenes religiosas.

Es el caso de Rosa Ma Font, adaptando a la realidad española el método Ward.

También es muy importante, especialmente por su carácter ecléctico y de un gran praticismo funcional, la labor de Javier Elizalde, cuya obra se divulga a través de las publicaciones de la orden claretiana. Este organista y pedagogo, crea un método propio específicamente dedicado a los niños españoles, fundamentado en el folklore de nuestro país. Sus libros sobre "Pedagogía del Canto escolar 1,2 y 3", y "Flauta dulce 1,2,y 3", en sus dos versiones de alumno y para el profesor, separa las dificultades melódicas y rítmicas, toma como punto de partida la canción popular española y diseña una progresión minuciosa y lenta de los contenidos musicales. Para ello propone ejercicios de respiración, vocalización y entonación, realización de dictados melódicos, improvisación melódica, ejercicios de ritmo, dictados e improvisación rítmica, dictados e improvisaciones melódico-rítmica y entonaciones de las partituras, así como una programación de introducción de la flauta a partir de canciones de dos notas e incorporando nota a nota las nuevas digitaciones, con piezas a una y dos voces.

En estos últimos años del franquismo está también iniciando su labor innovadora Alicia Martín Baró, en la que destaca la pedagogía de la enseñanza de la flauta como instrumento escolar y sobre todo la introducción de la flauta contralto por medio de un sistema que califica de "flauta traducida", es decir, una transcripción de la melodía adaptada a la digitación de la flauta en do. La mayor parte de su obra se publica en la editorial "Erviti" a lo largo de los 


\section{Capítulo 3. La formación musical de los maestros}

años 80 y contempla la progresión de los contenidos a lo largo de todo el sistema educativo general, desde la EGB al Bachillerato. Realiza numerosos cursillos en la Universidad Pontifica de Comillas y en la Escuela de Música Sagrada.

La importante presencia catalana que ya se había hecho patente en la primera generación, sigue adelante, con un peso específico de la importancia del Institut Llongueres, ahora retomado por su hija y nietas, y con la presencia de Mercé Cardoner, que pertenece al equipo directivo y al mismo tiempo inicia su trayectoria en las Escuelas Universitarias del Formación del Profesorado, llevando el método Dalcroze a la formación general de los maestros.

Las instituciones catalanas y valencianas en estos años finales del franquismo y sobre todo los dos decenios siguientes de inicio de la democracia crean todo un sistema de redes de profesorado, reconocido tanto a nivel oficial como extraescolar. La tradición musical de estas zonas, sobre todo a nivel coral y de agrupaciones instrumentales, supone un gran apoyo para la presencia de asignaturas y actividades complementarias vinculadas a la educación musical de la población general y de los niños en especial. Esta red de profesores se ve apoyada además por las instituciones educativas que envían a representantes de dicho colectivo a todos los cursos que se realizan de pedagogía musical a nivel nacional y a los más importantes centros internacionales, con posteriores jornadas de "puesta en común" entre todos los miembros y educadores.

En Madrid, destaca la labor realizada por Montserrat Sanuy I nicia su contacto con la pedagogía en un curso becada por la Sección Femenina en la Quinta del Pardo con Rafael Benedito y luego tiene el primer contacto con Herman Regner y Barbara Haselbach en un curso para el que es becada también por la Sección Femenina en Lisboa. A partir de este momento y con una beca de la fundación Juan March se traslada a estudiar el curso completo al Mozarteum de Salzburgo en el Orff Institut, lo que como hemos visto abre las puertas a la introducción de las pedagogía musicales modernas en España. La importancia de la adaptación del sistema Orff a la realidad española y la publicación del primer 


\section{La educación musical en el franquismo}

volumen del método Orff Schulwerk en Unión Musical Española traducidos por ella y Luciano González Sarmiento es enorme. Ejerce su actividad docente en varias instituciones educativas públicas y privadas: Colegio Santa Sofía, Montealto, Santa María, La guindalera, el Colegio Suizo de Madrid, el estudio Música y danza que funda con su hermana Conchita en la calle Lagasca, la Universidad de Educación a Distancia y el Instituto Nacional de Educación Física (INEF). Sus conciertos públicos con niños, tocando flautas, instrumentos Orff, danza y movimiento y coro se hicieron famosos, sobre todo a partir de sus colaboraciones con Odón Alonso y el maestro Blancafort en el Teatro Real ("La sinfonía de los juguetes" de Haydn o "Noé y el diluvio universal" de Britten que se suspendió por el asesinato de Carrero Blanco en 1973. También colaboraba con los Conciertos de la juventud dirigidos por Alberto Blancafort para la Sección Femenina, haciendo introducciones y comentarios de las obras que se iban a interpretar. Mayor difusión es la consigue aún con la colaboración que establece en Televisión Española dentro del programa "Ven a jugar con nosotros" (Los chipiritiflaúticos Valentina, Locomotoro, el Capitán Tan, los hermanos malasombra) con una sección dentro del programa titulado Musicando con Montse y que fue un auténtico éxito a nivel nacional en el único programa infantil de la programación. También obtuvo mucha popularidad con su programa en Radio 2 (Radio Nacional de España) titulado En clave de sol en el que realizaba clases prácticas de música y audiciones con sus alumnos del colegio La Guindalera". Desde 1971 estableció unas relaciones editoriales muy fructíferas con Edelvives con los que publicó una gran cantidad de material didáctico, libros, discos y cancioneros con sus aplicaciones para la enseñanza Además publicó entre otro mucho material, sus métodos adaptados al "área de expresión dinámica" de la ley de 1970 y el recopilatorio de "Canciones populares e infantiles españolas" para el MEC, con grabaciones sonoras de las interpretaciones hechas por los niños y con indicaciones de actividad y propuestas pedagógicas. Su contacto con la Universidad se inció con un curso de música para el Colegio de Doctores y Licenciados de Madrid, a partir del cual inició su colaboración con Pilar Lago (profesora de la UNED y una de las iniciadoras de la musicoterapia a nivel nacional) en la que dirigió desde 1974 


\section{Capítulo 3. La formación musical de los maestros}

hasta 1981 un curso sobre "Música y Dramatización para educadores" y continuó en las clases que impartía en el INEF de Madrid hasta su jubilación.

En los años 70 y 80, como resultado de este interés por la educación musical en España, surgen numerosos pedagogos cuya labor se va a ver plasmada en publicaciones posteriores, pero cuya labor se inicia en estas fechas tardías del último franquismo enmarcadas dentro del contexto de la ley de 1970 y su aplicación educativa de la educación musical en los centros escolares .Tal es el caso de Pilar Escudero ( y sus numerosas publicaciones con Real Musical), Matilde Murcia (cuyo libro de Formación musical para los alumnos de las Escuelas Universitarias del Profesorado de EGB tendrá una gran difusión), Pilar Lago (que a través de su docencia en la Universidad Nacional de Educación a Distancia UNED promoverá la introducción de la musicoterapia), José Peris (que desde 1965 hasta 1973 dirige los Cursos de Formación del Profesorado de EGB y BUP en "Música y movimiento elemental" del Ministerio de Educación. Su "Música para niños"101, con prólogo de Carl Orff, es un libro básico de la educación musical en la época del último franquismo. Desde 1973 organiza las actividades musicales de la Universidad Autónoma de Madrid, de la que luego se convertirá en profesor adjunto y catedrático), o María Cateura (que desde la Universidad de Barcelona dará un nuevo empuje a la educación musical de los maestros con un carácter más ecléctico aunando diversas metodologías).

La labor de los Institutos de Ciencias de la Educación (ICE) para la difusión y el conocimiento de todos estos métodos es fundamental. Estos centros de formación continuada del profesorado fueron creados en la ley de 1970 en el artículo 102. para garantizar una formación pedagógica adecuada y complementar la recibida por los profesores de Educación Preescolar y Educación General Básica en las Escuelas Universitarias, así como para la obtención de los Certificados de Aptitud Pedagógica (CAP) necesario para la docencia en Educación Secundaria y Superior. De hecho, en el artículo 103 se especifica que 
"la universidad, a través de los Institutos de ciencias de la educación y de los centros experimentales adjuntos (Escuelas Universitarias de formación del profesorado), asumirá una función de orientación y especial responsabilidad en la formación y el perfeccionamiento del personal docente de los centros de enseñanza y organizará de forma sistemática el perfeccionamiento del personal docente en ejercicio con las diferentes modalidades que impongan las características de cada nivel educativo".

\subsection{LA FORMACIÓN EXTERNA}

Al igual que los famosos artículos 44 y 45 de la Ley de Educación de 1945 autorizan la formación de actividades complementarias relacionadas con la escuela a Frente de Juventudes y Sección Femenina, también hay una parte de la formación de actividades complementarias que los maestros y maestras deben realizar separadamente y vinculadas a ambas organizaciones de Falange.

Ya el Decreto de 17 de octubre de 1940 que autorizaba la convocatoria de los cursos de ingreso al Magisterio Nacional, en sus artículos 60 y 70 señalaba la necesidad de que los maestros estuvieran en posesión del certificado de Instructores Elementales del Frente de Juventudes si se trataba de maestros 0 el de Instructoras elementales expedido oir kas Escuelas del Hogar de la Sección Femenina, así como la obligación de asistir a un curso de perfeccionamiento para su formación cultural. Así, en la Orden de 14 de agosto de 1942 (BOE de 15 de agosto) se establece que

todos los maestros y maestras ya aprobados en las oposiciones de 1941 deben obtener dichos certificados mediante la declaración de aptitud derivada de un curso teóricopráctico. Para ello se convocan cursos en todas las provincias españolas. Y la falta de asistencia significará la "pérdida de todos los derechos". Las lecciones de estos cursos son redactadas por el Frente de Juventudes y Sección Femenina, y la vigilancia e inspección de las prácticas también corresponde a las jerarquías de Falange. El título obtenido tiene carácter provisional a lo largo de un año y se ratifica como definitivo siempre que "el aspirante haya dado pruebas de conducta ejemplar, aptitud y fidelidad en el cumplimiento de las normas y consignas que dicte el Frente de Juventudes". EI título no sólo es considerado un requisito obligatorio para tomar posesión de una plaza por oposición, sino que también es un mérito en la carrera. Los asistentes deben redactar una memoria final con el resumen de las conferencias. Estos cursos se realizaban anualmente a inicios de las vacaciones estivales. 


\section{Capítulo 3. La formación musical de los maestros}

La Orden de 12 de noviembre de 1943 (BOE de 23 de febrero) sobre las bases orgánicas de la Delegación Nacional de Educación, establece en su Artículo $1^{\circ}$ que

\footnotetext{
"La Delegación Nacional de Educación es el organismo de Falange Española Tradicionalista y de las JONS que tiene por objeto:

a.- La creación, dirección y coordinación de los servicios profesionales que se alojan en su seno

b.- El asesoramiento y la iniciativa al Estado en materia docente y cultural y la colaboración con los organismos oficiales correspondientes en la más estricta fidelidad de la enseñanza pública y privada a la doctrina de F.E.T y de las JONS

c.- La difusión de la norma y del estilo de la Falange entre los profesionales de la docencia
}

d.- La realización de toda clase de actividades docentes y de difusión de la cultura en todos sus grados y aspectos en coordinación con las realizadas por el estado

e.- El asesoramiento y la ordenación de toda la actividad cultural realizada por las distintas secciones y servicios encuadrados en el movimiento"

En el Artículo 5o se organizan dentro de la Delegación Nacional de educación 4 servicios: El servicio español del profesorado de Enseñanza Superior, el servicio español del Profesorado de Enseñanza Media, el servicio español del profesorado de Enseñanza técnica y el Servicio español del Magisterio.

En el artículo $10^{\circ}$ explicita que sus fines son:

la colegiación de los componentes de cada rama de la enseñanza, velar por el fiel y digno cumplimiento de la función docente encomendada, proponer a la Delegación nacional cuantas reformas aconseje la experiencia docente y las mejoras profesionales, dentro siempre del espíritu del Movimiento, colaborar en las actividades dirigidas a la formación política, especialmente en el Frente de Juventudes y la Sección Femenina, participar activamente mediante representaciones oficiales en los organismos estatales docentes, llevando a la Educación Nacional el ímpetu y el estilo del Movimiento , y finalmente la cooperación social que asegure a sus afiliados la protección de asistencia. 


\section{La educación musical en el franquismo}

Por si quedaba alguna duda de la obligatoriedad de someter todos los estamentos educativos al control político del Movimiento, el artículo 11이 lo deja muy claro: "Serán afiliados a los servicios todos los profesionales de la enseñanza, pertenecientes a la docencia oficial y a la privada".

El artículo 250 muestra la organización bicéfala que resulta de tener en cada Delegación de Educación Nacional dos secciones: a).- El servicio profesional: con secciones de Enseñanza superior, media, técnica y el Servicio del Magisterio y b).- el Departamento de Cultura

No fue éste el único medio de control, sino que la obligatoriedad de asistir al "Curso de instructor elemental" de Frente de Juventudes o Sección Femenina adquirió rango de norma para toda actividad docente. Así consta claramente en el Estatuto del magisterio publicado en el Decreto de $\mathbf{2 4}$ de octubre de 1947 (BOE de 17 de enero).

En el Artículo 20으 se dice explícitamente que es

"requisito indispensable para tomar parte en las oposiciones a ingreso en el magisterio: Ser español, tener diecinueve años cumplidos en la fecha de la convocatoria, poseer el título profesional de Maestro de Enseñanza Primaria, d):- acreditar encontrarse en posesión del título de Instructor elemental del Frente de Juventudes o de Instructora de Escuela del Hogar de la Sección Femenina. Y en lo que respecta a otros aspectos no estar incapacitado para el ejercicio de cargos públicos y acreditar una conducta intachable en todos los aspectos, no padecer tuberculosis, enfermedad contagiosa ni defecto físico que imposibilite para el ejercicio de la profesión, y, por supuesto, abonar los derechos establecidos en la convocatoria

Es decir, que además de la formación en las Escuelas de Magisterio, era necesario haber realizado los cursos de Falange. Estos cursos ya estaban contemplados en la Orden de 8 de junio de 1943 (BOE de 26 de julio) en la que se crea el Servicio Nacional de Instructores de Falange para "organizar el personal que el Frente de Juventudes ha de emplear para la formación política, premilitar y física de la juventud e Inspección de la enseñanza". Los instructores elementales son la categoría más baja de la 


\section{Capítulo 3. La formación musical de los maestros}

jerarquía establecida y regulada por este artículo y su formación se realiza en las Delegaciones provinciales (los instructores nacionales se formaban en la Academia nacional de Mandos "José Antonio" y en la "Isabel la Católica" para las instructoras nacionales).

El Artículo $10^{\circ}$ de dicha orden explicita que son Instructores elementales provisionales aquellos que se forman bajo la dirección de las Delegaciones Provinciales del Frente de Juventudes y normas de la Delegación Nacional en cursillos de orientación que se celebran en los mismos. Asistirán a ellos obligatoriamente los Maestros nacionales que salgan de las Escuelas Normales del Magisterio, como condición precisa para poder hacerse cargo de sus escuelas.

Como esta Orden se centra en el Frente de Juventudes, hace sólo mención explícita de tres tipos fundamentales de contenidos de formación: educación política y formación del espíritu nacional, formación premilitar y educación física. Cuando esta Orden se aplica a las Escuelas del Hogar de la Sección Femenina, sin embargo, se explicita la presencia de otro tipo de contenidos, entre los que figura la música. La separación de Frente de Juventudes y Sección Femenina por la Orden de 24 de enero de 1945 (BOE de 26 de febrero) es la plasmación final de la diferencia de sexos y de su orientación educativa. Ello no significa que no esté presente la formación musical en el Frente de Juventudes, sino que está enmarcada mayoritariamente dentro de los contenidos de la formación premilitar, mientras que en Sección Femenina tiene una entidad cultural propia.

Por otra parte, la pérdida del título de Instructor del Frente de Juventudes e Instructora de Sección Femenina por expediente instruido en la correspondiente Delegación nacional, es considerada como falta grave en el Régimen disciplinario de la Ley de Educación de 1945, por lo que implicaba la suspensión en el ejercicio de su función como maestro. 


\section{La educación musical en el franquismo}

Es más, no sólo aquellos maestros que deseaban presentarse a oposiciones y tomar posesión de su plaza en las escuelas necesitaban el requisito del visto bueno de Falange. También los maestros rurales contemplados en el artículo 90ํ del decreto de 24 de octubre de 1947 (BOE de 17 de enero) como aquellas enclavadas en aldeas o lugares de población diseminada inferiores a 500 habitantes que queden desiertas en el concurso general de traslados y que constituyen una clase especial a efectos de su provisión, segregándose del sistema general de forma que los cambios de destino de los mismos sólo pudieran realizarse en la misma provincia por permuta tras al menos acreditar seis años de servicio en la misma. En el artículo 41 de dicho decreto se expone que para la provisión de las escuelas rurales se anunciará concurso de méritos entre maestros en cada provincia y necesitan tener más de 35 años de edad y acreditar haber prestado colaboración al Frente de Juventudes o a la Sección Femenina.

En conclusión, todos los maestros tenían que cursar, además de los estudios de la carrera del Magisterio, unos cursillos como Instructores Elementales de Falange (Frente de Juventudes y Sección Femenina) sin los cuales no podían tener acceso a ninguna plaza de maestro por oposición ni de otra manera en los colegios públicos. En dichos cursos estaba presente la música, aunque con un tratamiento diferente, pero siempre con contenidos ideológicos.

Además la Delegación Nacional de Falange tenía el poder sancionador de apartar mediante expediente disciplinario a cualquier maestro de su puesto de destino con la simple retirada del título de Instructor elemental.

Y finalmente, todos los maestros estaban por ley, obligados a pertenecer de manera automática a la Delegación Nacional de Educación, el órgano del Movimiento encargado de velar por la ideología dentro del sistema educativo.

Frente de Juventudes y Sección Femenina, separados totalmente en 1945, tomarán derroteros muy distintos a la hora de enfocar muchos de los aspectos 


\section{Capítulo 3. La formación musical de los maestros}

educativos, tanto en contenidos como en metodología a lo largo de los siguientes 30 años.

A partir de la Ley de 1970, será el MEC quien forme inicialmente al profesorado de EGB especialista para la Segunda Etapa y luego los nuevos planes de estudio de Magisterio Universitario.

A partir de este momento, los cursillos de instructores elementales dejan de ser una obligación necesaria para terminar la carrera y obtener la titulación como maestros, con lo cual prácticamente pierden a la gran mayoría del alumnado y toda su capacidad de influencia. 
La educación musical en el franquismo 


\section{CAPÍTULO 4. MÚSICA E IDEOLOGÍA 1. EL FRENTE DE JUVENTUDES}

\subsection{INTRODUCCIÓN}

A lo largo de estos 40 años comprendidos entre el inicio de la guerra civil en 1936 y la muerte de Francisco Franco en 1975 se suceden una gran cantidad de acontecimientos que cambiarán la faz política del país. Aunque aparentemente se mantiene el mismo jefe del Estado y el partido único en el poder es Falange, las cambiantes condiciones internacionales, las influencias de los cambios socioeconómicos en el ámbito nacional o las profundas tensiones en los diferentes sectores ideológicos de la jerarquía dominante, hacen que las actitudes de Falange y el Estado sufran grandes transformaciones para adaptarse a la realidad social que les toca vivir en cada momento.

Lo que se ha dado en llamar la "singularidad" del fascismo español ha sido profundamente estudiado por Payne.

\subsection{FALANGE Y EDUCACIÓN}

\subsubsection{Desde la guerra civil hasta 1945}

La época de la guerra civil no se centra, evidentemente, en los elementos educativos de toda la población, pero tiene una gran importancia desde el punto de vista educativo, ya que es en este momento cuando surgen las ideas más evidentes de manipulación ideológica de la juventud y de la población en general, se fundan las instituciones que han de llevarla a cabo y se establecen los principios ideológicos prioritarios para el nuevo régimen insurgente. 


\title{
La educación musical en el franquismo
}

Siguiendo los postulados de Sheelagh Ellwood ${ }^{\mathbf{1 0 2}}$, el franquismo y la Falange no sólo no son lo mismo, sino que interactuaron durante cuarenta años de manera bastante desigual. Los años previos a la derrota del eje fascista en la guerra mundial, son los de mayor peso ideológico de la Falange, aunque luchando constantemente por conseguir el control político frente a las otras fuerzas que habían apoyado el alzamiento militar.

\begin{abstract}
"En el reparto de los campos de acción sobre las distintas fuerzas que habían colaborado a la destrucción del estado republicano, la Falange ejerció el control sobre la gran masa de la población a través de los medios de comunicación, la organización sindical y la burocracia administrativa.(...)La Falange también inculcaba sus valores en las escuelas mediante profesores adiestrados en sus Escuelas de Mandos y mediante los materiales didácticos que se utilizaban"
\end{abstract}

\subsection{1.a. En la escuela}

En estos primeros años inmediatos a la guerra civil hay una gran intervención ideológica en la escuela, no tanto desde el punto de vista musical como desde el punto de vista general. Son los años de la depuración de maestros y del asalto para controlar la educación conforme a las ideas del nuevo régimen.

En palabras de Manuel Torres ${ }^{\mathbf{1 0 3}}$ ya desde los "Hogares azules" se pretende formar, tanto desde el punto de vista físico como cultural y religioso a ciudadanos ejemplares (...) y se organizan parques escolares y colonias en cuyas instituciones pronto se puso de manifiesto el ideario del nuevo estado". La organización falangista creó también orfanatos y Acción Social se encargó durante la guerra de tareas escolares en los Hogares escolares.

La preocupación por inculcar a los niños una formación basada en la "españolización" y el "patriotismo" lleva tan sólo un mes después del alzamiento

102 ELLWOOD, S. (1984) Prietas las filas. Historia de la Falange Española, 1933-1983. Barcelona: Crítica-Grijalbo

${ }_{103}$ TORRES, M. (1938) La obra social del nuevo estado españo/ Paris: Sorlot, Les amis de L'Espagne nouvelle. 


\section{Capítulo 4. Música e ideología 1. Frente de J uventudes}

a la creación de una Junta de Defensa Nacional, y poco más tarde la de la Junta técnica del estado que encomienda a la Comisión de Cultura y enseñanza

"el estudio de las modificaciones necesarias para adaptar la enseñanza a las orientaciones del nuevo estado (Ley de 1 de octubre de 1936, BO de 2 de octubre) bajo cinco grandes epígrafes: patriótica, militarista, católica, cívica, física y tradicional".

Como diría Antonio Tovar $^{\mathbf{1 0 4}}$ (Jefe del Servicio Nacional de Radio) en el I Curso de orientaciones Nacionales de la Enseñanza Primaria, celebrado en Pamplona:

"y ahora que resurge España, también la escuela rural quiere himnos y desfiles, es decir, arquitectura militar, para que se imprima en el pueblo".

No es, pues, de extrañar, que la educación musical de esta etapa a nivel escolar se refiera fundamentalmente a himnos y cantos patrióticos.

Las clases se reanudan en septiembre de 1936 en el área nacional y conforme va avanzando el frente, se van aplicando las características educativas impuestas por el nuevo régimen. El control ideológico de la educación pretende ser total y para ello se recurre a un proceso represivo de grandes dimensiones entre el cuerpo de Maestros: las depuraciones.

Las comisiones depuradoras, a la vista de los expedientes elevados por alcaldes, sacerdotes o cualquier acusador anónimo, resolvían la libre absolución, la proposición de traslado, la separación definitiva del servicio, la suspensión de empleo y sueldo hasta dos años o la inhabilitación para el desempeño de cargos directivos. La publicación de la Ley de 9 de febrero (BOE de 13 de febrero) sobre responsabilidades políticas supuso un agravamiento de la situación del cuerpo de maestros, ya que se aplicó con efectos retroactivos desde el 1 de octubre de 1934 e introducía sanciones que abarcaron desde la inhabilitación absoluta hasta la pérdida de la nacionalidad y consiguiente destierro y pérdida de bienes, así como el confinamiento en

\footnotetext{
104 TOVAR, A. (1938) Nación, Unidad e imperio. En Orientaciones nacionales de la Enseñaza primaria. Burgos: Ministerio de Educación Nacional, Hijos de Santiago Rodríguez
} 


\section{La educación musical en el franquismo}

prisión. Además se otorgó facilidades para investigar sobre la conducta seguida por cada funcionario docente en relación con el Movimiento Nacional.

Ello supuso una masacre en el cuerpo de Maestros que afectó a casi 3/4 partes del profesorado de educación primaria. Max Gallo (1972) ${ }^{\mathbf{1 0 5}}$ dice que "el régimen de Franco fusiló al 50\% del Magisterio Español"

Para el propio Vegas Latapié, miembro de la Comisión de Cultura, una de cuyas funciones primordiales era la depuración, dice que gran número de las acusaciones que contra maestros llegaban eran absurdas. $Y$ pone un ejemplo que subrayamos aquí por su carácter musical:

\footnotetext{
"Una de ellas, muestra de las dimensiones grotescas que adquirió a menudo esta tarea, consistió en denunciar a una maestra que ejercía en Castilla, tachándola de comunista porque había enseñado a los niños la canción "Asturias, patria querida", ya que en Asturias fue donde tuvo lugar en 1934 la revolución comunista. ${ }^{106}$
}

Es a la vez un gran ejemplo de la importancia que la selección del repertorio musical tenía en aquel momento y de la impregnación ideológica de las canciones y su enseñanza escolar.

Los maestros del nuevo estado tenían que ser según Antonio Onieva ${ }^{\mathbf{1 0 7}}$

“ejemplo de religiosidad, patriotismo, carácter firme y patriotismo, simpatía, respeto a la evolución del niño, juventud espiritual y cultura".

Así se redactaron conforme a estos principios los cursos de orientación que se iniciaron en Pamplona en 1938 y al que acudieron en régimen de internado casi militar 400 maestros no sujetos a expediente. $Y$ también organizaron sus propios cursos de formación las Asociaciones católicas de Maestros en Salamanca, Orense, Pontevedra, Valladolid, Burgos, Zamora, Sevilla, Huelva,

\footnotetext{
${ }^{105}$ GALLO, M. (1972) Historia de la España franquista. París: Ruedo I bérico

${ }^{106}$ Esta referencia está recogida en FERNÁNDEZ SORIA, J.M. (1984) Educación y cultura en la guerra civil (España 1936-1939). Valencia: Nau llibres. Capítulo IX, pag. 190

107 ONIEVA, A. (1939) La nueva escuela española (Realización práctica) Valladolid: Librería Santaren
} 


\section{Capítulo 4. Música e ideología 1. Frente de J uventudes}

Córdoba, Logroño, Pamplona, Granada, Cádiz, San Sebastián y Santander según las investigaciones de León Esteban Mateo ${ }^{108}$.

La selección ideológica, después de la depuración y la formación controlada por las directrices de Falange, se completó con la reserva del 50\% de las plazas de maestros para excombatientes en el Decreto de 12 de marzo de 1937 (BO de 16 de marzo) y en el año 1938 con la exención de examen para los mutilados de guerra, según la Orden de 13 de diciembre de 1938 (BO de 16 de diciembre).

En la educación secundaria, la presencia ideológica de Falange es menor. No porque no lo intentaran, sino porque como señalan Esteban Medina y Puelles Benítez ${ }^{109}$, la

"ley de 20 de septiembre de 1938 entregó la enseñanza media en manos de la Iglesia y de las órdenes religiosas"

provocando la desescolarización en los centros oficiales a la vez que apoyó , incluso financieramente, a los centros de la Iglesia. Así, mientras que en 20 años (desde 1939 a 1959) los institutos sólo aumentaron su número en seis (de 113 a 119), en sólo diez años se sextuplicaron los establecimientos privados en relación a 1939.

En la misma línea se pronuncia Cámara Villar ${ }^{\mathbf{1 1 0}}$ cuando dice que I báñez Martín, a la sazón Ministro de Educación Nacional entre 1939 y 1951,

\footnotetext{
“apoyaría en todo momento a la ACNP (Asociación Católica Nacional de Propagandistas) y a la Iglesia. Con una política hábil mantendría a Falange en unos límites reducidos de actividad y en unas posiciones simbólicas respecto del sistema de enseñanza. $Y$
}

\footnotetext{
${ }^{108}$ ESTEBAN MATEO, L. (1980) Evolución de los objetivos de formación de profesores. Concreción de un caso: Objetivos de formación magisterial durante el período bélico (1936-39). En La investigación pedagógica y la formación de profesores. Actas del VII Congreso Nacional de pedagogía. Madrid: Sociedad Española de pedagogía, Instituto San José de Calasanz del CSIC.

${ }^{109}$ MEDINA, E. Educación y sociedad: La lucha por la educación . En PUELLES BENÍTEZ, M. (1980) Educación e ideología en la España contemporánea (1767-1975). Barcelona: Labor 110 CÁMARA VILLAR, G (1984) Nacional-catolicismo y escuela. La socialización política del franquismo (1936-1951). J aén: Hesperia
} 


\section{La educación musical en el franquismo}

acentuaría el sentido católico del mismo, así como el de las instituciones específicamente falangistas que tenían relación con la educación, como las Organizaciones J uveniles".

Es la etapa del control de la educación primaria por parte de Falange, de la imposición y la represión más dura. Musicalmente se plasma en la predominancia absoluta de los himnos y las canciones paramilitares, de la censura y selección de canciones en función del carácter patriótico y de sus contenidos ideológicos. Es la época de la propaganda en el sentido fascista: el total adoctrinamiento por medio de los signos exteriores de carácter militar: los himnos y los desfiles, estilo las Juventudes hitlerianas o los Balillas de Mussolini.

La educación musical femenina, menos estudiada, sin embargo, aunque también incorpora los himnos fundamentales de Falange, ya empieza a demostrar una orientación más tradicionalista.

\subsection{1.b. En la vida social y extraescolar}

En fechas tan tempranas como Marzo de 1933, en pleno surgimiento ideológico de Falange, sin que se hubiera todavía producido el Alzamiento que se transformó en guerra civil, ya decía Onésimo Redondo ${ }^{111}$, que

"uno de los instrumentos para la conquista del Estado es la creación de un ejército de juventud o milicias nacionales".

Entrados en plena guerra civil, estas palabras serán llevadas a cabo por la fuerza de las circunstancias a toda la población masculina, que se vio obligada a integrarse militarmente en la contienda en uno $u$ otro bando. Pero su influencia, no terminaría con el enfrentamiento bélico, sino que, en consonancia con las ideologías fascistas del momento (en el poder en Alemania e Italia) se hacen, por el contrario, más fuertes, dando origen a una corriente de pensamiento y a una actuación educativa de toda la población, y muy especialmente de la juventud.

${ }^{111}$ REDONDO, O. (1939) El Estado Nacional. Barcelona: Ediciones de Falange Española 


\section{Capítulo 4. Música e ideología 1. Frente de J uventudes}

De hecho, en Europa entre las dos guerras mundiales, los partidos políticos habían ido mostrando cada vez mayor interés hacia la ideologización de la juventud como fundamento para su propia continuidad social. Este tipo de pensamiento se establece además claramente a través de organizaciones de tipo asociativo, tanto entre las ideologías comunistas (los "pioneros comunistas" la Unión de Juventudes comunistas de España o las Juventudes Libertarias) como fascistas (los "alillas" italianos de Mussolini, las Hitlerjugend o la Mocidade Portuguesa) cuyas relaciones con las organizaciones juveniles fascistas españolas estudia detenidamente J uan Sáez Marín ${ }^{\mathbf{1 1 2}}$.

El Decreto de 19 de abril de 1937 (Boletín del Movimiento, ํㅡ 1, de 5 de mayo) obliga a la unificación de los grupos juveniles del bando nacional, en la Delegación nacional de Organizaciones Juveniles (OJ) en el que destacan dos grupos fundamentales: falangistas y tradicionalistas, aunque también aglutinarían otras ideologías minoritarias como el carlismo de los requetés. Los "Pelayos" tradicionalistas y los "Flechas" falangistas vieron así unidos por la fuerza sus destinos futuros. Ejemplo de sus profundas luchas internas y de su rivalidad en el poder dentro de la organización unificada son las relaciones entre Iglesia y Falange que tan abiertamente se muestran en la revista fundamental de transmisión ideológica de la época: "Flechas y Pelayos" y cuyos enfrentamientos y características ideológicas analiza en profundidad Henar Herrero Suárez ${ }^{113}$

Y en 1938, el Secretario general de la Organización Juvenil, José Mạ Gutiérrez del Castillo detecta un cierto decaimiento en la presencia de jóvenes en las actividades programadas (fundamentalmente en aquel momento desfiles paramilitares a todas horas y por cualquier motivo), por lo que hace públicas unas directrices que nos llevan al verdadero contenido de las acciones que se van a emprender. En ellas se incluye

\footnotetext{
112 SÁEZ MARÍ N, J (1982) Asociacionismo juvenil en Europa hasta 1940. En De juventud, no 5 y también Asociacionismo juvenil en España hasta 1936-39. En De juventud, no 7 ${ }^{113}$ HERRERO SUÁREZ, H.(2007) Un yugo para los flechas. Educación no formal y adoctrinamiento infantil en Flechas yPelayos .Lérida: Milenio
} 


\section{La educación musical en el franquismo}

- la mayor importancia de la selección de los instructores promocionando que se escojan

"los de conducta intachable, rigurosamente disciplinados, conocedores del carácter y aficiones de los niños para los que deben ser un modelo constante"

- importancia de la educación física, organizando concentraciones para practicar el deporte y la gimnasia, y no sólo la instrucción militar

- Música y teatro: Se insiste en la atención a estos medios formativos:

"Nuestros muchachos deben acostumbrarse a cantar, no sólo en las marchas y excursiones, sino también al desfilar (usando muy pocas veces las cornetas y tambores) y procurando también la formación de coros". "A este fin las canciones españolas ocuparán el primer lugar; debiendo remitir cada provincia las típicas suyas, resucitándolas donde hayan sido olvidadas a los efectos de recopilación del folklore nacional"."Se estimulará el cultivo de la música (formación de orquestas y bandas) como, igualmente sencillas representaciones teatrales en que tomen parte nuestros flechas cuidando bien la selección de las obras".

- Además, propone la celebración de cursillos sanitarios, potenciar la actividad de prensa y propaganda y la celebración de conferencias sobre los 26 puntos de falange y los 12 puntos del flecha.

Como señala J uan Sáez Martín ${ }^{114}$, "se están dando los primeros pasos hacia la definición de un concepto nuevo hasta entonces salvo para muy reducidos sectores: las actividades extraescolares. Sin que podamos perder de vista la intención político-formativa (...) se intenta completar en el campo del tiempo libre y sin interferir con la escuela, la formación recibida en esta última"

La Organización Juvenil se organiza en dos grupos: masculina y femenina con sus diferentes grados y mandos (la femenina siempre sometida a la masculina hasta su separación en 1945). Tiene seis departamentos, uno de los cuales se denomina: Departamento de Cultura y Formación Nacional-sindicalista, dividido

\footnotetext{
${ }^{114}$ SÁEZ MARTín, J (1988) El Frente de Juventudes. Política de juventud en la España de la posguerra (1937-1970) Madrid: Siglo XXI
} 


\section{Capítulo 4. Música e ideología 1. Frente de J uventudes}

a su vez en seis secciones, de las cuales, una enteramente dedicada a la música).

La Sección Femenina que había surgido dentro de la Falange inicial entorno a la figura de Pilar Primo de Rivera y otras seis amigas, crece de forma increíble en los años de la guerra. Según Encarnación J iménez ${ }^{\mathbf{1 1 5}}$ en 1935 ya eran 800 las afiliadas y en vísperas del 18 de julio de 1936 había 2.500, organizadas en 18 secciones de diferentes provincias. Estas cifras se incrementarán aún más al final de la guerra civil, ya que Alvarez Puga ${ }^{\mathbf{1 1 6}}$ cifra en cerca de 600.000 las adhesiones a Sección Femenina en 1939.

Las intenciones de transmisión ideológica de Sección Femenina son patentes desde el discurso de 1938 en Segovia en el discurso de apertura de Pilar Primo de Rivera en el II Consejo nacional de Sección Femenina: "formar familias (...)donde se fomente todo lo tradicional, en donde se canten villancicos el día de Navidad alrededor del Nacimiento". Y todavía los son más en el III Congreso, celebrado en Zamora en 1939 donde dice: "lo que tenemos que hacer es preparar a todos los camaradas, para que cuando tengan una casa y cuando tengan unos hijos, sepan enseñarles, después del Padrenuestro, lo que José Antonio nos enseñó a nosotras." En 1939, en la concentración que se hizo en Medina del Campo (Valladolid) para celebrar la victoria de Franco, con él presente y en la que se hace referencia a la importancia de los cánticos entonados por los victoriosos, Pilar Primo de Rivera se dirige en estos términos a Franco:

\footnotetext{
"ampliaremos la labor iniciada en nuestras escuelas de formación para hacerles a los hombres tan agradable la vida de familia que dentro de la casa encuentren todo aquello que antes les faltaba y así no tendrán que ir a buscar en la taberna o en el casino los ratos de expansión. Les enseñaremos a las mujeres el cuidado de los hijos (...), el arreglo de la casa, el gusto por las labores artesanas y por la música. Les infundiremos este modo de ser que quería José Antonio (...) para que así, ellas, cuando tengan hijos, puedan formar a los pequeños en el amor a Dios y en esta manera de ser de la
}

\footnotetext{
115 JIMÉNEZ, E. (1981) La mujer en el Franquismo. Doctrina y acción de la Sección Femenina. En Tiempo de historia, 83.

${ }^{116}$ ALVAREZ PUGA, E. (1969) Historia de la Falange. Barcelona: Dopesa
} 
Falange. Y, a la vuelta de una generación, por obra de ella, aquel niño que desde chiquitín llevó puesto el uniforme, que entre sus cuentos infantiles oyó la historia de la guerra y del Caudillo y la vida y muerte de José Antonio, cuando llegue a mayor de edad, será un hombre cabal y tendrá ya metido dentro de sí este estilo de nuestra revolución".

Si en lo que se refiere a la educación de la infancia y juventud masculina, la acción del Frente de juventudes y la ideología de Falange tuvo seria oposición en la lucha por el poder en la educación con la Iglesia, y como expone Max Gallo ${ }^{117}$, "a pesar de la existencia de un equilibrio teórico a nivel de los principios entre las dos fuerzas, de hecho la Iglesia establece su dominación sobre la enseñanza a todos los niveles"; la absoluta declaración de principios católicos tradicionalistas de Sección Femenina, incluso por encima de la enseñanza del nacionalsindicalismo según J uan Manuel Fernández Soria ${ }^{\mathbf{1 1 8}}$, harán que, unido al "control que la Sección Femenina consiguió tener de buena parte de la enseñanza primaria a través de las maestras", hacen que la influencia de Sección Femenina sobre la infancia y la juventud femenina sea determinante para la comprensión de la educación de las mujeres españolas en los tres primeros del siglo XX.

También existió otro intento de extensión cultural, ligado al concepto del "dopolaborismo" italiano de Mussolini. Aunque no tenemos noticias de que fuera llevado a la práctica - probablemente porque su labor fue asumida por las instituciones vinculadas al Movimiento o a la Iglesia - del que nos habla Juan Manuel Fernández Soria y es la "Organización Hispana Circumlabor $(\boldsymbol{O H C})$ "cuyas directrices están recogidas en un "Plan para el resurgimiento de España en el mundo"119. Su finalidad se dirige a la mejora de la vida obrera atendiendo a la educación íntegra del individuo y a la restauración de las manifestaciones colectivas producto de la tradición popular (festividades, folklore, romerías). Lo que más nos interesa de este grupo, es que plantea

\footnotetext{
117 GALLO, M. (1971) Historia de la España Franquista París: Ruedo I bérico

${ }^{118}$ FERNÁNDEZ SORIAL, J.M. (1984) Educación y cultura en la guerra civil (España 1936-39).

Valencia: Nau Llibres. También en Cuadernos de Educación comparada e historia de la educación", XII, Universidad de Valencia

${ }^{119}$ ANONIMO. (1937) Plan para un resurgimiento de España y del mundo a un nuevo orden nacional y cristiano. Obra Nacional Corporativa. San Sebastián: Editorial Española
} 


\section{Capítulo 4. Música e ideología 1. Frente de J uventudes}

entre sus actividades, además de la asistencia social y sanitaria y la educación física, un plan de educación espiritual y de difusión de la cultura. Este último estaba dividido en cuatro grupos de acción: sentimiento patriótico, perfección profesional, perfección espiritual y un grupo dedicado a "Arte y moral" con subsecciones de Radiofonía, cinematografía, teatro, música, canto y danza. Tiene una visión religiosa y tradicionalista de la actividad musical.

Recuerda que "existen muchos cantares que encierran ideas patrióticas y morales", y que por tanto, hay que escoger como instrumentos para sus fines de difusión cultural. Es tarea de la sección de Canto y danza, además, la creación de coros y orfeones y de escuelas de corales provinciales, cuya conexión con el aspecto religioso y tradicionalista son evidentes en el siguiente texto:

"La asistencia de esos coros y orfeones a los actos religiosos que se celebren en la localidad, deberá ser obligatoria y habrán de concurrir, a ser posible, vistiendo el traje regional que, en realidad constituye el más vistoso uniforme que pudiera imaginarse" (pag. 154)

También se plantean como tarea a realizar la difusión de las obras de compositores españoles, bien por medio de discos o conciertos y la organización de bandas y orquestas creadas en las cabeceras de provincias. La sección de radiofonía debe colaborar a la difusión del canto y la música españoles. Siguiendo la influencia italiana se proponen activar la vida teatral mediante el cultivo de la comedía, la zarzuela e incluso la ópera, siempre a través de una selección de repertorios bajo criterios patrióticos. En general, fomentan el cultivo del sentimiento patriótico y popular mediante el arte y la literatura y proponen la iterada de ediciones baratas de las obras más significativas de la literatura española, la instalación de museos regionales de arte popular y sobre todo, la restauración de las solemnidades públicas, romerías, ferias, peregrinaciones y fiestas folklóricas y patrióticas. 


\section{La educación musical en el franquismo}

Muchos de estos principios serán retomados por otras instituciones, especialmente por Sección Femenina, pero también por Acción católica y, lo que es más curioso, aún perviven en algunas zonas rurales hasta hoy.

La Ley de 6 de diciembre de 1940 (BOE de 7 de diciembre) crea el Frente de Juventudes, que engloba obligatoriamente a toda la juventud masculina y femenina del país. La organización masculina se agrupa en grados de 7-11 años, de 11-15, de 15 a 18 años, de 15 a 18 años y de 18 hasta el ingreso en las filas del ejército. La femenina contempla a todas las niñas entre los 7 y los 16 años.

Hasta 1945 ambas secciones, masculina y femenina permanecerán juntas en teórico régimen de igualdad y dependencia del mando provincial, pero los evidentes choques entre los intereses de ambas (el Frente de Juventudes más vinculado a la educación política, premilitar y física y la Sección Femenina más volcada en la formación cultural y con muchas relaciones con la iglesia católica) les llevarán a dividirse.

De hecho, los intereses y la ideología política de la Falange, especialmente de los sectores más "radicales" o más puramente falangistas están en abierta pugna con los intereses de la Iglesia. Los contenidos "revolucionarios", la prioridad de la acción, la vinculación a los fascismos alemán e italiano, los ideales de creación de un hombre nuevo, la importancia de la camaradería, el elogio del cuerpo y el deporte, el sindicalismo de las masas obreras, todo ello y otros muchos rasgos de la Falange inicial entran en auténtico conflicto con las propuestas de la Iglesia. Por mucho que entre los puntos de Falange esté el ser católico, la pugna ideológica interna fue tremenda.

Además, toda la historia interna de Falange está llena de enfrentamientos y depuraciones internas. Desde el apoyo incondicional a la política de Franco que siempre ganaba incluso en contra de los propios intereses y principios ideológicos del partido hasta la liberación de los más radicales mediante la vuelta a la lucha armada en la "División Azul", pasando por una purga interna 


\section{Capítulo 4. Música e ideología 1. Frente de J uventudes}

llevada a cabo en 1941 llevada a cabo bajo el mando de José Luis Arrese. Incluso en estos años inmediatamente posteriores a la guerra civil en que Falange se instituye como Partido único y es el representante extraministerial de las relaciones hispanogermánicas e hispanoitalianas ( con numerosas visitas de sus dirigentes a las organizaciones juveniles de estos países, como la de Pilar Primo de Rivera a la Reunión Europea de la Juventud en Florencia en 1942 o el discurso de Antonio Elola en el Congreso de la Juventud Europea en Viena a finales del mismo año), Falange siempre está en una situación de difícil equilibrio con los otros componentes ideológicos: monárquicos, religiosos, y sobre todo, con el control absoluto y la desconfianza ante cualquier poder rival del propio Francisco Franco.

Lo que sí consiguió Falange fue introducirse profundamente en todos los rincones de la vida cotidiana mediante el "bombardeo propagandístico" masivo y continuo de la población. Como el propio Franco dijo en 1942 en el Servicio Social de Alta Cultura Económica de Barcelona:

"la vida civil va a discurrir por el camino de la Falange"

Y eso que la propia Falange reconocía que no eran del todo eficaces en la labor encomendada (achacándolo a la situación de la guerra y la posguerra que habían obligado a crear órganos y organizarlo a toda prisa) y percibían la falta de confianza popular en la revolución falangista, la general apatía con respecto a las posibilidades de llevarla a cabo y la pérdida de unidad en la inicial euforia falangista ${ }^{120}$. Ya en estos primeros tiempos el sector más realista de Falange triunfaba sobre el purismo ideológico en su deseo por sobrevivir y aprovechar las oportunidades que les ofrecía el régimen de Franco, el cual, por otra parte seguía reconociendo en la Falange una potencial capacidad de quebrar el delicado equilibrio de fuerzas que le mantenía en el poder.

\subsubsection{Desde 1945 hasta los años 60}

\footnotetext{
${ }^{120}$ Así se expresaba J osé Luis Arrese, en aquel momento Secretario General del Partido, ante el Sexto Congreso de Sección Femenina. Recogido en ELLWOOD, S (1984). Op. Cit., pag. 41
} 


\section{La educación musical en el franquismo}

A partir de 1945 - de hecho desde la derrota de Hitler en 1942 - la debacle del eje fascista supone una nueva situación internacional que condiciona la política interior y exterior de España.

Podemos distinguir dos épocas desde el punto de vista económico que, como veremos, cambiarán también los posicionamientos ideológicos.

Una primera etapa de autarquía, en la que España se ve sometida a un aislamiento internacional y obligada a sobrevivir a costa de su propia capacidad de producción, principalmente agrícola. Son los años del hambre, las cartillas de racionamiento y el extraperlo, en suma, la pobreza general de la mayor parte de la población. El Estado se construye en torno a tres pilares fundamentales: el Ejército, la I glesia y Falange.

Una segunda etapa de transformación, tanto económica como ideológica que ocupa los años 50 y no llega a evidenciarse en bienestar económico real para la población hasta los años 60. La victoria de las tropas aliadas contra AlemaniaItalia-J apón había supuesto un aislamiento total de España en la comunidad internacional. Pero los cambios en las relaciones que se generaron tras la guerra mundial estaban llevando a la configuración de un nuevo panorama en el enfrentamiento internacional: la guerra fría. En este ámbito, la guerra civil y su lucha contra el comunismo cobraba una luz diferente y así en Fulton, el 5 de marzo de 1946, el propio Winston Churchill insinuó que

"el anticomunismo de la causa nacionalista española era políticamente aceptable y moralmente justificable"121.

Los aliados (con Estados Unidos e Inglaterra a la cabeza) decidieron que en este nuevo contexto era muy deseable contar con los favores de España en la Europa occidental, dada su posición estratégica, y fomentar la estabilidad del régimen de Franco. Así, España volvió a recibir petróleo estadounidense, equipos militares y misiones económicas (plan Marshall), se restablecieron las relaciones diplomáticas y enviaron embajadores Francia, Gran Bretaña y

${ }^{121}$ Recogido en ELLWOOD, S. (1984). Op. Cit., Pag. 161 


\section{Capítulo 4. Música e ideología 1. Frente de J uventudes}

Estados Unidos, créditos de las instituciones financieras internacionales y, en fin, España ingresó en la UNESCO en 1952. Y Falange compensa su carácter antidemocrático con su ideología de profundo carácter anticomunista, que en este momento pasa a ser su principal rasgo ideológico.

Desde el punto de vista institucional, en 1945 se produce un cambio fundamental en la estructura de Falange ligada a la educación: La separación de Sección Femenina y Frente de Juventudes

\subsection{2.a En la escuela}

La Ley General de 1945 impone por fin un marco en el que se van a desarrollar las actividades educativas. Entre otras características importantes destacan:

- la obligatoriedad, gratuidad y separación de sexos (establecida en

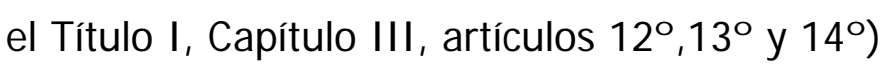

- la existencia y promoción de las misiones pedagógicas, organizadas por el estado y el Movimiento para extender la cultura en los medios rurales (art. 32ㅇ)

- la consideración por la ley de las escuelas al aire libre ( que incluye desde las colonias escolares a los campamentos, albergues u estaciones preventoriales organizados por el Frente de Juventudes y la Sección Femenina con la ayuda reconocida de la Ley de Protección escolar (art. 34우)

- la inclusión de la Formación del Espíritu nacional y la educación física entre los conocimientos de tipo formativo y de la música entre los de carácter complementario y la realización de su cuestionario por los órganos competentes de Falange (art. 37으)

- el reconocimiento de la extensión cultural de la escuela (art.43ํ).

Es decir, que la propia ley dentro de las actividades escolares obligatorias (no complementarias) prevé la colaboración entre el sistema docente y los organismos de Falange competentes en educación. 


\section{La educación musical en el franquismo}

Ello llevará a un confusionismo entre los deberes del maestro y los de otras instituciones. En realidad, leyendo la ley con detenimiento, parece bastante claro que dado que todos los maestros y maestras tenían que ser instructores elementales del Frente de Juventudes o de Sección Femenina, estas tareas les son encomendadas a ellos, (y además están capacitados ideológicamente para impartirlas dentro de la escuela) ya que están en un articulado diferenciado de las actividades complementarias. La ley, de hecho distingue dos capítulos diferentes:

- Capítulo IV: La enseñanza. Materias

- Capítulo V: Actividades complementarias de la escuela.

La asimilación de los contenidos de tres materias (junto con una cuarta de iniciación para el hogar) al área de intervención de Falange les otorga un carácter distintivo, falsamente vinculado al contenido ideológico excepto en el caso de Formación del espíritu nacional. La postulación en grados diferentes, unos como contenidos formativos (FEN y Educación Física) y otros como complementarios (Canto y música) puede también haber sido la causa de cierta confusión.

Pero es sobre todo la utilización del término "complementario" la que, desde mi punto de vista, induce a error y confusión con las posibilidades que ofrece el siguiente capítulo de la ley, ése sí referente a actividades de carácter voluntario.

\subsection{2.b En la vida social y extraescolar}

La misma Ley General de Educación de 1945 abre las puertas hacia una educación extraescolar dentro de la propia escuela, a través del Capítulo V: Actividades complementarias de la escuela y sus artículos 440 y $45^{\circ}$.

El propio articulado comienza diciendo que

"la función docente realizada en la escuela se complementará con actividades pedagógicas y sociales que tiendan a perfección la formación de los alumnos o a prestarles ayuda por medio de instituciones de carácter complementario". 


\section{Capítulo 4. Música e ideología 1. Frente de J uventudes}

Entre ellas se encuentran el apartado b) agrupaciones artísticas que organicen festivales con recitados, escenificaciones, conciertos, programas de radio y emisiones infantiles y e) la asistencia a campamentos, albergues, marchas de alta montaña, ejercicios deportivos, masas corales y grupos de danzas. Y se especifica que estos apartados se desenvolverán según la dirección del Frente de Juventudes y la Sección Femenina. $Y$ también se deja claro que estas actividades tendrán su desarrollo dentro de la escuela y en su gobierno deberán participar los propios escolares.

Es verdad que a lo largo de este período tanto Frente de Juventudes como Sección Femenina organizan muchísimas actividades de este tipo: actuaciones de los grupos de coros y danzas, colonias vacacionales infantiles, campamentos de montaña, actividades al aire libre, competiciones deportivas, coros, conciertos para niños y jóvenes, teatro infantil, cine escolar, etc.

¿Pero alguien ha tenido alguna vez duda de la obligatoriedad de dar FEN 0 Educación Física/gimnasia? ¿Se ha confundido alguna vez hacer deporte en competiciones escolares con la asignatura de Educación Física? ¿Alguien ha creído que por cantar en un coro villancicos o himnos eso fuera la asignatura de FEN? ¿Acaso la contemplación de la exposición de labores de Sección Femenina era lo mismo que la asignatura escolar y ya no había que coser, bordar o tejer?

No lo creo. Sin embargo sí que se ha confundido con la asignatura de música. Y averiguar por qué es uno de los objetivos de este trabajo.

\subsection{2.c La separación de Sección Femenina y Frente de J uventudes}

Una de las grandes novedades de este largo y central período de formación de la juventud es la separación de Sección Femenina y Frente de Juventudes que se produce a raíz de la Orden de 24 de enero de 1945 (BOE de 25 de febrero) titulada Sobre separación de la J uventud Femenina. 


\section{La educación musical en el franquismo}

Aunque es una ley corta - sólo consta de 8 artículos - es un fiel reflejo de las tensiones que se habían ido haciendo cada vez más grandes entre ambas secciones.

En principio, el concepto social del Estado franquista y de la propia Falange es totalmente machista, vinculado a la fuerza y potencia masculina y toda su simbología se centra en la figura del héroe-soldado mitologizada por la guerra civil. Pero ya en plena guerra, la labor social de Sección Femenina había tenido una gran importancia y había recabado apoyos en una gran parte de la población (dado que la mayor parte de las pérdidas humanas en la guerra habían sido los hombres, puesto que en el bando nacional apenas se habían incorporado mujeres excepto como enfermeras o Auxilio Social y éstas desde luego ya eran la base de Sección Femenina). En la retaguardia, la acción de Auxilio Social (con diferentes nombres como "gota de leche") se había atraído simpatías por ocuparse de gestionar la ayuda para la supervivencia de la población civil, muy especialmente de los niños. Enseguida empezaron a organizarse cursillos sobre higiene y salud que contribuyeron a un descenso notable en la mortalidad infantil en épocas de tantas carencias como la guerra y la posguerra. Esta fue su primera preocupación y por tanto su primera actividad formativa para la sociedad civil que se fue extendiendo a medida que los frentes avanzaban y la retaguardia se ampliaba.

Pero una vez terminada la guerra, y además con José Antonio Primo de Rivera muerto, se fueron haciendo cada vez más patentes las diferencias en los objetivos, los métodos empleados y en general la forma de entender el propio partido entre ambos sectores. Por una parte era una cuestión de género, sin duda, ya que las relaciones, aunque de aparente igualdad institucional en cuanto a jefaturas menores e intermedias, era de una sumisión obligada para la Sección Femenina (esta era también la "ideología" que impartía la propia Sección Femenina como papel de la mujer ante la sociedad, de obediencia al hombre y sumisión al guerrero valeroso que vuelve a casa). Pero en realidad, al igual que en la sociedad, se transmitía que la mujer debía y podía mandar "de otra manera". 


\section{Capítulo 4. Música e ideología 1. Frente de J uventudes}

De hecho, en los informes que José Antonio Elola eleva tras el Congreso de Viena (al que también había asistido Pilar Primo de Rivera) sólo se muestra un profunda silencio respecto a la Sección Femenina. Según Juan Sáez Marín

\footnotetext{
"pese a que sus actuaciones y realizaciones corrieran siempre al lado de las masculinas, incluso con mayores indicios de eficacia técnica, Elola aparenta ignorar tales cuestiones".
}

La Sección Femenina ya era otro mundo, de hecho. Las mujeres formaban ya una sumisa y discreta retaguardia en el Frente de Juventudes. $Y$ éste se decantaba como instrumento para actuación exclusiva sobre los varones".

Así, Sección Femenina logró su independencia de los mandos, quedando como su jefe superior la Delegada nacional: Pilar Primo de Rivera, hermana de José Antonio y una figura de enorme peso político original en la creación de la propia Falange, sin estar subordinada a ningún otro cargo de Falange (que en ningún caso tenía su peso histórico). Era, además, una forma de conservar vivo el apellido del fundador del partido $y$, por tanto, una forma simbólica de mantener la presencia del "ausente" que contentara a Falange, tan dada al simbolismo.

No supuso esta ley ninguna ventaja económica, pero no la necesitaban ni era eso lo más importante. La Sección Femenina disponía de una gran cantidad de afiliadas (frente al decaimiento y poca participación según iba pasando el tiempo tras la guerra de la parte masculina) y era capaz de generar sus propios recursos. De hecho, la ley prevé que el Frente de Juventudes se quede con todos los bienes muebles e inmuebles que hasta entonces disponían y además se quede con todos los que hayan sido de uso común o indistinto de ambas ramas. Es más, los donativos que se hicieran al Frente de Juventudes, quedaban exclusivamente adscritos a la organización masculina. Pues ante todo esto y por encima de todas las dificultades que ello generaba, Sección Femenina era capaz de pagar este precio a cambio de disfrutar de una total independencia para organizar sus actividades, ya que la realidad de los años anteriores había demostrado la poca atención que les dispensaban los mandos masculinos del Frente de Juventudes (aún común) 


\title{
La educación musical en el franquismo
}

Esta dejadez está presente en la propia introducción de la ley en la que se expresa que

\begin{abstract}
"la práctica ha demostrado que la duplicidad de mandos y dependencias originan estados de indecisión en las jerarquías, en unos casos por no mermar las atribuciones, nunca bien delimitadas, de unas delegaciones respecto de las otras, y en otros por adoptar iniciativas que no debieron corresponderles. Este estado de confusión que irremediable y prácticamente se ha producido, no podía ocasionar otros efectos que una merma de energías y actividades con el consiguiente perjuicio para la Sección Femenina del Frente de Juventudes".!
\end{abstract}

De hecho, a pesar de lo que se refleja en el párrafo anterior, la ley continúa en tono machista de discriminación y supremacía total de los intereses de la organización masculina:

\footnotetext{
"Por otra parte, la cada día más imperiosa necesidad de asegurar el futuro de la Patria sobre los sólidos cimientos de unas generaciones jóvenes, educadas rigurosamente en la disciplina y el servicio, obliga al Frente de Juventudes a dedicar toda su actividad, esfuerzo y medio, exclusivamente a la forja de estos hombres que han de constituir la vanguardia del Movimiento.
}

La misma denominación de Frente de Juventudes implica un sentido de acción y, de milicia propios de las juventudes masculinas, por lo que esta denominación deberá ser aplicada únicamente, en lo sucesivo, a este sector de la juventud"

El texto legislativo expone claramente algunas de las diferencias básicas entre ambas organizaciones, que no sólo causan su separación, sino que se van a agudizar cada vez más, tanto a lo largo de este período como en el siguiente.

Frente de Juventudes va a hacer todo su esfuerzo en la formación política y premilitar o paramilitar de la juventud. Sección Femenina, a pesar de estar estructurada igualmente de forma jerárquica como una milicia, a pesar de sus gestos militares en la época de la guerra y la posguerra (desfiles, uniformidad, saludo mano en alto), no tiene intención de hacer de esta simbología nada más que una parte de su parafernalia exterior, pero no el centro de su actividad formativa. Esta es la gran escisión ideológica que se esconde tras la separación de las dos organizaciones y afecta enormemente al desarrollo de la actividad 


\section{Capítulo 4. Música e ideología 1. Frente de J uventudes}

educativa y formativa en el sistema educativo (en el que ambos tienen presencia por la Ley general de educación de este mismo año).

Todo ello va a ahondar y hacer aún más grandes las diferencias en la educación de los niños y niñas. Y muy especialmente en su educación musical, que va a tener unas características completamente diferentes según el género y las entidades que la imparten.

Mientras el Frente de Juventudes se va a centrar en la formación política, los campamentos al aire libre, el encuadramiento y sometimiento a la disciplina militar, el ensalzamiento de los símbolos de la falange como manifestación externa del Estado, la competición y la educación física, la visualización de la propaganda y la creación y promoción de los futuros mandos políticos; Sección Femenina va a dedicar todos sus esfuerzos a la educación de las mujeres a través de campañas de alfabetización, promoción del mundo rural y mejora de la producción autárquica (esto es especialmente fundamental para contribuir a la mejora de la economía doméstica de los años de posguerra), cursos de higiene y salud infantil, cursos de cocina y labores del hogar (limpieza, mantenimiento, corte y confección, costura y bordado, tejido, otras artesanías) que complementen la formación de la "mujer como ama de casa" o "la mujer madre y esposa" que defendía como papel fundamental de la población femenina dentro del esquema social, todo ello teñido de dos connotaciones ideológicamente radicalmente diferentes a las masculinas: la religiosidad y la tradición.

Mientras Frente de Juventudes proyecta su labor fundamentalmente a la creación de una generación de "hombres nuevos", hacia el futuro, Sección Femenina hace un trabajo minucioso de reinstauración de la tradición, de los usos folklóricos (que en el momento sobreviven ya a duras penas y que son sin duda un recuerdo el pasado). Mientras Frente de Juventudes mantiene una fachada religiosa que se limita a la presencia de sacerdotes y misas en todas sus actividades públicas, pero tras la que se esconde una profunda lucha política de intereses y un cierto desdén por parte de los mandos (en cualquier 


\section{La educación musical en el franquismo}

caso un papel muy secundario y meramente formal con respecto a otros aspectos de su labor educativa), Sección Femenina hará del vínculo tradicional Mujer-iglesia todo un parangón educativo y social. Sección Femenina no quiere "mujeres nuevas", sino mujeres tradicionales, religiosas, aparentemente sumisas pero que en realidad sean el pilar económico y moral de la familia, que sean el pilar de la sociedad y el mejor "instrumentos ideológico y político"122 de transmisión a través de la familia, y sobre todo del control que ejerce sobre la educación de los hijos.

En lo que a la educación musical se refiere, se plasma en dos estilos completamente diferentes:

Frente de Juventudes se dedicará a cantar a pleno pulmón en todas sus actividades públicas todo tipo de himnos y consignas políticas, de clarísimo y evidente contenido ideológico, promocionando un repertorio de carácter paramilitar en muchos casos asociados a las marchas y los desfiles. Por otra parte, en sus actividades al aire libre, irá incorporando las llamadas "canciones de campamento", con un carácter más lúdico, a las que asocia un cierto sentimentalismo. La introducción de canciones del folklore, por clara influencia de la Sección Femenina, se hace como una clara demostración de nacionalismo y patriotismo, de ensalzamiento de lo español y su simbología.

Sección Femenina dedicará sus esfuerzos, sin embargo, a la recogida y difusión del folklore y la tradición, a la formación de coros y grupos de danzas en todos los rincones de la nación y su difusión como imagen del Estado en el extranjero, a la educación musical de los niños por medio de sus publicaciones y muy especialmente de su labor divulgadora a través de las maestras, a la elaboración de un cancionero infantil estandarizado para todos los niños del país con canciones de todas las partes de España, a la educación rítmica mediante la gimnasia, a cuidar el canto como un elemento femenino tanto en los ambientes religiosos como en el interior de los hogares, a la divulgación de

\footnotetext{
${ }^{122}$ En palabras de la propia Pilar PRIMO DE RIVERA en el III Congreso nacional de la Sección Femenina, celebrado en Zamora en 1939
} 


\section{Capítulo 4. Música e ideología 1. Frente de J uventudes}

la cultura musical y su historia. Algunas de las grandes manifestaciones de Sección Femenina en esta época son de tipo musical: los Concursos de villancicos, el Festival Nacional de Coros y Danzas, las representaciones públicas de ejecuciones rítmicas.

En una palabra, Frente de Juventudes y Sección Femenina toman durante toda esta etapa caminos diferentes con respecto a la transmisión de la ideología y a la educación. El rastro que nos ha dejado su documentación así lo atestigua, no sólo como un efecto secundario, sino como una auténtica intencionalidad.

\subsubsection{Desde los años 60 hasta 1975}

Los cambios sociológicos y económicos que se introducen en esta época van a configurar un mapa completamente nuevo.

El giro político que se produce en esta última parte del franquismo es abrumador aunque no tan evidente como algunos hubieron querido. Pero están ahí: La apertura de España al mundo en el nuevo contexto de abierto enfrentamiento de la guerra fría (cuyo episodio culminante son la crisis de los misiles rusos en Cuba en 1962) y los cambios vertiginosos que se están produciendo en la sociedad americana, en la que tenemos puestos los ojos como ejemplo de sociedad de bienestar económico y político (asesinato de J.F.Kennedy, protestas y cambio social de la sociedad negra en EEUU, rechazo social y especialmente juvenil a la guerra de Vietnam) dejan sentir su huella en la evolución de una sociedad española cada vez más deseosa de entrar en la sociedad de consumo y que siente la necesidad de una mayor libertad política. Aunque mientras viva Franco seguirá manteniendo el control unipersonal del poder bajo su sistema autoritario y militar del concepto del mando, las reformas del régimen se van haciendo cada vez más evidentes. Es el momento de la transformación de las instituciones.

Desde el punto de vista político, la cuestión de la sucesión, que en 1966 se zanja por la opción monárquica es un claro símbolo de lo que está pasando 


\section{La educación musical en el franquismo}

entre los diferentes grupos de poder sobre los que se asentaba el régimen. La Iglesia y la monarquía ganan peso específico, mientras que el partido único Falange y el ejército van perdiendo su poder y tienen que someterse a un largo proceso de transformación que abarca más allá de estos últimos 15 años de vida de Franco y se prolonga a lo largo de los primeros años de la posterior democracia.

\subsection{3.a En la escuela}

El cambio que se produce en el sistema escolar es uno de los más espectaculares ejemplos de la adaptación a las transformaciones que exigen las nuevas circunstancias sociales. Es un proceso largo, que se agudiza sobre todo a partir de 1965 y que lleva a la publicación de un texto reformado de la ley general hasta entonces vigente en 1967 de manera simultánea a la elaboración de un Libro Blanco para la Reforma educativa que culmina en el Ley General de Educación de 1970 (también llamada Ley Villar Palasí por ser el ministro de Educación que la firma).

La nueva ley de Educación reforma completamente el sistema escolar, incluyendo la obligatoriedad hasta los 14 años, una reforma profunda del sistema desde la educación preescolar e infantil, un nuevo concepto de educación secundaria y una regularización y reorganización de los estudios universitarios.

Además, implica la regularización de los contenidos artísticos dentro del sistema educativo general. La música es una asignatura obligatoria tanto en la educación primaria como en la secundaria. En la educación primaria va a estar vinculada a la educación física en una nueva área de conocimiento: la expresión dinámica y en secundaria se va a centrar en los contenidos culturales e históricos.

La denominación del área de expresión dinámica implica muchas más cosas de las que pudiera parecer: interacción de la rítmica en la educación musical, audición activa ligada al movimiento y sobre todo la gran innovación: "expresión". Por primera vez la música no va a centrarse sólo en contenidos de 


\section{Capítulo 4. Música e ideología 1. Frente de J uventudes}

aprendizaje teórico o meramente imitativo, sino que va a contemplar su función emocional y expresiva, sea de forma creativa o interpretativa.

En estos años, Frente de Juventudes y Sección Femenina han seguido ya caminos tan separados que apenas son reconocibles como miembros de una misma institución. Aunque algunos de los medios que usan siguen siendo similares (publicación de cancioneros a través de la editorial Doncel, revistas y producciones didácticas para maestros), en lo concerniente a la vida escolar musical, Sección Femenina es la que va a hacerse responsable de llevar a cabo un profundo cambio. Evidentemente, su nueva metodología implica más directamente a la enseñanza femenina, pero en algunos colegios y muy especialmente en los que tienden a la coeducación de ambos sexos, empiezan a extender su ámbito de influencia a lo que hoy calificamos de educación musical en el sistema escolar general.

Se trata de un cambio radical, influenciado por el contacto con los principales métodos de pedagogía musical extranjeros. Bajo la personalidad de Montserrat Sanuy, la introducción del Método Orff en las escuelas es divulgada a todos los niveles por Sección Femenina. Se organizan cursos de formación para profesores de música (algunos sólo para afiliadas, pero poco a poco se van incorporando titulados de conservatorio) con algunos de los grandes representantes de la educación musical en el momento como Barbara Haselbach, Regner, J oss Wuytack y J acques Chapuis. Se conceden becas de estudio en el extranjero para la formación de profesorado. Y sobre todo, se crea en la propia Sección Femenina un centro para la preparación del profesorado de música de Educación Secundaria, la llamada Escuela Nacional de Música en Barcelona. Desde La sección de Propaganda, que controlaba el ente público de Televisión Española, se crean los programas de Montserrat Sanuy "Musicando con Monstse" y "En clave de sol" que serán los mejores medios de difusión a nivel social y nacional de la nueva educación musical en la escuela.

¿Cuáles son los rasgos innovadores de esta nueva educación musical? 
- En primer lugar, aquellos colegios que pueden permitirse entrar en una dinámica de innovación educativa, contratan profesores $\mathbf{y}$ profesoras de música vinculados a las nuevas metodologías para que impartan las clases a todos los alumnos del colegio. Esto, desde luego, suponía unos gastos extraordinarios, pero no era algo tan extraordinario como podría parecer: se contrataban con frecuencia profesores para la educación física que estaban vinculados a frente de Juventudes y Sección Femenina como instructores deportivos y en general para muchas actividades realizadas en la escuela, y había muchos convenios entre las instituciones juveniles del Movimiento y los centros escolares que hacían posible dichas contrataciones a tiempo parcial.

- En segundo lugar, se introduce el aprendizaje paulatino y de manera práctica del lenguaje musical. Aprovechando las innovaciones pedagógicas y según las preferencias de cada uno, aparecieron varias aplicaciones de la quironimia de Ward y Kodaly, así como otras adaptaciones a partir de la solmisación de Orff, la escala pentatónica y otros sistemas más o menos modernos. Pero se empieza a tener claro que para poder tocar hay que empezar a leer música en el pentagrama, y que su introducción a nivel escolar no puede ser tan árida como el tradicional aprendizaje del solfeo en los conservatorios (de hecho las enseñanzas profesionales musicales también van en este período a iniciar una etapa de transformación de su metodología).

- En tercer lugar, se va a promueve un tratamiento de la música más vivencial y participativo, en la que lo importante es hacer música. Entre otros muchos aspectos que posibiliten la interpretación, estará no sólo el fomento del canto (fórmula casi exclusiva de interpretación musical escolar hasta el momento), sino la introducción de los instrumentos escolares (sobre todo la flauta y el instrumentarium Orff de placas y pequeña percusión no afinada).

- Se promueven la prosodia y la formación rítmica, es decir la unión del lenguaje, de la danza y el movimiento a la percepción musical y se va 


\section{Capítulo 4. Música e ideología 1. Frente de J uventudes}

a utilizar como elemento fundamental para la comprensión de audiciones y de la construcción a partir de las formas musicales. Los ejercicios rítmicos con percusión corporal, la ejecución de patrones rítmicos asociados a movimiento, la percepción de tempos e intensidades van a ser también contenidos de la educación física, además de la educación musical.

- Se va a introducir aunque lentamente, la potenciación de la creación y la composición infantil. La divulgación de la obra de Murray Schafer en los últimos años del franquismo es un ejemplo del interés por este nuevo concepto creativo de la educación artística en general y musical en particular.

- La ley de Educación del 70 resalta la nueva importancia que se le da a la educación artística, ya que aparece en los tres niveles educativos iniciales: en la educación preescolar en el artículo 14 aparece la expresión rítmica, en la educación general básica a aparece en el artículo 16 se hace referencia a la iniciación en la apreciación y expresión estética y artística y en el artículo 24 sobre las materias comunes (obligatorias, no optativas) del bachillerato va en el segundo enunciado "b) Formación estética, con especial atención a dibujo y música", sólo precedida por el área de lenguaje.

- El área de expresión dinámica es un elemento de formación evaluable más, y así lo expone la resolución de $\mathbf{2 5}$ de noviembre de $\mathbf{1 9 7 0}$ (BOE de 3 de diciembre) sobre las instrucciones para la evaluación continua en la EGB en su punto 2.4, donde expone que "el área de expresión dinámica incluirá en su calificación global los aspectos aptitudinales y hábitos referentes a la educación del movimiento, ritmo, juegos, gimnasia, canto, música, danza, dramatizaciones, etc.

En otras palabras, la educación musical deja de ser un medio de transmisión ideológica para centrarse en los aspectos de realización vivencial y experiencia expresiva-creativa de los niños. Un cambio radical desde el punto de vista del tratamiento que había tenido hasta ahora. 


\section{La educación musical en el franquismo}

Sección Femenina, que venía dedicándose con ahínco a la educación musical de las niñas en la escuela como una parte fundamental de su labor docente, supo adaptarse a estos cambios, de los cuales fue una de los principales impulsores.

\subsection{3.b En la vida social y extraescolar}

Los años 60 y 70 supusieron un cambio socio-económico radical de la sociedad, caracterizado por la apertura y la pluralidad de experiencias. Ello no significa que no se siguiera intentando ejercer un control ideológico por parte de los organismos correspondientes de Falange (censura, propaganda, educación política). Pero era francamente difícil de mantener ante la avalancha de nuevos estímulos culturales, principalmente del entorno anglo-americano. El cine, la televisión, la música, la literatura... todo hablaba de una sociedad de libertades que en la época aislacionista del régimen eran desconocidos prácticamente en nuestro país.

Aunque formalmente, Falange seguía siendo el partido único del régimen, tuvo que plegarse a los deseos de Franco cada vez más alejados de los ideales iniciales del partido, lo que provocaba fuertes enfrentamientos internos entre los sectores más pragmáticos y los más tradicionales, de los cuales siempre salían triunfantes los partidarios de la transformación a los nuevos tiempos. En palabras de Ellwood ${ }^{\mathbf{1 2 3}}$,

\footnotetext{
"la economía nunca había sido una prerrogativa de Falange en el reparto de campos de influencia mediante el cual Franco mantenía el equilibrio interno del poder, pero, mientras que en la década de 1940 los objetivos económicos se subordinaban a las consideraciones políticas, la situación iba a invertirse en la década de 1960, y los encargados de la esfera político-ideológica, los falangistas, quedarían relegados a una posición secundaria".
}

Frente de juventudes y Sección Femenina, si bien tenían a toda la juventud obligatoriamente afiliada durante un tiempo en sus filas y bajo su influencia formativa, apenas lograban retener más que a un ínfimo número de gente joven en sus filas. Y los que tenían, era porque lo utilizaban como trampolín

${ }^{123}$ ELLWOOD,S.(1984) Op. Cit. , pag. 183 


\section{Capítulo 4. Música e ideología 1. Frente de J uventudes}

para su incorporación a la vida pública y administrativa de la sociedad del momento. Es la época del pragmatismo, de la transformación a un mundo dominado por los intereses económicos y los cambios sociales, de la adaptación de la ideología.

Sección femenina lo entendió muy bien y se preparó para la transformación de su papel en la sociedad y concentró sus esfuerzos en formar y recolocar a su personal en la administración y en el sistema educativo. Frente de Juventudes fue más lento en sus reacciones, pero también fueron capaces de crear la élite política que realizó la transición a la democracia en el país en los años futuros, en lo que centraron sus esfuerzos, dejando un poco al margen los aspectos educativos.

Una de las grandes características de estos 15 últimos años del franquismo es que Falange perdió la exclusividad en la presencia política (adquiriendo cada vez mayor auge sindicatos y asociaciones políticas aún clandestinas) y en la vida social (nuevas asociaciones juveniles vinculadas a la iglesia 0 a otras ideologías, otros centros de formación y de ocupación del ocio, pérdida de capacidad efectiva de la propaganda frente a la capacidad de atracción de la sociedad de consumo).

En estos últimos años, Frente de Juventudes iba convirtiéndose casi exclusivamente en la asociación juvenil para realizar campamentos y deportes, desvinculándose poco a poco de sus tienes ideológicos a favor de la parte más lúdica de sus contenidos de ocio y tiempo libre.

Sección Femenina, sin embargo, se estaba transformando para desaparecer como institución evidente para permanecer establecida en la sombra de la administración pública, local y regional. Sus contradicciones pasadas entre la formación de la mujer y el mantenimiento de su papel tradicional en el hogar según Katleen Richmond ${ }^{124}$, se estaban viendo superadas por la evidencia

\footnotetext{
${ }^{124}$ RICHMOND, k. (2004). Las mujeres en el fascismo español. La Sección Femenina de la Falange 1934-1959. Madrid: Alianza
} 


\title{
La educación musical en el franquismo
}

cada día mayor de la incorporación de la mujer al trabajo y por una nueva forma de entender los deberes femeninos en la sociedad.

\subsection{FRENTE DE JUVENTUDES Y LA MÚSICA Frente de Juventudes y la música}

Como recoge Rafael Abella ${ }^{\mathbf{1 2 5}}$ cuando analiza las evasiones cotidianas,

\begin{abstract}
"en la sociología de la vida española, la radio dio a la cotidianeidad de la existencia que le era negado por otras vías. No menos importante fue el papel de la radio como divulgadora musical, porque si los años cuarenta y cincuenta estuvieron dominados por las privaciones, desde el punto de vista musical - de música ligera - fueron de gran riqueza. Como si la comunidad hispánica hubiera hecho suyo el aserto popular de que "quien canta la pena espanta", durante las dos décadas mencionadas el país vivió con un fondo musical que ha quedado como el anverso melódico de un reverso patético (...) El cancionero de toda una etapa de la vida española, significada por su dureza, fue el contrapeso lírico y sentimental de una humanidad que buscaba evasión en el tarareo de las melodías popularizadas [por la radio]".
\end{abstract}

\subsubsection{La primera etapa. Desde 1936 a 1945}

\subsection{1.a La visión propagandística y premilitar de la sociedad civil}

Junto a esta vida musical civil, (que por cierto era controlada por Falange a través del Servicio de Propaganda al que se sometían todos los medios de comunicación), hay otra vida musical., que Abella califica de

\footnotetext{
"fondo musical muy alimentado por el régimen, que había instituido el "Día de la canción", confiando en el fomento de las virtudes que proporcionan los cantos colectivos, y más si se hacen en correcta formación y marcando el paso. Este acompañamiento sonoro se orientó hacia las actividades del Frente de Juventudes (...) Como refugio de la juventud, apuntaba a fundir las nuevas generaciones educándolas en unos principios patrióticos que se manifestaban en el canto de Prietas las filas, Montañas nevadas o Yo tenía un camarada."
}

${ }^{125}$ ABELLA, R. (1984) La vida cotidiana bajo el régimen de Franco Madrid: Temas de hoy 


\section{Capítulo 4. Música e ideología 1. Frente de J uventudes}

Cierto, el Frente de juventudes representó a lo largo del franquismo la forma exterior de la simbología fascista del poder. Los desfiles paramilitares en formación y con uniforme (calzón corto, camisa azul y boina roja) son uno de los medios simbólicos para llevar a la vida civil la sensación del poder militar sin que sea necesario sacar a las tropas a la calle, una manera de recordar la capacidad represora del sistema y de la propia entidad de la justificación del régimen (un levantamiento militar al fin y al cabo) sin hacer evidente la presencia de las fuerzas armadas.

En los modelos de políticas de juventud que expone J uan Sáez Marín ${ }^{\mathbf{1 2 6}}$ las canciones de este período de Frente de Juventudes se pueden clasificar claramente en el apartado "b. Políticas POR la juventud, características de los regímenes políticos totalitarios y con conexiones con los fascismos alemán e italiano ${ }^{127}$. Sus principales características son que se trata de una política a realizar "por medio" o "mediante" los jóvenes y que fundamentalmente es:

- Movilizadora, prólogo o epílogo de los frentes de batalla

o Adoctrinadora y domesticadora mediante lo que Aranguren ${ }^{128}$ califica de inyección de estupefacientes ideológicos e "insensatos enstusiasmos"

o Retóricamente cargada de incitaciones a la tensión heróica

o Dinamizadora del potencial juvenil en provecho del sistema, que instrumentaliza el idealismo de los jóvenes en función de los objetivos y aspiraciones de la generación adulta

o Captora por tanto del esfuerzo joven que, en primer lugar recluta y moviliza. En un puesto más secundario puede pretender un difuso y declamatorio "pleno desarrollo" o "desarrollo integral" de la juventud, siempre en orden a su perfección como mero instrumento

\footnotetext{
${ }^{126}$ SÁEZ MARÍN, J (1988) Op. Cit. Pag 9-10

${ }^{127}$ Ver al respecto las obras de MONTERO DÍAZ, S (1944) Mussolini. Madrid, KOCH, H.W. (1976) La juventud hitleriana. Madrid y TANNEMBAUM, E (1975) La experiencia fascista: sociedad y cultura (1922-1945). Madrid: Alianza ${ }^{128}$ ARANGUREN, J.L. (1973) La juventud europea y otros ensayos. Barcelona
} 
- Disimétrica, en tanto que existe una absoluta contradicción entre los comportamientos observables y los valores que se aducen para justificarlos

- No sirve a los jóvenes, se sirve de ellos

- Pasiva por parte de los jóvenes. Impuesta o establecida de arriba abajo, a los jóvenes, simplemente se les encuadra. El Estado es el "amo absoluto de las juventudes"

- En lo político, los jóvenes son para el sistema una reserva movilizable cuando se duda de la fidelidad de los ciudadano, o ante cualquier peligro 0 inestabilidad.

Y este mundo paramilitar era simbolizado a través de actos acompañados de canciones. Ya desde las primeras manifestaciones inmediatamente después de la guerra observamos este tipo de actos. Daniel Sueiro y Bernando Díaz Nosty ${ }^{\mathbf{1 2 9}}$ recogen así los primeros momentos posteriores al final de la guerra:

"Si la jornada del día 19 de mayo había deslumnbrado con el despiegue militar, la del día 20 se caracterizaría por su "honda significación cristina". Madrid, recogido la noche anterior con la retreta de la legión Condor en la explanada de la plaza de Oriente, amaneció festivo. Cornetas y tambores, bandas musicales. Jóvenes, hombres y mujeres con vestimenta falangista. Miles de personas en multitud hacia el centro. Tropas del ejército y la Guardia Civil cubrían hasta los accesos a la iglesia de Santa Bárbara. Representaciones de las distintas armas acompañaban al cortejo, haciendo sonar sus trompetas. La guardia mora daba escolta al Caudillo, a quien seguían todos los generales laureados. Diez mil flechas y cinco mil féminas de la Falange aguardaban desde primeras horas de la mañana en las inmediaciones del templo, portando las palmas traídas desde Alicante. Al llegar a las Salesas, entre un bosque de brazos levantados con la palma extendida, un grupo de niños y señoritas inicia el canto del "cara al sol". Serrano Suñer se vuelve hacia ellos y con ambas manos conduce el cántico de un coro que gana a la multitud (...) El coro benedictino de Santo Domingo de Silos interpreta las "Antífonas en la recepción del Príncipe" del Liber Orbinus (S.VII)".

${ }^{129}$ SUEI RO, D. y DIAZ NOSTY, B. (1986) Historia del franquismo Madrid: Sarpe. Pag. 23-24 


\title{
Capítulo 4. Música e ideología 1. Frente de J uventudes
}

Es evidente que estaban asistiendo a una teatralización del poder, a una representación dramática de los símbolos que van a explicitar el régimen: el poder militar, la imposición política a través del control ideológico de Falange, y la fuerza de la Iglesia a través de sus elementos más tradicionales.

Este uso, se extendió a todos los actos públicos, cualquiera que fuera su carácter. De hecho, aun cuando se publicó el decreto que declaraba que la bandera española eran las tres bandas horizontales alternas roja/gualda (amarilla)/roja y que el himno nacional sería la antigua Marcha Real, Falange siguió acompañando los actos con su bandera (roja y negra) y el canto del "Cara al Sol" con el saludo mano en alto. El propio Ramón Serrano Suñer ${ }^{\mathbf{1 3 0}}$ explica en sus Memorias que Pilar Primo de Rivera difundió una circular oponiéndose las medidas tomadas por el decreto y reivindicando como símbolos nacionales la bandera de Falange y el "Cara al sol".

Y en efecto, así fue recogido en la ley, y tal como señalan Sueiro y Díaz Nosty

\begin{abstract}
“Madrid podía abrir sus calles al Caudillo. El puño se había abierto en mano extendida. Los madrileños habían aprendido pronto la nueva liturgia de la dictadura: Artículo 10: Se establece como saludo nacional el constituido por el brazo en alto, con la mano abierta y extendida y formando con la vertical del cuerpo un ángulo de cuarenta y cinco grados. Artículo $2^{\circ}$. Al paso de la enseñan de la Patria y al entonarse el himno y los cantos nacionales, en los casos previstos en el decreto 226, se permanecerá en posición de saludo.
\end{abstract}

De hecho, en la asignatura de Formación político-social (para niños), lo que más tarde configuraría Formación del Espíritu Nacional (FEN), se explicitan las siguientes lecciones. Lección primera: La bandera nacional. Lección 2ạ : La bandera del Falange. Lección 3ạ: La bandera tradicionalista. Lección 4ạ: El escudo nacional. Lección $5^{a}$ El yugo y las flechas. Lección 6o El himno nacional y los cantos nacionales (que se especifican que son estos otros tres: "Cara al sol", el "Oriamendi" y el "Himno de la Legión" "los cuales

\footnotetext{
${ }^{130}$ SERRANO SUÑER, R. (1977) Entre el silencio y la propaganda. La historia como fue. Memorias. Barcelona: Planeta
} 


\section{La educación musical en el franquismo}

nos recuerdan la valiosa aportación de los falangistas, requetés y legionarios en la guerra de liberación"). A la Marcha Real, ahora ya establecida por Decreto como Himno Nacional se le incorpora letra, y es obligatorio su aprendizaje así como el de los otros tres cantos nacionales (un ejemplo más de la difícil coexistencia y división de poderes dentro de las estructuras del Movimiento, unificadas a la fuerza por el decreto de 1937) Lección 7ạ: Otras canciones del Frente de J uventudes "Prietas las filas" Lección 8a: España, una, grande y libre. Lección 9o: ¡Arriba España!. Lección 9o El ¡Presente! A los caídos. Lección 11a Santo Domingo de Guzmán. Lección 12a Romance del Rey don Rodrigo. Lección 13a . Romance de Castilla en armas. Lección 14ạ Calvo Sotelo. Lección 15ạ : J osé Antonio. Lección 16o: Franco

Falange, y muy especialmente el Frente de Juventudes, van a hacer de esta parafernalia, una parte cotidiana de la vida española. Todos los actos comenzaban y se cerraban con el canto del Himno nacional y el "Cara al Sol", puestos en pie y con el saludo fascista, la presidencia de las banderas nacional y falangista (y a veces la tradicionalista) y los gritos de “iArriba España!” Y el “iPresente!". En algunos casos, especialmente si estaba presente el Caudillo, se le aclamaba al grito de "Franco, Franco, Franco". Y todo ello, aún de manera más evidente en los actos conmemorativos de una cierta importancia, en los

que Falange aportaba un gran número de simpatizantes uniformados y encuadrados en formación militar. Eran la visualización de la aceptación civil del régimen.

Es decir, que las J uventudes son el reflejo propagandístico del régimen personal de Franco, que supo aprovechar su estricto sistema jerárquico de obediencia al mando para controlar todas sus manifestaciones, tanto a nivel nacional como en sus actuaciones en las más pequeñas localidades rurales.

Así, en las primeras épocas después de la guerra y hasta bien avanzados los años 40 , asistimos a grandes muestras escénicas, cuyos referentes se hayan en consonancia con los desfiles fascistas alemanes e italianos. Así bajo el mandato 


\section{Capítulo 4. Música e ideología 1. Frente de J uventudes}

de Sancho Dávila, se organizó en Sevilla una "Demostración Nacional" que, según J uan Sáez Marín 131

"recuerda las aparatosas manifestaciones de las juventudes fascistas o el resonante Reichsjugendtag der NSDAP de 1934 en Postdam".

Este tipo de escenificaciones masivas, se repitieron sin cesar en los años anteriores a la caída de la Alemania nazi en 1942. Así, en Madrid al año siguiente tuvo lugar otra Demostración nacional de estas características con ejercicios premilitares, gimnásticos y deportivos, al son de las marchas y canciones, cuya finalidad era sobre todo propagandística, ya que acaparaban la atención de los medios periodísticos y la vida social del momento.

Muchas otras veces tenían, sin embargo, un trasfondo improvisado como narra Joaquín Villegas en sus Memorias, a la sazón incorporado al equipo organizador de las Organizaciones Juveniles de Cataluña en 1939:

"A la semana siguiente de la liberación de Tarragona, sucedió la de Barcelona (...) Con tan fausto motivo, llegó a Tarragona el Secretario General de FET y de las JONS, Raimundo Fernández Cuesta. Le improvisamos un gran recibimiento juvenil con más de 50 centurias de flechas y cadetes uniformadas procedentes de Tarragona y de las delegaciones más cercanas. Le presentamos una demostración gimnástica, un desfile por centurias al ritmo de Canciones de marcha, una exhibición de castillos humanos y un fuego de campamento. Raimundo quedó sorprendido. ¡Todas las centurias uniformadas! ¿Un milagro? ¡Quiá! Acaparé de mi peculio todos los sobres de tinte azul y negro existentes en Taragona, Reus, Valls, Vendrell, Falset, Mora de Ebro, Ulldecona, Tortosa. Hice la distribución del tinte por centurias, falanges y escuadras, y les di un plazo de 24 horas para presentarse a formar con camisa azul y pantalón negro teñidos en sus casas."

En fin, que hasta 1945, más o menos, el fin primordial de la Organización J uvenil, que es como se llama hasta la Ley de 6 de diciembre de 1940 por la que se funda el Frente de Juventudes, la actividad formativa se centró fundamentalmente en la aplicación y adaptación de reglamentos militares

${ }^{131}$ SÁEZ MARín, J (1988). El Frente de Juventudes. Política de juventud en la España de la posguerra (1947-1960). Madrid: Siglo XXI de Editores 


\section{La educación musical en el franquismo}

(formaciones, desfiles, instrucción premilitar) y deportivos, con dos claros objetivos: conseguir la disciplina y la unidad.

\subsection{1.b Música y educación}

De hecho, toda la política educativa de este período (bajo el ministerio de Ibáñez Martín) está según Cámara Villar

\footnotetext{
"dirigida a la consecución del control de la educación y de la cultura como uno de los instrumentos más poderosos de adoctrinamiento masivo de las futuras generaciones en los valores básicos de la nueva concepción ideológica y en los principios dimanantes de la nueva organización política. Y precisamente por poseer ese carácter clave dentro del campo de la ideología se constituirá en uno de los terrenos donde se concentra la lucha interna por la hegemonía política e ideológica entre las principales fuerzas políticas componentes del bloque en el poder (...) reducida en su actuación concreta en el seno del aparato educativo al binomio Falange/grupos católicos".
}

Con respecto a los niños, aunque se le habían asignado ya a Falange las tareas de creación de cuestionarios referentes a la educación política, deportiva y cultural, la formación premilitar y las actividades de socialización tuvieron una importancia primordial en estos primeros momentos, relegando a un segundo término las enseñanzas de carácter cultural. De hecho, es de destacar que, a pesar de las numerosas actividades vinculadas al canto, la gran cantidad de repertorio en estos años o la presencia específica del Canto en las enseñanzas de los Instructores, siempre aparece en el caso de la educación masculina como ámbitos de la educación del Frente de Juventudes explícitamente sólo la formación política y la educación física. Tal vez se interpretara en el momento que la formación musical recibida y vinculada a la ideología es tomada como una parte de la formación política.

Otra parte importante de la actividad formativa de Falange se inicia con la entrada a finales de 1939 de Julián Pemartín como responsable de la "Asesoría nacional de cultura y formación nacional-sindicalista". Su primer 


\title{
Capítulo 4. Música e ideología 1. Frente de J uventudes
}

objetivo consiste en conseguir formar instructores y cuadros de mando jóvenes".

Esta necesidad surge de la asignación por parte del Estado al Frente de Juventudes de la educación política, física y cultural de las nuevas generaciones, lo que según J osé I gnacio Cruz Orozco ${ }^{\mathbf{1 3 2}}$, constituye

\begin{abstract}
“la participación más relevante y de mayor trascendencia que llevó a cabo el Frente de Juventudes dentro del sistema de educación española y que se concretó en las materias de Educación Física y Formación del espíritu nacional (FEN). Ambas asignaturas se situaron siempre bajo la tutela directa de los responsables de la política de juventud del franquismo y durante más de 35 años se impartieron en todos los centros de enseñanza española sin distinción de grado. La incorporación de la entidad falangista al sistema educativo se inició a los pocos meses del final del régimen republicano y no finalizaron hasta 1977, con el comienzo de los trabajos de las Cortes Constituyentes (...) A todos los efectos - programas, profesorado, control y supervisión - la responsabilidad correspondía exclusivamente al Frente de Juventudes".
\end{abstract}

Este encargo docente (que también incluía la formación cultural, aunque la parte musical sólo se hace explícita para las escuelas femeninas, con lo que su ámbito pertenece a Sección Femenina, aunque en este período esté unificada con Frente de Juventudes) no encuentra a la Delegación Nacional de Juventudes bien preparada. De hecho, el Frente de Juventudes no contaba en 1941 con un número de cuadros suficiente para poder atender las competencias formativas en los centros docentes.

\section{Según Cámara Villar}

“la Orden de Octubre de 1941 que disponía que la formación política se regiría por instructores designados por el Frente de Juventudes y que, en ausencia de éstos serían los directores de los centros de enseñanza y los maestros, se convirtió en una aplicación más de la excepción que de la regla. Esta precariedad de medios haría que el Frente de Juventudes permaneciera durante todo el período 1940-45 en una situación de completa provisionalidad, posibilitada por la actitud (es de suponer que

\footnotetext{
${ }^{132}$ CRUZ OROZCO, J.I. (2001) El yunque azul. Frente de Juventudes y sistema educativo.
} Razones de un fracaso. Madrid: Alianza 


\section{La educación musical en el franquismo}

deliberada) enteramente pasiva de I báñez Martín (entonces Ministro de Educación y poco favorable a la intervención de Falange en la educación)".

Se organizan a toda prisa cursillos estivales en régimen de campamento, en los cuales además de religión, historia y doctrina nacional-sindicalista, historia de España, régimen interior de 0J, conocimientos militares, anatomía y psicología, mecánica del movimiento del cuerpo humano, campamentos, juegos y deporte y primeros auxilios, también se aprendía Canto. ¿Y cuáles eran esas nociones de Canto? Sin duda, el repertorio está formado mayoritariamente por himnos y marchas tal como se recoge en los primeros capítulos del Cancionero de Juventudes de José de Arriaca ${ }^{133}$, ya que ellas conforman la parte más ideológica del cancionero y perfectamente adecuada para las actividades premilitares y de propaganda que en ese momento predominan en la actividad juvenil.

\footnotetext{
“Falange Española y su organización de Juventudes han sido las instituciones modernas, y quizás las únicas en toda la historia de España que han alentado y promovido con mayor efectividad para que los españoles canten a la Patria y a sus héroes. (....) En las actividades el Frente de juventudes las canciones han desempeñado papel básico para conseguir la unidad y disciplina que el tiempo exigía. La eficacia de la canción de marcha con la intrínseca dificultad que al tiempo encierra ajustar el paso, el ritmo, las pausas y la respiración, sobre todo con jóvenes y niños, fue lograda cuando un campamento, una unidad juvenil, habían aprendido a cantar marchando: de este modo tenían recorrido ya la mitad del camino para la auténtica disciplina"134
}

Hay que recordar, además, que se hace obligatoria la titulación de Instructor Elemental del Frente de Juventudes para tomar posesión de cualquier plaza de magisterio como funcionario, por lo que Falange se pone a toda prisa a realizar cursillos específicos para maestros, dando incluso prioridad a los opositores sobre la formación de los propios instructores del Frente de Juventudes, lo que provoca una total insuficiencia de profesorado propio a la hora de cubrir las necesidades de los centros. Así pues, se tiene que realizar una escala de prioridad a la hora de dotar a los centros educativos de personal formado.

\footnotetext{
${ }^{133}$ ARRIACA, J. (1967). Cancionero de Juventudes. Doncel, Madrid

${ }^{134}$ ARRIACA, J. de (1967) Cancionero de juventudes/. Doncel, Madrid, pag. 12
} 


\section{Capítulo 4. Música e ideología 1. Frente de J uventudes}

Dicha prioridad es la siguiente: 1ㅇ Institutos de enseñanza media, 2ำ Grupos escolares estatales, 3o Colegios privados de enseñanza media y 40 Colegios privados de primera enseñanza. Ello tiene varias consecuencias:

- Los centros privados y religiosos de primera enseñanza (y también los de enseñanzas medias en su casi totalidad) lograron eludir la presencia de personal de Falange, ya que eran las últimas plazas solicitadas en poder ser cubiertas y ante la absoluta falta de personal formado por los cursos de Falange

- En la mayor parte de los centros estatales escolares, eran los maestros, titulados obligatoriamente como Instructores Elementales, los que fueron encargados de impartir estas enseñanzas

- Prácticamente la totalidad de Instructores oficiales (titulados con dos años de estudios en la Escuela de Mandos "José Antonio") fueron destinados a los escasos centros de Enseñanza Media del Estado

El plan de trabajo de los cursos para maestros estaba basado en las enseñanzas del curso nacional de la Academia de Mandos "José Antonio", pero reduciendo los contenidos de dos años a un mes en régimen de campamento. Hay que recordar, que en el caso de la formación musical, los conocimientos teórico prácticos del lenguaje musical habían sido aprendidos (al menos según los programas, porque de su eficacia no tenemos referentes) en las asignaturas correspondientes en los estudios de magisterio con una dedicación de dos horas semanales durante al menos dos cursos. Así que, suponemos y por lo que tenemos constancia por relatos personales, que se centraba en la interpretación y aprendizaje del repertorio más vinculado ideológicamente a los valores falangistas

Así lo refleja el Anuario del Maestro para $1940^{135}$ aparecen las normas dictadas sobre la asistencia al Santo Sacrificio de la Misa, presentación y saludo a

\footnotetext{
${ }^{135}$ ASCARZA, Victoriano (fundador) (1949) Anuario del maestro para 1940. Madrid: Magisterio Español.
} 


\section{La educación musical en el franquismo}

mandos y jerarquías superiores, el estudio de los himnos, etc., y que es recogido por Manuel Fernández Soria 136

En estos cursos que se realizaban para maestros, empezaba a consolidarse un programa de educación cerrado para el adoctrinamiento político, con la elaboración de cuestionarios y "guiones de formación" de periodicidad mensual, que aparecía publicado en la Revista Mandos. Las intenciones de adoctrinamiento se hacen explícitas en las palabras de Dávila en 1940:

"Reconociendo que lo doctrinal no tenemos más conocimiento con seguridad de cimientos que las directrices geniales de José Antonio, y éstas no al alcance de los mejores iniciados, nos obliga a la mayor cautela cuando tratemos de adoctrinar a los pequeños. Hemos de impresionar sus mentes con definiciones breves, frases, consignas."

Y también con canciones, hemos de añadir, ya que para hacer posible este ambiente de profundo patriotismo se hizo obligatorio para el maestro y los escolares la entonación en todas las sesiones de la escuela (es decir, todos los días) de cantos populares e himnos patrióticos, como materiales destinados a reforzar emocionalmente la identificación del escolar con el ideario y la actuación del Movimiento ${ }^{137}$

La creación de un "Catecismo" falangista o manual no se conserva, pero tenemos una referencia a su existencia y a su relación con la formación de los maestros muy interesante en las Memorias de Joaquín Villegas:

\footnotetext{
"Durante los cuatro meses que estuve en el Campamento de Flechas de Fuenfría, hice el "Catecismo" falangista para Flechas de la OJ (a ciclostyl) con la definición escueta y lacónica del significado de los signos externos y de las consignas y aforismos, tales como la bandera nacional, la bandera roja y negra, el yugo y las flechas, la camisa azul, el Cara al sol, el Himno del flecha, el saludo brazo en alto, al tratamiento de tú, Arriba España, los gritos de España Una, Grande y Libre, por el Imperio hacia Dios, Por la patria, el pan y la justica, lo que significa ser nacional-sindicalista, los gritos finales
}

\footnotetext{
${ }^{136}$ FERNÁNDEZ SORIA, M (1984). Educación y cultura en la guerra civil (España 193639).Valencia: Nau LLibres. También en Cuadernos del Departamento de Educación Comparada e Historia de la Educación, num 12. Universidad de Valencia

${ }^{137}$ En CÁMARA VILLAR, G (1984) Op. Cit.
} 


\section{Capítulo 4. Música e ideología 1. Frente de J uventudes}

de Viva Franco, Arriba España y J osé Antonio ¡Presente! (...) y así hasta 20 folios a dos espacios a ciclostyl. No guardo ningún ejemplar iqué lástima! Se tiraron más de dos mil ejemplares a ciclostyl en los talleres tipográficos de El Magisterio Español (...) Yo tenía la pretensión de que fuera editado por la Delegación nacional de OJ, pero a Julián Pemartín no le gustó, dijo que carecía de estilo literario y no se editó. D. Eduardo Cantos quiso editarlo en el Magisterio, y me regalaba 25.000 ejemplares. Pero a mí me pareció incorrecto aceptar aquello cuando había sido desestimado por Pemartín."

Y es que la formación de los maestros en los cursos de instructores elementales del Frente de Juventudes y la colaboración entre Falange y la escuela, "hicieron de ésta el más importante agente de socialización política de la infancia española", según Sáez Marín y Cámara Villar.

\subsection{1.c El repertorio}

Las fuentes más destacadas de información con respecto a la educación musical de estos primeros años las encontramos en el Cancionero de juventudes de J osé de Arriaca ${ }^{\mathbf{1 3 8}}$ en la clasificación temporal de canciones que contiene la edición electrónica de España es mi canción $^{139}$. El material que aportan ambos, aunque sin partituras, es muy valioso, sobre todo por los comentarios que hace de primera mano sobre el origen de las canciones y su ubicación temporal. Muchas de las canciones de este período están además interpretadas en MP3 en la edición digital, por lo que hemos procedido a analizarlas musicalmente.

La otra gran fuente, esta vez sí con partituras, es el Cancionero Falangista ${ }^{\mathbf{1 4 0}}$, destinado en principio a la Milicia Universitaria y que publicó el Departamento de Publicaciones de la Delegación Nacional del Frente de J uventudes en 1945.

\footnotetext{
${ }^{138}$ ARRIACA, J. de (1967). Cancionero de juventudes/. Doncel, Madrid ${ }^{139}$ VARIOS. HERMANDAD DONCEL (2000) España es mi canción. Edición electrónica en http://www.rumbos.net/cancionero/ 140 DELEGACIÓN NACIONAL DEL FRENTE DE JUVNETUDES (1945) Cancionero falangista. Madrid: Departamento de Publicaciones
} 


\section{La educación musical en el franquismo}

También son importantes - aunque menos numerosas (sólo 14 contienen partitura y hay otras 34 de las que sólo consta la letra, entre las cuales algunas folklóricas) - las aportaciones de Marchas y montañismo ${ }^{\mathbf{1 4 1}}$.

\section{España es mi canción (edición digital)}

Pertenecen a esta primera etapa, anterior a la derrota de la Alemania nazi y las esperanzas fascistas en la segunda guerra mundial tres bloques: Canciones anteriores al Frente de Juventudes (antes de 1940), canciones desde 1939 a 1942 y canciones desde 1942 a 1945. De algunas de ellas no conocemos la música, ya que era práctica habitual aprenderlas por imitación y son pocos los cancioneros que recogen la partitura. No obstante, de algunas disponemos de grabación en MP3 a partir de la cual hemos sacado al dictado la partitura. Con todo, de una pequeña minoría de ellas, sólo disponemos del testimonio histórico de la letra y de que fueron recogidas como himnos y marchas en los diferentes cancioneros de la época.

\section{Canciones anteriores al Frente de J uventudes (hasta 1940)}

Cara al sol. Himno de Falange. Compuesto por José Antonio Primo de Rivera con música de Juan Tellería. Por ser uno de los himnos obligatorios en la Formación Política, nos ocuparemos de él más tarde. Omnipresente en la vida española durante todo el régimen franquista, se entonaba además del Himno Nacional

Himno de combate. Apareció por primera vez en el semanario La conquista del estado en octubre de 1931, y es considerada la canción más representativa de las JONS. Letra de Juan Aparicio y música de José Guerrero Fuensalida. Su título inicial fue el de Himno de las falanges de combate, aunque en Marchas y montañismo (1943) se le subtitula también como Himno de las Viejas JONS

\footnotetext{
${ }^{141}$ DELEGACIÓN NACIONAL DEL FRENTE DE JUVENTUDES (1943) Marchas y montañismo. Madrid: Departamento de publicaciones
} 


\section{Capítulo 4. Música e ideología 1. Frente de J uventudes}

Isabel y Fernando. Es la canción de las JONS de Valaldolid una vez que se fusionan con las J CAH de Enésimo Redondo. Apareció en el semanario Libertad como himno de las J ONS de Valladolid.

Himno de las JONS de Valladolid. Aparece con un arreglo de Manuel Mira en el Cancionero de la O.J. de Asturias (1940) La música es un arreglo de una conocida marcha almena y consta que se cantó por primera vez después del acto celebrado en el cine Hispania en Valladolid el 21 de enero de 1935.

Himno de las milicias andaluzas

El camarada (I y //). La música es una adaptación de la canción alamena /ch hatt ein kameraden de Ludwig Uhland, escrita en 1809, pero muy popular entre las juventudes hitlerianas y durante la II Guerra Mundial. Existen varias versiones, pero ya aparece en el Cancionero de la O.J. de Asturias (1940)

Camisa azul. La música también es una adaptación de un himno alemán Die Fahne Hoch. Existe una variante recogida en el libro de Rafael García Serrano La fiel infantería

Himno de la bandera gallega de Falange. Surgida en 1936, se extendió rápidamente a otras regiones falangistas. Está recogida en Marchas $y$ montañismo (1943)

Canción del falangista. La letra es de Fernando Moraleda y tuvo mucha difusión en el período de la guerra civil

Si un camarada falangista. Surgida en la guerra civil y de marcado carácter consista, aparece recogida en Marchas y montañismo (1943)

las JONS. Recogida en el Cancionero de la OJ de Asturias (1943) es una de las primeras canciones consistas con referencias al Caudillo

Cadetes de las JONS. Recogida en el Cancionero de la O.J. de Asturias (1940) 
Flechas y yugo de las JONS. Recogida en el Cancionero de la 0.J. de Asturias (1940)

La centuria "Ruiz de Alda". Al parecer surgió en la O.J. de Sevilla y es posible que se cantase en la Concentración nacional de octubre de 1938

Por España seguiré luchando

Allí. Con letra de I. Laguna y A. de Pablos y música de Manuel Mira. Aparece recogida en Himnos y canciones (1942)

Si cayeras, camarada Por su contenido es evidente una canción de la época de la guerra civil

Amargura

Por la España imperial. Recogida en Himnos y canciones (1942)

Coplas de guerra. Ejemplo del intercambio entre las canciones más o menos populares cantadas en el frente bélico con las juventudes falangistas en la retaguardia

Flechas de Castilla. Aparecen en el Cancionero de la O.J. de Asturias (1940) y también más tarde en ciclostyl en Granada en 1954

Los flechas. Es una versión con otra letra de Alfredo Martínez Leal del Himno del Alcázar. También recibió el nombre de Flechas de Toledo. Aparece en Himnos y canciones (1942)

La centuria de Castilla. Aparece recogida en el Cancionero de la O.J. de Asturias (1940)

Canción del flecha (I y //) Son dos versiones sobre una letra de Agustín de Foxá y fue creada en 1938 


\section{Capítulo 4. Música e ideología 1. Frente de J uventudes}

Una España mejor. También conocida como Camaradas caídos, fue adoptada como himno de la Centuria "Legión Azul" de Granada. Está recogida en el Cancionero de la O.J. de Asturias (1940)

Adelante. Está recogida en el Cancionero de la O.J. de Asturias (1940) y más tarde en la revista Mandos, esta ve con el título de "Himno de campamento".

Himno del trabajo. Con letra de Tomás Borrás y música del maestro Moreno Torroba. Está recogida en el Cancionero de la O.J. de Asturias (1940)

Marchando. Hay dos versiones con letra diferente, una recogida en el Cancionero de la O.J. de Asturias (1940) y otra en Marchas y montañismo (1943). Se conocía también como Al venir del campamento

El alto de los Leones. Escrita sobre el "Romance de Castilla en Armas" de Federico de Urrutia.

\section{Canciones desde 1939 a 1942}

Prietas las filas. Desde los primeros tiempos hasta 1977 fue el Himnos del Frente de Juventudes. A veces se le denominaba también Himno del flecha. Era una de las canciones de obligatorio aprendizaje en la asignatura de Formación del Espíritu Nacional. Con letra de Joaquín Villanueva y música de A. Cabañas. Está recogida en Himnos y canciones (1942)

¡Arriba España!. La letra de de Dionisio J. Negueruela y la música de Aurelio González. Está recogida en Himnos y canciones (1942)

Marchad. Aparecer recogida en unas "Hojas impresas" a ciclostykl editadas en Granada en 1948, pero la edición electrónica de España es mi canción de Doncel, la atribuye a la época de 1939 a 1942 


\section{La educación musical en el franquismo}

Gloria y honor a José Antonio. Aparecida tras la muerte del líder de Falange, probablemente en 1938, está recogida en el Manual del Jefe de Centuria (1942)

¡Al pe pri!. El título hace alusión a una cárcel flotante llamada "Alfonso Pérez prisión". Está recogida en Canciones de Marchas y campamentos (1942)

Impulso imperial. Cita tres versos de Prietas las filas y está recogida en Marchas y campamentos (1942)

Águilas del imperio. Aunque aparece en unas "Hojas a multicopista" publicadas en Granada en 1954, la versión electrónica de España es mi canción de Doncel la atribuye a esta época temprana.

Marcha de los aprendices. La letra es de Ezequiel Jaquete y la música de Joaquín Gascón. Está recogida en el Cancionero juvenil (1947), pero la edición electrónica de España es mi canción de Doncel, la atribuye a épocas anteriores

Ser español. Aunque también aparece por primera vez recogida en el Cancionero del Frente de Juventudes (1963), la edición electrónica de España es mi canción de Doncel sitúa su nacimiento en 1942

Juventud española. Está recogida en Himnos y canciones (1942)

Mi camisa azul. Está recogida en Canciones de Marchas y campamentos (1942)

Falanges juveniles de cadetes. Aunque aparece recogida por primera vez en el Cancionero de Juventudes (1967), la edición electrónica de España es mi canción sitúa su origen anterior por el tipo de consignas, lemas y metáforas que utiliza, propias de la primera etapa de la organización juvenil

Centuria de cadetes. Letra y música de S. Cecilia, aparece en el Cancionero Juvenil (1947). Era utilizada como marcha por la Centuria de Belchite, a la que se le sustituyó esta última palabra por la más general de Cadetes para acoplarla a todas las unidades. 


\title{
Capítulo 4. Música e ideología 1. Frente de J uventudes
}

\begin{abstract}
Centurias juveniles. Aunque aparece recogida en el Cancionero juvenil de bolsillo (1954), la edición electrónica de España es mi canción de Doncel la sitúa en esta primera etapa de identificación y afirmaciónde los símbolos falangistas
\end{abstract}

Águilas de España. Aparece recogida en Canciones de Marchas y campamentos (1942)

Juventudes de la España heroica. Localizada en la zona de El Ferrol en los comienzos de la organización juvenil, hace alusión a una consigna del almirante Casto Méndez Núñez "Más vale honra sin barcos que barcos sin honra"

Canción de los Flechas. Aparece recogida en Canciones de Marchas y campamentos (1942), y puede servir para la Sección Femenina también, sustituyendo Hombres/ mujeres del mañana.

Arriba el corazón. Se conocen varias versiones de esta canción, aparentemente realizada sobre una música alemana.

Voces de imperio. La música es de Odón Alonso. Utiliza la consigna "Pro el imperio hacia Dios" y tiene claras referencias consistas. Está recogida en unas “Hojas impresas” publicadas en Granada en 1948.

Montañas nevadas. La letra es de Pilar García Noreña y la música de Enrique Franco Manera. Es una de las canciones más conocidas de Falange. Aparece recogida en el Cancionero falangista (1945)

Fidelidad .También conocida como "Es tan hermoso ser cadete". Surgió en el Primer Curso Nacional para J efes de Falange, celebrado en el campamento de El Escorial el verano de 1942. Aparece recogida en el Cancionero falangista (1945) 


\section{Canciones desde 1942 a 1945}

Soy español. Está recogida en Canciones de Marchas y montañismo (1942)

Voluntarios de la División Azul. Adaptada sobre una música fascista italiana titulada Giovenezza.

Primavera. Realizada sobre una música popular rusa y con algunas referencias a la cultura rusa: Wolchow, Ladoga, vodka.

Himno de la División Azul. La letra es de José Mạ Alfaro y Agustín de Foxá y la música de Juan Tellería. Se cantó por primera vez en un homenaje a la División Azul en el Teatro Calderón de Madrid el 8 de diciembre de 1941. Está recogida en Himnos y canciones (1942)

Desde Rusia. Realizada sobre una marcha alemana, apareció publicada en la Hoja de Campaña, no 24 el 20 de abril de 1942

Lili Marlen. Versión realizada sobre la famosísima canción de Hans Leip (1915) y de gran divulgación en la época por las interpretaciones que de ella realizaron Lale Andersen (durante la guerra mundial en Radio Belgrado) y en el cine Greta Garbo

¡Gibraltar! ¡Gibraltar!. Canción sobre una marcha traída de Rusica, con alusiones a la campaña de la División Azul. La enseñó Agustín Paíno en el Curso para J efes de Campamento que se realizaó en la Casa de Campo. Está recogida en el Cancionero de Valencia (1953)

Cubre tu pecho. La letra es de José Mạ García-Cernuda Calleja y la música de Agustín Paíno Mendicoagüe. También conocida como Llámame camarada, con cuyo título se creó en el Segundo curso para jefes de Falange y el Primero de 


\section{Capítulo 4. Música e ideología 1. Frente de J uventudes}

J efes de Centuria que se realizó en el Campamento Nacional "Sancho el Fuerte" en el año 1943. Está recogida en el Cancionero Juvenil (1947)

Ven con nosotros. Aunque no aparece publicada hasta 1953 en el Cancionero de Valencia, la edición electrónica de España es mi canción de Doncel la sitúa en esta primera época

Canción del Cid. La edición electrónica de España es mi canción sitúa a esta marcha en la primera época, aunque no aparece recogida hasta el Cancionero del Frente de Juventudes (1963)

Una vez oí una canción. I gualmente, esta canción no aparece hasta la publicación en el Cancionero de juventudes (1963) de Doncel, pero la edición electrónica de España es mi canción la sitúa en fechas tempranas de la organización juvenil

Himno de campamentos. Con letra de Anselmo Redondo y música de Félix Tellería, se escribió en el año 1944 en el Campamento Nacional "Ordoño II" en Riaño (León). Aparece recogida en el Cancionero Juvenil (1947)

Nuestras escuadras jóvenes. Otro himno del Campamento "Ordoño II" realizado en 1944 en Riaño (León), con letra de Carlos Alonso del Real y música de Félix Tellería. Fue publicado en Mandos bajo el título de Canción del campamento Ordoño //

Pequeños arqueros. Canción compuesta por el maestro Joaquín Rodrigo para celebra el "Día de la canción" de 1944. Está recogida en el Cancionero Juvenil (1947)

Como se puede apreciar, ya sólo por los títulos, se trata de la época más ideológica de las canciones del Frente de Juventudes. Son himnos, casi todos con connotaciones militares y bélicas, profundamente asociada al carácter violento e idealista de Falange. 


\section{Cancionero falangista (1945)}

Se trata de una publicación de la Delegación Nacional del Frente de Juventudes que incluye las partituras de las canciones, por lo que tiene un gran interés musical. Algunos de sus contenidos son fuente a su vez de la edición electrónica de España es mi canción, especialmente en la etapa 1942-45, ya que refleja perfectamente lo que se estaba cantando en los últimos años de esta época. Cuatro de las canciones incluidas proceden del Concurso Nacional de marchas y canciones convocado por el Departamento Nacional de Propaganda del SEU en 1943.

Destaca su estructura, claramente dividida en cuatro tipos de contenidos: religiosos, folklóricos, himnos y marchas de Falange e himnos militares

\section{Cantos religiosos \\ Oración del Frente de Juventudes}

Salve Regina

Salve marinera

Canciones regionales

Asturias

A raiz d'o toxo verde

La pastoreta

Eres alta y delgada 


\begin{tabular}{|c|}
\hline Folías \\
\hline Los cordones \\
\hline Aunque me des veinte duros \\
\hline Caminito de Avilés \\
\hline No se va la paloma \\
\hline $\begin{array}{l}\text { Desiderio. De esta canción se señala en el prólogo que se incluye en el } \\
\text { cancionero "como concesión a la actualidad" y que es parte de un pasacalle de } \\
\text { una zarzuela remozado por la inspiración de los campamentos y para los } \\
\text { campamentos. Es la primera constatación escrita de esta colaboración entre lo } \\
\text { popular y lo que se canta en las actividades de aire libre del Frente de } \\
\text { juventudes. El mismo editor se pregunta en el prólogo "¿dónde nació el } \\
\text { Desiderio? Nadie lo sabe; es como si en un mismo día hubiera empezado a } \\
\text { cantarse en todos los campamentos porque sí" }\end{array}$ \\
\hline Fui al Cristu \\
\hline Himnos y marchas de FET y de las J ONS \\
\hline Himno de falange: Cara al sol \\
\hline Prietas las filas \\
\hline Juventud. Marcha- canción del SEU \\
\hline $\begin{array}{l}\text { Camino del sol. Finalista del Concurso de marchas y canciones de 1943. Sus } \\
\text { autores son Antonio Hernández Carreras y Luis González Villemenot }\end{array}$ \\
\hline $\begin{array}{l}\text { Unión juvenil. Finalista del Concurso de marchas y canciones de 1943. Sus } \\
\text { autores son Isidoro Almazán y José Sanchos Bosch }\end{array}$ \\
\hline
\end{tabular}




\section{La educación musical en el franquismo}

Bajo las banderas imperiales. Finalista del Concurso de marchas y canciones de 1943. Sus autores son J osé Gordón paso y Francisco Esbrí

Juventud estudiante. Según el prólogo de la edición, esta cnación fue la ganadora del Concurso de marchas y canciones de 1943. Sus autores son Luis Muñoz Cazorla y Juan Ocaña

Isabel y Fernando

Y fieles al Caudillo son

Soy nacionalsindicalista

Adelante

Amanece

Canción del falangista

Gloria y honor a José Antonio

Montañas nevadas

Himnos y marchas militares

Himno de la División azul

La canción del legionario

Himno de la Academia de infantería

Himno de la Marina

Himno del 1o Regimiento de Infantería de Marina. Tercio sur 


\section{Capítulo 4. Música e ideología 1. Frente de J uventudes}

Lealtad. Himno de Infantería de marina. Tercio Norte. Su autor es el maestro G. Bandot

Himno de Infantería de Marina. Tercio de Levante

Precisamente porque éste es un cancionero para los campamentos, se hacen alusiones a su estructura cuatripartita: tiene que haber canciones viejas y nuevas, folklóricas e ideológicas, himnos y canciones con un objetivo:

\footnotetext{
"Ilevar a los campamentos de la Milicia universitaria la canción, seria o alegre, pero siempre animosa, que luego se recuerda siempre y se canta muchas veces".
}

Esta finalidad pedagógica, de enseñanza de valores que luego serán inconscientemente recordados es la característica básica de la educación musical del Frente de Juventudes. Ciertamente hay piezas en el repertorio cuyo carácter es más doctrinal: los himnos y las marchas militares, pero la introducción de los elementos folklóricos y populares le aportan un carácter lúdico y menos cargado ideológicamente, que se irá haciendo cada vez más importante en el período inmediatamente posterior (1945-60)

\section{Cancionero de Juventudes de José Arriaca ( 1967, Ed. Doncel)}

Hace una revisión del repertorio de canciones del Frente de Juventudes que no sólo incluye la totalidad de las letras y su clasificación temporal (aunque no las partituras), sino que además incorpora valiosísima información sobre su creación (compositores, época y ámbito para el que fueron creadas) y sobre el entorno en que se interpretaban. Además aporta numerosas citas de otras fuentes secundarias especialmente interesantes para comprender la magnitud del impacto social de las canciones y analiza la funcionalidad de las mismas, así como las influencias recibidas tanto desde el punto de vista ideológico como musical. Hace una revisión del proceso histórico de la música en la Falange con mucha información detallada y desde el punto de vista del propio movimiento 


\section{La educación musical en el franquismo}

falangista lo que proporciona una perspectiva interna de la evolución del pensamiento juvenil en la organización.

Respecto a las canciones de esta primera época separa cuatro apartados diferenciados:

\section{De 1930 a 1936}

El Himno de combate de las JONS que aparece en el semanario "La conquista del Estado" en 1931, con letra de juan Aparicio y música de José Guerrero Fuensalida

Isabel y Fernando apareció en el semanario "Libertad" como himno de las J ONS vallisoletanas de Enésimo Redondo y Ramiro Ledesma

Amanece para mí, también llamado el Antiguo himno de las JONS de Valladolid, a la que atribuye una clara influencia de las organizaciones juveniles nazis alemanas

El camarada es una traducción de una canción alemana no fascista, de Silcher y Uhland (1787-1826). Aunque no tiene un carácter de marcha, se convirtió en una canci' ñon fundamental del repertorio de la juventud falangista y hasta la llegada del Cara al so/servía en numerosas ocasiones como himno principal.

Cara al sol. Es el Himno de Falange, especialmente tras los mítines de José Antonio en los cines Europa y Padilla de Madrid en febrero de 1936. Fue creada el 3 de diciembre de 1935.

Cara al sol es el Himno de Falange y está rodeada de la mitología asociada a que fuera escrita de manera colectiva e informal por el propio José Antonio Primo de Rivera y otros miembros fundadores de Falange (J uan Tellería -autor de la música-, Luis Bolarque, Pedro Marlene Michelena, Rafael Sánchez mazas, 


\title{
Capítulo 4. Música e ideología 1. Frente de J uventudes
}

José Mạ Alfaro, Agustín Aznar y Dionisio Ridruejo), tal como se narra en la novela "Madrid de corte a checa" de Agustín de Foxá142

\begin{abstract}
“En la casa del Marqués de Bolarque... Juan Tellería tocó una tarde una canción alegre y decidida, Bolarque y Miquelarena hicieron unos proyectos de estrofas. Días después fuimos a cenar con José Antonio a "Or-Kompon", un restaurante vasco en la calle de Miguel Moya (...) Trazó el plan José Antonio: -Nuestros muchachos exigen una canción alegre, de guerra y de amor, pero exenta de odio. No ha de ser ni engolada ni solemne. En la primera parte debemos hablar de la novia; luego de la muerte, haciendo una alusión a al guarida eterna en las estrellas, y después, algo sobre la paz y sobre la victoria (...) Eran las dos y media de la madrugada. Encendí un pitillo, algunos querían marcharse pero Agustín Aznar y Luis Aguilar vigilaban la puerta: - De aquí no sale nadie (...) J osé Antonio se frotaba infantilmente las manos y nos agrupamos todos alrededor del piano. Se abrieron los primeros compases. Comenzamos a cantar. La música sonaba vibrante: eran voces juveniles que invocábamos a la muerte y a la victoria; nos poníamos firmes inconscientemente y levantábamos el brazo. Era que estaba allí el himno, arrebatándonos, sorprendiéndonos a nosotros mismos, vivo ya, independiente, desgajado de sus autores. En los ojos de José Antonio brillaba una luz de entusiasmo velada por una ligera tristeza. Le parecía escuchar en la apartada calleja las pisadas rítmicas de sus camaradas que marchaban hacia el frente desconocido. Y se imaginó a sus mejores pronunciando moribundos en la tierra, en el mar y en el aire aquellas palabras que hacía unos minutos pertenecían a los poetas"
\end{abstract}

\section{De 1936 a 1939: La guerra civil}

Es el período que Arriaca llama de "Canciones de la guerra de liberación" y destaca como principales características de la misma la creación y exaltación de los símbolos nacionales (la bandera, el himno nacional proveniente de $L a$ marcha real de granaderos al que se le incorporaron diversas letras autores como H. Miguel Antonio, Eduardo Marquina o José Mạ Pemán) y la incorporación de himnos militares (Legionario, el himno de infantería, el

142 FOXÁ, A (1938). Madrid de corte a cheka.Madrid: Ediciones J erarquía También aparece citada la creación del himno de Falange en otros testimonios de primera mano como la narración de Luis de Bolarque en la Revista "Y" en noviembre de 1938; la edición ilustrada "Canción de la Falange", prologada por Agustín de Foxá y con estampas de Carlos Sáenz de Tejada y publicada por Ediciones Españolas en 1938; en la Biografía que escribe Felipe Ximénez de Sandoval; el relato de Dionisio Ridruejo recogido en la Historia de la Falange de las JONS de Francisco Bravo Martínez (1943, Editora nacional); en De la vida de José Antonio de Enrique Pavón Pereira (1947, Ediciones FC): Davida Jato Miranda en La rebelión de los estudiantes(1953, CIES) 


\section{La educación musical en el franquismo}

himno de artillería, de marina, de ingenieros, de Aviación e incluso de la guardia civil, formaron parte de los cancioneros falangistas en la época bélica y quedaron incorporados para épocas posteriores).

La unificación de fuerzas políticas por el Decreto de 19 de abril de 1937, hace que se incorpore el himno requeté, el Oriamendi, a pesar de su evidente contradicción de principios con el falangismo.

Sigue habiendo notables influencias extranjeras fascistas, como la de Die Fahne hoch alemana, o la Giovanezza y la Facetta Nera italianas, pero también algunas otras canciones bélicas procedentes de la primera guerra mundial como la francesa La madelon.

En esta época es cuando se empiezan a recoger los temas musicales para configurar un cancionero propio, de los que el precursor es el Cancionero de la Organización Juvenil de Asturias, publicado por la Editorial F.E.T de Oviedo que contiene 20 canciones. Los temas son primordialmente jonsistas, destacando la asociación “Muerte-victoria” y la exaltación de los caídos por la patria. Las principales canciones de este período son el Himno de la bandera gallega de Falange, las JONS, Cadetes de las JONS, Flechas y yugo de las JONS, El campamento, Flecha de las JONS, Si un camarada falangista, la canción del falangista, Morir por España, Si cayeras camarada y Por la España imperial. También destaca la incorporación de canciones procedentes del ambiente militar como La asamblea, El ataque, En la noche se oye el fusil, la Marcha de fusileros, Bajo las banderas imperiales, Rataplán, Por España seguiré luchando, El día de mañana o las adaptaciones de letras a canciones de carácter más popular como las Coplas de guerra, la Rumba del cañón y Se van los falangistas

Las canciones juveniles empiezan a surgir vinculadas a la estructura de la organización juvenil y los campamentos: Los flechas, Flechas de Castilla, El guión, La marcha del flecha y Por el imperio hacia Dios, La centuria de Castilla, Centuria Ruiz de Alda. La canción del flecha, iAdelante!, Soy 


\section{Capítulo 4. Música e ideología 1. Frente de J uventudes}

nacionalsindicalista, El campamento, Toque de queda, Somos los flechas del campamento y Marchando

\section{De 1939 a 1942}

Arriaca llama a esta etapa la de la "Organización juvenil de la paz"

El tema de la exaltación de los caídos y la propaganda de la formación premilitar se generalizan a través de canciones como prietas las filas, Marchad, Caídos por España ipresentes!, Gloria y honor a José Antonio, iAl pe pri!, Juventudes del mar.

La ambición imperial bajo la que se ocultaba el voluntarismo y el esfuerzo necesario para la reconstrucción de las infraestructuras del país tras los años de guerra se refleja en las canciones como Impulso imperial, Águilas del imperio, Himno del trabajo , la Marcha de los aprendices y Flecha imperial

Las canciones juveniles de campamentos se decantan por la autoafirmación y las marchas como Soy español, Juventud española, Camisa azul, Ser español, Falanges juveniles de cadetes, Centuria de cadetes, Centurias juveniles, legión de flechas, iArriba España!, Reina Isabel y Arriba el corazón. Y sobre todo, la más famosa Canción del flecha (de Villanueva y Cabanas) conocida más popularmente por su inicio"Prietas las filas".

La institucionalización del "Día de la Canción" para conmemorar el 1 de abril como día de la Victoria ratifica el papel de las canciones y los desfiles de las juventudes de Falange y el uso propagandístico que de ello hace Franco. La necesidad de recoger y difundir dichas canciones da lugar a la elaboración de los primeros cancioneros con entidad y ligados a las publicaciones de Falange, como Canciones para marchas y campamentos y las das ediciones diferentes de Himnos y canciones ${ }^{143}$. La publicación interna del Manual del jefe de centuria de las Falanges de Voluntarios sirvió para dar las instrucciones necesarias para

\footnotetext{
${ }^{143}$ VVAA(1942). Himnos y canciones. Vicesecretaría De Educación Popular. Talleres Tipográficos Boileau (Madrid) y Bernasconi (Barcelona)
} 


\title{
La educación musical en el franquismo
}

formar coros al unísono y bandas con cornetas y tambores en todas las agrupaciones masculinas del país

\begin{abstract}
"Sobre la significación de los himnos y el reconocido valor que tuvieron en la victoria española, a la vez que para dejar el Estado constancia de su consideración, con fecha d17 de julio de 1942, desde la Jefatura del Estado, se decreta que en adelante gocen de categoría de cantos nacionales el Cara al sol, el Oriamendi y el Himno de la legión de tanta tradición, con cuyas estrofas se obtuvieron muchas victorias resonantes y se entonaron en momentos decisivos"144
\end{abstract}

Se inicia una etapa en la que empiezan a aparecer las loas a Franco como Caudillo, de la que es precursora la canción Fidelidad que fue interpretada y aprendida en el Primer Curso Nacional para Jefes de Falange celebrado en El Escorial en 1942.

\section{De 1942 a 1945}

La incorporación de voluntarios españoles a la II Guerra Mundial como colaboradoras del ejército alemán supuso una nueva introducción en el cancionero de temas musicales de origen extranjero, fundamentalmente alemán y ruso como Lili Marlen o Katiuska. Pero la mayor parte de los temas que se generaron a partir de esta experiencia son españoles, cargados de nostalgia del país y de las experiencias vividas vistas a través un romanticismo idealizador para soportar la derrota. Algunas eran una adaptación de temas hispanos, bailes de moda o populares (Voluntario alegre, Chaparrita, Limón limonero, La Parrala). Otras fueron más reivindicativas como Desde Rusia, Tómala sí un día y Primavera. Mientras las tropas de la División Azul estaban cercadas en medio de la nieve, el 8 de diciembre de 1941 en Madrid se celebraba un homenaje en el teatro Calderón en el que se interpretaba la canción que más éxito obtuvo con respecto a esta intervención internacional: el Canto de la División Azul, compuesto por Félix Tellería

${ }^{144}$ ARRIACA, J. de (1967) Op. Cit. pag. 78 


\section{Capítulo 4. Música e ideología 1. Frente de J uventudes}

El regreso de las tropas diezmadas y derrotadas tras la experiencia rusa acabó con los afanes imperialistas internacionales, que se concentraron con más fuerza en las reivindicaciones nacionales de ;Gibraltar, Gibraltar!

La labor del Frente de Juventudes empieza a centrarse en la actividad de campamentos. De estas actividades surgen nuevas canciones cuya finalidad es la captación de nuevos afiliados juveniles, más esperanzadoras y llenas de energía como Llámame camarada (himno del Campamento "Sancho el Fuerte"), Ven con nosotros, Ven a mi centuria, Una vez oí una canción y La canción del Cid (todas ellas provenientes del Campamento "Sancho el Fuerte" realizado en 1943) o Nuestras escuadras jóvenes y el Himno de campamentos (compuestas por Félix Tellería como profesor de canciones del campamento "Ordoño II" celebrado en 1944)

Especial atención merece la canción Pequeños arqueros que compuso para Falange J oaquín Rodrigo, una pieza compleja para un coro de aficionados

Es de destacar la labor en estos años y los siguientes de Enrique Franco Manera, director de los coros de la Academia de mandos "José Antonio" y que fue el encargado principal de la difusión entre los jefes de centuria del repertorio propio de canciones del Frente de Juventudes a través de las actuaciones públicas y las grabaciones de los primeros discos.

Es el momento en el que aparecen varios cancioneros fundamentales de Falange: Marchas y montañismo (Madrid 1943) - en el que se incluyen 14 himnos y marchas, 6 canciones de marcha de los primeros tiempos y 28 canciones regionales - y que es la fuente de la reedición de 1943 del Manual de jefe de Centuria de las F:J:F. También aparece en 1943 Marchas y canciones que contiene 22 himnos y canciones de marcha y 56 canciones regionales. El folleto Canciones para la mochila editado por el Departamento de Publicaciones del Frente de Juventudes en 1944 contiene 26 himnos y marchas, 2 cantos religiosos y 6 canciones religiosas.

\section{Los cantos patrióticos}




\section{La educación musical en el franquismo}

¿Cuáles de estas canciones eran aprendidas en el entorno escolar y cuáles fuera del mismo? Esto es muy difícil de precisar. En esta primera etapa, fuertemente ideologizada, en la que los maestros toman como parte fundamental de su educación los cursos realizados por Falange (porque era condición sine que non el obtener el título de Instructor elemental y porque, en los años posteriores a la guerra civil el beneplácito político era absolutamente imprescindible para conseguir hacer carrera en el Magisterio), no se sabe muy bien dónde se marcan los límites entre sociedad civil y premilitarizada.

Un buen ejemplo de ello es este texto de 1939 publicado por el Sindicato español del Magisterio ${ }^{145}$ :

"¿Y qué estilo data a nuestra educación? Muy sencillo el señalarlo, si se interpreta fielmente nuestro pasado y el momento crítico actual. He aquí: milicia y juventud(...) La milicia es inseparable de la vida, es la manera de entenderla cumplidamente(...) Ese espíritu de milicia - en el que está contenido el de disciplina, jerarquía, sacrificio y es siempre factor de toda verdadera formación - va unido a todas nuestras glorias nacionales y el que animó desde el principio de su actuación a las Juntas Ofensivas Nacional-Sindicalistas (JONS), la encarnación más pura de los precursores del alzamiento salvador, cuyo estilo simpar ha brillado siempre por la iniciativa en la lucha y el sacrificio (...) La educación nacional ha de esforzarse con todo empeño en alcanzar tre finalidades u objetivos: 10 la formación de la conciencia ético-religiosa(...), 2으 La educación Nacional ha de formar la conciencia nacional, porque bien echamos de ver ahora lo desdichadamente abandonado que ha estado esta finalidad que debiera ser la preferente del Estado en todas sus disposiciones, y como es natural, en todos los grados y centros de enseñanza. La influencia de este objetivo logrado es enorme. La conciencia nacional en la que radica el verdadero patriotismo al sertirnos solidarios de un común destino histórico es uno de los estímulos y factores más poderosos de nuestra voluntad y ha de contribuir grandemente al resurgir de nuestra amada España".

La propia Falange otorga premios y reconocimientos a los maestros que se muestran más colaboradores con sus fines, y dichos galardones suponen cualificaciones para los concursos de traslado y promoción en el cuerpo. Así que es de suponer que muchos maestros colaboraron intensamente en la difusión del cancionero de Falange.

${ }^{145}$ SINDICATO ESPAÑOL DEL MAGISTERIO (1939). Hacia una educación nacional. Salamanca 


\section{Capítulo 4. Música e ideología 1. Frente de J uventudes}

Así pues, ¿hasta dónde llegó el entusiasmo de los maestros en enseñar los cantos patrióticos? Está claro que el aprendizaje de algunos de ellos era obligatorio a nivel escolar, ya que vienen explicitados en la materia de formación política: Por lo menos había que conocer el Cara al sol, el Oriamendi, el Himno del legionario y parece ser que también Prietas las filas según el documento sobre Formación Político-social para niños.

Cara al sol es el himno de Falange por excelencia. Como tantas otras cosas de la Falange anterior al franquismo, disfruta precisamente de ese sabor de improvisación, de creación no premeditada, casi juvenil, con la asociación de imágenes poéticas a los símbolos básicos de la organización: El iluminismo, lo varonil, el compañerismo, la superación de la muerte y el sacrificio personal, la asociación de la paz con una nueva primavera, la camisa azul con el yugo y las flechas en rojo, la asociación de las flechas y las rosas, las banderas y la formación paramilitar (estar en formación, hacer la guardia), incluso la asociación a los tres cuerpos del ejército: tierra, mar y aire, y desde luego, preconiza la victoria.

Todo ello, pero muy especialmente que la letra fuese realizada en una reunión política informal por el propio líder carismático y mártir glorificado J osé Antonio, lo convierten en el símbolo fundamental de la organización. Si el fundador cantaba y componía canciones ¿cómo no iban a hacerlo sus seguidores? Y además reúne todos los símbolos iniciales. Se interpretaba siempre, en todos los campamentos, en todos los actos públicos, en todas las reuniones en las que estuviese Falange presente como organización, a la par del himno nacional (al que se le había añadido una letra de lo más falangista).

Caso muy diferente es el del Oriamendi, ya que éste no es un himno falangista, sino de sus acérrimos enemigos dentro del difícil equilibrio de fuerzas del régimen. Pero la presencia de las fuerzas tradicionales carlistas en el Frente en la Guerra Civil, obliga a que exista una presencia en el cancionero como agradecimiento a su aportación bélica. Son las contradicciones que desde el principio lleva consigo el Decreto de Unificación de 1937 y que tantos 


\section{La educación musical en el franquismo}

quebraderos de cabeza origina en las tensiones internas de Falange. ¿Cómo iban ellos a cantar y enseñar un himno monárquico, cuando los ideales falangistas son los opuestos? Pues tuvieron que hacerlo, porque así se lo imponía el autonombrado jefe de todos ellos: Franco. Es como las otras imposiciones simbólicas que también se plasmaron en el uniforme: la gorra roja, las Barras cruzadas en la cruz de San Andrés en el lado derecho de la camisa (en el lado del corazón estaban el yugo y las flechas falangistas), y tuvieron que entonar "que viva la bandera de la Santa Tradición", cuando ellos defendían unos ideales que autocalifican de "revolucionarios". Otro de sus términos simbólicos adquirirá también una fuerte presencia educativa en la parafernalia política retórica: los cruzados a que hace alusión el himno y que será utilizado como enlace histórico justificativo para el alzamiento y la guerra civil por las fuerzas tradicionalistas y la Iglesia.

La inclusión del Himno de la legión se debe sin duda al reconocimiento que se hace así de las primeras tropas que participaron en el Alzamiento de Franco, ya que en ese momento era general del Tercio en África. Auténtico canto apologético de la violencia, el valor, el sacrificio, la vida militar más belicosa y azarosa, la heroicidad anónima, el amor a la bandera como símbolo de la Patria, el olvido del pasado anterior a la vida militar, el ensalzamiento del sufrimiento, la desesperación, la superación del miedo y la obsesión por la victoria y la muerte. Es un claro resto de la heroicidad y la locura belicista, de la consigna de "vencer o morir", propia de la época de la guerra, pero poco llevadera después de la misma, excepto como una postura de homenaje y un ensalzamiento de los valores masculinos: valentía, sacrificio, desprecio de la propia vida, lealtad, temeridad.

Es el primero, pero no el único de los himnos de origen militar que va a utilizar Falange en su carácter de formación premilitar de la juventud.

Otro caso singular es el del Himno nacional. Al declarar Franco como tal la Marcha Real de Granaderos (con harto disgusto de los sectores más poderosos de Falange), se busca la manera de imprimirle un carácter más afecto al 


\section{Capítulo 4. Música e ideología 1. Frente de J uventudes}

régimen, y para ello se crea y se divulga una letra en la que se vuelve a insistir sobre algunos de los "topics" del discurso falangista: el iluminismo (el caminar del sol), el saludo fascista, la Patria, el triunfo, los yunques, la vida nueva de trabajo y de paz. La religiosidad y el catolicismo aparece también en la alusión a los nuevos himnos de fe. A pesar de todo, esta letra nunca llegó a tener carácter oficial, aunque sí gran difusión, precisamente a través de la labor educadora de Falange en la enseñanza de Formación política escolar.

Todos estos himnos había que escucharlos y cantarlos con "respeto y emoción", siempre en postura de firmes, de pie, y con el saludo de la mano en alto.

No es éste el caso de Prietas las filas, que aparece recogida en la versión electrónica de la editorial Doncel como el himno de Frente de Juventudes desde sus primeros tiempos. Con letra de Joaquín Villanueva y música de A. Cabañas, fue sin duda el himno más conocido por los jóvenes de esta época y probablemente entonado casi siempre acompañado de movimiento de desfile, con carácter más dinámico. Está llena de alusiones al Cara al sol como un referente de comportamiento e ideal político. Recoge algunas de las primeras reivindicaciones Consistas como la consigna "Patria, Justicia y Pan". Es una canción posbélica, con el reconocimiento a los caídos falangistas y que da por conseguidos los logros que proclamaba el himno joseantoniano: ya las banderas cantan victoria al paso de la paz, las rosas-flechas florecen. Y plantea también nuevos retos para las nuevas generaciones juveniles: la perfección en la ejecución de la formación premilitar (que da origen al título), la búsqueda del "imperio", la idea de futuro ideal inmediato hacia el que marchan las escuadras.

La propia edición electrónica de Doncel dice que fue recogida por primera vez en el Cancionero "Himnos y canciones" de 1942.

\subsection{1.d Algunas reflexiones sobre las canciones de la primera época}

¿Y qué pasa con el resto de las canciones de este repertorio que no son las obligatorias de la asignatura de Formación cívico-social o de Formación del Espíritu Nacional (FEN) como se llamó más tarde? Es difícil establecer una 


\section{La educación musical en el franquismo}

norma. Muy probablemente, algunas de ellas eran enseñadas por los propios maestros a los niños, con el fin de ensalzar los valores patrióticos y afianzar el adoctrinamiento político. Sin embargo, la mayoría de ellas eran más bien aprendidas, entonadas e interpretadas acompañando a los desfiles ligados a la vida extraescolar y a la educación no formal. Hay que recordar que Frente de Juventudes también inicia en esta época la que luego se convertirá en su actividad principal hasta nuestros días: tiempo libre y ocio, en la que sobre todo destacan el montañismo y los campamentos. Es en este contexto, una vez finalizada esta primera época donde pervivirán con una cierta utilidad las marchas y los himnos, con el fin de crear un ritmo dinámico de movimiento y un espíritu identificador como colectivo.

Y también están ya presentes las canciones de otro tipo no tan ligado a la vida premilitar, especialmente folklóricas. Aunque en este momento juegan un papel cultural secundario para el sector masculino del Frente de Juventudes, para Sección Femenina - como veremos - constituyen el centro de su actividad cultural y formativa. Aún así, tenemos constancia de que en el manual de Jefe de Centuria (1943) aparecen 28 canciones regionales provenientes de Navarra, León, Andalucía, Castilla, Aragón, Cataluña y Murcia. Y según hace constar Manuel Parra Celaya ${ }^{\mathbf{1 4 6}}$ en el Programa de Educación Musical de 1943 y 1944 aparecen textos en vasco, catalán y gallego.

Manuel Rodríguez ${ }^{\mathbf{1 4 7}}$ en el Cancionero juvenil ya expone que se trata de "un cancionero para la soledad y la camaradería, para el gozo y la adversidad, para lo serio y lo humorístico, para la escuela y la calle, para el reposo y el avance, para la marcha y el campamento, para la casa y el cuartel, las aulas y las trincheras". Es decir, que en este período hay un constante convivir sin fronteras entre los ámbitos escolar y extraescolar, entre la actividad del frente de Juventudes dentro del aula y en las actividades de ocio, entre la educación formal y no formal, ya que las actividades formativas de los campamentos y de

\footnotetext{
${ }^{146}$ PARRA CELAYA, M. "Pedagogía de la canción". En España es mi canción en edición electrónica de la editorial Doncel. http://www.rumbos.net/cancionero/oedag_c.

${ }^{147}$ RODRÍGUEZ, M. (1947) Cancionero juvenil.
} 


\section{Capítulo 4. Música e ideología 1. Frente de J uventudes}

la formación premilitar eran tenidas por parte de la formación escolar y vital de la juventud (de carácter obligatorio y organizadas desde la propia escuela).

Tan grande era la presencia de las canciones que Cesáreo J arabo J ordán ${ }^{\mathbf{1 4 8}}$ en su tesina sobre las actividades de ocio y campamentos de Frente de Juventudes dice que

"El Frente de J uventudes no puede ser entendido sin la canción".

Tanto es así que en la Instrucción de 20 de febrero de 1942 (Boletín del Movimiento no 140) se instituye el "Día de la canción" asociado a los actos de celebración del Día de la Victoria del 12 de Abril, lo que representó según Manuel Parra Celaya ${ }^{149}$

"una institucionalización de la canción como elemento propio. Así, los concursos de canciones, los coros, la promoción del cántico, traspasaron el estrecho marco de los campamentos y cuarteles para adoptar dimensiones provinciales y nacionales".

La revista Mandos incluía en cada número la letra y música de una canción, así como aportaciones para el acompañamiento con algunos instrumentos (armónica, guitarra).

El Manual del Jefe de Centuria de 1943 establece que los mandos deben conocer, además de los Himnos de la Falange y del Frente de Juventudes, seis canciones de marcha de música y letra españolas (lo que indica que además circulaban popularmente otras con origen extranjerizante, probablemente alemanas e italianas), los jefes de grupo cuatro y los de escuadra por lo menos dos.

Y en el material musical que se divulgaba a través de Frente de Juventudes, no sólo había canciones propias (21, fundamentalmente himnos y marchas), sino que en el cancionero adjunto a dicho Manual del Jefe de Centuria de 1943,

\footnotetext{
${ }^{148}$ J ARABO J ORDÁN, C. Los campamentos del Frente de Juventudes. Tesina de licenciatura. Barcelona: Universidad de Barcelona

${ }^{149}$ PARRA CELAYA, M. "Pedagogía de la canción” En España es mi canción en edición electrónica de la editorial Doncel. http://www.rumbos.net/cancionero/pedag_c.
} 


\section{La educación musical en el franquismo}

aparecen 28 canciones regionales. Y también un gran trasvase de otros orígenes: de la guerra, extranjeras adaptadas, himnos militares. Nos consta además que se realizaron varios cancioneros, como el Cancionero de las 00JJ de Asturias de 1940 y el Programa de Educación Musical de la Delegación provincial del Frente de Juventudes de Barcelona (que en realidad está realizado y dirigido por Sección Femenina, todavía no separada del Frente de Juventudes), pero casi todos ellos han desaparecido o están guardados en colecciones particulares de difícil acceso.

Las fuentes originales principales para conocer el material musical de esta época son:

Cancionero de las O0JJ de Asturias (1940)

Himnos y canciones (1942: Madrid)

Canciones para marchas y campamentos (1942)

Manual del J efe de Centuria (1943)

Marchas y montañismo (1943)

Mil canciones españolas (1943)

Cancionero falangista (1945)

La revista Mandos

Manuel Parra Celaya analiza algunas de las canciones de esta primera época.

Por una parte, analiza los rasgos ideológicos que caracterizan esta primera época como el llamado componente jonsista, en el que destaca:

- La invocación a las juventudes 


\section{Capítulo 4. Música e ideología 1. Frente de J uventudes}

- El mundo carece de "justicia, belleza, Dios" y sólo la alternativa española puede devolvérselos

- Los dos temas de nacionalsindicalismo: nación y lo social,

- El pasado no como inmovilismo de la tradición, sino para emularlo

- Carácter revolucionario inicial

- Leitmotiv antimonárquico

- Lema: "No parar hasta conquistar"

Como claros ejemplos de este tipo de pensamiento, latente en el protocancionero falangista, anterior en muchos casos a la fundación de la propia Falange como tal el 4 de marzo de 1934, destaca el Himno de las Falanges de Combate (1931) con letra de Juan Aparicio y música de José Guerrero Fuensalida, también conocido como Himno de las Viejas JONS, el Isabel y Fernando (marzo de 1934), considerado como el Himno de las JONS vallisoletanas.

Ya en la etapa de Falange plenamente establecida, aparecen nuevos rasgos como el marcado antimarxismo de Amanece para mí (1935) o el Himno de las Milicias andaluzas de Falange.

La influencia del Cara al sol, con letra de José Antonio y música de Juan Tellería se extiende por todo el cancionero de la primera época de Falange. La exaltación de la figura del fundador, a raíz de su muerte en Alicante antes de que terminara la contienda civil, aprovechada por Franco para hacerse con el poder y autoproclamarse J efe del partido, convierten el texto en una fuente de la que beben los nuevos textos, con constantes alusiones a sus metáforas e imágenes: la novia, la muerte, el servicio heroico, los caídos, los luceros, el símil de la primavera, la dualidad victoria-paz, la iluminación del sol como verdad, la camisa bordada, el nuevo amanecer, el yugo y las flechas transformadas en rosas.

Las alusiones a la guerra también son frecuentes y reiterativas, con un marcado belicismo: luchar, morir, coger las armas, espadas, el imperio. Se 


\section{La educación musical en el franquismo}

introducen canciones procedentes del frente, como Crucero Baleares, La batalla del Ebro, Al Pe Pri, Coplas de guerra o El alto de los Leones.

Las influencias extranjeras fascistas (alemanas e italianas) empiezan a hacerse patentes pronto en canciones como El camarada realizada sobre una canción original alemana, pero se intensificarán notablemente a partir de la introducción de las tropas españolas en otros frentes europeos por medio de la intervención de la División Azul: Himno de la división azul, Lili Marlen, Fidelidad.

\subsubsection{La segunda etapa. Desde 1945 hasta 1960}

La etapa que se abre en 1945 viene condicionada por la existencia de la nueva Ley General de Educación y la institucionalización del Frente de Juventudes (ya separado de Sección Femenina), como un actor participante en el sistema educativo entre áreas de conocimiento dentro de la vida escolar: la formación política, la educación física y la formación cultural y de tiempo libre de la población infantil y juvenil masculina.

Otra clara característica es el ensalzamiento de Franco y la creación de la figura del Caudillo. Un gran ejemplo de hasta dónde podían llegar las consecuencias de la más mínima discrepancia sobre el liderazgo incontestable del jefe del estado son los hechos que se produjeron el 20 de noviembre de 1955

\footnotetext{
"Franco acude a El Escorial por primera vez al funeral de José Antonio y lo hace vestido de Capitán General y no con el uniforme negro que por rango le correspondía como J efe Nacional de Falange. Las Falanges Juveniles de Madrid se dieron media vuelta al paso del generalísimo. Y ello supuso la destitución fulminante de José Antonio Elola, Delegado Nacional del Frente de Juventudes desde 1941,ya que, como lo narra Franco Salgado-Araujo ${ }^{150}$ supuso un auténtico escándalo que "unos imbéciles que deben dar ejemplo de disciplina y sostener el Estado hagan propaganda contraria el pensamiento de Franco"
}

\footnotetext{
${ }^{150}$ FRANCO SALGADO-ARAUJ O, F. (1976) Mis conversaciones privadas con Franco. Barcelona: Planeta y (1977) Mi vida junto a Franco. Barcelona: Planeta
} 


\title{
Capítulo 4. Música e ideología 1. Frente de J uventudes
}

Respecto a las actividades organizadas por el Frente de Juventudes, la principal característica de esta época es la convivencia, especialmente a partir del desarrollo de las actividades de ocio y tiempo libre y campamentos, de los elementos de adoctrinamiento, que según Henar Herrero ${ }^{151}$

\begin{abstract}
"son aquellos en los que se ejerce una "influencia de forma volitiva, premeditada y explícita (...) en el que la educación se convierte en un instrumento de manipulación de las conciencias y de propaganda del poder establecido", con "los de transmisión ideológica del llamado "currículo oculto", de carácter menos consciente, involuntario o por lo menos, implícito de intervenir e interferir en el proceso educativo, más vinculado con el dominio de las mentalidades que con el de las ideologías, y probablemente, más inocente o menos agresivo - por cuanto puede no sugerir de la intencionalidad -, pero desde luego, en absoluto inocuo o inofensivo"
\end{abstract}

\subsection{2.a Los cursos para maestros y el espíritu de campamento}

Los cursos de maestros se empiezan a organizar con más seriedad y Frente de Juventudes incluye siempre en ellos un repertorio de canciones. Pero parecen impregnarse del sentido de ocio y de campamento que tiene la propia formación recibida en período vacacional.

\section{Cruz Orozco considera que}

"la situación de provisionalidad de los cursos de formación de maestros se puede dar finalizada con la aprobación en julio de 1950 del "Reglamento para las Escuelas del magisterio" que desarrollaba los planes de estudio de la ley de 1945, y que "supuso el espaldarazo definitivo para mejorar la presencia del Frente de Juventudes en los centros de formación de maestros". A partir de 1950, los responsables de la política de juventud contaron con una presencia constante en todos los cursos de Magisterio, además de ampliar el número de horas totales: Se pasaron de las dos horas semanales de Formación del Espíritu Nacional en tercer curso, previsto en el plan de estudios de 1945, a tener presencia en los tres cursos, con 2, 1,30 y 1 horas semanales. Y además en el artículo 31 de dicho Reglamento se señala la "obligación de cursar con

\footnotetext{
${ }^{151}$ HERRERO SUÁREZ, H. (2007) Un yugo para los flechas. Educación no formal y
} adoctrinamiento infantil en Flechas y Pelayos. Lérida: Milenio 


\section{La educación musical en el franquismo}

aprovechamiento un turno de campamentos o albergues organizado por el Frente de Juventudes".

Esta obligación era absolutamente novedosa en el contexto del plan de estudios, ya que ninguna otra asignatura contemplaba este tipo de enseñanzas prácticas fuera del recinto educativo. Con ello,

\footnotetext{
“además de intentar efectuar un planteamiento pedagógico lo más eficaz posible, los dirigentes del Frente de Juventudes buscaban reforzar los lazos con el magisterio, guiados siempre por la necesidad de contar con colaboradores eficaces para propagar sus actividades entre los niños y los jóvenes españoles"
}

Los campamentos de los años50 y 60 tuvieron prácticamente el mismo plan de trabajo que los anteriores, pero tenían la novedad de trasladar el entrono tradicional de las aulas a ubicaciones al aire libre.

Con todo, había que adaptarse a las posibilidades y recursos reales que podía ofrecer el Frente de juventudes, siempre menores que la totalidad del número de estudiantes que había que capacitar como instructores elementales. Por ello se desarrollaron, además de la forma habitual de campamento a final de curso en el inicio del período estival específico para maestros, otras soluciones: campamentos volantes llamados "marcha por etapas", otros cursos para formación de personal afiliado del Frente de Juventudes, participar como mandos mayores o auxiliares en los campamentos provinciales ordinarios e incluso un "turno nacional" para aquellos alumnos que no habían logrado obtener plaza en los cursos que organizaba la delegación de su provincia, así como turnos especiales para las convocatorias extraordinarias de exámenes, ya que era requisito indispensable para la obtención del título de maestro. Como ejemplo, en 1961 habían acudido a los turnos un total de 3.182 alumnos de Magisterio, de los cuales $1.706(53,62 \%)$ habían obtenido el título en campamentos provinciales, mientras los $1.476(46,38)$ restantes habían tenido que obtenerlo en el resto de tipos de convocatorias. Ello demuestra que las Delegaciones provinciales no eran capaces ni mucho menos de satisfacer las demandas legales y se requería un enorme esfuerzo de los organismos 


\section{Capítulo 4. Música e ideología 1. Frente de J uventudes}

centrales, con lo que la imagen del Frente de Juventudes a mediados de los años 69 y de las materias que tutelaba, fueron sufriendo un fuerte deterioro entre las nuevas generaciones de maestros. La poca eficacia de la burocracia interna del Frente de Juventudes, y la frecuente falta de entendimiento real entre los organismos centrales y las delegaciones provinciales que tenían que ejecutar las tareas encomendadas contribuyó a que se recurriera a soluciones improvisadas que facilitaban que la casuística entre los diferentes campamentos fuera muy variada y con poca unidad. La propia Delegación Nacional del Frente de Juventudes recoge en un esquema de una reunión celebrada en Madrid el 17 de marzo de 1961 que

\footnotetext{
"espera poner orden en la manera despreocupada y anárquica con que algunas Delegaciones han permitido que se desenvuelva la asistencia campamental de los alumnos de Magisterio"152.
}

El control sobre el profesorado y el temario de la asignatura de Formación político-social era totalmente responsabilidad del Frente de Juventudes, y así se consiguió introducir personal del Frente como profesores en las Escuelas del Magisterio, si bien como profesores especiales

Se distinguen claramente dos períodos diferenciados en esta etapa:

- Los años de reconstrucción de la posguerra, el aislamiento internacional, la autarquía

- Los años de apertura inicial y el positivismo

Con la separación de Frente de Juventudes y Sección Femenina, se hace aún más patente que los primeros no pretenden hacer explícitamente una formación musical, sino un medio de transmisión de valores. De hecho, a partir de este momento su presencia educativa figura siempre referida únicamente a la educación política (en la que se supone que se inscribe el aprendizaje y repetición de canciones de alto contenido ideológico) y a la educación física. Para el Frente de Juventudes, la música es un elemento de formación indirecta

${ }^{152}$ Citado en CRUZ OROZCO , J.I. (2001). El yunque azul. Madrid: Alianza. Pag. 132 


\section{La educación musical en el franquismo}

que mejor no hacer demasiado evidente, sino seguir manteniéndolo como algo de carácter lúdico. Pero no nos engañemos, detrás de ello hay una auténtica intencionalidad de transmisión política e ideológica. Son conscientes de su valor como elemento de primer orden que aporta disciplina y cohesión al grupo, tal como lo expresa José de Arriaca ${ }^{\mathbf{1 5 3}}$ en la primera gran publicación del Cancionero de Juventudes en 1967 para la editorial Doncel:

\footnotetext{
"la juventud, reunida en torno a una bandera y encuadrada en filas uniformes no puede cantar más que al compás de su marcha al unísono, con canciones fuertes y exponiendo las viejas ambiciones y deseos".
}

El número de canciones de campamento aumenta notablemente y los temas del amor, la reconstrucción, la revolución como ideal falangista especialmente encargada a los jóvenes, el deber, el ensalzamiento de la figura de Franco, la identificación de las diferentes unidades, las reivindicaciones sobre Gibraltar, la grandeza de la "nueva" España, la necesidad de sacrificio y la grandeza de la tarea a realizar, se convierten en los principales temas de las nuevas canciones.

Así lo expresa en Arriba el periodista Enrique de Aguinaga el 30 de mayo de 1950 cuando dice que

“Junto a la hoguera, en la caminata, o simplemente cara al sol, cantábamos a la Patria. La canción es así pluralidad, es "nosotros". Y nosotros éramos la juventud generosamente unida, sin distingos folklóricos, sin reparaciones sociales... Todos contribuíamos a que una sola y fuerte voz estremeciese los campos con el nombre de España y aquello otro que, metido en el corazón y en la cabeza, se hacía fácil estrofa. En la alegría de nuestra canciones hemos aprendido de memoria el orgullo de la Patria"

Manuel Parra Celaya afirma que

"afirmación, alienación, catarsis, vehículo de unidad y disciplina... Quizás todo ello fue la canción en el Frente de Juventudes."

Esta época es en la que el Frente de Juventudes se expande y desarrolla por todo el Estado como única organización juvenil reconocida, articulada a partir

${ }^{153}$ ARRIACA, J.J. (1967) Cancionero de Juventudes. Madrid: Doncel 


\section{Capítulo 4. Música e ideología 1. Frente de J uventudes}

de unas relaciones peculiares y privilegiadas con el sistema educativo y poseedora de una dualidad presencial como educación formal y no formal de límites muy difusos.

\subsection{2.b Las escuelas del Patronato del Frente de J uventudes}

Un gran ejemplo de ello es la creación de las Escuelas de Patronato del Frente de Juventudes que ha estudiado Cruz Orozco ${ }^{\mathbf{1 5 4}}$. Efectivamente, la ley de Educación de 1945 contemplaba tres tipos de escuelas: nacionales, de la Iglesia y de patronato. A petición del propio ministerio de Educación y en un intento de colaborar en la campaña contra el analfabetismo, se crea el Patronato Escolar Primario del Frente de Juventudes mediante la Orden de 9 de julio de 1951 (BOE de 20 de julio). La intención era aumentar el número de plazas escolares, para lo cual la Delegación del Frente de Juventudes colaboró cediendo locales y terrenos para la construcción de escuelas, así como la dotación de profesorado. Dichos profesores debían estar en posesión del título de maestros y del de instructor del Frente de Juventudes, pero además su contratación era directamente controlada por el Patronato, con lo que se aseguraba su mayor cercanía ideológica y su ajuste a las pautas de enseñanza de Falange, el llamado "estilo falangista". Su selección por concurso tendría en cuenta como méritos destacados los servicios políticos prestados al Movimiento y la colaboración con el Frente de Juventudes. Para ello reorganizaron algunos aspectos del currículum con la finalidad de influir en la educación de los alumnos, especialmente en lo referente a la formación política. Los modelos organizativos que empleaba el Frente de juventudes en sus actividades de educación no formal, fueron llevadas estas escuelas, desarrollando así los objetivos de socialización política a través de la responsabilidad en el ámbito de la educación formal, reforzando las actividades que ya se realizaban fuera de las aulas y aprovechando la eficaz complementariedad de ambas plataformas de intervención. Eran el paradigma de lo que a Falange le hubiera gustado que fuera la colaboración del Frente de Juventudes con el sistema escolar, no conformándose solamente con la formación extraescolar de los maestros como

\footnotetext{
${ }^{154}$ CRUZ OROZCO, J I I (2001) El yunque azul. Frente de Juventudes y sistema educativo.
} Razones de un fracaso. Madrid: Alianza 


\section{La educación musical en el franquismo}

instructores y la elaboración de cuestionarios de formación política y educación física, que les parecía insuficiente. Ya en estos años y según nos vamos acercando a los años 60, el Frente de Juventudes tenía cada vez más problemas para conectar con importantes sectores de maestros (que se resistían a los cursos impuestos y que en realidad eran los que impartían la formación política en las escuelas primarias). El Frente de Juventudes pretendió con este tipo de escuelas ofrecer una alternativa con un estilo formativo propio muy marcado y mostrar su interés por tener una mayor presencia en el sistema educativo de los jóvenes. En estas escuelas se enseñaba el sistema premilitar que imperaba en la vida de campamentos como un sistema cotidiano de vida: uniformidad, izar y arriar la bandera, saludo, entonación de cánticos falangistas acompañando a casi todas las actividades, marchas al ritmo de himnos, actividades de coros sobre el repertorio falangista en las ocasiones festivas.

Pero nunca consiguieron tener sino Escuelas primarias con este sistema de Patronato, ya que las escuelas secundarias estaban mayoritariamente copadas por la educación religiosa (hasta los años 60 apenas habían sido creadas 3 nuevos institutos de Enseñanza Media en todo el Estado desde la guerra civil, frente al gran crecimiento de los centros de órdenes religiosas, los cuales eran radicalmente opuestos a la influencia de Falange en este sector del sistema educativo). De hecho, el control de Falange sobre los centros de educación secundaria durante estos años fue mínimo y sólo circunscrito a los centros estatales. Los centros religiosos contrataban a profesorado mayoritariamente formado en sus propias escuelas de Magisterio de la Iglesia, que obligatoriamente - habían cursado los complementos de formación para maestros de Falange, pero a cuya ideología eran francamente resistentes. En los centros de Enseñanza Media religiosos, estas asignaturas eran dejadas en manos de personal con resistencia a darlas de forma ideológica y en un plano muy secundario. Frente de Juventudes siempre se sintió dolido, pero nunca fue capaz de ofrecer profesorado titulado superior en las Escuelas Oficiales de Mandos para cubrir la docencia en todos los centros, por lo que aplicó su listado 


\section{Capítulo 4. Música e ideología 1. Frente de J uventudes}

de prioridades: primero los centros de Secundaria Públicos, luego los colegios de primaria públicos, y luego los centros privados.

En total, el patronato logró tener bajo su tutela 49 centros docentes, de los cuales 4 tenían consideración de colegios nacionales, 19 eran escuelas graduadas y 26 escuelas unitarias, extendidos en 19 provincias y 45 localidades. Contaba con 144 maestros y 5.845 alumnos al final de su período de existencia a finales de los años 60. $Y$ en todo caso no contaron nunca con presencia en Canarias, Baleares, Aragón, Navarra, Cantabria, Asturias o la Rioja. Aunque fue un intento de introducirse en los años 50 en el sistema educativo general, ciertamente fracasó como analiza José I gnacio Cruz Orozco. Nunca logró calar profundamente y en el fondo la educación que ofrecía tenía un carácter "excesivamente marcado", un estilo - en el sentido falangista de la palabra- demasiado militar y político. Conforme avanzamos en el tiempo y la política nacional va evolucionando hacia otros intereses y se aleja cada vez más de los ideales falangistas, mayor es su disfunción y más se alejan de la realidad social.

En ellas el repertorio musical falangista se entroncó dentro del sistema educativo formal. Fuera de este contexto, la formación musical masculina a nivel escolar sigue sin ser delimitada excepto por su presencia en la Formación del Espíritu Nacional.

\subsection{2.c El repertorio}

La división temporal de las canciones que realiza la edición electrónica de España es mi canción sigue siendo especialmente útil. Otra fuente musical de primer orden es el Cancionero Juvenil de Manuel Rodríguez, que incluye partituras y aparece en 1947, pero que todavía refleja, aunque catalogadas por temas, el tipo de canciones de la época inmediatamente anterior

España es mi canción (versión electrónica). 


\section{Período de 1945-1960}

España es mi canción. Tan popular, que dio título al que luego sería el cancionero de la OJE (a partir de 1960). Fue presentada en el campamento nacional para jefes de Falange rurales "Vigil de Quiñones", celebrado en febrero de 1945

Canción de las FF. JJ. De Franco. La letra es de Enrique Llovet y la música de Juan Tellería.

Con nuestro emblema

Saludo a las juventudes de Franco. Letra de Manuel Rodríguez y música de J. Torres. Apareció publicada en la revista Mandos

A la voz del capitán. La letra es de Calos Alonso del Real y la música de Juan Tellería. Está recogida en el Cancionero Juvenil de 1947

Tenemos un caudillo La letra des de J osé Antonio Medrano y la música de Félix Tellería. Cantada en el campamento "Ordoño II" y recogida en el Cancionero juvenil de 1947

Único capitán. Letra de Moreno Crespo y música de Félix Tellería. Fue cantada en masa por el campamento nacional "Francisco Franco" en su clausura con asistencia del J efe del Estado en 1954. Está publicada en la Revista Mandos

Surgirá el imperio. Todavía utiliza la melodía de una canción alemana Dem wir fahren gegen Engeland en alusión a ganar a los ingleses la reclamación de los territorios de Gibraltar, y muchos otros rasgos de la época anterior

Nuestro destino. Letra de Manuel Rodríguez y música de C. Clavel. Está recogida en el Cancionero juvenil de 1947 


\section{Capítulo 4. Música e ideología 1. Frente de J uventudes}

Mi camisa vieja vestiré. La letra es de Antonio Pedro Cuyas y la msuica de Félix Tellería. Aparece recogida en el Cancionero juvenil de 1947 como Canción de la guardia de Franco

Caminos abiertos. La edición electrónica de España es mi canción dice que apareció en el año 1947

Nuevo Gibraltar. La letra y la música son de Enrique Franco. Se cantó con motivo del "día de Gibraltar" y fue publicada en el Boletín de órdenes de la Delegación Nacional en 1951

iJ uventudes! iJ uventudes!. La letra es de José Antonio Elola (Delegado Nacional del Frente de Juventudes) y la msuica de Félix Tellería. Está recogida en el Cancionero juvenil de 1947

Curso de mandos. Es el himno del Curso de Jefes de Centurio de Madrid. Está recogida en un Cancionero Juvenil de bolsillo publicado en Granada en 1954

Campamento "Vigil de Quiñones". La letra es de Tomás Calvo Rubio y la música del maestro Del Campo.

Titán de España La edición electrónica de España es mi canción la fecha en torno al año 1948

La batalla del Ebro. Segundo gran éxito de Agustín Paíno tras ¡Gibraltar!, ;Gibraltar! Aparece impresa en unas Hojas editadas por la Delegación Nacional den 1953

Luceros. La letra es de Enrique LLovet y la m'suica de Enrique Franco. Fue encargada por José Antonio Elola en 1949 y dedicada al recién fallecido Juan Tellería. Existe una copia impresa en una Hoja de la Delegación nacional de 1952 
El dardo vivo de un quehacer. Es el himno de la Academia Nacional de mandos "José Antonio". La letra es de Daniel Pato Movilla y la música de Enrique Franco Manera. Fue grabada en disco por el coro de la academia en 1946, pero no apareció impresa hasta el Cancionero del Frente de Juventudes de 1963

Joven mando cursillista. Es una adaptación de la canción Arriba el corazón para los alumnos de los cursos de Mandos

Academia "Onésimo Redondo". Esta canción surgió dicha academia creada para la formación de instructores auxiliares rurales en 1946, en el curso celebrado en el Castillo de Belmonte. Está recogida en el Cancionero de juventudes de 1967

Covaleda. Canción del campamento "Francisco Franco" que se realizaba en esta localidad

Pregones de un imperio. Su música está tomada de unacanción tirolesa (todavía influencias de la época anterior y la División Azul). Está recogida en unas Hojas impresas publicadas en Granda en 1948

España, Franco y la cruz. Creada para el décimo aniversario de la creación del Frente de juventudes en 1950, aparece en el Cancionero de Valencia de 1953

Décimo aniversario. Al igual que la canción anterior, fue creada para los actos de conmemoración de la creación del Frente de Juventudes. También está recogida en el Cancionero de Valencia de 1953

Himno a San Fernando. Himno al patrón de la juventud y muy específicamente del Frente de Juventudes. Aunque aparece recogido en el Cancionero de Valencia de 1953, su uso se generalizó especialmente a partir de 1960 en la OJ E

Himno de la centuria "Cid Campeador". Este himno aparece en un Cancionero de bolsillo publicado en 1953 por la Sección de Enseñanza del Frente de 


\section{Capítulo 4. Música e ideología 1. Frente de J uventudes}

Juventudes de Vizcaya (de donde es originaria dicha centuria) con motivo del “Día de la canción” de dicho año.

Falanges de Granada. Está recogida en el Cancionero juvenil de bolsillo de Granada en 1954

Garra hispánica. La letra es de Francisco Soto Rodríguez y la música está tomada de una canción italiana Giovenezza. Se cantó en el campamento de verano instalado junto al balneario de Lanjarón

Falanges de Marruecos. La letra de esta canción fue proporcionada en versión oral por J.L. Taboado en 1954, para su publicación posterior en el Cancionero de juventudes de 1967

Centuria "Gran capitán". Es el himno de la centuria de El Ferrol del Caudillo

Centuria "Churruca". Es el himno de la centuria de Albacete

\section{Cancionero de Juventudes de José de Arriaca}

J osé de Arriaca establece una temporalización diferente, abarcando como una segunda etapa diferenciada toda la producción desde 1956 hasta 1965 (hay que recordar que su publicación es contemporánea a la época y que se realiza en 1967, con lo que sólo se refiere a esa época y que realiza su análisis desde una visión interna del Frente de Juventudes y no tanto desde una perspectiva global). Para él, el evento que marca una nueva orientación política fundamental - aunque no se refleje desde el punto de vista educativo que es al que nosotros damos prioridad hasta unos años más tarde - es la incorporación de España a la ONU en 1955, lo que significa una nueva época de apertura ideológica dentro del franquismo.

De 1945 a 1955 


\section{La educación musical en el franquismo}

Para él la etapa de 1945 hasta 1955 se caracteriza por la organización campamental, en lo que califica de "España a la intemperie". Ciertamente la actividad física al aire libre se convierte en la fuente principal de ingresos y de presencia de Falange a nivel infantil y juvenil. Los desfiles y marchas de propaganda política dan paso a las marchas juveniles en pantalón corto y botas de montaña, con las mochilas a la espalda y a las concentraciones en tiendas de campaña y albergues, preferentemente en zonas rurales y de montaña. Siguen paseando las camisas azulas y las boinas rojas pero ahora parece más una ropa adecuada para el ejercicio físico que un uniforme militar. El Frente de Juventudes se va transformando cada vez más en una organización juvenil de tipo civil y pierde sus connotaciones militares asociadas a la guerra civil.

Igualmente, el repertorio de canciones se va alejando de las reminiscencias belicistas 0 de las imágenes jonsistas originales (exaltación de la muerte, importancia de la victoria, caídos en la guerra transformados en estrellas) y va a girar en torno a nuevos temas: la lealtad a Franco, el desarrollo de la Organización de Juventudes, el SEU, el destino de España en el mundo. El momento culminante de esta transformación ideológica en el repertorio musical se plasma para Arriaca en el Concurso de canciones y marchas convocado por la Delegación nacional en 1945, en el que las diferencias conceptuales de los contenidos son evidentes. Aunque el primer premio quedó desierto y el 20 y el 3o se distribuyeron en seis canciones, las canciones premiadas aluden a elementos más poéticos y sentimentales como en Yo seré para tus ojos.

Así destaca algunas canciones del SEU como Juventud del SEU, Juventud estudiante, Unión juvenil, Camino del sol

De tema de lealtad al Caudillo como ;Alhucemas!, Victoria, $A$ tus órdenes, $A$ la voz del capitán, Tenemos un Caudillo, Al aire los guiones y Único capitán.

Sobre las reclamaciones territoriales españolas aparecen canciones como Gibraltar tierra irredenta, Gibraltar español, Gibraltar, Castilla por Gibraltar, Nuevo Gibraltar 


\section{Capítulo 4. Música e ideología 1. Frente de J uventudes}

Respecto a la hispanidad y el destino universal e imperial destacan la Canción de las F.J.F., il uventudes juventudes!, Campamento "Vigil de Quiñones", Titán de España, La batalla del Ebro, Pregones de imperio, El dardo vivo de un quehacer

Otro tema emergente es la importancia de las marchas montañeras y de las canciones para el fuego del campamento, que se añaden a las tradicionales folklóricas, como Olarí, Pasión juvenil, Vale quien sirve, Marchad, Guarda tus penas, Covaleda

\subsection{2.d Algunas reflexiones sobre esta etapa 1945-1960}

Estamos asistiendo a los años centrales de la influencia del Frente de Juventudes sobre la juventud española.

Perdida la segunda Guerra Mundial, se desvanecen los elementos más "fascistas" del Frente de Juventudes, dando paso a un nuevo tipo de repertorio menos ideológico y más centrado en las actividades de tiempo libre y ocio, especialmente el montañismo y los campamentos.

Según el análisis de Manuel Parra Celaya en esta etapa predominan los temas que se relacionan con el sentido de camaradería y el grupo (escuadra, centuria), invitación al servicio, la importancia de la transmisión de lo aprendido, la juventud como encargada de la revolución, el amor como quehacer, evocaciones a la antigua Falange de la que son continuidad, un sentido más poético y menos violento, y sobre todo, aparece con gran importancia el tema de la loa a Franco y la figura personal del caudillo. No es de extrañar, ya que la sección de voluntarios de la propia Organización Juvenil se llaman "Falanges J uveniles de Franco".

En este contexto, la formación que va a ofrecer el Frente de Juventudes da un giro hacia la consideración de la importancia de las actividades culturales, que adquieren preeminencia mientras las de orden premilitar van desapareciendo hasta dejar de existir. Excepto formalmente en los actos 


\section{La educación musical en el franquismo}

públicos, desaparecen los desfiles uniformados, los saludos militares y los rituales de izar y arriar banderas. Este tipo de actos sólo se conserva en las Escuelas de Patronato del Frente de Juventudes.

Para el resto de la influencia escolar del Frente de Juventudes, se hace cada vez más evidente la necesidad de abordar una reorientación de los objetivos hacia la cultura y en todo caso hacia la transmisión de contenidos ideológicos menos evidente e intencionada. Según avanzamos en el tiempo y vamos pasando a mediados de los años 50, nos vamos encontrando con más transmisión ideológica y menos adoctrinamiento.

Para reflejar esta transformación, dentro del desordenado y caótico material de Frente de Juventudes que se conserva en el Archivo General de la Administración he de destacar el siguiente texto de Formación de dirigentes sociales ${ }^{155}$ por su significación documental en este proceso de transformación:

\footnotetext{
"Dentro de las actividades a desarrollar en una escuela, ocupan un puesto muy importante las actividades culturales. Junto al desarrollo del vigor y de la creación de un espíritu político-social, el papel de la cultura viene a ser el aglutinante de la más clara manifestación del afán de amplios horizontes que la juventud posee.
}

Son muchísimas las actividades de tipo cultural que pueden realizarse en la escuela. Unas llevan el fin implícito en sí mismas y buscan una elevación estética del muchacho; otras son mejor instrumento para causar mayor impacto formativo dentro de la educación general. Todas ellas tienen facetas importantes en cuanto a la formación, tanto de la personalidad y el carácter del joven como en cuanto a la formación de su espíritu social.

a).- En cuanto a la formación de su personalidad y carácter

1o. La influencia más visible de las actividades de este tipo en la personalidad del muchacho, se da en cuanto a la formación de su sentido estético. Los murales, las obras de títeres, los concursos de dibujo, los recitales etc., deben de ir conformando y elevando la apreciación de la belleza por parte del chico.

\footnotetext{
${ }^{155}$ Archivo General de la Administración. Documento sobre Formación de dirigentes sociales. Delegación nacional de Juventudes. Departamento de Formación. Caja 1557
} 


\section{Capítulo 4. Música e ideología 1. Frente de J uventudes}

2‥ En segundo término. es importantísimo del instrumento que pone en nuestra mano sus posibilidades en cuanto al desarrollo del ingenio, de la fantasía, de la capacidad expresiva, que ayudarán siempre a la formación de la personalidad del chico y al descubrimiento de un mundo de satisfacciones espirituales que le compensará ampliamente.

3‥ De igual forma, este tipo de actividades, bien dirigido, puede dar lugar fácilmente al desarrollo de una confianza en sí mismo por parte del muchacho y ser configuradores de su carácter al hacer que, chicos introvertidos o simplemente retraídos, tengan que representar en público o exponer su obra a la crítica de los demás.

4․ También exigen estas actividades paciencia y continuidad en el esfuerzo y, por ende, sacrificio constante en el trabajo. Los métodos de trabajo dejan una profunda huella espiritual que viene a formar parte del "status individual".

5o. Por último, este tipo de actividades puede llevarnos a descubrimientos interesantes dentro del campo vocacional. Estos descubrimientos facilitarán, de manera notable, la utilización de aptitudes, y la posibilidad de ofrecer a la sociedad los hombres más preparados dentro de este campo. Es importante que ningún valor artístico, por pequeño que sea, se malogre dentro de la comunidad cultural de nuestro país.

\section{b) En cuanto a la educación social}

En estas actividades, como en otras muchas, el trabajo en equipo, la cooperación, la necesidad de una autoridad y de una dirección crean hábitos instintivos en el muchacho, siempre y cuando estas actividades estén controladas y dirigidas por un buen educador.

Es necesario hacer hincapié en un enorme peligro: el divismo. La figura del "Jaimito", del niño prodigio, es siempre nefasta, tanto desde el punto de vista personal como desde el social. Nunca el maestro deberá alentarla ni apoyarla, por grandes que sean las dotes del educando. El educador deberá recordar siempre "la parábola de los talentos", exigiendo más a aquel que pueda dar más y apoyando amorosamente a aquel cuyas dotes naturales sean inferiores

\section{Las actividades culturales como instrumento}

Si este tipo de actividades tiene importancia en sí mismo, se acrecienta aún más en cuanto, por lo general, son un instrumento idóneo para la educación de facetas concretas del muchacho. 


\section{La educación musical en el franquismo}

Así, a través de los murales, podremos hacer entrar por el camino fácil de la vista, en la mente del muchacho, ideas abstractas de tipo político, histórico, científico, religiosos, etc. A través de obras de títeres o lecturas teatrales podremos llevar siempre a la mente del educando la exaltación de virtudes conformadoras del carácter. A través de colecciones filológicas podremos despertar en el chico la curiosidad científica desarrollando el hábito de la paciencia y la continuidad en el esfuerzo. A través de trabajos manuales pondremos a prueba la destreza del muchacho y despertaremos posibles vocaciones técnicas. A través de los coros podremos despertar afición por la música, habituando el oído a la vez que llevarnos hacia un conocimiento del folklores, de las costumbre naciones y del idioma con toda la rica gama de matices que se presente en el variado panorama hispánico.

$\underline{\text { Importancia y responsabilidad del educador en este aspecto }}$

Hemos visto hasta aquí cómo este tipo de actividades tienen una cierta importancia en sí misma y cómo, todas ellas, son fáciles instrumentos para nuestra misión educativa. Pero también es cierto que como toda actividad educacional encierra en sí misma cierto peligro.

Es indudable que una de las facetas de la cultura de un pueblo es su sensibilidad estética y esta sensibilidad es algo que se forja en las primeras edades del hombre. De ahí que todas estas actividades deben estar previstas siempre y encauzadas hacia la consecución de una mayor gusto en la nueva generación. El educador debe de preocuparse de la gama de colores y de la disposición de los dibujos de un mural (la plástica entra siempre por la vista), de la calidad literaria de una lectura, de la poesía de una obra de títeres, etc. con la seguridad de que, sólo por este camino práctico, conseguirá elevar el nivel estético de los muchachos, elevación que difícilmente podrá conseguir por un camino memorístico.

En estas, como en todas las demás actividades volveremos a hacer hincapié en la necesidad de encauzar la originalidad del muchacho sin coartarla en aspecto alguno. Hemos de ser muy objetivos en este campo, huyendo siempre de todo subjetivismo que imponga un pie forzado a esta originalidad. La belleza es un valor, y como todo valor es objetivo.

Como vemos, es un texto, que aunque extenso, muestra muy bien la preocupación del Frente de Juventudes por reorientar la educación que da a los jóvenes, especialmente en el campo cultural que tiene asignado por la ley. $Y$ 


\section{Capítulo 4. Música e ideología 1. Frente de J uventudes}

aún más específicamente de la importancia que tiene en este nuevo contexto la figura del profesor o instructor en el ámbito de la escuela.

Aunque se habla de una enseñanza con margen para la creatividad, la fantasía y la pluralidad expresiva, no son éstas en si mismas las finalidades que busca, sino su utilización como un instrumento para forjar la personalidad de los niños y los jóvenes dentro de los pilares ideológicos del franquismo: religiosidad, tradición, disciplina y obediencia.

Los beneficios de la educación artística parecen ser un enriquecimiento espiritual que afecta a la estabilidad personal y deben ser promovidos en aras del bienestar social de la colectividad, dejando un margen más amplio al desarrollo de la personalidad del individuo.

Otro de los documentos del Archivo General de la Administración nos permite obtener unos datos fiables sobre algunas de las actividades de la actividad musical del Frente de Juventudes en $1953^{156}$. En el Resumen estadístico de actividades del Frente de Juventudes de 1953 constan las siguientes referidas al servicio de música:

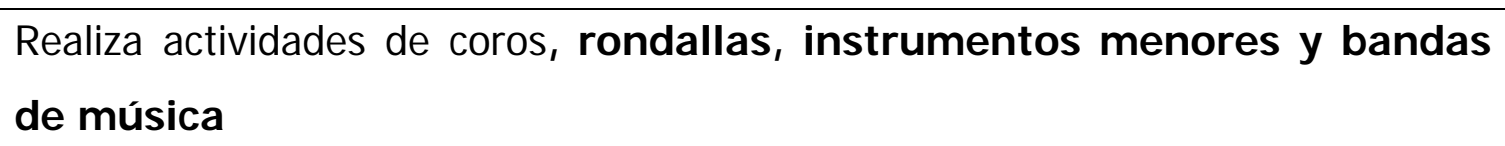
de música

Coros que existen............................ 70

Número de voces...................................70 a 90

Voces de coro de Madrid....................1.000

Número de camaradas que forman estos coros.....................7.500

RONDALLAS

\footnotetext{
${ }^{156}$ Archivo General de la Administración. Resumen estadístico de actividades del Frente de Juventudes (1953) Caja 1557
} 


\begin{tabular}{|c|c|}
\hline & 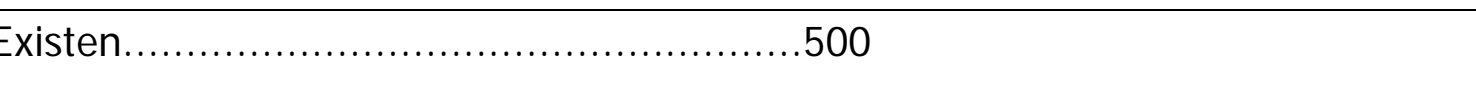 \\
\hline & Vúmero de camaradas..........................9.000 \\
\hline & De nueva creación...................................24 \\
\hline & Camaradas que las forman ....................28 \\
\hline & Partituras repartidas en provincias..........3.700 \\
\hline & Vúmero de ejemplares enviados a cada una............52 \\
\hline & NSTRUMENTOS MENORES \\
\hline & Adquisición anual aproximada......................600 \\
\hline & Armónicas distribuidas.......................... 7.500 \\
\hline & Escuadras de instrumentos menores...........500 \\
\hline & BANDAS DE MÚSICA \\
\hline & Existen.................................................... \\
\hline & Vúmero de camaradas.................................480 \\
\hline & $\begin{array}{l}\text { Se gestionó un permiso de importación de instrumentos de música ahorrando el } \\
40 \%\end{array}$ \\
\hline
\end{tabular}

Como vemos, se centra en las actividades corales e instrumentales, no escolares, sino probablemente vinculadas a los Hogares del Frente de J uventudes. Pero es un dato a tener en cuenta la presencia de coros, bandas y rondallas. La enorme cantidad de las últimas y la poca presencia de las bandas de cornetas implica que ya casi no se realiza música de tipo militar. Parece evidente que es mucho más popular tocar guitarras, bandurrias 0 


\section{Capítulo 4. Música e ideología 1. Frente de J uventudes}

armónicas. Esta tendencia, desde luego, irá en incremento según avanzan los años 50 y a lo largo de toda la etapa posterior.

Como ejemplo de ello transcribo un documento sobre la presencia de algunas de estas agrupaciones corales y rondallas del Frente de Juventudes en los actos de las fiestas de San Isidro de Madrid en $1955^{157}$

Día 14 de mayo

- A las 6 de la tarde: actuación de los Grupos de Cultura y Arte en:

Plaza de la Moncloa; Coro de Zaragoza, Armónicas de Castellón, Teatro de títeres de Zaragoza, Rondalla de Zaragoza, Grupo de danzas de Zaragoza, Banda de música de Alde del Rey (Ciudad Real)-

Plaza de José Piernas; Coro de Valencia, Armónicas de Valencia, Teatro de títeres de Jaén, Rondalla de Rorredonjimeno (Jaén), Grupo de danzas de Baracaldo (Vizcaya), Grupo de gaitas de Orense.

Plaza de Bilbao: Coro de Santander, Armóniccas de Alava, Teatro de títeres de Madrid, Rondalla de Madrid, Grupo de danzas de Torrejoncillo (Cáceres), Banda de música de Córdoba.

Plaza del General Alvarez de Castro; Coro de León, Armónicas de Orense, Teatro de títeres de Pontevedra, Rondalla de Oviedo, Grupo de danzas de Portalrubio (Cuenca), Banda de música de Almagro (Ciudad Real).

Plaza de los Nuevos Ministerios; Coro de Madrid, armónicas de Sevilla, Teatro de títeres de Tetuán, Rondalla de Mérida, Grupo de danzas de Montalvo (Cuenca), Banda de música de Utrera (Sevilla).

- A las 7 de la tarde, actuación de un coro en: Paseo de Rosales, Plaza de las Comendadoras, Plaza de Chamberí; Plaza de María de Molina yPlaza de dos de Mayo

Día 16 de mayo

${ }^{157}$ Archivo General de la Administración. Programa de actuación de los grupos de la Assesoría Nacional de Cultura y arte del Frente de Juventudes, con motivo de las fiestas de San Isidro de Madrid, mayo de 1955. Caja 914 
-A las 6 de la tarde, actuación de un coro en: Plaza de la Perla, Plaza Mayor, Quiosco de música del Retiro, Plaza de Cascorro y Plaza de Luca de Tena

- A las 7 de la tarde, actuación de un coro en: Jardines de Eva Duarte de Perón, Plaza de Oriente, Paseo del Prado, Plaza de San Andrés y Plaza de Peña Corbea (Puente de Vallecas)

Todo ello son muestras de la intención de acercar la música, especialmente la música folklórica y popular a los jóvenes y a la población por parte del Frente de Juventudes, potenciando una imagen más cultural de la organización juvenil.

Para J osé de Arriaca, desde 1945 hasta 1960 son los años de mayor actividad musical en el Frente de Juventudes. En las estadísticas de la Jefatura de Estudios del Campamento de Covaleda del año $1954^{158}$ figura el listado de las 25 canciones preferidas por los acampados y su conocimiento por acampados y su difusión por provincias

\begin{tabular}{|l|l|l|}
\hline Título & Acampados & Provincias \\
\hline 1. Avanzada de nuestra nación & 743 & 50 \\
\hline 2.Montañas nevadas & 730 & 50 \\
\hline 3. Nuevo Gibraltar & 702 & 50 \\
\hline 4.Fidelidad & 636 & 49 \\
\hline 5.Llámame camarada & 635 & 50 \\
\hline 6.Himno de campamentos & 553 & 50 \\
\hline 7.Isabel y Fernando & 534 & 50 \\
\hline 8. iJ uventudes, juventudes! & 514 & 50 \\
\hline 9.Himno a San Fernando & 512 & 50 \\
\hline 10. Marchando & 511 & 50 \\
\hline 11.La batalla del Ebro & 508 & 50 \\
\hline 12.Único capitán & 504 & 50 \\
\hline 13.Tenemos un caudillo & 502 & 49 \\
\hline 14.Himno del trabajo & 413 & 49 \\
\hline
\end{tabular}

158 recogidas en ARRIACA, J. de (1967) Op. Cit. pag. 122 y 123 
Capítulo 4. Música e ideología 1. Frente de J uventudes

\begin{tabular}{|l|l|l|}
\hline 15. Mi camisa vieja vestiré & 403 & 48 \\
\hline 16. Canción del flecha & 372 & 49 \\
\hline 17. Juventud española & 330 & 49 \\
\hline 18. iArriba españa! & 284 & 47 \\
\hline 19.El alto de los Leones & 250 & 45 \\
\hline 20.El camarada & 237 & 49 \\
\hline 21.Canción de las F.J.F. & 184 & 44 \\
\hline 22. Tengo una novia que es mi ilusión & 163 & 47 \\
\hline 23. Canto de la División Azul & 156 & 40 \\
\hline 24. Pregones de un imperio & 136 & 37 \\
\hline 25. Una España mejor & 131 & 43 \\
\hline
\end{tabular}

\subsubsection{La tercera etapa. Desde 1960}

A partir de los años 60 se suceden una serie de importantes cambios sociales, políticos y económicos que cambian los intereses del país. En el ámbito político España se abre a las relaciones con los países del ámbito americano en el entorno de la guerra fría. Ello conlleva la introducción de capital extranjero que acelera la economía española exponencialmente, con lo que por fin se produce un auténtico proceso de industrialización liberal que se ve acompañado por una mejora sustancial de la renta per capita y la calidad de vida de los ciudadanos. La sociedad en general se vuelve más exigente, especialmente con su formación y empieza a hacerse consciente de sus derechos y necesidades de pluralidad.

Desde el punto de vista del Frente de Juventudes ello implica una competencia con nuevos sectores dedicados a la formación y organización del ocio de los jóvenes. Si hasta ahora habían mantenido una lucha abierta con los intereses en educación de la Iglesia (en la que siempre perdieron por su propia 


\section{La educación musical en el franquismo}

falta de previsión, medios y organización), a partir de este momento van a enfrentarse por el interés juvenil y de las instituciones que se organizan en torno a sus estructuras básicas: los colegios de las órdenes religiosas y las parroquias, donde se empiezan a programar todo tipo de actividades deportivas, campamentales, culturales e ideológicas. También entran en competencia con un movimiento reforzado por la introducción hegemónica de la sociedad americana movimientos extranjeros como el escultismo, respecto a los que merece la pena conocer los estudios de Cruz Orozco ${ }^{159}$ y Balcells y Samper ${ }^{160}$.

El Frente de Juventudes sigue siendo aparentemente la única y todopoderosa institución juvenil, pero en realidad se enfrenta a fuertes enfrentamientos internos y externos. Internamente, tiene que hacer frente a una férrea actitud oficial que defiende disciplinadamente las tesis de Franco, incluso cuando están en contra directamente de sus propias bases ideológicas. Como ejemplo, nada mejor que el apoyo que el Frente de Juventudes hace a la propuesta de sucesión de 1966 - siendo como es una de sus bases ideológicas el más profundo antimonarquismo -. Como ésta, otras muchas situaciones de menor envergadura, pero que hacen que el pragmatismo de Franco y del Estado, sometan a los más idealistas y tradicionales falangistas a una tensión interna que les termina alejando de las cumbres del partido. Externamente tiene que hacer frente a los numerosos intereses de otras instituciones en ocupar su lugar privilegiado en la educación, con lo que tiene que afrontar una profunda renovación de los métodos que utiliza. Se inicia un período crítico para realizar las nuevas adaptaciones necesarias para el futuro inmediato, pero en esta situación de inestabilidad y debate interno, tiene que contemplar la creación de una nueva ley de educación que cambia el panorama educativo general y que les tiene poco o nada en cuenta. Por si ello fuera poco, la obligatoriedad de realizar sus actividades es criticada y rechazada por la sociedad cada vez más, con lo que se produce un auténtico proceso de

\footnotetext{
${ }^{159}$ CRUZ OROZCO, J.I. (1995) Escultismo, tiempo libre y educación. Historia del asociacionismo scout en Valencia. Valencia:Institut Valenciá de la Joventut.

${ }^{160}$ BALCELLS, A. y SAMPER, G. (1993) L'escoltisme catalá (1911-1978) Barcelona: Barcanova
} 


\section{Capítulo 4. Música e ideología 1. Frente de J uventudes}

absentismo. Y para colmo, el crecimiento económico del país no llega a las arcas del Frente, que se ve abrumado por una inmensa estructura de personal burocrático, pero que apenas puede hacer frente a los gastos de las actividades que organiza: se trata de un auténtico proceso de muerte por estrangulamiento económico de la asociación.

Respecto a la pérdida de control de Falange de las asignaturas que en la Ley de 1945 le correspondían, la Ley General de educación y financiamiento de la reforma educativa de 4 de agosto de 1970 (BOE de 6 de agosto de 1970) establece en el artículo 136, párrafo que

\footnotetext{
“sin perjuicio de lo dispuesto en el artículo 135 (sobre el control ministerial de la inspección de todas las enseñanzas), las enseñanzas de Formación Política cívico-social y educación física deportiva, así como las enseñanzas de actividades domésticas en los centros estatales y no estatales, serán reguladas por el Gobierno teniendo en cuenta las competencias de los Organismos del Movimiento. Las actividades extraescolares y complementarias de las mismas y el procedimiento para la selección del profesorado serán establecidas por el gobierno, a propuesta conjunta del MEC y la Secretaría general del Movimiento. Esta ordenación y las plantillas y remuneraciones del personal docente se fijarán por analogía con las correspondientes a los profesores de los diferentes niveles educativos."
}

\subsection{3.a Los cursos para la formación de maestros}

Los años 60 supusieron una reflexión y reestructuración de todo el sistema de campamentos, a cargo de la Delegación nacional en la época de la dirección de J esús López Cancio para mejorar su calidad.

La percepción de que la situación social, política y económica de los estudiantes había evolucionado desde las épocas anteriores, era sin duda una de las razones que exigían la necesidad de dicho cambio. La centralización de la parte organizativa desde la Jefatura Central de enseñanzas supuso la introducción y oferta de plazas en campamentos interprovinciales. Ello supuso que algunas Delegaciones Provinciales fueran consideradas por su experiencia las 


\section{La educación musical en el franquismo}

adecuadas para la realización de los cursos (porque habían demostrado en la experiencia de años anteriores ser capaces de llevarlos a buen término) mientras otras quedaron relegadas a pequeñas tareas burocráticas de inscripción. Las provincias que perdieron estos privilegios, vieron cómo sus Escuelas provinciales pasaban a ocuparse casi exclusivamente a la formación de sus afiliados, abandonando otras iniciativas relacionadas con colectivos ajenos a la organización juvenil. A partir de 1962 se intentaron eliminar zonas de acampada con instalaciones poco adecuadas y, en la medida de lo posible, se seleccionaron aquellas que contaban con mejores servicios intentando ofrecer mayores comodidades a los cursillistas. También se agilizaron al máximo los trámites burocráticos y se intentó simplificar la documentación necesaria para la inscripción. Se intentó repetidas veces y de diferentes formas reducir el coste que los campamentos de formación tenían para los cursillistas, pero resultaba imposible debido a las dificultades económicas por las que atravesaba el Frente de Juventudes. Y este coste para el alumnado, era muy elevado en comparación con el del resto de asignaturas de la carrera - y además había que añadirle otros gastos: uniformidad, libros, transporte hasta el campamento.

También se intentaban introducir, aunque lentamente, algunas innovaciones pedagógicas en los cursillos para maestros, como se hace constar en la Instrucción técnica $3 / 65^{161}$ en la que se insiste en el consejo de que prevalezca un sentido práctico en todas y cada una de las manifestaciones de estos cursos, incluído el desarrollo de los cuestionario teóricos. Mejor que la exposición magistral de los temas, resulta el empleo de procedimientos activos, tales como seminarios, diálogos, ponencias, coloquios y trabajos en equipo

Hay que contemplar el cambio social que se produjo en el alumnado de Magisterio. La ley reformada de 1967 implica que los alumnos necesitan el Bachillerato superior para acceder a los estudios y la Ley de educación de 1970 implica la cualificación de estos estudios como universitarios. Ya no son jóvenes

\footnotetext{
161 "Instrucción técnica 3/65" de las Normas reguladoras del régimen interno de los turnos de campamentos y albergues para los alumnos de magisterio. Delegación nacional de Juventud, Fondo documental, caja 31. Citado en CRUZ OROZCO, J.I. (2001) El yunque azul.
} 


\section{Capítulo 4. Música e ideología 1. Frente de J uventudes}

estudiantes don un bachillerato elemental, ya no es necesario a toda costar formar rápidamente maestros. Ahora son estudiantes universitarios, adultos que llevan difícilmente el tener que realizar por obligación unos cursillos extraescolares, en régimen de campamento y menos aún en épocas vacacionales. Un sector cada vez más amplio del alumnado no manifestaba el menor interés por acudir a los turnos de campamentos y sólo lo hacían por la necesidad de cumplir con un requisito ineludible para la consecución del título de maestro. Algunos ejemplos de ellos son el "Informe sobre único turno interprovincial de Madrid" de la Delegación Nacional del Frente de Juventudes, Caja 90, que recoge Cruz Orozco y en el que se refleja que

"resulta ciertamente conocido que un porcentaje muy elevado de los alumnos se incorporan al campamento con "recelo y antipatía".

Incluso se refleja en los medios, como se muestra en esta circular interna recogida en el material del Frente de Juventudes que se encuentra en el Archivo General de la Administración ${ }^{162}$

NOTA DE SERVICIO INTERIOR DEL DIRECTOR DEL GABINETE TÉCNICO, José Antonio García Cotarelo AL DIRECTOR DEL DEPARTAMENTO DE FORMACIÓN, Joaquín Navarro Esteban, con fecha 17 de junio de 1971

Por considerarlo de interés para ese Departamento, adjunto noticia que se publica en el Diario "Informaciones" de hoy, titulada "Los estudiantes de magisterio contra los cursillos de verano"

Como reacción a este rechazo de los alumnos y ante la necesidad de realizar nuevas propuestas educativas para los cursos, se conserva por primera vez material específico interesante respecto a la educación musical en los sucesivos planes de reforma.

\footnotetext{
${ }^{162}$ Archivo General de la Administración. Nota de servicio interior del director del Gabinete Técnico al Director del departamento de Formación, con fecha de 17 de junio de 1971.Caja 1671
} 
Así, en el Curso de capacitación de alumnos de Magisterio en "actividades juveniles de tiempo libre" organizadas por el Instituto de la J uventud en marzo de $1969^{163}$ se especifica:

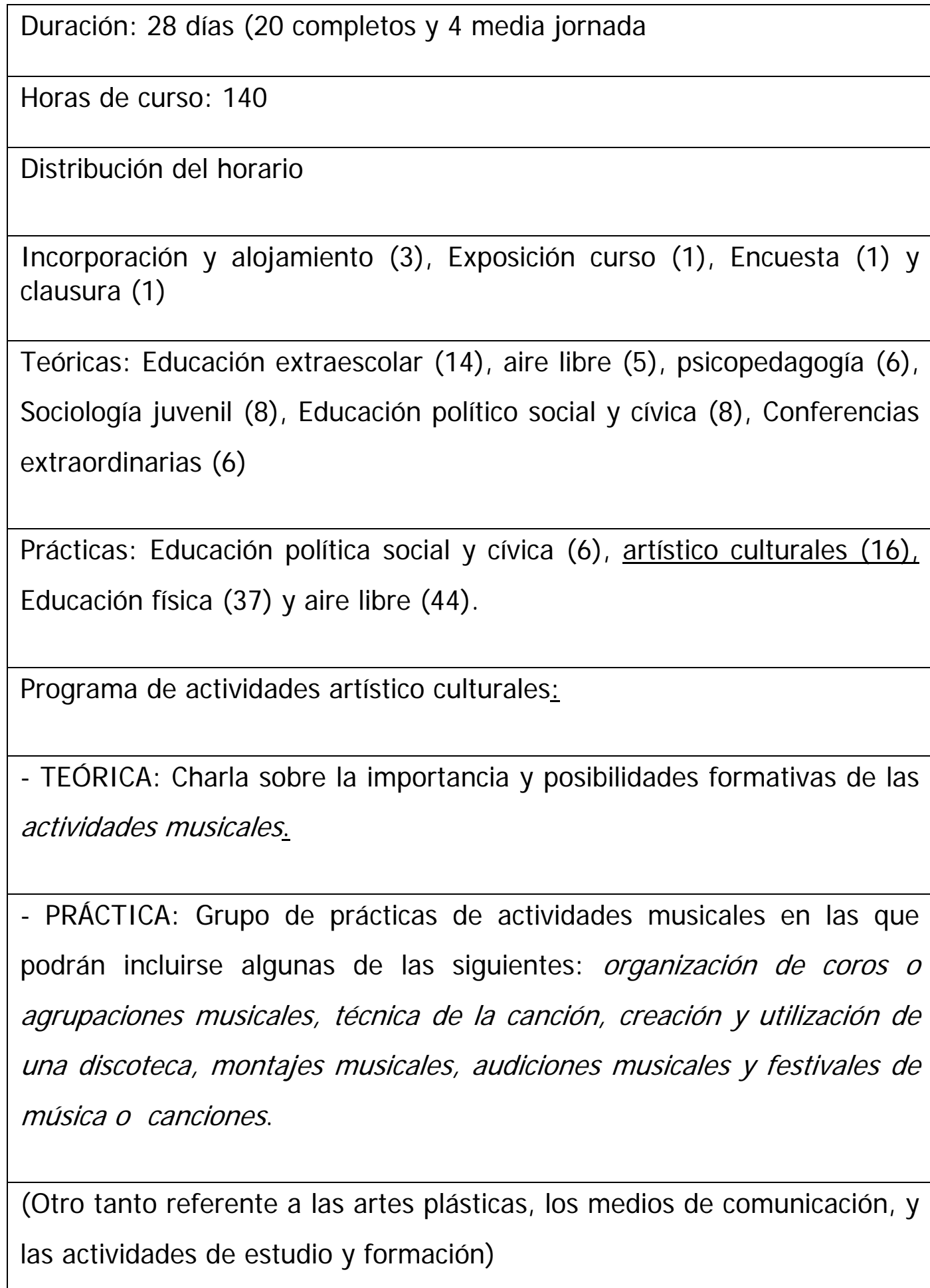

${ }^{163}$ Archivo General de la Administración. Cruso de capacitación de alumnos de magisterio en "actividades juveniles de tiempo libre" organizadas por el Instituto de la Juventud en marzo de 1969. Caja 236 


\section{Capítulo 4. Música e ideología 1. Frente de J uventudes}

Los alumnos deberán adscribirse a dos de los 4 grupos de prácticas. Por
ello sería conveniente organizar dichos grupos en paralelo, de dos en
dos. Por ejemplo, en la primera parte del curso podrían montarse los
grupos de prácticas de actividades relacionadas con las artes plásticas y
de actividades relacionadas con los medios de comunicación, debiendo
los cursillistas inscribirse en el que les interesara. En la segunda parte,
funcionarían los grupos de prácticas de actividades musicales y de
actividades de estudio y formación, adscribiéndose, igualmente, los
cursillistas al que crean más conveniente.
Las prácticas en cada uno de estos grupos ocuparán seis sesiones dentro
del horario general del curso.
Los directivos de los cursos, en base al profesorado, medios y material
disponible, determinarán las prácticas concretas a realizar en cada uno
de los citados grupos.
mace algún festival), 1 colección de discos seleccionados y libros y
la música: 1 tocadiscos, 1 micrófono y un par de altavoces (por si se
manuales nesidos a estas actividades.

Curiosamente, en las materias de educación extraescolar, psicopedagogía, sociología juvenil, educación político-social, educación física y aire libre, se proporciona una bibliografía mínima para los cursos de capacitación en actividades juveniles. En las actividades artísticas-culturales no sólo no se proporciona dicha bibliografía, sino que incluso se dice textualmente:

"en unos casos, se realizarán así todas estas actividades, en otros, no. Depende del nivel de los participantes y del número de expertos disponibles".

Y, como es evidente, las actividades ya no sólo se resumen a cantar himnos y marchas o canciones regionales. Estamos hablando de organización de 


\section{La educación musical en el franquismo}

discotecas, dirección de agrupaciones corales e instrumentales, técnica de la canción, audiciones.

¿Cómo eran estos contenidos? La mejor información al respecto, sin duda, es la contenida en los Apuntes de actividades artístico-culturales para los cursos de capacitación en actividades de tiempo libre para alumnos de Magisterio (1970) ${ }^{164}$ en la que se explicitan muchos de los contenidos del curriculum. En ellos son evidentes los rasgos didácticos innovadores que se aplican con la introducción de la Ley de 1970. Se trata de un documento extenso, pero de enorme significación para entender cómo se contempla la enseñanza de la música en la escuela en un documento, que aunque no procede de Sección Femenina, sí tiene muestras de la enorme influencia que ejerce la forma de dar los contenidos musicales del otro sector de Falange. Es, curiosamente, una aplicación de los principios pedagógicos que Sección Femenina había conseguido difundir para la aplicación general escolar de la nueva ley (en la que Sección Femenina tuvo una enorme influencia).

Técnicas y Planificación de un programa de actividades artístico-culturales; organización y preparación de concursos, certámenes, exposiciones y festivales; organización y utilización de bibliotecas y discotecas, manejo y utilización de material audiovisual.

Actividades de estudio y formación: turismo juvenil, actividades musicales (Audiciones musicales y cómo enseñar y ensayar canciones), prensa, teatro, coleccionismo, trabajos manuales con diversos materiales y artes plásticas.

Actividades optativas: cine de aficionados, cine-forum, fotografía, actividades científicas, misiones juveniles, coros, pequeñas agrupaciones vocales y grupos

\footnotetext{
${ }^{164}$ Archivo General de la Administración. Apuntes de actividades artístico-culturales para los cursos de capacitación en actividades de tiempo libre para alumnos de Magisterio, editado a ciclostyl por el Gabinete de Actividades de tiempo libre del Instituto de la Juventud en 1970. Caja 236
} 


\section{Capítulo 4. Música e ideología 1. Frente de J uventudes}

instrumentales, periódicos a ciclostyl, revistas orales, teatro de títeres, teatro leído.

Prácticas a realizar durante las acampadas: aprendizaje de canciones, realizar diversos periódicos murales, coleccionismo, realizar diversos trabajos manuales y algunas obras de modelado o mosaico, montar una representación o lectura teatral, organizar un festival ( a realizar en un fuego de campamento), organizar una exposición con las realizaciones prácticas llevadas a cabo por los propios cursillistas.

Las técnicas se desarrollarán a lo largo de 25 lecciones durante los cursos de capacitación y tendrán carácter teórico - práctico. Expuestas las técnicas, los alumnos deberán realizar, individualmente o en grupo, las prácticas que el profesor les indique.

Las prácticas de estas actividades se desarrollarán durante 18 horas en la acampada o campamento.

Los directores de los cursos, teniendo en cuenta el profesorado y medios de que disponen, darán a cada actividad obligatoria el tiempo que consideren oportuno.

Esta división estructural entre planificación de actividades y formación técnica para llevarlas a cabo y la realización práctica de las mismas es un marco teórico nuevo que obliga a desarrollar explícitamente contenidos sobre la organización, objetivos y procedimientos de la educación musical, de lo cual surgen los documentos sobre Cómo enseñar la canción, Cómo llevar a cabo las audiciones musicales, Creación de una discoteca y programación de actividades musicales: agrupaciones vocales e instrumentales contenidos en este mismo documento.

El primero y más importante de todos Cómo enseñar y ensayar una canción son la primera pauta que tenemos de cómo se proponía metodológicamente la realización de la enseñanza musical. Estas pautas, 


\section{La educación musical en el franquismo}

realizadas por Frenando Soto Campos ${ }^{\mathbf{1 6 5}}$. fueron además publicadas por la revista Mástil.

\section{CÓMO ENSEÑAR Y ENSAYAR CANCIONES}

Entre las actividades infantiles y juveniles, la canción debe ocupar un lugar destacado. Sin embargo, algunas veces, se considera a esta actividad como accesoria, como suplemento o complemento de otra u otras, y como consecuencia, la de minusvalorarla a la hora de plantearse la rentabilidad de las actividades a realizar. Pero esto no es cierto.

Si bien la canción acompaña a la realización de cierto tipo de actividades, no es menor realidad la de que la canción tiene una entidad sustantiva y un valor educativo tal que no se la puede postergar, so pena de perder una instrumente muy valioso para la formación de los muchachos.

Cantar bien no es difícil si se tiene perfecta consciencia de los elementos que componen toda canción y de cómo manejarlos para el mejor aprendizaje de la misma por parte de los chicos.

El primer elemento y fundamental de la canción es su música. La música es la sustancia de la canción, su latido. Sin música, no hay canción. La música posee un ritmo, una serie de cadencia. El ritmo es el nervio de la canción. Jamás se podrá interpretar bien ésta, si antes no nos hemos impregnado de su música, de su ritmo, respetando íntegramente ambos. Un frívolo afán de cambio, la más pequeña modificación de la música o del ritmo de una canción harán que ésta deje de ser la misma para convertirse en otra, salvo raras excepciones, peor.

El segundo elemento de la canción es su letra. En la letra, la misma canción nos dice lo que quiere decir. Su mensaje externo, materializado. La letra expresa en palabras el mensaje que encierran las notas de la canción. Por ello, es también necesario respetar íntegramente la letra.

\footnotetext{
${ }^{165}$ SOTO CAMPOS, F. (1969). Canciones. En la Revista Mástil. Madrid. También fueron publicadas en las instrucciones para el Grado - cadetes (1973), publicado internamente por la OJE
} 


\section{Capítulo 4. Música e ideología 1. Frente de J uventudes}

Toda expresión artística quiere decir algo, lleva implícito un mensaje. Toda canción, como expresión artística que es, es portadora de un mensaje que el hombre que la creó quiere comunicar a los demás. Este es el tercer elemento de la canción: el mensaje. El mensaje es su alma. Hay que desentrañarlo para llegar a conocer realmente la canción, ya que casi nunca la letra agota el mensaje de aquélla. Nos dice algo, pero no todo.

Un elemento de gran valor para ayudarnos a conocer, a desentrañar el mensaje íntimo de una canción es su historia, las circunstancias que rodearon su nacimiento y su vida hasta llegar a nosotros. Así como muestro conocimiento de un hombre será incompleto si no sabemos los rasgos más significativos de su historia y, en consecuencia, mal podremos interpretarla.

Son, pues, tres elementos fundamentales de toda canción: la música, la letra y el mensaje. El educador tiene que manejarlos con la suficiente maestría para que los chicos lleguen realmente a conocerla y cantarla.

Un MÉTODO ELEMENTAL para realizar tal labor puede ser el siguiente:

Para introducir a los chicos en el ambiente de la canción, el educador les explicará su naturaleza y su historia.

Se cantará, por el educador o cualquier asesor, o especialista, la canción, una o varias veces, ante los chicos, para que éstos tengan una primera idea de la música y del ritmo. También pueden utilizarse al respecto, discos o grabaciones magnetofónicas.

Se entregará la letra a cada uno de ellos para que la estudien y aprendan

Inmediatamente se procederá a ensayar la canción, estrofa por estrofa, no pasando de una a otra sin estar perfectamente aprendida la anterior, pero abandonando la labor al primer asomo de cansancio por parte de los chicos. 
Una vez que la canción se cante entera correctamente, se matizarán las notas o las frases que lo requieran.

Estas son las primeras y únicas pautas que tenemos al respecto sobre cómo proponía el Frente de Juventudes tratar las canciones: prioridad absoluta del mensaje del texto, procedimientos de aprendizaje memorísticos, repetitivos e imitativos, carácter lúdico y no obligatoriedad de continuar con la tarea hasta finalizarla (porque puede ser aburrido y cansado).

En cuanto a la creación de coros y agrupaciones instrumentales, Frente de J uventudes las considera actividades optativas, pero en estos apuntes de las sesiones para maestros les dedica un espacio sobre su organización y algunas pautas de intervención.

Estas actividades son muy sugestivas para la juventud, encerrando, aparte de un enorme cúmulo de posibilidades formativas, tales como el cultivo de la sensibilidad, del trabajo en equipo, autodisciplina, etc., un gran caudal de goce, alegría, satisfacción y entretenimiento al practicarlas.

Sin embargo, el montaje de estas actividades, y más concretamente la constitución y continuada preparación de coros, agrupaciones vocales y grupos instrumental, requiere ineludiblemente, contar con un experto, no siempre fácil de encontrar.

Por otra parte, el reducido espacio de los apuntes, no nos permite explicar el conjunto de conocimientos, tanto de índole musical como de técnica organizativa de estos grupos. Quede, pues, subrayada la importancia de estas actividades, y la incitación a la búsqueda de esa persona cualificada que permita el desarrollo de las mismas en los centros de convivencia juvenil.

A continuación incluimos algunas normas elementales sobre la organización de estos grupos, repitiendo que somos conscientes de que, sin un experto a su frente, difícilmente podrán cristalizar. 


\section{Capítulo 4. Música e ideología 1. Frente de J uventudes}

\section{Coros y pequeñas agrupaciones vocales}

Los componentes de un coro o de una pequeña agrupación vocal deben poseer unas dotes naturales mínimas para el canto y una gran afición al mismo, ya que la continuidad en los ensayos, muchas veces monótonos, es básica para el éxito de estas actividades.

Deberá buscarse un equilibrio entre los componentes del coro, en base a la categoría a que pertenezcan sus voces: tenor, barítono y bajo en voces masculinas, y soprano, mezzo soprano y contralto, en las femeninas.

Estas categorías son las esenciales, ya que, aunque hay otros tipos de voces, todas se pueden encuadrar en algunas de las citadas. Sin embargo, pueden formarse coros o agrupaciones con una sola categoría de voz.

El grado de dificultad de las canciones elegidas para ser interpretadas, debe seguir un proceso de menor a mayor, estando siempre adaptadas las piezas elegidas al grado de preparación y progreso que vaya experimentado el coro o agrupación. Muchos coros fracasan porque intentan ir más aprisa de lo que sus posibilidades les permiten.

Es conveniente que las canciones elegidas, aparte de su mayor o menor grado de dificultad, estén conectadas o sepan conectarse con el interés y gustos de los jóvenes. El repertorio debe renovarse, aunque sigan cantándose las piezas aprendidas antes, a fin de no caer en la rutina o el desinterés.

Conviene que el coro o agrupación vaya reuniendo la mayor cantidad posible de canciones o estudios sobre el repertorio que cultive. También es interesante hacerse con discos o grabaciones magnetofónicas, siempre que sea posible, de las canciones que se vayan incorporando a su repertorio. 


\section{Grupos instrumentales}

Es conveniente, a la hora de constituir un grupo de este tipo, que sus miembros tengan un cierto dominio de los instrumentos. Sin embargo, esto no es un requisito indispensable, ya que con un buen profesor puede adelantarse rápidamente en el aprendizaje.

Es muy importante la continuidad en los ensayos, así como la puntualidad y asiduidad de cada uno de sus miembros.

Es conveniente que los miembros del grupo aprendan lo antes posible a conservar, cuidar y afinar sus instrumentos.

Téngase sen cuenta que no es preciso conocer la notación musical para tocar un instrumento. Hoy existen métodos cifrados, de fácil comprensión que suplen la citada notación. Asimismo, hay métodos que emplean simultáneamente los dos sistemas, lo que facilita el aprendizaje de la notación musical.

Antes de comenzar un ensayo, se deben afinar los instrumentos.

Los ensayos deben iniciarse agrupando por separado los distintos instrumentos, de forma que, al llegar el ensayo de conjunto, dominen la parte que les corresponda interpretar.

Conviene que el grado de dificultad de las melodías a interpretar vaya de menor a mayor y siempre según la preparación de los componentes del grupo. Asimismo se procurará que dichas melodías estén conectadas con los gustos y aficiones de los componentes del mismo.

Es interesante que el grupo reúna el mayor material posible sobre las melodías que incorpore a su repertorio: trabajos, discos, grabaciones magnetofónicas, etc. 


\section{Capítulo 4. Música e ideología 1. Frente de J uventudes}

Para mayor estímulo del grupo, debe renovarse continuadamente el repertorio, así como realizar actuaciones en público o participar en certámenes 0 concursos.

Estas pautas reflejan algunos de los "lastres" del pasado que aún abundan en el pensamiento popular musical de hoy en día: son necesarias unas cualidades vocales para entrar en un coro aficionado, sin embargo no es necesario dominar un instrumento para entrar en una agrupación instrumental porque ya te irán dando partes de dificultad creciente según vas aprendiendo, en ningún caso se propone un acercamiento al lenguaje musical, sino el ensayo memorístico por cuerdas o timbres y la utilización de otros tipos de transcripción musical, escuchar interpretaciones de otros para imitarlas, aspectos lúdicos priorizados sobre los aspectos formativos, satisfacción de actuación sobre la escena.... Estas son unas constantes que vemos reflejadas en el ámbito musical amateur en la actualidad, siendo la pauta de comportamiento habitual de la mayor parte de coros y rondallas de aficionados.

También prevé este plan de formación la creación de discotecas y fondos musicales en los centros educativos y ofrece unas pautas iniciales para su organización y una ejemplificación de programación de las audiciones. Está tomada directamente de las directrices de Sección Femenina al respecto y se refiere a una discoteca de música clásica y a las audiciones correspondientes a materia de Historia de la música que se imparte en el primer año del BUP

\section{LA DISCOTECA}

\section{Organización}

Las fases de organización de una discoteca juvenil o escolar, teniendo en cuenta que normalmente será reducida son las siguientes: Clasificación, fichado, etiquetado y conservación.

La clasificación de los discos adquiridos para la discoteca se hará de acuerdo con los siguientes datos: género del disco, compositor e intérprete. 
Los géneros se diferencian por el contenido del disco. A este respecto se sugiere la siguiente división:

a.- Música clásica: Música sinfónica instrumental (sinfonías, conciertos, suites, oberturas, poemas sinfónicos); música de cámara (sontas, tríos, cuartetos, quintetos, etc.); música religiosa; música coral y vocal (ópera, zarzuela, etc.)

b.- Música folklórica: música instrumental; música vocal o coral.

c.- Música ligera: música instrumental; solistas vocales,; conjuntos musicales

d.- Discos literarios: poesía, teatro, cuentos, etc.

Otro sistema de clasificación consiste en ordenar la discoteca por géneros y dentro de cada género, seguir un orden cronológico por periodos. En cada uno de estos períodos los autores se clasifican de más antiguo a más moderno. Al final de este tema se incluye, como anexo, un ejemplo de este tipo. Dicho ejemplo, puede ser, además, orientador acerca del contenido básico de una discoteca de música clásica.

\section{Etiquetado}

Para el etiquetado se puede seguir el sistema reseñado para los libros.

El fichado del disco deberá hacerse paralelamente en dos fichas, una por el título de la obra y otra por autores. En música ligera, conviene hacerla por el nombre del intérprete o del conjunto.

En las fichas deberá hacerse constar además, el género de música, la clave del disco - la consignada en la etiqueta-, autor o intérprete según los casos, la fecha de entrada y la fecha de baja del disco por pérdida o deterioro, etc.

Para aquellos discos que contengan una serie de obras musicales de autores o intérpretes diversos, se hará en la ficha una enumeración de todas ellas, señalando los títulos de las piezas y los intérpretes de cada una. 


\section{Capítulo 4. Música e ideología 1. Frente de J uventudes}

También se señalará si son de larga duración, normales o single y si son estéreos o monoaurales

Una vez fichado el disco pasará a ocupar el lugar en los estantes preparados para ellos

Su colocación deberá hacerse siguiendo un sistema similar al de la biblioteca

Para la mejor conservación de los ciscos, conviene que siempre se guarden en sus propias cubiertas

Su posición en los estantes debe ser vertical. Esta posición es la idónea para evitar deformaciones

Periódicamente se revisarán los discos y sus cubiertas. Si fuera preciso dar de baja el disco, se anotará en las fichas correspondientes, indicando las causas de su baja

Conviene evitar la adquisición de grabaciones inútiles o mal orientadas. Antes de adquirir un nuevo disco, es preciso pensarlo un poco para decidir si realmente es interesante o podría invertirse el dinero en otro título más sugestivo.

\section{UTILIZACIÓN DE LA DISCOTECA}

La discoteca deber tener uno o más aparatos tocadiscos

Si hay más de un tocadiscos, se colocarán en habitaciones separadas

Al solicitar uno o varios discos para su audición, se rellenará una ficha, indicando los discos solicitados

En una discoteca, a no ser que no posea aparatos de audición, no debe permitirse la salida de discos del local 
En todos los aparatos tocadiscos debe haber una bayeta electrostática para discos, y un cepillo para limpiar la aguja. Todos los discos deben limpiarse antes de su audición y al guardarlos en sus cubiertas.

Esta normativa se ajusta a las que tienen también las discotecas de los círculos Medina de Sección Femenina, una de las instituciones de difusión cultural que primero estuvieron dotadas de este tipo de medios audiovisuales.

En un anexo a este sistema de clasificación de las discotecas, que implica la creación de dotaciones económicas por parte del ministerio para proporcionar los fondos musicales en los centros educativos, se hace también una propuesta para la realización de las audiciones de música clásica y folklórica con carácter formativo, lo que nos hace pensar en unas orientaciones para su aplicación en la asignatura de Historia de la música del Bachillerato, en el que la experiencia de Sección Femenina era ya dilatada. Estamos, pues, asistiendo a una primera etapa de dotaciones y creación de bibliotecas audiovisuales en los centros escolares e infantiles. Pero parece bastante lejana la posibilidad de aplicación sistemática entre el profesorado escolar, sino de unas pautas iniciales.

\section{AUDICIONES MUSICALES}

El objetivo primordial que se persigue con la audición musical es llegar a un mayor conocimiento y gusto por al música

Por regla general cada audición musical que se realice debe estar dentro de un ciclo coherente, que pretenda cumplir unos determinados objetivos. Estos ciclos dependen en gran medida de la información y conocimientos musicales del auditorio, así como de sus posibilidades. No puede especificarse con carácter general el contenido de estos ciclos, aunque lo más corriente es que tengan como base el conocimiento de un determinado período, la obra de un autor concreto, un estilo, un intérprete, etc.

Preparación de la audición musical 


\section{Capítulo 4. Música e ideología 1. Frente de J uventudes}

De acuerdo con el tema que se vaya a trata en la audición musical, se debe elegir una bibliografía adecuada para documentarse sobre la obra, autor, director e intérprete.

El local donde vaya a realizarse la audición debe prepararse respondiendo a las necesidades de la audición: la colocación de los asientos, la luz -que no debe ser demasiado fuerte ni extremadamente débil, y a ser posible, indirecta-. La colocación del que vaya a dirigir la audición debe hacerse de forma que esté a la vista de los asistentes.

Asimismo, deberá cuidarse de que estén en condiciones para su utilización los aparatos y material previstos: bien el tocadiscos y los discos, bien el magnetófono y las cintas, cien la radio, la televisión, etc.

Todos los asistentes deben conocer con antelación suficiente el programa fijado para la audición

Los asistentes deber tener en cuenta que la puntualidad es una elemental norma de convivencia y de respeto a los demás

Desarrollo de la audición musical

En toda audición musical pueden distinguirse claramente tres fases; introducción, audición de los temas seleccionados y coloquio.

a.- Introducción.

La introducción de una audición debe ser corta

En ella se darán los detalles precisos para que los asistentes comprendan la obra que van a escuchar y conozcan unas notas biográficas del autor, director e intérpretes de la misma

Debe huirse de la utilización de tecnicismos, hasta que el auditorio tenga preparación suficiente. En todo caso, debe buscarse la sencillez y la claridad de conceptos. 
La audición puede componerse de una serie de fragmentos y obras representativas de una autor o de un estilo, en cuyo caso se hará un breve comentario ante cada obra o fragmento de una obra completa, en cuyo caso se expondrán antes de comenzar la audición, cuantos datos sean necesarios sobre la misma

b.- Audición

Una vez concluida la presentación de la obra o fragmento a escuchar en absoluto silencio y procurando evitar cualquier tipo de interrupción, se procederá a oírla.

Una vez comenzada la audición de la obra, y mientras dure ésta, nadie debe entrar o salir del salón. Igualmente, debe evitarse todo tipo de ruidos, toses, cuchicheos, etc.

El que dirige, o cualquier otra persona, no deber dar explicaciones de ninguna clase mientras se escucha la música. Tampoco debe formularse ninguna pregunta hasta que cese ésta. La audición de una obra musical requiere una concentración por parte de todos los participantes y cualquier interrupción, del tipo que sea, la destruye.

C. - Coloquio

El coloquio tiene una importancia fundamental porque en el mismo se aclaran las cuestiones que lo precisen y se sintetizan o enriquecen las ideas expuestas al comienzo

Hay que crear un clima de confianza entre los asistentes. En la audición todos van a aprender y a cambiar puntos de vista. El coloquio no es algo reservado a los más entendidos. Por ello, todos deben participar.

Las respuestas que el dirigente dé a las preguntas que se le formulen, deben ser claras y precisas. Para ello, el dirigente debe ir suficientemente preparado. 


\section{Capítulo 4. Música e ideología 1. Frente de J uventudes}

En caso de que no encuentre la respuesta apropiada, tomará nota de ella para contestarla en una sesión posterior.

El concepto de audición es pues una escucha pasiva con información añadida, sin elementos técnicos de análisis y comprensión formal. Es un tipo de audición inicial, de tipo cultural, en la que los objetivos son primordialmente estéticos y poco exigentes desde el punto de vista cognoscitivo.

Es muy interesante, sin embargo, el hincapié que se hace en la participación en el coloquio posterior a la audición, animando a todos los asistentes a participar, sin sentirse coartados por su formación musical anterior.

Esta forma de comprender la audición también está muy extendida en nuestros días, dando prioridad a unos vagos conceptos culturales y estéticos sobre procesos de aprendizaje más intelectual, ya que se considera que la primera es más satisfactoria y fácil para la población, mientras que la segunda exige un mayor esfuerzo intelectual tanto por parte de los profesores como de los alumnos.

\subsection{3.b La música y las juventudes de la OJ E}

En los años 60 se produce una transformación profunda del Frente de Juventudes. La población infantil y juvenil en general se halla cada día más alejada de los conceptos ideológicos que animaron en épocas anteriores el Frente de Juventudes. La vida escolar con influencia de Falange se reduce a las asignaturas de Educación Física y Formación del Espíritu Nacional, y esta última tiene cada vez menos importancia en el contexto curricular.

En consecuencia, la Organización Juvenil Española $(\mathrm{OJE})$, nueva denominación de las juventudes afiliadas a partir del Decreto Ordenador de 1961, prefiere centrar su campo de acción en las deportivas, de ocio y de tiempo libre, lo que implica una enorme ampliación de la tarea de 


\section{La educación musical en el franquismo}

campamentos y montañismo, a las que incorpora un carácter cada vez más desideologizado con respecto a las épocas anteriores.

En lo que se suele calificar como la etapa de declive de Falange en la vida política española, la pérdida de poder en el equilibrio de las fuerzas que conforman el franquismo se hace evidente. Por una parte, Franco se decanta firmemente por la sucesión monárquica. En un discurso ante el Consejo Nacional el propio Franco dijo que "los puntos programáticos de la Falange eran anacrónicos "y el proyecto de José Luis Arrese de imponer algunos rasgos falangistas a los nuevos Principios Fundamentales del Estado fue un rotundo fracaso. Falange quedó así marginada de los centros de poder político del franquismo y toda su estructura se tambaleó a raíz de ello, incluida su presencia en el sistema educativo, que se tuvo que transformar radicalmente, siendo cada vez más conscientes de la necesidad de formación de profesorado específico (no a través de la escuela de mandos como instructores oficiales) y la realización de oposiciones hasta que se produce la supresión total de las asignaturas vinculadas.

La contraposición entre los elementos más idealistas y nostálgicos del pensamiento falangista y la realidad del practicismo real en aras de la supervivencia de los políticos del partido, crean una sensación nostálgica y de fracaso en las filas de los asociados voluntarios que encontrará una gran vía de expresión controlada por medio de la canción.

\section{Según Manuel Parra Celaya}

"a partir de la década de los sesenta se advierte la sensible evolución del cancionero como reflejo de objetivos más generales, menos ambiciosos y más pragmáticos".

Es la época de plasmar el desaliento, el desengaño y la ruptura de los viejos sueños, buscando la solución en la hermandad del grupo, la tristeza y la nostalgia de las viejas canciones de otras épocas. Las nuevas aportaciones al cancionero tienen un carácter completamente diferente, sustituyendo las letras activistas por conceptos más sociológicos. En los años 70, la Delegación de 


\section{Capítulo 4. Música e ideología 1. Frente de J uventudes}

Juventud, ya relegada en sus actividades prácticamente a la OJE adopta un camino de neutralidad política y desideologización evidente, que

"transmite un mensaje destinado, crípticamente, a quienes van a experimentar la transición política en el naufragio de sus ilusiones".

Las canciones toman una importancia cada vez mayor y su ejecución se hace más consciente. En las pautas para la interpretación que publica Fernando Soto Campos en Mástil, dedicado a los jóvenes de Juventudes y no a los maestros, añade dos puntos más de gran trascendencia desde el punto de vista educativo:

- Localizar y hacer callar a los que desafinan inicialmente. Se sumarán más tarde.

- Localizar a los que "no entran bien"; que lo hagan al segundo o tercer verso inicialmente

\section{La exclusión de los alumnos que no son capaces de cantar bien la} melodía o no tienen la suficiente agilidad rítmica y respiratoria, en vez de preparar recursos para que puedan resolver las deficiencias, es un ejemplo de los errores educativos que cometemos hasta hoy. Cantar no es sólo un hecho natural, es una actividad que se puede mejorar con la realización $r$ preparación de actividades técnicas. Pero ello parece requerir demasiado esfuerzo cuando el objetivo final es simplemente la realización vocal aceptable del grupo y no el crecimiento musical del individuo como parte del mismo.

Por otra parte, el proceso de aprendizaje propuesto, si bien analítico formalmente en cuanto a la letra, sigue planteándose como un proceso de imitación memorístico en cuanto a la melodía. Si bien la letra merece ser analizada y comprendida por el bien de la interpretación, la música sólo es fragmentada para facilitar el aprendizaje imitativo y la fijación se produce por mera repetición. No se plantea en absoluto el aprendizaje de las bases del lenguaje musical, la educación vocal personalizada, el acompañamiento armónico salvo que sea espontáneo. Se pretende sólo que "se cante bien", 


\section{La educación musical en el franquismo}

como sinónimo de que se cante con corrección: sin gritar, sin desafinar y a la vez, para que la letra pueda ser bien entendida. Es decir, que se le da una primacía total al mensaje y al contenido conceptual de la canción que a la parte musical

Lo que sí tiene claro Soto Campos es que a la meta educativa que se pretende con la canción no se puede llegar por casualidad. Pero ¿cuál es esa meta? De las propuestas que nos hace podemos sacar la conclusión de que cantar con corrección en el Frente de Juventudes sigue implicando fundamentalmente cantar canciones durante las marchas, eso sí, de forma consciente e intencional.

El canto es, por lo tanto, una actividad formativa, sobre todo desde el punto de vista de transmisión ideológica, no es una actividad accesoria, sino fundamental.

En sus notas técnicas desglosa los contenidos en tres bloques:

Cómo se canta (preparación técnica): Se desglosan armonía, melodía y ritmo de la canción. La mejor posición para cantar es de pie o sentado con el tórax erguido y la cabeza elevada. O bien andando, ya que la dinámica del paso ayuda a mantener el ritmo. Deben evitarse las aceleraciones en las canciones de marcha. En este tipo de canciones los compases fuertes corresponden al pie izquierdo y los débiles al derecho, sabiéndolo se evita perder el compás o comerse los silencios. Además, cantar marchando ayuda al ritmo respiratorio. Es importante vocalizar, no cantando con los dientes apretados ni la barbilla caída ni con la garganta bloqueada y hay que evitar las distracciones. En el coro, las voces resuenan armónicas, uniformes, moduladas, sin que ninguna destaque. Y hay que tener en cuenta la modulación de intensidades.

Que se canta (el mensaje). La música y la letra se complementan para conformar el mensaje de la canción: la letra materializa el mensaje y la música le infunde el énfasis de su cadencia, de su tono, de su ritmo, de su intensidad Las canciones de Juventudes son, en cuanto al mensaje: lección de historia, 


\section{Capítulo 4. Música e ideología 1. Frente de J uventudes}

exaltación patriótica, consigna política, compromiso de honor, recuerdo a los caídos". Hay que captar ese mensaje, interpretar el texto en su conjunto, e incluso la historia de la canción y las circunstancias en las que se compuso

Para qué se canta (intencionalidad). En primer lugar, porque las canciones comunican "la verdad interior", en segundo lugar porque alguien las escucha y son convocatorias de "armonía y amistad", en tercer lugar porque la canción "templa el espíritu de los hombres y los hace recios en el afán de permanencia y de conquista". En palabras de Unamuno: No hay doctrina más profunda y luminosa que la que se ha cantado.

Por otra parte, Soto Campos le atribuye al hecho de cantar otros "objetivos intencionales" como son:

- Ejercitar la atención

- Mejorar la vocalización

- Educar el oído

- Ensanchar la cavidad torácico y mejorar la capacidad y control respiratorio

- Ensayar la convivencia y comunicar el mensaje juvenil

La introducción de este último elemento de ámbito socializador(los otros cuatro son fisiológicos), nos habla del objetivo primordial subyacente: comunicar el mensaje ideológico, es decir transmitir eficazmente el objetivo propagandístico, específicamente políticos en lo doctrinal, según Manuel Parra Celaya: atraer simpatías y afiliados, comunicar cuál es verdaderamente la ideología del grupo que canta, expresar los sentimientos colectivos del grupo desde el punto de vista político y emocional.

A este respecto aporta un enfoque nada poético y más crítico José Luis Alcocer $^{\mathbf{1 6 6}}$, para quien las canciones fueron una forma de alienación y tal vez

\footnotetext{
${ }^{166}$ ALCOCER, J.L. Radiografía de un fraude. Recogido en CELAYA, M. Pedagogía de la canción. Apéndice a la edición electrónica de España es mi canción http://www.rumbos.net/cancionero/pedag_c
} 


\section{La educación musical en el franquismo}

de manipulación, y al final de la época franquista una "válvula de escape" emocional de las frustraciones políticas y personales de la juventud de Falange.

\footnotetext{
“Las canciones constituían una afirmación de vida, pero también la instancia más grave para lograr una alienación política importante (...). Cuando se grita no se razona... Nosotros tampoco gritábamos; hacíamos algo pero: cantar y creer en aquello que cantábamos. Cantar es una manera de desahogarse. Y en eso se convirtió al final el Frente de Juventudes: en el desahogo de la nostalgia por lo que no habíamos hecho (...) Acumulamos demasiadas emociones. Quizás reflexionamos demasiado poco, llevados de un extraño pudor de lealtad"
}

\subsection{3.c Las publicaciones}

Estos son los años de las publicaciones más importantes. La editorial Doncel publica el Cancionero de Juventudes elaborado José Arriaca ${ }^{\mathbf{1 6 7}}$, acompañado por la grabación en disco de $\mathbf{1 5}$ de las canciones más significativas del Frente de Juventudes a lo largo de la historia. Las canciones son interpretadas por los Coros y orquesta de la Cadena Azul de Radiodifusión y la dirección musical está a cargo de Alberto Blancafort y Odón Alonso.

\begin{tabular}{|l}
\hline Las canciones interpretadas son \\
\hline Prietas las filas (Villanueva- Cabañas) \\
\hline Es tan hermoso ser cadete (Herms Niel) \\
\hline Isabel y Fernando \\
\hline En pie Flechas de España (A. de Foxá) \\
\hline Juventudes, juventudes (J:A:Elola y F. Tellería) \\
\hline El dardo vivo de un quehacer (D. Pato y E. Franco) \\
\hline En marcha las centurias (A. Romero y F. Tellería)
\end{tabular}

${ }^{167}$ ARRIACA, J. (1967) Cancionero de Juventudes. Madrid: Doncel 


\section{Capítulo 4. Música e ideología 1. Frente de J uventudes}

\begin{tabular}{|l|}
\hline Pequeños arqueros (J. Rodrigo) \\
\hline Juventud española \\
\hline Llámame camarada (F: Villanueva y A. Cabañas) \\
\hline Guarda tus penas \\
\hline Si madrugan los arqueros (A. Gómez Molina y M. Cuesta Polo) \\
\hline En marcha campamentos (J. Ferrán y J. Peris) \\
\hline Único capitán (M. Crespo y F. Tellería) \\
\hline Montañas nevadas ${ }^{168}$.
\end{tabular}

Otras publicaciones del catálogo de la editorial Doncel en $1970^{169}$ son:

PERIS, J. Música para niños. Iniciación musical siguiendo del método de Carl Orff

También se publican otros discos grabados por el Coro y orquesta de la Cadena azul de radiodifusión bajo la dirección de Alberto Blancafort:

Himnos: Himno nacional, Cara al sol, Oriamendiy Canción del legionario

Himnos militares: Marcha de granaderos, Himno de la Acadeia del aire, Himno de la Escuela naval militar y el Himno de la Academia de infantería

Canciones del Frente de Juventudes: Envío, Me gusta lo difícil, Desperta ferro,. Vale quien sirve.

Canciones del Frente de Juventudes: Canción de la hermana mañana, Canción de la hermana noche, Canción de la hermana Iluvia, Canción del hermano fuego.

\footnotetext{
${ }^{168}$ Hoy se puede conseguir una reedición en CD de este disco Cancionero juvenil 1. online en secretaria@plataforma2003.org

${ }^{169}$ Archivo General de la Administración. Catálogo de la Editorial Doncel (1970) Caja 1670
} 
Misa de la juventud. Halfter, Cristóbal. Coro de la Juventud. Director: Jesús López Cobos. Kyrie, Credo, Sanctus, Agnus Dei, Procesional de entrada, Procesional de comunión, Procesional de salida.

\subsection{3.d El repertorio}

Es un período en el que se escriben gran cantidad de canciones. La edición electrónica de España es mi canción cataloga en esta época de 1960-75 las siguientes:

Guarda tus penas. Está recogida en el "Cancionero del Frente de juventudes" de 1963

Pasa la juventud. Letra de Jaime Ferrán y música de José Peris Lacasa. Se estrenó en el Primer Curso de Iniciación Coral celebrado en la Escuela de capactiación social de trabajadores de Madrid en 1960.

Si madrugan los arqueros. Letra de Adriano Gómez Molina y música de Marciano Cuesta Polo. Se estrenó en 1061 en Burgos, con motivo del "XXV aniversario de la exaltación del Caudillo a la J efatura del Estado". Está recogida en el "Cancionero Juvenil de la OJ E" de 1962

Canción de los almogávares. Letra de Francisco Riego y música de Marciano Cuesta Polo. Himno de los especialistas de Aire Libre en los cursos de Covaleda. Está recogida en el "Cancionero Juvenil de la OJ E" de 1962

Me gusta lo difícil. Letra de Adriano Gómez Molina y m'suica de Marciano Cuesta Polo. Está recogida en el "Cancionero juvenil de la OJ E" de 1962

Envío. Letra de Angel María Pascual y música de Marciano Cuesta Polo. Se subtitula "Canción del Foro nacional de la Juventud". Está recogida en el "Cancionero Juvenil de la OJE" de 1962

Caminos de mi España. Letra de José García Nieto y música de Asins Arbó. Está recogida en el "Cancionero del Frente de Juventudes" de 1963

Vale quien sirve. Letra de Francisco Riego y música de Marciano Cuesta Polo. Está recogida en el "Cancionero del Frente de Juventudes" de 1963

Doncel. Con música de Marciano Cuesta Polo. Está recogida en el "Cancionero del Frente de Juventudes" de 1963 


\section{Capítulo 4. Música e ideología 1. Frente de J uventudes}

Amadís. Letra de Francisco Riego y música de Marciano Cuesta Polo. Está recogida en el "Cancionero del Frente de Juventudes" de 1963

Himno de la Centuria "Plus ultra". Letra de Jesús Martínez sobre música de la película "El día más largo". Se creó en el segundo turno del Campamento Alonso Ercilla en 1964

Himno de la Centuria "Lepanto". Letra y música de Monreal (jefe de servicios culturales de la Delegación provincial de Frente de Juventudes de Madrid) por encargo del jefe del distrito de Vallecas Rafael Martínez López. Se creó a finales de 1964

Eran cuatro camaradas. Elaborada sobre una canción de la época de la guerra civil titulada "El frente de Gandesa", se estrenó en el Primer encuentro de Escuadra de Flechas celebrado en Los Palancares y en la VI Competición Nacional de actividades de Sevilla. Está recogida en "España es mi canción " de 1976

A cinco que había en mi escuadra. Está recogida en "España es mi canción " de 1976

Salve, mi España. Letra y música de I. M. Resaga. Premiada en los Primeros Juegos Florales de la Juventud de 1964 celebrados en Salamanca

Canción de vida. Letra y música de P. Chamorro González. Premiada también en los Primeros Juegos Florales de la Juventud de 1964 celebrados en Salamanca

Un quehacer. Se tiene noticia de ella en el campamento de Covaleda en 1965. Está recogida en el "Cancionero de Juventudes" de 1967

Himno del distrito de Chamberí.

Himno del círculo "Tambor del Bruch". Tenían fama de ser la mejor banda de cornetas y tambores de Madrid.

Himno de la Centuria Alejandro Salazar. Es la centuria más antigua del distrito de Chamberí y la edición electrónica de "España es mi canción" la data a finales de los años 60. 
Himno del círculo "Cardenal Cisneros". Letra de Antón Riestía Pita sobre la música de una marcha alemana

Avanzan las escuadras. Proviene de las escuadras montañeras de Santa María y fue enseñada en el campamento de Hoyos del Espino (Ávila) en 1965

Arqueros de mi España

Palabras limpias

Juventudes de azul. Fue el himno del grado de cadetes "Hispanidad" de Chamberí. Procede de camaradas del FES del año 1963 y fue divulgada por Javier Carro en el Curso de J efes de Centuria de la XVII promoción en 1975.

Si no puedes tú solo

Himno de la Centuria "Reconquista".Fue la ganadora de un concurso para dotar de himno propio a esta unidad en el año 1970

Cuatro de marzo. Canción del distrito de Chaberí para la ofrenda de coronas en homenaje a los caídos.

Mi canción. Letra y música de Javier Arcenillas.

Marcharás. Letra y música de Víctor Manuel Prada (jefe provincial de OJE de Madrid)

Himno de la Centuria "Águilas doradas". Letra de Juan Eduardo Martínez Salles sobre la música de "Marcharás". Se creó en 1973

Las siguientes siete canciones fueron muy populares gracias a su grabación en un disco publicado por la editorial Doncel a finales de los años 60 (están recogidas en un catálogo de 1970) y tienen un carácter moderno y son versiones más para ser escuchadas que cantadas, para el fuego del campamento y la actividad personal en momentos de reflexión y nostalgia, con rasgos poéticos y nada adecuadas para la marcha o la actividad física.

Canción de la hermana lluvia

Canción de la hermana mañana 


\section{Capítulo 4. Música e ideología 1. Frente de J uventudes}

Canción del hermano fuego

Canción de la hermana noche

Nunca estaremos solos si cantamos

En las calles de cualquier ciudad

La gloria del camino

Para José de Arriaca se inicia ya a partir de 1955 una nueva etapa completamente diferente a las anteriores desde el punto de vista tanto ideológico como funcional de las canciones y de las propias estructuras de la organización juvenil de Falange, en lo que el califica de "Nuevos rumbos". El SEU se desgaja de la organización juvenil, se cambia el aspecto externo de los uniformes, se crea una Red Nacional de Albergues juveniles, se establecen acuerdos para realizar viajes educativos (el TIVE), nacen las actividades de voluntariado juvenil, surgen nuevas instituciones juveniles con las que entrar en competencia. Las actividades de la OJE se centran en la ocupación del tiempo libre y el ocio juvenil, con el fin de "instalar en el alma de las futuras generaciones la alegría y el orgullo de la Patria".

Juega un importantísimo papel en la difusión de las canciones y de otros contenidos juveniles la creación por parte de la Delegación de Juventudes de la editorial Doncel que editará de forma lujosa y con numerosas ilustraciones tanto las nuevas ediciones de los principales cancioneros (Mil canciones españolas, Canciones de navidad, el propio Cancionero juvenil de Arriaca) como de otras obras fundamentales desde el punto de vista de la pedagogía musical y literaria (Premios Doncel de Literatura infantil y juvenil).

La temática de las canciones evoluciona hacia temas de convivencia y esperanza de la juventud en nuevos títulos como Pasa la juventud, Si madrugan los arqueros,, la Canción de los Almogávares, Juventud misionero, Caminar, Doncel, Amadís y Un quehacer

\subsection{3.e Otras actividades}

La Sección de cultura adquiere un papel destacado dentro del Frente de Juventudes, ahora que se le va dando cada vez más importancia a las actividades menos cargadas ideológicamente en el nuevo contexto social. 


\section{La educación musical en el franquismo}

Dedica buena parte de su presupuesto a la organización, en muchos casos conjuntamente con Sección Femenina de actividades musicales ante la sociedad: publicaciones, concursos, cursillos.

Ello suponía una gran cantidad de gastos y capacidad organizativa. Los datos sobre el presupuesto para actividades culturales de 1967 demuestran hasta qué punto era alto el porcentaje destinado a este tipo de eventos:

IV Certamen Mejor concertista juvenil del año...........102.850

IV Certamen nacional juvenil de coros.........650.500

III Certamen nacional de música de campamentos o al aire libre.....428.000

V Concurso nacional juvenil de villancicos 605.500

Actuaciones del grupo coral "Cantores de polifonía.....290.000

El gasto de 2.076.850 de pesetas sobre un total del presupuesto anual de todas

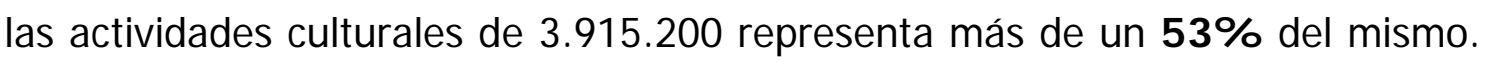
Las otras actividades programadas abarcan el teatro, el cine, la radio, la literatura, la fotografía y las artes plásticas .

Una de las actividades musicales de prestigio que reflejan este cambio de carácter es el encargo que Frente de Juventudes le hace a uno de los nuevos compositores del momento: la Misa de la Juventud a Cristóbal Halfter, lo cual no es sino una clara muestra del intento de asunción de la vanguardia musical por el franquismo (todavía más claramente expuesta en la I Bienal de música contemporánea celebrada en Madrid en el otoño de 1964, o el macroconcierto de encargos oficiales del Concierto de los XXV años de paz). Este es el contrato que se conserva en los fondos del Frente de Juventudes que se conservan en el 


\section{Capítulo 4. Música e ideología 1. Frente de J uventudes}

Archivo General de al Administración ${ }^{170}$ para la composición de dicha Misa de la juventud

CONTRATO DE CRISTOBAL HALFFTER Y LA DELEGACIÓN NACIONAL DE JUVENTUDES PARA LA COMPOSICIÓN DE LA "MISA DE LA JUVENTUD"

La Delegación Nacional de Juventudes (representada por el Excmo. Sr. D. Eugenio López y López, Delegado Nacional de la misma) y el compositor y director del Conservatorio de Música de Madrid, IImo. Sr. D. Cristóbal Halffter, acuerdan y convienen lo siguiente:

1‥- La Delegación Nacional de Juventudes, encarga a D. Cristóbal Halffter la composición de una Misa que se titulará "Misa Comunitaria de la Juventud".

2o.- Esta Misa será compuesta a una sola voz en general - quizá en algún instante convenga el realizar dos voces, aunque siempre dentro del simple espíritu que supone el dicho de "llevar la tercera" o parecida polifonía espontánea - aunque, naturalmente, pueda dialogarse en "coros" si el músico lo desea. La Misa, incluirá dos o más cánticos para la comunión.

3‥- De ser incluidos algunos instrumentos - siempre de fácil tocar, tambores, cornetas, etc.- el compositor lo hará pensando en su supresión. Es decir, que la Misa objeto de este encargo, ha de ser concebida para su interpretación "a capella" y, caso de serle añadidos tales instrumentos, lo serán dentro de un carácter totalmente supletorio.

4‥- La Misa, será para ser cantada en castellano y, por supuesto, sujeta a las reformas litúrgicas más actuales. El compositor, con tiempo suficiente, someterá a la Delegación Nacional de Juventudes, el texto que utilizará en la misma, con el fin de obtener la aprobación de la Asesoría Religiosa de dicha Delegación.

5o.- La partitura, completa y claramente legible, conteniendo toda suerte de indicaciones para su más ideal interpretación, será entregada por el compositor al Asesor Musical de la Delegación Nacional de Juventudes, antes del 15 de marzo de 1965.

6o.- La obra musical en cuestión, será estrenada en la culminación de la peregrinación que la Delegación Nacional de Juventudes realizará este año, con ocasión del Año Santo, siguiendo la ruta del Camino de Santiago, para finalmente postrarse ante el

${ }^{170}$ Archivo General de la Administración Contrato de Cristóbal halffter y la Delegación Nacional de Juventudes para la composición de la "Misa de la Juventud". Caja 252. 
Sepulcro del Apóstol en Santiago de Compostela, luego de una Misa al aire libre extremo este que tendrá en cuenta asimismo el compositor- en la que la gran masa de jóvenes allí concentrados dará la "primera audición" de la "Misa Comunitaria para la Juventud" de Cristóbal Halffter. No obstante, la Delegación Nacional de Juventudes podrá interpretarla en alguna otra ocasión anterior, en donde designara.

70.- El compositor, en cuanto haya entregado la partitura de la Misa a que este compromiso se refiere, percibirá de la Delegación Nacional de Juventudes, la cantidad de VEINTE MIL PESETAS, retribución total que se conviene como abono de este "encargo".

8․- Aunque pudieran impedirlo compromisos previos de edición por parte del compositor, la Delegación Nacional de Juventudes, queda autorizada por el mismo para imprimir partitura y partes de la obra, ya que sin ello sería imposible el preparar su audición en la solemnidad que antes se cita.

En Madrid a 16 de febrero de 1965.

Firma de Cristóbal Halffter. Firma de Eugenio López.

La actividad de Frente de juventudes afectaba musicalmente, no sólo ya a lo que estudiaban como canciones los niños en la escuela y fuera de ella, sino a la organización de toda una red nacional de conciertos y actividades musicales extraescolares. También se extendía a la música culta oficial, mediante la creación de las orquestas nacionales, el control de la radio y la televisión y la promoción de concursos.

El papel que juega la figura del falangista Enrique Franco al frente de la cadena de Radio Azul en los años 60 y muy especialmente en relación con la promoción de los nuevos compositores "cultos" españoles es considerada por Xoan María Carreira (1996) ${ }^{\mathbf{1 7 1}}$ importante. Según su opinión,

\footnotetext{
${ }^{171}$ CARREIRA, X.M. (1996) Contemporary music in Spain during the sixties. En Transgression as integration, publicación del congreso celebrado en Cascais (Portugal). También se puede encontrar, traducido al español en la red en http://www.mundoclasico.com/articulos
} 


\section{Capítulo 4. Música e ideología 1. Frente de J uventudes}

"en los años sesenta el fascismo español precisaba de signos de identidad caracterizadamente modernos y exportables (...). Al igual que sucedió en las artes plásticas, en la música estos signos se desarrollaron dentro de un grupo elitista promocionado por un militante fascista, Enrique Franco, y en el que había una cantidad suficiente de personas dignas de la confianza del régimen. Así, el único experimento musical del franquismo tuvo como resultado la integración política de la transgresión estética".

Ciertamente, a partir de 1962, se sucedieron los encargos oficiales y los estrenos por la orquesta estatales de las obras de un reducido grupo de compositores promovidos desde las estructuras del Movimiento.

\subsection{3.f. La colaboración entre Frente de J uventudes y Sección Femenina}

Es muy evidente que se produce un acercamiento profundo de intereses y se mejora notablemente la colaboración de nuevo entre Sección Femenina y Frente de Juventudes. Las razones que sin duda llevaron a este acercamiento tras la separación abrupta de los años anteriores son:

- La necesidad de aunar fuerzas ante el cambio social e ideológico que se están produciendo en el panorama político. Falange y las instituciones vinculadas al Movimiento se están viendo amenazadas en su situación de exclusividad, tanto en las áreas educativas como en las organizativas de la vida cultural.

- Este proceso se agravará aún más con la situación de penuria económica que sufren ambas entidades ante el incremento de la presencia cultural que demanda la sociedad y en los años 70 se transforma en una situación de total precariedad para hacer frente a los compromisos adquiridos en la última etapa.

- Desde el punto de vista educativo, la ley de 1970, aunque cuidadosa con no menoscabar los derechos adquiridos, deja sin embargo muy claro que el principal actor educativo - incluidas las enseñanzas hasta entonces vinculadas y de total responsabilidad del Movimiento - es siempre el Ministerio de Educación y Ciencia. Si hasta ahora habían sido Frente 


\section{La educación musical en el franquismo}

de Juventudes y Sección Femenina los encargados de elaborar los contenidos y proporcionar el profesorado, ahora se ven relegados a meros ejecutores y obligados a reclamar su presencia en la elaboración de los documentos que tratan sobre los cambios legales que les afectan.

Ello trae consigo también algunas reacciones positivas. En concreto, con respecto a la educación musical, Sección Femenina había desarrollado todo un sistema educativo escolar diferente al de Frente de Juventudes. Estaba mucho más presente en la vida cultural mediante la organización de actividades escolares (concursos de villancicos, de dibujo escolar, de teatro infantil, de coros escolares) y extraescolares en el ámbito social (festivales de coros y danzas, coros populares, difusión del folklore, organización de conciertos). Sus sistemas pedagógicos se volvían desde hacía algunos años a las innovaciones europeas y empiezan a difundir entre el profesorado las nuevas metodologías, más acordes con las intenciones de la nueva ley educativa.

Todo ello influye en la forma de plantearse en estos últimos años del franquismo su actividad musical el propio Frente de Juventudes.

La realización de encuestas sobre el asociacionismo juvenil les ofrecen respuestas inesperadas. Tal es el caso del Informa sobre la // Encuesta nacional de la Juventud española realizada en 1968 por el Gabinete de sociología y estadística del Instituto de la Juventud ${ }^{172}$, que expones que

"Frente a la creencia que consideramos casi generalizada de la importancia de la "asociatividad", nos encontramos con que sólo el 31\% del total de la muestra pertenece a alguna asociación u organización, un $66 \%$ dice no pertenecer a ninguna, y un $2 \%$ no responden.

De los que pertenecen a alguna asociación u organización (606 en total), la proporción mayor ( $36 \%$ lo es de asociaciones deportivas, $30 \%$ de religiosas, el $13 \%$ de culturales, el $11 \%$ de juveniles, el $10 \%$ de antiguos alumnos, el $6 \%$ de musicales, el $5 \%$ de políticas, sindicales, excursionistas y videoclubs; los varones pertenecen con más frecuencia a asociaciones deportivas, y las mujeres a religiosas

\footnotetext{
${ }^{172}$ Archivo General de la Administración. // Encuesta nacional de la Juventud española. Instituto de la J uventud, 1968. Caja 913
} 


\section{Capítulo 4. Música e ideología 1. Frente de J uventudes}

También es muy significativo el informe sobre la encuesta realizada por el Instituto de la Juventud en 1969 sobre la Realidad juvenil y la posible acción de juventudes ${ }^{173}$, en la que aparecen los siguientes datos:

Actitud ante las Actividades culturales:

“Todas las provincias están de acuerdo en señalar que estas actividades son muy minoritarias, aún en la posición de espectadores.

Plan de actuación de las Delegaciones provinciales de Juventudes en orden a la promoción de estas actividades entre los jóvenes: Organización de concursos y certámenes, actividades de Hogar, cine, teatro, música, prensa.

¿Qué problemas tiene planteados la Delegación Provincial de Juventudes en orden a su actuación en este campo de actividades juveniles de tiempo libre? Prácticamente la totalidad señala como problemas básicos para una eficaz actuación de los servicios de juventud que funcionan en las Delegaciones Provinciales de Juventudes, la falta de dirigentes, instalaciones, material y medios económicos.

Bien es verdad que Sección Femenina va a sufrir los efectos de la transformación política del entorno, pero sus medios están en general mejor distribuidos, han sido más eficaces en sus tareas de formación y se han introducido mejor en el sistema educativo primario a través de las maestras, sus relaciones con la Iglesia y sus intereses son menos conflictivas y más complementarias.

Frente de Juventudes va a colaborar por tanto más estrechamente a partir de finales de los años 60, sobre todo en las tareas de formación del profesorado vinculado a la educación musical. Tal es el caso de los cursos conjuntos para maestros sobre método Orff. Hay que tener en cuenta que el Asesor de música de Frente de Juventudes ya era José Peris y él había publicado en Doncel Música para niños prologado por el propio Carl Orff y organizaba los cursos de especialización en segunda etapa del Ministerio de Educación.

\footnotetext{
${ }^{173}$ Archivo General de la Administración. Encuesta sobre la realidad juvenil de las distintas provincias españolas y sobre la posible acción de Juventudes en base a dicha realidad. Instituto de la J uventud, 1969. Caja 913
} 


\section{La educación musical en el franquismo}

También se inicia una etapa de colaboración con el Ministerio de Educación a través de proyectos pilotos educativos vinculados a las actividades extraescolares de tipo cultural, como por ejemplo en Concurso abierto de especialidades musicales ${ }^{174}$ o la concesión de Cinco misiones-pilote de modalidades culturales en el ámbito rural ${ }^{75}$. Hasta este momento, estas actividades habían sido fundamentalmente asignadas a Sección Femenina, pero las tendencias hacia una coeducación de niños y niños favorece la colaboración entre la Delegación Nacional de Juventudes y Sección Femenina, cada vez más necesaria para programar actividades conjuntas.

\footnotetext{
${ }^{174}$ Archivo General de la Administración. Concurso abierto de especialidades entre las escuelas nacionales. Caja 1671

175 Orden de 3 de octubre de 1970 (BOE de 21 de noviembre).
} 


\section{CAPÍTULO 5. MÚSICA E IDEOLOGÍA 2.: LA SECCIÓN FEMENINA}

\section{Introducción}

La Sección Femenina de Falange Española y de las JONS es una institución que surgió en el seno de Falange antes de que se iniciara la guerra civil, en torno a un pequeño grupo de mujeres vinculadas a los líderes iniciales del falangismo. Sus dos líderes fundamentales fueron sin duda la hermana de José Antonio Primo de Rivera, Pilar, que fue nombrada la Directora vitalicia de la Sección Femenina y Mercedes Sanz Bachiller, viuda de Enésimo Redondo y creadora del Servicio Social.

Desde que en 1934 el propio José Antonio institucionalizara la Sección Femenina de Falange a partir del reducido grupo de mujeres que asistían a sus mítines y que reclamaban una participación como miembros activos lideradas por su propia hermana, y nombrara a ésta jefe de la organización, no paró de crecer e incorporar nuevas funciones a su actividad.

En la época prebélica, sus funciones se centraron fundamentalmente en ayudar a los falangistas en sus campañas, recaudar fondos, visitar a los prisioneros falangistas en la cárcel y proporcionar ayuda a las familias de los militantes, difundir propaganda, coser banderas y brazaletes y ocultar armas en sus hogares ${ }^{176}$. Según los primeros estatutos su objetiva era "secundar a los militantes nacionalsindicalistas en su lucha contra la Antiespaña".

Contra todo pronóstico, la Sección Femenina creció desmesuradamente durante los primeros años, muy por delante de la propia Falange, hasta el punto de contar en julio de 1936 con 2.500 afiliadas en 18 provincias. A finales de la

\footnotetext{
176 PRIMO DE RIVERA, P. (1938) Historia de la Sección Femenina. En la Revista Y, febrero y octubre de 1938.Citado en RICHMOND, K (2004) Las mujeres en el fascismo español. Madrid: Alianza ensayo
} 


\section{La educación musical en el franquismo}

guerra contaban según sus propios datos ${ }^{177}$ con más de 580.000 mujeres afiliadas. Sus tareas se habían ampliado a servicios asistenciales en la retaguardia y los territorios que se iban incorporando a la zona nacional. Desde octubre de 1936 Pilar Primo de Rivera transformó los estatutos iniciales en una estructura administrativa desarrollada y eficaz, a partir del marco jerárquico del partido de Falange, constituyendo una organización a nivel nacional, provincial y local. Las delegadas provinciales informaban a la delegación nacional sobre sus progresos en los Consejos anuales, el primero de los cuales se llevó a cabo en Salamanca en enero de 1937. Al finalizar la guerra, estaban representadas en todas las provincias. La eficacia de las actividades asistenciales, especialmente del Auxilio Social creado por Mercedes Sanz Bachiller en Valladolid, atrajo a muchas mujeres a la colaboración con la organización en actividades que mejoraban la terrible situación posbélica en la que se veía envuelta la población civil, especialmente las mujeres y los niños.

Al terminar la guerra, las actividades de la Sección Femenina se ampliaron hacia auténticos programas de propaganda y educación para la población femenina. Rápidamente se empezaron a impartir cursos para crear mandos e instructoras en tres especialidades principales: agricultura, educación física y música. Desde el principio, en el ideario de Sección Femenina destacó la importancia de la música como un elemento fundamental de transmisión ideológica para conseguir la unidad "espiritual" de España a través de la formación de las mujeres y los niños.

Las palabras de Pilar Primo de Rivera en la I Concentración Nacional de Medina del Campo hacían explícita esta intención de difusión de la música y del folklore como un medio de unificación y construcción del concepto de estado-nación a partir de la educación musical.

\footnotetext{
"Cuando todos los españoles tengan metido dentro de sí las consignas de Falange Española Tradicionalista y de las J ONS, cuando los catalanes sepan cantar las canciones de Castilla,cuando en Castilla se conozcan también las sardanas y se toque el chistu,
}

\footnotetext{
${ }^{177}$ FET de las J ONS (1939) La Sección Femenina: historia y organización. Bilbao: Talleres Gráficos de J esús Alvarez
} 


\section{Capítulo 5. Música e ideología 2: La Sección Femenina}

cuando en el cante andaluz se entienda toda la profundidad y toda la filosofía que tiene, en vez de conocerlo a través de los tabladillos zarzueleros; cuando las canciones de Galicia se canten en Levante; cuando se unan cincuenta o setenta mil voces para cantar una misma canción, entonces sí que habremos conseguido la unidad entre los hombres y entre las regiones de España (...) Queremos por medio de la música unir las regiones de España. Queremos lograr la compenetración del pueblo español, la armonía entre las provincias, la unidad entre los hombres de España por medio del ritmo, de la música y del arte. Cuando Zaragoza baile sevillanas y Sevilla cante jotas, se habrá hecho un gran paso hacia la unidad de la patria"

Esta declaración de principios inicial se vio sometida a las tensiones y contradicciones propias de la puesta en práctica real en las tareas de formación, pero fueron un referente del ideal político propuesto por la Sección Femenina. Las mujeres no eran por sí mismas un elemento político activo explícito en la vida pública española (aunque el papel que jugó Pilar Primo de Rivera como Delegada nacional tenía un peso político excepcional y formaba parte del Consejo de Estado de Franco), pero eran las colaboradoras fundamentales para la creación de un estado de pensamiento y consciencia, especialmente por su carácter como educadoras de las nuevas generaciones a través de la vida familiar. En palabras de Thébaud ${ }^{\mathbf{1 7 8}}$

\footnotetext{
“el Estado franquista fue un estado dictatorial, basado en principios ideológicos, no sólo conservadores, sino reaccionarios: autoridad y jerarquía que implicaban dominación y subordinación. Fue, de este modo, un estado patriarcal y androcéntrico en el que prevaleció un sistema de género masculino con profunda incidencia en las relaciones sociales. En él, las mujeres fueron utilizadas como pieza clave para su política de dominio social y económico".
}

La Sección Femenina fue, pues, la organización encargada de la formación de las mujeres para la transmisión ideológica.

En este sentido, la actividad de Sección Femenina se ajusta más al tipo de modelos de educación de la juventud propuesto por Juan Sáez Marín ${ }^{179}$ a

\footnotetext{
178 THEBAUD, (1993)

179 SÁEZ MARÍ N, J.(1988) El Frente de Juventudes. Política de juventud en la España de la postguerra (1937-1960). Madrid: Siglo XXI
} 


\section{La educación musical en el franquismo}

partir de los esquemas de Jean Jousselin y de Mendizábal ${ }^{\mathbf{1 8 0}}$ dentro del tipo de Política PARA la juventud (frente al tipo de política POR la juventud del Frente de Juventudes).

Este tipo de relación implica:

“Paternalismo: la generación adulta piensa y decide por todos. A ella se transfieren los problemas y contradicciones de los jóvenes

Ubicación de la juventud en lugares periféricos y externos al cuerpo social activo

Proteccionismo generalizado en cuantas medidas se refieran a los jóvenes, que lo precisan por su especial condición de seres débiles y sin experiencia

Fiabilidad en las resultantes de los procesos de enseñanza y aprendizaje, férreamente controlados, que aseguran una socialización inequívoca en el sentido previsto por los adultos

Prolongación a través de las asociaciones juveniles de la acción de la familia, acogiendo y protegiendo a los jóvenes, y la escuela, sugiriéndoles una ética y haciéndoles adquirir comportamientos sociales predeterminados.

Se perfecciona así el control del trinomio familia-escuela-calle (...) El resultado será un dirigismo social generalizado.(...) Las sociedades o grupos en donde predominan valores de tipo conservador, tendrán a desarrollar una política PARA la juventud."

Ello, junto con la fuerte vinculación de Sección Femenina a la Iglesia y el pensamiento religioso católico tradicional, la distinguen, muy especialmente a partir de la separación de Frente de Juventudes en 1945, centrando toda su actividad en la formación de las mujeres y los jóvenes como su principal objetivo, constitutiva de su contribución social a la intención política de fondo. Y dentro de esta actividad de formación, la cultura, y muy especialmente la música, tienen un papel destacado, incluso claramente superior en volumen material y efectivos personales a otros contenidos más obvios político-sociales.

\footnotetext{
${ }^{180}$ MENDIZÁBAL OSES, L. (1968) La política de Juventud: determinación de su concepto" En Revista de Estudios Políticos, no 162. Madrid y JOUSSELIN, J. (1967) Al servicio de la juventud en $R I J, n^{\circ} 14$
} 


\section{Capítulo 5. Música e ideología 2: La Sección Femenina}

\subsection{SECCIÓN FEMENINA Y SU CONTEXTO HISTÓRICO}

La Constitución republicana aprobada en diciembre de 1931 había reconocido a las mujeres por primera vez en España los mismos derechos electorales que a los hombres. Pero la escasa duración de la república en España no hizo posible que ello se viera acompañado de una mejora real social, económica y sobre todo cultural de la mujer en la vida real de la mayoría de las mujeres españolas. La neutralidad de España en la I Guerra Mundial tuvo como consecuencia que las mujeres no sustituyeran a los hombres en el trabajo como en otros países europeos y por lo tanto, que no se incorporasen mayoritariamente al sistema productivo industrial y urbano. La España de los años 30, y muy especialmente después de la guerra civil, era de carácter fundamentalmente agrícola y rural. Según las estadísticas recogidas por Carmen Borderías ${ }^{\mathbf{1 8 1}}$ las mujeres trabajadoras representaban entre el 9,16 y el 14,51\% de la población activa entre los años 1900 y 1930. El índice de analfabetismo entre las mujeres de más de diez años superaba el 38,4\%, duplicando las cifras de analfabetismo masculino recogidas por Payne $\mathbf{P}^{\mathbf{1 8 2}}$ que se estimaba en un 19,5\%. La disminución de la población masculina a causa del enfrentamiento bélico , la destrucción de la mayor parte del tejido industrial, así como la imposición de las ideas más tradicionalistas y el enorme influjo de la ideología de la iglesia sobre el papel de la mujer en la sociedad no supusieron desde luego una mejora.

Las expectativas que la II República habían generado entre las mujeres ideológicamente más avanzadas de la época se vieron seriamente frustradas y de hecho habían generado todo tipo de temores en la población masculina ante el llamado "feminismo" contra el que el régimen de Franco reaccionó violentamente, potenciando una imagen de la mujer como ama de casa, centro del núcleo familiar, madre ante todo para regenerar la población del país, promocionando que jugara un papel como ser subordinado al hombre y en absoluto en competencia con él.

\footnotetext{
${ }^{181}$ BORDERÍ AS MONDÉJ AR, C. (1993) Entre líneas. Trabajo e identidad femenina en la España Contemporánea: La compañía Telefónica 1924-1980. Barcelona: Icaria Editorial 182 PAYNE, S. (1993) Spain's first democracy: the Second Republic 1931-36. Madison: University of Wisconsin
} 


\section{La educación musical en el franquismo}

Evidentemente, la larga duración del franquismo obligó a asistir a una transformación paulatina del papel social de las mujeres. Y Sección Femenina jugó un papel importante en dicha transformación.

Amparándose en la importancia del papel educador de las madres hacia sus hijos, la Sección Femenina desarrolló y promocionó programas para la educación y mejora de la cultura femenina.

Envuelta en las contradicciones básicas del papel sumiso y secundario en la sociedad ante los varones, tuvo que buscar, según $\mathbf{R i c h m o n d}^{\mathbf{1 8 3}}$ la manera de crear un ideal de feminidad que

“situara a las mujeres por encima de la crítica, permitiéndoles realizarse plenamente en el terreno educativo y profesional, pero sin constituir un desafío a la autoridad masculina".

Actitudes como el intelectualismo en la mujer eran asociadas a comportamientos republicanos y profundamente rechazadas. La belleza, la coquetería, la diversión y el esparcimiento eran radicalmente opuestos a los ideales de mujer madre que promocionaba la iglesia católica (no sólo obligatoria, sino mayoritaria y de una gran influencia en la población femenina).

Así pues, ¿cómo hacer realidad las palabras de Mercedes Sanz Bachiller ${ }^{\mathbf{1 8 4}}$ sobre que

"el Estado y el Movimiento se preocuparán de dar cauce limpio a las legítimas aspiraciones de las jóvenes que sientan los estímulos de seguir una carrera y de dar ocupación a todas las demás que, por no contraer matrimonio, tengan que ganarse la vida con el esfuerzo personal"

Éste fue uno de los grandes retos de Sección Femenina, creando toda una infraestructura educativa que ofreciera a las mujeres:

\footnotetext{
183 RICHMOND, K. (2004) Las mujeres en el fascismo español. La Sección Femenina de la Falange, 1934-1959. Madrid: Alianza Ensayo

${ }^{184}$ SANZ BACHILLER, M. (1939) La mujer y la educación de los niños. Madrid: Ediciones del Auxilio Social, FET y de las J ONS
} 


\section{Capítulo 5. Música e ideología 2: La Sección Femenina}

Mejoras de formación cultural e intelectual de la población general (de la cual casi el $40 \%$ era analfabeta y vivía mayoritariamente en medios rurales donde dicha formación no era percibida como una necesidad)

Promocionar la educación y la cultura de las nuevas generaciones femeninas mediante becas para acceder a la educación secundaria y superior, la creación de centros de estudios y la habilitación de posibilidades profesionales dentro de la propia Sección Femenina

En el primer ámbito se sitúan las acciones encaminadas a mejorar la vida de todos los españoles a través de la mejora técnica de las funciones que tradicionalmente realizaba la mujer en el hogar: cursos de higiene, sanidad infantil, cocina, costura y decoración. Además de realizar esta labor a través de las delegaciones locales donde se impartían cursos de corta y larga duración, también se crearon las famosas "cátedras ambulantes" que a imitación de las que ya habían existido durante la II República se trasladaban con el material necesario a las comarcas más recónditas.

Pero en ningún caso Sección Femenina se conformaba con estas acciones "útiles", sino que insistía en incorporar además otros tipos de formación cultural.

A través de la creación de los Colegios Menores, realizaban la captación de las generaciones más jóvenes proponiéndoles el acceso a la educación secundaria (inicialmente sólo había institutos en las capitales de provincia y hasta muy avanzados los años 60 no se empezaron a crear centros públicos de enseñanza secundaria en poblaciones de gran tamaño).

Todas las Delegaciones provinciales además estaban dotadas con los llamados "Centros Medina", en los que se disponía de biblioteca, se daban clases complementarias y de apoyo para las asignaturas de educación secundaria, había discotecas, diccionarios, zonas de trabajo y estudio, materiales didácticos, -y lo que es más importante- personal orientador. 


\section{La educación musical en el franquismo}

Las becas de la Sección Femenina iban desde ayudas de pequeña cuantía hasta becas internacionales (en el caso de la didáctica de la música española, sin duda fueron definitivas las ayudas que recibió Montserrat Sanuy para cursar los estudios del método Orff).

En el terreno político y legislativo de los derechos de las mujeres, como siempre en todos los temas relativos a Falange (masculina o femenina), las contradicciones entre la lealtad "incondicional" a Franco y la ideología básica hicieron difícil la toma de decisiones. Parece ser que el papel de "Pilar de Primo de Rivera y su influencia, tanto directa como indirecta, allanaron el terreno a los avances producidos en la ley de 1960 al convencer gradualmente a los sectores más críticos de la necesidad de un cambio"185, aunque otros sostienen que su actitud con respecto a los daños sufridos por las familias en las que la mujer trabajaba fueron más bien un impedimento para avanzar en estos términos durante la década de los años 50.

\subsubsection{De 1934 a 1945}

Desde sus orígenes, la Falange creada como partido en 1934 por José Antonio Primo de Rivera, tuvo como "alter ego" la Sección Femenina, al principio sólo formada por tres mujeres, a cuya cabeza se situaba su propia hermana, Pilar. El hecho de que no sólo fueran seguidoras, sino que se decidieran a participar de forma activa, hizo que se convirtieran en afiliadas y que así se creara en ese mismo año la Sección Femenina de Falange y nombrara a su hermana jefe de la organización.

Durante los primeros años, su labor consistió en ayudar a los falangistas en sus campañas, recaudar fondos y asistir a los presos falangistas en la cárcel, crear y difundir la propaganda, coser banderas y brazaletes y ocultar armas. Según

${ }^{185}$ En RICHMOND, K. (2004) Las mujeres en el fascismo. Op. Cit. Pag. 36 


\section{Capítulo 5. Música e ideología 2: La Sección Femenina}

los primeros estatutos de la Sección Femenina, su objetivo consistía en secundar a los militantes nacionalsindicalistas ${ }^{186}$.

La guerra hizo que se involucraran en las tareas, fundamentalmente asistenciales, muchísimas mujeres provenientes de otros orígenes ideológicos (CEDA, organizaciones religiosas católicas). Mientras a finales de 1935 sólo tenían tres delegaciones fuera de Madrid (Valladolid, Vigo y Pamplona) y no más de 800 afiliadas en total, en Julio de 1936 tenía delegaciones en 18 provincias españolas y contaba con 2.500 afiliadas $^{187}$ y a finales de 1939 y la afiliación creció hasta 580.000 según cálculos de la propia organización ${ }^{188}$

La celebración del Primer Consejo Nacional en enero de 1937 en Salamanca con la ayuda de Dionisio Ridruejo - entonces jefe de propaganda de Falange - y al que asistieron 50 delegadas de toda España, marca algunas de las pautas sobre las que se edificará el "estilo" de la Sección Femenina: El liderazgo de Pilar Primo de Rivera, la mitificación de la figura de su hermano José Antonio (ya entonces ejecutado en Alicante, pero cuya muerte se mantenía en secreto) como "el Ausente", el sentimiento de que la Sección Femenina era "la reserva ideológica de Falange" y que guardaba celosamente algunos de los principios revolucionarios de los ideales anteriores a la absorción por el franquismo, la creación de "escenarios" históricos como símbolo de un pasado glorioso y de lo que Richmond ${ }^{\mathbf{1 8 9}}$ califica de "tiempo mítico" (el reinado de Isabel la Católica, la ubicación en el Castillo de la Mota (Medina del Campo, Valladolid) y en el de Las Navas (Madrid), la celebración de los primeros consejos nacionales en Salamanca, Valladolid, Segovia, Toledo; la idea de "reconquista" y de "cruzada" asimiladas a la guerra civil, la reutilización del término "Regiduría", los símbolos de la "Y" y el yugo isabelinos, la imagen de Santa Teresa de Jesús como patrona).

\footnotetext{
${ }^{186}$ PRIMO DE RIVERA, P. (1938) Historia de la Sección Femenina. En Revista "Y", no septiembre.

${ }^{187}$ FET y de las J ONS (1939) Concentración nacional de las falanges femeninas en honor del Caudillo y del ejército español. Bilbao: Talleres Gráficos de J esús Álvarez, pag. 13

${ }^{188}$ FET y de las J ONS. (1952) La Sección Femenina: Historia y organización. Madrid: SF de FET $\mathrm{y}$ de las Jons, pag. 20

${ }_{189}$ RICHMOND, K (2004). Las mujeres en el fascismo español. Op cit., pag. 84
} 


\section{La educación musical en el franquismo}

Ya en el primer congreso se formalizó la apertura de la primera escuela de formación de mandos en Málaga en la que se impartieron durante dos cursos las pautas para constituir las jerarquías esenciales a nivel provincial. La organización se dividió en dos tipos de jerarquías:

- Jerarquía política, que vinculaba a Pilar Primo de rivera con su equipo de trabajo en provincias y pueblos

- Jerarquía de servicio, constituida por el grupo de especialistas que gestionaban las regidurías de la Sección Femenina

1937 fue un año importantísimo para Falange, pues en él se vieron forzados a unirse con las otras fuerzas políticas - ideológicamente diversas y en algunos temas incluso contrapuestas - por el Ilamado "Decreto de Unificación". Ello implicó la absorción de las fuerzas tradicionalistas, carlistas, religiosas y de derecha (a las que tanto se había opuesto José Antonio y contra las cuales había nacido en realidad Falange) por un único partido, identificado con Falange: el Movimiento Nacional. Todo ello conllevaría un constante enfrentamiento de tensiones internas y contradicciones ideológicas dentro del "partido único" de las que es fiel reflejo la evolución histórica del franquismo. Y en consecuencia, la desnaturalización de algunos valores en aras del interés político ya desde los primeros momentos en que el partido se asocia al poder (que en realidad estaba en manos de Franco). Pero también, la generalización de sus símbolos a nivel nacional y la extensión de su aparato de gestión por todo el territorio nacional hasta convertirse en la base de la burocracia del Estado.

En esta primera etapa, Sección Femenina y Falange son además el medio de representación exterior de la política española en conexión con el eje fascista (Hitler-Mussolini). Aunque ideológicamente hay diferencias importantes entre el caso español y el europeo (algunos estudiosos califican el régimen como franquista y no fascista), los representantes de Falange y Sección Femenina viajan en estos años en numerosas ocasiones con el fin de aprender y en algunos casos copiar algunas ideas de las organizaciones 


\section{Capítulo 5. Música e ideología 2: La Sección Femenina}

juveniles de estos países: la importación del "dopolaborismo" italiano, el apoyo maternal copiado de la OMNI (Opera Nazionale por la Maternitá ed Infancia), o los 16 viajes - de los que Pilar Primo de Rivera tomó parte en ocho - a Portugal, Italia, Austria y Alemania. Richmond ${ }^{\mathbf{1 9 0}}$ señala que Carmen Werner delegada nacional de juventud - y su sucesora Julia Alcántara, realizaron sendas visitas a la escuela de formación de muchachas de la Reichsfrauenführung en 1938 y 1939, acompañadas de diecinueve mandos para estudiar durante tres meses cómo había constituido sus escuelas de hogar la organización alemana. De hecho, la Sección Femenina basó parte de su estructura jerárquica en la organización femenina nazi, creando departamento y subsecciones en áreas paralelas.

Algunas de las actividades que desarrollaron tanto Sección Femenina como Frente de Juventudes en estas primeras épocas de estrecho contacto con las organizaciones juveniles fascistas europeas estuvieron marcadas por elementos claramente importados de ellas: los campamentos juveniles, los desfiles, el saludo con el brazo en alto, los uniformes. Aunque al terminar la guerra civil ese primer "estilo" resultó útil para la propaganda del régimen, los acontecimientos históricos (la "neutralidad" de España en la II Guerra Mundial y la pérdida de las fuerzas del eje fascista en la confrontación bélica - y por lo tanto la necesidad de establecer nuevas alianzas con los Estados Unidos -) hicieron que algunos de estos símbolos externos se convirtieran en un lastre que dificultó la "reinvención" de Falange.

La muestra de la vinculación con el nazismo fue el envío de enfermeras de la Sección Femenina al frente ruso con la División Azul en 1941 (en la que sólo se aceptaron solicitudes de afiliadas que hubiesen ejercido como enfermeras en la guerra civil y por tanto tuviesen experiencia asistencial bélica). Y el último gran acto público en que la Sección Femenina presentó sus actividades como una declaración política fue la concentración masiva de 1944 en El Escorial, a la que asistieron unas 15.000 afiliadas a las manifestaciones públicas, marchas, charlas y exhibiciones deportivas.

${ }^{190}$ RICHMOND, K (2004) Las mujeres en el fascismo español. Op. Cit. Pag. 69 y 70 


\section{La educación musical en el franquismo}

Con todo, la actividad fundamental de Sección Femenina no se hallaba en el ámbito político, sino en el ámbito de formación de la mujer, a la que se dedicó plenamente desde mediados de los años 40 .

Este distanciamiento y diferenciación en los ámbitos de intervención e interés se hicieron aún más patentes con el Decreto de $\mathbf{1 9 4 5}$ por el que se produce legalmente la separación de Sección Femenina y el Frente de J uventudes.

Aunque aparentemente Sección Femenina es la gran perdedora (tiene que buscar nuevos locales y se les coloca por encima la estructura política masculina) en el fondo es una gran victoria: han conseguido la libertad de poder llevar a acabo sus tareas de formación con total autonomía y dedicarse a ofrecer cursos a la población femenina de todo el país - tanto a nivel escolar como adulto, en educación formal y no formal- sin tener que depender del tipo de formación más político-ideológica de la parte masculina del partido. A partir de este momento, Sección Femenina va a fomentar, aún más la creación y difusión de un "estilo propio"que abarca desde la forma de vestir, el control de la economía y la salud doméstica y la formación de las mujeres en el terreno cultural, hasta la creación de toda una burocracia femenina para la gestión administrativa del país.

Este espacio propio se venía gestando desde tiempo atrás. Ya en 1939 durante la concentración masiva celebrada en Medina del Campo tras la victoria de las fuerzas franquistas en la guerra civil, Franco le prometió a Pilar Primo de Rivera una Academia nacional para los mandos de Sección Femenina en el mismo Castillo de la Mota.

El castillo fue restaurado por Pedro Muguruza, director general de arquitectura, utilizando algunas reproducciones de Beatriz Galindo ${ }^{191}$. Abierto en mayo de 1942 como "Academia José Antonio" fue el centro de la actividad formativa de Sección Femenina. Constituido en un auténtico escenario "mítico", se convirtió

${ }^{191}$ Beatriz Galindo (1451-1534), “La Latina”, fue tutora de Isabel la Católica en latín y literatura 


\section{Capítulo 5. Música e ideología 2: La Sección Femenina}

según Richmond ${ }^{\mathbf{1 9 2}}$ en "el corazón espiritual y emocional de la organización". Desde allí se gestionó la creación y difusión de un estilo que combinaba el pasado imperial con las tradiciones rurales, la síntesis de la tradición y la revolución del modo joseantoniano ${ }^{193}$, una entidad reinventada en el pasado y la modernidad de hábitos educativos en los que el ahorro, la inventiva y la alegría podían interpretarse como manifestaciones externas de la convicción política.

La Mota fue el modelo para otras instituciones de formación creadas por la SF en los primeros años de la década de los años 40 como la Academia "Isabel la Católica" en Madrid que primero estaba dentro del Pardo y luego fue trasladada al Castillo de Las Navas (Ávila)

Es en estos años cuando se crean algunos de los procedimientos característicos de la enseñanza en la Sección Femenina. Aparecen las primeras publicaciones de difusión y los grandes manuales y en la materia a que este trabajo se refiere, muy especialmente dos grandes parámetros de educación musical: El Cancionero de la Sección Femenina y la Revista Consigna para maestras. Además de estas publicaciones existen otras muchas, como el famoso Libro de Cocina (sin duda el mayor éxito comercial de la editorial de Sección Femenina) o la Revista "Y".

La imagen pública de Sección Femenina se moldea también en estos años y se caracteriza por su rectitud moral, el apoyo y la ayuda en el período de autarquía y su papel en el control de la población civil. Las piedras angulares de las relaciones con el poder político fueron la negociación y la persuasión sin suponer una amenaza para los sectores masculinos y la evidente eficacia de sus programas de formación.

La primera se refiere sobre todo a la actitud que mantenía la Sección Femenina de total rechazo a las actividades del estraperlo, no aceptando sobornos y suministrando ayuda a los pobres y consejos nutricionales a la población

\footnotetext{
192 RICHMOND, K (2004) Las mujeres en el fascismo español. Op. Cit. Pag. 92

193 PRIMO DE RIVERA, P. (1983) Recuerdos de una vida. Madrid: Dyrsa
} 


\section{La educación musical en el franquismo}

femenina. La meticulosidad en la contabilidad de la organización era legendaria y se extendía a través de sus programas de formación a todos los sectores de la población, especialmente los más necesitados y las zonas rurales. La Sección Femenina había hecho de la austeridad una virtud, no sólo en su organización interna, sino en la imagen que fue capaz de proyectar durante estos años difíciles y caracterizados por el hambre generalizada y sus programas de formación doméstica hicieron creer a la población que el éxito personal en la gestión del hogar era la base de la mejora en la economía nacional global.

Con respecto a su intervención en el control de la población civil, en esta época de venganzas, denuncias y represalias, la Sección Femenina se negó a tomar parte en gran parte de la maquinaria represiva del Estado y su actividad fue mucho menor que la llevada a cabo por el Servicio Español del Magisterio masculino - hasta el punto de que

"el departamento de Educación recibió ordenes de ignorar los testimonios de la Sección Femenina pues se sabía que eran declaraciones caritativas y los únicos informes aceptados eran los procedentes de los párrocos y otros miembros del clero"194

prefiriendo el adoctrinamiento por medio de la revista Consigna y la reeducación a través de los cursos de formación. Respecto a la población general, la Sección Femenina utilizaba más bien sistemas de atracción por medio de su programa asistencial y promoción (canastillas, ayudas, becas, premios y distinciones) a los que se unía una presión "moral".

No obstante, el peso político personal de Pilar Primo de Rivera fue importantísimo. Su relación personal con Franco, su liderazgo total en la rama femenina de Falange- una vez superada la rivalidad con Mercedes Bachiller e incorporar el Auxilio Social a la Sección Femenina después de la guerra- y su rol específico dentro de Falange en el sector "legitimista" le garantizaron el acceso directo a las más altas esferas del poder durante el franquismo, aunque no bajo un conducto formal. Los cambios de gobierno daban pie a reuniones

\footnotetext{
${ }^{194}$ Según la entrevista realizada a Enrique de Sean el 3 de junio de 1995, recogida por RICHMOND, K.(2004) en Las mujeres en el fascismo español, Op. Cit. Pag. 161
} 


\section{Capítulo 5. Música e ideología 2: La Sección Femenina}

informativas de la directora con las Regidoras centrales en la Calle Almagro 36 para compartir confidencia sobre las realidades del régimen y en especial, sobre "el posible efecto de los ministros recién nombrados en sus programas" 195

\subsubsection{De 1945 a 1960}

Tras la derrota del eje fascista europeo en la II Guerra Mundial, España tiene que recolocarse en el nuevo entorno de la política mundial. En el nuevo equilibrio de poder entre los dos grandes bloques (Estados Unidos y Rusia), está claro que la ideología anticomunista y la mera geografía nos colocan en el entorno de acercamiento a Estados Unidos. Todos los esfuerzos políticos del momento se realizan para conseguir una distensión de la situación de aislamiento internacional que había seguido a la guerra civil y un mayor acercamiento a las posturas del bloque occidental. Desde las primeras ayudas del Plan Marshall americano hasta la instalación de bases militares norteamericanas en el territorio nacional, la balanza se inclina a dejar atrás el sistema de autarquía y entrar a formar parte de un contexto económico global de carácter industrial y urbano. Aunque sus efectos económicos no se verán hasta la década de los 60 a nivel de la población, estos quince años están marcados por un giro en la orientación política e ideológica del régimen que afecta a todo el sistema.

Desde el punto de vista político interno el hecho más notorio es la Ley de Sucesión de 1947 por la que Franco prevé la reinstauración del sistema monárquico. Esta es una de las grandes contradicciones del régimen, ya que Franco era el autoproclamado J efe del partido único del Movimiento Nacional cuya base en principio era Falange (unificada con los otros partidos de derechas en 1937). Es evidente que el equilibrio de fuerzas políticas había cambiado, porque Falange era desde su fundación profundamente antimonárquico, y sin embargo, el peso de los tradicionalistas y los partidarios de la vuelta a la monarquía, apoyados por la I glesia católica, estaban ganando.

\footnotetext{
${ }^{195}$ Entrevista a la afiliada 8b) de la ANA del 29 de octubre de 1977 y 30 de mayo de 1996 recogida en RICHMOND, K. (2004) Las mujeres en el fascismo, Op. Cit. Pag.145
} 


\section{La educación musical en el franquismo}

Por si no fuera poco, en 1959 se decide el traslado de los restos de José Antonio Primo de Rivera desde el monasterio de El Escorial al nuevo recinto del Valle de los Caídos. Si su entierro en 1939 en el monasterio donde estaban enterrados los reyes de España fue acto cargado de simbología, su exhumación y traslado fue un hecho aún más cargado de significado. Supuso la deslegitimación de Falange en el poder mientras Franco se mantenía en el mismo de manera unipersonal durante el resto de su vida.

Ambos hechos hicieron intervenir a Pilar Primo de Rivera y fueron causa de profunda decepción en Falange. El Frente de Juventudes (masculinas) reaccionó ante ello con una profunda - y continuamente expresada a través de las canciones - decepción política. Sección Femenina, como siempre en su actitud negociadora, reaccionó incrementando su labor formadora y distanciándose cada vez más de sus vinculaciones políticas.

Por otra parte, la separación del Frente de Juventudes había dejado a Sección Femenina casi sin financiación, aparte de ciertas concesiones otorgadas puntualmente, como el acuerdo de 1948 por el que las entidades provinciales debían cederse locales a la Sección Femenina de forma gratuita o por alquileres casi simbólicos y el decreto de 1952 que exigía a los gobernadores civiles poner a disposición de la Sección Femenina sus fondos asistenciales. Esta carencia de medios económicos ${ }^{196}$ fue subsanada por medio de proyectos subvencionados para los programas formativos por el Ministerio de Educación y Ciencia, pero aún así desde 1947 se tuvieron que introducir cuotas por alojamiento en las escuelas mayores y menores, campamentos y sanatorios.

Estos años son, pues, difíciles para Sección Femenina que tiene que hacer frente a la absoluta necesidad de una transformación y modernización para adaptarse al nuevo entorno político. Pilar Primo de Rivera reconoció que se

\footnotetext{
${ }^{196}$ La financiación más elevada que recibió el Movimiento Nacional correspondió a 1945 y supuso el 1,92\% del gasto público. En 1946 cayó a un 0,38\% y llegó al 0,21\% en 1958.Según CHUECA, R. (1983). El fascismo en los comienzos del régimen de Franco: un estudio sobre FETJONS. Madrid: Centro de Investigaciones Sociológicas. Pag- 203
} 


\section{Capítulo 5. Música e ideología 2: La Sección Femenina}

abría un período de crisis y transformación ya en el Consejo de 1952 que exigía dejar atrás la retórica y el simbolismo que las había distinguido y distanciarse de las alusiones y usos que les asociaban a los fascismos europeos. En el Consejo de 1956 expuso que "debemos renovarnos o morir" e inició la reforma que implicó la retirada de los signos de militarización más visibles (el saludo y el uniforme) y diluyó una parte de la doctrina política impartida a las no afiliadas en los cursos y manuales. Sin embargo no cambió aspectos fundamentales como las demandas de mejoras salariales para su personal especializado, la rigidez del sistema jerárquico establecido o los hábitos de imponer ciertas creencias a la población femenina.

Se inició un proceso de transformación interno sobre su propio futuro que llevó a que en diciembre de 1957 se reunieron todas las regidoras centrales para debatir cómo hacer frente a las nuevas circunstancias en el que, según Richmond $^{\mathbf{1 9 7}}$, se llegaron a hacer tres propuestas:

- la racionalización y modernización desde dentro de todas las regidurías (que fue la que finalmente se adoptó)

- eliminar cualquier contenido político de sus programas transformándola en una corporación puramente profesional y educativa

- segregar la Sección Femenina del Movimiento Nacional y convertirla en

\section{una asociación no política}

Ciertamente había signos de que el mensaje político de la Sección Femenina no interesaba a la población femenina y la afiliación juvenil voluntaria descendía. La falta generalizada de medios económicos, el enfrentamiento cotidiano con el machismo tradicional y los prejuicios contra la mujer de la sociedad española, el voluntarismo y el sentido de "misión" que caracterizaban a los primeros mandos no suponían un atractivo para las nuevas jóvenes en una época de grandes cambios.

${ }^{197}$ RICHMOND, K. (2004) Las mujeres en el fascismo español. Op. Cit. pag. 182 


\section{La educación musical en el franquismo}

Sí lo hacían en cambio sus programas de formación, cuyos resultados sociales y educativos eran mucho más apreciados por el régimen y la aportación a la cultura nacional de la Sección Femenina fue mucho menos controvertida que sus acciones en los ámbitos legislativo y político.

La actividad de Sección Femenina en estos campos, sin embargo, tuvo cierta relevancia durante este período, aunque no una gran aceptación social. A partir del Congreso Femenino Hispanoamericano el 3 de junio de 1951, en el que se trató sobre el empleo femenino, la educación superior y la función de la mujer en la política ${ }^{198}$, la organización se decidió a intervenir a favor de algunos cambios en la legislación referente a las mujeres. La líder innegable de estas propuestas fue Mercedes Fórmica, directora de un equipo de once mujeres profesionales del Instituto de Estudios Políticos. Sus esfuerzos culminaron en 1958 con el cambio en el código civil de 66 puntos favorables a las mujeres, fundamentalmente vinculados al matrimonio, las propiedades en caso de separación legal o sucesivos matrimonios, la reivindicación del patrimonio de los bienes compartidos y la supresión de la distinción entre el adulterio masculino y femenino, considerando ambos como causa de separación legal ${ }^{199}$. A partir de las propuestas realizadas por la regidora de la Hermandad de la Ciudad y el Campo se realizó también una propuesta para instaurar un plan de seguridad social a las empleadas de hogar que no vio la luz hasta 1959 (tras cuatro años de trabajar en ello) y cuya forma de negociar, tan representativa de la época, está recogida por Richmond a partir de una entrevista:

\footnotetext{
“En la primera sesión (del Consejo de Ministros) no había sido aceptada por falta de tiempo y se decidió que fuera presentada aquel día. En el último mintuo, el ministro responsable, Fermín Sanz Orrio, llamó a su despacho a la regidora de la Hermandad de la ciudad y el campo y le dijo que no se presentaría a debate porque las esposas de los ministros habían oído hablar de las propuestas y se oponían a ellas basándose en que el plan aumentaría sus gastos salariales en el servicio doméstico. La respuesta de la
}

\footnotetext{
198 SUÁREZ FERNÁNDEZ, L (1992) Crónica de la Sección Femenina y su tiempo. Madrid: Asociación Nueva andadura, pag. 254

199 LORING, T. (1993) Promoción político-social de la mujer durante los años del mandato de Franco. En VV.AA El legado de Franco. Burgos: Fundación nacional Francisco Franco
} 


\section{Capítulo 5. Música e ideología 2: La Sección Femenina}

Sección Femenina consistió en invitarlas a un té en el Círculo Medina, junto con Doña Carmen, la mujer de Franco. El personal de la SF expuso a Doña Carmen la necesidad de legislación y ella prometió explicárselo a su marido y el proyecto fue aprobado sin oposición en el siguiente Consejo de Ministros"200

El "Montepío del Servicio Doméstico" fue creado por decreto del 17 de marzo de 1959.

No obstante, la labor política de la Sección Femenina, aparte de negociada por canales no oficiales, no fue reconocida ni especialmente valorada por las mujeres, ya que no se ajustaba al mensaje predominantemente doméstico que todavía mantenía de manera generalizada.

La que sí obtuvo gran aceptación tanto a nivel popular como oficialmente fue su actividad de propaganda de España llevada a cabo por el Servicio Exterior por medio de los grupos de Coros y Danzas. El trabajo de recopilación y difusión del folklore, tanto de melodías como de danzas, llevado a cabo con tanto ahínco y esfuerzo en los años anteriores (premios de recogida de materiales, concursos a nivel local y nacional de grupos de coros y de danzas, constitución de grupos instrumentales, vocales y coreográficos, selección de materiales procedentes de todas las regiones españolas) dio sus frutos visibles cuando en 1948 realizó por propia iniciativa una gira por Argentina y Brasil para actuar en embajadas y asociaciones culturales. El impacto que dicha actividad tuvo sobre los emigrantes y comunidades españolas en el extranjero fue extraordinario "reavivando sentimientos de patriotismo entre los españoles en el exilio" según Pilar Primo de Rivera ${ }^{201}$ y, sin duda, la nostalgia de un país al que tardarían en volver fuera por cuestiones políticas o puramente económicas. Lo que empezó siendo una mera actuación cultural se convirtió en un triunfo político, que abría las puertas de España a Hispanoamérica en un momento en el que se intentaba denodadamente romper el bloqueo internacional. La labor de Sección Femenina armonizaba con los esfuerzos del régimen por promover los lazos culturales en

\footnotetext{
${ }^{200}$ Entrevista a la afiliada (b) de la AN de 30 de mayo de 1996. En RICHMOND, K (2004) LaS mujeres en el fascismo español. Op. Cit. Pag. 174

201 PRIMO DE RIVERA, P. (1983) Recuerdos de una vida. Madrid: Dyrsa
} 


\section{La educación musical en el franquismo}

el extranjero y contrarrestar el aislamiento internacional de España ${ }^{202}$. En 1951 La Sección Femenina logró organizar el Congreso Femenino Hispanoamericano que continuó su labor a través de foros culturales con seis de los países participantes y que culminaron en acuerdos de colaboración con los Círculos Medina y la concesión de becas para estudios y estancias anuales de mujeres profesionales latinoamericanas en España y viceversa.

En cuanto a la situación política interior, las expectativas de Sección Femenina crecieron ante el nombramiento de J oaquín Ruiz Jiménez al frente del Ministerio de Educación en 1951. El nombramiento de Pedro Laín Entralgo, Antonio Tovar y Torcuato Fernández Medina como rectores de universidad ponían de manifiesto su confianza en los sectores más intelectuales del Movimiento Nacional. La Sección Femenina esperaba que sus propuestas de mejorar los cursos de formación, la ampliación de especialidades y la creación de titulaciones encontrarían apoyo en el ministro. Y así fue. Lamentablemente, los incidentes del SEU - bajo la dirección de Jorge Jordana - entre 1954 y 1956 que culminaron en protestas violentas y el cierre temporal de la Universidad de Madrid y la suspensión de dos puntos del Fuero de los españoles que permitieron la detención de varios estudiantes. Todo ello conllevó la destitución de Ruiz Jiménez como ministro e incluso la del Secretario General del Movimiento Raimundo Fernández Cuesta. La Sección Femenina se vio dividida entre sus deseos de renovación cultural y pedagógica y su preocupación porque los sucesos de las universidad y la implicación de la Sección Femenina del SEU pudieran comprometer la posición del Movimiento nacional dentro de la nueva situación de equilibrio de fuerzas del régimen (en la que ya su situación era mucho menos influyente con respecto a otras corrientes ideológicas en alza) y desplazar el apoyo de Franco hacia otros sectores.

Con todo, inició un proceso de reformas importantes que incluían desde su propia identidad hasta los programas de formación que se habían mantenido

\footnotetext{
202 En noviembre de 1945 se había retirado al embajador de EEUU en Madrid y en marzo de 1946 el gobierno francés había cerrado la frontera. En diciembre de 1946 las Naciones Unidas pidieron la retirada del reconocimiento diplomático. En PAYNE, S. (1987) The Franco Regime 1939-1975. Madison: University of Winconsin Press
} 


\section{Capítulo 5. Música e ideología 2: La Sección Femenina}

como el reflejo de su labor en la sociedad. La parte impuesta a la sociedad de forma obligatoria y gratuita, el Servicio Social, provocaba un serio rechazo en la población femenina, que procuraba eludirla, por lo que las estadísticas son bajas (en torno al 2,4\% de la población soltera femenina trabajadora en 1950).

Sin embargo la participación en los cursos de cocina, educación física y otras especialidades fueron en constante aumento. $Y$ también crecieron las escuelas de especialización en áreas nuevas de incorporación de la mujer al trabajo: divulgadoras rurales, practicantes y visitadoras sanitarias. En lo referente a la educación, la ley general de Educación de 1945 abrió un nuevo campo con la introducción de las escuelas del hogar. La formación del profesorado de educación física, música y ciencias del hogar, así como la alfabetización de adultos, supuso un enorme incremento de la actividad de la Sección Femenina para formar el personal que impartiera estas asignaturas en los centros educativos, tanto en la educación primaria como en la secundaria, que se vería en aumento durante toda la década hasta consumarse en las escuelas de especialidades de los años 60 . Y también una nueva oportunidad laboral para muchas mujeres: en 1951 había 6.293 instructoras de la Sección Femenina que impartían las asignaturas de política, educación física, ciencias del hogar y música en sus propios centros, y otras 939 docentes que ocupaban puestos retribuidos por el Estado y enseñaban las asignaturas preceptivas dentro del programa general ${ }^{203}$. Ello hizo necesario la creación de centros especializados en los que se expedían títulos oficiales (Instructoras nacionales) y de nivel inferior (instructoras locales y divulgadoras). También hizo crecer durante la última etapa de este período los centros de formación provinciales y locales en los diferentes ámbitos educativos y asistenciales, con la creación de nuevos colegios mayores y menores, talleres de artesanía, granjas escuela, y centros culturales.

\footnotetext{
${ }^{203}$ SECCIÓN FEMENINA. Labor realizada en 1951. pag. 18-19. en RICHMOND, K. (2004) Las mujeres en el fascismo español, Op. Cit. pag. 189
} 


\section{La educación musical en el franquismo}

\subsubsection{Desde 1960}

La Sección Femenina había sufrido una transformación fundamental, alejándose de su idealismo político doctrinal hacia una función más vinculada a la formación y la promoción de la mujer.

El mensaje doméstico de las épocas anteriores ya no tenía ninguna aceptación social debido a las transformaciones económicas y sociales que trajeron consigo la apertura al bloque occidental en el ámbito político y las medidas económicas del llamado "gobierno tecnocrático". España dejaba de ser un país eminentemente rural, tradicional y agrícola, para convertirse en una sociedad urbana, industrializada y moderna.

En este nuevo contexto, la incorporación de la mujer a los sectores productivos de la población era inminente. Las necesidades de formación de las mujeres eran cada vez mayores y su incorporación a los estudios medios y superiores fue incrementándose de manera exponencial desde los primeros años 60.

Desde el punto de vista político, era evidente que Falange (tanto en su versión masculina como femenina) había perdido gran parte de su influencia en el núcleo de poder y que Franco se había ido afirmando en un sistema de mando unipersonal. El control que ejercía en la propia institución al haberse autonombrado jefe de todos los partidos unificados en el Movimiento Nacional en 1937, se trasladaba dentro de las filas falangistas a un constante conflicto de lealtad y temor a las consecuencias políticas de cualquier gesto de oposición. Franco no dudó nunca en destituir a directores generales, ministros, al Delegado nacional 0 al jefe del SEU en cuanto cualquiera de ellos o sus subordinados mostraron la más mínima crítica a su actuación o ésta no se ajustaba a su conveniencia política.

Los años 60 supusieron la entrada en la política española con fuerza de otros sectores, especialmente la Iglesia y los monárquicos, que veían como sus expectativas crecían en el nuevo entorno económico (aperturismo) y sucesorio (la ley de sucesión proclamaba que España era un reino). La aparición de 


\section{Capítulo 5. Música e ideología 2: La Sección Femenina}

especialistas vinculados a la formación católica y de ciertas asociaciones religiosas que los promovían políticamente (Opus Dei) es lo que se ha llamado "el período tecnocrático", en el que Falange se vio cada vez más relegada del poder que hasta entonces había tenido para pasar a ocuparse meramente de las necesidades burocráticas del régimen.

En el caso de la actividad dedicada a la juventud, era cada vez más evidente la competencia con otros grupos y asociaciones de tipo católico (Acción Católica, comunidades de base parroquiales) o lúdico (scultismo, grupos de montañismo y asociaciones deportivas). Tanto Sección Femenina como Frente de Juventudes perdieron en esta década su monopolio en la influencia y organización de las actividades juveniles. Ambos fueron perdiendo y desvinculándose de los matices políticos de tiempos anteriores y la afiliación dejó de ser necesaria para participar en sus actividades, cursos de formación y especialidades.

La ley de Educación de $\mathbf{1 9 7 0}$ institucionalizó su presencia en las áreas de educación física, política y música, las tres áreas principales de acción educativa en el medio escolar. Sección Femenina se dedicó fundamentalmente a partir de 1960 a promover la formación de nivel superior en estos tres planos a través de las titulaciones en las escuelas de Especialidades y colocar a su personal en la mayor cantidad posible de centros educativos del Estado.

Ello y la organización administrativa del propio Estado (organización de los gobiernos civiles, delegaciones provinciales y expansión de los servicios del Ministerio de Educación y Cultura, constituyeron las principales salidas laborales que Sección Femenina canalizó para las mujeres en los años 60.

Ciertamente la actividad de los mandos en los años anteriores no había coincidido para nada con la imagen doméstica y subordinada de la mujer en la sociedad franquista: tenían actividad política, muchas de ellas eran solteras y económicamente independientes (aunque los sueldos del personal interno eran 


\section{La educación musical en el franquismo}

bastante bajos), tenían una imagen de modernidad ligada a la actividad deportiva y el trato abierto a la hora de expresar sus opiniones, católicas (aunque la práctica religiosa propuesta por Fray Justo Pérez de Urbel era mucho más participativa que la habitual), dinámicas y activas parecían decididas a cambiar la sociedad española a través del propio esfuerzo y de la educación de las mujeres (y a través de ellas a sus hijos).

Los años 60, sin embargo, trajeron consigo unos cambios que hicieron que parte de su modernidad quedara ligeramente desfasada. La emigración del campo a la ciudad de una gran parte de la población agrícola, atraída por los mejores sueldos y las perspectivas de vida (escuelas, institutos, sanidad) supuso una transformación profunda a nivel social.

Entre los que más afectaron a Sección Femenina y su labor podemos destacar:

- El olvido de las tradiciones rurales y el desprecio por lo que estaba ligado a ellas (el folklore, que había sido la niña mimada de los intereses culturales y musicales de la Sección Femenina durante los 35 años anteriores)

- la incorporación creciente de la mujer a los sectores productivos remunerados e industriales por imperativo económico para sacar económicamente adelante a la familia en la nueva ubicación urbana y que hacía que la figura doméstica de la mujer entrara en retroceso

- el rechazo político e ideológico al pasado y a los principios de "esfuerzo personal" como elemento de transformación de la sociedad y el Estado (la Revolución de José Antonio) y la proyección hacia un futuro en el que es el Estado quien tiene obligaciones para con el ciudadano

- el crecimiento en la importancia de otras ideologías y en cualquier caso el rechazo y el absentismo - cuando no la oposición abierta - a la política promocionada por Franco

- sus formas y estilo se habían quedado anticuados, especialmente len lo referente a la autoridad, así como gran parte de su ideología originaria. 


\section{Capítulo 5. Música e ideología 2: La Sección Femenina}

Sección Femenina era consciente de que los tiempos estaban cambiando vertiginosamente rápido para las mujeres, pero no se decidió a desligarse completamente de su pasado político. Aunque su actividad en los últimos años fuera sin duda la formación y cada vez estaba más alejada sentimental, ideológica y físicamente del poder y de Franco, se mantuvo en sus posiciones de control y exclusividad y en un erróneo sentido de la lealtad que la hicieron irse quedando desfasada.

Mientras, se dedicaban a la formación de personal femenino en un plano cada vez más ambicioso, que abarcaba la educación superior, las salidas laborales en el sector administrativo y educativo, la activación de la vida cultural (teatro, radio, televisión, conciertos) y la innovación metodológica en las áreas de la Educación Física y la Música.

En los años 70 tuvieron un nuevo acercamiento a la OJE (antes Frente de Juventudes), especialmente en el área de cultura, cuando accedió a su jefatura Juan Van Halen, introduciendo a los niños y los jóvenes en el acceso a la formación cultural que hasta entonces había sido fundamentalmente femenina, iniciando - aunque muy someramente - un proceso de coeducación. Empezaron a programar cursos y actividades indistintamente del sexo y a coordinar algunas de sus actuaciones (cursos de música para maestros y maestras, actividades deportivas mixtas, espectáculos de Coros y Danzas).

A partir de la muerte de Franco en 1975, así como el sector masculino Movimiento Nacional fue el que realizó la transición política hacia la democracia, la sección Femenina se dedicó fundamentalmente a reorganizar la situación laboral de su personal que se transformó en parte de la administración del Estado. Poco a poco fue desposeyéndose de sus características anteriores y diluyéndose en el olvido. Sus programas educativos, sus publicaciones (muy numerosas y de gran calidad en los últimos años), sus cursos y sus actividades organizadas fueron adquiriendo otros nombres y aspectos, pero dejando su legado en la formación de toda la siguiente generación. 


\subsection{LA ESCTRUCTURA DE LA SECCIÓN FEMENINA}

La Sección Femenina de FET y de las JONS formó parte a partir de la guerra civil de la Jefatura Nacional del Movimiento y a partir de la Orden de 25 de julio de 1938 y la Ley de 21 de mayo de 1941 estuvo integrada dentro de la Vicesecretaría General del Movimiento (formada por las Delegaciones Nacionales de Sección Femenina, Frente de Juventudes, Delegación nacional de Exterior y la J efatura de provincias.

Se estructuró en una jerarquía vertical, que regulaba la actividad a partir de cuatro grandes ramas, de menor a mayor rango: Afiliadas, delegaciones locales, delegaciones provinciales y delegación nacional.

La Delegación nacional es pues la responsable y coordinadora final de todas las funciones que se refieren a la formación, promoción e integración política y social de la mujer española, en colaboración con otros órganos del Estado y bajo la dirección del Ministro Secretario General del Movimiento ${ }^{204}$.

\subsubsection{Organigrama de los órganos centrales de la Sección Femenina}

Bajo la dirección de la Delegada Nacional vitalicia, Pilar Primo de Rivera, la Sección Femenina se organizó en varios departamentos.

- Secretaría Nacional, de la cual dependen cinco departamentos y el gabinete técnico.

- 1. Departamento de coordinación. Su función es informar, asesorar e inspeccionar todos los órganos y servicios de la Delegación nacional.

o Sección de inspecciones. Su función consiste en analizar y conocer las provincias a través de la información que reciben, coordinar la Delegación nacional y las delegaciones provinciales, coordinar y controlar las actividades interprovinciales y coordinar y controlar las inspecciones nacionales. Se subdivide a su vez en dos Oficinas:

- Oficina de información provincial y análisis de datos

${ }^{204}$ Artículo 48 del Estatuto Orgánico del Movimiento 


\section{Capítulo 5. Música e ideología 2: La Sección Femenina}

- Oficina de inspección nacional y recogida de datos

o Sección de asesoramiento e información. Su función es asesorar en la elaboración del plan de actividades e inversiones, la elaboración del calendario de actividades, la información sobre normas nacionales (a través de circulares, resoluciones e instrucciones) y el asesoramiento de instituciones ajenas a Sección Femenina. Se subdivide en dos Oficinas:

- Oficina de estudio informativo

- Oficina de información coordinada

- Sección de relaciones exteriores. Su función es prestar asistencia a las representantes de la Delegación nacional en organismos internaciones, coordinar las relaciones de la Delegación nacional con el extranjero, fomentar y asistir la relación de las asociaciones españolas con otras del extranjero y hacer llegar a los españoles residentes en el extranjero los servicios de la delegación. Se subdivide en tres Oficinas:

- Oficina de Extranjeros y Emigración

- Oficina de Hispanoamérica

- Oficina de becas

- 2. Departamento de promoción. Su función es promover y gestionar los servicios y actividades que conduzcan especialmente al desarrollo humano y social de la mujer y de las comunidades rurales y urbanas, así como de gestionar el acceso e incorporación de la mujer a la vida laborar y profesional. Se subdivide en dos Secciones:

- Sección de promoción humana y social, que a su vez se compone de dos Oficinas y un servicio:

- Cátedras ambulantes y permanentes de la Sección Femenina

- Oficina de Atención social

- Servicio de educación sanitaria

o Sección de promoción rural y profesional, que a su vez se compone de tres Oficinas y un servicio: 
- Oficina de formación profesional

- Oficina de promoción rural

- Oficina de actividades socio-laborales

- Servicio de Ayuda al hogar

- 3. Departamento de participación. Es uno de los departamentos de mayor interés con respecto a la música, ya que entre sus funciones destaca la promoción de actividades de tipo cultural y artístico, entre las que destaca la actividad musical. Está dividida en varias secciones

- Sección de participación política y asociaciones

o Sección de centros de convivencia y actividades culturales y artísticas. Es la encargada de organizar y dirigir todo tipo de actividades, concursos y certámenes que convoque la Delegación nacional. Se subdivide en tres Oficinas:

- Oficina de Centros de convivencia

- Oficina de Programación y proyección cultural y artística. A su vez se dividía en dos unidades:

1. Programación, asesoramiento y selección de actividades en centros culturales

2. Dirección de certámenes, exposiciones y concursos.

- Oficina de música y folklore. A su vez se dividía en:

1. Oficina de actividades folklóricas y musicales (certámenes, concursos, intercambios con otros grupos)

2. Oficina de Enseñanza de la música y el foklore, que se ocupaba de todo lo referente al asesoramiento de planes de enseñanza, programas y textos para todos los centros de enseñanza dependientes del departamento de Participación y todas aquellas actividades docentes en relación con la música y el folklore. 


\section{Capítulo 5. Música e ideología 2: La Sección Femenina}

- Sección de educación física y actividades deportivas, que se subdivide en tres Oficinas:

- Oficina de Educación Física

- Oficina de actividades deportivas

- Oficina de instalaciones y clubes

o Sección de servicio social, que a su vez se subdivide en cuatro Oficinas:

- Oficina de Planificación

- Oficina de inspección y asesoramiento

- Oficina de tramitación y control

- Oficina de medios y resultados

- 4. Departamento de formación y participación de la juventud. Es el gran departamento del que depende la gestión de los asuntos que son competencia de la Delegación nacional en materia de Educación cívicosocial y política, educación física, enseñanzas del hogar y ciencias domésticas, así como la edición de los textos correspondientes

o Sección de enseñanzas fundamentales, que tiene como función colaborar con el Gabinete Técnico en la elaboración de planes de estudio, cuestionario y programas, colaborar en el nombramiento y cese de asesores y profesores, gestionar las relaciones entre los centros educativos y el profesorado de enseñanzas fundamentales, la programación de los espacios dedicados a las enseñanzas en los medios de comunicación y la programación de los cursos de tiempo libre. Se subdivide en los oficinas:

- Oficina de orientación técnico-legal

- Oficina formativa

- Sección de centros docentes, que tiene como función la responsabilidad de los centros de EGB y Preescolar, la formación de las colegiales y alumnas, la formación complementaria y actividades de las alumnas menores y realizar el informe sobre el nombramiento del personal directivo de las instituciones encomendadas a esta sección. Se organiza en dos Oficinas: 
- Oficina de colegios

- Oficina de Centros de la Sección Femenina

- Sección de centros de convivencia. Su función es estimular, promover y dirigir las actividades de los centros de convivencia, elaborar los programas de actividades de estos centros y responsabilizarse de su dirección. Se organiza en dos Oficinas:

- Oficina de Círculos Medina

- Oficina de Albergues al aire libre

- Sección de servicios a la juventud. Se organiza en dos Oficinas:

- Oficina de Actividades de Educación Física y Deporte

- Oficina de Actividades culturales y artísticas

o Sección de participación. Se organiza en dos Oficinas

- Oficina de asociaciones

- Oficina de Organización juvenil

- 5. Departamento económico-administrativo

o Sección de administración, cuya función es la elaboración y control del presupuesto, el registro de las operaciones contables y de los balances económicos, intervención de tesorería y liquidación de toda la gestión económica. Se organiza en tres Oficinas:

- Oficina de presupuestos

- Oficina de contabilidad

- Oficina de habilitación y justificación

o Sección de personal, que confecciona las plantillas, expedientes, hojas de servicio, nóminas y retribuciones, tareas de selección, formación y perfeccionamiento del personal, realiza los estudios sobre puestos de trabajo y tramita la Seguridad Social de todo el personal de la Delegación nacional. Se subdivide en tres oficinas y una Unidad:

- Oficina de organización

- Oficina de gestión administrativa

- Oficina de destinos 


\section{Capítulo 5. Música e ideología 2: La Sección Femenina}

- Unidad de escuelas

o Sección de patrimonio e instalaciones, cuya función es la orientación, dictamen técnico y ejecución de los proyectos de obras nuevas, la gestión de compra y adquisición de bienes y servicios y el registro de los bienes inventariables

- Gabinete técnico

- Sección de estudios y elaboración técnica, cuya función es asistir técnicamente a la Delegada y a la Secretaría Nacional, coordinar los trabajos preparatorios de las disposiciones generales de carácter reglamentario, tramitar la publicación de las disposiciones de la Delegación Nacional, estudiar y recopilar documentación técnica y legal y elaborar las estadísticas, planes de estudio, cuestionario y planes de actividades de tiempo libre. Se orgniza en dos Oficinas y una Unidad:

- Oficina de Planes de estudio y elaboración técnica

- Oficina de documentación

- Unidad de normas y planificación

o Sección jurídica, cuya función es asistir a la Delegación nacional en orden a estudios, relaciones e informes de carácter legal a través la Unidad de Cortes y la Unidad de Letrados.

o Sección de medios de comunicación: prensa, archivos y censura, propaganda, radio, fotografía y cine. Su función es elaborar información para su difusión en los medios de comunicación social, prensa y revistas. También se encarga de las relaciones públicas y el protocolo. Se organiza en dos Oficinas:

- Oficina de Gabinete de prensa y redacción de entrevistas

- Oficina de medios audio-visuales

o Sección de ediciones y publicaciones. Es la encargada de editar y distribuir los libros de texto para las enseñanzas que imparte la Delegación nacional y las publicaciones de la misma. Se organiza en

- Servicio técnico de publicaciones y producción 
- Oficina comercial administrativa

- Unidad de distribución y administración de revistas

- Servicio de orientación política y formación integral. Depende directamente de la Delegación nacional como órgano permanente de asistencia para fijar los criterios y directrices sobre orientación política y formación integral, determinar los objetivos políticos en las programaciones anuales y la preparación de mandos y directoras de instituciones y actividades

- Servicio de promoción universitaria. Depende directamente de la Delegada nacional. Su función es ofrecer a la mujer universitaria servicios y medios humanos y materiales, fomentar el espíritu asociativo y estimular el funcionamiento y dirigir los Colegios mayores, residencias universitarias y Centros de formación de Mandos

Se regían por un sistema de órganos colegiados y representación constituidos por un consejo rector, la asesoría central (formada por asesores y sus auxiliares) y la junta consultiva (formada la secretaria general, las regidoras centrales de servicio, los asesores y militantes escogidos por la delegada nacional).

\subsubsection{Estructura de la Regiduría Central de Cultura de la Sección Femenina en su relación con la música}

A mediados de los años 1960, la Regiduría Central de Cultura de la Sección Femenina, bajo la dirección de MMa Josefa Sampelayo, explicita su relación con respecto a la educación musical integrada dentro de las escuelas del hogar. Así, en la documentación del Archivo General de la Administración ${ }^{205}$ consta que su "misión" es

\footnotetext{
“la dirección y orientación de las Enseñanzas del Hogar ordenadas por la Orden de 1 de Febrero de 1966 en todo el ámbito femenino; la dirección y orientación de las Escuelas de música en todos los centros de Sección Femenina; la planificación de todos los programas culturales en todos los centros de la Sección Femenina y la
}

${ }^{205}$ ARCHIVO GENERAL DE LA ADMINISTRACIÓN (AGA). Caja 3 de 51.20 


\section{Capítulo 5. Música e ideología 2: La Sección Femenina}

colaboración y control con los servicios técnicos de proyección provincial para la ejecución de estas normas".

Entre sus funciones destacan :

1. La coordinación con el MEC en todo lo referente a las enseñanzas que por ley tiene encomendadas

2. Confeccionar los cuestionarios, programas y todas las orientaciones didácticas para todo lo referente a las escuelas de hogar

3. Capacitar a todo el profesorado de Hogar y Música en sus distintos niveles: profesoras y auxiliares

4. Comprobar el cumplimiento de las materias técnicas y formativas en las Escuelas nacionales de Hogar t de Música

5. Realizar todos lo planes que por los distintos servicios le son encomendados en cuanto se refiere a la enseñanzas de Hogar y Música

6. Asesorar a todos los centros que lo soliciten en estas materias

7. Programar y asesorar a todos los servicios de la Sección Femenina en todo cuanto a música y hogar se refiere

8. Participar en todas las Juntas de Hogar del MEC

9. Vigilar el cumplimiento de planes en todas las escuelas nacionales y provinciales

10. Nombrar, de acuerdo con la sección de personal, el profesorado de dichos centros

11. Promover todo el resurgimiento del folklore por medio de concursos, cursos, etc.

12. Confeccionar con los distintos gabinetes técnicos los textos, boletines, etc. para las enseñanzas de hogar y música

13. Coordinar con todos los organismos oficiales la programación de las enseñanzas de hogar y música

14. Coordinarse con todos los organismos extranjeros relacionados con las materias de hogar y música 
15. Dirigir y vigilar la función de los Círculos Medina, promoverlos y coordinar sus actividades

16. Asesorar y confeccionar los planes culturales que los distintos servicios le soliciten

17. Dirigir toda la economía de servicio

Para ello se acuerda la creación de:

- Gabinete Técnico de Música y Gabinete Técnico de Hogar

- Departamento de Música, Departamento de Hogar y Departamento de extensión cultural (que se ocupaba de los Círculos Medina, las bibliotecas y las actividades culturales)

Las funciones del Gabinete Técnico son:

a. La planificación, programación y cuestionario referente a Hogar y Música en todos sus niveles

b. La investigación de todas las enseñanzas que tiene encomendadas el servicio y el estudio de cuantos planes se le entreguen

c. La dirección de Boletines especializados para las escuelas

d. El estudio de todos los textos de sus materias específicas

e. El estudio de todos los planes de estudio nacionales y extranjeros relacionados con sus materias

f. La condenación con las Escuelas Nacionales a través de los Departamentos centrales

g. El asesoramiento de todas las publicaciones nacionales y extranjeras para los diferentes servicios

h. Los ficheros de investigación y la bibliografía relacionada con sus materias

Las funciones del Departamento de Música son: 


\section{Capítulo 5. Música e ideología 2: La Sección Femenina}

a. Dirigir, de acuerdo con el Gabinete Técnico, la Escuela Nacional de Música y danza

b. Planificar, promover y vigilar todas las actividades obligadas y voluntarias, de todos los servicios de la Sección Femenina

c. Orientar y aconsejar acerca de todas las enseñanzas de música en el ámbito general a todos los centros e instituciones que lo soliciten

d. Investigar y promover, de acuerdo con el gabinete técnico y a través de sus instructoras, en todo lo referente al folklore y la orientación a los grupos de nueva creación en cuanto a la selección de danzas, trajes y canciones

e. Organizar y planificar los cursos provinciales de renovación y cursos monográficos referentes a música

f. Estudiar, de acuerdo con el gabinete técnico, nuevos métodos musicales educativos

g. Coordinarse con los organismos oficiales implicados en la enseñanza de la música

h. Confeccionar, de acuerdo con el gabinete técnico, textos, cancioneros y folletos relacionados con la enseñanza de la música

i. Organizar y controlar todos los viajes que se realicen por la península y el extranjero

j. Programar y seleccionar las canciones y danzas que deben interpretarse en toda clase de muestras y concursos

Las funciones del Departamento de Extensión cultural se refieren más bien a la actividad realizada a través de las formas de educación no formal, especialmente a través de los Círculos Medina y son:

a. La programación y asesoramiento de todos los planes culturales de la Sección Femenina de acuerdo con los distintos Servicios Centrales

b. Programación, de acuerdo con las jefes de los Círculos Medina, de sus actividades y vigilancia de las mismas

c. Creación y orientación y vigilancia de los Círculos Medina 
d. Coordinación con el Ministerio de Información y Turismo para la programación de actos en los Círculos Medina

e. Estudio económico y administración de los Círculos Medina en cuanto a las subvenciones nacionales

f. Asesoramiento de conferencias, concertistas y otros intérpretes para la organización de actos en los Círculos Medina

g. La organización de reuniones de ámbito nacional de las directoras de los Círculos Medina

h. Asesoramiento bibliográfico de todos los servicios de la Sección Femenina

i. La selección de libros para todas las bibliotecas, tanto de los Círculos Medina como de las Escuelas nacionales

Según la documentación que consta en el Archivo General de la Administración ${ }^{206}$, la estructura del Departamento de música de la Regiduría Central de Cultura en los años de su mayor apogeo (en torno a 1970) estaba compuesta por el siguiente personal:

\begin{tabular}{|c|c|c|c|c|}
\hline \multicolumn{5}{|c|}{ Estructura de la Regiduría Central de Cultura de la Sección Femenina } \\
\hline \multirow[t]{3}{*}{ Altos cargos } & \multicolumn{4}{|c|}{1 mando político } \\
\hline & \multicolumn{4}{|c|}{1 mando de confianza } \\
\hline & \multicolumn{4}{|c|}{1 técnico formativo } \\
\hline $\begin{array}{l}\text { Funcionarios } \\
\text { nivel } 8\end{array}$ & 2 de música & $\begin{array}{l}1 \text { de escuela } \\
\text { del hogar }\end{array}$ & $\begin{array}{l}2 \text { de Círculos } \\
\text { Medina }\end{array}$ & $\begin{array}{l}1 \text { secretaria } \\
1 \text { de revistas }\end{array}$ \\
\hline $\begin{array}{l}\text { Funcionarios } \\
\text { nivel } 7\end{array}$ & 3 de música & $\begin{array}{l}2 \text { de escuela } \\
\text { del hogar }\end{array}$ & & \\
\hline $\begin{array}{l}\text { Funcionarios } \\
\text { de nivel } 6\end{array}$ & 2 de música & $\begin{array}{l}1 \text { de escuela } \\
\text { del hogar }\end{array}$ & $\begin{array}{l}1 \text { de Círculos } \\
\text { Medina }\end{array}$ & \\
\hline $\begin{array}{l}\text { Funcionarios } \\
\text { de nivel } 5\end{array}$ & 1 de música & $\begin{array}{l}1 \text { de escuela } \\
\text { del hogar }\end{array}$ & & 1 de revistas \\
\hline Funcionarios & 1 de música & 1 de escuela & & 1 secretaria \\
\hline
\end{tabular}

${ }^{206}$ ARCHIVO GENERAL DE LA ADMINISTRACIÓN (AGA). Caja 1 del fondo 51.20 
de nivel 4 del hogar

Las tareas encomendadas a la Sección de Música son las siguientes:

MANDO POLÍTICO DE LA SECCIÓN DE MÚSICA

Planificación general de todos los estudios de música que por el técnico formativo le sean presentados, para las Escuelas Nacionales y todos los cursos de esta especialidad dependientes de la Sección Femenina, en sus escalas nacionales, provinciales y locales

\section{Aprobación de los planes musicales del Bachillerato}

Inspección de la Escuela nacional de música de Barcelona y de las que en su día se creen. Informe de su labor política y formativa

Promoción de cursillos provinciales y de todos aquellos extraordinarios que se organicen: Orff, Gregoriano, etc

\section{Revisión}

Concurso: Planificación general de los concursos nacionales en sus distintas fases, llevando las directrices generales de todas las pruebas

Selección de jurados provinciales y nacionales

Aprobación de itinerarios de las pruebas

Aprobación de canciones en los concursos nacionales y programas del año Aprobación de canciones de libre elección. En estos concursos participan unas 44.500 personas en las distintas pruebas y 2.000 en la fase final. Se movilizan unos 120 jurados

Inspección de las pruebas regionales para comprobar su autenticidad

Control de la investigación que en provincias se lleve en todo lo referente a canciones, danzas y trajes

Promoción de nuevos grupos: Insistir con las provincias para la creación de éstos y fomentar la investigación en las provincias

Viajes al extranjero y por la península: elección, de acuerdo con la Delegada Nacional de los grupos que saldrán al extranjero. Responsabilizarse del programa que lleven los grupos. Estudio de contratos, itinerario y actuaciones 
Aprobación de viajes organizados directamente por las provincias

Elección de los grupos que intervienen en los Congresos nacionales

Textos y creación de nuevos libros de folklore. Estudio para su puesta en marcha de todos los libros oque se editen para los distintos planes de música. Elección de las personas idóneas para realizarlas. Promoción de libros de danzas, trajes, postales y elección de las personas para realizarlos

Supervisión de los ficheros de la Regiduría Central

Cine: Revisión y aprobación de contratos en los que se solicita la autorización para la filmación de grupos

TVE: Selección de grupos para los concursos que ésta promueva o cualquier actuación en sus canales

Discos: Estudio de acuerdo con la casa Hispavox de los grupos que más interese grabar. Propuesta de nuevas grabaciones de villancicos y de cuantas canciones considere interesantes

Formación musical religiosa: De acuerdo con la Regiduría de Formación y el Técnico formativo, estudio y creación de cantos orientados a una mejor formación musical religiosa

Trajes regionales: Estudio y aprobación de todas las compras que se efectúen en las provincias, comprobando su autenticidad y calidad

Organización de exposiciones de trajes regionales en el extranjero

Adquisición de pianos e instrumentos musicales. Estudio para la adquisición de pianos para las escuelas mayores y los círculos Medina, así como para todos los grupos de coros y danzas

Aprobación de los conciertos en todas las escuelas nacionales de la Sección Femenina

MANDO DE CONFIANZA DE LA SECCIÓN DE MÚSICA

Inspección de los Cursos Nacionales de Música

Ayudar en la promoción de los cursos y cursillos musicales sean 
interesantes para una mejor capacitación de las Instructoras de música Comprobación de que las personas encargadas en la confección de los programas los hayan entregado y aportación de ideas para su elaboración Cumplimentar con sus colaboradoras directas toda la planificación para la Regidora Central en lo referente a los Concursos. Elaborar los presupuestos para su realización y enviarlos a Administración Central

Comprobar directamente la actualización de los ficheros y que contengan los datos necesarios

Responsable de cumplimentar toda la documentación referente a viajes al extanjero y por la península, intervención de grupos en los Festivales Nacionales y Congresos internaciones

Reclamar los informes sobre viajes. Revisión, comprobación y anotación en los libros de todo lo relacionado con concursos y en general con la parte administrativa del departamento

Discos: contacto directo con las provincias que acuden a grabar

Trajes regionales: responsable del inventario

Control de las discotecas

FUNCIONARIO TÉCNICO DE CATEGORÍA A, NIVEL 10

Debe ser Licenciado en Filosofía y Letras, rama de Pedagogía y conocer un idioma

Entregar a la Regidora Central de Cultura, para su estudio, los planes formativos relacionados con la música

Elaboración de los planes y programas que serán impartidos en las Escuelas oficiales del hogar y en los cursos provinciales

Estudio y confección de los Cuestionarios y programas de Primera y Segunda Enseñanza en lo que respecta a las Enseñanzas de Escuela del Hogar: Música

Colaboración con el gabinete de estudio de la Secretaría Técnica para 
informa sobre las cuestiones propuestas por Sección Femenina respecto a los planes de estudio, modificación de sistemas didácticos, etc

Conocer y examinar los planes de estudios de otros países, hacer un estudio comparativo y sugerir aportaciones y modificaciones

Estudio de los textos presentados por los diferentes colaboradores

Lectura de revistas de educación y enseñanza, señalando los artículos de mayor interés para la realización de ficheros de consulta

Proponer a la Regidora Central de Cultura los planes culturales que con respecto al Departamento considere oportunos

Asistir a las J untas centrales del profesorado de las escuelas oficiales del hogar

2 FUNCIONARIOS NIVEL 8.

- Jefe del departamento de música a nIVEL formativo. Debe estar en posesión de un título del Conservatorio y ser especialista en Folklore y Danzas

- JeFE DEL DEPARTAMENTO DE MÚSICA A NIVEL ADMINISTRATIVO

Estudio de planes formativos musicales, revisión de canciones y todo lo referente a la parte formativa del departamento, en estrecha colaboración con la Regiduría Central de Cultura

Inspeccionar periódicamente la Escuela nacional de Música de Barcelona

Planificar el Curso Nacional de Música y la coordinación con los profesores

Planificar los cursos provinciales en su parte técnica

- Formación de instructoras generales de música y danza para todos los centros de Sección Femenina y entidades que lo soliciten

- Seleccionar las instructoras que seguirán el curso nacional

Planificar cursillos para informar y poner al día en cuanto a nuevas tendencias 


\section{Capítulo 5. Música e ideología 2: La Sección Femenina}

educativas en el campo musical

Planificar todos los programas de bachillerato

Estudio técnico y clasificación de todas las canciones que se envíen a provincias

Estudio e informe técnico de las fichas de danzas enviadas por las provincias

Estudio e informe técnico de las fichas de trajes regionales enviadas por las provincias

Estudio e informe técnico de los villancicos inéditos. Primera selección anterior al asesor para el concurso nacional

Supervisión del contenido técnico, grabaciones y discos

Estar en contacto con la Regiduría de Formación para ayudar en todo lo referente a la educación musuical

Estudio técnico de los cancioneros y libros de formación musical editados por Sección Femenina

Estudio técnico de los planes de Bachillerato de otros países en lo referente a la educación musical

3 FUNCIONARIOS DE NIVEL 7

- JEFE DE NEGOCIADO DE MÚSICA. NIVEL FORMATIVO

- JEFE DE NEGOCIADO DE MúSICA. VIAJES. COROS Y DANZAS

- JeFE dE nEgOCIADO dE músiCA. INFORMACIÓN GENERAL Y NIVEL ADMI NISTRATIVO

Cumplimentar lo relativo a formación musical que le entreguen las Jefes de Departamento

\section{Ordenación de ficheros}

\section{Control de ficheros de canciones, danzas y trajes}

\section{Ordenación de cancioneros}

Ordenación de carpetas musicales con todas las partituras que se reciben de las provincias 
Envío de partituras a las provincias cuando éstas lo soliciten

Relacionarse con el personal para todas las propuestas de nombramiento y cese del profesorado de música y danza

Organización de rondallas

Organización de la festividad de Santa Teresa

Libro de inventario de trajes regionales

Correspondencia del asesor nacional

Correspondencia relativa a los cursos de música

Correspondencia y administración relativa a los viajes de los grupos de Coros y Danzas

Archivos de recortes de prensa, programas de actuaciones

Relación de material: magnetófonos, pianos, tocadiscos e instrumentos regionales en provincias

Correspondencia con Hispavox y contabilidad de la venta de discos

2 FUNCIONARIOS DE NIVEL 6

- CONCURSOS

- ADMINISTRACIÓN

Realizar los trámites de todo lo relativo a la movilización de los concursos nacionales

Comunicar a todas las provincias las normativas y circulares referentes a las pruebas, jurados e itinerarios en la fase inicial

Comunicar a los jurados las provincias y días de actuación que les corresponden

Archivo de relaciones nominales

Alojamiento de los jurados

Pases para el estudio de canciones y danzas nuevas

Comunicación a las provincias de las calificaciones obtenidas en las distintas pruebas 


\section{Capítulo 5. Música e ideología 2: La Sección Femenina}

\begin{tabular}{|l|}
\hline Archivo de fichas de nuevos componentes \\
\hline Recepción y tramitación de las reclamaciones relacionadas con las pruebas \\
\hline Organizar toda la documentación del concurso, una vez terminado \\
\hline Envío a provincias de las instrucciones sobre el concurso de villancicos \\
\hline $\begin{array}{l}\text { Tramitar la documentación para la realización de los concursos desde la fase } \\
\text { inicial hasta la final }\end{array}$ \\
\hline Tramitar la relación de villancicos inéditos para su estudio y clasificación \\
\hline $\begin{array}{l}\text { Tramitar la documentación de otros concursos (dulzaineros, TVE) que } \\
\text { puedan organizarse }\end{array}$ \\
\hline $\begin{array}{l}\text { Llevar la parte administrativa del departamento, el libro de cuentas de } \\
\text { subvenciones varias y el libro de cuentas correpondientes al presupuesto } \\
\text { asignado a esta Regiduría }\end{array}$ \\
\hline Revisión de las cuentas del Departamento de Música \\
\hline $\begin{array}{l}\text { Confección de los presupuestos del Departamento de Música para: viajes } \\
\text { al extranjero y península, actuación de grupos, concurso nacional de coros y } \\
\text { danzas, concurso de villancicos, concurso de dulzaineros y otros. }\end{array}$ \\
\hline $\begin{array}{l}\text { Preparación de dietas para los componentes de los grupos en sus actuaciones } \\
\text { y salidas }\end{array}$ \\
\hline $\begin{array}{l}\text { Llevar el libro de cuentas con el presupuesto interno asignado para la } \\
\text { recogida de canciones y danzas, trajes y premios. }\end{array}$ \\
\hline
\end{tabular}

1 FUNCIONARIO ADMINISTRATIVO DE MÚSICA. NIVEL 5

Realizar en su parte administrativa todo el trabajo que le entreguen los jefes del Departamento de Formación y funcional

Realización de las copias y trabajos a ciclostyl

Catalogar la biblioteca de textos musicales existentes en la Regiduría

Registro de entrada y salida de libros y documentación

Correspondencia necesaria para que se realicen los Conciertos que le entregue la jefe del Departamento Funcional

Control de las partituras editadas y su venta 


\section{La educación musical en el franquismo}

Las personas que ocupaban estos puestos eran según dicho documento:

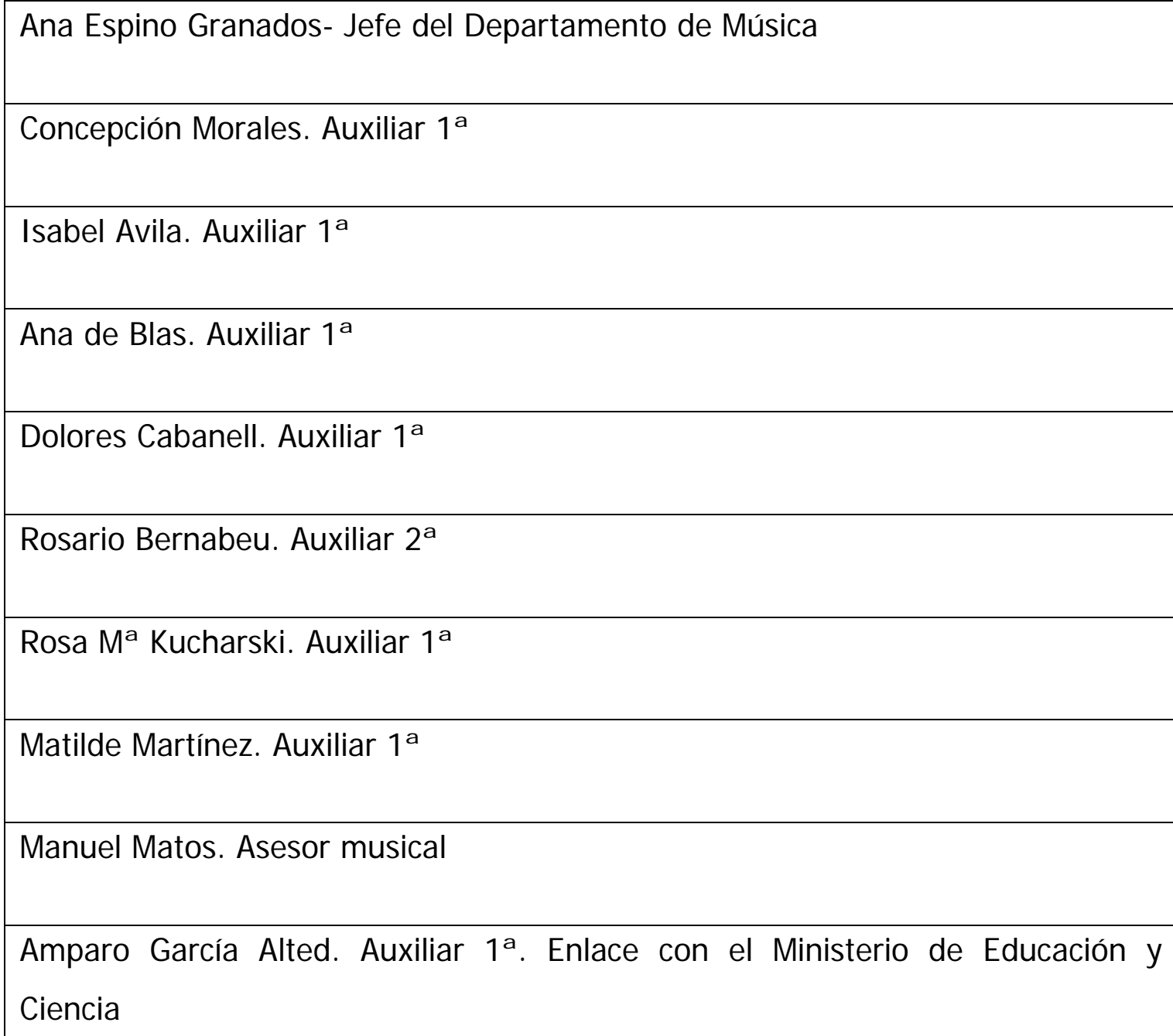

\subsubsection{Funcionamiento interno de la Sección Femenina}

La Sección Femenina funciona por medio de una organización interna muy estructurada y jerarquizada formada de mayor a menor por:

- Delegaciones provinciales

- Delegaciones locales

- Afiliadas

Al frente de cada Delegación Provincial se encuentra una Delegada Provincial, que es la máxima jerarquía de la Sección Femenina en la provincia. Bajo su mando están un Secretaria Provincial y una Regidora Provincial en cada uno de los siguientes servicios: 


\section{Capítulo 5. Música e ideología 2: La Sección Femenina}

\section{Cultura}

2. Prensa y propaganda

3. Hermandad de la ciudad y el campo

4. Intendencia

5. personal

6. Organizaciones juveniles

7. Enfermeras

8. Sindicatos

A su vez, estas regidurías o servicios son los elementos que recaban la información de las Delegaciones locales. Siempre bajo el esquema de una J efe y una Secretaria, éstas delegaciones locales se subdividían a la vez en distritos (con más de 10.000 habitantes), secciones y grupos. Cada sección estaba formada por tres grupos, en los que se podían hallar todos los servicios, cada uno de ellos dirigidos por una Regidora y una Auxiliar local de servicio.

Por otra parte, cada servicio o Regiduría, tenía una estructuración y normativas propias relacionadas con las tareas que le eran asignadas y que regulaba su actuación desde el ámbito estrictamente local hasta el ámbito nacional e internacional. Tal es el caso de la Regiduría de cultural, que publica en 1954 las Normas relacionadas con el departamento de música de la Regiduría Central de Cultura ${ }^{\mathbf{2 0 7}}$ y en la que aparecen detalladas minuciosamente todas la tareas encomendadas a la misma.

En ellas se especifica que la Regidora provincial de Cultura, ayudada por la Instructora y el Asesor de música "es la encargada en cada provincia de realizar, de acuerdo con la Delegada Provincial y siempre a través de las Delegadas locales, la labor musical según las normas e instrucciones de la Regiduría Central de cultura, no llevando a cabo ni una sola modificación sin contar antes con la autorización de dicha Regiduría Central".

\footnotetext{
${ }^{207}$ Delegación Nacional de la Sección Femenina de FET y da las J ONS (1954) Normas relacionadas con el Departamento de música de la Regiduría Central de Cultura. Madrid: Servicio de Publicaciones. Industrias Gráficas Magerit
} 
Las funciones que debe cumplir la Regidora Provincial de cultura ${ }^{208}$ son:

- Organizar los cursos de instructoras provinciales

- Encargar a cada de las instructoras de su provincia de la formación de uno o varios grupos de Coros y Danzas y encomendar una labor mensual fija, vigilando su cumplimiento

- Asistir con regularidad a los ensayos para controlar la labor que en ellos se realiza

- Trasladarse con frecuencia a las delegaciones locales para animarles en la formación de dichos grupos.

"La Regidora de Cultura, con la colaboración de las instructoras nacionales y provinciales, asesores de música y demás colaboradores musicales, deben considerar como su más importante misión que no quede en su provincia ni una sola Local que tenga alguna danza o canciones de interés folklórico sin que los recoja y organice algún grupo con ellas.

- Comprobar que en todos los cursos se den las clases de música señaladas en el plan de formación, como también las conferenciasconcierto que se exigen en cada curso y vigilar el cuidado de gramolas y discotecas

- A través de la Delegada local de capital y delgadas locales se hará llegar a las instructoras de música y a los asesoras, todas las normas referentes a la música que les dirija la Regiduría Central de cultura, los textos, cancioneros, revista Consigna, oficios, circulares y cartas sobre concursos.

- Confeccionar, junto con las delegadas locales e instructoras de música, los ficheros ordenados por la Regiduría Central de Cultura, el cual debe estar siempre al día

- Enviar a través de las delegadas locales de capital los partes trimestrales de las instructoras de música

\footnotetext{
${ }^{208}$ Normas relacionadas con el Departamento de música de la Regiduría Central de Cultura Op. Cit. Capítulo 1, pag 23-26
} 


\section{Capítulo 5. Música e ideología 2: La Sección Femenina}

- Llevar la organización directa de los concursos de Coros y Danzas y enviar la documentación correspondiente. Es preciso que tenga en cuenta que todo lo referente al concurso es importantísimo ya que ello reflejará la labro que en música se realiza durante todo el año.

- Llevar los libros de a) recompensas y medallas, b) inventarios de instrumentos musicales y trajes regionales y c) concursos de coros y danzas

- Asistir a las reuniones trimestrales de instructoras de música y generales

- Destacar por medio de inspecciones a las camaradas con vocación musical y proponer a la Regiduría Central de Cultura para becas

- Procurar la colaboración de todas las personalidades musicales, interesarles en los concursos y en las publicaciones que se preparan y en general en toda la albor musical que la Sección Femenina realiza

- Alentar a las instructoras de música, asesores y a toda persona con vocación musical a participar en los concursos de recogida de canciones

- Organizar los concursos de canto, piano y violín

- Insistir con la instructora de música y asesores para que inspecciones todas las secciones locales donde puedan existir canciones y danzas auténticamente folklórica aún no recogidas

- Conocer y cumplimentar las normas y documentación relativas a las actividades musicales

\subsection{NORMATIVA DE MÚSICA DE LA REGIDURÍA CENTRAL DE CULTURA}

Para comprender la enormidad de la tarea que realiza Sección Femenina en lo relativo a la formación musical de la población, basta con observar con atención el Capítulo 3 de la Normativa ${ }^{209}$ de la Regiduría de Cultura, titulado Obligatoriedad de dar las clases de música en todos los cursos.

\footnotetext{
${ }^{209}$ Normas relacionadas con el Departamento de $m$ 'suica de la Regiduría Central de Cultura, Op. Cit. Capítulo 3, pag. 37-49
} 


\section{La educación musical en el franquismo}

Se inicia el capítulo con la precisión de que todo lo que consta tiene la misma validez para la Capital como para las Locales, es decir que es de aplicación obligatoria y regularizada en todo el territorio nacional.

\subsubsection{Los centros educativos}

La educación musical a la que se debe aplicar en los siguientes centros:

1. .- en todos los Centros dependientes de Sección Femenina

a. Escuelas de Mandos Mayores

b. Escuelas de Mandos Menores

c. Plan de formación de la Masa

d. Cursos de Escuelas de Hogar

e. Albergues de Sección Femenina, SEU, Juventudes de la Sección Femenina y Sindicadas

f. Casas de flechas, preventorios y talleres

En todos los cursos de Sección Femenina es obligatoria esta enseñanza, "ateniéndose para el número de clases en cada uno de éstos a las señaladas en el Plan de Formación de la Delegada Nacional. Es preciso, por tanto, que se le dé la debida importancia y se le considere como una asignatura con el mismo interés que las otras, sin excluirla nunca".

2. en aquellos que, sin depender directamente de Sección Femenina, tiene ésta confiada por Decreto y ördenes del Ministerio de educación Nacional esta formación

a. Institutos

b. Colegios nacionales

c. Institutos y colegios privados

En lo que respecta a estos centros, se puntualiza que "es preciso que también se dé por la Sección Femenina la formación musical" según las normas y programas que tiene para sus propios centros. 


\section{Capítulo 5. Música e ideología 2: La Sección Femenina}

\subsection{1.a Normativa para los I nstitutos de Bachillerato}

La enseñanza de la Música en los Institutos de Bachillerato estaba integrada dentro de las denominadas enseñanzas del hogar, y asignada en su docencia a las instituciones educativas del Movimiento: Frente de Juventudes (para los institutos masculinos) y Sección Femenina (para los institutos femeninos).

En su normativa. Sección Femenina destaca que

"es preciso dar a esta enseñanza de la música en los I nstitutos, como en la SF, toda la importancia que merece",

ya que la calificación de esta asignatura es necesaria para el título de enseñanzas del hogar.

Las alumnas oficiales realizan exámenes parciales anuales y será la profesora de la asignatura la que les dará paso al curso siguiente, están exentas de examen de reválida, aunque si suspenden cualquier curso deberán aprobarla antes de empezar el nuevo curso.

Las alumnas libres deben realizar el examen anual en el Instituto donde están matriculadas. El examen de reválida lo realizan al mismo tiempo que el de las demás asignaturas

Las alumnas de centros no oficiales (colegios privados) reciben el pase anual de la asignatura en su colegio y realizarán un examen de reválida al mismo tiempo que el de las demás asignaturas.

El examen de reválida consiste en la exposición oral de dos temas elegidos a sorteo del programa editado por la Delegación nacional de Sección Femenina en el apartado de Escuelas de Hogar.

Respecto a los libros y material didáctico se utilizan únicamente los editados por la Delegación Nacional de Sección Femenina. Las canciones que se enseñen serán también las autorizadas por la Sección Femenina. 


\section{La educación musical en el franquismo}

Para ser profesora de música de un Instituto es preciso haber realizado un curso nacional - 0 en su lugar provincial hasta que realice el curso nacional- 0 ser Asesor de música. Las profesoras de música de las Escuelas de Hogar de los Institutos tienen las mimas obligaciones y derechos que el resto del profesorado y están sometidas a la doble dependencia de la Sección Femenina y del Director del Instituto. Entre sus obligaciones destacan:

- Asistir a las juntas mensuales de profesorado

- Presentar Coros en los actos de clausura de fin de curso

- Deben participar en los concursos de Villancicos

Se realizan inspecciones periódicas y controles en los colegios y academias para comprobar si se dan las enseñanzas de música conforma a la normativa. En todo caso se controla que se den las clases de música y danza y que las instructoras asisten a sus clases con puntualidad y uniformidad, que las clases se ajusten a los programas y divulgar la normativa sobre formación musical entre los jefes de curso (enviando los programas, partituras y otros materiales).

Es obligación de las Instructoras de música y profesorado

- cumplimentar con exactitud las normas sobre canciones y danzas

- conseguir de las alumnas interés en las clases

- entregar al fin de cada curso calificación de comportamiento

- someter sus iniciativas a su Mando directo, tanto para interpretar canciones que no estén en los programas o textos permitidos

\subsubsection{Los contenidos}

Según la Normativa de la Regiduría Central de Cultura ${ }^{210}$ las clases de música comprenden:

\footnotetext{
${ }^{210}$ Normas relacionadas con el Departamento de Música de la Regiduría Central de cultura. Op. Cit. Pag. 39
} 


\section{Capítulo 5. Música e ideología 2: La Sección Femenina}

- Enseñanza de solfeo

- Canciones

- Conferencias musicales: historia de la música

La finalidad principal de estas clases es despertar el gusto musical y dar a conocer los bailes y canciones del folklore nacional.

\subsection{2.a. La enseñanza del solfeo}

“La Instructora deberá distribuir el tiempo de clase entre la enseñanza del solfeo y de canciones".

A este respecto hace diferentes propuestas según la presencia horaria de la asignatura, señalando que "la presencia en los cursos internos será de frecuencia diaria, y que en los cursos de las Escuelas de Mandos Menores y en los cursos largos de Escuelas de Hogar, así como en todos aquellos en los que por su duración se dé un número de clases de música superior a tres meses, la enseñanza de solfeo se procurará sea obligatoria".

\footnotetext{
"Si la enseñanza de música es de media hora, distribuirá una clase exclusivamente dedicada al solfeo, en la del día siguiente se repasará lo aprendido y el resto del tiempo se dedicará a la enseñanza de canciones. Y si la clase diaria tiene una duración de tres cuartos de hora, por lo menos dedicará media hora a la enseñanza del solfeo y el resto a canciones. Sólo en el caso de que la presencia horaria sea insuficiente y no dé margen para una enseñanza elemental del solfeo, se dedicará íntegramente el tiempo al aprendizaje de canciones".
}

Ello nos lleva a pensar en una cierta disparidad de presencia real en los centros, en al que se aplicaría lógicamente la jerarquía interna: al menos en los centros vinculados a Sección Femenina (Escuelas de Mandos Mayores y Menores) se impartiría entre 30 y 45 minutos de clase diaria obligatoria de música, de la que aproximadamente un $\mathbf{3 0} \%$ serían dedicados al aprendizaje del solfeo.

En cuanto a la metodología para dicha enseñanza, en los años 40-50 a los que se refiere la Normativa sólo aparece que 


\section{La educación musical en el franquismo}

"se procurará que la enseñanza del solfeo resulte siempre lo más amena posible, alternando desde el primer día la teoría con la práctica, con el fin de evitar la monotonía, y por tanto, el aburrimiento de las alumnas. Los ejemplos musicales se harán siempre sobre fragmentos sencillos de canciones populares".

A partir de mediados de los años 60, Sección Femenina se vinculará muy estrechamente a todo un proceso de renovación metodológica y pedagógica de la enseñanza de la música para los niños en edades escolares.

\subsection{2.b Las canciones}

El capítulo $\mathrm{V}$ de la normativa se dedica íntegramente a las normas para la recogida, catalogación y enseñanza de las canciones

No se podrán interpretar más canciones que aquellas autorizadas por la Regiduría Central de Cultura, es decir, las recogidas en el siguiente repertorio:

- Cancionero de la Sección Femenina

- Mil canciones españolas

- Las que aparecen en la Revista Consigna

- Aquellas que se distribuyen a través de las hojas y partes trimestrales

En el caso de querer enseñar otras canciones que las pertenecientes a este repertorio, debían enviar a la Regiduría Central a través de su mando provincial, una solicitud con la partitura de las mismas, para su aprobación.

Las instructoras de música deben explicar antes de empezar

“a qué región pertenece, y por consecuencia, las características especiales de la canción, procurando que se percaten muy bien de ello, evitando de esta forma el confusionismo que podría crearse por falta de datos concisos al tomar una canción por originaria de otra región distinta a la cual pertenece".

Las canciones se interpretarán al unísono o a dos voces, salvo en los casos muy especiales de mucha seguridad en el coro y siempre que "no se le dé tono orfeónico. 


\section{Capítulo 5. Música e ideología 2: La Sección Femenina}

Con respecto a las canciones religiosas, "sólo se autoriza el canto gregoriano".

El principio de clasificación originaria de la procedencia de las canciones tradicionales tuvo una gran importancia en la enseñanza de la Sección Femenina. De hecho, se refleja claramente en todas sus publicaciones, donde a cada canción se le atribuye un origen regional. Hoy este procedimiento se considera poco fiable, ya que hay mucha contaminación entre zonas limítrofes, comunidades trashumantes y viajeras, patrimonios culturales de orígenes familiares diversificados. Sección Femenina asistía a los últimos coletazos de una sociedad rural con poco intercambio cultural, pero esta situación se transformó completamente durante el franquismo, empezando por los desplazamientos consiguientes a la propia guerra civil y siguiendo por la movilidad dentro de un estado-nación debido a las condiciones económicas, laborales y sociales. También jugaron un papel determinante en el cambio de estas circunstancias la radio y más tarde la televisión como elementos de globalización cultural. Y de hecho, la propia Sección Femenina, al difundir un cancionero popular que recogía canciones de todas las regiones y no procedentes de la tradición oral propia sino global de todo el país, realizó una labor de mezcla a favor de un sentimiento nacional desarraigado. Las palabras de Pilar Primo de Rivera se volvieron en contra de esta voluntad de identificación de la raíz popular local.

Ese afán de clasificar el origen localizado de las canciones tradicionales, se muestra en todo el proceso de elaboración, presentación y selección del material didáctico musical de la Sección Femenina.

Para la interpretación y selección de las canciones se plantearon una serie de normas comunes:

- Autenticidad y pureza folklórica

- Aprenderlas en el idioma original, pero dando traducción para que los intérpretes entiendan lo que cantan

- Huir de la interpretación orfeónica 
- Que una de las canciones, por lo menos, sea de la región a la que pertenece el coro y el resto de otras provincias

- Que en todos los programas debe interpretarse algo religioso y que esta música siempre será gregoriana

- Explicar el origen geográfico de cada canción y el sentido con que debe interpretarse

- Estar tomada de los programas y textos editados por la Sección Femenina o bien contar con la previa autorización escrita

La Sección Femenina distingue a la hora de enseñar las canciones el tipo de público al que están dirigidas. Así en los Cursos de Mandos Menores, se aconseja a las instructoras elementales enseñar con preferencia canciones de corro y cuna, a las de Hermandad canciones propias del entorno rural y el campo. En los cursos de albergues para margaritas se les enseñan canciones de corro, cuna, humorísticas e himnos y a las flechas y luceros pueden enseñárseles canciones amatorias a dos voces.

En los cursos de Maestras, se advierte a las instructoras de música que:

Enseñen única y exclusivamente canciones apropiadas para los niños publicadas en Consigna o autorizadas por la Regiduría Central de Cultura. El programa de canciones tiene que ser completamente infantiles

Como las maestras, en su mayoría, “no saben musica” tendrán que ser aprendidas de memoria, sin fallo de entonación y ritmo para poder enseñarlas después sin defectos a sus alumnos

También se insistirá, hasta que se convenzan plenamente de ello, que al formar los coros de niños 0 al hacerles cantar en la escuela no deben consentirles que canten gritando, defecto al que se da fácilmente el niño y muy generalizado en todas las escuelas. Esto se ha de cuidar muchísimo, especialmente en los himnos

Las clases o ensayos de canciones con los niño no debe exceder de un cuarto de hora o media hora según las edades

\subsection{2.c Conferencias musicales e historia de la música}




\section{Capítulo 5. Música e ideología 2: La Sección Femenina}

Las conferencias de historia de la música son obligatorias en todos los cursos, dependiendo su número de la duración de los mismos. Se imparten en la hora de la clase de música y tienen que ser consignadas en el parte trimestral, indicando tema, fecha e ilustraciones musicales realizadas.

Para impartirlas, se dispone de:

- Gramófonos y tocadiscos

- Colecciones de discos

- Libro de Historia de la Música del Maestro Rafael Benedito 211

- Conferencias musicales y apuntes sobre formas e historia de la música publicados en la Revista Consigna, especialmente la serie Cada autor y su obra en su época y en su ambiente, escrita por Rafael Benedito.

Estas conferencias están abiertas al público en general cuando se desarrollan dentro de cursos de la Sección Femenina o en las actividades en sus locales.

Destaca la conveniencia de prepararlas cuidadosamente para evitar la pesadez - la monotonía, eligiendo variadas y numerosas ilustraciones musicales para cada tema, así como su presentación en temas cíclicos de tres o cuatro conferencias. Deben ser presentadas en un estilo ameno y atractivo, y no leídas, "evitando la aburrida erudición de acopio de fechas y datos que aburren al auditorio".

Su principal finalidad es la difusión general no especializada. Es una actividad de formación para todo tipo de público con la intención de introducir el amor por la música clásica.

Tal como destaca Rafael Benedito en su Historia de la Música

\footnotetext{
“El trabajo que con el título La música a través de los tiempos destina la Sección Femenina de FET y de las JONS a los cursos de formación, no tiene - ni debe tener más pretensiones ni más objetivo que el de iniciar, orientar, guiar, conducir a sus
}

\footnotetext{
${ }^{211}$ BENEDITO, R. (1955) Historia de la música. La música a través de los tiempos. Madrid: Publicaciones de la Delegación Nacional de la Sección Femenina de FET y de las JONS
} 
afiliadas en la amplia, intrincada y hermosa selva de la música por caminos fáciles, floridos y amenos, haciéndolas llegar, sin cansancio, a un punto desde el cual puedan contemplar, apreciar y distinguir panorámicamente es diverso y espléndido conjunto que el espíritu de los hombres ha ido formando siglo tras siglo.

Para conseguirlo hemos procurado: primeramente sintetizar con claridad las lísneas, los planos que más caracterizan cada época, así como la transición, el paso de unas a otras, y para complementar la visión de conjunto, explicar los rasgos peculiares más notorios de las formas, pero sobre todo, la parte "emocional" que cada una de ellas encierra, ya que siendo la música una de las Bellas Artes y el arte patrimonio inapreciable del alma, de los sentimientos, es lo que más interesa para una verdadera formación artísticomusical"

Además se pueden organizar conciertos locales y establecer acuerdos con las sociedades y entidades musicales locales para disponer de algunas entradas que se regalan o sortean entre las mejores alumnas de las clases de música y del coro.

\subsubsection{El profesorado}

El profesorado de música en las Escuelas de Sección Femenina y en los centros docentes donde tenía asignado el Movimiento la educación musical estaba formado por:

- Instructoras nacionales de música

- Asesores de música

- Instructoras provinciales

- Instructoras generales

- Profesoras particulares

En el caso de las danzas, también existían instructoras especializadas, instructores provinciales y profesoras particulares.

Los nombramientos se realizaban por medio de la Regiduría de personal y sus destinos eran asignados por mutuo acuerdo entre la Delegación local y la Regiduría Provincial de Cultura. 


\section{Capítulo 5. Música e ideología 2: La Sección Femenina}

La distribución de tareas se realizaba anualmente en la primera junta mensual del mes de septiembre a la vista de todo el personal especializado en música con el que se contaba, asignando horarios y días de labor docente con la obligación de asistir a las clases y los ensayos.

Las Instructoras nacionales de música son aquellas que están en posesión del título otorgado por la Escuela de Especialidades tras cursar dos años de estudios específicos. Sus principales obligaciones son:

- Organizar los coros de las capitales de provincia

- Inspeccionar los coros de las delegaciones locales y Comarcales

- La recogida de canciones y danzas

- La organización y dirección de los ficheros técnicos musicales

- La inspección de todos los grupos provinciales, tanto de Sección Femenina como de Frente de Juventudes

- La dirección de las conferencias musicales

- La asistencia a las juntas trimestrales con el profesorado de música

- La dirección técnica en los concursos de Coros y danzas, villancicos, instrumentales, etc

Los Asesores de música pueden ser personas que no pertenezcan a la Sección Femenina y deben elegirse entre las personalidades con más destacada formación musical de la ciudad. Sus principales obligaciones son:

- Labor de investigación, de recogida de canciones y danzas populares

- Supervisión de los grupos en canciones y danzas

- Selección de canciones para los concursos

- Dirección de las conferencias-concierto

Las Instructoras provinciales son aquellas que han realizado el curso provincial de formación. Pueden preparar a los grupos de coro y danzas de distrito, pero sólo con el repertorio de la provincia a laa que pertenecen. También puede preparar y dirigir coros de juventudes. 


\section{La educación musical en el franquismo}

Las Instructoras generales son las encargadas de impartir la formación de Escuela del Hogar que la Sección Femenina tiene encomendadas en la Enseñanza Secundaria. Tienen que haber realizado el curso anual de la Escuela Especial de Instructoras Generales.

En los casos en que no se dispone de ninguna afiliada con formación musical en las delegaciones locales y comarcales, se contratan profesoras particulares para colaborar en la recogida de canciones y en la enseñanza musical y la formación de coros.

\subsubsection{El material regulado}

Además de las publicaciones de Sección Femenina en las que se recogen las partituras y materias musicales generales, hay otro tipo de material complementario para los coros:

- Programas trimestrales de canciones enviados por la Regiduría Central de Cultura

- Programas de coros y danzas enviados por las Delegaciones Provinciales

En el primer caso, los Programas trimestrales de la Regiduría Central están compuestos por canciones de tres tipos: a) Canciones folklóricas, b)Canto gregoriano y c) Himnos y marchas. Son iguales para Coros de distrito y locales, Escuelas de Hogar de Sección Femenina, Escuelas de mandos Mayores y Menores, Escuelas Normales (si las instructoras son solicitadas para algún festival), Juventudes, casa de flechas, escuela de hogar de institutos, colegios e institutos laborales y talleres de aprendices.

Incluían además los programas de canciones obligatorias apara los coros en los concursos, las piezas obligatorias para el concurso de villancicos, los programas para los albergues y los programas para actuaciones extraordinarias de los coros. 


\section{Capítulo 5. Música e ideología 2: La Sección Femenina}

Los concursos nacionales de coros tenían tres canciones obligadas: una de gregoriano y una popular y una clásica. Había dos secciones con repertorio obligatorio igual en cada una: a) Sección Femenina, SEU, Sindicadas y Escuelas de Hogar y b) Juventudes, Escolares y aprendices.

El concurso de Villancicos tenía además una fase provincial en las fechas navideñas. A él tenían acceso todos los niños y niñas en edad escolar. El repertorio consistía en dos partes: una obligatoria y otra libre, cada una compuesta por dos villancicos. En la parte obligatoria, uno era de carácter gregoriano y otro de tipo popular. En la parte de libre elección se sugería que pertenecieran a la región del coro.

\subsubsection{El sistema de ficheros}

Para Sección Femenina fue una prioridad absoluta la recogida de las canciones y danzas populares del folklore. El carácter ideológicamente tradicionalista, el deseo de hacer renacer un pasado glorioso de tradiciones y costumbres y revivirlo en nuestros días, se plasma especialmente en el esfuerzo por recoger y divulgar aquellas manifestaciones culturales aún vivas. La Sección Femenina, sin embargo, tenía muy claro que estas manifestaciones (especialmente las canciones, danzas y los trajes regionales) iban a desaparecer muy pronto y por ello se encargó de la tarea ímproba de su recogida documental a través de fichas formalizadas. Esta tarea la realizaban tanto los asesores de música como las instructoras y estaba abierta a la colaboración de todo tipo de músicos, danzantes, informantes y colaboradores. Existía un apartado económico para la financiación de estas recogidas de datos del folklore y se preveían los gastos de transporte y dietas, así como los pagos a profesionales contratados para la elaboración de las fichas. Era considerada la labor prioritaria de las delegaciones provinciales y locales, hasta el punto de poder solicitar la colaboración de los Gobernadores civiles y los alcaldes. Se creó un Concurso nacional sobre recogida de canciones y danzas con frecuencia anual y dotación de 3.000 pesetas 


\section{La educación musical en el franquismo}

La Sección Femenina utiliza un sistema de fichas ordenadas para la recogida de música y danza. Los ficheros de música pueden ser:

- Técnicos
o Canciones
o Danzas
o Trajes

- De personal
o Fichas de instructoras
o Asesores
o Colaboradores
o Afiliadas

- De concursos

o Boletines de inscripción de los diversos concursos

La Sección Femenina es consciente de la importancia de la ordenación y catalogación de todo el material musical que recopilaban, hasta el punto de considerarlos

"la base de nuestra organización musical en lo que respecta a su parte técnica, ya que estos ficheros suponen una labor de investigación que quedará para siempre y que será una gran aportación a la cultura musical, porque tenemos que conseguir no sólo desentrañar el perdido folklore y arraigarlo de nuevo, sino dejar constancia con documentos escritos con una labor profunda y cuidada" ${ }^{212}$

El sistema de archivo se realiza por regiones, y dentro de éstas por provincias, siguiendo el organigrama general de funcionamiento de Falange en el territorio nacional.

Se realiza una primera clasificación por géneros: himnos, romances, rondas, corros, nanas, humorísticas... Dentro del repertorio religioso se subdividen en dos grandes apartados: Gregoriano y polifónico.

\footnotetext{
${ }^{212}$ Normas relacionadas con el Departamento de música de la Regiduría Central de Cultura. Op. Cit., pag. 85
} 


\section{Capítulo 5. Música e ideología 2: La Sección Femenina}

Cada ficha era acompañada de su partitura, convenientemente revisada por los asesores de música y tiene un número que corresponde a su ordenación en el catálogo provincial.

Estaba absolutamente prohibido que alguien ajeno a la organización de la Sección Femenina hiciera copia de este archivo de canciones.

El fichero de canciones se compone de:

- Canciones aportadas en la labor de recogida

- Canciones enviadas por la Regiduría Central de Cultura

La recogida de canciones y danzas en las zonas rurales fue una de las mayores labores realizadas por Sección Femenina. Conscientes de que la clase de vida rural tradicional española estaba en vías de transformación, se intentó realizar una recogida masiva de datos por medio del "trabajo de campo". En dicho trabajo colaboraron todas las afiliadas, coordinadas por sus mandos jerárquicamente, con la colaboración de numerosos asesores musicales y todo tipo de colaboradores voluntarios o bajo contrato (directores de banda, músicos con formación de conservatorio, aficionados musicales, sacerdotes, maestros).

Para ello se realizaban viajes de inspección regulares, animando a todas las personas del pueblo que quisieran colaborar a participar en dicha labor. Ciertamente, existían ciertas reticencias por diversos motivos: la falta de apreciación del valor de la propia tradición cultural, la autoselección del repertorio que hacían los propios informantes, las connotaciones políticas (y los rechazos ideológicos) tras los enfrentamientos de la guerra civil... Pero a lo largo de los 40 años de franquismo, la cantidad de material recogido es realmente enorme. Y la actitud de Sección Femenina de valorar el folklore y la tradición popular fue probablemente el mejor impulso para conseguir la colaboración de la población, especialmente rural, que veía cómo en muy pocos años sus formas de vida iban desapareciendo en aras de una sociedad industrial y urbana. 


\section{La educación musical en el franquismo}

Los asesores y colaboradores de Sección Femenina se trasladaban a las zonas rurales para tomar los datos musicales de forma directa. Para que estas informaciones no fueran olvidadas, recogían en partitura las canciones y las acompañaban de los datos que consideraban pertinentes sobre su entorno de interpretación. Lamentablemente, en aquellas épocas no había la facilidad de medios audiovisuales de que disponemos hoy en día, por lo que rara vez podía trasladarse un equipo magnetofónico de grabación.

Dicha ficha, con su partitura, era entregada a la Regidora Provincial de Cultura al regreso de la visita, y una copia de la misma era enviada a la Regiduría Central de Cultura en Madrid. Se especificaba la importancia de la claridad y exactitud en la transcripción de la melodía y en conservar el idioma o dialecto original, aunque acompañado de la correspondiente traducción al castellano. Se permitía realizar armonizaciones a las melodías y se hacía constar el autor de las mismas. En el caso de que la canción hubiera sido tomada de algún cancionero en vez de forma directa, se debía citar la referencia bibliográfica (título y página).

Como complemento a los ficheros, se llevaba además un catálogo de canciones en cada Delegación provincial y un Catálogo General de Canciones en la Regiduría central de Madrid

Para incentivar este tipo de trabajo de recogida de nuevas canciones y danzas mediante el "trabajo de campo", la Sección Femenina crea los Concursos nacionales de recogida de canciones y de villancicos. Ambos están abiertos a toda persona interesada en esta labor musical. La convocatoria de los mismos se realizaba con una fecha de al menos cuatro meses anteriores a su realización y se cuidaba la difusión de la misma no sólo entre instructores, asesores, directores de coros y rondallas, sino que la Regiduría Provincial de Prensa y Propaganda se encargaba de su difusión en los medios de prensa y radio locales. 


\section{Capítulo 5. Música e ideología 2: La Sección Femenina}

En las bases de ambos concursos consta que se pueden recoger de todo tipo de géneros: profanos, canciones de faena, de coro, romances, villancicos populares o religiosos, campanilleros... a condición de que su carácter sea eminentemente folklórico y las melodías sean inéditas, es decir, que no aparezcan en ningún cancionero publicado. Deben ir acompañadas de la mayor cantidad de datos del entorno posibles que identifiquen su origen, antigüedad, ocasiones en que se cantan, así como los datos del informante (nombre, edad, profesión y si es posible un retrato fotográfico). Las canciones se deben presentar sin armonización y si están acompañadas por uno o varios instrumentos de percusión, transcribiendo el ritmo por escrito. En el caso de que se presenten canciones-danzas, se debe incluir también el acompañamiento instrumental y los movimientos coreográficos. Si alguna de las canciones cantadas fuera a más de una voz, en la transcripción se debe cuidad al máximo la fidelidad, sin modificar las armonías resultantes (hipercorreciones). Se pueden presentar un número ilimitado de canciones al concurso, en copia musical de partitura clara y con letra legible en el Departamento de Música de la Regiduría de Cultura en dos sobre lacrados, uno con lema y la canción y otro conteniendo en su interior los datos personales del lema propuesto. El jurado estaba compuesto por personalidades y asesores técnicos musicales. El fallo se hacía público a través de prensa y radio. Había tres premios en cada una de las dos especialidades.

\subsection{LA EDUCACIÓN MUSICAL NO FORMAL}

Sección Femenina desarrolla su trabajo musical tanto en el ámbito escolar como fuera del mismo de manera complementaria. Las tareas se planifican de forma que se interrelacionen ambos medios, realizando la formación básica en los centros escolares e Institutos y ampliándola en las otras actividades de carácter voluntario, pero con un seguimiento mayoritario.

\section{Así, la enseñanza en las Casas de Flechas, los Centros Medina y los} Albergues está planificada para que se aplique la enseñanza del solfeo y las canciones. En el primer caso se ampliaban los conocimientos musicales en los 


\section{La educación musical en el franquismo}

cursos de más de tres meses y se completaba el repertorio de canciones, iniciándose en el repertorio a dos y tres voces. Los Centros Medina por su parte eran el núcleo de la difusión cultural, especialmente dedicados desde el punto de vista musical, a la divulgación de la historia de la música y a la audición de piezas clásicas y del folklore, tanto a través de conferencias como de la disponibilidad de fonotecas y medios audiovisuales. Los Albergues, principalmente realizados en el verano, son la ocasión para la divulgación del folklore y otras canciones con carácter lúdico y participativo, menos reflexivo.

A lo largo de todo el año, y especialmente en los albergues veraniegos, se fomenta la actividad coral y la interpretación vocal en grupo. Las canciones se interpretan generalmente al unísono, en canon o a dos voces, acompañadas de percusión corporal, juegos y dramatizaciones musicadas.

Otra de las grandes actividades de Sección Femenina fue la realización de Concursos de Villancicos a nivel local y nacional, con la consiguiente dedicación en infraestructura administrativa. Para ello consiguieron la participación mayoritaria de las instituciones escolares, ya que las instructoras de música de los centros pertenecían o estaban vinculadas a la Sección Femenina y al Movimiento. También consiguieron la participación del Frente de Juventudes, bien a través de sus órganos propios, bien a través de colaboraciones puntuales para la creación de coros infantiles de niños en edad escolar.

La estructuración del concurso se realizaba a nivel provincial y en ella colaboraban todas las instituciones locales. Se interpretaban dos villancicos obligatorios - uno popular y otro religioso - y un villancico de libre elección. La celebración del festival provincial se realizaba en las fechas inmediatamente anteriores a las vacaciones escolares de navidad, por lo que la parte administrativa se iniciaba en octubre: convocatoria, selección de villancicos obligatorios, copia y envío a todos los coros de las partituras correspondientes, inscripciones de los coros participantes, envío de las partituras de los villancicos de libre elección a la Regiduría, selección del jurado, realización de las pruebas 


\section{Capítulo 5. Música e ideología 2: La Sección Femenina}

y publicación de las actas y premios. También se requería la colaboración de la Regiduría de propaganda para la divulgación a través de los medios de comunicación. Y finalmente, se realizaba un concurso de villancicos a nivel nacional con aquellos ganadores de los concursos provinciales que se celebraba en Madrid ante un jurado compuesto por el asesor de música, el asesor de religión, el director del Conservatorio de Madrid y otra personalidad de reconocido prestigio musical, la regidora central de cultural y la regidora central de Juventudes.

La asignación a Sección Femenina de las actividades de formación musical en las escuelas hacía que estas actividades, en principio vinculadas al ámbito no formal, se trasladaran también a los medios escolares, siendo difundidas entre gran cantidad de población escolar general y entre las maestras, generalmente deseosas de colaborar con este tipo de acciones culturales, aunque realizadas de forma voluntaria.

Por su parte los Círculos Medina también realizaban una labor de divulgación de la cultura y en especial de la historia de la música que repercutía en la juventud a través de las maestras. Si bien las audiciones y conferencias de carácter musical, así como la sección de "Cada autor y su obra en su época y en su ambiente" realizada por Rafael Benedito en la Revista "CONSIGNA", estaban dirigidas a la formación cultural de las personas adultas, se animaba con ello al profesorado generalista a que realizaran una labor de difusión cultural y la educación del gusto estético por medio de la música clásica.

Si bien esta labor era desigual, tanto por la diferencia de medios disponibles en unos centros y otros, como por el seguimiento y la participación dispar en unas provincias y otras, eran sin embargo un núcleo significativo, ya que en la época apenas existían discotecas de música clásica a nivel público. En los años 60 todavía era infrecuente que la población particular dispusiera de tocadiscos y ni siquiera estaban dotados con ellos la mayor parte de los institutos de secundaria, menos aún los centros de educación primaria. La distribución discográfica en España era casi inexistente y la producción de música clásica 


\section{La educación musical en el franquismo}

escasa, casi toda ella realizada por compañías internacionales, lo que encarecía notablemente el precio de los discos y dificultaba su accesibilidad por parte de la mayoría de la población. Sólo a partir de los años 60 se iniciaron las publicaciones de Decca, Deustche Gramophon y Emi en España, casi siempre con introducciones y traducciones de los textos en idiomas extranjeros, incomprensibles para la mayoría de la gente. Las tiendas de discos eran pocas, casi exclusivamente en las capitales de provincia y su volumen principal de negocio se centraba en los "single" de los títulos pop de moda difundidos por la radio. Los LP (discos de larga duración) eran de un precio elevado, difíciles de conseguir y en pocos casos se podía disponer de más de una versión de la piezas que se deseaba comprar. Por todo ello, los centros Medina hicieron asequible a una parte interesada de la población femenina el acceso a la cultura musical de forma inicial, ya que hasta bien entrados los años 60 , este tipo de eventos estaban prácticamente restringidos a una minoría urbana con cierto potencial económico-social.

También hay que destacar la labor que realizaron las llamadas "cátedras ambulantes" de la Sección Femenina en el ámbito rural, donde, además de recoger registros de canciones y danzas populares, dignificando el patrimonio de que la población tenía y haciéndoles recapacitar sobre la importancia del mismo, también realizaban tareas aunque mucho más puntuales de difusión de la cultura musical (aunque sus tareas principales se centraban en la formación en temas del hogar y religiosos). Principalmente en los años 40 y 50, su labor fue prácticamente el único contacto con la música culta del que pudieron disfrutar las personas del medio rural.

La actividad concertística en provincias se centraba en la música de cámara y solistas, así como en la actuación de las bandas y agrupaciones corales. Apenas existían orquestas de cuerda profesionales fuera de las principales ciudades (Madrid, Barcelona, Bilbao) o eran de carácter aficionado. Los repertorios que se interpretaban eran limitados y bastante repetitivos en la mayor parte de los casos. El apoyo económico necesario a nivel estatal se centraba en la creación de la Orquesta Nacional y la Orquesta de RTVE posteriormente. En este sentido 


\section{Capítulo 5. Música e ideología 2: La Sección Femenina}

hay que destacar la enorme labor que se realizó especialmente dedicada a los escolares (hasta entonces generalmente excluidos de las salas de concierto) por medio del programa de Conciertos para Escolares a lo largo de todo el país en las capitales de provincia, y en las que además de la interpretación de las piezas se realizaba una pequeña introducción sobre las mismas.

La creación de Radio 2 en Radio Nacional de España, dedicada a la música culta y al folklore, supuso una auténtica revolución cultural, poniendo a disposición de las masas de forma gratuita un patrimonio hasta entonces simplemente inasequible. No obstante, su emisión en FM aún estaba restringida a las zonas predominantemente urbanas y eran notorias las dificultades para captarla en gran parte del país.

La creación de TVE supuso también otro gran aporte para la divulgación musical en el ámbito no formal. Se realizaban retransmisiones semanales de todos los conciertos de la Orquesta de Radio Televisión Española desde el Teatro Monumental de Madrid, así como algunos eventos culturales de tipo musical: Concurso Nacional de Coros y Danzas, Concurso Nacional de villancicos, Concurso Nacional de Bandas. Enseguida se empezaron a realizar programas sobre cultura musical, desde selecciones de audiciones musicales (que aparecían a última hora de la noche antes del cierre o como elementos de continuidad de la emisión entre programas) hasta programas con clara intención didáctica destinados tanto a adultos como a niños. El papel que jugó Sección Femenina en los mismos fue muy señalado, ya que TVE dependía directamente del Departamento de Propaganda del Movimiento (que nombraba hasta a su director general del Ente). Su experiencia organizando conciertos didácticos por todo el país y su trabajo en el ámbito escolar, se plasmaron directamente en los programas dedicados a la juventud, dando a conocer a la población general las nuevas líneas de trabajo en educación musical, con colaboraciones de los directores de la orquesta nacional, intervención de la orquesta de Madrid y el coro nacional y la divulgación del recién introducido método Orff a través de la colaboración de Montserrat Sanuy en los años 70. 


\section{La educación musical en el franquismo}

\subsubsection{Los conciertos didácticos}

En los años 60, Sección Femenina toma la iniciativa de organizar una de las actividades de educación musical no formal más importantes: los Conciertos Sinfónicos para la Juventud. Aunando las capacidades organizativas de la infraestructura nacional de la Regiduría de Cultura con la colaboración de Juventudes Musicales, determinados artistas y el patrocinio económico de instituciones locales (Diputaciones, Ayuntamientos) y las Cajas de Ahorro, se consigue planificar una gira de conciertos especialmente dedicados a los niños y los jóvenes escolares en un programa ambicioso de conciertos con material didáctico y conferencias.

En el Archivo General de la Administración (AGA) de Alcalá de Henares se conserva mucha documentación sobre dichos programas de conciertos entre los años 1962 y $1970^{213}$.

En los cuatro primeros años de esta actividad (cursos 62/63 hasta 65/66), sólo se producen un ciclo de 5 conciertos el primer curso y 9 conciertos los años siguientes en Madrid. A partir del curso 1966/67, y en vista del éxito de asistencia alcanzado - se pasa de 4.000 a 21.000 oyentes en cuatro años - se amplia la iniciativa a otras provincias cercanas: Toledo y Guadalajara. A partir de ahí, se convierte en uno de los recursos didácticos musicales más trascendentes desde el punto de vista no formal, expandiéndose cada vez más por las provincias.

La llegada de estos ciclos de conciertos sinfónicos era un auténtico acontecimiento en las ciudades de provincias, donde apenas existía vida sinfónica. El tipo de presentación, los cuidadosos programas acompañados de introducciones musicales y conferencias, la colaboración de los directores de los colegios, la asistencia mayoritaria de los alumnos, la realización de los mismos en teatros o salas de conciertos (hasta entonces reservados principalmente

\footnotetext{
${ }^{213}$ Archivo General de la Administración. Registro Tipográfico 51.31. Sección 23/31.306-31.507, grupo 1, no 2, Cajas 165,166,167 y 168. También en el Registro 51.39. Sección 23/21.307, grupo 3, no 9, paquete 291, caja 7 bis.
} 


\section{Capítulo 5. Música e ideología 2: La Sección Femenina}

para el público adulto), la participación de grupos musicales prestigiosos, la selección del repertorio por ciclos, la complementación con preparación anterior de las maestras en los Círculos Medina sobre los compositores y obras que se iban a escuchar, la gran divulgación de los conciertos a través de los medios de comunicación locales como un evento de importancia cultural dirigido a la formación de las nuevas generaciones, todo ello estaba encaminado a destacar la importancia y la singularidad de esta iniciativa. Desde luego, su crecimiento fue exponencial. He aquí algunos de los datos sobre su extensión y difusión:

\begin{tabular}{|c|c|c|c|c|}
\hline Curso & Provincia & Ciudades & № de conc. & $\begin{array}{l}\text { Asistentes (a } \\
\text { la totalidad } \\
\text { del ciclo de } \\
10 \text { conciertos) }\end{array}$ \\
\hline $1962 / 63$ & Madrid & Madrid & 5 & 4.000 \\
\hline $1263 / 64$ & Madrid & Madrid & 9 & 8.000 \\
\hline $1964 / 65$ & Madrid & Madrid & 9 & 14.000 \\
\hline $1965 / 66$ & Madrid & Madrid & 9 & 21.000 \\
\hline \multirow[t]{3}{*}{$1966 / 67$} & Madrid & Madrid & 9 & 28.000 \\
\hline & Toledo & Toledo & 6 & \\
\hline & Guadalajara & Guadalajara & 2 & \\
\hline \multirow[t]{4}{*}{$1967 / 68$} & Madrid & Madrid & 9 & 40.000 \\
\hline & Toledo & Toledo & 7 & \\
\hline & Guadalajara & Guadalajara & 6 & \\
\hline & San Sebastián & S. Sebastián & 6 & \\
\hline \multirow[t]{8}{*}{$1968 / 69$} & Madrid & Madrid & 5 & 210.000 \\
\hline & Toledo & Toledo & 5 & \\
\hline & & Talavera & 10 & \\
\hline & Guadalajara & Guadalajara & 5 & \\
\hline & Soria & Soria & 10 & \\
\hline & Cuenca & Cuenca & 5 & \\
\hline & Granada & Granada & 10 & \\
\hline & & Motril & 10 & \\
\hline
\end{tabular}


La educación musical en el franquismo

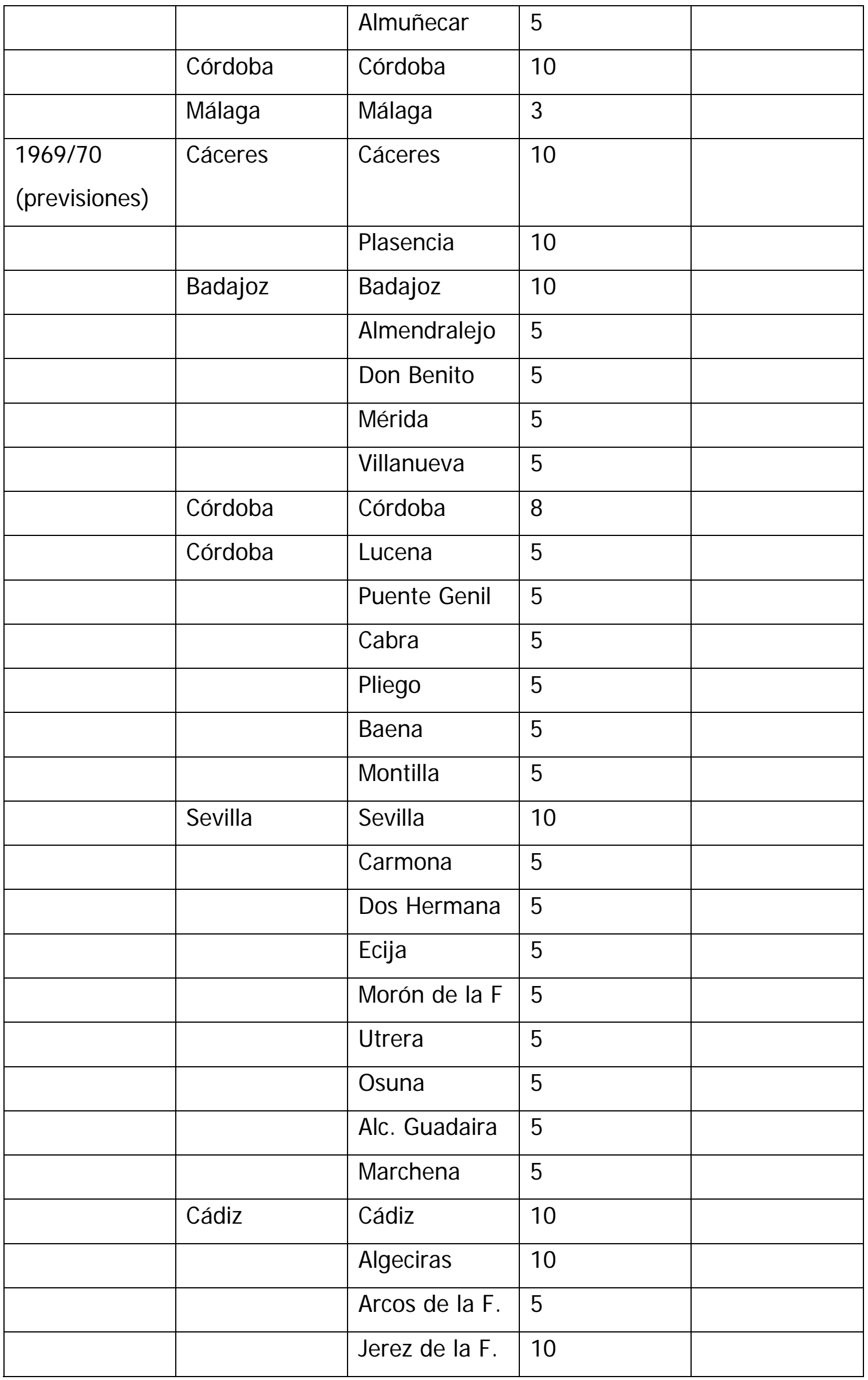


Capítulo 5. Música e ideología 2: La Sección Femenina

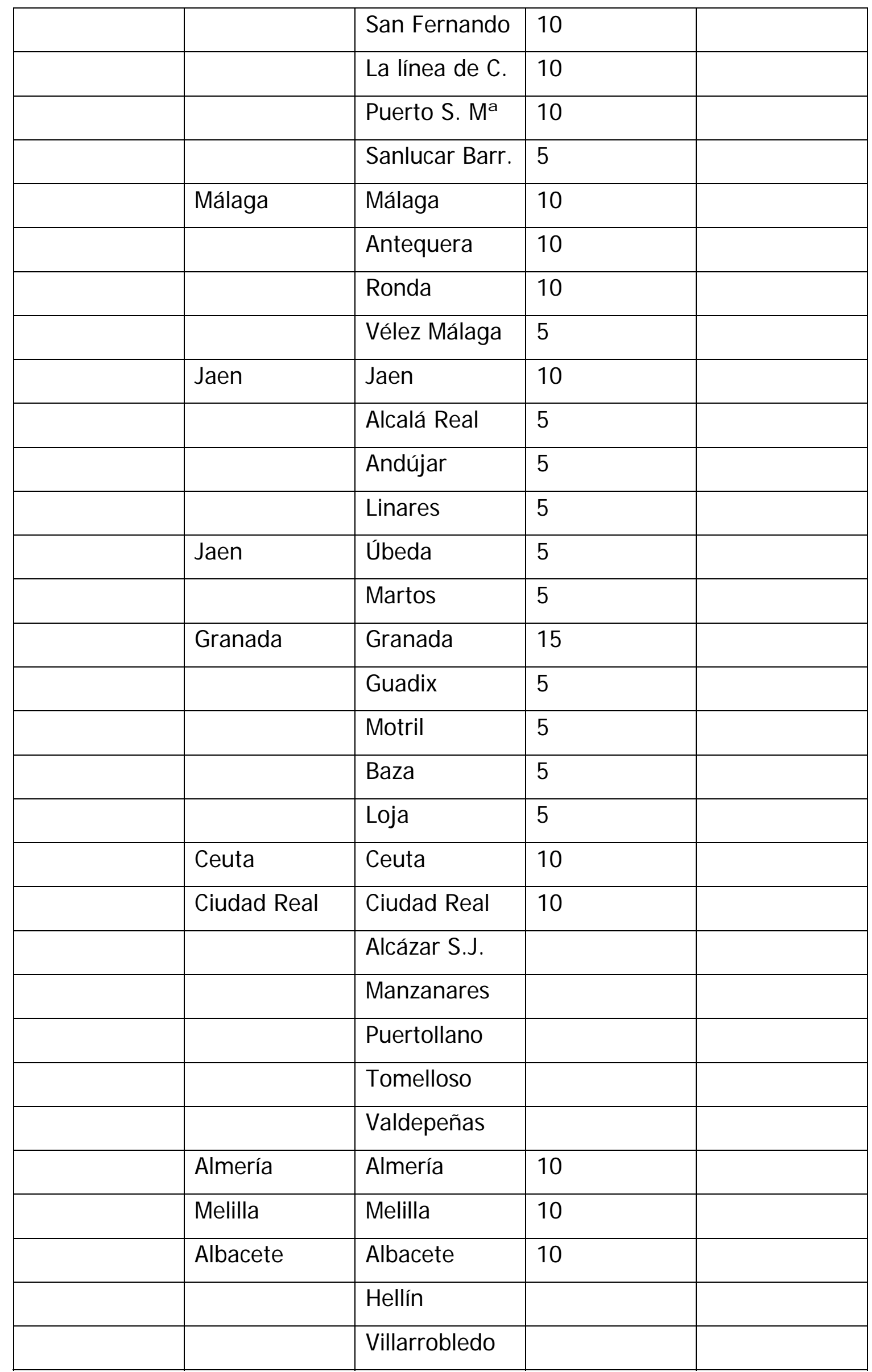


La educación musical en el franquismo

\begin{tabular}{|c|c|c|c|}
\hline Murcia & Murcia & 5 & \\
\hline & Cartagena & & \\
\hline & Cieza & & \\
\hline & Lorca & & \\
\hline & Caravaca & & \\
\hline & Tecla & & \\
\hline Alicante & Alicante & 10 & \\
\hline & Alcoy & 10 & \\
\hline & Elche & 10 & \\
\hline & Elda & 10 & \\
\hline & Orihuela & 10 & \\
\hline & Villena & 10 & \\
\hline Valencia & Valencia & 10 & \\
\hline & Alcira & 5 & \\
\hline & Gandía & 5 & \\
\hline & Játiva & 5 & \\
\hline & Requena & 5 & \\
\hline & Sagunto & 5 & \\
\hline & Sueca & 5 & \\
\hline & Torrente & 5 & \\
\hline Castellón & Castellón & 10 & \\
\hline & Burriana & 5 & \\
\hline & Villarreal de I. & 5 & \\
\hline Burgos & Burgos & 5 & \\
\hline & Miranda de $\mathrm{E}$. & 5 & \\
\hline Santander & Santander & 10 & \\
\hline & Torrelavega & 10 & \\
\hline Bilbao & Bilbao & 10 & \\
\hline & Baracaldo & 10 & \\
\hline & Santurce & 10 & \\
\hline & Sestao & 5 & \\
\hline
\end{tabular}


Capítulo 5. Música e ideología 2: La Sección Femenina

\begin{tabular}{|c|c|c|}
\hline & Guecho & 5 \\
\hline & Basauri & 5 \\
\hline S. Sebastián & S. Sebastián & \\
\hline & Eibar & \\
\hline & Irán & \\
\hline Vitoria & Vitoria & 10 \\
\hline Pamplona & Pamplona & 10 \\
\hline & Tudela & 5 \\
\hline Logroño & Logroño & 10 \\
\hline & Calahorra & 5 \\
\hline Soria & Soria & 5 \\
\hline & Almazán & \\
\hline Guadalajara & Guadalajara & 5 \\
\hline & Molina de A. & \\
\hline Zaragoza & Zaragoza & 10 \\
\hline & Calatayud & 5 \\
\hline Huesca & Huesca & 10 \\
\hline Teruel & Teruel & 5 \\
\hline Cuenca & Cuenca & 5 \\
\hline Salamanca & Salamanca & 10 \\
\hline & Béjar & 5 \\
\hline Zamora & Zamora & 10 \\
\hline Orense & Orense & 10 \\
\hline Pontevedra & Pontevedra & \\
\hline & Vigo & 10 \\
\hline & La Estrada & 5 \\
\hline La Coruña & La Coruña & 10 \\
\hline & Carballo & 5 \\
\hline & Santiago de C & 10 \\
\hline & El Ferrol & 10 \\
\hline Lugo & Lugo & 10 \\
\hline
\end{tabular}


La educación musical en el franquismo

\begin{tabular}{|c|c|c|}
\hline & Monforte de L & 10 \\
\hline & Villalba & 5 \\
\hline Valladolid & Valladolid & 10 \\
\hline & Medina del C & 5 \\
\hline León & León & 10 \\
\hline & Ponferrada & 5 \\
\hline Oviedo & Oviedo & 10 \\
\hline & Gijón & 10 \\
\hline & Langreo & 5 \\
\hline & Mieres & 5 \\
\hline & Pola Siero & 5 \\
\hline & Luarca & 5 \\
\hline Oviedo & LLanes & 5 \\
\hline & S. Martín R. & 5 \\
\hline & Avilés & 10 \\
\hline & Aller & 5 \\
\hline & Cangas Narc. & 5 \\
\hline Palencia & Palencia & 10 \\
\hline Madrid & Madrid & 14 \\
\hline & Alcalá Hen. & \\
\hline & Aranjez & \\
\hline Segovia & Segovia & 5 \\
\hline Avila & Avila & 5 \\
\hline Toledo & Toledo & 5 \\
\hline & Talavera R. & 10 \\
\hline Tenerife & Tenerife & 10 \\
\hline & La Laguna & 5 \\
\hline & La Orotava & 5 \\
\hline & Los Realejos & 5 \\
\hline & I cod de V. & 5 \\
\hline
\end{tabular}




\section{Capítulo 5. Música e ideología 2: La Sección Femenina}

Las piezas que se interpretaron en los diversos programas fueron las siguientes:

Curso 1962/63. La orquesta y su función

\begin{tabular}{|l|l|l|}
\hline Cuentos Musicales & Cascanueces & Tchaikovski \\
\hline & Ma mère L'oie & Ravel \\
\hline Descripción orquesta & Guía de orqu. jóvenes & Britten \\
\hline & J uegos de niños & Rodrigo \\
\hline La orquesta clásica & Serenata nocturna & Mozart \\
\hline & Oberón (obertura) & Weber \\
\hline & Los esclavos felices (ob) & Arriaga \\
\hline & Rosamunda (ballet) & Schubert \\
\hline La orquesta moderna & Murmullos de la selva & Wagner \\
\hline & La pájara pinta & Esplá \\
\hline Grandes obras & Cuadros de una exposic. & Mussorgski \\
\hline
\end{tabular}

Curso 1963/64. Formas musicales

\begin{tabular}{|l|l|l|}
\hline La orquesta e instrument & Variaciones sobre Purcell & Britten \\
\hline & Pedro y el lobo & Prokofiev \\
\hline La suite & Suite en si menor & Bach \\
\hline La obertura & Carnaval de los animales & Saint-Saëns \\
\hline & Il signor Bruschino & Rossini \\
\hline & Don J uan & Mozart \\
\hline & Rosamunda & Schubert \\
\hline & Coriolano & Beethoven \\
\hline La sinfonía & La gruta de Fingal & Mendelssohn \\
\hline El poema sinfónico & Sinf del Nuevo Mundo & Dvorak \\
\hline & En las estepas Asia Cent & Borodin \\
\hline & La oración del torero & Turina
\end{tabular}


La educación musical en el franquismo

\begin{tabular}{|l|l|l|}
\hline & Noche en monte pelado & Mussorgski \\
\hline El concierto & La primavera & Vivaldi \\
\hline & Conc de Aranjuez & Rodrigo \\
\hline
\end{tabular}

Curso 1964/65. Grandes compositores

\begin{tabular}{|l|l|}
\hline Mozart & Serenata nocturna \\
& Concierto para arpa, flauta y orquesta \\
\hline Beethoven & 5a Sinfonía \\
\hline Mendelssohn & Sueño de una noche de verano \\
\hline Chopin & Concierto para piano y orq en mi m. \\
\hline Wagner & Idilio de Sigfrido \\
\hline Falla & Tanhäuser (obertura \\
\hline Stravinski & El retablo de Maese Pedro \\
\hline Compositores españoles & Sinfonía de los Salmos \\
& Los esclavos felices (Arriaga) \\
& Melodías vas (Guridi) \\
& Antífona pascual (Halffter) \\
\hline
\end{tabular}

Curso 1965/66. Grupos e instrumentos de la orquesta

\begin{tabular}{|l|l|l|}
\hline $\begin{array}{l}\text { Los instrumentos de } \\
\text { cuerda }\end{array}$ & $\begin{array}{l}\text { Ejemplos musicales de Purcell, Britten, Mompou, } \\
\text { Respighi } \\
\text { Concierto en Mi mayor para violín y orq de Bach }\end{array}$ \\
\hline $\begin{array}{l}\text { Los instrumentos de } \\
\text { madera }\end{array}$ & $\begin{array}{l}\text { Ejemplos musicales de Tomkins, Vivaldi, Bonet, } \\
\text { Schütz, Mussorgski } \\
\text { Sinfonía concertante de Mozart }\end{array}$ \\
\hline
\end{tabular}




\section{Capítulo 5. Música e ideología 2: La Sección Femenina}

\begin{tabular}{|l|l|}
\hline $\begin{array}{l}\text { Los instrumentos de } \\
\text { metal }\end{array}$ & Ejemplos musicales de Weber. Falla, Finck, Ravel \\
Concierto para trompeta y orq de Haydn \\
Obertura de Tanhäuser de Wagner
\end{tabular}

Curso 1966/67. Formas principales de la música

\begin{tabular}{|l|l|l|}
\hline La variación & $\begin{array}{l}\text { Variaciones sobre un } \\
\text { tema de Haydn } \\
\text { Variaciones sobre un } \\
\text { tema de Purcell }\end{array}$ & Brahms \\
\hline $\begin{array}{l}\text { Pequeñas formas de la } \\
\text { suite }\end{array}$ & $\begin{array}{l}\text { Zarabanda lejana y } \\
\text { villancico } \\
\text { Suite en si menor }\end{array}$ & J oaquín Rodrigo \\
\hline La gran forma & 6a Sinfonía "Pastoral" & Beethoven \\
\hline Organum-Motete-Misa & Cathollicorun cancio & Códice de las Huelgas \\
& Más dura que el mármol & Guerrero \\
\hline
\end{tabular}


La educación musical en el franquismo

\begin{tabular}{|l|l|l|}
\hline & Ave María & Victoria \\
\hline La forma concertante & $\begin{array}{l}\text { Concierto en la menor } \\
\text { para piano y orquesta }\end{array}$ & Schumann \\
\hline
\end{tabular}

\begin{tabular}{|l|l|}
\hline \multicolumn{2}{|l|}{ Curso 1967/68. El concierto y la sinfonía } \\
Concierto de Brandemburgo no 3 & J.S.Bach \\
\hline Concierto grosso en la menor & A. Vivaldi \\
Sinfonía no 88 en sol mayor & J. Haydn \\
\hline Concierto grosso op.6 en si b Mayor & F. Haendel \\
Sinfonía no41 en do mayor & W.A. Mozart \\
\hline Concierto no3 en sol mayor & A. Soler \\
\hline Sinfonía no8 en fa mayor & L. Beethoven \\
\hline Concierto en mi menor & F. Mendelssohn \\
\hline
\end{tabular}

\begin{tabular}{|l|l|l|}
\hline \multicolumn{2}{|l|}{ Curso 1668/69 } & Mozart \\
\hline La orquesta de cuerda & Serenata nocturna & Zarabanda/giga/badinerie \\
& Corelli \\
& Suite en re mayor & Bach \\
& Sinfonía simple & Britten \\
\hline
\end{tabular}


Capítulo 5. Música e ideología 2: La Sección Femenina

\begin{tabular}{|c|c|c|}
\hline & Oración del torero & Turina \\
\hline Cuarteto de cuerda & $\begin{array}{l}\text { Cuarteto op. } 57 \\
\text { Cuarteto } n=3\end{array}$ & $\begin{array}{l}\text { Haydn } \\
\text { Arriaga }\end{array}$ \\
\hline Quinteto de viento & $\begin{array}{l}\text { Divertimento } \\
\text { Rigaudon } \\
\text { Tres piezas breves } \\
\text { El pequeño negro }\end{array}$ & $\begin{array}{l}\text { Mozart } \\
\text { Rameau } \\
\text { I bert } \\
\text { Debussy }\end{array}$ \\
\hline Quinteto de viento & $\begin{array}{l}\text { Divertimento nㅇ } 8 \\
\text { Cuarteto op. } 8 \text { n-2 } \\
\text { Quinteto op. } 88 \text { n2 } \\
\text { Scherzo op. } 48\end{array}$ & $\begin{array}{l}\text { Mozart } \\
\text { Stamitz } \\
\text { Reicha } \\
\text { Bozza }\end{array}$ \\
\hline Coro de cámara & $\begin{array}{l}\text { Christi.patientia } \\
\text { Benedicamus Kyrie } \\
\text { Dadme.albricias Un } \\
\text { niño nos es nacido Riu } \\
\text { riu chiu } \\
\text { Ecce Virgo } \\
\text { Los Reyes siguen la } \\
\text { estrella } \\
\text { Ave María }\end{array}$ & $\begin{array}{l}\text { Códice de las Huelgas } \\
\text { Cancionero de Upsala } \\
\text { Morales } \\
\text { Guerrero } \\
\text { Victoria }\end{array}$ \\
\hline Coro de cámara & $\begin{array}{l}\text { Ensalada } \\
\text { Adoramos } \\
\text { Exultante }\end{array}$ & $\begin{array}{l}\text { Flecha } \\
\text { Mozart } \\
\text { Scarlatti }\end{array}$ \\
\hline
\end{tabular}




\begin{tabular}{|l|l|l|}
\hline & O salutaris & Beethoven \\
Pater noster & Tchaikovski \\
Dos tonadas levantinas & Esplá \\
& Canta el alma & Morera \\
& Eres como la nieve & C. Halffter \\
\hline
\end{tabular}

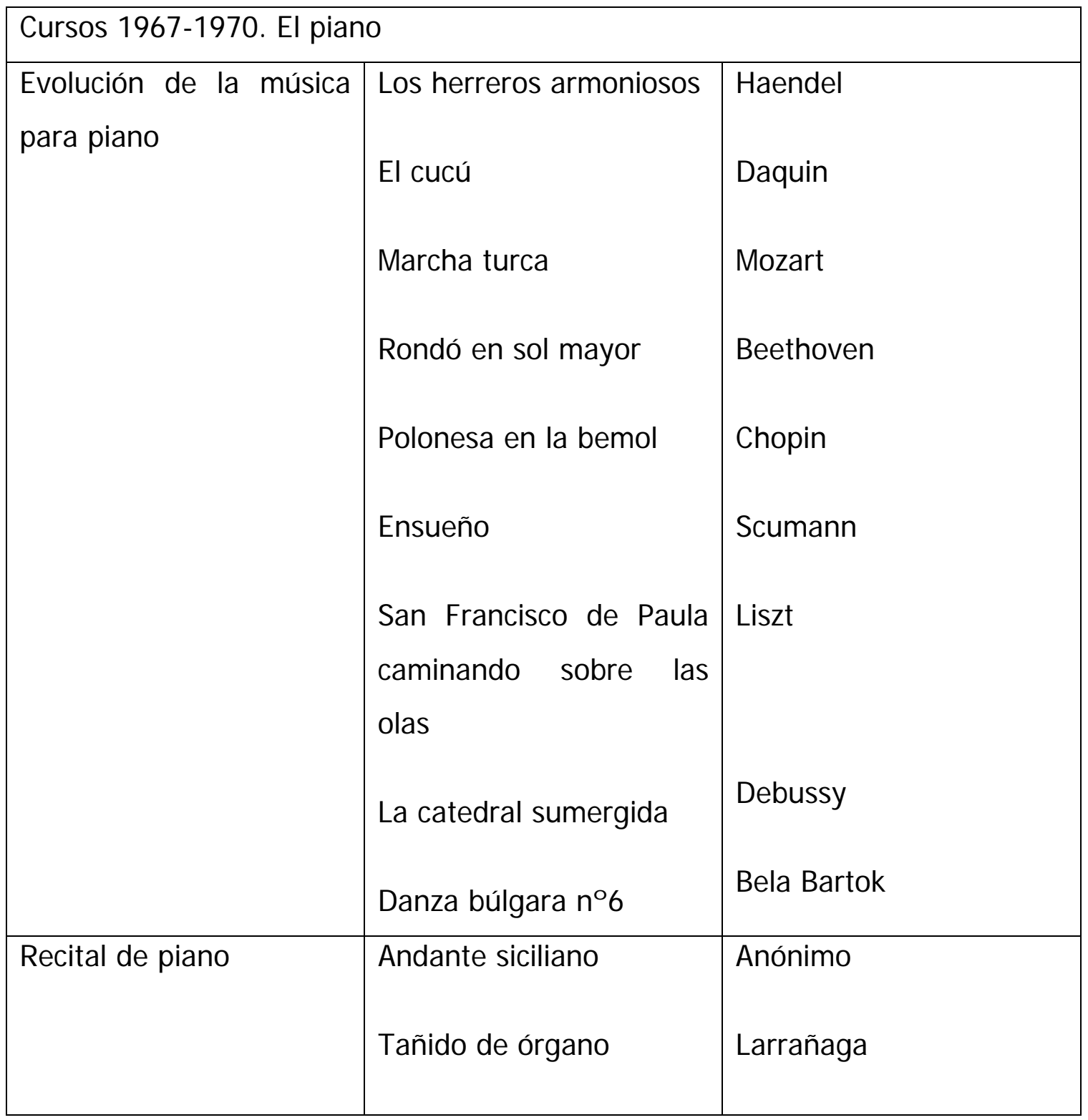


Capítulo 5. Música e ideología 2: La Sección Femenina

\begin{tabular}{|c|c|c|}
\hline & $\begin{array}{l}\text { Sonata } \\
\text { Seis escocesas } \\
\text { Gran polonesa en Mi b } \\
\text { Escenas de niños } \\
\text { Rapsodia húngara no12 } \\
\text { Jardines bajo la lluvia } \\
\text { Evocación (Iberia) } \\
\text { Danza no } 10 \\
\text { Allegro bárbaro }\end{array}$ & $\begin{array}{l}\text { Haydn } \\
\text { Beethoven } \\
\text { Chopin } \\
\text { Schumann } \\
\text { Liszt } \\
\text { Debussy } \\
\text { Albéniz } \\
\text { Granados } \\
\text { Bela Bartok }\end{array}$ \\
\hline Recital de piano & $\begin{array}{l}\text { Preludio y fuga en fa M } \\
\text { Sonata en si menor } \\
\text { Sonata en fa Mayor } \\
\text { Escenas de niños } \\
\text { Balada en fa menor } \\
\text { Danza en sol mayor } \\
\text { El Albaicín }\end{array}$ & $\begin{array}{l}\text { Bach } \\
\text { Scarlatti } \\
\text { Soler } \\
\text { Schumann } \\
\text { Chopin } \\
\text { Granados } \\
\text { Albéniz }\end{array}$ \\
\hline El arpa & $\begin{array}{l}\text { Tema y variaciones } \\
\text { Dos sonatas } \\
\text { Sonata } \\
\text { Trespiezas }\end{array}$ & $\begin{array}{l}\text { Haendel } \\
\text { Soler } \\
\text { Prati } \\
\text { Ibert }\end{array}$ \\
\hline
\end{tabular}




\begin{tabular}{|l|l|l|}
\hline & $\begin{array}{l}\text { Tema y variaciones } \\
\text { Serenata }\end{array}$ & Parish-Alvars \\
\hline
\end{tabular}

En el informe que redactó en Junio de 1969 Carlos González de Lara como organizador de los conciertos para la Delegación nacional de la Sección Femenina hace constar que hasta ese momento

"los conciertos sinfónicos para la juventud han superado todos los record previstos (...) con asistencia de más de $\mathbf{1 4 7 . 0 0 0}$ escolares, 57 conciertos en 114 sesiones". Los ciclos de divulgación musical para escolares constan de cinco conciertos, se realizan entre Noviembre y Marzo, agrupados en 10 sesiones, con una duración aproximada de hora y cuarto y se celebran en día laborable en sesiones matinales en los teatros de mayor aforo de las capitales de provincia (Teatro Monumental y el Palacio de la Música de Madrid, Teatro Alcázar de Toledo, Coliseum Luengo de Guadalajara, Teatro Xúcar en Cuenca) 0 en los Salones de Actos de los institutos. Antes del concierto, se introduce a través de una charla conferencia una orientación sobre la forma de escuchar y comportarse en la sala de conciertos, la historia de las obras que se van a escuchar y una presentación de las diversas familias de instrumentos de la orquesta. El precio que pagan los escolares por asistir es de 15 pesetas por sesión"

Los programas que se elaboraban para la ocasión, contenían comentarios sobre las obras, autores e instrumentos de la orquesta y eran una pequeña guía didáctica para la audición. Entre los colaboradores y comentaristas de los mismos constan figuras tan prestigiosas como Federico sopeña, Cristóbal Halffter, Antonio Fernández-Cid, Manuel Carra, Luis de Pablo, Miguel Angel Coria y Enrique Franco (que elaboraron los de la tercera temporada en Madrid en el teatro Monumental el curso 1964-65)

En el programa de Conciertos Sinfónicos para la Juventud participaron las siguientes intérpretes y grupos musicales

Agrupaciones Orquesta Sinfónica de Madrid 
Capítulo 5. Música e ideología 2: La Sección Femenina

\begin{tabular}{|l|l|}
\hline Orquesta Sinfónica de Málaga \\
Orquesta Sinfónica de Asturias \\
Orquesta de cámara de Sta Cruz de \\
Tenerife \\
Orquesta municipal de Valencia \\
Orquesta municipal de Bilbao \\
Orquesta Santa Cecilia de Pamplona \\
Orquesta de cámara Mozart de \\
Valencia \\
Orquesta de niños del colegio de San \\
Benito de Madrid \\
Coro de RTVE de \\
Coro de cámara de Pamplona \\
Coro de la Caja de Ahorros de \\
Alicante. Pequeño teatro de ópera de \\
Cámara de Madrid \\
Quinteto de viento Koan de \\
Juventudes Musicales \\
Cuarteto de cuerda de Madrid \\
Cuarteto de voz de la Orq. De RTVE \\
Alberto Blancafort \\
Narciso Bonet \\
\hline
\end{tabular}




\begin{tabular}{|l|l|}
\hline Perfecto Artola \\
Fernando Badía \\
Armando Alfonso \\
Pedro Pilfano \\
Luis Antonio García Navarro \\
Luis Morondo \\
Cristóbal Halffter \\
Montserrat Sanuy \\
Rosa Má Kucharski (Piano) \\
Ana Ma Blancafort (Piano) \\
Esteban Sánchez (Piano) \\
Giselle Herbert (Arpa) \\
Roberto Cuesta (Flauta) \\
José Domínguez (flauta) \\
Roberto Liñana (oboe) \\
Adolfo Garcés (clarinete) \\
Pelegrin Caldés (trompa) \\
Rafael angel (fagot) \\
\hline osé Chicano (trompeta)
\end{tabular}


Capítulo 5. Música e ideología 2: La Sección Femenina

\begin{tabular}{|l|l|}
\hline Rubén Antón (Violín) \\
Pedro León (violín) \\
José Fernández (viola) \\
Pedro Corostola (violoncello) \\
Rafael González (Contrabajo) \\
Pablo Tiñuel (timbal) \\
Pablo González (percusión) \\
Narciso Yepes (guitarra) \\
José Tomás (guitarra) \\
Dolores Ripollés (soprano) \\
Julián García León (tenor) \\
José Luis Ochoa (Tenor) \\
Oscar Monzo (bajo) \\
Rosa Máa Kucharski \\
Tomás Marco \\
Carlos González de Lara \\
Juan Manrique de Lara
\end{tabular}




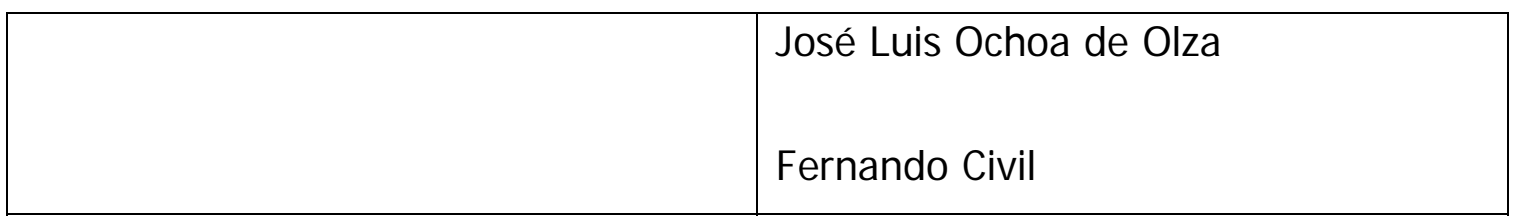

El promedio de gastos por concierto - según el citado informe - asciende a 75.000 pesetas de promedio ( 375.000 pesetas el ciclo completo) incluyendo gastos de orquesta, director, conferenciante, solista, desplazamientos, organización, alquiler de material, sala de ensayos y teatro, pagos a sociedad de autores, policía y protección de menores, micrófonos, programas y otros gastos.

Los conciertos eran posibles gracias a la aportación económica de:

- Los escolares asistentes (15 pesetas por concierto)

- La subvención de la Delegación Nacional de Sección Femenina (aproximadamente el $12 \%$ del total)

- Subvenciones oficiales de ayuntamientos, diputaciones, Cajas de Ahorro, delegaciones provinciales de turismo y gobernación civil.

De entre los 210.000 escolares asistentes en la totalidad de los 10 conciertos en el curso 1968/69, se calcula que un 53,14 \% fueron alumnos de educación primaria, entre 7 y 11 años de edad, frente a un $42,8 \%$ de alumnos de educación secundaria, mayores de 12 años, siempre en cifras aproximadas, ya que la contabilidad que se hace en el informe se realiza en números redondos. 


\section{Capítulo 5. Música e ideología 2: La Sección Femenina}

Escolares asistentes a los Conciertos Sinfónicos de la Juventud en el curso 1968/69

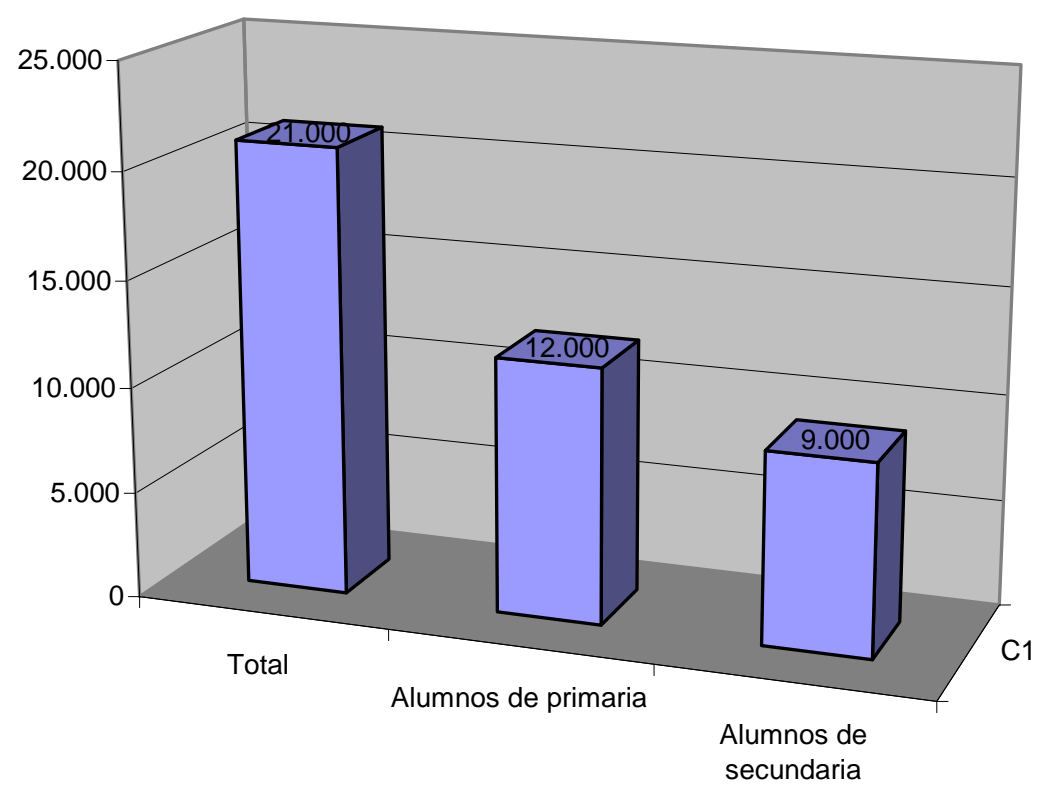

El coordinador de los Conciertos Sinfónicos de Juventudes es Carlos González de Lara, en aquellos años profesor interino y Ayudante de Cátedra del Real Conservatorio de Madrid, Secretario fundador de la Orquesta Pro-Música, Vicepresidente de Juventudes Musicales (cuyo presidente desde 1958 es el director de orquesta Alberto Blancafort), colaborador con la Orquesta Sinfónica de RTVE y asesor de Televisión Española en programas músicales.

Entre el personal de Sección Femenina que participaba en la J unta organizadora del programa de Conciertos para la Juventud se encuentran, según consta en un programa del curso 1967/68 Ma Nieves Sunyer (Regidora Central de J uventudes), Elisa de Lara (Regidora Central de prensa y propaganda), Ma del Carmen Cuesta (Auxiliar Central de Juventudes), Ma Josefa de Acevedo (Regidora provincial de Juventudes de Madrid) y Ma Ascensión Delgado (J efe Departamento Central de Afiliadas), además de las Delegadas provinciales de SF de todas las provincias afectadas.

A partir del año 1970, las actuaciones se disparan en número, extendiéndose por todo el territorio nacional, no sólo a capitales de provincia, sino también a 


\section{La educación musical en el franquismo}

centros urbanos y rurales grandes (generalmente dotados de institutos de secundaria). En el curso 1970/71 se crean cinco rutas, que abarcan un total de 45 capitales de provincia y 43 grandes pueblos. Ello conlleva una gran difusión entre la población escolar y refleja el gran éxito obtenido por la iniciativa de divulgar la música sinfónica de la que son claro reflejo las siguientes cifras:

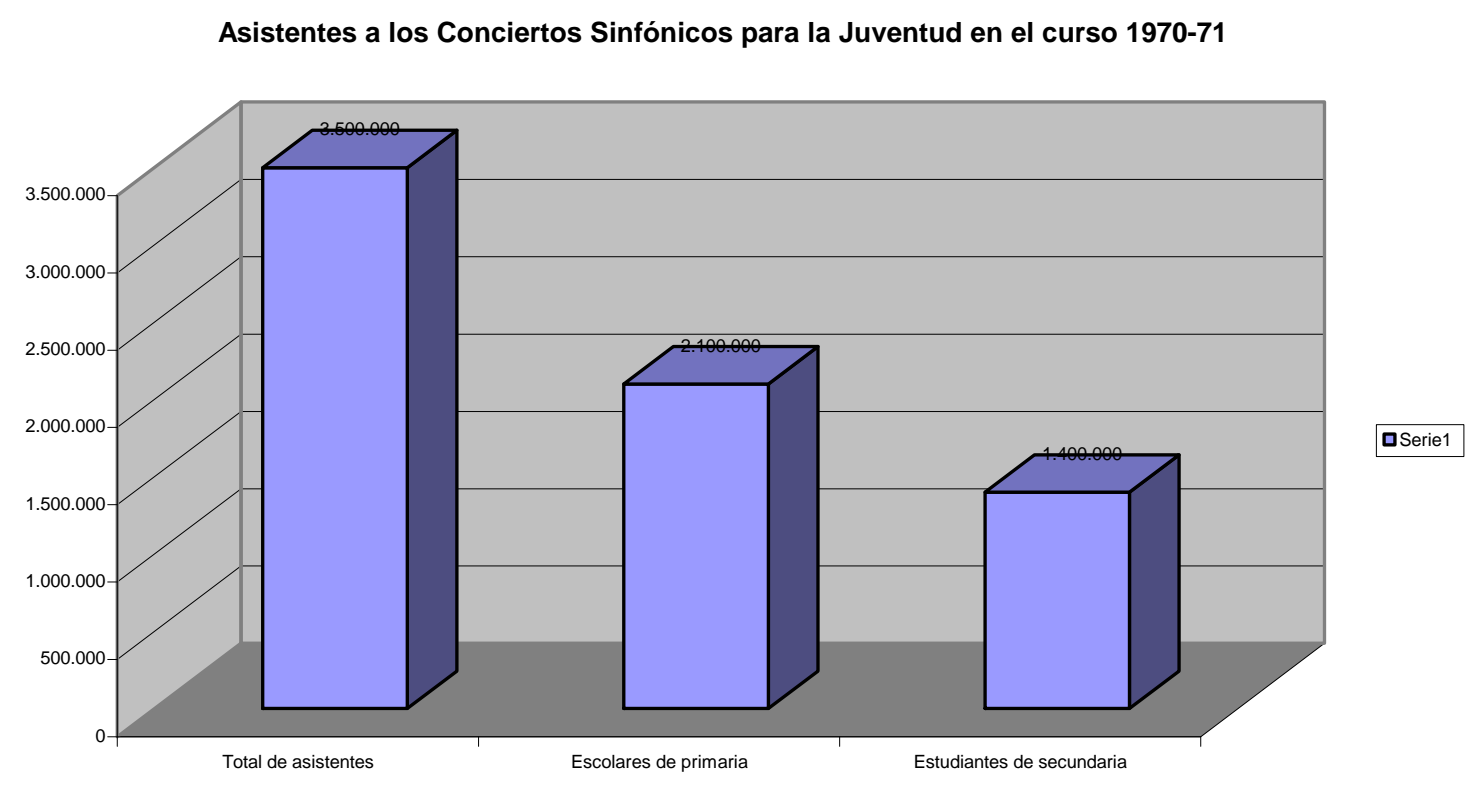

De hecho, a lo largo del curso $1970-71$ se realizaron una totalidad de 90 ciclos provinciales de conciertos, de los cuales 11 tuvieron lugar en diferentes zonas de Madrid (un 12\%).

Los gastos que semejante organización conllevan se disparan a los 42.600 .000 pesetas, más otros 20.000 .000 para la I Exposición Nacional y los Festivales de Música que se realizan en las provincias de Vigo, Alicante, Salamanca, Pamplona, Bilbao, Tenerife, Granada, Badajoz, Zaragoza y Barcelona (prácticamente todas las regiones españolas).

La presencia de la Sección Femenina sigue siendo muy importante desde el punto de vista organizativo y de la estructura para llevar a cabo los conciertos en todas las provincias, pero su aportación económica disminuye 


\section{Capítulo 5. Música e ideología 2: La Sección Femenina}

considerablemente. El patrocinio económico recae fundamentalmente en Ayuntamientos, Diputaciones, el Ministerio de Información, el Ministerio de Cultura y la Fundación FENOSA, que cubren un 30\% de los gastos, así como sobre las Cajas de Ahorros que aportan otro 40\%. La aportación de los escolares cubre un $28 \%$, y sólo el $2 \%$ restante es cubierto por la Delegación Nacional de la Sección Femenina, en un claro ejemplo de la época de deterioro económico y de traslado de poderes desde el Movimiento a los servicios centrales de la administración del Estado.

\subsubsection{Las cátedras ambulantes}

Las cátedras ambulantes de Sección Femenina surgen en el entorno de una España mayoritariamente rural, en la que una gran parte de la población femenina no tiene accesibilidad a los elementos culturales, en una situación económica de potenciación de la autarquía y afrontando las dificultades consecuentes a una alta tasa de analfabetismo.

En el concepto misional de formación de la mujer que tiene la Sección Femenina, el sector agrario de la población femenina necesitaba una tarea de transformación que deciden iniciar trasladándose "in situ" a los lugares de la acción (resultaba impensable que las mujeres abandonaran sus hogaresincluso por pequeños períodos de tiempo- para cubrir sus necesidades de formación en las ciudades, ya que llevaban sobre sus hombros las responsabilidades del hogar y los hijos, además de participar activamente en las tareas de producción).

Ya a partir de 1907 se habían creado Misiones Pedagógicas para sacar al pueblo de la ignorancia y extirpar las lacras sociales ${ }^{214}$, pero fue a partir de la acción legislativa en el marco educativo de la II República con la creación del Patronato de Misiones Pedagógicas (creado por Orden de 29 de mayo de 1931) bajo la tutela de Manuel Bartolomé Cossío cuando su labor se hizo más efectiva. Son beneficiarios de su labor toda la población rural, sin diferencias de edad ni sexo y abarcaban contenidos relativos a la mejora de la

${ }^{214}$ Real Decreto de 10 de enero de 1907 
cultura ciudadana que abarcaban desde la creación de bibliotecas circulantes, sesiones cinematográficas y musicales, sesiones de audiciones por radio y discos y exposiciones de arte, además de las clases de alfabetización. También tenían una función de orientación y visita de las escuelas para conocer sus condiciones y necesidades, así como la organización de quincenas pedagógicas de perfeccionamiento del profesorado ${ }^{215}$.

Según Pérez Moreno ${ }^{\mathbf{2 1 6}}$ existen características equivalentes entre las Misiones Pedagógicas de la II República y las posteriores Cátedras Ambulantes de la Sección Femenina,

\begin{abstract}
"compartiendo la formulación básica de la finalidad general, los destinatarios geográficos y personales, algunas materias y actividades de formación, los recursos, el carácter errante, el planteamiento secuencial de diagnóstico inicial y la consecuente planificación y desarrollo diferencial de la intervención, así como el hecho de que ambas iniciativas se movieran al margen de la educación reglada. Su principal diferencia estaba en el fondo o ideario que las sustentaban, y por tanto en el contenido y las temáticas de las actividades, estrategias y materias de formación".
\end{abstract}

Sección Femenina crea la primera Cátedra nacional motorizada (compuesta por cuatro camiones y cuatro remolques) en $1946^{217}$ e inicia su acción pedagógica por las provincias de Guadalajara, Ávila, Teruel, Segovia, Albacete, Cuenca, Ciudad Real. En los primeros años 50 se extiende su labor a Orihuela y Murcia, así como a la Sierra de Madrid (Torrelaguna, Puebla de la Sierra, Venturada, Redueña, Horcajo). En el año 1954 se sumaron dos nuevas dotaciones de Cátedras creadas por el Ministerio de la Gobernación y otras dos

\footnotetext{
${ }^{215}$ CANES GARRIDO, F. (1993) “Las misiones pedagógicas: educación y tiempo libre en la II República" en Revista Complutense de Educación, vol 4, ํ1, pag. 150 ${ }^{216}$ PEREZ MORENO, H.M. (2003) Educación y Sección Femenina en Huelva. La Cátedra Ambulante: una escuela rural de formación integral e intensiva (1956-1977). Tesis Doctoral no publicada de la Universidad de Huelva

${ }^{217}$ Hay una cierta disparidad sobre la fecha exacta de la creación de esta primera cátedra. Pilar Primo de Rivera y Sánchez Llamas la anuncian en 1944, los fondos de Sección Femenina de la Real Academia de la Historia la sitúan en 1945, Jiménez Losantos la retrasa a 1948. Sin embargo, apoyan esta datación en 1946 los documentos de la Sección Femenina sobre la Organización de las cátedras, la publicación de DELEGACIÓN NACIONAL DE SECCIÓN FEMENINA (1970) Cátedras ambulantes. Editorial Almena, pag. 4, SUÁREZ FERNÁNDEZ , L. (1993) Crónica de la Sección Femenina y su tiempo. Madrid: Asociación Nueva Andadura, pag. 191 y AGULLÓ DÍAZ, M.C. (1993) La educación de la mujer durante el franquismo y su evolución en Valencia. Valencia: Servicio de publicaciones de la Universidad de Valencia
} 


\title{
Capítulo 5. Música e ideología 2: La Sección Femenina
}

por el Ministerio de Educación Nacional. Con el apoyo de los gobernadores civiles y a petición de las Jefaturas Provinciales del Movimiento, su acción se exctendió a casi todas las provincias, y en 1958 ya estaban dotadas con una Cátedra Ambulante todas las provincias españolas excepto las de África. A partir de los años 60 la dotación siguió creciendo, de manera que se contaba con 62 cátedras en 1963 (a los que se iban adjudicando dentro del Primer Plan de Desarrollo 40 remolques viviendas y 27 remolques clínica), 72 en 1968 con un total de 360 profesoras, y más de 80 en el año 1977, en el que dejaron de existir como tales oficialmente. Francisco Javier Sánchez LLamas ${ }^{\mathbf{2 1 8}}$ expone que

\begin{abstract}
“desde su creación las Cátedras Ambulantes persiguieron una doble finalidad. Por un lado la formación y promoción de la mujer en los pueblos pequeños, donde no tenían medios para hacerlo de una forma adecuada. Por otro, la mejora general de las poblaciones que visitaban, recuperando costumbres, insistiendo en la realización de algún proyecto urbanístico, preocupándose, en suma, por la población general, no sólo la femenina".
\end{abstract}

Aunque siempre cargado de rasgos de transmisión ideológica, podemos concluir con Pérez Moreno ${ }^{219}$ "que de forma resumida, la misión de las Cátedras Ambulantes fue la formación integral - y también asistencial - de la población rural, sirviendo de base esta formación para despertar la conciencia ciudadana y activar la conducta orientándola hacia una implicación responsable en el propio desarrollo comunitario a nivel económico, social y cultural. La mayor incidencia integral se ejercía sobre las mujeres (casadas y mozas) y en menor medida en las niñas, niños y hombres (casados y mozos). Hay que subrayar también que algunos ámbitos de la integridad formativa tenían el sesgo del régimen, pero ello no cercena que la acción educativa fuera sobre el global de rasgos y estados de la personalidad - con pretendido esmalte partidista y confesional -. Los rasgos de sesgo más evidentes fueron la formación política y religiosa - pero sobre todo que llegue a todos los pueblos el

\footnotetext{
${ }^{218}$ SANCHEZ LLAMAS, F.J . (1998) Las Cátedras ambulantes de la Sección Femenina en Málaga. Tesis doctoral de la Universidad de Málaga

219 PEREZ MORENO, H.M. (2003). Op. Cit.
} 


\section{La educación musical en el franquismo}

conocimiento de nuestras verdades religiosas y falangistas - y la formación para el modelo franquista de mujer, o si se prefiere la capacitación perfectiva para el ejercicios de las labores de ama de casa, esposa y madre."

Pérez Moreno asigna a las Cátedras 5 tipos de funciones en su labor misional:

- Función formativa. Es la que considera función principal y consiste en ofrecera la ciudadanía conocimientos, técnicas, habilidades y actitudes en distintos ámbitos (político, religiosos, ocupacional, nutricional, higiéncio, folklórico, cultural, lecto-escritor)

- Función asistencial

- Función prospectiva-continuadora

- Función inspectora

- Función recopiladora

La labor divulgativa cultural de las cátedras ambulantes dentro del marco de la educación no formal abarca pues a toda la población infantil y adulta, sin grandes distinciones. Desde el punto de vista de la educación musical, su labor cumple todas estas funciones. La labor formativa es fundamental, ya que la visita de instructoras y especialistas musicales implica la ocasión de tener personal cualificado y poner a disposición de la población una serie de materiales audiovisuales y didácticos innovadores hasta entonces fuera de su alcance. La colaboración con los maestros y maestras, la dotación con materiales musicales - cancioneros, revistas -, la realización de conferencias y clases teórico-prácticas, la programación de audiciones y visitas a la discoteca, la tramitación de ayudas para la consecución de bibliotecas y discotecas básicas y de visitas de las mismas programadas en ciclos, la función inspectora de que se realizaran las enseñanzas musicales previstas por la ley educativa y la aportación de los especialistas musicales en la difusión de las técnicas y procedimientos para la enseñanza musical entre el profesorado generalista fueron muy significativas. 


\section{Capítulo 5. Música e ideología 2: La Sección Femenina}

Pero sin duda, la actividad más evidente desde el punto de vista de las cátedras, fue la recogida y clasificación del material folklórico. No sólo cumplían con ello uno de los preceptos más importantes para la Sección Femenina, al recoger y salvaguardar el patrimonio musical, sino que lograban con su actitud e interés hacer que se valoraran especialmente las danzas y canciones tradicionales, utilizadas en la realización de tareas cotidianas canciones de trabajo, juegos populares - y en las ocasiones festivas -danzas, melodías, rituales -. De estas visitas al medio rural, Sección Femenina sacó una gran parte de sus fondos folklóricos, ya que desde los años 50, se había convertido en una auténtica prioridad la preservación de las danzas y canciones populares. La labor realizada en este sentido por la Regiduría de Cultura en el Servicio de Música fue determinante, pagando a profesionales y enviando a su personal especializado a recoger cualquier documento de este tipo para recoger tanto las melodías como las coreografías con los medios disponibles (transcripciones en partitura, fotografías, dibujos de vestuario, coleccionismo de trajes tradicionales, filmación, grabación magnetofónica, transcripción Laban de los movimientos coreográficos). Todos estos materiales eran enviados a la Delegación provincial y de allí a la Regiduría Central de Cultura. Allí se clasificaban y volvían a su vez a la provincia, donde eran divulgadas entre la población general. Muchas de las danzas y canciones que se mostraban en los festivales locales de coros y danzas eran fruto de las recogidas en estos viajes, dando a conocer la riqueza de la cultura popular en una sociedad que cada vez más se trasladaba a las zonas urbanas, perdiendo e incluso despreciando sus orígenes rurales y tradicionales.

La colaboración con las maestras era fundamental, ya que uno de los cometidos específicos de la Instructora de Juventudes dentro de la Cátedra era la orientación y el asesoramiento didáctico en las materias que correspondían al Movimiento dentro del sistema educativo, entre las cuales, como hemos visto, 


\section{La educación musical en el franquismo}

se encuentran de manera fundamental la música y la educación física. Así se recoge en las Fondos de la Sección Femenina ${ }^{220}$ que la Instructora debe

\footnotetext{
“Dar las clases de canciones a las niñas y a los niños. Y lograr que la maestra enseñe y siga nuestros programas de canciones; si lo juzga oportuno puede ayudar personalmente en esta tarea a la maestra"

“(...) Se trata de logra que la Escuela lleva a fondo y con ilusión todas las enseñanzas a que la ley les obliga y que nuestra misión es asesorarla para que las dé perfectas"
}

La Instructora de Juventudes era la persona encargada habitualmente de las enseñanzas de: Música, danzas y educación física. Su principal actividad estaba dirigida a los niños y niñas en edad escolar, pero también a los adultos.

Los escolares de ambos sexos recibían las clases de canciones y educación física, y las niñas, además, las de danzas. Sin embargo, en las actividades con los adultos, se animaba a los mozos y a los hombres a participar activamente en todas las danzas y bailes regionales formando un grupo mixto. Pérez Moreno $^{\mathbf{2 2 1}}$ refleja en su tesis doctoral sobre la Cátedra Ambulante de Huelva la existencia del siguiente programa de Música y Baile:

Para las J uventudes aparecen las siguientes canciones:

\begin{tabular}{|l|}
\hline Canciones de coro \\
\hline Quisiera ser tan alta \\
\hline Estaba el Sr. D. Gato \\
\hline Una tarde gresquita de Mayo \\
\hline La farola de palacio \\
\hline Al farolero \\
\hline Ambo Ato \\
\hline Arroyo claro \\
\hline Aserrín, aserrán \\
\hline
\end{tabular}

${ }^{220}$ Real Academia de la Historia RAH. Fondos de la Sección Femenina, legado de Pilar Primo de Rivera, Carpeta Azul n1 255, Circular no 73 "Tarea de las Cátedras en lo que se refiere al servicio de Juventudes", de 13 de noviembre de 1961

221 PEREZ MORENO, H.M.(2003). Op. Cit.. Fondos de la Delegación Provincial de la Sección Femenina conservados en el Archivo Histórico Provincial de Huelva, Legajos 66,87 y 88 


\section{Capítulo 5. Música e ideología 2: La Sección Femenina}

\begin{tabular}{|l|}
\hline Ya se murió el burro \\
\hline El balcón de palacio \\
\hline Mambrú se fue a la guerra \\
\hline Tengo una muñeca \\
\hline Romances \\
\hline En Cádiz hay una niña \\
\hline El conde Olinos \\
\hline Rosalinda \\
\hline Divino Antonio \\
\hline Populares \\
\hline Como vives tan alta \\
\hline Canción de siega \\
\hline Tengo un arbolito \\
\hline Gregoriano \\
\hline Responsorio de Prima (tono común del año) \\
\hline Responosrio de completas (tono común del año) \\
\hline Ave maría \\
\hline Mave María Stella \\
\hline Puer natus \\
\hline Adorote Devote (Ambrosiano= \\
\hline Adeste Fideles (Navidad) \\
\hline
\end{tabular}

Todas estas canciones estaban recogidas a su vez en el libro publicado por Sección Femenina de Canciones para escolares dedicado fundamentalmente al repertorio que se debía impartir en la Escuela Primaria.

Igualmente existe un repertorio de canciones para "Mozas", es decir, para el personal adulto, que incluye:

\section{Canciones regionales \\ Tu pañuelo y el mío (Castilla) \\ No voy por agua (Aragón) \\ Fui al Cristo (Asturias)}




\section{La educación musical en el franquismo}

\begin{tabular}{|l|}
\hline Arroro (Canarias) \\
\hline El rossinyol (Cataluña) \\
\hline Salamanca la blanca (Galicia) \\
\hline El carbonero (Andalucía) \\
\hline Los mayos (Murcia) \\
\hline Si vas a San Benitiño (Galicia) \\
\hline Como la flor (Asturias) \\
\hline El tío Pep (Valencia) \\
\hline La niña que está en la bamba (Andalucía) \\
\hline De los álamos vengo, madre (Castilla) \\
\hline Aurtxoa Seaskan (Vasconia) \\
\hline Goeizeke Izarra (Vasconia) \\
\hline No hay carretera sin barro (Castilla) \\
\hline Límpiate con mi pañuelo (Castilla) \\
\hline Casóse Maruja (Galicia) \\
\hline Agora non (Asturias) \\
\hline Dicen que no me quieres (Castilla) \\
\hline Gregoriano \\
\hline Salve \\
\hline Jesu dulcis memoria \\
\hline Puer natus \\
\hline Misa de Angelis \\
\hline Ecce nomen domini \\
\hline O quam amabilis est \\
\hline Regina coeli \\
\hline Danzas (según localidades, en este caso en la provincia de Huelva) \\
\hline Niñas \\
\hline El Pino de San Juan de Alonso \\
\hline El Tomillo de Salcedo \\
\hline La danza de la Esperanza \\
\hline Mozas y grupo mixto \\
\hline
\end{tabular}




\section{Capítulo 5. Música e ideología 2: La Sección Femenina}

\begin{tabular}{|l|}
\hline El Pino de San Juan Alonso \\
\hline El fandango de El Cerro \\
\hline El fandango de Huelva \\
\hline El Tomillo de Salcedo \\
\hline La Danza de la Esperanza \\
\hline El Vito \\
\hline El olé de la Curra \\
\hline Las peteneras de Paterna \\
\hline Las peteneras de Córdoba \\
\hline El fandango de Santa Eulalia \\
\hline
\end{tabular}

Las canciones se aprendían de forma monódica o como máximo a dos voces. Se hace especial hincapié en el aprendizaje y difusión de las canciones de la propia región, aunque, como se aprecia en el repertorio, a nivel de canciones se tiende a una unificación del cancionero nacional. Sin embargo en el caso de las danzas se insiste en el localismo, en

"bailar lo de su pueblo concreto, y si no lo de la región, pero jamás lo de ninguna otra".

La frecuencia de las clases era diaria, alternando canciones y danzas, según las necesidades se daban dentro (niños) o fuera del horario escolar (adultos, mozas y grupo mixto).

Es de resaltar la presencia del canto gregoriano y la preocupación por su difusión y participación por parte de la comunidad, animando al coro mixto a la buena pronunciación y el uso de un tono medio de voz.

Por su parte, la enseñanza de danzas tenía también mucha aceptación, especialmente entre la población adulta, ya que era la actividad que daba lugar posteriormente a la creación de formaciones de coros y danzas, bien femeninos o mixtos, lo que les permitía exponer sus trabajos en los festivales provinciales, y en el caso de ser finalistas, en el concurso nacional. Se fomentaba además la posibilidad de salir fuera del ambiente rural, bien a la capital de la provincia, bien a otras de ámbito nacional e internacional a través de intercambios con otros grupos, mostrando la riqueza cultural propia, 


\section{La educación musical en el franquismo}

desarrollando y cultivando el aprecio por el folklore y sobre todo dando prestigio y orgullo a la tradición popular.

Según los datos sobre la asistencia a las actividades formativas de música y danzas de la Cátedra ambulante de Huelva durante los cursos 1964/65 a 1969/70 que aporta Pérez Moreno ${ }^{222}$ se aprecia:

Frecuencia acumulada de actividades formativas de música y danzas de la Cátedra ambulante de Huelva. Cursos 1964/65 a 1969/70

\begin{tabular}{|c|c|c|c|c|c|}
\hline \multicolumn{3}{|l|}{ Canciones } & \multicolumn{3}{|l|}{ Danzas } \\
\hline Niños/as & Mozas & Generales & Niños/as & Mozas & Mixto \\
\hline Clases & Clases & Clases & Clases & Clases & Clases \\
\hline 1542 & 426 & 75 & 1566 & 586 & 736 \\
\hline Asistentes & Asistentes & Asistentes & Asistentes & Asistentes & Asisten \\
\hline 2.455 & 1320 & 1088 & 2069 & 285 & 469 \\
\hline
\end{tabular}

Como él mismo destaca,

"en los seis años de referencia que se recogen, no cabe duda de que el colectivo de alumnos que más clases recibieron tanto de canciones como de danzas, fue el denominado J uventudes, es decir, el de niños y niñas en edad escolar".

También destaca que el grupo mixto de danzas recibió mayor número de sesiones y fue más exitoso en cuanto a asistencia que la enseñanza de mozas por separado.

\subsubsection{La formación interna de las afiliadas: el Servicio social y los Círculos Medina}

La Sección Femenina realizaba una gran labor musical en el ámbito educativo no formal para sus afiliadas y, especialmente a partir de los años 1960 también

222 PEREZ MORENO, H.M. (2003) Op. Cit. pag. 1022, Tabla № 10.76 


\section{Capítulo 5. Música e ideología 2: La Sección Femenina}

para personas interesadas en la vida cultural a través de los llamados Círculos Medina. Aunque inicialmente esta formación se centraba en las actividades voluntarias dentro de las delegaciones provinciales (coro, grupos de danzas, albergues), poco a poco estas actividades fueron extendiéndose a la población general de cualquier edad por medio de conferencias, audiciones musicales comentadas, bibliotecas y bibliografía específicamente musical, y sobre todo la creación de fondos discográficos especializados en música clásica y folklore.

Ya desde 1941, la Revista CONSI GNA para maestras, incluye un apartado de "Nuestras actividades" o "Actividades voluntarias" en las que se incluyen canciones, en un principio desglosadas según la edad de las afiliadas (consta explícitamente la indicación para flechas, margaritas o flechas azules). También aparecen una serie de normas sobre cómo se deben impartir las enseñanzas de música para las afiliadas que forman el coro de la sección: lecciones de solfeo progresivo, aplicado a las canciones que se están aprendiendo, con el fin de fijar bien los conocimientos prácticos; directrices sobre la pronunciación, entonación y cuidado en la intensidad de la interpretación; especificación del origen regional de las canciones y traducción de las letras en otras lenguas (latín, euskera, catalán, valenciano, gallego). Aunque en principio estas normas estaban destinadas también a la educación formal en las escuelas e institutos, parece evidente que se trabajaban de forma especial en el contexto del coro y las agrupaciones musicales de las afiliadas en las delegaciones provinciales con vistas a los posibles concursos y actuaciones organizadas por la Sección Femenina (todo ello englobado dentro de las llamadas "Escuelas de Hogar de la Sección Femenina".

Así, por ejemplo, este es el programa de canciones para los Cursos de las Escuelas de Hogar de la Sección Femenina en 1957

CANCIONES para las Escuelas del Hogar de Sección Femenina. 1957

MARCHAS

Amanece para mí. En pie, camarada. Cubre tu pecho

GREGORIANO 
La educación musical en el franquismo

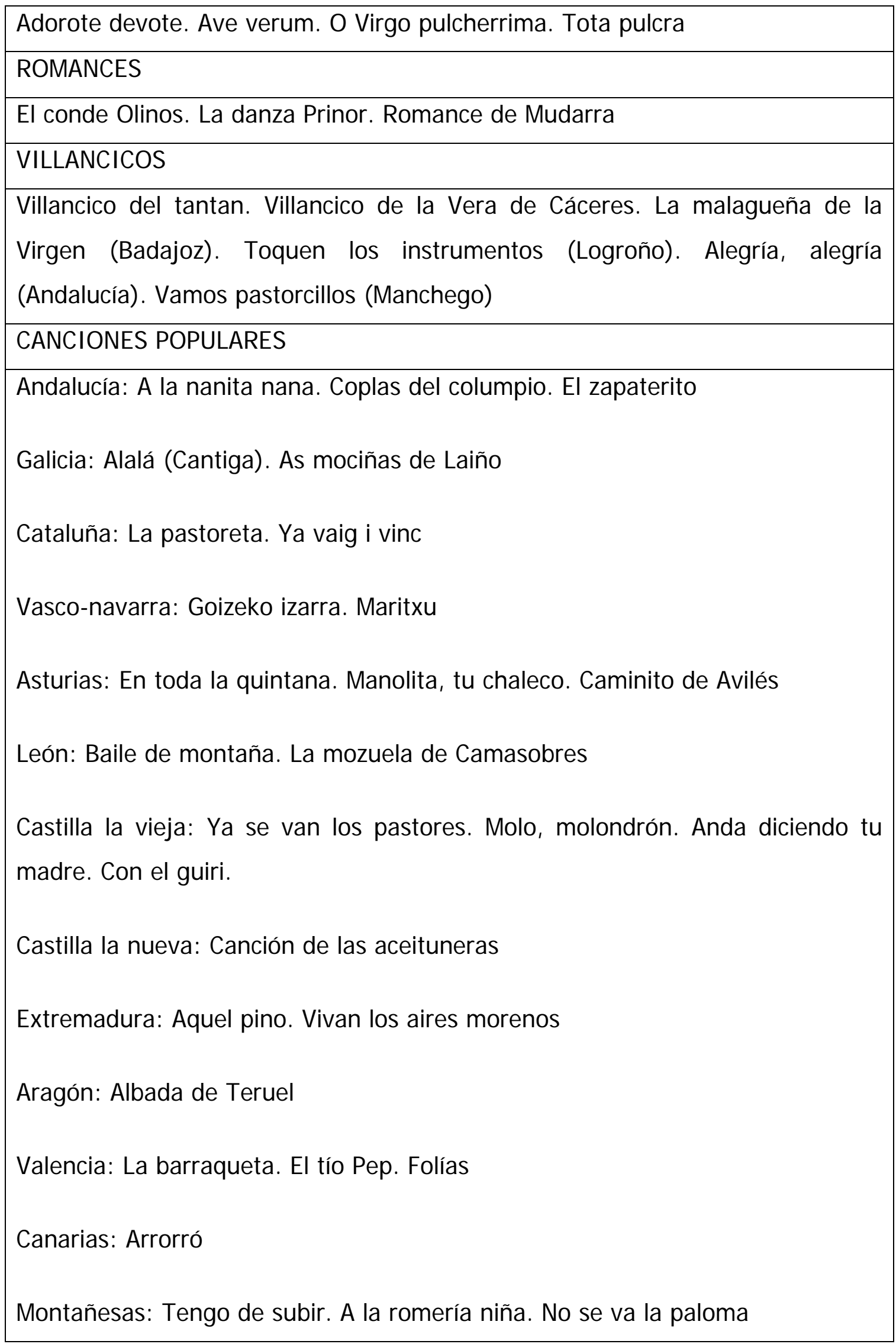




\section{Capítulo 5. Música e ideología 2: La Sección Femenina}

En el campo de la cultura musical, también se empleaban a fondo los escasos recursos personales y materiales de las delegaciones: instructoras, bibliotecas y discotecas. La formación inicial sobre Historia de la música se extendía a la formación de las jóvenes a través del llamado "Servicio Social" de carácter obligatorio. En la documentación del Archivo General de la Administración ${ }^{223}$ podemos encontrar los programas referentes a la Cultura Musical que debían recibirse tanto a través de las Escuelas del Hogar (ordinario) como en la sección de trabajadoras (Obreras y Empleadas), editados en 1966.

En ambos casos (ordinarias y trabajadoras) la duración del curso total era de 3 meses, pero dentro de ambos se produce una gran diferencia en la dedicación a la cultura musical.

MUJERES TRABAJADORAS (Obreras y empleadas). La dedicación total a las actividades culturales de tipo musical serán de 12 horas, distribuidas en

\begin{tabular}{|c|c|}
\hline \multicolumn{2}{|l|}{$\begin{array}{l}\text { Duración: Tres meses. } \\
\text { Cultura musical: } 12 \text { horas }\end{array}$} \\
\hline \multicolumn{2}{|c|}{3 clases de 2 horas dedicadas a audiciones o lectura teatral } \\
\hline \multicolumn{2}{|l|}{6 clases de 1 hora dedicadas a charlas } \\
\hline $\begin{array}{l}\text { 1. Elementos de la música: Ritmo, } \\
\text { melodía y armonía. La voz humana y } \\
\text { la música vocal. Grandes familias de } \\
\text { instrumentos y la música instrumental }\end{array}$ & $\begin{array}{l}\text { 2. La polifonía. La vihuela española y } \\
\text { la guitarra. El Renacimiento y el } \\
\text { madrigal. La música dramática y la } \\
\text { ópera. El ballet }\end{array}$ \\
\hline $\begin{array}{l}\text { 3. El barroco y el clasicismo. Bach, } \\
\text { Haendel, Haydn, Mozart y Beethoven }\end{array}$ & $\begin{array}{l}4 . \quad \text { Romanticismo. } \\
\text { nacionalistas. Schubert, Schumann, } \\
\text { Chopin y Liszt. Compositores } \\
\text { nacionalistas }\end{array}$ \\
\hline a música $f$ & \\
\hline
\end{tabular}

${ }^{223}$ ARCHIVO GENERAL DE LA ADMINISTRACIÓN (AGA), Caja 3 de 51.10 


\begin{tabular}{|l|l|l|}
\hline dignificación. La canción popular. Las & siglo XX. El blues. La orquesta en el \\
danzas y los trajes regionales de & jazz. Solistas de jazz \\
España
\end{tabular}

Evidentemente,

“debido a la gran extensión de este programa, la profesora deberá escoger escuetamente lo más necesario para que las alumnas comprendan con claridad lo que en él se cita".

También hay una ejemplificación de horario en la que se propone que la asignatura de música se imparta los miércoles de la $1^{\underline{a}}$ y $3^{\underline{a}}$ semana de cada mes.

En el caso del Servicio Social ordinario, la extensión y detalle del temario es mucho mayor, dada la mayor presencia horaria: 72 clases de 45 minutos de duración a lo largo de los tres meses que dura la etapa de formación. El programa que se detalla contiene tres contenidos: Cultura musical, Canciones y Metodología.

\section{CULTURA MUSI CAL. Servicio social ordinario. 1966}

Duración: Tres meses

72 clases de 45 minutos

1. Elementos que integran el arte musical: Ritmo, melodía y armonía. Ej. Musicales: Ritmo Historia del Jazz y Remeros del Volga (fragmentos), Melodía Canto gregoriano y Armonía Mesias de Haendel (fragmento)

2. Artes plásticas y artes musicales. El creador y el intérprete. La voz humana. Música vocal e instrumental. Ej. Musicales Coro de peregrinos a Santiago, Lamento de Arianna de Monteverde, un fragmento de un Cuarteto de Haydn o Mozart

3. Las grandes familias instrumentales. Instrumentos de percusión, viento madera, viento metal, cuerda. La orquesta. Ej. Musical Piccolo, sazo y compañía y Guía de orquesta para jóvenes de Britten 


\section{Capítulo 5. Música e ideología 2: La Sección Femenina}

4. Desenvolvimiento de la melodía. La música en la antigüedad y en el paleocristianismo. Ej. Musical 2.000 años de música de Curt Sachs (fragmento)

5. El canto gregoriano. Ej. Musical Canto gregoriano de los Benedictinos de Solesmes (fragmento)

6. Nacimiento de la polifonía vocal. Ej. Musicales 2000 años de música de Curt Sachs y Obras de Martin Codax y T.L. de Victoria

7. Melodía vocal con acompañamiento instrumental. Ej. Musicales Cantigas de Alfonso X el Sabio y Corales de la Pasión según S. Mateo de Bach

8. La música en el pueblo. El movimiento trovadoresco. Madrigales y villancicos.

9. Polifonía religiosa española. Escuela vihuelística española. Ej. Musicales Obras de T.L. de victoria y Morales. Grabaciones de música para vihuela por Segovia, Yepes o Tarrago

10. La música instrumental de cámara. Iniciación a las formas musicales. Ej. Musical Cuarteto de Mozart o Haydn

11. El madrigal. Formas contrapuntísticas clásicas: La fuga. Ej. Musicales. Obras de la grabación de "Los madrigalistas de Radio Nacional", una fuga de El clave bien temperado de Bach

12.-Formas vocales y vocales instrumentales: El oratorio, el motete, la cantata.

Ej. Musicales de Palestrina, Morales, Cabezón. Mesias de Haendel, una Cantata de Bach, Corales de la Pasión según San Mateo de Bach

13. Nacimiento de la ópera: Monteverde y Gluck. Lamento de Arianna de Monteverde y Ifigenia en Aulide de Gluck

14. La ópera y el drama lírico. Mozart, Verdi, Puccini, Wagner Ej. Musicales de Las bodas de Fígaro (Mozart), Rigoletto (Verdi), La Boheme (Puccini) y Tristan e /solda de Wagner

15. El ballet y el mimo. Ej. Musicales Cascanueces (Tchaikovsky), Petrouschka (Stravinski) y Pedro y el lobo (Prokofiev)

16. Pequeñas y grandes formas intrumentales: La suite, la sontal, la sinfonía, la obertura y el concierto. Ej. Musicales Suite en re mayor de Bach, una Sonata de Beethoven, una Sinfonía de Beethoven o Schubert, Concierto para violín y 
orquesta de Mendelssohn y Concierto de Aranjuez de J oaquín Rodrigo

17. Barroco y clasicismo. Ej. Musicales Mesias de Haendel y Sonata en la mayor de Mozart

18. El siglo XIX: Romanticismo. Ej. Musicales Un lied de Schubert, una Escena de niños de Schumann, la obertura de El sueño de una noche de verano de Mendelssohn, un lied de Brahms, un Nocturno o Vals de Chopin

19. El nacionalismo. Ej. Musicales La kovantchina de Mussorgski, una Rapsodia húngara de Listz, una Danza noruega de Grieg, una Danza española de Granados, Triana de Albéniz, una de las Canciones españolas de Falla y La procesión del Rocío de Turina

20. La música folklórica en España desde Pedrell hasta nuestros días. La canción popular. Ej. Musicales Antología del folklore musical de España de Manuel garcía Matos

21. Ideas sobre nuevas tendencias musicales desde el impresionismo, politonía, atonalismo, dodecafonismo, música concreta, música electrónica, el jazz. Ej. Musicales Preludios de Debussy, Bolero de Ravel, Cinco piezas para orquesta de Schoenberg, Sinfonía para un hombre solo de Schoeffer, Canto de los adolescentes de Stockhausen, Historia del jazz y Espirituales negros por el cuarteto vocal "The Goleen Gate"

También explicita que "deberá procurarse que las alumnas tengan todos los días práctica coral hasta terminar el curso, aprendiendo las canciones que dé tiempo del siguiente programa.

PROGRAMA DE CANCIONES. Servicio Social ordinario. 1966

CANCIONES DE CORRO

Las ovejuelas. Este corro es un jardín. La pastora. Milano. Mi abuelo tenía un huerto. Una tarde fresquita de mayo. Como quieres que tenga. Estaba el señor don Gato. En el balcón de palacio. El petit valet

CANCIONES POPULARES

Miás nay por me casare (Galicia). Tres hojitas madre (Asturias). Viva León, porque tiene (León). Me quisiste, me olvidaste (Castilla). Marichu 


\section{Capítulo 5. Música e ideología 2: La Sección Femenina}

(Vascongadas). Una matinada fresca (Cataluña). La barraqueta (Valencia) Las torras (Murcia). Con el trípili (Andalucía). Vivan los aires morenos (Extremadura). Vou-veri-vou (Baleares). Palmero sube a la palma (Canarias)

VILLANCICOS

Alegría, alegría (Andalucía). Pampanitos verdes (Andalucía). Villancicos de Santurdejo (Logroño). En Belén tocan a fuego (Castilla). Zumba, zúmbale al pandero (León). El desembre congelat (Cataluña). Esta noche es nochebuena (Valencia). Agur (Navarra). Esta noche nace el niño (Canarias). La Noragüena (Extremadura)

ROMANCES Y CANCIONES ANTIGUAS

Els tres tambors (Cataluña). La infanta encantada. Las tres cautivas. El conde Olinos. Ay, que non era (S. XVI). Tan buen ganadico (Juan del Encina). Quién te trajo, caballero (J uan del Encina)

HI MNOS Y MARCHAS

Prietas las filas. Se oyen ya los pasos. Cubre tu pecho. Juventud española. Montañas nevadas

En cuanto a las indicaciones metodológicas, la citada documentación de 1966 hace referencia a que

La profesora deberá realizar las lecciones de Historia y cultura musical de la forma más sencilla posible, procurando ser breve y sólo dando los datos más importantes del tema de cada clase, destacando las obras y hechos más sobresalientes de cada autor y época, tratando de que sea en realidad una preparación para la Audición musical, forma ésta a la que debe dársele la mayor importancia, ya que es la base de la educación del oído y el sentido artístico de la alumna. Antes de cada charla deben tenerse previamente preparados los discos que se van a escuchar.

Desde las primeras clases la profesora ordenará éstas de forma que en cada una de ellas tenga tiempo suficiente para dedicarlo también a la enseñanza de las canciones. Para conseguir que una canción se aprenda brevemente y con más seguridad, se explicará primero la letra, enseñándola a continuación con el ritmo que ha de tener la canción. Una vez conseguido esto, se procederá a cantar la melodía. Después de aprendida la melodía, se debe atender a la expresión y estilo apropiado, siendo importantísimo esto último. La interpretación que la canción requiera debe 


\section{La educación musical en el franquismo}

hacerse siempre sin exageraciones que pueden ser ridículas. Las canciones se cantarán siempre en el idioma original y nunca con letras traducidas.

A partir de los años 1960, la Sección Femenina se hace cada vez más consciente de la importancia de la audición como procedimiento para la difusión de la cultura musical entre la población, y cada vez se va dotando (dentro de las posibilidades económicas de cada delegación) a los Círculos de Juventudes de discotecas con grabaciones de folklore y música clásica, tanto para impartir las clases en los centros escolares e institutos de enseñanza secundaria (casi ninguno disponía de este tipo de material y la profesora de Sección Femenina debía proporcionarlos) como en las enseñanzas dentro de sus recintos (Servicio social, albergues y campamentos, coro).

Poco a poco, estos llamados "Círculos de Juventudes" fueron ampliando su actividad a la población femenina general, ya que cada vez se realizaban más cursos destinados a adultos (cátedras ambulantes, grupo de coros y danzas, cursos de adultos, extensión cultural). Así desde mediados de los años 60 y hasta 1977 se denominaron "Círculos Medina", abiertos a la población general (aunque mayoritariamente seguían siendo centros de mujeres, a las charlas y conferencias de tipo cultural y también a la sala de audiciones/biblioteca/discoteca acudían cada vez más hombres interesados en temas de cultura general 0 de divulgación musical específica). En esta apertura hacia la sociedad en general, colaboraban en sus actividades con instituciones externas (Juventudes musicales, ayuntamientos y diputaciones, cajas de ahorro, instituciones culturales) para la organización de conferencias, charlas y conciertos en locales externos a la Sección Femenina.

Entre las actividades que se promovían en los Círculos Medina además de audiciones comentadas, también se impartían conciertos en los que colaboraron intérpretes y conferenciantes de prestigio como Luis Galve, Manuel Carra, Renata y Graciano Tarragó, el Coro de Radio Nacional, Regino Sáinz de la Maza, Carmen Pérez Durías, Leopoldo Querol, narciso Yepes, Rafael López 


\section{Capítulo 5. Música e ideología 2: La Sección Femenina}

Cid, Esteban Sánchez, la Agrupación nacinal de música de Cámara o la Ópera de Cámara de Barcelona.

Constan datos de 75 conciertos en 1961, 53 conciertos en 1962, 159 conciertos en 1968 y 110 concierto (más otras diez conferencias-concierto y 34 recitales de canto) en el año 1969.

Las subvenciones que recibían los Centros Medina provenían de los planes de Promoción Cultural de la Dirección General de Cultura Popular. He aquí algunos ejemplos de los años 1968 y 1969

\begin{tabular}{|l|l|l|}
\hline \multicolumn{3}{|l|}{ RELACIÓN DE SUBVENCIONES a los CIRCULOS MEDINA } \\
\hline Círculo Medina & 1968 & 1969 \\
\hline Alicante & 15.000 ptas & 10.000 \\
\hline Barcelona & 20.000 & 20.000 \\
\hline Castellón & 20.000 & 10.000 \\
\hline Ciudad Real & 25.000 & 25.000 \\
\hline Cuenca & 20.000 & 25.000 \\
\hline León & 20.000 & 15.000 \\
\hline Lérida & 15.000 & 15.000 \\
\hline Logroño & 20.000 & 15.000 \\
\hline Madrid & 40.000 & 30.000 \\
\hline Palma de Mallorca & 20.000 & \\
\hline Soria & 15.000 & 10.000 \\
\hline Valencia & 20.000 & \\
\hline Zaragoza & 30.000 & 20.000 \\
\hline Cieza & 5.000 & 10.000 \\
\hline Jumilla & 5.000 & 10.000 \\
\hline Jaén & 15.000 & \\
\hline Albacete & 20.000 & 15.000 \\
\hline Toledo & 10.000 & \\
\hline Las Palmas & & \\
\hline & & \\
\hline
\end{tabular}


Guadalajara

15.000

\section{En el III Plan de desarrollo en el sector de la acción cultural ( 1971)}

elaborado por la Comisión de Turismo e Información y Actividades culturales ${ }^{224}$ se muestra de forma explícita que la nueva situación de desarrollo económico debe ir acompañada de un crecimiento significativo en el sector cultural, que se percibe como claramente "deficitario en comparación con otros países de mayor desarrollo económico y con otros sectores del conjunto nacional" Para corregir esta situación "son precisos medios", inversiones importantes para desarrollar el sector cultural.

El Plan analiza lo que considera una "falta de auténtica política cultural en nuestro país, debido en gran parte a la inexistencia de un organismo centralizador de todas las actividades de contenido cultural, tanto emanadas de los propios organismos oficiales como actividades privadas sobre la que el Estado realiza una función de protección y fomente" para ello surgiere la necesidad de la creación de un Ministerio de Cultura, hasta entonces inexistente.

El Plan propone materializar las actuaciones en 5 puntos concretos:

1. Creación de centros culturales en áreas urbanas periféricas

2. Sostenimiento de los centros culturales ya existentes

3. Potenciación de los valores culturales y folklóricos de las distintas regiones

"el desarrollo industrial del país está produciendo el deterioro y la casi desaparición de manifestaciones culturales de carácter popular que es necesario defender (...) La forma más idónea para la consecución de este fin sería la protección a entidades privadas que ya desarrollan una importante labor en este sentido y especialmente la creación de una

\footnotetext{
${ }^{224}$ ARCHIVO GENERAL DE LA ADMI NISTRACIÓN (AGA). Caja 3 de 51.20. Carpeta Plan de desarrollo
} 


\section{Capítulo 5. Música e ideología 2: La Sección Femenina}

serie de instituciones que recogiesen las manifestaciones de arte popular características de cada región y velasen por la no adulteración de las mismas, evitando la inminente desaparición de un auténtico tesoro cultural con el que el pueblo se encuentra identificado. Entre estas manifestaciones cabe destacar las labores de alfarería, madera, metal, bordados, etc. Al mismo tiempo estas instituciones conservarían tradiciones populares tales como fiestas, ritos, juegos, literatura oral.."

4. Promoción de la pintura

5. Campañas de divulgación musical.

Ya que "una de las mayores lagunas culturales del pueblo español es su falta de formación musical, paradoja poco comprensible en un pueblo con una riquísima tradición de música popular. Por ello sería muy acertado que el III Plan de Desarrollo incluyera campañas de divulgación musical que se desarrollaran a al o largo de los 4 años que comprende el plan. Existen actualmente en el país una serie de músicos especializados que dominan las nuevas técnicas de divulgación de la música a través de unos sistemas pedagógicos que hacen que la audiencia con menos experiencia en esta materia comprenda fácilmente las distintas formas de creación musical en su significado, creándose con ello una sensibilidad para esta forma de arte y una afición general a la música

El III Plan revisa también las dotaciones económicas que considera necesarias para conseguir estos objetivos con las siguientes previsiones

\begin{tabular}{|l|l|l|l|l|}
\hline \multicolumn{6}{|l|}{ Previsión económica para la consecución de los objetivos } \\
\hline & 1972 & 1973 & 1974 & 1975 \\
\hline 1. Creación & 10.000 .000 & 5.000 .000 & 5.000 .000 & 5.000 .000 \\
\hline 2. Sostenim. & 2.000 .000 & 2.000 .000 & 2.000 .000 & 2.000 .000 \\
\hline 3. Valores folk & 8.000 .000 & 8.000 .000 & 4.000 .000 & 4.000 .000 \\
\hline 4. Pintura & 3.500 .000 & 3.500 .000 & 3.500 .000 & 3.500 .000 \\
\hline 5. Div. Música & 5.000 .000 & 5.000 .000 & 5.000 .000 & 5.000 .000 \\
\hline
\end{tabular}

A esta propuesta hay unos comentarios manuscritos en la documentación del Archivo General de la Administración, provenientes de la Delegación Nacional 


\section{La educación musical en el franquismo}

de Sección Femenina : "Me parece en todos los apartados poquísimo y no da para investigación , ni adquisiciones de material de trajes, etc."

Efectivamente, comparándolo con las cuentas del ejercicio económico de la Sección de actividades culturales y artísticas en 1974 (sin incluir personal, ni otros concursos como el de villancicos, pintura o mejor concertista joven del año, los conciertos para jóvenes o las publicaciones) se puede ver claramente la disparidad económica:

\begin{tabular}{|l|l|}
\hline \multicolumn{2}{|l|}{ Ejercicio económico Sección de Actividades culturales y artísticas. 1974} \\
\hline Limpieza y alumbrado Esc. Del hogar & 693.652 \\
\hline Becas & 255.000 \\
\hline Actos en las escuelas & 250.755 \\
\hline Concurso de coros y danzas & 4.000 .000 \\
\hline Adquisición de material Gab. Técnico & 150.000 \\
\hline Archivo de folklore & 150.000 \\
\hline Limpieza y alumbrado Círculos Medina & 125.000 \\
\hline Conciertos y actos Círculos Medina & 940.000 \\
\hline Adquisición de libros para bibliotecas & 700.000 \\
\hline Adqu. material para el Inst. Est. Mús. & 400.000 \\
\hline Total & 7.659 .407 \\
\hline
\end{tabular}

En 1973 la Sección de Actividades Artísticas y culturales tenía por misión la de dirigir el "fomento del interés de la mujer por el arte, la ciencia y en general por la cultura, así como promover el espíritu creador en dichos campos". Como vemos, ya no se dirige sólo a afiliadas o a jóvenes, sino que está claramente destinada y abierta a toda la población femenina, sea cual sea su edad. Se organizaba en cuatro grandes Oficinas:

- Oficina de centros de convivencia. La misión principal de estos centros es fomentar y servir a las necesidades de convivencia referidas a la mujer, posibilitándolas para una mayor participación en la vida 


\section{Capítulo 5. Música e ideología 2: La Sección Femenina}

cultural, social y política, perfeccionando su formación total y proporcionándole un lugar de reunión, diálogo y convivencia

- Oficina de promoción cultural y artística. Es la unidad que organiza toda serie de actos relativos a una formación cultural más completa en todas las ramas del saber, dirigida a una mejor preparación cultural de la mujer, facilitándole los medios de información artística como conciertos, exposiciones y conferencias y todo cuanto pueda contribuir a una mayor formación cultural y humana. Es la unidad que proyecta a la sociedad la labor cultural que organiza la Sección Femenina

- Oficina de folklore y música. Se encarga de I formento del folklore en toda España, de su recogida, revitalización y conservación, organizando ficheros, promoviendo textos, documentales folklóricos, antologías de discos... -asimismo debe ocuparse de la creación de un "ballet nacional folklórico". Se relaciona con todas las entidades internacionales folklóricas y realiza de acuerdo con la Oficina de Servicio Exterior todo tipo de viajes e intercambios

- Oficina de ciencias domésticas.

En el informe de la Sección de Actividades Artísticas de 1973 en relación con la Dirección General de Cultura Popular constan:

1. La creación de 31 Círculos Medina, en los que se han celebrado unos 699 actos (conferencias, conciertos, coloquios, recitales) con una asistencia de entre 10.000 y 12.000 personas en total. La mayor parte están en capitales de provincia, excepto en Murcia (que cuenta con 7 círculos en la provincia, además del de la capital), Castellón (con uno más en Burriana) y Pontevedra (en Vigo y Villagarcía)

2. La celebración de los aniversarios de Bécquer, Beethoven, Baroja y Azorín.

3. Bibliotecas: Hay un total de 68 bibliotecas ( 31 en los Círculos Medina y 37 en las anteriores Escuelas del Hogar)

4. Actividades folklóricas: En el último concurso de Coros y danzas se han presentado 1.859 grupo con un total de 57.764 participantes 


\section{La educación musical en el franquismo}

5. Edición de libros: Durante estos últimos años se han editado los tres libros sobre folklore dirigidos por Manuel García Matos y se han grabado 37 discos (163 canciones y danzas) con Odeon-Hispavox. Archivo de películas de danzas y realización de un documental en color: "Don Aire de España"

Está en proyecto

el libro sobre el traje regional en España

la creación de premios importantes para la investigación del folklore en sus aspectos de danza, canción y traje

la edición de folletos sobre los más destacados grupos de danzas

Continuación de la serie de documentales en color "Don Aire de España" con otros tres capítulos: tierra, fuego y agua, con las danzas y costumbres populares más características de España, dirigido por Manuel Augusto García Viñolas.

Continuación de la edición de discos y postales de trajes regionales.

En cuanto a la dotación de libros de música en las bibliotecas de los Centros Medina, éste es un listado de la biblioteca de la Delegación Nacional $^{225}$

\begin{tabular}{|l|}
\hline BIOGRAFÍAS \\
\hline LAPLANE. Albéniz, su vida y su obra \\
\hline ESPINA, A. Chopin \\
\hline PERLEN. Falla \\
\hline SEROF. Rachmaninoff \\
\hline LISZT, F. Chopin \\
\hline GOSS, M. Sinfonía inconclusa. La historia de Franz Schubert \\
\hline GOSS y SCHAUFFE. Brahms. Un maestro de la música \\
\hline STENDHAL. Vida de Rossini \\
\hline
\end{tabular}

${ }^{225}$ ARCHIVO GENERAL DE LA ADMINSITRACIÓN (AGA). Caja 6 de 51.20 


\section{Capítulo 5. Música e ideología 2: La Sección Femenina}

\begin{tabular}{|l|}
\hline BERLIOZ. Beethoven \\
\hline SOPEÑA, F. Vida y obra de Franz Liszt \\
\hline EHINGER. Clásicos de la música \\
\hline GARA. Carusso \\
\hline EINSTEIN. Mozart \\
\hline \\
\hline MÚSICA \\
\hline \\
\hline ANGLÉS. Diccionario de la música (2 vol.) \\
\hline HERZFELD. Tú y la música \\
\hline MANTECON. Introducción al estudio de la música \\
\hline NETTI, P. La música en la danza \\
\hline QUEROL. Breve historia de la música \\
\hline SOPEÑA. Historia de la música \\
\hline LÓPEZ CHÁVARRI. Música popular española \\
\hline ARAIZ. La música religiosa en España \\
\hline SUBIRÁ. Historia de la música teatral en España \\
\hline HERZFELD. La magia de la batuta \\
\hline HERZFELD. Música nova \\
\hline SACHS, K. La música en la Antigüedad \\
\hline VOLBACH. La orquesta moderna \\
\hline WELLESZ, E. Música bizantina \\
\hline SUBIRÁ, J. La tonadilla escénica \\
\hline MANEN. El violín \\
\hline ARCONADA, C. En torno a Debussy \\
\hline BOSCH, C. Espíritu pretérito en horas actuales. Anales de música y sensibilidad. \\
\hline DIEGO, RODRIGO y SOPEÑA. Diez años de música en España \\
\hline ESPINÓS, V. El maestro Arbós \\
\hline PASTENER, J. Compás de tres por cuatro \\
\hline SALAZAR, A. La música de España \\
\hline STOKOWSKI, L. Música para todos nosotros \\
\hline THIEL, T. Firmamento musical \\
\hline WILD, R. Iniciación a la música \\
\hline
\end{tabular}




\subsection{LA FORMACIÓN DEL PROFESORADO ESPECIALIZADO DEMÚSICA}

Desde sus inicios, la Sección Femenina intenta formar al profesorado que tiene que impartir la asignatura de música para las jóvenes: escuelas del hogar, institutos, centros escolares.

Así, en la abundante documentación que existe en torno a la Escuela Nacional de Música “Roger de Lauria” recogida en el Archivo General de la Administración ${ }^{226}$, consta una relación de cursos para la formación de profesoras de música organizados por Sección Femenina anteriores a los años 60. Gracias a este documento tenemos constancia de la existencia de los siguientes cursos:

\begin{tabular}{|c|c|c|c|c|}
\hline 1939 & \multicolumn{4}{|c|}{$\begin{array}{l}\text { Curso de preparación en todas las provincias bajo la dirección de } \\
\text { Rafael Benedito. De enero a mayo }\end{array}$} \\
\hline 1939 & $\begin{array}{l}\text { Curso para Instructoras } \\
\text { nacionales de música }\end{array}$ & $\begin{array}{l}3 \text { meses } \\
\text { verano }\end{array}$ & 189 alumnas & Barcelona \\
\hline 1940 & \multicolumn{4}{|c|}{$\begin{array}{l}\text { Curso de preparación en todas las provincias dirigido por Rafael } \\
\text { Benedito }\end{array}$} \\
\hline 1943 & $\begin{array}{l}\text { Curso para Instructoras } \\
\text { nacionales de música }\end{array}$ & $\begin{array}{l}3 \text { meses } \\
\text { verano }\end{array}$ & 64 alumnas & Barcelona \\
\hline 1944 & $\begin{array}{l}\text { Curso para Instructoras } \\
\text { nacionales de música }\end{array}$ & $\begin{array}{l}3 \text { meses } \\
\text { verano }\end{array}$ & 46 alumnas & Madrid \\
\hline 1953 & $\begin{array}{l}\text { Curso de renovación de } \\
\text { instructoras de música }\end{array}$ & & 71 alumnas & El Pardo \\
\hline 1954 & $\begin{array}{l}\text { Curso de renovación de } \\
\text { instructoras de música }\end{array}$ & & 71 alumnas & El Pardo \\
\hline $\begin{array}{l}1956 \\
1963\end{array}$ & $\begin{array}{l}\text { Cursos de Gregoriano y } \\
\text { liturgia }\end{array}$ & & 29 personas & $\begin{array}{l}\text { Madrid } \\
\text { Madrid }\end{array}$ \\
\hline
\end{tabular}

\footnotetext{
${ }^{226}$ Archivo General de la Administración.(AGA) Topográfico 51.23. SF 23/27.704, grupo 7 №1,
} caja 17 


\section{Capítulo 5. Música e ideología 2: La Sección Femenina}

\begin{tabular}{|l|l|l|l|l|}
\hline 1964 & & & 51 personas & Barcelona \\
1965 & & 23 personas & Madrid \\
\hline $1959 / 61$ & $\begin{array}{l}\text { Curso nacional en la } \\
\text { Escuela Ruiz de Alda }\end{array}$ & & 23 alumnas & Madrid \\
\hline
\end{tabular}

Este último curso, celebrado en la Escuela "Ruiz de Alda" se lleva a cabo en 15 meses (6 meses desde enero del 1960 y nueve meses del curso 1960/61).Se puede considerar como el primer intento de Escuela Nacional de música, pero no hay constancia de su continuidad y parece similar y simultáneo al primero que se realiza en la Escuela "Roger de Lauria" de Barcelona, donde se impartirá posteriormente la especialidad de Música. Sobre él se conserva poca información, pero están recogidas las materias y el horario que se impartían en el artículo de Alonso Medina (2002) ${ }^{227}$ a partir de la documentación conservada en la Real Academia de la Historia ${ }^{228}$ :

\begin{tabular}{|l|l|l|l|}
\hline $\begin{array}{l}\text { Curso nacional de } \\
\text { música }\end{array}$ & \multicolumn{4}{|l|}{ Primer año. Duración: 6 meses } \\
\hline Materias & $1-2$ & $3-4$ & $5-6$ \\
\hline Religión & 4 & 4 & 4 \\
\hline $\begin{array}{l}\text { Form. Nacional } \\
\text { sindicalista }\end{array}$ & 6 & 4 & 4 \\
\hline Gimnasia & 20 & 20 & \\
\hline Solfeo y transporte & 24 & 24 & 20 \\
\hline Gregoriano & 10 & 10 & 24 \\
\hline Danzas populares & 13 & 13 & 10 \\
\hline Dirección de coros & 10 & 10 & 13 \\
\hline Folklore & 12 & 12 & 10 \\
\hline Historia música & 10 & 10 & 12 \\
\hline Rítmica & 6 & 4 & 10 \\
\hline Teatro & 36 & & 4 \\
\hline
\end{tabular}

${ }^{227}$ ALONSO MEDINA, J.A. (2002). “Cursos de formación musical para instructoras de la Sección Femenina" en El Guiniguada, no 11

${ }^{228}$ Real Academina de la Historia. Madrid. Archivo Documental de la Asociación Nueva Andadura (ANA), carpeta azul 159, doc. 11 (1960) 
Total de horas de clase

373 horas totales de clases

\begin{tabular}{|l|l|}
\hline Curso nacional de música & Segundo año. Duración: 9 meses \\
\hline Materias & Horas \\
\hline Religión & 35 \\
\hline Form. Nacional sindicalista & 37 \\
\hline Organización & 24 \\
\hline Gimnasia & 204 \\
\hline Solfeo y transporte & 180 \\
\hline Historia de la música & 54 \\
\hline Armonía y contrapunto & 100 \\
\hline Gregoriano & 90 \\
\hline Danzas populares & 114 \\
\hline Dirección de coros & 102 \\
\hline Folklore & 86 \\
\hline Canto & 45 \\
\hline Rítmica & 38 \\
\hline Historia de la Cultura & 30 \\
\hline Horas de clases mensuales & \\
\hline Horas totales de clases & \\
\hline
\end{tabular}

Como se puede observar, hay una gran disparidad en la dedicación horaria y en el número de materias a estudiar del primer y segundo año. Además todavía gozan de una presencia enorme otras especialidades, como la gimnasia y la formación nacional sindicalista, lo que indica más bien una formación destinada a profesora de Escuela del hogar, englobando las materias de Educación Física, Música y FEN ( faltarían las asignaturas del hogar más tradicionales: costura, cocina, limpieza, sanidad) 


\title{
Capítulo 5. Música e ideología 2: La Sección Femenina
}

A partir de los años 60, se imparten los cursos nacionales de la especialidad de música en la Escuela de especialidades "Roger de Lauria" y a través de cursillos especializados.

\subsubsection{El primer intento de creación de la Escuela nacional de Pedagogía musical}

Ya en 1943, la Sección Femenina había iniciado sus intenciones de crear una escuela en la que formar a las profesoras de música. Así lo recoge un documento titulado Proyecto de la escuela de Pedagogía de la música' del que se conserva una copia en la documentación del Archivo general de la Administración ${ }^{229}$ que por su interés transcribo literalmente:

\begin{abstract}
"Los excelentes resultados obtenidos hasta la fecha desde que se emprendió la obra de exaltación, fomento y cultivo de la música y el canto, preferentemente en su aspecto folklórico - resultados que huelga enumerar, por ser harto conocidos- inspiran a esta Delegación Nacional la idea de continuar esta obra dotándola de los elementos necesarios que le den continuidad y permunidad, toda vez que este mismo sector de la educación espiritual ha de contribuir de un modo especial y positivo a la elevación cultural de la mujer española, misión que de modo especial le está encomendada a la Falange Femenina.
\end{abstract}

A este efecto, esta Regiduría de Cultura estima que, basándose en la experiencia, lo más conveniente y práctico sería la creación de un organismo que, fundamentalmente cimentado, pueda funcionar sin interrupción y que llenaría cuantos extremos abarca la idea.

Sería este organismo la Escuela de Pedagogía musical, en la que constantemente se formaría un número ilimitado de Instructoras de música que, convenientemente instruidas y con una práctica concienzudamente realizada, previa la obtención de un certificado de aptitud, se esparcirían por toda la patria para cumplir esta misión cultural y artística, llevando sus beneficios hasta el último rincón de nuestra geografía.

La Escuela de Pedagogía Musical dependerá directamente del Servicio Central de Cultura de la Sección Femenina..

\footnotetext{
${ }^{229}$ ARCHIVO GENERAL DE LA ADMI NISTRACIÓN (AGA). Topográfico 51.23.SF 23/27, no 1, caja
} 17 


\section{La educación musical en el franquismo}

Establecida la escuela y con objeto de que sus frutos puedan beneficiar no solamente a la Falange, sino también a todo el pueblo español, se recabará que sea reconocida oficialmente por el estado como de utilidad pública y de interés patrio, adscribiéndola al Ministerio de Educación Nacional. La eficacia sería completa si este Ministerio reconociera como válidos y le diera obligatoriedad o por lo menos preferencia a los títulos de aptitudes que la Escuela conceda en las oposiciones a cuantas cátedras hayan de cubrirse que tengan relación con la música escolar: profesorado especial de música en escuelas primarias, grupos escolares, escuelas de Artes y oficios, Institutos, Universidades, y sobre todo, en las Normales, excluyendo los Conservatorios y aquellas instituciones docentes en las cuales específicamente se formen los músicos de profesión.

Vamos a detenernos en este punto, que sin duda, es la causa de los grandes conflictos surgidos en torno a esta escuela y a toda la formación musical en este país.

Como se puede apreciar claramente en este documento, se pretendía crear una Escuela donde se impartieran títulos con validez académica para ser docente, ajenos al sistema universitario, controlados por Sección Femenina. Esto pasaba también en las Escuelas de especialidades de Educación Física que posteriormente se transformaron en el INEF. Así que, ¿por qué razón causaba más conflicto la escuela de música?

Porque ya existía un tipo de centro de formación que impartía titulaciones validadas (aunque no capacitaba a nivel docente) de carácter musical: el Conservatorio.

Y también, porque la música era una asignatura que se estaba impartiendo por titulados de los conservatorios en las Escuelas Normales, donde se formaba parte del profesorado: los maestros de las escuelas primarias.

Sin embargo, la docencia de la asignatura de música, estaba asignada por la Ley General de Educación a partir de 1942 al Movimiento (al igual que las asignaturas de Formación política, Educación Física y Hogar). 


\section{Capítulo 5. Música e ideología 2: La Sección Femenina}

Ello conlleva un gravísimo conflicto, que no hizo sino agravarse y enquistarse durante todo el franquismo, sin que se generaran vías definitivas de solución. Los intereses de los conservatorios (centros donde se formaban los músicos profesionales) y de las Escuelas Normales (donde el profesorado estaba formado por titulados de conservatorio y en las que se impartían de forma obligatoria materias de música no vinculadas en principio a personal del Movimiento o la Sección Femenina) chocaban frontalmente con las aspiraciones de Sección Femenina de crear centros de especialidades que formaran profesorado para impartir la docencia en los niveles educativos que tenían asignada.

Incluso cuando, finalmente, se llegue a la consecución de la titulación en la Escuela de especialidades "Roger de Lauria" en el año 1960, nunca se conseguirá una validación del título fuera del marco de la docencia estricta asignada a Sección Femenina. Esta situación, se hará aún más patente, finalizado el franquismo y ya en plena transición, cuando se inicie el proceso de las primeras oposiciones de música, correspondientes a la asignatura de Música en primer curso del BUP, y los títulos reconocidos para poder presentarse a las mismas sean las titulaciones de conservatorio anteriores, en contra de la normativa en vigor. E incluso entonces, sólo fue una validación a nivel profesional, consistente a una equiparación a titulación de licenciado a nivel docente, que no académica.

El resto del documento del proyecto de creación de una Escuela de Pedagogía Musical de la Sección Femenina en 1943 se centra en el estudio de las características administrativas, necesidades de personal y acceso de los alumnos y recoge los siguientes datos:

\footnotetext{
"La Escuela de pedagogía de la Música de la Sección Femenina de FET y de las JONS radicará en Madrid y en local adecuado para que sus trabajos puedan llevarse a cabo con toda eficacia y a estos mismos fines estará dotada del material que se indica más adelante. Para que los cuatro grupos de voces de que ha de constar el conjunto coral puedan realizar su labor independiente, este local, aparte del salón donde han de
} 


\section{La educación musical en el franquismo}

celebrarse los conjuntos, deberá tener tres clases o aulas más, una habitación despacho para el director y otro para la secretaría, así como archivo y discoteca.

La escuela constará del personal fijo siguiente:

Un director capacitado que haya demostrado ampliamente no sólo la teórica, sino también de modo práctico, su competencia en el aspecto técnico así como en el de la organización

Una auxiliar técnica solvente, preparada y de la confianza absoluta de la dirección que pueda sustituir a ésta en los casos de enfermedad, ausencias o especiales que se presentasen y que lleve a cabo los trabajos de Secretaria de la Escuela.

Cuatro auxiliares o J efaturas de grupos que serán nombradas por la dirección y elegidas, bien entre las Instructoras que posean el certificado obtenido en los cursos celebrados anteriormente, bien entre el alumnado de la Escuela que se distinga.

El personal subalterno que las necesidades del buen orden, limpieza, etc. indiquen

Eventualmente y según las necesidades se vayan presentando, la dirección de la escuela propondrá a la superioridad la contratación o convenio periódico con profesores que se encarguen de las clases de aquellas materias que se designen (los contratos 0 convenios serán rescindibles o prorrogables según el rendimiento pedagógico de dichos profesores)

Misión del director: Asumirá la responsabilidad de la labor total de la Escuela a cuyo efecto se le concederá la amplia autonomía que corresponde a esta responsabilidad, ordenará el plan de disciplina, distribución del horario, marcha de los trabajos, calificaciones parcial y final del alumnado mediante pruebas o exámenes celebrados durante el curso y al final de éste, para expedir o no los títulos de aptitud. Vigilará las clases encomendadas a los auxiliares. Explicará personalmente en clases de conjunto aquellas materias de carácter teórico que no estén encomendadas a otros profesores, dará la lección de canto colectivo y dirigirá las clases de conjunto coral. En cuantas manifestaciones artísticas - ya de carácter privado o público- que se celebren, dirigirá al conjunto coral formado por el alumnado o delegará esta dirección en otra persona que él designe. Dará cuenta periódicamente a la superioridad de la marcha de la Escuela, tanto en sus aspectos artístico y musical como en el moral, de comportamiento y psicológico del profesorado a sus órdenes y del alumnado. 


\section{Capítulo 5. Música e ideología 2: La Sección Femenina}

Misión de la auxiliar de secretaría: Auxiliará a la dirección en cuanto ésta le encomiende. Preparación de trabajos, explicación de clases, exploración previa del alumnado, repasos, etcétera, formando también parte de los tribunales de examen. Llevará los trabajos de secretaría en toda su amplitud.

Misión de los cuatro auxiliares: Secundarán las órdenes de la dirección en cuanto ésta directamente o por intermedia de la Auxiliar de Secretaria disponga. Asumirán la responsabilidad de los cuatro grupo de las distintas voces, ensayándolas y preparándolas aisladamente para el conjunto coral. Aceptarán la Jefatura del grupo parcial que la dirección les designe, según su especialidad o determinadas condiciones, tanto en carácter técnico como en el moral. En los ensayos de conjunto coral, estarán siempre al frente del grupo de voces que se les haya asignado, respondiendo de su labor.

Respecto a los alumnos, tras superar las pruebas de ingreso ante un tribunal, tendrían como obligaciones: Asistir con rigurosa puntualidad a cuantas clases, ejercicios, prácticas y conjuntas disponga la dirección, observando siempre disciplina, atención y tomando apuntes en cuanto sea necesario. Presentar resúmenes de las explicaciones de las clases teóricas redactadas a base de los apuntes tomados y ampliados con datos obtenidos en la bibliografía que se les indique o que ellos puedan encontrar para consultar y estudiar, a cuyo efecto, tendrán a su disposición la biblioteca de la escuela, además de facilitarles el acceso a otras bibliotecas. Realizar los trabajos escritos que la dirección y el profesorado determine, ya de carácter general o colectivo, ya de carácter individual. Formar parte del grupo de voces, que previa prueba y determinación de la dirección se le haya asignado a cada alumno según sus condiciones vocales y del Conjunto coral. Asistir y tomar parte activa del conjunto coral en cuantas demostraciones y actos celebre este conjunto, ya sean de carácter público 0 privado. Únicamente podrán dejar de cumplir este requisito en caso de enfermedad o fuerza mayor con autorización de la dirección. Mostrar durante el curso buen espíritu y comportamiento, corrección y disciplina, tanto durante las clases como en los descansos y en la vida total de la escuela. No podrán efectuar las pruebas de exámenes para la obtención del certificado o título de aptitud los alumnos que no hayan asistido a las clases durante siete de los ocho meses que constituye la duración del curso,. Cuando la dirección lo estime conveniente los alumnos realizarán prácticas y realizarán exposiciones en las clases. Se someterá a los alumnos a una prueba de exploración del sentido rítmico y auditivo de la de la memoria retentiva musical. Los alumnos que, sometidos a las pruebas anteriormente citadas merezcan ingresar y que no practiquen ningún instrumento, deberán realizar durante el curso serios estudios en el que elijan, mereciendo preferencia en esta elección el piano. 
En el caso de que esta Escuela tenga carácter oficial y validez o preferencia para oposición el título que en ella se obtenga, podrán solicitar el examen de ingreso cuantas personas de ambos sexos se consideren capacitados para ello, pertenezcan o no a la Falange. En el caso de que esta Escuela no tenga carácter oficial será necesario para solicitar el ingreso estar afiliada en la Falange, siendo requisito indispensable que las propuestas sean hechas por las Delegaciones Provinciales, previo un examen concienzudo que estas Delegaciones harán a los solicitantes.

En cuanto a las enseñanzas que se impartirían en dicha escuela, están contempladas las siguientes: SOLFEO. Modernos procedimientos para las enseñanzas, solfeo individual, solfeo colectivo, teoría y prácticas, distintas metodologías según las edades, dictado musical, transporte y armonización de canciones. CANTO. Formación y desarrollo del oído y de la memoria musical, fonética y dicción como preliminares de la vocalización, ejercicios de vocalización, defectos de la emisión y sus correcciones, canto individual y colectivo, diversos procedimientos y prácticas, canto coral al unísono y polifónico. MÚsı CA FOLKLÓRICA. Su historia y sus variantes en España, geográficas e históricas. Influencias. Música popular, música folklórica, música natural o del pueblo. Las regiones y su repertorio. Formación de instructoras para la recolección de cantos folklóricas. Creación de masas corales populares y su evolución en España. RíTMICA Y DANZAS. Danzas clásicas por medio de las rítmica, danzas regionales. MÚsıCA RELIGIOSA Y SU ASPECTO LITÚRGICO. FISIOLOGÍA DE LOS ÓRGANOS VOCAL Y AUDITIVO. Como complemento de todas las enseñanzas y como primordial objetivo, merecerá especial atención la disciplina del CONJ UNTO CORAL, con abundantes prácticas de los alumnos, ya como cantotes de este conjunto, ya como directores del mismo, para que obtengan una formación que les ponga en condiciones de poder organizar, ensayar y dirigir los núcleos corales que hayan de formar si obtienen el título.

Aunque el texto es muy largo, es de suma importancia, ya que supone la demostración documental del interés de Sección Femenina por crear una titulación específica dedicada a la formación del profesorado de música desde fechas tempranas. La voluntad de dotar a esta formación de una titulación legalizada y reconocida va acompañada de un elemento muy importante: la apertura a ambos sexos de la escuela.

Lamentablemente, el proyecto de esta escuela nunca llegó a realizarse. Sección Femenina no cejó en su empeño y con su característica firmeza, insistió enella hasta que en 1960 consiguió que se instituyera la Escuela Nacional de Música 


\section{Capítulo 5. Música e ideología 2: La Sección Femenina}

en la escuela de Especialidades "Roger de Lauria" en Barcelona, pero nunca consiguió el reconocimiento oficial de la titulación, por lo que se tuvo que limitar al personal de Sección Femenina y a la segunda vía de selección interna (sólo accedía personal de Sección Femenina, previa propuesta de cada Delegación Provincial). Sin embargo, este documento inicial nos demuestra una apertura a toda la sociedad, con pruebas de acceso ante tribunal libre de afiliaciones y sexo.

También es sumamente interesante el hincapié que se hace en la formación vocal y el conjunto coral como elemento básico de dinamización musical a crear en todos los centros, en consonancia con la importancia de los concursos corales y de villancicos que la Sección Femenina organizaba en todo el país a nivel escolar.

Es evidente que se crea un grave conflicto de intereses con los conservatorios, hasta eses momento las entidades que ofrecían titulaciones musicales profesionales, pero siempre con problemas de reconocimiento y validación académica respecto al marco global de las titulaciones del Ministerio de Educación. Esta nueva propuesta de titulación está destinada a la formación de "profesores de música" y no de intérpretes, y parte de sección Femenina ya que es Falange quien tiene asignada a lo largo de todo el franquismo la educación musical en los centros escolares de enseñanza primaria y secundaria.

De hecho, Sección Femenina puso todas sus fuerzas en la consecución de esta Escuela de pedagogía musical, hasta el punto de no volverse a organizar ningún curso de Instructoras nacionales de música desde el de 1942, hasta que en 1959 inició la enseñanza de esta especialidad en la Escuela "Ruiz de Alda" de Madrid, ya con dos años de duración, y que se trasladó ya de forma más continuada a la Escuela "Roger de Lauria" de Barcelona. A lo largo de estos años, la formación corrió a cargo de cursos provinciales, y a la selección del personal que impartía música en los centros docentes entre las afiliadas con conocimientos musicales reconocidos por los conservatorios. Hay que destacar que en los institutos (rara vez más de uno por provincia en los años 40 y 50 ) 


\section{La educación musical en el franquismo}

estaban instituidas las escuelas de Hogar, dentro de las cuales se contemplaba la educación musical, en las que estaban bien reguladas las relaciones entre el Ministerio de educación y el personal contratado de Sección Femenina. En los colegios públicos, estas relaciones no estaban tan reguladas, de forma que la educación musical (al igual que la educación física, las asignaturas de formación para el hogar o la formación política) era a veces impartida por maestros que se sentían suficientemente formados en dichas materias, lo que servía para cumplimentar el horario de las dotaciones de profesorado. En todo caso, si se quería contar con personal del Movimiento, las escuelas tenían que solicitarlo a las Delegaciones Provinciales y éstas tenían que valorar igualmente sus capacidades de asignar profesorado a los mismos (en numerosas ocasiones sólo se podía dotar al centro de una única profesora, generalmente especializada en educación física con una formación elemental y muy básica en música). Estas dificultades eran aún mayores en los centros rurales, donde se solía limitar la presencia de especialistas musicales a las visitas de las Cátedras ambulantes y de los asesores de los grupos de coros y danzas. Y los colegios privados, desde luego, se resistían enormemente a cualquier presencia, por mucho que lo impusiera la ley, de todo personal ajeno a las órdenes religiosas, prefiriendo formar a sus maestras en los cursos de música de las escuelas religiosas del magisterio.

\subsubsection{La Escuela nacional de música "Roger de Lauria"}

La abundante documentación al respecto que se conserva en el AGA (Archivo General de la Administración) muestra que la formación del profesorado especializado en música se realiza a partir del año 1960 en la Escuela de especialidades "Roger de Lauria", en la Calle Maestro Nicolau, 19 de Barcelona.

Aunque, efectivamente, hay una gran documentación (planes de estudio, profesorado, listado de alumnas tituladas,), la creación oficial de esta escuela 


\title{
Capítulo 5. Música e ideología 2: La Sección Femenina
}

como centro de Formación del Profesorado de Enseñanzas de Hogar no se produce hasta la Orden de 1 de febrero de $1966^{230}$ según la cual

\begin{abstract}
“en cumplimiento a lo dispuesto en el art. 3o del Decreto 2168/1963 de fecha 10 de noviembre (BOE del 28 de octubre), regulador del título oficial de Profesores de Enseñanzas de Hogar y en lo prevenido en la Orden Ministerial de 3 de abril de 1963 (BOE 23 de febrero) sobre el plan de estudios y régimen de tales enseñanzas

Considerando que la Sección Femenina de FET y de las JONS, impulsora de las Enseñanzas de hogar hoy oficialmente establecidas en diferentes centros docentes y grados de enseñanza, ha venido dedicada en meritoria y eficaz labora a la formación del correspondiente profesorado que a su vez con carácter general ha desempeñado su cometido con plena competencia desde que tales enseñanzas han sido establecidas, por lo que las escuelas de aquella dependientes cumplan o reúnan las condiciones exigidas,
\end{abstract}

Este Ministerio, a petición de la Delegación Nacional de la Sección Femenina de FET y de las JONS, previos los informes de la Junta Central de Estudios de Profesoras de Enseñanzas de hogar y dictamen del Consejo Nacional de Educación ha resuelto:

1 - Crear, bajo la dependencia de esa Dirección General de Enseñanzas Técnicas y a través de la Delegación Nacional de la Sección Femenina de FET y de las JONS, las Escuelas oficiales de profesoras de Enseñanzas del Hogar "J ulio Ruiz de Alda" en Madrid, “Roger de Lauria” en Barcelona y “J oaquín Sorolla” en Valencia.

2․ El sostenimiento económico de estos centros seguirá como hasta la fecha, a cargo de la Delegación nacional de la Sección Femenina de FET y de las JONS

30 El plan de estudios y régimen de enseñanzas de las Escuelas que por esta Orden se crean con carácter oficial se regularán por lo establecido en la Orden Ministerial de 8 de abril de 1963 (BOE de 23 de febrero)

40 Por esa Dirección General se adoptarán las medidas necesarias para el mejor cumplimiento de lo determinado en la presente Orden.

Sin embargo, se venía impartiendo la especialidad de "Instructora nacional de música" en la escuela "Roger de Lauria" desde 1960, cuya titulación ${ }^{231}$ estaba destinada a ejercer las siguientes actividades:

${ }^{230}$ Archivo General de la Administración (AGA) Caja 36, grupo 7 no 


\section{La educación musical en el franquismo}

- Profesoras de coro en centros reconocidos y autorizados

- Profesoras oficiales de música en centros oficiales, reconocidos y autorizados

- Profesoras de música y coros en colegios particulares

- Profesoras de danza en colegios particulares

- Profesoras de música en Escuelas de Hogar

- Profesoras de música en albergues u otros centros de la Sección Femenina

\section{Curso 1960-1962}

Se convoca el Curso Nacional de Música (simultáneo al de Madrid en la Escuela Ruiz de Alda) en el año 1960 por la Delegación Nacional de la Sección Femenina para capacitar a las asistentes como Instructoras de música.

Para acceder a él es necesario:

- Haber aprobado el Curso Provincial de música del año 1957 o estar en posesión del Bachillerato Elemental. Se realiza una prueba de acceso de cultura general

- Haber aprobado cuatro años de solfeo y cinco de Piano en un centro oficial.

Las enseñanzas se realizaban en régimen de internado, por lo que se abonaban las siguientes cuotas

750 pesetas mensuales por manutención

250 pesetas por tasa de enseñanza

200 pesetas por material pedagógico

Se matricularon 15 alumnas en esta primera promoción del curso 1960-62, con los siguientes resultados:

\footnotetext{
${ }^{231}$ Titulación convalidada por el Ministerio de Educación y Ciencia según Orden de 21 de diciembre de 1968
} 


\section{Capítulo 5. Música e ideología 2: La Sección Femenina}

Barquero Benítez, Inés

Bigorra Señán, Bibiana

Bosch Soler, Dolores

Candela Acha, Blanca

Castro Martínez, Carmen

Comadira Moragriesa, Montserrat

Fernández Borges, Dolores

García García, Rosario

García Sainz, Isabel

López García Bermejo, Fuencisla

Marrero Martín, Ma Luz

Pérez de Obanos, Consuelo

Ramón Ramis, Catalina

Sabaté Carmen, Marina

Samper Cucalón, Rosario
Badajoz

Barcelona Carrera de piano

Gerona $\quad 5^{\circ}$ piano. Comercio

Cáceres $\quad 7^{\circ}$ piano. Bachiller superior

Palencia Carrera de piano

Gerona Carrera de música. Comercio

Tenerife $\quad 6^{\circ}$ piano. Bachiller elemental

Barcelona Carrera de piano

Logroño Carrera de piano

$3^{\circ}$ piano. Magisterio. Instructora elemental de

Segovia junventudes

Tenerife $\quad 8^{\circ}$ música

Pamplona Carrera de piano

Mallorca $\quad 6^{\circ}$ piano

Barcelona 7 cursos de música en Conservatorio

Zaragoza $\quad 2^{\circ}$ piano. Bachiller elemental

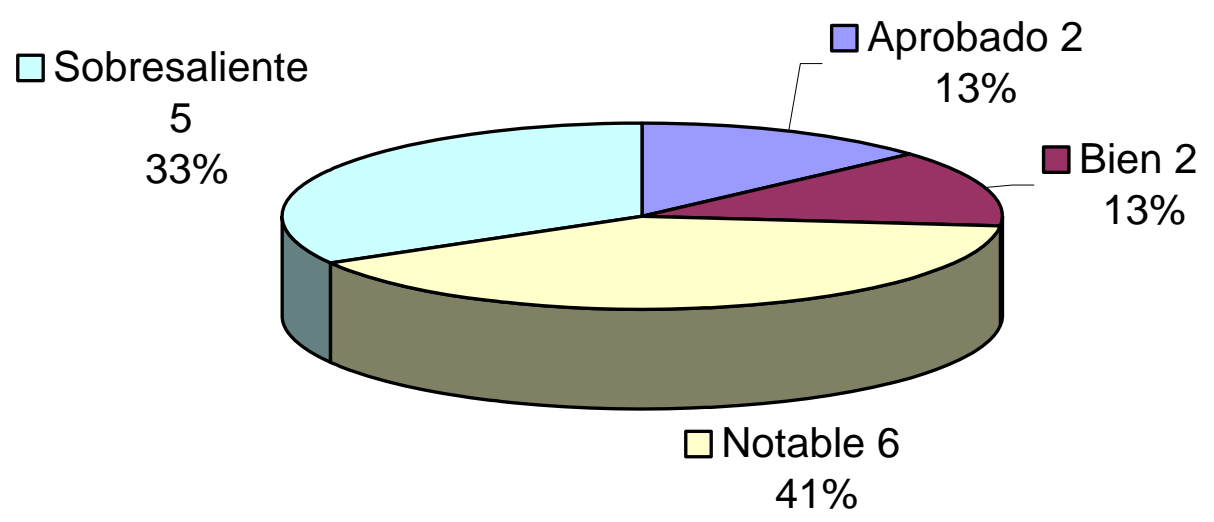

Las materias que se impartieron durante esta primera promoción fueron

\begin{tabular}{|l|l|l|}
\hline Materias & Profesor & Horas \\
\hline Solfeo y su pedagogía & Montserrat Soler & \\
\hline
\end{tabular}


La educación musical en el franquismo

\begin{tabular}{|l|l|l|}
\hline Transporte y dictado musical & Montserrat Soler & \\
\hline Canto e impostación de la voz & J osé Colomer & \\
\hline Dirección de coros & Angel Colomer del Romero & \\
\hline Folklore & Enrique Roig & \\
\hline Canto gregoriano & Miguel Altisent & \\
\hline Historia General de la Música & Juan Pich Santasusana & \\
\hline Armonía y Contrapunto & Juan Pich Santasusana & \\
\hline Rítmica y coreografía & Ana Ma Maleras & \\
\hline Danzas populares & Juan Bullich & \\
\hline Historia del teatro & Antonio Chic & \\
\hline Pedagogía musical para los niños & Teresa Tullot & \\
\hline Nacionalsindicalismo & & \\
\hline Organización & & \\
\hline Gimnasia & Instructora Sección Femenina & \\
\hline Religión & Rvdo Misser & \\
\hline
\end{tabular}

Las alumnas provenían de varias provincias del territorio nacional

Procedencia regional 1960-62

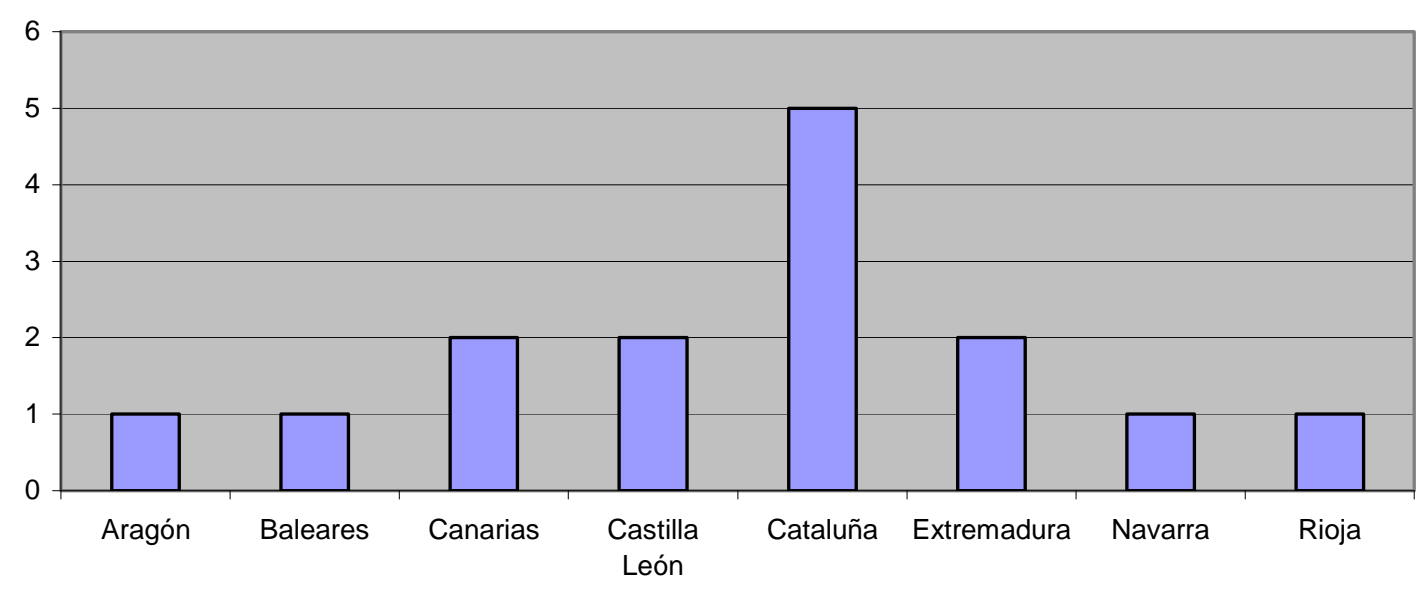

\section{Curso 1961-63}




\section{Capítulo 5. Música e ideología 2: La Sección Femenina}

El año 1961 la dirección de la Escuela se mantuvo bajo la dirección de Ma

Teresa Tullot, y aunque se matricularon 13 nuevas alumnas sólo terminaron el bienio 11 de ellas, con los siguientes resultados

$\begin{array}{lll}\text { Blanco López, Adela } & \text { Madrid } & \text { 3 solfeo y } 7^{\circ} \text { de piano } \\ \text { Chaques Girona, Marina } & \text { Valencia } & \text { Profesor de música } \\ \text { España Espino Granado, Ana Ma } & \text { Burgos } & \text { Bahiller superior. Farmacia } \\ \text { Lozano Esbert, Asunción } & \text { Zaragoza } & \text { Carrera de piano } \\ \text { Ortiz Esparcia, Teresa } & \text { Madrid } & 4^{0} \text { piano } \\ \text { Pérez Frías, Nieves Dorotea } & \text { Tenerife } & 7^{\circ} \text { de piano } \\ \text { Pique Tessa, Aurora } & \text { Lérida } & \text { Carrera de piano } \\ \text { Tarrago Domínguez, Dolores } & \text { León } & \text { Carrera de piano } \\ \text { Terrón Batista, Rosa Delia } & \text { Cáceres } & \text { Bachiller y carrera de música } \\ \text { Velasco Rodríguez, Aurita } & \text { León } & 6^{0} \text { de piano y bach. Elemental } \\ & & \text { Magisterio, bach. Tíulo de } \\ \text { Victoriano Sánez, Carmen } & \text { Madrid } & \text { música }\end{array}$

Calificaciones 1961-63

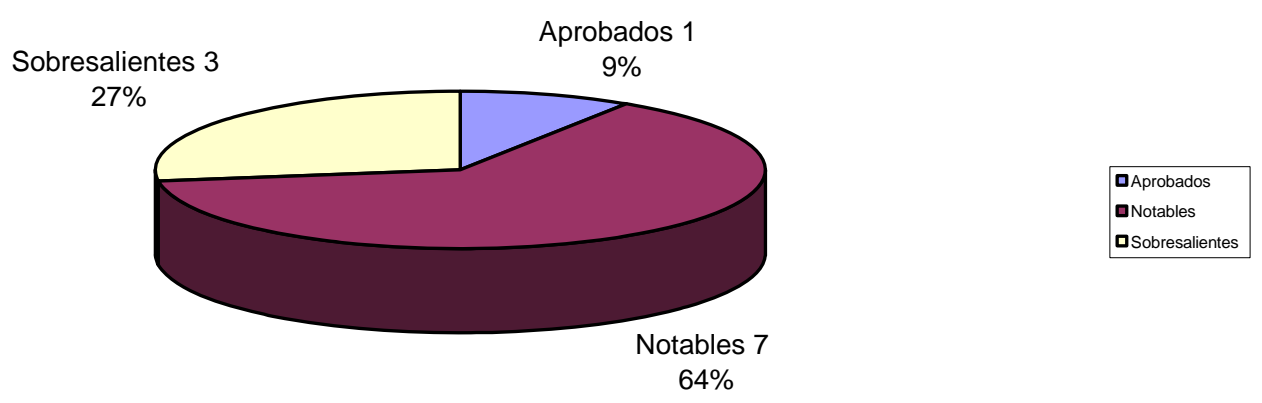

Su procedencia era variada y se incorporaron nuevas regiones como Valencia y Madrid 


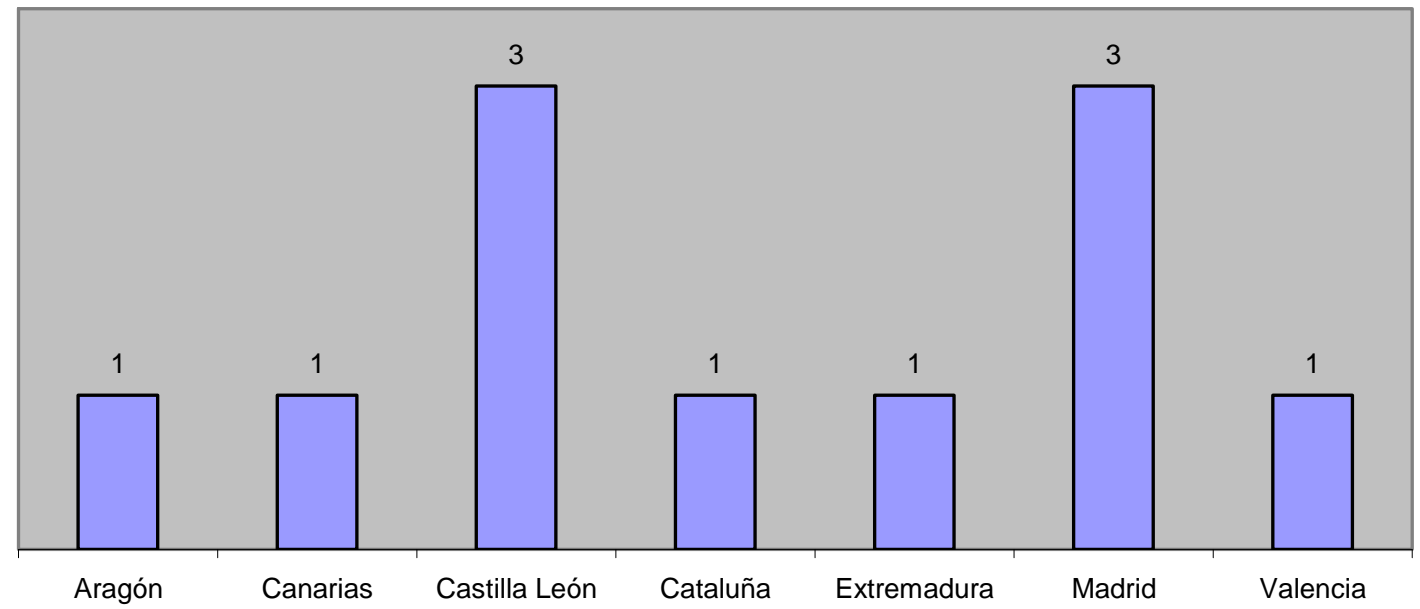

Durante este período las taifas de las cuotas mensuales aumentaron a

\begin{tabular}{|l|l|}
\hline Internas: manutención y tasa de enseñanza & 1200 pesetas \\
\hline Medio pensionistas & 750 pesetas \\
\hline Alumnas externas & 300 pesetas \\
\hline
\end{tabular}

\section{Curso 1962-64}

En este bienio se matricularon 9 nuevas alumnas, de las que 1 abandonó tras cursar los estudios el primer año solamente.

\begin{tabular}{|c|c|c|}
\hline Blas Cuena, Ana Ma de & Santander & Bachiller y $5^{\circ}$ piano. Afiliada \\
\hline Borras Llompart, María & Mallorca & Profesora de música \\
\hline Dies Caballero, Mercedes & Valencia & Título deConservatorio. Afiliada \\
\hline Fariñas Pérez, Concepción & Tenerife & $7^{\circ}$ de piano \\
\hline García Martínez, Ana & Almería & $\begin{array}{l}\text { Profesora de piano } \\
7^{\circ} \text { de piano y Bahiller }\end{array}$ \\
\hline García Menéndez, Josefa & Oviedo & $\begin{array}{l}\text { elemental } \\
\text { Título de Conservatorio en }\end{array}$ \\
\hline Madrid Herrera, Teresa & Jaén & piano \\
\hline Sánchez García, Dolores & Murcia & Título deConservatorio. Afiliada \\
\hline Vaz Reigosa, Edelmira & Coruña & Título deConservatorio. Afiliada \\
\hline
\end{tabular}




\section{Capítulo 5. Música e ideología 2: La Sección Femenina}

Estos fueron los resultados académicos obtenidos

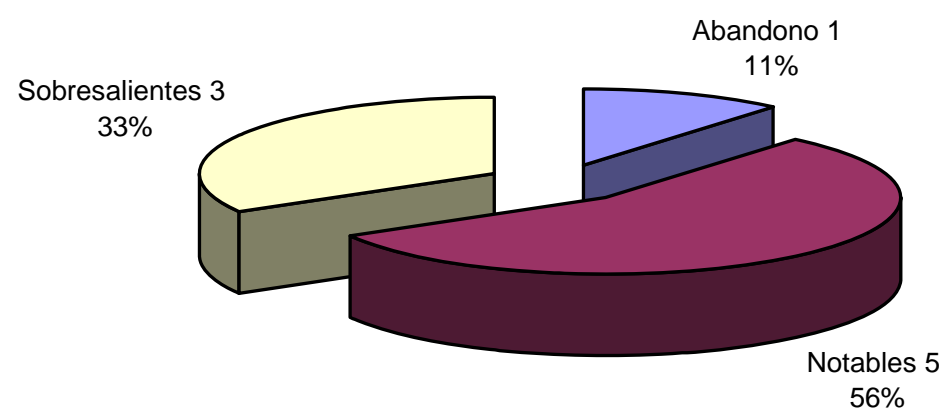

En la procedencia regional de las alumnas, sigue habiendo nuevas incorporaciones, como Galicia, Murcia, Asturias y Cantabria.

Pprocedencia regional 1962-64

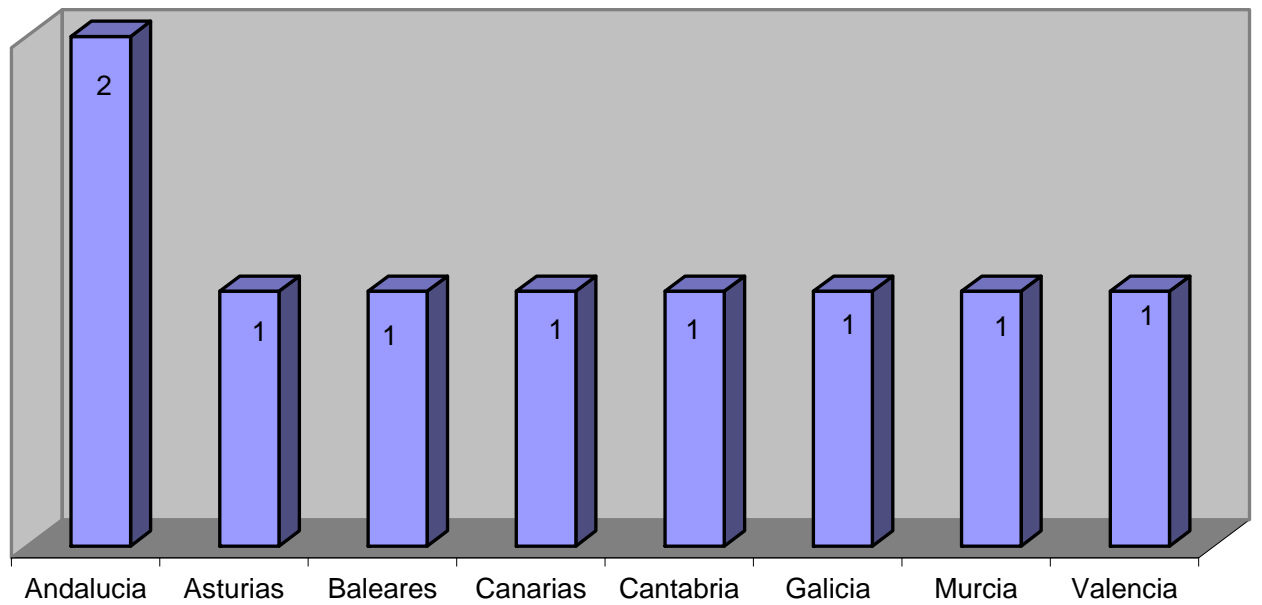

\section{Curso 1963-65}

Fue uno de los bienios con mayor cantidad de alumnas en la Escuela, ya que se titularon 19 alumnas

Aguiló Agne, Montserrat Carrera Goñi. Concepción
Tarragona Carrera de música. Comercio. Afiliada

Guipuzcoa $7^{\circ}$ piano y bachiller elemental 


\section{La educación musical en el franquismo}

$\begin{array}{lll}\text { Esparza Ros, Teresa } & \text { Pamplona } & 6^{\circ} \text { piano } \\ \text { Estopa Miró, Dolores } & \text { Lérida } & \text { Bachiller superior. Profesora música } \\ \text { Fuestes López, Angeles } & \text { Orense } & 5^{\circ} \text { piano. Afiliada } \\ \text { García Rodríguez, Pilar } & \text { León } & \text { Carrera de música. Afiliada } \\ \text { García Tomassoni, Dolores } & \text { León } & \text { Carrera de música. Afiliada } \\ & & \text { Estudio conservatorio sin título. No es } \\ \text { Gutiérrez Ramírez, Isabel } & \text { Oviedo } & \text { afiliada } \\ \text { Hernández Delgado, Carmen } & \text { León } & \text { Bachiller elemental y } 7 \text { música } \\ \text { Hernández Delgado, Eufrasia } & \text { León } & 7 \text { años de música y } 3 \text { bachiller. Afiliada } \\ \text { Huelin Baina, Dolores } & \text { Melilla } & \text { Estudios de música sin título. Afiliada } \\ \text { Izuzquiza González, Rosario } & \text { Palencia } & 7 \text { años de música y 4 bachiller } \\ \text { Jodar Martínez, Isabel } & \text { Murcia } & \text { Profesora de piano. Afiliada } \\ \text { Manchón Lafuente, Begoña } & \text { Bilbao } & \text { Profesora de piano. Afiliada } \\ & \text { Ciudad } & \\ \text { Martínez Alhambra, Ma José } & \text { Real } & \text { Profesora música. Afiliada } \\ \text { Martínez García, Ma Socorro } & \text { León } & \text { Carrera de música. Afiliada } \\ \text { Segovia Aroca, Carolina } & \text { Barcelona } & 4^{\circ} \text { solfeo y piano } \\ \text { Sulla Cano, Mercedes } & \text { Gerona } & \text { Carrera de piano. Comercio } \\ \text { Villar López, Carmen } & \text { Cuenca } & 7^{\circ} \text { piano. Bachiller superior }\end{array}$

Los resultados académicos obtenidos fueron los siguientes

Calificaciones 1963-65

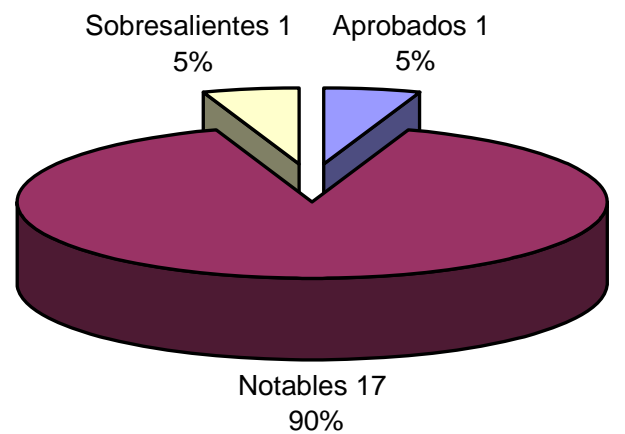

En cuanto a la procedencia regional de las aspirantes, se incorporan País Vasco y Melilla 


\section{Capítulo 5. Música e ideología 2: La Sección Femenina}

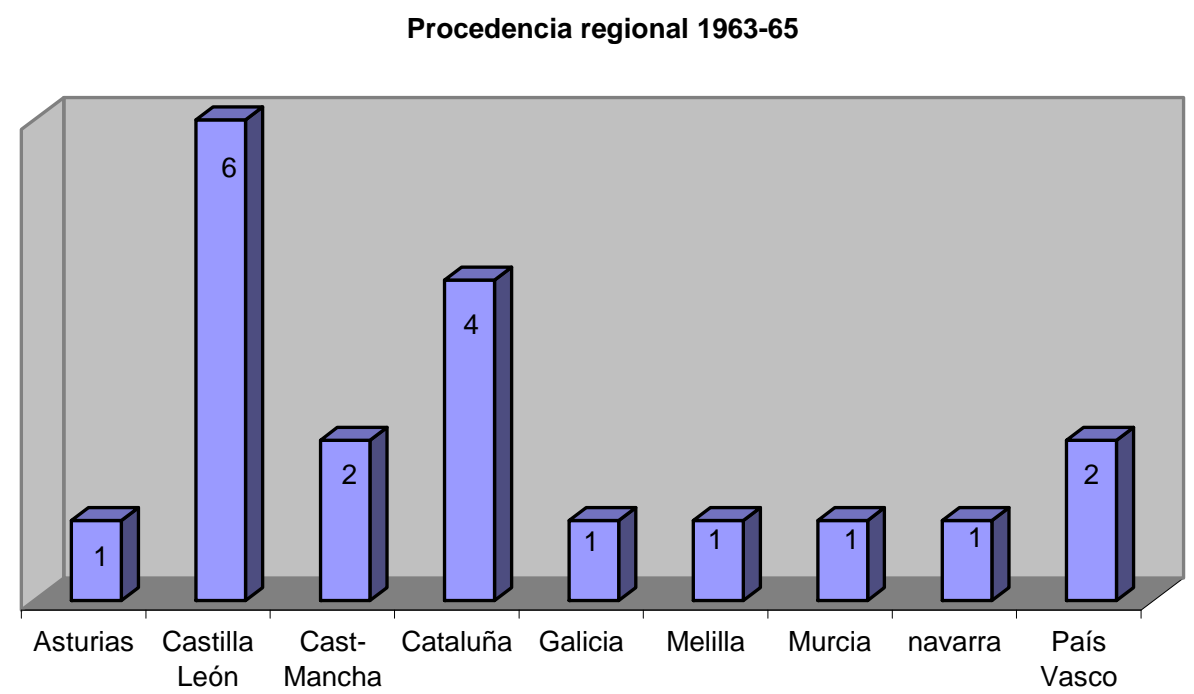

\section{Curso 1964-66}

Empiezan tiempos difíciles para la escuela, con una disminución importante del alumnado. De hecho, sólo se gradúan 6 alumnas de las 9 que se matricularon inicialmente con los siguientes resultados

Alcón Vilaubi, Gloria

Delgado Rubio, Angeles

Hoeltken Hernández, Rosario

Madorrán Antoñanzas, Adoración

Marín Melchor, Concepción

Marín Melchor, Pilar

Medina Tarrero, Isabel

Quesada Suárez. Ma del Angel

Serra Masdeu, Rosa Ma
Bachiller elemental y título de

Barcelona música

León

Burgos

Burgos

Melilla

6 años de música y bachiller elemental

6 años de música y bachiller

Melilla

Granada

Burgos

Tarragona 


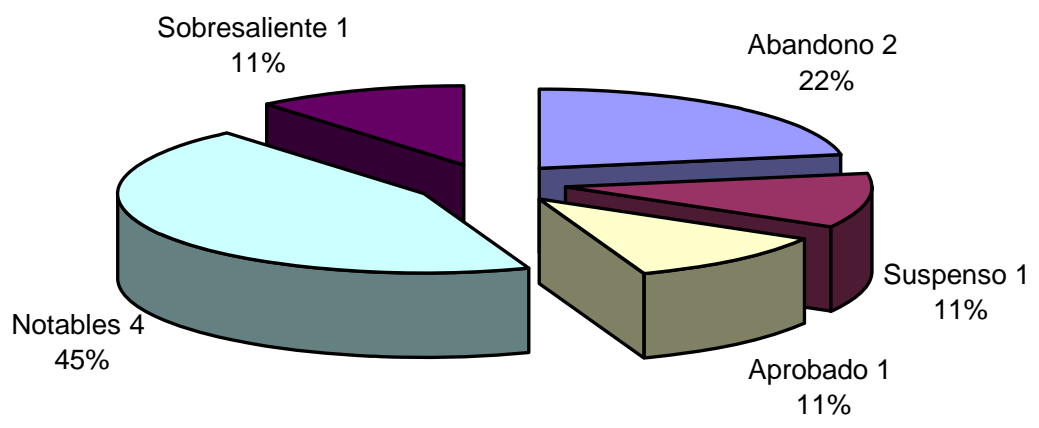

En cuanto al origen regional de las estudiantes hay que destacar la enorme importancia de Castilla y León y Cataluña, como las dos fuentes principales de profesorado de música en estos años.

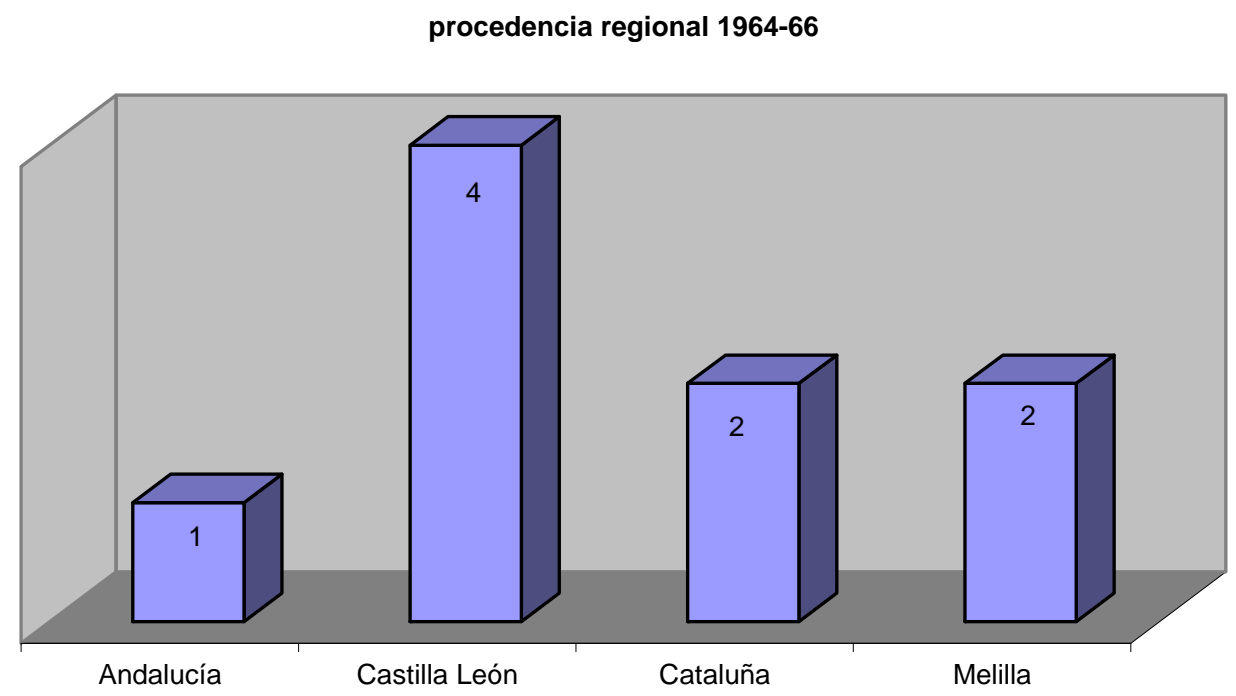

\section{Curso 1965-67}

En este curso se realizan varias innovaciones de profesorado

\begin{tabular}{|l|l|}
\hline Materia & Profesor \\
\hline Armonía & Montserrat Soler \\
\hline
\end{tabular}


Capítulo 5. Música e ideología 2: La Sección Femenina

\begin{tabular}{|l|l|}
\hline Método Orff & Mạ Teresa Tullot \\
\hline Teoría & Carmen Bravo \\
\hline Historia de la cultura & Rvdo. Juan Ubeda \\
\hline Dirección de coros & Angel Colomer \\
\hline Rítmica & Ma Rosa Marsillach \\
\hline $\begin{array}{l}\text { Impostación de la voz y } \\
\text { canto }\end{array}$ & J osé Mạ Colomer \\
\hline Historia de la música & Ma Esther Oliveras \\
\hline Folklore & José Ricart i Matas \\
\hline Gregoriano & Miguel Altisent \\
\hline Danzas & Enriqueta Cortés \\
\hline $\begin{array}{l}\text { Además, aunque no se mencionan los profesores que las imparten existen las } \\
\text { asignaturas de Teatro, Política, Religión, Historia de España, Educación Física y } \\
\text { Decoración }\end{array}$ \\
\hline
\end{tabular}

Las alumnas matriculadas en este bienio son solamente 4 , y de ellas sólo se graduaron 3, con los siguientes resultados académicos

Campomanes Marrugan, Soledad Cazaux González, Susana Marcos García, Regina Moreno Meca, Francisca
Oviedo Profesora de piano

Montevideo Profesora de música y canto

Barcelona Superior de piano

Almería $\quad 8^{\circ}$ piano 

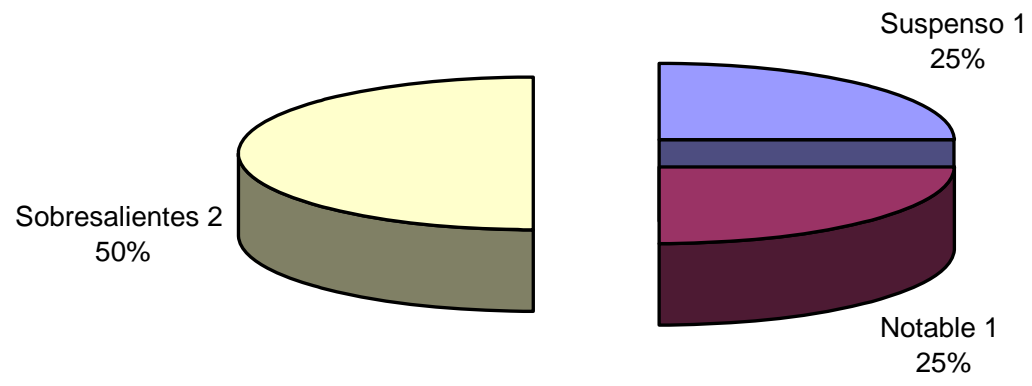

Respecto a la procedencia de las alumnas, destaca una de origen uruguayo. Fue la única alumna extranjera de la Escuela de la que tenemos datos documentales.

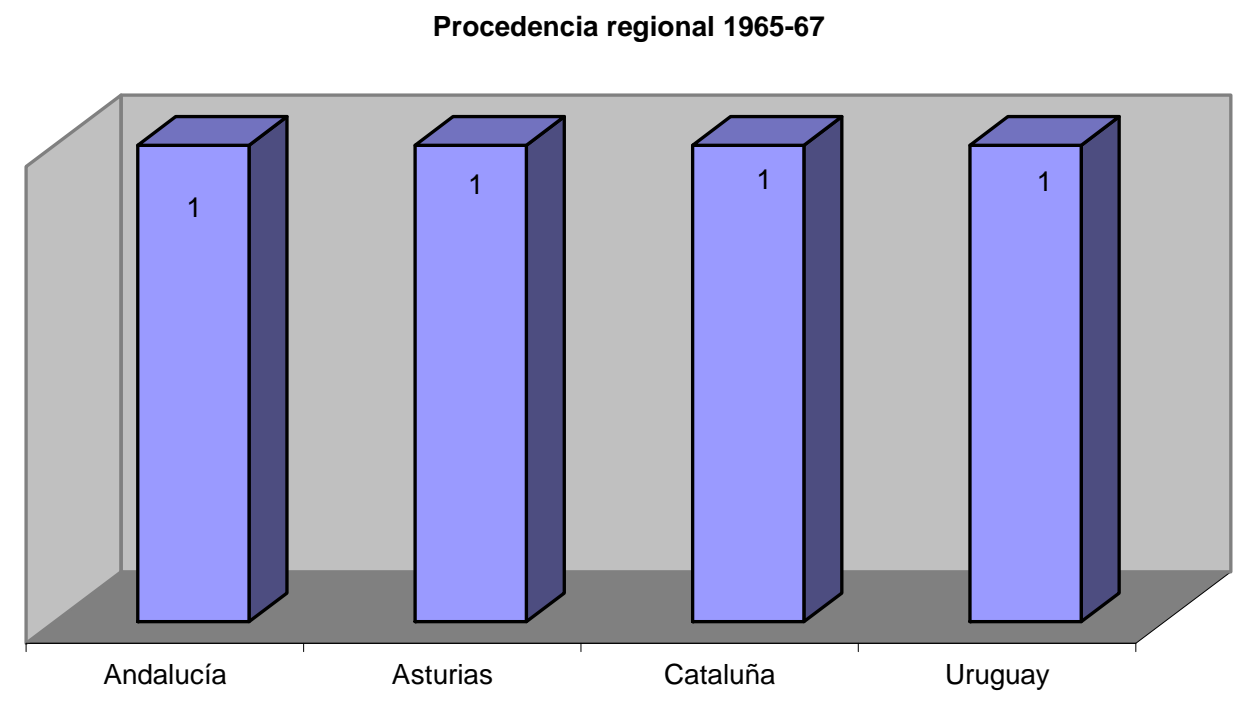

\section{Curso 1966-68}

Asistimos a un profundo período de crisis, con escasez de alumnas hasta el punto de que no consta ninguna graduación en el año 1969, lo que implica que no hubo matrículas en el curso 1967. La escuela está sufriendo un período de transformación importante, y a partir de 1966 se integra dentro del programa 


\section{Capítulo 5. Música e ideología 2: La Sección Femenina}

de estudios el método Orff, impartido por la recién titulada en Salzburgo y antigua directora de la escuela Teresa Tullot, con el siguiente programa:

Ritmo: Esquemas rítmicos. Introducción. Improvisación de frases rítmicas con percusión corporal

Movimiento: Formas elementales del movimiento. Distintos pasos rítmicos.

Relajación. Cambios de compás

Acompañamientos rítmicos con pandero en el movimiento

Prosodia. Fórmulas. Frases del lenguaje con acompañamiento de ritmo

Instrumentos de percusión: manejo y técnica. Improvisación, acompañamiento

Técnica de movimiento. Creación de formas en el espacio. Dinámica.

Coreografía

Manejo de todos los instrumentos Orff. Ostinatos. Piezas instrumentales

Flauta y pandero.

Canon. Formas musicales básicas

Didáctica: Teoría. Metodología. Práctica de los modos

Improvisación melódica vocal e instrumental

Canciones infantiles. Escenificación y musicalización de cuentos.

Las alumnas matriculadas en esta promoción son

\begin{tabular}{|c|c|c|}
\hline Albero Sanz, Nuria & Zaragoza & Carrera de piano \\
\hline Iglesias Díaz, Carmen & Coruña & $5^{\circ}$ piano, $4^{\circ}$ solfeo, bachiller elemental \\
\hline Lamote de Grignon Isuar, Cintia & Tarragona & Título de profesora de música \\
\hline Río Sendino, Piedad del & Palencia & $1^{\circ}$ piano, $4^{\circ}$ solfeo, bachiller. Elemental \\
\hline Rodríguez Baixeras, Asunción & Segovia & $\begin{array}{l}6 \text { años de piano y } 4 \text { de solfeo } \\
\text { Magisterio, bachiller. Elemental, } 5 \text { de piano y } 4 \text { de }\end{array}$ \\
\hline Serrat Melet, Pilar & Huesca & solfeo \\
\hline
\end{tabular}

Este curso los resultados académicos fueron de 6 notables

La procedencia regional de las alumnas es la siguiente 


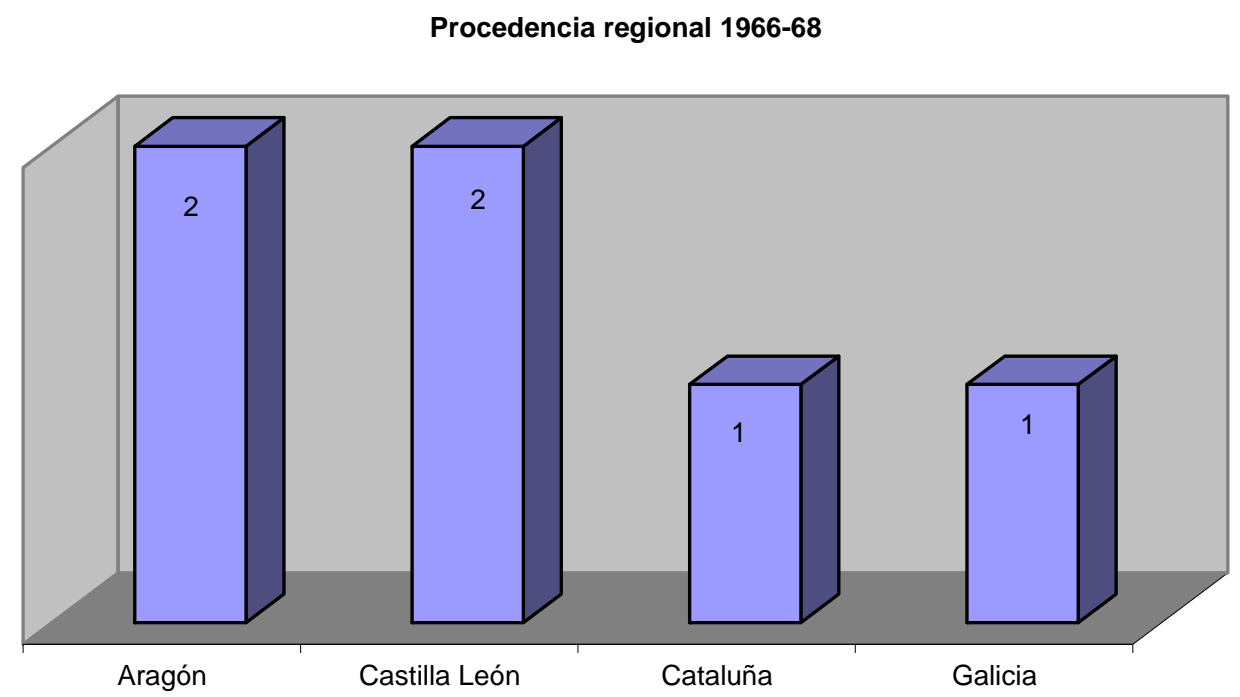

\section{Curso 1968-70}

Es el momento de resurgir de la Escuela, con la incorporación de novedades en la renovación del profesorado, la implantación de las novedades didácticas y pedagógicas musicales. Las perspectivas de obligatoriedad de la asignatura de Historia de la Música en el nuevo BUP, crean grandes expectativas entre los profesionales, ya que en principio ésta es la titulación que califica al personal que se va a incorporar a esta docencia en los institutos de todo el país. La Reforma educativa en marcha incorpora novedades tanto en Educación primaria como en secundaria: se extiende la enseñanza musical de manera oficial a todos los niveles escolares, se introducen las nuevas metodologías pedagógicas (el sistema Orff fue difundido preferentemente por la Sección Femenina), y se produce un incremento de fondos para dar accesibilidad y gratuidad a la educación, obligatoria hasta los 14 años, así como un importantísimo incremento del número de institutos de secundaria estatales. La nueva EGB y el BUP suponen una revolución y una gran oportunidad para las tituladas en esta promoción.

Por todo ello, el número de alumnas se incrementa notablemente, siendo la promoción más numerosa en toda la historia del centro. Hay que recordar que el sistema de acceso era la propuesta por parte de las Delegaciones Provinciales según sus previsiones de necesidad de profesorado. La mayor 


\section{Capítulo 5. Música e ideología 2: La Sección Femenina}

parte de las alumnas se incorporaron inmediatamente a los nuevos centros de primaria y secundaria e incorporan las innovaciones pedagógicas y didácticas musicales. La nueva directora de la escuela es Angela Cuenca y la Jefe de estudios es Conchita Carrea. Las clases del método Orff son impartidas por Mạ Teresa Tullot.

\begin{tabular}{|c|c|c|}
\hline Acosta romero, Amalia & Granada & Carrera de piano \\
\hline Antolín rodríguez, Cristina & Valladolid & $\begin{array}{l}\text { Carrera de piano } \\
\text { Profesora de piano en }\end{array}$ \\
\hline Chavarría hernández, Teresa & Tenerife & conservatorio \\
\hline Crespo Cabañuz, Lourdes & Huesca & magisterio, superior de piano \\
\hline Cruz Escalona, Amelia & Cádiz & Superior de piano \\
\hline Devesa Cano, Esperanza & Alicante & Carrera de piano \\
\hline $\begin{array}{l}\text { Fernández de Alba, Rosa Ma } \\
\text { Font Vila, Montserrat }\end{array}$ & Granada & $4^{\circ}$ de solfeo y $5^{\circ}$ de piano \\
\hline $\begin{array}{l}\text { García González, Lucía } \\
\text { Gil García, Montserrat }\end{array}$ & Melilla & Bachiller y estudios de piano \\
\hline González Uldemolins, Lidón & Castellón & Carrera de piano \\
\hline Hidalgo Sánchez, Elia & Granada & $5^{\circ}$ de piano y $4^{\circ}$ de solfeo \\
\hline López López, Pilar & Lérida & Superior de piano \\
\hline Martínez González, Teresa & Burgos & Carrera de música. \\
\hline Martínez Guinea, Antonia & Logroño & Profesora de música \\
\hline Pamies Herranz, Cristina & Barcelona & Superior de piano \\
\hline Ruiz Durán, Ana Ma & Ceuta & Superior de piano y magisterio \\
\hline Sánchez Cano, Laura & Toledo & $5^{\circ}$ piano y bachiller elemental \\
\hline Sánchez García, Teresa & Valencia & $7^{\circ}$ de piano y bachiller superior \\
\hline $\begin{array}{l}\text { Sanchís Torro, Carmen } \\
\text { Terriza Rodríguez de Guzmán, } \\
\text { Carmen }\end{array}$ & $\begin{array}{l}\text { Valencia } \\
\text { Ciudad } \\
\text { Real }\end{array}$ & $\begin{array}{l}\text { Carrera de piano } \\
4^{\circ} \text { de solfeo y } 6^{\circ} \text { de piano }\end{array}$ \\
\hline Viguri Goicoechea, Sagrario de & Pamplona & magisterio, carrera de piano \\
\hline
\end{tabular}

Aunque faltan los datos de 2 de las alumnas, es evidente que casi todas las regiones enviaron propuestas de alumnas (incluyendo Ceuta y Melilla) para poder formar al nuevo personal que impartiría música en niveles escolares. $Y$ que su formación musical anterior era elevada: carreras superiores de piano, bachilleres superiores, magisterio, profesoras en conservatorios, carreras completas de instrumento. Los resultados obtenidos fueron los siguientes 
Calificaciones 1968-70

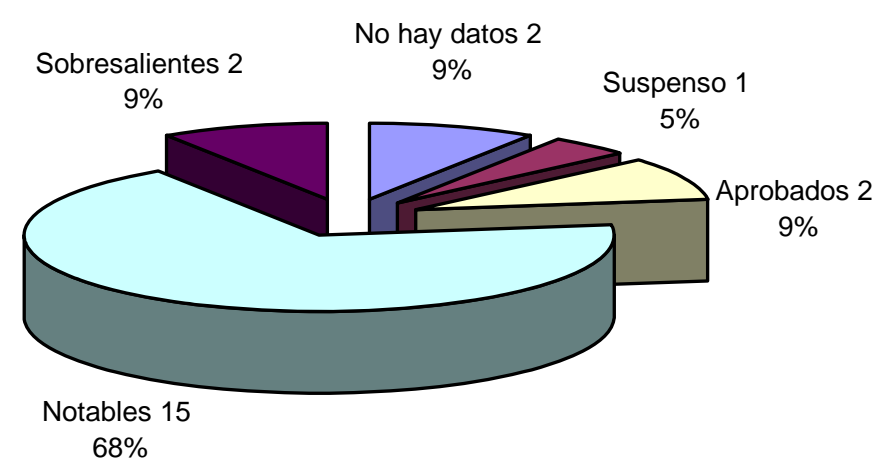

En cuanto a la procedencia regional de las alumnas, se observa un incremento notable de Andalucía y Valencia, ligado al incremento de población y de dotaciones de centros de secundaria en estas zonas.

Procedencia regional 1968-70

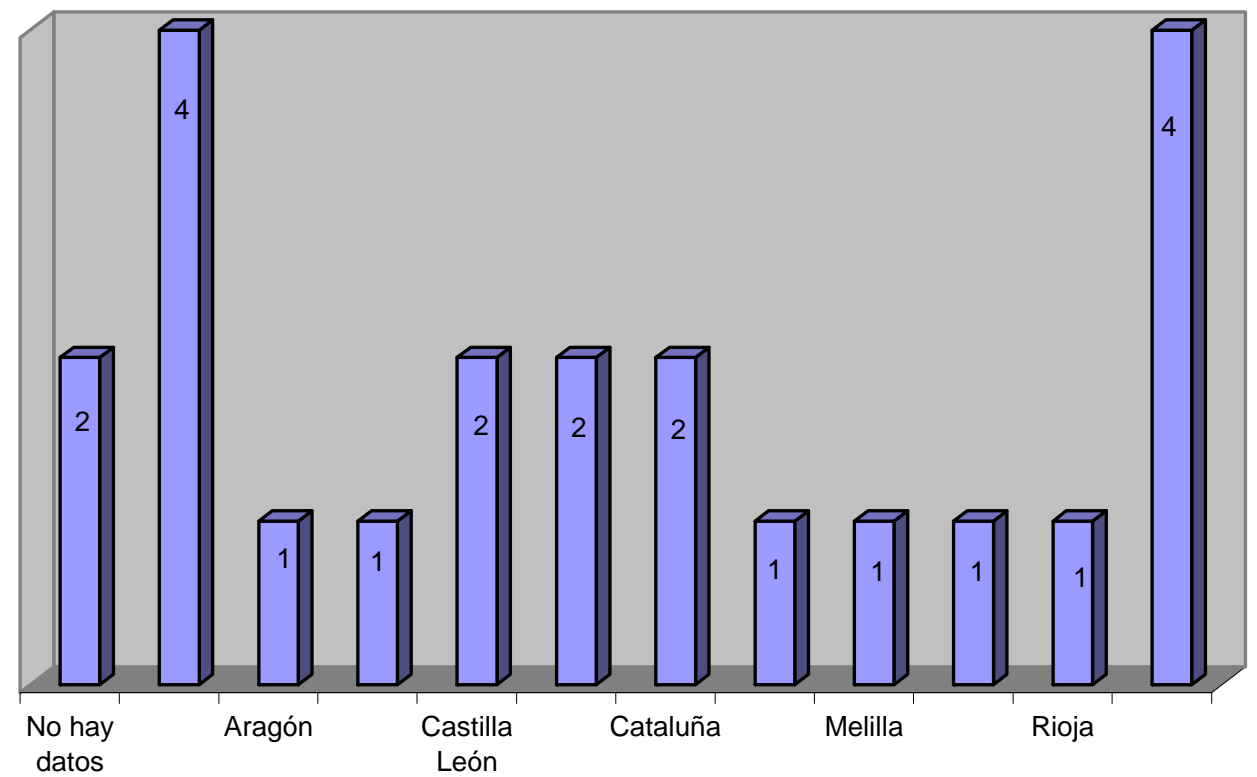




\section{Capítulo 5. Música e ideología 2: La Sección Femenina}

\section{Curso 1969-71}

En este curso se sigue manteniendo niveles bastante altos de alumnado, aunque ya volvemos a porcentajes más normales (la mitad de alumnas que la promoción inmediatamente anterior), lo cual indica que sigue habiendo necesidad de profesorado.

\author{
Gómez Navas, Fátima \\ González Fernández, Carmen \\ López-Araus pérez, Angela \\ Lozano Martínez, Mercedes \\ Miguel Peña, Carmen \\ Ponsoda Masobro, Rosario \\ Punyed Recasens, Pilar \\ Rincón Toledano, Paz \\ VitoriaPeso, Luisa
}

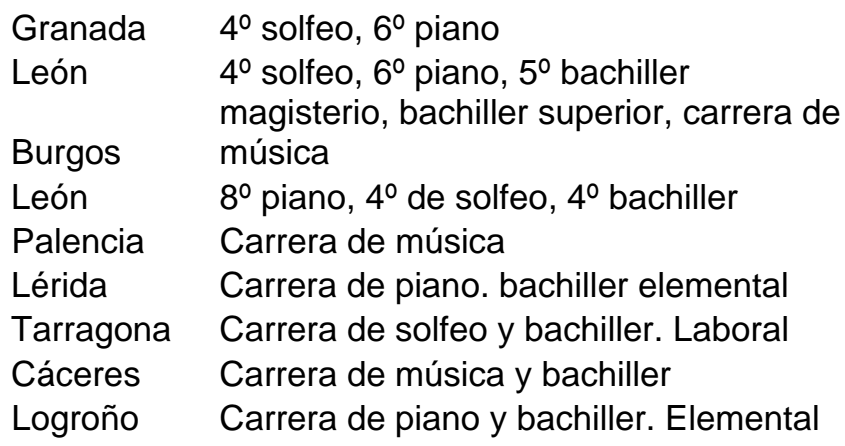

Entre las novedades que incorpora la reforma educativa está la inclusión del a música dentro de una nueva área de conocimiento: expresión dinámica. La escuela se adaptó a esta propuesta, incorporando la asignatura de "Técnicas de expresión corporal" impartida por Ma a Paz Güell, así como otras materias complementarias: "Literatura" impartida por Ma a Carmen Esteban o "Trabajos manuales" impartida por Ma Paz Sanz. La importancia de las indicaciones pedagógicas de la nueva ley se ve reflejada en la aparición de una asignatura de "Pedagogía" impartida por Ma Esther Oliveras.

Los resultados obtenidos fueron 


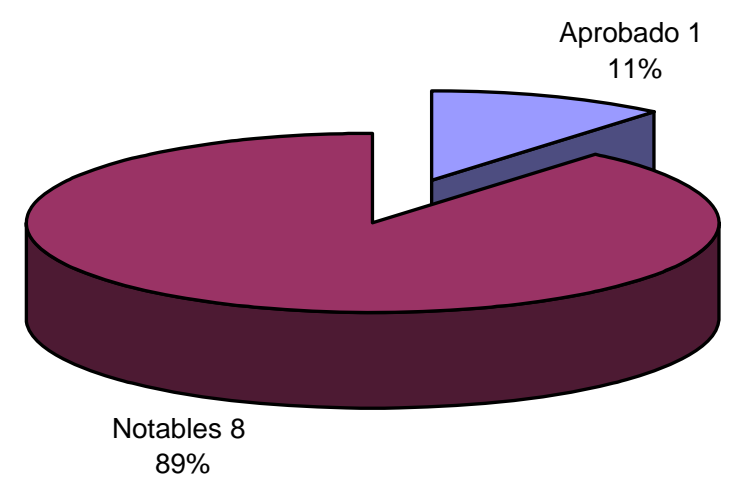

En cuanto a la procedencia regional de las alumnas, Cataluña y Castilla León siguen siendo las que necesitan más formación e incorporación de nuevo profesorado.

Procedencia regional 1969-71

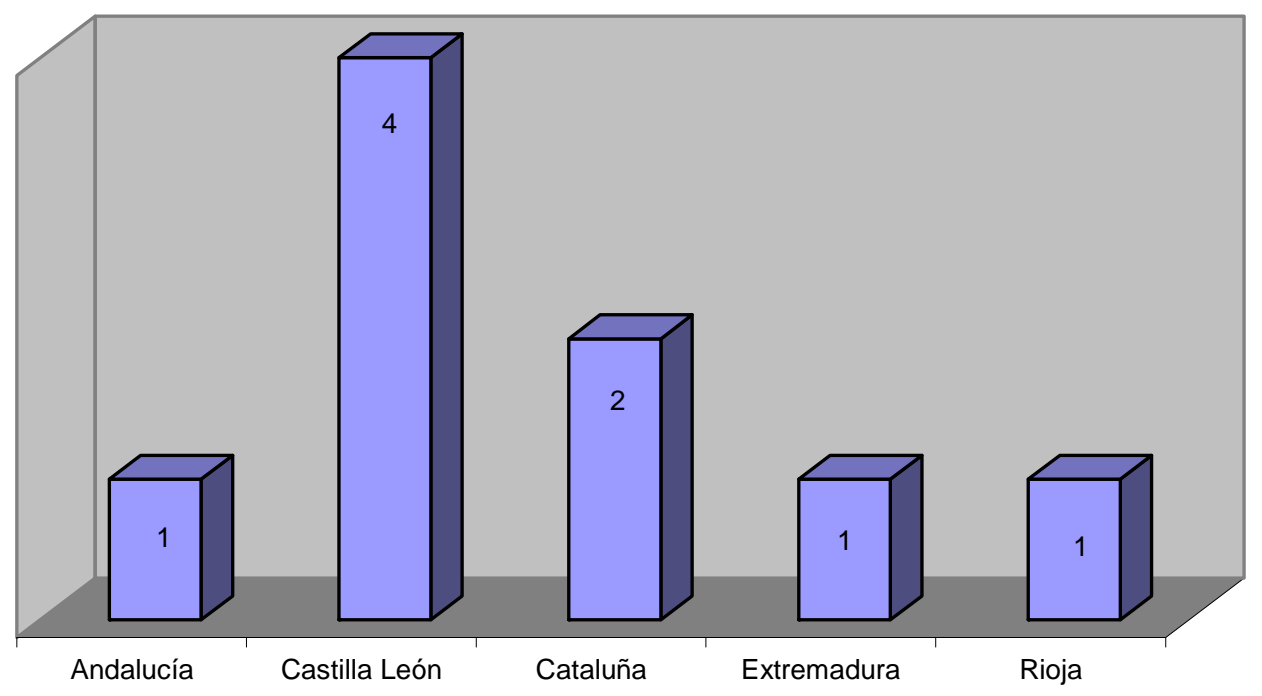




\section{Capítulo 5. Música e ideología 2: La Sección Femenina}

\section{Curso 1970-72}

Es el último año del que se conservan datos de alumnas en el topográfico del Archivo General de la Administración ${ }^{232}$

Vuelve a apreciarse un descenso paulatino de la matrícula de alumnas. Estamos viviendo el final de franquismo y Sección Femenina se va a centrar más en intentar con insistencia el reconocimiento de esta titulación y en asegurar el futuro de las graduadas.

Casasempere Gisbert, Angeles

Cidón Madrigal, Pilar

Farre Morancho, Dolores

Giménez de Lafuente, Concepción

Morán López, Adela

Roncero Herrero, Teresa

Los resultados obtenidos son
Alicante
$6^{\circ}$ violín, magisterio, bach. Elem
Zamora
Instr. Elemental, afiliada
$7^{\circ}$ de piano, $4^{\circ}$ de solfeo, bach.
Lérida
Almería
León
Elem
Elemental de piano y $4^{\circ}$ solfeo
Carrera de piano
Valladolid

Calificaciones 1970-72

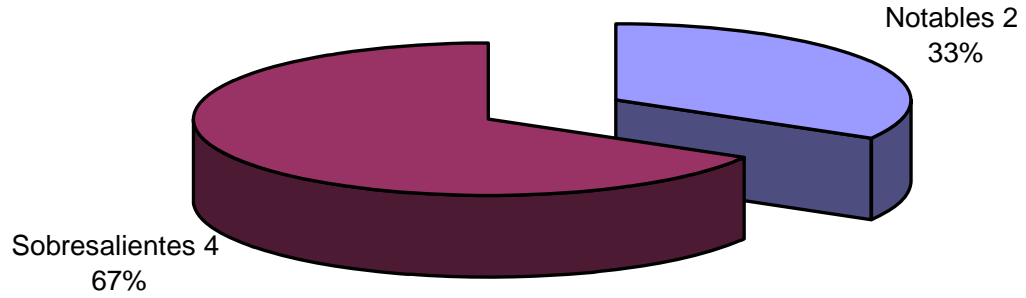

En cuanto a la procedencia regional, Castilla y León sigue siendo la que proporciona mayor número de alumnado.

\footnotetext{
${ }^{232}$ Archivo General de la Administración (AGA). Sección de fondo de Cutlrua/ Sección Femenina, IDD 51.23, Top SF 23/27.704, grupo 7 no 1 , caja 25
} 
Procedencia regional 1970-72

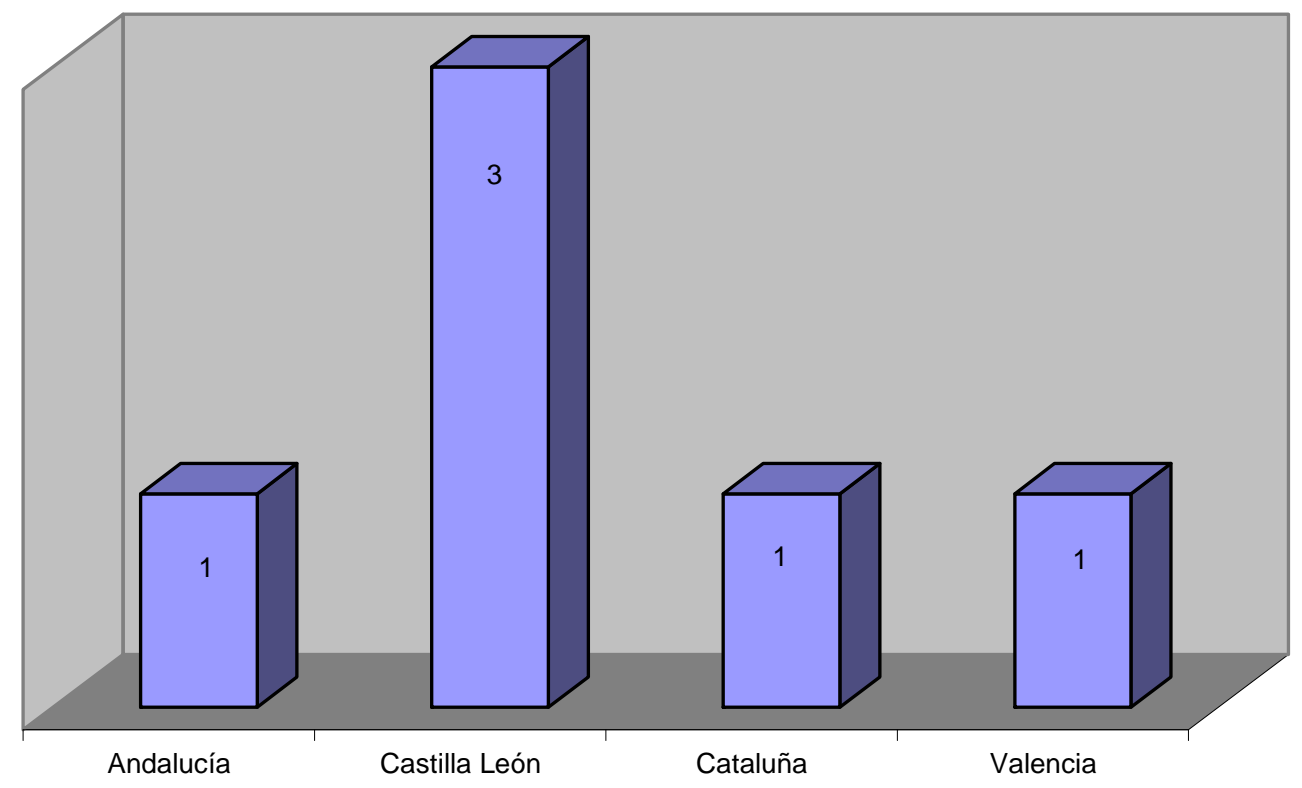

Hasta aquí los datos individuales que hemos obtenido en el Archivo General de la Administración sobre la Escuela Roger de Lauria, con respecto a la Especialidad de Música (1960-1972).

De los datos podemos obtener las siguientes conclusiones:

\begin{tabular}{|l|l|l|l|l|l|l|l|l|l|l|}
\hline & 1962 & 1963 & 1964 & 1965 & 1966 & 1967 & 1968 & 1970 & 1971 & 1972 \\
\hline And & & & 2 & & 1 & 1 & & 4 & 1 & 1 \\
\hline Arag & 1 & 1 & & & & & 2 & 1 & & \\
\hline Ast & & & 1 & 1 & & 1 & & & & \\
\hline Bale & 1 & & 1 & & & & & & & \\
\hline Canr & 2 & 1 & 1 & & & & & 1 & & \\
\hline Cant & & & 1 & & & & & & & \\
\hline C-L & 2 & 3 & & 6 & 4 & & 2 & 2 & 4 & 3 \\
\hline C-M & & & & 2 & & & & 2 & & \\
\hline Catal & 5 & 1 & & 4 & 2 & 1 & 1 & 2 & 2 & 1 \\
\hline Ceut & & & & & & & & 1 & & \\
\hline Extr & 2 & 1 & & & & & & & 1 & \\
\hline
\end{tabular}




\section{Capítulo 5. Música e ideología 2: La Sección Femenina}

\begin{tabular}{|l|l|l|l|l|l|l|l|l|l|l|}
\hline Galic & & & 1 & 1 & & & 1 & & & \\
\hline Madr & & 3 & & & & & & & & \\
\hline Melill & & & & 1 & 2 & & & 1 & & \\
\hline Murc & & & 1 & 1 & & & & & & \\
\hline Nav & 1 & & & 1 & & & & 1 & & \\
\hline PVas & & & & 2 & & & & & & \\
\hline Rioj & 1 & & & & & & & 1 & 1 & \\
\hline Vale & & 1 & 1 & & & & & 4 & & 1 \\
\hline Uru & & & & & & 1 & & & & \\
\hline
\end{tabular}

Procedencia regional de las alumnas

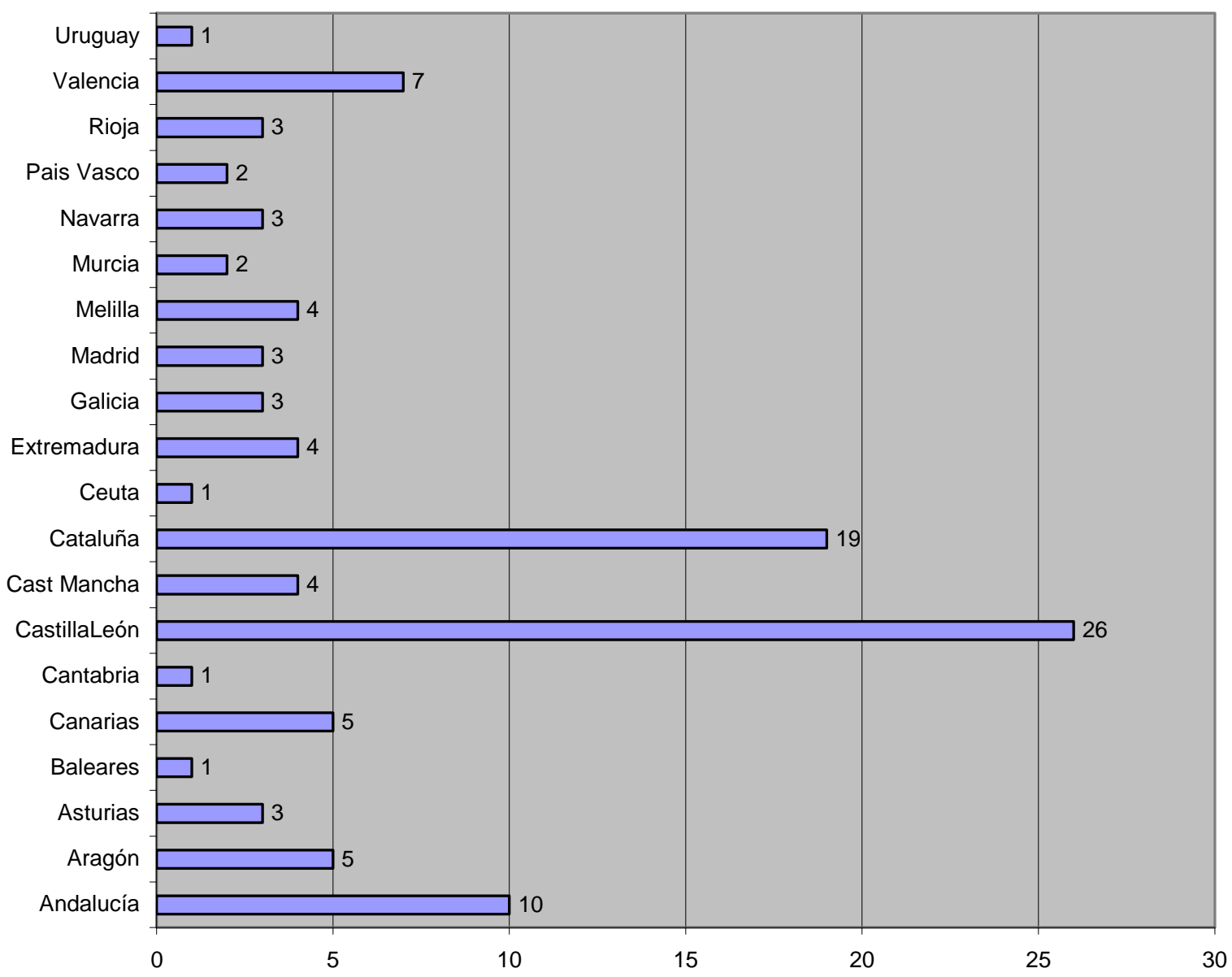




\section{La educación musical en el franquismo}

Ello implica que las principales regiones en las que había profesoras formadas en la Escuela "Roger de Lauria" eran Castilla y León (24\%), Cataluña (18\%) y Andalucía (9\%)

\section{Porcentajes por regiones}

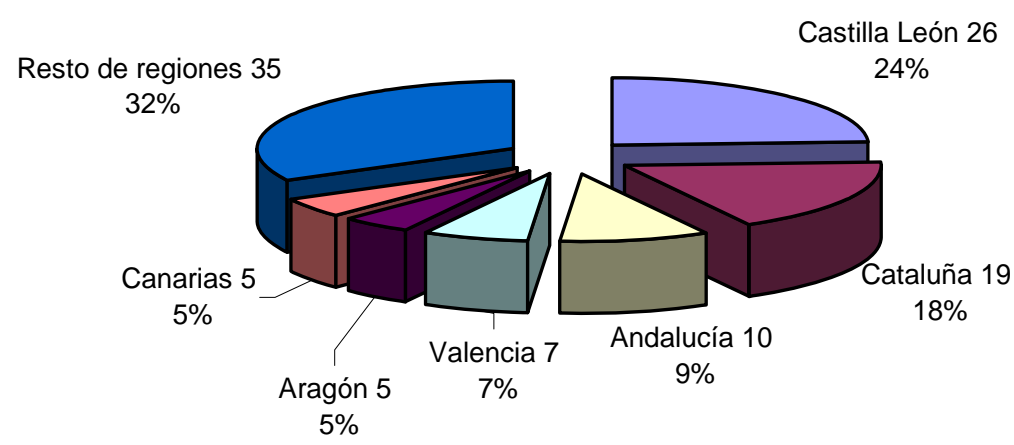

El total de alumnas formadas en este centro fue de 107 alumnas, aunque nos consta que al menos tres abandonaron o abandonaron tras el primer curso. Las calificaciones otorgadas son generalmente altas, con el siguiente porcentaje:

\begin{tabular}{|l|l|l|}
\hline No hay datos & 2 & $2 \%$ \\
\hline Abandonos & 3 & $3 \%$ \\
\hline Suspensos & 3 & $3 \%$ \\
\hline Bien & 2 & $2 \%$ \\
\hline Notables & 71 & $69 \%$ \\
\hline Sobresalientes & 21 & $21 \%$ \\
\hline
\end{tabular}




\section{Capítulo 5. Música e ideología 2: La Sección Femenina}

Porcentaje de calificaciones

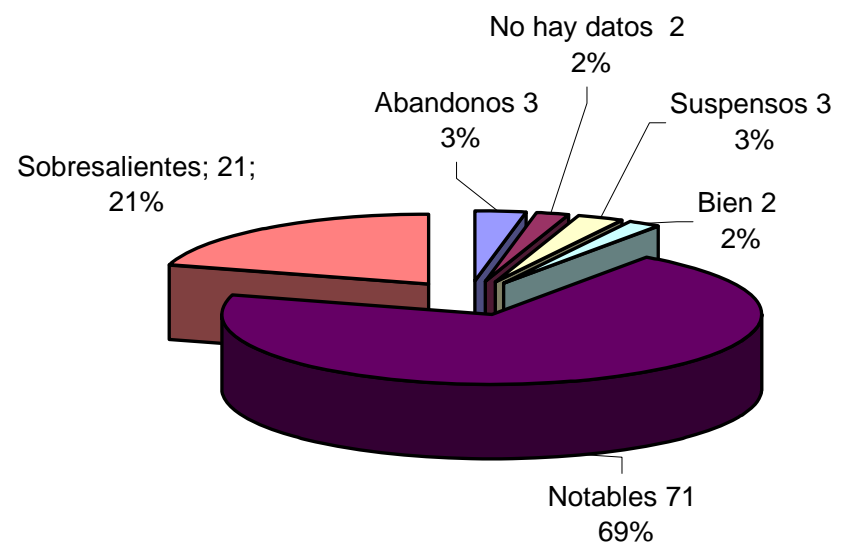

Las edades de las alumnas al ingresar en la Escuela abarcan desde los 16 años a los 38 años, pero la mayoría iniciaron los estudios entre los 17 y los 22 años de edad. (75\% del alumnado)

\section{Edad al comenzar los estudios}

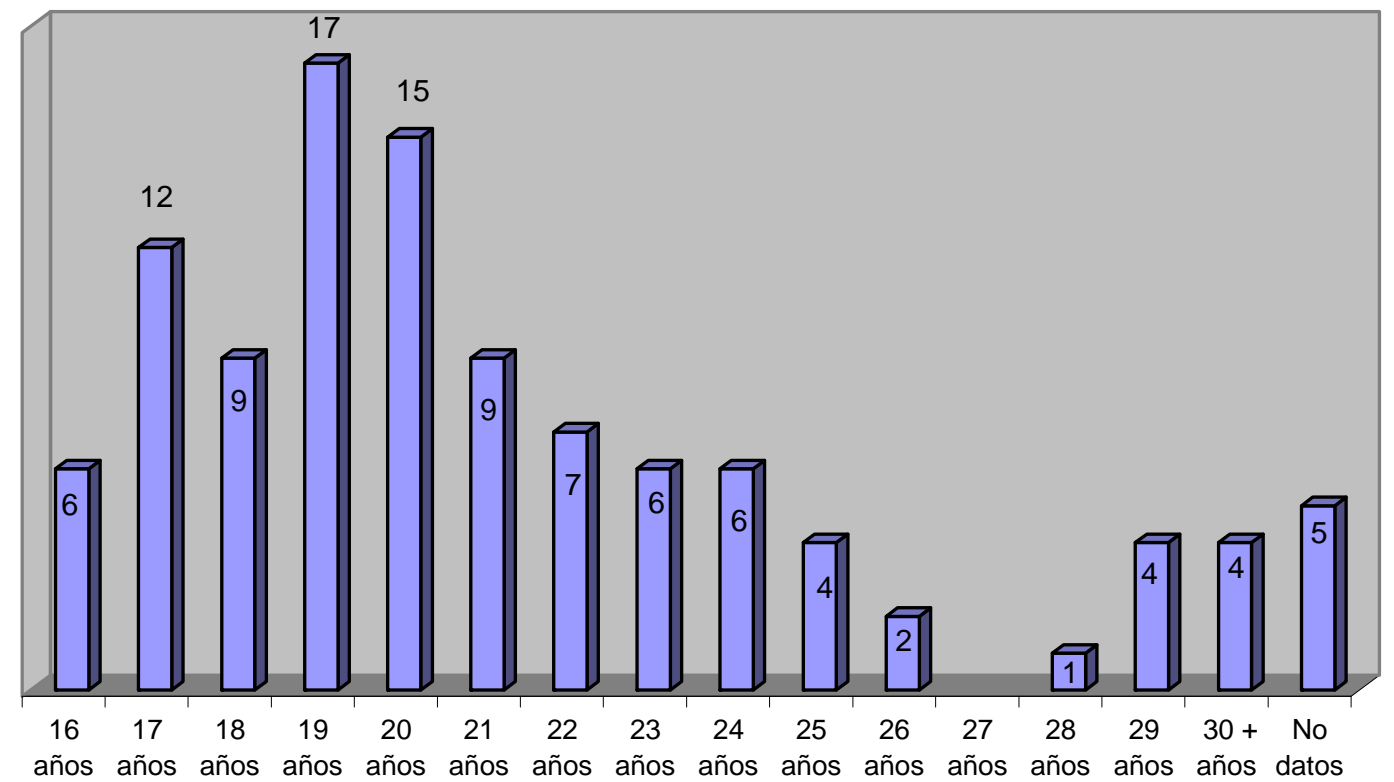




\section{La educación musical en el franquismo}

En cuanto a la Escuela Roger de Lauria tuvo bastantes fluctuaciones en el número de alumnado a lo largo del período 1960-1972, con especial presencia en las promociones 1960/62, 1963/65 y 1968/70. Y la reforma educativa se plasma en el período de espera 1967/69 y en la espectacular recuperación en la siguiente promoción (la que alcanza mayor número de alumnas en la historia de la Escuela)

Número de alumnas

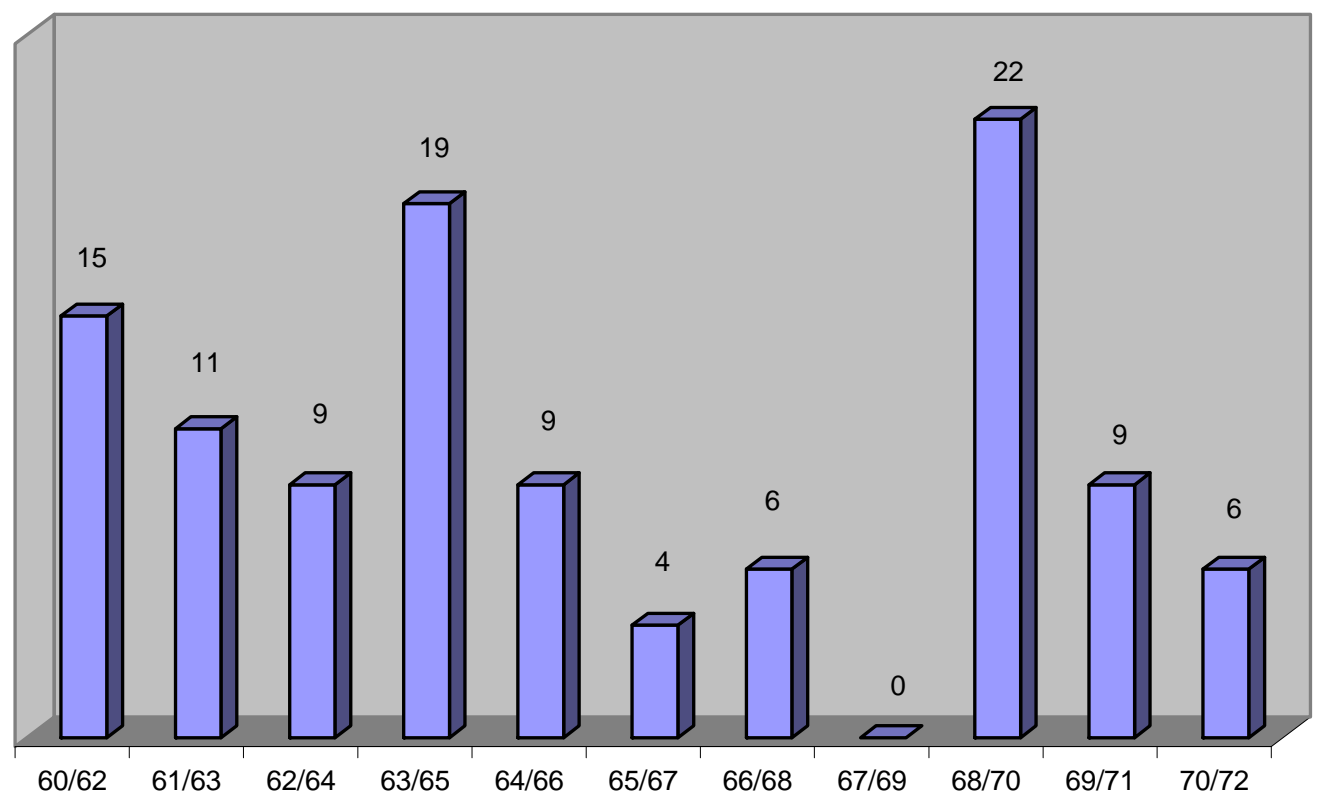

\subsubsection{La formación a través de cursos especializados de pedagogía musical}

A partir de 1960, Sección Femenina afronta un proceso de renovación de la educación musical en España, interesándose por los métodos de pedagogía musical en vigor en otros países europeos.

\section{Método Orff}

La Sección Femenina crea una serie de becas para que algunas instructoras de música seleccionadas vayan al extranjero a cursar estudios y entablar así 


\section{Capítulo 5. Música e ideología 2: La Sección Femenina}

relaciones con los creadores e instituciones oficiales de dichos métodos. Sin duda, el método que obtuvo mayor aceptación para la Sección Femenina es el creado por Carl Orff ${ }^{233}$, para cuya difusión, como refleja Luengo Sojo ${ }^{234}$ se

- Enviaron profesoras de música preparadas para realizar cursos de aprendizaje del sistema Orff entre 1960 y 1966

- Organizaron cursillos intensivos con profesorado español y extranjero para profesores de música, maestros y educadores a partir de 1965

- Organizaron cursillos con profesorado española para maestros y educadores

- Implantación del sistema Orff en la Escuela Nacional de Música de la Sección Femenina y en la Escuela de Magisterio "Isabel la Católica.

Las personas becadas para los cursos en el extranjero son:

Carmen Pérez Durias que asistió en Austria durante dos años (1960-62) a los cursos Orff. En 1964 asistió al curos de Lisboa

Teresa Tullot asistió al curso de Lisboa en 1964 y en 1966 al curso de Salzburgo para diplomarse en el Orff Institute. Es la profesora del método en la Escuela Roger de Lauria

Montserrat Sanuy asistió también al curso de Lisboa en 1964 y en 1966 al curso de Salzburgo para diplomarse en el Orff Institute.

Estas dos últimas, emiten un informe ${ }^{235}$ sobre el curso de Lisboa, en el que se muestra el interés de la escuela Orff de Lisboa (patrocinada por la Fundación Gulbekian) por entrar en contacto con Sección Femenina. La escuela Orff

\footnotetext{
${ }^{233}$ Carl Orff (1895-1982) fue un compositor y pedagogo alemán. Además de su famoso Carmina Burana (en el que utiliza los instrumentos de placa y percusión en la orquesta clásica) es el autor de un importante método de educación musical basado en el cultivo del sentido rítmico y del lenguaje. Las fuentes folklóricas tienen gran importancia en el desarrollo del sentido melódico y utiliza la pentatonía y los modos. También fomenta el desarrollo rítmico y armónico a través de la utilización infantil de los instrumentos de placas adaptados a las edades escolares ${ }^{234}$ LUENGO SOJ O, A. La activida musical de la Sección Femenina. Tesis doctoral inédita presentada en el Departamento de Historia del Arte de la Universidad de Barcelona bajo la dirección del DR. Xosé Aviñoa

${ }^{235}$ Archivo General de la Administración (AGA). Caja 133, grupo 7 №1
} 


\section{La educación musical en el franquismo}

portuguesa disponía de profesorado formado en Salzburgo y llevaba trabajando diez años con el método bajo la dirección de María Lourdes Martins. Tenía tres secciones: niños, maestros y profesores de música y realizan cursos de verano cada dos años. Así se realizó el primer contacto, que dio pie al curso de 1965 en Pamplona y más tarde al envío de ambas por un período anual al Instituto Orff.

Además se envió para realizar el curso de verano al Instituto Orff de Salzburgo a otras tres profesoras: Marisa Hortelano, Elisa Ma Roche y Conchita Sanuy.

Ya en 1965 se iniciaron los cursos del método Orff en España, con presencia del mismo Carl Orff y de los profesores Hermann Regner (instrumentación) y Barbara Hasselbach (movimiento) y se aplicó la versión española del método realizada por J osé Peris ${ }^{\mathbf{2 3 6}}$. Este curso se celebró en Pamplona de 20 al 26 de septiembre, bajo el patrocinio de la Dirección General de Bellas Artes y la colaboración del Conservatorio de Música de Pamplona y la Delegación Nacional de Juventudes (a iniciativa de López Cancio) y a él asistieron 45 alumnas, entre las que se encontraban futuras instructoras del método en todo el país (como Montserrat Sanuy, Teresa Tullot, Ana Ma Espino y Rosa Ma Kucharski). A partir de este momento se decidió que las dos primeras fueran a Salzburgo a realizar el curso de formación completo y titularse.

El primer curso del método Orff que organiza por propia iniciativa Sección Femenina se realiza en Valladolid del 21 al 25 de agosto de 1966. En él se requiere que las participantes tengan el título de magisterio, una edad inferior a 40 años, un examen de ingreso y 2000 pesetas de matrícula. No se requería ninguna afiliación a Sección Femenina. Se trabajó instrumentación (se trajeron las placas de la Escuela Roger de Lauria), dirección, movimiento (se solicitaba ropa cómoda para realizar danzas) y flauta. El horario era intensivo, en régimen de internado. Asistieron 68 alumnas de varias provincias españolas (Álava, Alicante, Barcelona, Burgos, Madrid, Soria, Toledo, Valencia, Valladolid y Zaragoza)

${ }^{236}$ PERIS, J. ( Música para niños. Iniciación al método Orff. Doncel 


\section{Capítulo 5. Música e ideología 2: La Sección Femenina}

En 1967 se volvió a celebrar otro curso del método Orff en Valladolid durante el mes de agosto, esta vez con incorporación de alumnos masculinos. Las asignaturas fueron: flauta, movimiento, dirección y prosodia, canciones populares, improvisación, instrumentación, armonización, formas musicales, técnica instrumental y bailes regionales. El profesorado incorporaba a las recién tituladas y profesoras formadas en el Orff Institute: Montserrat Sanuy y su hermana Conchita, Rosa Ma Kucharski, Elisa Mạ Roche, marisa Hortelano, Antonio Malonda (profesor de mimo y expresión corporal en la Escuela de Danza del Real Conservatorio de Madrid) y José Ma Martín Porras (Profesor de percusión del Real Conservatorio de Música de Madrid. Asistieron 80 alumnos.

En 1968 se realiza entre el 15 y el 30 de julio un curso Orff en Santander, bajo la asesoría técnica de teresa Tullot. Contó con una conferencia inaugural de Hermann Regner y entre el profesorado figuran Barbara Hasselbach, Montserrat y Conchita Sanuy y Luciano Gómez Sarmiento. Asistieron 92 alumnos de ambos sexos.

En 1969 se realiza un curso Orff en León, entre el 5 y el 20 de agosto, con asistencia de 102 alumnos de ambos sexos, todos ellos profesores de música, maestros o educadores.

En estos años hay otros cursos Orff que se mencionan en documentos del AGA, pero de los que no se conserva documentación detallada. Tal es el caso de cursos en Madrid en 1966, en Granada en 1967, en Las Palmas en 1968, en Barcelona y Tenerife en 1969.

Está claro que el éxito de los cursos Orff de quince días de duración para profesores de música y maestros tiene una gran aceptación y se instituyen al inicio del período veraniego en los años siguientes (1970 en Tenerife, 1971 en Málaga y Ávila, 1972 en Madrid y Barcelona). El profesorado se institucionaliza de forma estable con las profesoras tituladas y el personal formado en los cursos de verano del Orff Institut. 


\section{J os Wuytack}

A partir de 1974, se inician los cursos que da en España Jos Wuytack ${ }^{237}$ sobre aplicaciones del método Orff de carácter más práctico. Tras un informe de dos instructoras que habían asistido en Barcelona a un curso, Sección Femenina inició una colaboración con el profesor holandés que se extendió a lo largo de los años siguientes.

En 1974 se imparte el curso en Madrid, entre el 8 y el 12 de abril, con asistencia de 70 alumnos de todas las provincias, a los que se exigió el título de Profesores de música y una matrícula de 2000 pesetas (1500 para las oyentes).

En 1975, el curso se imparte en la Escuela de especialidades "Julio Ruiz de Alda" en Madrid. Se redujo el número de alumnos a petición del profesor. 21 repitieron y hubo un total de 33 alumnos.

En 1976, se vuelve a impartir un curso en la Escuela "Julio Ruiz de Alda" en Madrid, con una asistencia de 50 alumnos - tras un proceso de selección en base a la formación musical previa -, que tuvieron que abona matrículas de 2800 pesetas (1500 para las oyentes)

\section{La pedagogía musical en la EGB y la incorporación de los ICEs ${ }^{238}$}

En 1971, la Dirección General de Bellas Artes en colaboración con la Dirección General de Ordenación Educativo y el Instituto de Ciencias de la Educación de la Universidad de Madrid organizaron el I curso de Pedagogía Musical para la formación del profesorado en el área de Expresión dinámica de la primera y segunda etapa de EGB. Aunque ya no fue un curso organizado a través de la Sección Femenina, ésta envió como parte del profesorado a $M \underline{a}$

\footnotetext{
${ }^{237}$ Profesor de la Universidad de Lovaina en aquel momento y conocido pedagogo que realiza aplicaciones del Método Orff, con instrumentaciones para placas, flautas y voces, aplicaciones rítmicas y de movimiento. En la actualidad, sigue siendo uno de los pedagogos fundamentales en el campo de la educación musical en España, donde continúa impartiendo cursos de corta duración en numerosas provincias, en colaboración con las Universidades y los Conservatorios. ${ }^{238}$ Los Institutos de Ciencias de la Educación (ICE) son una creación de la Ley de Reforma Educativa (1970) llevada a cabo por Villar Palasí, que contempla la formación del profesorado en las nuevas metodologías didácticas.
} 


\section{Capítulo 5. Música e ideología 2: La Sección Femenina}

Teresa Tullot, que impartió 15 horas de docencia en la materia de "Instrumentos musicales en la escuela".

Además de este curso, se celebraron en el año 1971 otros dos de gran importancia, patrocinados aún por Sección Femenina. El Curso de pedagogía Musical se celebró entre Abril y Mayo en el Instituto de música y Danza de la Sección Femenina de Madrid, con una dedicación de 12 horas semanales. También se celebró un Curso intensivo de Pedagogía musical bajo el patrocinio de la Dirección General de Bellas Artes en el mes julio, también en el Instituto de Música y Danza de la Sección Femenina de Madrid.

A partir de este momento, Sección Femenina y el Instituto de Ciencias de la Educación de la Universidad de Madrid inician una fructífera colaboración que se plasma en la organización del II Curso de Pedagogía musical, que se celebró a lo largo de todo el curso escolar 1971/ 72, con una duración de 360 horas y que se celebró en el Instituto de Música y Danza de la Sección Femenina de Madrid, con certificados del ICE de la Universidad de Madrid. Y también se celebró el II Curso intensivo de Pedagogía musical, celebrado del 3 al 15 de julio de 1972, también con reconocimiento y certificados expedidos por el ICE.

En 1973 se realizaron conjuntamente el I I I Curso de Pedagogía Musical, del 26 de febrero al 26 de junio, y un III Curso intensivo de Pedagogía Musical, del 2 al 14 de julio, en el Instituto de Música y Danza de la Sección Femenina en Madrid con reconocimiento del ICE de la Universidad de Madrid.

Por otra parte, también se realizaron algunos cursos específicos fuera de la capital, en los que colaboraron la Sección Femenina y los ICEs de otras Universidades.

En 1972 se realizó un Curso de pedagogía musical para la EGB en Valencia, organizado por la Delegación Nacional de la Sección Femenina en colaboración con el ICE de la Universidad de Valencia y que tuvo lugar en la Escuela de Hogar "Joaquín Sorolla". A este curso asistieron 136 mujeres y 6 


\section{La educación musical en el franquismo}

hombres, a los que se les exigió la carrera elemental de música, además del título de magisterio y el certificado de hallarse en activo en ese momento en la enseñanza. La jefe del curso fue Elisa Ma Roche, y entre el profesorado se encontraban, entre otros, Conchita Sanuy, Carmen Pérez Durías y Manuel García Matos, además de otros profesores provenientes del Real Conservatorio de Madrid como Carmen Miracle y Julián García de la Vega.

En 1973 se organizó un Curso de pedagogía musical en la EGB en Barcelona, al que asistieron 34 alumnas, y que tuvo lugar entre el 2 de marzo y el 6 de julio, con una dedicación de 160 horas, reconocido por el ICE de la Universidad Autónoma de Barcelona.

\subsection{EL PROFESORADO DE MÚSICA VINCULADO A LA SECCIÓN FEMENINA}

\section{En 1975, Sección Femenina tenía un total de 215 profesoras de música} impartiendo las enseñanzas correspondientes en los Institutos de Bachillerato y un número aún mayor si se tiene en cuenta a otro personal que impartía enseñanzas musicales en centros de primaria, centros de Sección Femenina y actividades en zonas rurales.

Estos son los datos que se conservan en el Archivo General de la Administración tras el informe emitido por las diferentes delegaciones provinciales de la Sección Femenina en el año 1975.

\begin{tabular}{|l|l|}
\hline Álava & 4 profesoras con título en regla \\
\hline Albacete & 2 profesoras en la capital con título en regla \\
& $\begin{array}{l}\text { En Almansa } 1 \text { con título de Hogar pero incompleto de música } \\
\text { En La Roda } 1 \text { profesora con título superior de música }\end{array}$ \\
\hline Alicante & 10 profesoras con titulación en regla \\
\hline Almería & 1 profesora con titulación en regla \\
\hline
\end{tabular}




\section{Capítulo 5. Música e ideología 2: La Sección Femenina}

\begin{tabular}{|c|c|}
\hline & $\begin{array}{l}\text { I Instructora General con título Superior de Conservatorio } \\
2 \text { profesoras de hogar completan sus clases con música } \\
4 \text { Instructoras generales completan sus clases con música }\end{array}$ \\
\hline Ávila & 2 profesoras con titulación en regla \\
\hline Badajoz & $\begin{array}{l}4 \text { profesoras con título superior } \\
2 \text { profesoras con título elemental de música }\end{array}$ \\
\hline Baleares & $\begin{array}{l}5 \text { profesoras con título en regla } \\
1 \text { instructora sin título musical imparte las clases en I biza }\end{array}$ \\
\hline Barcelona & $\begin{array}{l}17 \text { profesoras con titulación en regla } \\
3 \text { profesoras con } 7 \text { años de piano }\end{array}$ \\
\hline Burgos & $\begin{array}{l}\text { No tienen profesorado titulado. Imparten la materia de música } \\
\text { las profesoras de hogar }\end{array}$ \\
\hline Cáceres & $\begin{array}{l}2 \text { profesoras con titulación en regla } \\
1 \text { Profesora con } 7 \text { de piano }\end{array}$ \\
\hline Cádiz & 2 profesoras con titulación en regla \\
\hline Castellón & 1 profesora con título en regla \\
\hline Ciudad Real & $\begin{array}{l}2 \text { profesoras con titulación } \\
4 \text { profesoras sin terminan la carrera del conservatorio }\end{array}$ \\
\hline Cuenca & 1 profesora con titulación \\
\hline Coruña & 5 profesoras con titulación \\
\hline Gerona & $\begin{array}{l}\text { Las clases de música de bachillerato son impartidas por } \\
\text { licenciados del propio centro }\end{array}$ \\
\hline Granada & $\begin{array}{l}3 \text { profesoras con el Curso Nacional de Música pero sin titulación } \\
\text { de conservatorio }\end{array}$ \\
\hline Guadalajara & 2 profesoras con titulación \\
\hline Guipuzcoa & 5 profesoras con titulación \\
\hline Huelva & 2 profesoras con títulación. \\
\hline
\end{tabular}




\begin{tabular}{|c|c|}
\hline Huesca & $\begin{array}{l}4 \text { profesoras con titulación } \\
1 \text { profesora de hogar imparte también música }\end{array}$ \\
\hline Jaen & 3 profesoras con titulación \\
\hline Las Palmas & $\begin{array}{l}2 \text { profesoras con titulación } \\
2 \text { Profesoras sin terminar la carrera del conservatorio }\end{array}$ \\
\hline León & $\begin{array}{l}5 \text { profesoras con titulación } \\
1 \text { profesora con el Curso nacional de música, pero sin titulación } \\
\text { de Conservatorio da las clases en Astorga }\end{array}$ \\
\hline Lérida & 1 profesora con titulación \\
\hline Logroño & 3 profesoras con titulación \\
\hline Lugo & $\begin{array}{l}1 \text { profesora con titulación } \\
1 \text { profesora sin título (5o piano) } \\
7 \text { profesoras de hogar comparten la materia en la provincia }\end{array}$ \\
\hline Madrid & 19 profesoras con titulación \\
\hline Málaga & 4 profesoras con titulación \\
\hline Murcia & 9 profesoras con título \\
\hline Navarra & 4 profesoras con título \\
\hline Oviedo & $\begin{array}{l}12 \text { profesoras con título } \\
6 \text { profesoras sin título de música completan horario }\end{array}$ \\
\hline Palencia & 2 profesoras con título \\
\hline Pontevedra & 3 profesoras con título \\
\hline Salamanca & 1 profesora con título \\
\hline Santa Cruz & 9 profesoras con título \\
\hline Santander & 3 profesoras con título \\
\hline Segovia & 1 profesora con título \\
\hline Sevilla & 6 profesoras con título \\
\hline Soria & 1 profesora con título \\
\hline
\end{tabular}


Capítulo 5. Música e ideología 2: La Sección Femenina

\begin{tabular}{|c|c|}
\hline Tarragona & 2 profesoras con título \\
\hline Toledo & $\begin{array}{l}1 \text { profesora con estudios de música. } \\
4 \text { profesoras completan horario }\end{array}$ \\
\hline Valencia & $\begin{array}{l}6 \text { profesoras con título de forma total } \\
4 \text { profesoras con título de acuerdo con la normativa } \\
1 \text { profesora con título elemental } \\
2 \text { sin título de música completan horario }\end{array}$ \\
\hline Valladolid & 3 profesoras con título \\
\hline Vizcaya & 4 profesoras con titulación \\
\hline Zamora & 3 profesoras con título \\
\hline Zaragoza & $\begin{array}{l}4 \text { profesoras con título } \\
6 \text { profesoras sin título de conservatorio completan horario }\end{array}$ \\
\hline Ceuta & 1 profesora con titulación \\
\hline Melilla & 1 profesora con titulación \\
\hline Teruel & No hay profesora titulada en música \\
\hline Orense & Falta el informe \\
\hline
\end{tabular}

En los últimos años del franquismo ( a partir de 1970), la actividad principal de Sección Femenina se centra en dos frentes:

- La formación musical en los nuevos métodos pedagógicos musicales de todo tipo de profesorado (ampliando su ámbito a maestros, titulados de conservatorios, indistintamente de su sexo) por medio de cursos en todo el territorio nacional y de becas para realizar cursos en el extranjero. Se refuerza la colaboración con las Escuelas de magisterio (que con la nueva ley se convierten en Escuelas Universitarias) y con los conservatorios. 
- La preocupación por el futuro del personal docente que está impartiendo Música en los Institutos Nacionales de Enseñaza Media. La nueva ley prevé la existencia de una asignatura de "Música" en el primer curso de BUP. Las aspiraciones de Sección Femenina son el reconocimiento de dicho profesorado, que venía impartiendo los programas oficiales y reconocidos de Enseñanzas Musicales como parte de las "Escuelas del Hogar" en los centros femeninos desde 1941 con nombramiento oficial, a lo que se había unido su nombramiento como "Directoras de coro" desde el año 1961

A este respecto se conserva documentación referente a las peticiones y solicitudes que realiza la Delegación Nacional de Sección Femenina a diversas instancias del Ministerio de Educación y Ciencia. Entre ellos, una carta de la Delegada nacional dirigida al Ministro con registro de salida de la Delegación nacional no34 y fecha 18 de febrero de 1977 y de la que consta entrada en el Regsitro General del Ministerio de Educación y Ciencia con la misma fecha. En él se se

"SUPLICA que sea considerada con toda justicia, la existencia de $\mathbf{1 8 3}$ profesoras de música nombradas por el Ministerio de Educación y Ciencia en Centros de Bachillerato, teniendo en cuenta.

-que estas profesoras en virtud del propio nombramiento tienen adquirida una antigüedad en el servicio

-que reúnen las condiciones de titulación académica, además de la preparación pedagógica adecuada

-que se encuentran en disposición de pasar las pruebas restringidas que el Ministerio estime oportuno convocar para acceder con carácter definitivo al puesto que ahora ocupan de profesoras de música, considerando las circunstancias personales que les amparan

-que se considere ya de hecho, por el Ministerio de Educación y Ciencia, la renuncia de la Delegación Nacional de la Sección Femenina a la facultad de propuesta para el 


\section{Capítulo 5. Música e ideología 2: La Sección Femenina}

nombramiento de futuras profesoras de enseñanza de música y por tanto que no se incluirán en la Ley 3/71 de Febrero, que establece los derechos, obligaciones y remuneraciones para el profesorado nombrado por el Ministerio de Educación y Ciencia a propuesta de la Secretaría General del Movimiento.

Esta solicitud que se realiza a ese Ministerio para consolidar en sus puestos a las profesoras de música, ha sido expuesta en diferentes ocasiones y escritos que se adjuntan como anexos(...)

Finalmente, es preciso aclarar, que si bien en los distintos escritos cursados a ese Ministerio, en relación con las profesoras de música nombradas en los Institutos de Bachillerato aparecen en número de doscientas quince se puede observar que en el presente escrito, las profesoras tituladas por los Conservatorios de Música alcanzan la cifra de ciento ochenta y tres. La diferencia de treinta y dos profesoras que vienen actuando desde el año 42, se produce por no estar en posesión de Titulación Oficial, sino que adquirieron su capacitación en la materia a través de cursos de esta Especialidad organizados por Sección Femenina, que las habilitaron en su día para el ejercicio de esta docencia, y por tanto, los diplomas que poseen no tienen validez académica. Para las profesoras de música que se encuentran en estas condiciones, se solicita un tratamiento especial, estudiando cada caso por separado con el fin de consolidarlas en sus puestos con el carácter de "a extinguir".

Madrid, a quince de febrero de mil novecientos setenta y siete.

Firmado por la Delegada Nacional (Pilar primo de Rivera)

Dirigida al Excmo. Sr, Ministro de Educación y Ciencia

Este documento nos permite comprobar que:

- Las titulaciones de Sección Femenina en música (ni siquiera las de la Escuela Nacional de Música) nunca obtuvieron un reconocimiento oficial, quedando relegadas a una formación complementaria de tipo pedagógico. Sólo obtuvieron reconocimiento después del franquismo las titulaciones obtenidas a través de los Conservatorios.

- A pesar de haber ejercido la docencia con reconocimiento oficial (nombramientos, plantillas, programas oficiales), su situación no quedaba clara una vez terminado el período franquista, ya que sus 


\section{La educación musical en el franquismo}

propuestas para realizar la docencia se habían realizado a través de la Sección Femenina

- La existencia de 183 profesoras tituladas por el conservatorio y 32 sin titulación de conservatorio que estaban ejerciendo la docencia en Música en la educación Secundaria a fecha de 1977

- Que dicha enseñanza musical se venía impartiendo en los institutos femeninos y mixtos desde 1941

- Que Sección Femenina está dispuesta a renunciar a sus derechos de propuesta de nombramientos, pero también que pretende consolidar a su profesorado titulado cara a la inminente puesta en marcha del Bachillerato Unificado Polivalente por medio de la realización de oposiciones restringidas.

Todo este proceso culminó finalmente en la realización de las primeras oposiciones libres de profesorado para la asignatura de Música en el primer curso de BUP que tuvo lugar en 1984. Hasta entonces, transitoriamente, las plazas de música de los institutos fueron cubiertas indistintamente por el personal titulado anterior y por los profesores licenciados universitarios de otras asignaturas que deseaban completar horario con esta docencia. Finalmente, para la oposición se requirió la titulación del conservatorio regulada en el Real Decreto 1194/1982 de 28 de mayo (BOE de 14 de junio )$^{239}$ que "equipara determinados títulos expedidos por los Conservatorio de música a los de licenciado universitario a efectos de impartir la docencia de Música en los centros de educación secundaria"

${ }^{239}$ http://www.boe.es/g/es/bases_datos/doc.php?coleccion=iberlex\&id=1982/14157 
Capítulo 5. Música e ideología 2: La Sección Femenina 


\section{CAPÍTULO 6. ANÁLISIS MUSICAL DEL CANCIONERO Presentación}

Una vez analizado el entorno educativo y político en que se desenvuelve la educación musical durante el período franquista, es necesario afrontar el análisis del material musical publicado destinado a la educación de los niños.

Es en estas publicaciones donde encontramos la documentación de la música real que se hace en los centros escolares: las canciones.

Tanto Sección Femenina como Frente de Juventudes publican varias recopilaciones de canciones en varios formatos: libros (sin partituras), cancioneros y revistas periódicas.

La publicación musical escolar más importante ajena a las instituciones de Falange es Música y Canto / y // ${ }^{240}$, publicado por la editorial Luis Vives para los centros de Educación Secundaria - en los que tenía una gran presencia la enseñanza religiosa - a partir de la Ley de Ordenación de1953.

A través de estas publicaciones logramos conocer el repertorio que realmente se enseñaba y cantaba en todo el país, sus características musicales y cómo se entiende la educación musical.

\subsection{EL ANÁLISIS MUSICAL: LA ELABORACIÓN DE LAS FICHAS}

El análisis de algunos datos sobre una parte significativa del repertorio nos permite obtener una visión de conjunto y una apreciación cuantitativa del peso específico de algunos componentes del mismo en el conjunto total de la producción musical de Frente de Juventudes y Sección Femenina durante el franquismo.

${ }^{240}$ VARIOS (1960) Música y canto / y //. Zaragoza: Editorial Luis Vives 


\section{La educación musical en el franquismo}

Los datos analizados se presentan como anexo en formato CD (documento en PDF) a este trabajo y contemplan la aplicación mediante formato Acces de la aplicación sistemática de la siguiente ficha de ítems:

\begin{tabular}{|l|}
\hline Título \\
\hline Incipit \\
\hline Autor de la letra \\
\hline Autor de la música \\
\hline Título de la publicación en que aparece recogida \\
\hline Tipo de publicación: Libro/Cancionero/Revista \\
\hline Sección Femenina/ Frente de J uventudes \\
\hline Idioma: Castellano/Catalán/Gallego/Vasco/Latín/Otros \\
\hline Género: Folklore/Gregoriano/Infanti//Himno/Marcha/Danza/Otros \\
\hline Compás inicial: 2/4, 3/4, 4/4, 6/8, 9/8, 12/8, 3/8, 5/8 y otros \\
\hline Tónica \\
\hline Modalidad tonal: Mayor/ menor \\
\hline Modal (no tonal) \\
\hline Intervalo inicial \\
\hline Extensión en no de compases \\
\hline Vocal/Instrumental \\
\hline
\end{tabular}


№ de voces: Monódica/ a 2/ a 3/ a 4

Con o sin acompañamiento instrumental

Origen regional (y si se especifica también provincial)

Tipología (sólo cuando consta: de cuna, de corro, de campo, de campamento, militar, danza : sevillana, isa, jota )

Observaciones: Autor de la armonización, Cancionero de procedencia original

El corpus total analizado está compuesto por 2987 canciones, de las cuales 359 no tienen música, ya que han sido recogidas de libros fundamentales, pero que no incluyen las partituras (como en el caso del Cancionero de Juventudes de J osé de Arriaca)

Los gráficos que se incluyen en este capítulo son una realización Excell de los elementos analíticos recogidos en la base de datos y permiten una visualización general de los resultados obtenidos con el fin de justificar comprensivamente el proceso y permitir obtener unas conclusiones fiables y documentadas mediante la abstracción de los datos cuantitativos y la elaboración de hipótesis y tesis de carácter deductivo.

\subsection{LAS PUBLICACIONES}

\subsubsection{Las publicaciones de Sección Femenina}

La Sección Femenina tiene muy claro desde el primer momento la importancia de extender un repertorio unificado por todo el territorio como forma de crear una conciencia nacional del estado unificadora y aglutinadora de los elementos regionales.

En todas sus ediciones intenta introducir de forma bastante paritaria melodías, danzas y canciones con procedencias de todas las regiones. 


\section{La educación musical en el franquismo}

Las temáticas fundamentales de sus repertorios se refieren a la recuperación y difusión de las canciones folklóricas, las melodías vinculadas a los actos religiosos (gregoriano y villancicos), la creación de un repertorio común de canciones de corro e infantiles, las canciones de cuna, la recuperación de los romances y las canciones antiguas, y también difunde himnos.

Sección Femenina es la institución que más publicaciones musicales realiza durante todo el franquismo. En los primeros años (1940-60) se centran en la publicación de cancioneros y material escolar a través de su revista para maestras y en la última etapa (1960-1975) sus publicaciones adquieren un nivel de calidad mayor (mejor impresión, diseño modernizado, partituras tipografiadas - no manuscritas -, ediciones lujosas de la editorial Doncel, papel de buena calidad) y se dedican a un nuevo campo: la didáctica de la música.

Las publicaciones más notables de la Delegación Nacional de la Sección Femenina son:

Consigna, desde 1941 hasta 1975 la revista mensual para maestras

Cancionero de Sección Femenina (1943)

Mil canciones españolas (1953 y 1976)

Canciones populares para escolares (1954)

Villancicos y canciones religiosas de navidad(1956)

Canciones infantiles (1964)

Cancionero popular español (1968)

Villancicos y canciones religiosas de navidad(1974)

Iniciación a la Educación Musical Preescolar(1975) 


\section{Capítulo 6. Análisis musical del cancionero}

\subsection{1.a Cancionero de Sección Femenina}

Es la publicación más importante de la Sección Femenina durante los primeros años del franquismo. Fruto de una monumental laboral labor de recogida del folklore de los primeros años de la institución, fija en cierto modo el repertorio.

Tuvo una gran divulgación y está considerada como uno de los referentes fundamentales de cancioneros de la época.

Además de la edición original en papel del mismo, también he consultado la reproducción digital de la edición facsimil que se encuentra en la Biblioteca Virtual Miguel de Cervantes en http://www.cervantesvirtual.com

Ficha de catalogación

Título: Cancionero / [de la Sección Femenina del Frente de Juventudes de FET $y$ de las JONS]

Departamento de Publicaciones de la Delegación Nacional del Frente de Juventudes

Año de publicación: 1943

Lugar de publicación: Madrid

№ de páginas: 597

Las canciones están ordenadas por regiones y en un segundo nivel por tipología (de cuna, de campo, de ronda, alalás y danzas, romances y antiguas, religiosas, de corro, villancicos y varios) 
Contiene las siguientes canciones ordenadas alfabéticamente por título

CANCI ONERO SECCIÓN FEMENINA

¿A dónde tienes las mientes? ¿Dónde vas, Mariquilla?

¿Quién te trajo caballero?

A Belén

A Belén marchaba

A donde va

A esta puerta llama un niño

A la nana, nanita

A la orilla del mar

A la rorro, a la rorro

A la rorro, mi niño

A la valerosa

A la Virgen de Bótoa

A la virgen del Carmen

A las armas

A lo alto y a lo bajo

$A$ los árboles altos

A mi me gusta lo blanco

$A$ raiz do toxo verde

A raya do sol

A rula

Abrem'a portiña

Adeste Fideles

Adiós, castillo de flores

Adiós, Málaga

Adiós, non; ti non $\mathrm{m}^{\prime}$ oigas

Agur Estebe

Ai, la le lo

Aire que vienes del alto

Airecillo serrano

Airiños d'a miña terra

Airiños, airiños

Al alba

Al entrar en Sevilla

Al entrar en Sevilla

Al lado de mi cabaña

Al pasar el puente

Al pasar la barca

Al recoger la hoja de la morera

Al salir el sol dorado

Ala ro, a la ro

Alborada
Aldapeko

Alicantina

Alleluia

Anda, corre y ponte

Andregaya

Antífona Sálvanos Domine

Apañando aceitunas

Aquel sombrero de monte

Aquelarre

Arada

Arre, buey

Arrieiros no son homes

Arrorró

Arrorró

Arroyo claro

Asturias

Atiendan, que canta Gila

Aunque la Mancha tenga

Aunque me des veinte duros

Aurtxo txikia

Ay de mi alhama

Ay ondas que eu vin veer

Ay, de la labradora

Ay, Inés

Ay, miña xoiña

Ay, niñas, las tres garridas

Ay, que bien no hay

$A y$, que en esta tierra

$A y$, triste que vengo

Baila, nena

Baile a lo alto

Baile de paloteo

Baile del copeo

Baile del pandero

Barcala, barcalesiña

Barqueiros de ribadavia

Basa txoritxu

Benedicamos

Bolero

Bolero nuevo

Boyero

Brincan y bailan

Buen pastor

Burgalesa 


\section{Capítulo 6. Análisis musical del cancionero}

Burgalesa

Calla, niño, calla

Camina la Virgen

Camina la Virgen pura

Caminando el buen Jesús

Caminito de Avilés

Campanas de Belén

Campaniñas

Canción

Canción de cuna

Canción de cuna

Canción de cuna

Canción de siega

Canción de siega y trilla

Canción vasca

Cançó de Bressol

Canço de mar

Cándida

Canta tú y cantaré yo

Cantaba la rana

Cantar do pandeiro

Cantaréis, pajarillo nuevo

Canteiros e carpinteiros

Cantiga "A creer debemos"

Cantiga "O que pola Virxen"

Cantiga "Porque trobar"

Cantiga de Pontevedra

Cantinela

Canto antiguo

Canto de Altreya

Canto de arrieiros de la Lamosa

Canto de Berce

Canto de cuna

Canto de cuna

Canto de cuna

Canto de Granada

Canto de pandero

Canto de romería

Canto de trilla

Canto de trilla

Canto del país de la Ulla

Canto popular antiguo

Cara al sol

Carcelera

Catalina

Charada
Charada

Chin-chi-rin-chín

Colores de sangre y oro

Columpio

Como queres que navegue

Cómo quieres que te dé

Cómo quieres que tenga

Cómo te va con el ave

Completas

Completas

Con el guri

Con el trípili

Con el vito

Con mi caballo trotón

Conde Lino

Conde Olinos

Coplas de Jorge Manrique

Cordón de Valencia

Córtame un ramito verde

Cuando salí de Marbella

Cuantas sabedes amar amigo

Cuatro lunares tienes

D' una maseta

Damos gracias a ti, Dios

Danza

Danza de arcos

Danza de cintas

Danza pastoril carreña

Danza prima 1

Danza prima 2

De esquileo

De la uva

De lino

De los álamos vengo

Delgadina

Desafío

Día de fiesta

Dile que sospiro e choro

Dime niño, ¿de quién eres?

Dímelo, morena

Dios te salve, Reina y madre

Do, re, mi, fa

Dolores

Don Bueso

Don Bueso

Don Bueso 
Dónde los pondré

Dónde vas a por agua

Dónde vas buen caballero

Dónde vas, gitanilla

Duélete del dolor mío

Dueño de mi vida

Duerme mucho

Duerme, mi niño, duerme

Duerme, niño, duerme

Duérmete niño en la cuna

Duérmete, niñito

Durandarte

Durmete meu neniño

Ea la nana

Echa poca sopa, Juan

El agua de la ermita

El amigo verdadero

El carbonero

El carbonero

El cazador

El delantal

El enamorado y la muerte

El gato

El labrador

El lino

El mariner

El martirio de Santa Catalina

El mio Xuan

El mundo tiene

El nacimiento de Dios

El niño perdido

El niño querido

El pájaro bobo

El pájaro verde

El paño

El pañuelo de seda

El pastorcillo

El patio de mi casa

El pon pon

El prisionero

El ramito

El rosario de la aurora

El ruiseñor

El sagrado nacimiento

El u y el dos

El zurrón del gofio
Elas eran de Laíño

Elisa de Mambrú

Els tres tambors

Embarcóse mi amado

En el portal de Belén

En el portal de Belén

En la cima del monte

En la fuente del rosel

En la raya del monte

En las calles de Reinosa

En París está doña Alda

En pasando

En toda la quintana

En un delicioso lago

Entra mayo

Entre el buey y la mula

Era feliz la niña

Era unha noite

Eres alta y delgada

Eriko oestak

Esta noche es Nochebuena

Esta noche no alumbra

Estando cosendo

Este é o tempo

Estreliña do luceiro

Excelso Dios

Fandango

Fandanguillo

Foliada

Folías

Folías

Forosa

Fuego y nieve despiden

Fui al Cristu

Gabazco kantua

Gabon Kantak

Gatatumba

Gitana, gitana

Granadina

Gritos de la morenica

Guerra de Africa

Ha visto usted a mi marido

Habas verdes

Has de cantar

Hermosa Santa ana

Himno eucarístico 


\section{Capítulo 6. Análisis musical del cancionero}

I sabel

I te missa est

J ota castellana

Jota de quintos

J ota de segadores

J ota del carrer

Juglaresca

Kataliñ

Kyrie Fons bonitatis

L'esquerpa

L'hereu Riera

La adoración de los Reyes

La aldeana

La alegría del querer

La cadena del amor

La carbonerita de Salamanca

La casa

La Clara

La cucaracha

La despedida

La doncella

La doncella guerrera

La enamorada

La espigadora

La infanta encantada

La madre abadesa

La manzana nació verde

La mañana de San Juan

La meva chiqueta

La molinera

La muñeca

La niña adormecida

La noragüena

La pastora

La pastoreta

La pastoreta 2

La praviana

La sinda

La tarara

La tortolita

La ví llorando

La Virgen va caminando

La Virgen va caminando

La Virgen va caminando

La Virgen y San José

La viudita del conde de Cabra
La viudita del conde laurel

Labradores de Castilla

Las flores del cementerio

Las mis penas, madre

Las mozas de porqueriza

Las niñas de merino

Las ovejuelas

Las palabras, amor mío

las torrás

Las tres cautivas

Las tres cautivas

Las tres niñas

Las tres niñas

Leonesa

Levántate morenita

Lo que se goza escuchando

Lo, lo, lo

Los caracoles

Los cordones

Los gallos cantan

Los mayos

Los mozos de Monleón

Los muleros

Los pastores

Los pastores

Los toritos de Calera

Malaguita. Malaguita

Malo es de guardar

Mambrú se fue a la guerra

Manda d'ei conmigo

Maneo

Manolita, tu chaleco

Mañanaitas de mayo

María, miña María

Maruxiña, ao teu refaixo

Mary Blanca

Más vale trocar placer

Matsaren orpotik

Mayo

Me casó mi madre

Me llamaste morenita

Me quisiste

Me voy, madre

Menga, la del bustar

Mi abuelo tenía un huerto

Mi carbonero, madre 
Mi pensamiento

Mi primer amor

Milano

Miña nay por me casare

Miña Virxen

Mira, mira

Míralo, por allí viene

Misa de angelis. Agnus

Misa de angelis. Credo

Misa de angelis. Credo

Misa de angelis. Gloria

Misa de angelis. Kyrie

Misa de angelis. Sanctus

Molinero, maquilandero

Molinero, molinero

Monjita del monasterio 1

Monjita del monasterio 2

Montanyes del Canigó

Montanyes regalaades

Motete de comunión

Muiñeira

Muñeira para gaita

Muñeira para gaita

Muriéndose de risa

Nadie plante su parra

Nana

Nana de Málaga

Nanita, nana

Ni tú, ni periquito

No hay tal andar

No la llames

No le daba el sol

No lloréis, mis ojos

No se puede llamar fe

No se va la paloma

No te compongas

Non che quero

Non me mires d'ese modo

Non me tires

Nona Responsorio

Nosa Señora da guía

O cantar

O neniño está no berce

0 rio cuando vai cheo

O sol preguntou

Ojitos míos, llorad
Ojos morenicos

Olé ahí

Olé, son de mi pare

Ondas do mar de Vigo

Oración del Frente de

Juventudes

Orellana está en un cerro

Otoñal

Pajarito que cantas

Parado de Valldemosa

Parranda del campo de Lorca

Parranda del tres

Parranda llamada del uno

Pastorcito que te vas

Pastores, venid

Páxaro que vas voando

Petenera antigua

Piedrezuca de tu calle

Polo

Popular de Castilla

Por bonitas que sean las flores

Por la Sierra Morena

Por unos puertos arriba

Prima Responsorio

Pues que dejas el canto

Qu'estás besada

Qué llevas en el pico

Que llueva

Qué tienes por mi persona

Quen dirá la carbonerita

Quiero y adoro

Quisiera ser tan alta

Quita la mula rucia

Ramón del alma mía

Redoble

Regueifa

Rema, barqueriño, rema

Remendé

Rey moro tenía una hija

Rin, rin

Romance de la condesita

Romance del Conde Linos

Romance histórico

Romancillo

Romerico

Ronda 


\section{Capítulo 6. Análisis musical del cancionero}

Rosalinda

Rosalinda

Ruliño

Sal a bailar, mnorenita

Sale mi niña

Salve Regina

San Antonio y los pajaritos

San J osé

San Serenín

Santo Domingo

Santo santo

Se van los quintos

Segador, segadorzuco

Seguidillas del J o y del Ja

Serrana

Serranilla

Serranilla de la zarzuela

Sexta Responsorio

Si de León me ausento

Si de rama en rama

Si la nieve resbala

Si quiés que cante

Si se va la paloma

Si te casaras conmigo

Si tuviéramos aceite

Sierra de Mariola

Sobre tu cunita

Soleá

Soy de Mieres

Sube un alto caballero

Tan buen ganadico

Tantum ergo

Tantum ergo

Tarde de mayo

Tengo de pasar el puerto

Tengo de subir

Tengo un arbolito

Tengo un galán

Tercia Responsorio
Terra, terriña

Tienes la cara, mañica

Tienes una garganta

Toda la noche

Toda mi vida os amé

Torneos

Tres hojitas madre

Tres morillas

Tres morillas

Tres pregones mañaneros

Tu cabeza

Tus ojos, morena

Txeru

Un rey tenía tres hijas

Una estrella

Una matinada

Una pandereta suena

Una vieja y un candil

Una, dos y tres

Unha noite

Unos consejos

Valencianita del alma

Vámonos a León

Vamos cantando

Vente sentar a meu lado

Verdiales

Vestido nuevo

Villancico andaluz

Vinde nenas

Vinde picariñas

Vite, vite, vite

Viva Aragón

Viva Sevilla

Vivan los aires morenos

Y de alhelíes

Ya los días son cortos

Yo no soy la del cántaro 


\section{La educación musical en el franquismo}

\subsection{1.b Mil canciones españolas}

Es el otro gran referente como cancionero de Sección Femenina.

Aunque consta que existe una edición anterior en 1953, la versión que se ha utilizado para la base de datos - por ser la más completa - es la edición de 1978, en dos volúmenes, realizada por la Dirección General de Desarrollo Comunitario del Ministerio de Cultura.

Ficha de catalogación

Título: Mil canciones españolas / [volúmenes I y II]

Editorial Almena

Año de publicación: 1978

Lugar de publicación: Madrid

no de páginas: $565+218=783$

El primer volumen está dedicado a las canciones populares de España, clasificadas por regiones y se le aplica una clasificación secundaria por tipología (de cuna, de corro, de campo, danza y varios).

El segundo volumen está dedicado a villancicos, canciones antiguas y romances y canciones infantiles (de corro)

Contiene las siguientes canciones ordenadas alfabéticamente por título

\section{L CANCI ONES}

¡Ene, qué risas hisimos!

¿Cómo quieres que tenga?

¿Dónde vas Alfonso XII?

¿Dónde vas Mariquilla?
¿Ha visto usted a mi marido?

A Belén marchaba

A Belen $n$ 'en vulim anar

A dónde tienes las mientes 
A la ciutat de Napols

A la nanita, nanita

A la ro, a la ro

A la rorro, al arorro

A la rorro, mi niño

A la una, a las dos, a las tres

A la valerosa

A la víbora, víbora del amor

A la virgen del Carmen

A la voreta del mar

A las armas

A las orillas del Arga

A lo alto y a lo bajo

A los árboles altos

A mí me gusta lo blanco

A raiz d'o toxo verde

A rula

A tu puerta hemos llegado

Abrem'a portiña

Adiós, castillo de flores

Adónde va

Agora non

Agur jaunak

Aire que vienes del alto

Airecillo serrano

Airiños 2

Airiños d'a miña terra

Al aire sí, al aire no

Al alba

Al aldo de mi cabaña

Al alimón, al alimón

Al pasar el puente

Al pasar la barca

Al pasar la barca

Al pasar por Sevilla

Al salir el sol dorado

Aldapeko

Aldapeko 2

Alsa Bayona

Ama

Ambó ható

Amigas, buenas tardes

Amor mío si te vas

Anda diciendo tu madre
Anda, corre y ponte

Andregaya

Angeleta

Anoche me salió un novio

¡au, chúngala!

Apañando aceitunas

Aquel sombrero de monte

Arada

Arre, buey

Arrieiros no son homes

Arrorró

Arrorró

Arroyo claro

Asturias

Atzo, atzo, atzo

Aunque la Mancha tenga

Aunque me des treinta

reales

Aur gaisua lo eta lo

Auré, auré

Aurtxoa seaskan

Ay de mí Alhama

Ay niñas, las tres garridas

Ay que non hay

Ay triste que vengo

Ay, de la labradora

Ay, miña xoiña

Ay, que en esta tierra

Ay, que murallas tan altas

Ay, Sálvora

Baila, nena

Barqueiros de Ribadavia

Basa txoritxu

Boga, boga

Bolero de Algodre

Bolero nuevo

Brincan y bailan

Buen pastor

Burgalesa

Calla, niño, calla

Camín del baile

Caminito de Avilés 1

Caminito de Avilés 2

Camiña a Virxen

Camiña Don Sancho

Camiña Don Sancho 
Campanas de Belén

Campaniñas

Campito del moro

Canción

Canción danza del pandero

Canción de carnaval

Canción de carro 1

Canción de carro 2

Canción de cuna 1

Canción de cuna 2

Canción de cuna 3

Canción de ronda 1

Canción de ronda 2

Canción de ronda y arada

Canción de siega

Canción de siega y trilla

Canción de trilla

Canción del romerito

Canço d' hivern

Cançó de Bresol

Canço de Bressol

Cançó del lladre

Canço del sapo

Cándida

Canta tú y cantaré yo

Cantando van los pastores

Cantar de amigo

Cantar de amigo

Cantar do pandeiro 1

Cantar do pandeiro 2

Cantaréis, pajarillo nuevo

Cantgia de Alfonso $X$

Cantiga de Alfonso $X$

Cantiga de Alfonso $X$

Cantiga de Marcon

Cantiga de Pontevedra

Canto antiguo

Canto de arrieiros de la

Lamosa

Canto de berce

Canto de cuna

Canto de cuna

Canto de cuna

Canto de Granada

Canto de los anisicos

Canto de nochebuena
Canto de trilla

Canto de trilla

Canto gallego

Canto gallego de Martin

Godas

Canto gallego de Martín

Godas

Canto popular antiguo

Cariño mío

Carrasclás

Carta del rey ha venido

Catalina

Charrada

Chin chi rin chin

Chin, chin, chirriquitín

Como la flor

Cómo quieres que la yedra

Cómo quieres que te dé

Cómo retumba el pandero

Cómo te va con el ave

Con el guri

Con el tríipili

Con el vito

Con ese collar de perlas

Con guitarras y almireces

Conde Lino

Coplas de columpio

Coplas de J orge Manrique

Cordón de Valencia

Cordoncillo se casa

Correo que te pilla el toro

Corta el cerco que tienes

Córtame un ramito verde

Cristo sortzenduzu gaur

Cuando los pastores vieron

Cuando salí de Marbella

Cuatro lunares tienes

D'a miñ 'aldea

Danza de arcos

Danza pastoril carreña

Danza prima 1

Danza prima 2

De lino

De los álamos vengo

Demos gracias a ti, Dios

Dentro la zarza 


\begin{tabular}{|l|}
\hline Desafío \\
\hline Despedida \\
\hline Día de fiesta \\
\hline Dicen que larga ausencia \\
\hline Dicen que no la quieres \\
\hline Dicen que no me quieres \\
\hline Dicen que no nos \\
queremos \\
\hline Dicen que te casas \\
\hline Dime niño, de quién eres \\
\hline Dímelo morena \\
\hline Dolores \\
\hline Don Bueso \\
\hline Don Bueso \\
\hline Don Bueso 2 \\
\hline Dónde los pondré \\
\hline Doneu-me el guirlando \\
\hline Dos hombres tuvo Navarra \\
\hline Duélete del dolor mío \\
\hline Duerme mi niño, duerme \\
\hline Duerme, niño, duerme \\
\hline Duermete meu neniño \\
\hline Duérmete, niño \\
\hline Duérmete, niño en la cama \\
\hline Durandarte \\
\hline Ea la nana \\
\hline Echa María \\
\hline Echa poca sopa, Juan \\
\hline Edurra \\
\hline El agua de la ermita \\
\hline El amigo verdadero \\
\hline El bon J esuset \\
\hline El campanar de la Seu \\
\hline El canto del milano \\
\hline El carambelo \\
\hline El carboner \\
\hline El carbonero \\
\hline El carbonero \\
\hline El carbonero \\
\hline El cazador \\
\hline El concón, señores \\
\hline El Conde Olinos \\
\hline El cribero \\
\hline El enamorado y la muerte \\
\hline El galant desairat \\
\hline El gato \\
\hline
\end{tabular}

\begin{tabular}{|l|}
\hline El gavilán \\
\hline El juego chirimbolo \\
\hline El labrador \\
\hline El lino \\
\hline El mandilín \\
\hline El maridet \\
\hline El mariner \\
\hline El martirio de Santa \\
Catalina \\
\hline El Mayo \\
\hline El mestre \\
\hline El mestre "Bella Escusa" \\
\hline El milano \\
\hline El mio Xuan \\
\hline El mundo tiene \\
\hline El nacimiento de Dios \\
\hline El niño perdido \\
\hline El noi de la mare \\
\hline El pájaro bobo \\
\hline El pájaro verde \\
\hline El paño \\
\hline El pañuelo de seda \\
\hline El pastorcillo \\
\hline El patio de mi casa \\
\hline El patio de mi casa \\
\hline El periñal \\
\hline El picotín \\
\hline El ramito \\
\hline El rosario de la aurora \\
\hline El rossinyol \\
\hline El sagrado nacimiento \\
\hline El tío Babú \\
\hline El tío Pep \\
\hline El triquitrí \\
\hline El zurrón del gofio \\
\hline Elas eran de Liaño \\
\hline Elisa de Mambrú \\
\hline Els estudiants de Tolosa \\
\hline Els tres tambors \\
\hline En Astudillo tengo mi \\
querer \\
\hline En el balcón de palacio \\
\hline En el lavadero \\
\hline En el portal de Belén \\
\hline En el puenteGalilea \\
\hline En esta calle hay un pino \\
\hline
\end{tabular}


En esta plazuelita

En la calle del Turco

En la pila de Ronda

En la raya del monte

En las calles de Reinosa

En las orillas del Ebro

En los montes de Navarra

En medio de la plaza

En París está Doña Alda

En San Vicente

En toda la quintana

Engánchate

Entra Mayo

Era de nogal

Era unha noite

Eres alta y delgada

Eres guapa chica

Erico bestak

Est noche es Nochebuen

Esta noche es nochebuena

Esta noche no alumbra

Esta noche, caballeros

Estaba el señor Don Gato

Estaba la pájara pinta

Estando cosiendo

Estando una niña

Este corro es un jardín

Este e o tempo

Estreliña do luceiro

Fandango

Fandanguillo

Fiesta en la aldea

Fill de Deu

Folías

Forosa

Fuego y nieve despiden

Fuente clara

Fuentecilla

Fui al Cristu

Gabazko kantua

Galaitxo txiki

Gasta la molinera

Giraldilla

Goiko mendiyan

Goizeko izarra

Granadina
Habas vwerdes

Hay estrella, sol y luna

Hay un puchero de miel

Hermosa Santa Ana

Hi ha neu a la montanya

Hoy es día de todos

Imos todos para Belén

Ja plora el xic

Jardinerita que entraste

Jo tinc un burro

Jo vaig i vinc

J ota alicantina

J ota castellana

J ota de Guadalupe

Jota de romería

J ota de segadores

J ota del carrer

Jota del U y del dos

J ota olivarera

J otilla de Olivenza

Juglaresca

J unto al reino de Judea

Kapitan pilotu

Kataliñ

L'Antonia

L'esquerpa

L'hereu Riera

$L^{\prime}$ heura i el grevol

L'ocellet

La adoración de los Reyes

La aldeana

La alegría del querer

La barraqueta

La calle ancha

la carbonerita de

Salamanca

La casa

La Clara

La cucaracha

La dama d'Aragó

La doncella guerrera

La donçelleta

La enamorada

La filadora

La filla del carmesí

La huevera 
La infanta encantada

La jota de los quintos

La jota quiso cantar

La llantia del rei moro

La manzana nació verde

La mañana

La mañana de San Juan

La Mare de Deu

La melitona

La meva dhiqueta

La molinera

La mort de la nuvia

La muntanya venerada

La muñeca

La noia d'Empordá

La noragüena

La pastora

La pastoreta

La pastoreta

La pava, la pava

La petenera

La praviana

La rana

La sinda

La tarara

La tortolita

La vi llorando

La Virgen de las Nieves

La virgen va caminando

La virgen va caminando

La virgen va caminando

La virgen y San José

La viudita del conde de

Cabra

La viudita del Conde Laurel

Labrador es mi amor

Labradores de Castilla

Las espadas de un cadete

Las mis penas madre

Las ovejuelas

Las torras

Las tres cautivas

Las tres cautivas

Las tres niñas

Les folies

Levántate morenita

\begin{tabular}{|l}
\hline Lo,lo,lo \\
\hline Los aires de Lima \\
Los caballos \\
Los chopos \\
Los cordones \\
Los gallos \\
\hline Los gallos están cantando \\
Los mayos \\
\hline Los mozos de Monleón \\
\hline Los muleros \\
\hline Los pastores \\
\hline Los pastores \\
\hline Lotan dago zure \\
\hline Maitasun oñazea \\
\hline Malaguita, malaguita \\
\hline Malo es de guardar \\
\hline Mamá, si me dejas ir \\
\hline Mambrú se fue a la guerra \\
\hline Manolita. tu chaleco \\
\hline Mañana me voy a Palma \\
\hline Mañana por la mañana \\
\hline Mañana, mañanita \\
\hline Maragata popular \\
\hline Mareta \\
\hline María \\
\hline María Rosa \\
\hline Mariagneta \\
\hline Marieta del molí nou \\
\hline Maritxu nora zuaz \\
\hline Maruxiña, ao teu refaixo \\
\hline Mas vale trocar placer \\
\hline Matsaren orpotik \\
\hline Me casó mi madre \\
\hline Me llamaste morenita \\
\hline Me puse a considera \\
\hline Me quisiste \\
\hline Menga, la del Bustar \\
\hline Mi abuelo tenía un huerto \\
\hline Mi amante cuando se fue \\
\hline Mi carbonero, madre \\
\hline Miña nay por me casare \\
\hline Miña Virxen \\
\hline Mira, mira \\
\hline Molinero, maquilandero \\
\hline Molinero, molinero \\
\hline Molo molondrón \\
\hline
\end{tabular}


Montanyes del Canigó

Montanyes regalades

Moreniñas por te vere

Muñeira 1

Muñeira para gaita 1

Muñeira para gaita 2

Muriéndose de risa jay,

chúngala!

Nadie plante su parra

Nana de Málaga

Nana, naneta

Nanita, nana

Neure senar

No hay carretera sin barro

No hay tal andar

No la llames

No le daba el sol

No lloréis mis ojos

No me diga usted morena

No me tires del manto

No se va la paloma

No se va la paloma

No voy por agua

Nochebuena, nochebuena

Non me mires d'ese modo

Non me tires

O cantar

O neniño está no berce

0 sol preguntóu

Ojos morenicos

Olé ahí

Orellana está en un cerro

Orra or goiko

Os mozos de San Martiño

Osena y media

Otoñal

Pajarito que cantas

Pakea

Palmero sube a la palma

Papá, si me deja usted

Parado de Valldemosa

Parado de Valldemosa 2

Parranda del tres

Parranda llamada del uno

Pastorcito que te vas

Pastores, venid
Pastoresta, qué li portes

Páxaro que vas voando

Petenera antigua

Piedrezuca de tu calle

Polo

Popular de Asturias

Popular de Castilla

Por bonitas que sean las

flores

Por la Sierra Morena

Por ser aplicadita

Por unos puertos arriba

Qu'estás besada

Que llueva

Que se fuera a retirar

Que sonaba la campanilla

Que te tengo que dar

Qué tienes por mi persona

Quen dirá la carbonerita

Quién te trajo, caballero

Quisiera ser tan alta

Quita la mula rucia

Quítate de esa esquina

Ramón del alma mía

Redoble

Regueifa

Remendé

Remerino

Rey moro tenía una hija

Rin, rin

Romance de la condesita

Romance del Conde Lino

Romance gallego

Romance histórico

Romancillo

Romerico

Ronda

Rondeña

Rosalinda

Saeta

Saeta

Sal a bailar, morenita

Sal mirandillo

Salamanca la Blanca

San Antonio y los pajaritos

San José 
San José, toma este niño

San J uan Ante-Portaletaña

San Pantaleón

San Serení, a la buena

buena vida

San Serenín

San Serenín del Monte

Santo Domingo 1

Santo Domingo 2

Santo Domingo 3

Se van lo quintos

Segador, segadorzuco

Seguidillas canarias

Seguidillas del Jo y del Ja

Señor zapaterito

Señoritas ¿a dónde van

sutedes?

Serra de Mariola

Serrana

Serrana

Serrana

Serranilla

Serranilla de la zarzuela

Si canto me dicen loco

Si chove deixa chovere

Si chove deixa chovere 2

Si de León me ausento

Si de rama en rama

Si la nieve resbala

Si n' eren tres ninetes

Si quieres que te cantemos

Si quies que cante

Si se va la paloma

Si tuviéramos aceite

Sobre tu cunita

Sobre tu cunita

Soleá

Son de mi pare

Soy de Santurce

Soy el farolero

Soy la reina de los mares

Sube un alto caballero

Súbela, molinera

Tajaraste

Tan buen ganadico

Tanganillo
Tatareta

Tengo de pasar el puerto

Tengo de subir

Tengo un arbolito

Tengo un galán

Tengo, tengo, tengo

Tienes la cara mañica

Tienes una garganta

Titana amorosa

Tonada de ronda

Toqu' es timbal

Torneos

Tres hojitas 2

Tres hojitas, madre

Tres moricas

Tres morillas

Tus ojos, morena

Txarmangarri bat badut

Txarmangarria zera

Txeru

Txiribogin andrea

Un cuc de terra

Un francés se vino a

España

Un rey tenía tres hijas

Una natinada fresca

Una pandereta suena

Una tarde de Mayo

Una tarde salí al campo

Una vieja muy vieja

Una vieja y un candil

Unha noite

Urrundik

Vente a sentar a meu lado

Verdiales

Villancico popular

Vinde nenas

Vinde picariñas

Vite, vite, vite

Viva León

Viva Sevilla

Vivan los aires morenos

Vou veri Vou

Y de alhelíes

Ya está el pájaro verde

Ya no quiere mi madre 
Ya se murió el burro

Ya sé que estás
Yo me quería casar

Zapateado

\subsection{1.c Consigna}

\section{Es la Revista para maestras de la Sección Femenina de Falange} Española de las FET y de las JONS. Su primer ejemplar aparece en Diciembre de 1940 y se publica sin interrupción y una periodicidad mensual hasta el año 1977.

Aunque su formato sufre varias transformaciones y mejoras (es evidente que a partir de los años 60 se produce una notable mejora en la calidad del papel, la tipografía de las partituras y el formato se hace más grande) mantiene una misma línea editorial de orientación pedagógica destinada tanto a las maestras como a las Instructoras de Sección Femenina que tenían encomendadas las tareas de educación musical.

Tiende a mezclar los elementos educativos formales y no formales y no siempre distingue claramente entre el material escolar y el destinado a los albergue y, centros medina.

A partir de los años 60 se observa una clara transformación desde la predominancia del folklore (canciones y temas teóricos) e historia de la música (la serie de artículos Cada autor y su obra en su época y en su ambiente de Rafael Benedito así lo demuestran) hacia una educación musical más centrada en las cuestiones metodológicas (en 1958 aparece un artículo sobre Didáctica musical de Carmen Queralt ${ }^{\mathbf{2 4 1}}$, al que siguen La lección de la canción ${ }^{242}$ ) y en

\footnotetext{
${ }^{241}$ QUERALT, C. (1958) "Didáctica musical" en Consigna (Revista para las maestras de Sección Femenina), Noviembre de 1958 , pag. 41-44.

${ }^{242}$ Editorial no 240 de Consigna (Revista para las maestras de Sección Femenina), Abril de 1961, pag. 1 y 2
} 


\section{Capítulo 6. Análisis musical del cancionero}

las aplicaciones didácticas del área de Expresión dinámica en la EGB (Normas para las maestras orientadas a la formación musical de las escolares ${ }^{243}$ )

Además de las canciones, que siempre están presentes como material fundamental de la educación musical, la parte de conocimientos más teóricos también se explicita a través de series de artículos temáticos. Así, aparecen colecciones periódicas sobre El folklore musical en España (1941-1943), Una cruzada necesaria y Bailes regionales (1943-44), Guía pedagógica e interpretativa del Cancionero o El cancionero y su interpretación y La voz humana (1944), La música en el hogar y Morfología de la música (1945-46), la ya citada Cada autor y su obra en su época y en su ambiente (desde 1946 hasta 1953)

El inicio del programa de Conciertos para la juventud hace que se introduzcan también series sobre las familias de instrumentos y los grandes géneros musicales desde el año 1966.

En el año 1965, Consigna dedica un número monográfico en su Sección de Pedagogía a la Educación Musical con colaboraciones de Montse Sanuy ${ }^{244}$, Antonio Ramírez Miguel $^{245}$, Octavio Aparicio ${ }^{246}$, Mario García Acevedo ${ }^{247}$, Helga Hertz de Epstein ${ }^{248}$, Amalia Roales-Nieto ${ }^{249}$

\footnotetext{
${ }^{243}$ VARIOS. "Normas para las maestras orientadas a la formación musical en las escolares" en Consigna (Revista para maestras de Sección Femenina), Octubre de 1946, pag. $36-38$ y con continuidad hasta 1963)

${ }^{244}$ SANUY, M (1965) "La educación musical" en Consigna (Revista para maestras de Sección Femenina), Abril de 1965, pag. 10-11

245 RAMIREZ ANGEL, A. (1965) "El coro" en Consigna (Revista para maestras de Sección Femenina), Abril de 1965, pag. 5-9

${ }^{246}$ APARICIO, O. (1965) "La voz y el oído del niño" en Consigna (Revista para maestras de Sección Femenina), Abril de 1965, pag. 12-14

${ }^{247}$ GARCÍA ACEVEDO, M (1965) "Los principios fundamentales en la Educación Musical general y básica" en Consigna (Revista para maestras de Sección Femenina), Abril de 1965, pag. 15-19

${ }^{248}$ HERTZ DE EPSTEIN, H (1965) "Impostación e higiene de la voz infantil" en Consigna (Revista para maestras de Sección Femenina), Abril de 1965, pag. 20-23

249 ROALES NIETO, A. (1965) "El canto popular como valor social" en Consigna (Revista para maestras de Sección Femenina), Abril de 1965, pag. 34-37
} 


\section{La educación musical en el franquismo}

El año 1966 termina con una serie de tres artículos de Ma Rosa Kucharski ${ }^{250}$ sobre los cuestionarios de música que incluyen dudas y soluciones en la aplicación escolar de la enseñanza de la música a nivel escolar por los maestros, que tendrá continuidad a lo largo de todo el año 1967 y 1968

En el número de Abril de 1974, la música se convierte en elemento de portada, mostrando la relación entre la formación clásica de programa de Conciertos de la juventud y la enseñanza musical escolar: un contrabajista prfoesional toca acompañado de una niña en edad escolar que interactúa con un instrumento de percusión no afinada (ristra de cascabeles).

El área de expresión dinámica de la Ley de 1970 se plasma perfectamente en el artículo de Ana Espino ${ }^{251}$, en el que se reflejan actividades de movimiento, la danza y la expresión corporal vinculadas a la enseñanza de elementos del lenguaje musical.

La revista Consigna tuvo una amplia difusión en las Escuelas Nacionales de Educación Primaria (de EGB a partir de 1970). Su carácter dinámico y de adaptación a los tiempos se muestra claramente en los cambios que presenta a lo largo de los 35 años de publicación continuada.

Aunque no he podido consultarla en su totalidad, he logrado digitalizar para su estudio, el fondo -incompleto - que se conserva en el Castillo de la Mota (Medina del Campo. Valladolid) y que consta de los siguientes registros:

Año

1941

Diciembre. Número inicial

1942 Mayo, junio, julio, agosto, septiembre, octubre, noviembre y diciembre Enero, febrero, marzo, abril, mayor, junio, julio, agosto,

\footnotetext{
${ }^{250}$ KUCHARSKI, R. (1966) “Comentario alrededor de los cuestionarios nacionales de Enseñanza Primaria" en Consigna (Revista para maestras de Sección Femenina), Noviembre y diciembre de 1966 y todo el año de 1967.

${ }^{251}$ ESPINO, A. (1974) "1a Etapa de la Enseñanza General Básica: el ritmo binario" en Consigna (Revista para maestras de Sección Femenina), Octubre de 1974, pag. 19-21
} 


\section{Capítulo 6. Análisis musical del cancionero}

septiembre, octubre y noviembre

1944

Completo

1945

Febrero, agosto y diciembre

Abril, julio, agosto, septiembre, octubre, noviembre y diciembre

Marzo, abril, mayo, septiembre, octubre, noviembre y diciembre

Completo

Febrero, marzo, abril, mayo, junio, julio, agosto, septiembre y noviembre

Febrero, marzo, abril, mayo, junio, julio, agosto, septiembre, octubre, noviembre y diciembre

Julio, septiembre, octubre y diciembre

Completo

Marzo, abril, mayo, junio, julio, septiembre, octubre, noviembre y diciembre

Enero, febrero, marzo, abril, mayo, junio, julio, septiembre, octubre, noviembre y diciembre Marzo, julio-agosto y septiembre

Enero, febrero, marzo, abril, mayo, junio y julio-agosto

Completo

Completo

1960

Enero, febrero, marzo, abril, mayo y junio

Completo

1962

Completo

Completo

Abril, marzo, junio, septiembre, octubre, noviembre y diciembre

Completo

Enero, febrero, marzo, abril, mayo, junio, julio-agosto, septiembre, octubre y noviembre

Enero, abril, mayo, junio, julio-agosto, septiembre, octubre y diciembre 
1970

Abril

1971

Mayo y noviembre

1972

Septiembre

1973

Noviembre y diciembre

1974

Enero, febrero, marzo, abril, julio, octubre, noviembre y diciembre

1975

Enero

El material consultado finalmente contiene las siguientes canciones ordenadas alfabéticamente por título

\section{CONSI GNA}

A Atocha va una niña

A Belén llegan

A Belén pastorcitos

A Belén van caminando

A cantar

A esta puerta llama un niño

A fonte do Salgueiriño

A la cinta, cinta de oro

A la ciutat de Napoli

A la feria de Airoa

A la la

A la orilla de la mar

A la puerta del molino

A la rama, a la rama

A la víbora, víbora del amor

A la voreta del mar

A mi burro

A mi burro

A mi me gusta lo blanco

A vinticinc de desembre

Aceitera, vinagrera

Achia mochia

Ad laudes

Ad regias agni dapes

Adeste fideles

Adeste fideles

Adorote devote
Adriana tiene un jardín

Aeterne rex altissime

Aeterne rex altissimo

Agua menudita

Agua menudita

Aire que vienes del alto

Airiños da miña terra

Aitak eman daut

Al alimón

Al alimon, al alimon

Al alimón, al alimón

Al chiguiri pun

Al chirigui pum

Al corro de la hoja

Al lado de mi cabaña

Al pasar la barca

Al pasar la barca

Al pasar la barca

Al pasar la barca

Al pasar por Sevilla

Al salir el sol dorado

Al salir el sol dorado

Albada

Albada

Alegría, alegría

Alegría, caballeros

Alirón

Alirón

Alirón

Allá en Belén 
Alleluia

Alleluia psallite

Alleluia psallite

Amanece

Ambo ato

Ambo ato

Anbo hato

Anda diciendo tu madre

Anda diciendo tu madre

Anda diciendo tu madre

Angulé o Margandu

Antifona

Antifona

Antifona a le purificacion

de Marie

Antífona del domingo de ramos

Antífona del sábado santo

Antífonas mariales

Anuncio de la primavera

Anuncio de la primavera

Aquel sombrero de monte

Aquelarre

Arbolito, arbolito

Arin, arin, kristanar

Arre buey

Arre caballito

Arre caballito

Arriba camaradas

Arrojóme las naranjicas

Arrorró

Arrorró

Arroyo claro

Arroyo claro

Artizara zeruan

Aserrín, aserrán

Asómate a esa ventana

Atabales tocan

Ator, ator, mutill

Attende domine

Audi benigne

Audi benigne

Aunque la Mancha tenga

Aura eguizu loto, loto

Auré, auré

Auré, auré
Ave Maria

Ave maria

Ave maria

Ave Maria

Ave María

Ave María

Ave María

Ave maris stella

Ave maris stella

Ave maris stella

Ave mater

Ave mater salvatoris

Ave mater salvatoris

Ave Regina caelorum

Ave Regina caelorum

Ave regina caelorum

Ave verum

Ay de la labradora

Ay del chiquirritín

Ay labradora

Ay Pachín, cásate conmigo

Ay qué gracioso

Ay, guindilla, guindilla

Ay, niñas, las tres garridas

Ay, que en esta tierra

Ayer te vi en el río

Baile de la carrasquilla

Baile de las carrasquillas

Baile de montaña

Ball del ciri

Baxa tosritxu

Beata dei genitrix Maria

Belen'en sortu zaigu

Bendición del miércoles de

ceniza

Benedictus deus

Berducido

Berducido, berducido

Beso tu tierra, España

Binbilin-bonbolon

Bolero

Burgalesa

Caballo de cartón

Caídos por Éspaña,

presentes

Calla niño, calla 
Calla, niño, calla

Calle del carmen

Camina la Virgen pura

Caminaba la aurora

Caminaba la aurora

Caminito de Avilés

Caminito de Avilés

Campanas de Belén

Campanín

Campanita del lugar

Campito del moro

Canción

Canción asturiana

Canción de corro

Canción de corro

Canción de corro

Canción de corro

Canción de corro

Canción de cuna

Canción de cuna

Canción de cuna

Canción de cuna

Canción de cuna

Canción de cuna

Canción de cuna

Canción de cuna

Canción de cuna

Canción de mayo

Canción de primavera

Canción de Reyes

Canción de siega y trilla

Canción de vendimia

Canción de vendimia

Canción gallega

Canción infanitl

Canción infantil de corro

Canción popular

Canción vasca

Cançó de I'infant

Canço del Bressol

Cansó del sapo

Canta la griva

Cantaba un rano

Cantaba un rano

Cantaba un rano

Cantar de amigo
Cantico de María

Cantiga antigua

Cantiga de Alfonso $\mathrm{X}$

Canto de aguinaldo

Canto de boda

Canto de la sierra de

Cameros

Canto de la trilla

Canto de los mayos

Canto de mayo

Canto de romería

Canto de tercia del día de epifania

Canto de tercia del día de epifanía

Canto de trilla

Canto para pedir la paz

Carbonerita de Salamanca

Carbonerita de Salamanca

Carretera abaxo va

Carta del rey

Casose Maruxa

Catalina

Chalaneru

Chalaneru

Chin chin chiriquitín

Chin chin chirriquitín

Chin, chin, chirriquitín

Chinn chi rin chin

Christum regem

Christum regem

Churrusca

Cieerra la ventana

Cinco duros me costó

Claro abril resplandeció

Clo, clo

Cómo queres que navegue

Cómo quieres que tenga

Cómo quieres que tenga

Cómo quieres que tenga

Cómo quieres que tenga la

cara blanca

Cómo quieres que tenga la cara blanca

Como se colean as troitas

Como vengo de la sierra 
Como vives tan alta

Como vives tan alta

Como vives tan alta

Completas

Comunión

Con el guri

Con el guri

Con el guri

Con el picotín

Con el trípili

Con el trípili

Con ese collar de perlas

Con ese collar de perlas

Concordi laetitia

Conquista de Alhama

Cor Jesu sacratissimum

Cordón de Valencia

Coros y danzas en

Argentina

Credo

Crucem tuam

Crudelis Herodes

Crudelis Herodes

Crux Fidelis

Crux fidelis

Crux fidelis

Cu cú cantaba la rana

Cu cut

Cuando los carpinteros

Cuando los carpinteros

Cuándo me vas a dar el cordón

Cuándo me vas a dejar el cordón

Cuando sales al campo

Cuatro vueltas de corales

Cubre tu pecho de azul español

Cucú cantaba la rana

Cucú cantaba la rana

Dale, minerito, dale

Dame confites

Dancemos

Danza prima

De codín

De codín, de codán
De codín, de codán

De la uva

De los álamos vengo

De los álamos vengo

De los árboles frutales

De los árboles frutales

Debajo un botón

Debajo un botón

Dengue, dengue

Desde pequeñito

Desde que te ví

Despedida

Despertad

Despertad

Día de fiesta

Día de fiesta

Día de fiesta

Dicen que te casas

Dicen que te casas

Dices que no la quieres

Dímelo morena

Distribución de las

candelas

Divino Antonio

Domine, non sum dignus

Domingo de Ramos

Don gato

Don melitón

Dónde los pondré

Dónde va de mañana

Dónde va de mañana

Dónde va de mañana

Dónde va mi morena

Dónde vas Adelaida

Dónde vas gitanilla

Doña Alda

Duerme, niño, duerme

Duérmete

Duérmete

Duérmete niño

Ecce nomen domini

Ecce nomen domini

Ecce quam bonum

Echa la barca al agua

Ego sum panis

Ejipto'ra 


\begin{tabular}{|l|}
\hline El alili \\
\hline El buen cazador \\
\hline El buen cazador \\
\hline El buen rabadán \\
\hline El caballero \\
\hline El caballo trotón \\
\hline El caballo trotón \\
\hline El calangrejo \\
\hline El cant dels ocells \\
\hline El cantal de loh gallego \\
\hline El carbonero \\
\hline El carbonero \\
\hline El carrasco \\
\hline El cocoroco \\
\hline El conde de Lara \\
\hline El conde Olinos \\
\hline El conde Olinos \\
\hline El dengue dengue \\
\hline El dengue dengue \\
\hline El desembre congelat \\
\hline El día de los torneos \\
\hline El día de los torneos \\
\hline El dijous a I' escola \\
\hline El enrame de la fuente \\
\hline El enrame de la Ifuente \\
\hline El gato \\
\hline El gato y el ratón \\
\hline El gorrión y el gato \\
\hline El juego chirimbolo \\
\hline El labrador patio de mi casa \\
\hline El lucerito está malo de mi casa \\
\hline El mandilín \\
\hline El manzano \\
\hline El mayo \\
\hline El mayo \\
\hline El milagro de la calanda \\
\hline El olivito \\
\hline El pájaro era verde \\
\hline El pájaro verde \\
\hline El paro verde \\
\hline
\end{tabular}

El patio de mi casa

El petit vailet

El petit vailet

El petit vailet

El poder del cant

El poll i la puça

El pollito

El rabadá

El ramito verde

El ramo

El ramo

El ratolí

El reloj

El rossinyol

El sereno

El tío Pep

El zurrón del glfio

Els tres reis

Els tres tambors

Els tres tambors

Emazteki bat

Embustes

En Belén tocan a fuego

En Cádiz hay una niña

En Cádiz hay una niña

En el balcón de palacio

En el balcón de palacio

En el balcón de palacio

En el lugar de Terrubias

En el palacio del frío

En el salón del prado

En esta plazuelita

En la calle del turco

En la calle del turco

En la macarenita

En las calles de Reinosa

En las calles de Reinosa

En las montañaras de

cataluñara

En los palacios del rey

En los palacios del rey

En Madrid hay un palacio

En mi vida he visto

En Olabarri

En París está doña Alda

En París está doña Alda 
En pie, camaradas

En pie, flechas de España

En pie, flechas de España

En Trefacio canta el gallo

Ene maitia

Engánchate

Era un gato grande

Era unha noite

Erase una viejecita

Erase una viejecita

Eres chiquita y bonita

Esta noche es Nochebuena

Esta noche nace el niño

Estaba el señor don gato

Estaba el señor don gato

Estaba el señor don gato

Estaba la pájara pinta

Estaba la pájara pinta

Estaba la pastora

Estaba la pastora

Estando cosendo

Estando cosendo

Estando cosendo

Estando la mora

Estando la virgen

Este corro es un jardín

Este es la mambrú

Estribillo aragonés

Fandanguillo

Fandanguillo

Fary Antón tenía una burra

Flos virginum

Foliadas

Folías

Folías

Folías

Fray Francisco

Fuente clara, fuente clara

Fuente clara, fuente clara

Fuentecilla

Fui a la feria una vez

Gatatumba

Gatatumba

Gloria

Gloria a dios en las alturas

Gloria in excelsis
Gloria in excelsis

Gloria Missa Lux et origo

Gloria y honor a José

Antonio

Gozosos y triunfantes

Gracias a dios que

llegamos

Habas verdes

Has de cantar

Hermosas doncellas

Hermosas doncellas

Himno de coros y danzas

Himno de vísperas

Hodie beata virgo

Imonos xa pr' aldea

Imperatrix angelorum

In natale domini

In natali domini

Introito a la dominica I de

adviento

Introitus a la Missa pro

defunctis

Inviolata

Inviolata

Inviolata

Isa canaria

Ite missa est

Jacob autem

Jam sol recedit

Jardinerita que entraste

Jesu corona virginum

Jesu redemptor omnium

Jesus jaio zan bako

Jo vaig i vinc

Jota

Jota

Jota

J ota castellana

J ota de Guadalupe

J ota de guadalupe

J ota de segadores

J ota oliventina

J otilla de Olivenza

Jotilla de Olivenza

Jotilla Toledo

Juego de la gallinita ciega 


\begin{tabular}{l|}
\hline Juego rítmico \\
\hline Juglaresca \\
Juglaresca \\
Juglaresca \\
\hline Juglaresca \\
\hline Juventud española \\
\hline Juventudes, juventudes \\
\hline Kyrie \\
\hline Kyrie Missa Lux et Origo \\
\hline L'angel i els pastors \\
\hline L'hereu riera \\
\hline La adoración de los reyes \\
\hline La alondra mañanera \\
\hline La barca \\
\hline La barca \\
\hline La calle ancha \\
\hline La calle ancha \\
\hline La calle Valencia \\
\hline La campaneta \\
\hline La carbonerita de \\
Salamanca \\
\hline La dama de Valencia \\
\hline La doncella \\
\hline La doncella \\
\hline La farola \\
\hline La farola de palacio \\
\hline La filadora \\
\hline La flor de la primavera \\
\hline La gitanita \\
\hline La infanta encantada \\
\hline La lámapara del rey moro \\
\hline La lámapara del rey moro \\
\hline La lancha de Tolín \\
\hline La lancha de Tolín \\
\hline La loba parda \\
\hline La luna ma \\
\hline
\end{tabular}

\begin{tabular}{|l|}
\hline La pastorcita \\
\hline La pastoreta \\
\hline La pastoreta \\
\hline La perdiz en el campo \\
\hline La perrita chita \\
\hline La petenera \\
\hline La pirroquia \\
\hline La ploma de perdiu \\
\hline La portillera \\
\hline La purificación de María \\
\hline La ronda y la contrarronda \\
\hline La sinda \\
\hline La tarara \\
\hline La tortolita \\
\hline La vendimia \\
\hline La virgen camina a Egipto \\
\hline La virgen de las nieves \\
\hline la virgen lava pañales \\
\hline La virgen lava pañales \\
\hline La virgen tiene los ojos \\
\hline La virgen va caminando \\
\hline La virgen va caminando \\
\hline La viudita del conde de \\
\hline cabra \\
\hline La viudita del conde laurel \\
\hline La xáquera vella \\
\hline Levántatate morenita \\
\hline Labradores de Castilla \\
\hline Laetabundus \\
\hline Las carrasquillas \\
\hline Las esquilitas \\
\hline Las manitas \\
\hline Las ovejuelas \\
\hline Las ovejuelas madre \\
\hline Las ovejuelas madre \\
\hline Las ovejuelas, madre \\
\hline Las Pascuas \\
\hline Las pascuas \\
\hline Las torrás \\
\hline
\end{tabular}




\begin{tabular}{|l|}
\hline Los campanilleros \\
\hline Los caracoles \\
\hline Los corzos van por el \\
monte \\
\hline Los mayos \\
\hline Los mayos \\
\hline Los pastorcitos de Belén \\
\hline Los pastores que supieron \\
Los pastores que supieron \\
\hline Los pastores y los reyes \\
\hline Los pastores y los reyes \\
\hline Los pastores y pastoras \\
\hline Los peregrinos \\
\hline Los tres tambores \\
\hline Lugareña \\
\hline Madre mía del Carmen \\
\hline Malo es de guardar \\
\hline Mambrú se fue a la guerra \\
\hline Mambrú se fue a la guerra \\
\hline mambrú se fue a la guerra \\
\hline Maneo \\
\hline Manolita tu chaleco \\
\hline Mañana voy a Burgos \\
\hline Mañanita de San J uan \\
\hline mañanitas de Mayo \\
\hline Mañanitas de mayo \\
\hline Marcha del flecha \\
\hline Mareta \\
\hline Margarita va por agua \\
\hline María de las Nieves \\
\hline Maria quae mortalium \\
\hline Maria quae mortalium \\
\hline María Rosa \\
\hline Marichu, marichu \\
\hline Marza \\
\hline Mayo \\
\hline Mayo \\
\hline Mayo \\
\hline Mayo \\
\hline Mayo \\
\hline Mayo \\
\hline Mayo \\
\hline Mayo \\
\hline Mayo \\
\hline Mayo \\
\hline Mayo de Zulema \\
\hline
\end{tabular}

\begin{tabular}{|l|}
\hline Mayos populares \\
\hline Me casó mi madre \\
\hline Me casó mi madre \\
\hline Me casó mi madre \\
\hline Me dijiste que era fea \\
\hline Me llamaste morenita \\
\hline Me llamaste morenita \\
\hline Media vita \\
\hline Melenchones \\
\hline Memento rerum conditor \\
\hline Memento rerum conditor \\
\hline Memorare \\
\hline Mi abuelo tenía un huerto \\
\hline Mi abuelo tenía un huerto \\
\hline Mi carbonero madre \\
\hline Mi niña \\
\hline Mi prima Santa Isabel \\
\hline Miau miau \\
\hline Milano \\
\hline Milano \\
\hline Milano \\
\hline Milano \\
\hline Miña nai por me casare \\
\hline Miña nay por me casare \\
\hline Miña virxen da peneda \\
\hline Misa de Angelis \\
\hline Misa de Angelis \\
\hline Misa de Angelis \\
\hline Misa Orbis factor \\
\hline Misa Orbis factor \\
\hline Misereminimei \\
\hline Miserere Dei \\
\hline Miserere et parce \\
\hline Miserere et parce \\
\hline Montañas nevadas \\
\hline Motete \\
\hline Muñeira \\
\hline Muñeira \\
\hline Muriéndose de risa \\
\hline Muriéndose de risa \\
\hline Nadie plante su parra \\
\hline Nadie plante su parra \\
\hline Nana \\
\hline Nana de Málaga \\
\hline Nana de Montehermoso \\
\hline Nativitas tua \\
\hline
\end{tabular}


Ni tú, ni tú, ni tú

Ni tú, ni tú, ni tú

Ni tú, ni tú, ni tú

Niño chiquito

Niño chiquito

No hay carretera sin barro

No la debemos dormir

No la llames

No llores niña

No te compongas

No voy por agua

Noche clara y serena

Nochebuenos

Nosa señora da guia

0 filii et filiae

0 quam amabilis es

0 quam glorifica

0 rex gloriae

O sacrum convivium

Offertorium

Oh sanctissima

Oh virgen purísima

Oliveras

Ora or Goiko

Ora or goiko

Oración del Frente de

J uventudes

Orex gloriae

Os mozos de San Martiño

pajarito

Pajarito que cantas

palmero sube a la palma

Pange lingua

Panxolina de nadal

Papá si me deja usted

Papá si me deja usted

Papá, si me deja usted

para qué quieres el pelo

Parado de Valldemosa

Parce domine

Parce Domine

Parce domine

Parce domine

Parranda de tres

Parranda del campo de

Lorca
Paseaba una señó

Paseaba una señó

Pastorela

Pastores venid

Pastores, venid

Pax in caelo

Páxaro que van voando

Pero mira como beben

Piedrezuca de tu calle

Pinto, pinto

Por estarte peinando

Por la calle abajito, lerén

lerén

Por la sierra morena

Por las mañanitas

Por ser aplicadita

Preces Marianae

Pregón de las flores

Prietas las filas

Prietas las filas

Prima responsorio

Puer natus

Puer nobis

Puer nobis nascitur

Pueri hebraeorum

Pues que dejas el canto

Purificación de María

Qué bonita está la sierra

Qué bonita está la sierra

Qué bonita está una parra

Que vengo del baño

Quédate con Dios, morena

Quisiera ser tan alta

Quisiera ser tan alta

Quisiera ser tan alta

Ramón del alma mía

Ramón del alma mía

Ramón del alma mía

Ramón del alma mía

Regina caeli laetare

Regina coeli lactare

Remendé

Resonet in laudibus

Resonet in laudibus

Responsorio de completas 
Responsorio de Misa Pro defunctis

Responsorio de prima

Rey a quien reyes adoran

Rey moro tenía una hija

Rey moro tenía una hija

Romance infantil

Romance de Bartolo

Romance de Cerdedo

Romance de la Peña de

Francia

Romance del conde de

Lara

Romance del conde de lara

Romance del conde de

Lara

Romance del conde de

Lara

Romance del conde niña

Romance del conde niño

Romance del conde niño

Romance histórico

Romancillo infantil

Romancillo navideño

Ronda de las marzas

Rorate caeli

Rosalinda

Rosalinda

Sa Ximbobmba

Saeta

Sal a bailar morenita

Sal a la ventana

Salamanca la blanca

Salamanca la blanca

Saludo

Salutis humanae sator

Salve festa dies

Salve J oseph

Salve J oseph

Salve latus salvatoris

Salve mater

Salve mater

Salve mira creatura

Salve mira creatura

Salve mundi domina

Salve mundi domina
Salve mundi, domine

Salve Regina

Salve Regina

Salve regina

Salve regina

Salve regina

Salve Regina caelitum

Salve Virgen pura

Salve virgo

Salve virgo

Salve virgo

Salve, virgen pura

San Antonio y los pajaritos

San Benitiño

San José era carpintero

San José era carpintero

San Millán

San Pantaleón

San Serenín

San Serenín del monte

Sanctus

Sant Farriol

Se chover, deixa chover

Segaba

Segador

Segador

Segador que ves la liebre

Segador, segadorzuco

Seguidillas

Seguidillas

Seguidillas manchegas

Seguidillas manchegas

Serrana

Serranilla de la zarzuela

Sevillanas

Si los pastores supieran

Si se va la paloma

Si tuviéramos aceite

Si vas pa la mar

Siembra semilla

Soledad en que yo vivo

Somos héroes

Somos los flechas

Soy de Mieres

Soy el farolero

Soy el farolero 
Soy el farolero

Soy la reina de los mares

Soy la reina de los mares

Stabat mater

Sub tuum praesidium

Sube un alto caballero

Súbela, jardinera

Tajaraste

Tam, tam, van por el desierto

Tantum ergo

Tarde de mayo

Te registientem gaudiis

Tejamos guirnaldas

Tengan santas noches

Tengo un arbolito

Tengo un arbolito

Tengo un arbolito

Tengo un grillo

Tengo una muñeca

Tengo una muñeca

Tengo, tengo, tengo

Tengo, tengo, tengo

Tengo, tengo, tengo

Tengo, tengo, tengo

Tengo, tengo, tengo

Terrena cuncta iubilent

Terrena cuncta jubilent

Tiene la tarara

Tiene la tarara

Tío pelacaña

Tocan las campanitas

Tono de pascua

Tono de pascuas

Toquen los instrumentos

Torneos

Torneos

Torneos

Torneos

Tota silescit

Traemos luz y alegría

Tralarán

Tres almireces traemos

Tres hojas madre

Tres hojitas, madre

Tres morillas me enamoran
Tú me criaste señor

Tu pañuelo y el mío

Tu pañuelo y el mío

Tu pañuelo y el mío

Tu pañuelo y el mío

Tu tururum tun tun

Tum Tururum tum tum

Tun tu ru run tun tun

Un cuc de terra

Un ou fa la gallina

Un rey

Un rey tenía tres hijas

Una estrella guiadora

Una palomita blanca

Una pandereta suena

Una tarde fresquita de mayo

Una tarde salí al campo

Una vez en el mercado

Una vieja muy vieja

Una, dos y tres

Ut omnes unum sint

Vamos a quemar las rosas

Vamos a ver señores

Vamos corriendo

Vamos, pastorcillos

Vaqueira

Veni de Libano

Venid para acá

Verbun supernum

Viaje a Oriente de coros y

danzas

Victima paschali

Victimae paschali

Villancico al nacimiento de

N. S. J esucristo

Villancico andaluz

Villancico de la Vera de

Cáceres

Villancico de Monforte de

Lemos

Villancico de Salamanca

Villancico de Santurdejo

Villancico de Segovia

Villancico del tantan

Villancico popular 


\section{Capítulo 6. Análisis musical del cancionero}

Virgo dei genitrix

Virgo dei genitrix

Vísperas

Viva Pineda la sierra

Vivan los aires morenos

Vola volando

Vos sou la meva prendeta

Xiringüelo

Xiringüelu

Y la parra al suelo vino

Zumba, zúmbale

Zumba, zúmbale al pandero
Ya ha venido mayo

Ya se murió el burro

Ya va la niña por agua

Ya viene la vieja

Yo me iba mi madre a

Villareale

Yo no soy la del cántaro, madre

Zagalita, zagalita

Zubi berian

\subsection{1.d Canciones populares para escolares}

Ficha de catalogación

Tíulo: Canciones populares para escolares

Servicio de Publicaciones de la Delegación Nacional de Sección Femenina de FET y de las JONS

Año de publicación: 1954

Lugar de publicación: Madrid

no de páginas: 47

Es un folleto publicado por la Delegación nacional de Sección Femenina para su uso en centros escolares. Aparece citado en el número de Mayo de 1954 de la Revista Consigna

[Imagen de la portada de Canciones populares para escolares] "La Sección Femenina tiene editado un folleto con las Canciones populares para escolares en el que están 


\section{La educación musical en el franquismo}

contenidas todas las canciones que se exige en los cuestionarios publicados por Orden Ministerial de 6 de febrero de 1953"

En él sólo parecen las partituras y texto de las canciones, clasificadas en 4 epígrafes:

1.- Período de enseñanza elemental

2.- Período de perfeccionamiento

3.- Período de iniciación profesional

4.- Marchas

No contienen indicaciones pedagógicas ni aplicaciones didácticas de ningún tipo.

Contiene las siguientes canciones ordenadas por orden alfabético:

\begin{tabular}{|l|l|}
$\begin{array}{l}\text { Canciones populares } \\
\text { para escolares }\end{array}$ & $\begin{array}{l}\text { En pie, flechas de } \\
\text { españa }\end{array}$ \\
\hline Adeste fideles & $\begin{array}{l}\text { Esta noche es } \\
\text { nochebuena }\end{array}$ \\
\hline Arroyo claro & Estando la virgen maría \\
\hline Ave maria & $\begin{array}{l}\text { Fray antón tenía una } \\
\text { burra }\end{array}$ \\
\hline Ave maris stella & Gibraltar \\
\hline Baile de la carrasquilla & Mambrú \\
\hline Calla, niño, calla & Montañas nevadas \\
\hline Campanas de belén & O virgo pulcherrima \\
\hline Canción de cuna & Piedrezuca de tu calle \\
\hline Cómo quieres que tenga & Puer natus \\
\hline la cara blanca & Que llueva \\
\hline Como vives tan alta & Quisiera ser tan alta \\
\hline Cu cú cantaba la rana & Regina caelis \\
\hline Cubre tu pecho & Rosalinda \\
\hline De codín de codán & San antonio y los \\
\hline El conde olinos & pajaritos \\
\hline El enrame de la fuente & Soy el farolero \\
\hline El patio de mi casa & Tarde de mayo \\
\hline El picotín & Tengo una muñeca \\
\hline En el balcón de palacio & \\
\hline En la calle del turco &
\end{tabular}




\section{Capítulo 6. Análisis musical del cancionero}

Tengo, tengo, tengo

Tiene la tarara

Tu pañuelo y el mío
Villancico de vestidito

Ya se murió el burro

\subsection{1.e Música: Teoría del solfeo y canciones}

Ficha de catalogación

Título: Música: Teoría de solfeo y canciones

Servicio de Publicaciones de la Delegación nacional de Sección Femenina de FET y de las JONS

Año de publicación: 1961

Lugar de publicación: Madrid

no o de páginas: 172

Es una publicación de la segunda época que obtuvo gran difusión en los años 60.

Ofrece, además de unas Normas a seguir por el profesorado de música para desarrollar las lecciones del programa, una división en dos secciones:

1.- Teoría de solfeo

1er. curso Música, solfeo, pentagrama, notas, claves en general, clave de sol, líneas y espacios adicionales, figuras, silencios, compás en general, compases de combinación doble, compás de compasillo, línea divisoria, valor de las figuras en compás de compasillo, compases de dos tiempos, compás binario, compás de 2/4, compás de 2/8, signos de prolongación del sonido, ligadura, puntillo, calderón, compases de tres tiempos, compás 
de 3/4, compás de $3 / 8$ y subdivisión de compases simples 0 de combinación doble

2 curso Tono y semitono, signos de alteración del sonido, alteraciones, alteraciones accidentales, alteraciones propias, compases de combinación triple en general, compás de 6/8, compás de 9/8, compás de 12/8, intervalos en general, clasificación de intervalos, tabla de intervalos, inversión de intervalos, escala en general, escalas diatónicas, escalas cromáticas, tonalidad, tono, orden de los grados en la escala diatónica, modalidad, formación de escalas mayores y formación de escalas menores

3er. curso Notas partidas, síncopas, notas a contratiempo, aires o movimientos principales, valores irregulares, tresillos y seisillos, dosillos y cautrillos, anacrusa, notas de adorno, apoytrua, mordente, trino, fermata o cadencia, compases de amalgama y compuestos, compás de $5 / 8$, compás de $7 / 4$, compás de $5 / 4$, signos de repetición, signos de expresión, intensidad del sonido, reguladores, ejecución de las notas, géneros de música, diatónico, cromático y enarmónico

La segunda parte de este libro es un cancionero clasificado por cursos (seis cursos) y con una ordenación secundaria en canciones de corro/ regionales, villancicos, clásicas, himnos y gregoriano

Los contenidos clasificados por orden alfabéticos de títulos son:

\section{TEORI A DEL SOLFEO Y CANCIONES}

A esta puerta llama un niña

Adeste fideles

Adorote devote

Al chiguiri punm

Al salir el sol dorado

Alegría, alegría

Alma redemptoris mater

Ator, aotr
Aupa la ronda

Ave maria

Ave regina caelorum

Ave verum

Ay que non era

Baila, nena

Baile de montaña

Caminito de avilés

Campanita del lugar

Canción de navidad 


\section{Capítulo 6. Análisis musical del cancionero}

Cantiga antigua

Cantiga de santa maria

Cantiga de santa maría

Chi chi rin chin

Churrusca

Como quieres que tenga la cara

blanca

Con el guri

Con el picotín

Con el trípili

Coplas del columpio

Córtame un ramito verde

De la uva sale el vino

De los álamos vengo

Debajo un borón

Despertad

Dicen que no me quieres

El carbonero

En cádiz hay una niña

En el balcón de palacio

En el portal de belén

En la macarenita

En medio de la plaza

En pie, camaradas

Esta noche es nochebuena

Este corro es un jardín

La barraqueta

La vitgen de las nieves

Límpiate con mi pañuelo

Los pastorcitos de belén

Mareta

María rosa

María sé que te llamas

Marichu

Miña nay por me casare

Misa de angelis
Misa de angelis

Misa de angelis

Misa de angelis

Misa de angelis

Misa orbis factor

Misa orbis factor

Misa orbis factor

Misa orbis factor

Misa orbis factor

Molinero, molinero

Montañas nevadas

No hay carretera

Palmero sube a la palma

Paloma del palomar

Piedrezuca de tu calle

Por la calle abajito, leren, leren

Prietas las filas

Que llueva

Quién le trajo caballero

Romance del conde de lara

Romance del conde niño

Rorate caeli

Salve regina

San vicente

Tan buen ganadico

Tengo un arbolito

Tu pañuelo y el mío

Tum tururum tum tum

Unha noite no muiño

Vamos a belén

Vamos pastorcillos

Virgo dei genitrix

Viva león porque tiene

Vivan los aires morenos

Yo vaig i vinc

\subsubsection{Las publicaciones del Frente de Juventudes}

Las publicaciones del Frente de Juventudes tienen un gran interés. Aunque algunas de ellas no aportan partituras - es decir, que son sólo una recopilación de los textos de las canciones - presentan otras características importantes: 


\section{La educación musical en el franquismo}

- Datación temporal de las canciones

- Autores del texto

- Autores de la letra

- Usos de las canciones

El repertorio recogido por Frente de Juventudes tiene unas características propias y diferentes del de Sección Femenina, lo que sirve de base para algunas de las conclusiones finales de este trabajo sobre las diferencias de género en el repertorio musical aprendido durante el franquismo.

\subsection{2.a Cancionero falangista}

Es uno de los pocos cancionero de Frente de Juventudes que incluye partituras de todas las canciones, por lo que tiene un gran valor documental.

Ficha de catalogación

Título: Cancionero Falangista

Departamento de Publicaciones de la Delegación Nacional del Frente de Juventudes

Año de publicación: 1945

Lugar de publicación: Madrid

no de páginas 77

Está clasificado en las siguientes secciones:

1.- Cantos religiosos

2.- Canciones regionales

3.- Himnos y marchas de FET y de las JONS 


\section{Capítulo 6. Análisis musical del cancionero}

4.- Himnos y marchas militares

El contenido de canciones ordenadas alfabéticamente por títulos es:

\begin{tabular}{|l|}
\hline Cancionero falangista \\
\hline Adelante \\
\hline Amanece \\
\hline A raiz d'o toxo verde \\
\hline Asturias \\
\hline Aunque me des veinte duros \\
\hline Bajo las banderas imperiales \\
\hline Caminito de Avilés \\
\hline Camino del sol \\
\hline Canción del falangista \\
\hline Desiderio \\
\hline Eres alta y delgada \\
\hline Folías \\
\hline Fui al Cristo \\
\hline Himno de falange \\
\hline Himno de la Academia infanteria \\
\hline Himno de la División Azul \\
\hline Himno de la Infantería de marina \\
\hline Himno de la Infant. Marina Levante \\
\hline
\end{tabular}

\begin{tabular}{|l|}
\hline Himno de la Marina \\
\hline Gloria y honor a J osé Antonio \\
\hline Isabel y Fernando \\
\hline J uventud \\
\hline J uventud estudiante \\
\hline La canción del legionario \\
\hline La pastoreta \\
\hline Lealtad \\
\hline Los cordones \\
\hline Montañas nevadas \\
\hline No se va la paloma \\
\hline Oración del FJ \\
\hline Prietas las filas \\
\hline Salve \\
\hline Salve regina \\
\hline Soy nacionalsindicalista \\
\hline Unión juvenil \\
\hline Y fieles al caudillo son \\
\hline
\end{tabular}

\subsection{2.b El Frente de J uventudes en la escuela}

Es un libro sobre la actividad general del Frente de Juventudes a nivel escolar, con material e indicaciones sobre FEN (Formación del Espíritu Nacional), Educación Física y una parte dedicada a Canciones. 


\section{La educación musical en el franquismo}

Sólo incluye la letra de las canciones - no las partituras - , pero es un ejemplo específico de la obligatoriedad de aprender determinadas canciones en la escuela.

Al final del libro aparece la siguiente nota sobre las Recompensas para el Magisterio

La Delegación de Juventudes reconoce en cada instante la valiosa colaboración que encuentra en el Magisterio Primario. En las ocasiones en que es patente el entusiasmo prestado, otorga premios y recompensas a los maestros. Estas distinciones han adquirido un prestigio entre el Magisterio y una seriedad en su concesión mediante el establecimiento de las J untas Provinciales de recompensas.

Ficha de catalogación

Título: El Frente de Juventudes en la escuela

Frente de Juventudes

Año de publicación: 1960

Lugar de publicación: Valencia

no de páginas: 59

Están clasificas en dos tipos de canciones:

1.- Himnos y marchas

2.- Canciones folklóricas

Las canciones que contiene son:

\section{EL FRENTE DE J UVENTUDES DE LA ESCUELA}

Caminito de avilés

Canción del flecha 


\title{
Capítulo 6. Análisis musical del cancionero
}

\author{
El vito \\ Eres buena moza \\ Himno a san fernando \\ Himno de la falange española \\ Himno de la legión \\ La sardinera \\ Llámame camarada \\ Mi camisa vieja vestiré \\ Oriamendi \\ Sierra de mariola \\ Venimos de Senegüey
}

\subsection{2.c Manual de campamentos}

Es un pequeño manual para las actividades de ocio y tiempo libre de los campamentos. Incluye todo tipo de información, desde la Normativa para el mando directo de juventudes hasta la clasificación, preparación y organización de campamentos (instalaciones, sanidad, intendencia,, administración, horarios y actividades)

Entre las actividades constan la Formación política, la educación religiosa, la educación premilitar y la educación física. Y entre las actividades varias se encuentran las canciones para el fuego de campamento y los juegos

Ficha de catalogación

Título: Manual de campamentos

Ediciones del Frente de Juventudes

Año de publicación: 1948

Lugar de publicación: Madrid

no de páginas: 473 
Las canciones que contiene son:

\section{MANUAL DE CAMPAMENTOS}

Adiós, lucrecia

Canción alegre

Canción báquica

Compañeiro que sabe tocaire

Date el bote

El bergantín

La macarenita

Las vacas en la primavera

Los pollitos

Mi barba tiene tres pelos

Poupurrit de canciones montañesas

Si yo fuera un gatito

Un día en las carreras

Vals Pepito

\subsection{2.d Marchas y montañismo}

Este pequeño librito es también un manual de actividades de tiempo libre con todo tipo de información sobre campamentos. Sin embargo es el primer ejemplo de recogida de 14 partituras de himnos y marchas en el Frente de Juventudes. Sin embargo, otros 6 himnos y las canciones folklóricas incluídas sólo reflejan el texto de la letra.

Ficha de catalogación

Título: Marchas y montañismo 


\section{Capítulo 6. Análisis musical del cancionero}

Departamento de publicaciones de la Delegación Nacional del Frente de Juventudes.

Año de publicación: 1943

Lugar de publicación: Madrid

no de páginas: 217

\subsection{2.e Cancionero juvenil}

Es sin duda la obra más importante para el conocimiento de las canciones del Frente de Juventudes antes de 1965. Se trata de una auténtico cancionero y la mayor fuente de música, ya que todas las canciones incluyen su partitura.

Ficha de catalogación

Título: Cancionero juvenil

Autor/ recopilador: Manuel Rodríguez

Ediciones de la Delegación Nacional del Frente de Juventudes

Año de publicación: 1947

Lugar de publicación: Madrid

no de páginas: 294

La obra está dividida en varias secciones:

1.- Cánticos religiosos

2.- Himnos y marchas del quehacer de España 


\section{La educación musical en el franquismo}

3.- Marchas militares

4.- Marchas y canciones juveniles

5.- Canciones regionales

6.- Fuego de campamento

Las canciones que contiene son las siguientes en orden alfabético:

\begin{tabular}{|l|}
\hline Cancionero juvenil \\
\hline Abreme la puerta \\
\hline Abrid paso, españoles \\
\hline Adelante, muchachos de España \\
\hline Adelante, valientes camisas azules \\
\hline Adios, adiós, madre mía \\
\hline Adiós, madre querida \\
\hline A esta puerta hemos llegado \\
\hline Agnus Dei \\
\hline Agua menudita llueve \\
\hline A la puerta del molino \\
\hline A la virgen del Carmen \\
\hline Al buen pan de Aragón \\
\hline Alerta, juventudes \\
\hline A lo alto y a lo bajo \\
\hline Alora, la bien cercada \\
\hline Al lado de mi cabaña \\
\hline Al son de los tambores \\
\hline Anda, corre y ponte \\
\hline Anda, dile a tu madre \\
\hline Aquel que no tenga madre \\
\hline
\end{tabular}

\begin{tabular}{|l|}
\hline Aquella palomina \\
\hline Aquí los cocineros \\
\hline Ardor guerrero vibre \\
\hline Arriba, juventudes \\
\hline Asturias tierra querida \\
\hline Ayer tarde en la función \\
\hline Ay, Sálvora \\
\hline Bajo los montes altísimos \\
\hline Bandera de España \\
\hline Bartolo, qué vida \\
\hline Bendita y alabada sea \\
\hline Benedicamus Domino \\
\hline Bien por Fulano \\
\hline Camarada, camarada \\
\hline Camaradas, dormid en paz \\
\hline Camaradas juveniles \\
\hline Caminando el buen Jesús \\
\hline Caminito de Avilés \\
\hline Camisa azul y boina colorada \\
\hline Camponaraya \\
\hline Candelines, candelines \\
\hline
\end{tabular}


Capítulo 6. Análisis musical del cancionero

\begin{tabular}{|l|}
\hline Canta mi centuria \\
\hline Cantemos al amor de los amores \\
\hline Cantemos del Alcázar las glorias \\
\hline Capullito de rosa \\
\hline Cara al sol \\
\hline Caricia y beso de auras y brisas \\
\hline Carrasclás \\
\hline Carretera abaxo va \\
\hline Centinela que en la noche \\
\hline Colores de sangre y oro \\
\hline Hollín, Mollendo flores \\
\hline Combatir por dios y el césar \\
\hline Cómo quieres que tenga \\
\hline Con el hurí \\
\hline Con el rumor de la faena \\
\hline Con el vito \\
\hline Con mi canción la gloria va \\
\hline Con su voz conocida \\
\hline Contra viles injurias \\
\hline Corazón santo, tú reinarás \\
\hline Credo \\
\hline Cuando de los remedios \\
\hline Cuando Fernando VII \\
\hline Cuando llegué al campamento \\
\hline Cuando salí de Marbella \\
\hline Cuatro pañuelucos tengo \\
\hline Cubre tu pecho de azul \\
\hline Christus vincit \\
\hline Date el bote, cara dura \\
\hline
\end{tabular}

\begin{tabular}{|l|}
\hline Debajo de un botón \\
\hline Del cielo cayeron rosas \\
\hline Desde Santurce a Bilbao \\
\hline De sepulcro en sepulcro \\
\hline Diana \\
\hline Dicen que tus manos pinchan \\
\hline Dicen que vienen \\
\hline Dime, morenita \\
\hline Dios te salve \\
\hline Dominus vobiscum \\
\hline Dónde los pondré, los claveles \\
\hline Dónde vas a por agua \\
\hline Dorotea \\
\hline El carbonero por las esquinas \\
\hline El cuscús que hacen los moros \\
\hline El pañuelo de seda \\
\hline El tío Pimiento dice \\
\hline El viento plácido \\
\hline En casa del tío Vicente \\
\hline En la alameda primera \\
\hline En la huerta de Gracia \\
\hline En las montáñaras \\
\hline En marcha las centurias \\
\hline En pie, camaradas \\
\hline En pie, flechas de españa \\
\hline Eran cinco camaradas \\
\hline Era un puñado de hambrientos \\
\hline Eres como la rosa \\
\hline Eres hermosa en extremo \\
\hline
\end{tabular}


La educación musical en el franquismo

\begin{tabular}{|c|}
\hline Escucha, españa, la voz potente \\
\hline España nace en nuestra canción \\
\hline Españoles: la patria bendita \\
\hline Esta calle es un jardín \\
\hline Esta es nuestra jota \\
\hline Es tan hermoso ser cadete \\
\hline Estando yo en la mi choza \\
\hline Estudiantes: alcemos la bandera \\
\hline Falangista soy \\
\hline Gaudamus igitur \\
\hline Generala \\
\hline Gibraltar \\
\hline Gloria de cruces nostálgicas \\
\hline Gloria in excelsis \\
\hline Grandes guerras se publican \\
\hline Hurra \\
\hline Himno nacional para trompetas \\
\hline Ite missa est \\
\hline Juventudes, cantemos \\
\hline Juventudes, juventudes \\
\hline J uventudes de vida española \\
\hline Juventud española \\
\hline Juventudes que un imperio vemos \\
\hline Kyrie eleison \\
\hline La bandera de cadetes \\
\hline La Clara cuando va a misa \\
\hline Ladrón, vas a morir \\
\hline La farola de palacio \\
\hline La mirada clara, lejos \\
\hline
\end{tabular}

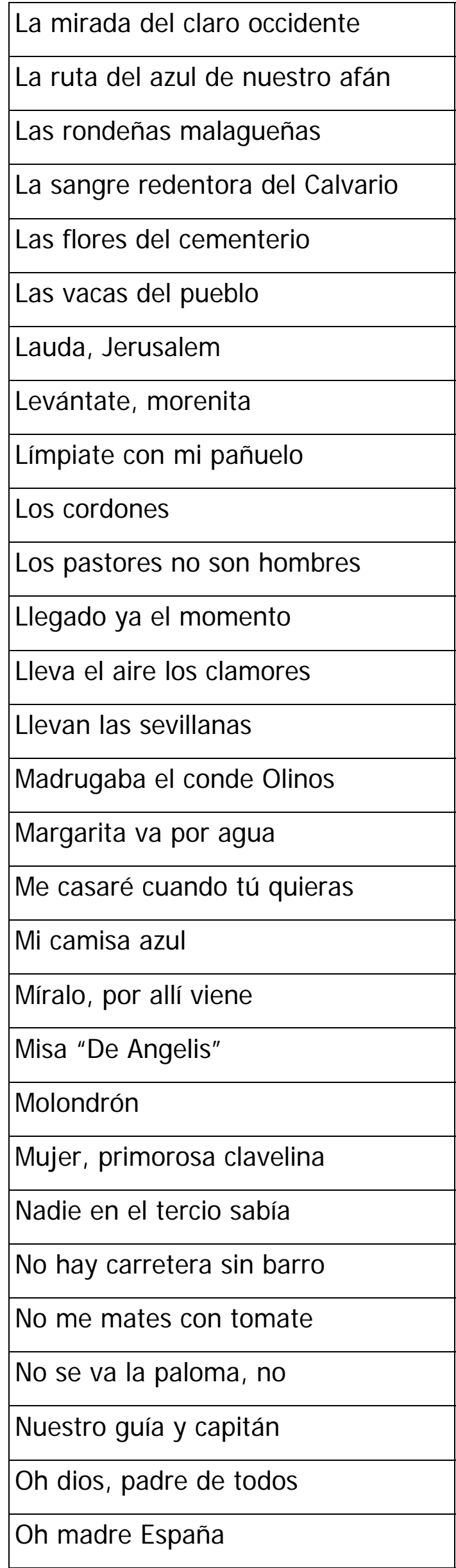


Capítulo 6. Análisis musical del cancionero

\begin{tabular}{|l|}
\hline Oración \\
\hline Pange lingua \\
\hline Para ser España una \\
\hline Pasábase el rey moro \\
\hline Paso de ataque \\
\hline Paso ligero \\
\hline Pater noster \\
\hline Pax domini \\
\hline Per omnia saecula \\
\hline Por detrás de los montes \\
\hline Por Dios, por la patria y el rey \\
\hline Por medio de los mares \\
\hline Por la senda de la vida \\
\hline Por los campos de Castilla \\
\hline Prietas las filas \\
\hline Qué dirá la carbonerita \\
\hline Qué li donarem a la pastoreta \\
\hline Que por mayor era \\
\hline Quién es el caradura aquí \\
\hline Quién es el hombre más bueno \\
\hline Quisiera volverme hiedra \\
\hline Recuerda, camarada \\
\hline Retreta y parte \\
\hline Rey don Sancho \\
\hline Rondar que te rondaría \\
\hline Sal a bailar morenita \\
\hline Salí de la Habana un día \\
\hline Salve, estrella de los mares \\
\hline Salve regina \\
\hline
\end{tabular}

\begin{tabular}{|l|}
\hline Salve, salve, bandera \\
\hline Sanctus \\
\hline Segaba yo aquella tarde \\
\hline Siempre viví en las montañas \\
\hline Sierra de Mariola \\
\hline Silencio, oración y paz \\
\hline Si llega hasta ti un suspiro \\
\hline Si nos preguntan, alto \\
\hline Si se van que se vayan \\
\hline Si te quieres casar \\
\hline Sobre campos y trincheras \\
\hline Soldado soy de España \\
\hline Soldados a luchar \\
\hline Somos, ay, de la tierra \\
\hline Somos flechas de nuestra España \\
\hline Somos flechas que siempre llevamos \\
\hline Somos héroes del mañana \\
\hline Somos la juventud de España \\
\hline Somos los flechas, la guardia \\
\hline Soplen serenas las brisas \\
\hline Soy caballero de las Milicias \\
\hline Soy de Santurce \\
\hline Soy un rayito de luna \\
\hline Soy valiente y leal legionario \\
\hline Sube un alto caballero \\
\hline Subirás en alpargatas \\
\hline Surja el grito del honor \\
\hline Tantum ergo \\
\hline Tengo de subir \\
\hline
\end{tabular}


La educación musical en el franquismo

\begin{tabular}{|l|}
\hline Tengo la fe del falangista \\
\hline Tiene la tabernera \\
\hline Tienes unos ojos, niña \\
\hline Trabajando, la falange \\
\hline Tres hojitas, madre \\
\hline Tú, que dispones de cielo y mar \\
\hline Una mañana de niebla \\
\hline Una tarde fresquita \\
\hline Un mantón de la China \\
\hline Un automóvile, dos automóviles \\
\hline Villaviciosa hermosa \\
\hline
\end{tabular}

\begin{tabular}{|l|}
\hline Virgen de Guadalupe \\
\hline Vite, vite, vite \\
\hline Viva nuestro gran Bilbao \\
\hline Viva Sevilla y olé \\
\hline Volverán con más plumas \\
\hline Ya las mieses están secas \\
\hline Ya se marchan los quintos \\
\hline Ya se van los pastores \\
\hline Ya vienen los mozos por la calle \\
\hline Yo tenía un camarada \\
\hline Yugos y flechas \\
\hline
\end{tabular}

\subsection{2.f España es mi canción}

Además de ser el título de una famosa canción, es la denominación desde los años 60 del cancionero recopilatorio de las canciones de la Organización Juvenil (OJ E).

La edición que he consultado para la base de datos está publicada en formato digital en http://www.rumbos.net/cancionero y recoge la edición de Doncel, incluyendo una presentación, una datación temporal en cinco apartados con comentarios y grabaciones de algunas canciones en formato MP3 y un anexo realizado por Manuel Parra Celaya titulado Pedagogía de la canción en el que resume su tesis doctoral.

La datación de las canciones se apoya en los datos aportados por José de Arriaca en su Cancionero de Juventudes ${ }^{252}$.

La clasificación temporal se divide en:

1.- Canciones anteriores al Frente de Juventudes

${ }^{252}$ ARRIACA, J. (1967) Cancionero de Juventudes .Madrid: Editorial Doncel 
2.- Período 1939-1942

3.- Período 1942-45

4.- Período 1945-1960

5.- Período 1960-1975

6.- Período 1975-1985

No contiene ninguna partitura, sólo los textos de las letras, y en algunos casos una referencia sonora.

Ficha de catalogación

Título: España es mi canción

Editorial Doncel. Edición electrónica en http://www.rumbos.net/cancionero . Última consulta realizada el 1 de junio de 2009

Año de publicación: En constante elaboración dirigiéndose a cancionero@rumbos.net

Es la principal fuente recopilatoria de canciones vinculadas a Frente de J uventudes. Todas las canciones incluídas son de carácter ideológico (himnos) y de actividades de ocio y tiempo libre (marchas de campamento)

El contenido de canciones ordenadas alfabéticamente es:

\section{España es mi canción}

A cinco que había en mi escuadra

A la voz del capitán

A tus órdenes

Academia Onésimo Redondo

Adelante
Aguilas de españa

Aguilas de imperio

Al pe, pri

Allí

Amadís

Arqueros de mi españa

Arriba el corazón

Arriba españa 
Avanzan las escuadras

Cadetes de las JONS

Camino del sol

Caminos abiertos

Caminos de mi españa

Camisa azul

Campamento Vigil de

Quiñones

Canción de la hermana lluvia

Canción de la hermana

mañana

Canción de la hermana noche

Canción de las F. J. de

Franco

Canción de los almogávares

Canción de los flechas

Canción de vida

Canción del cid

Canción del falangista

Canción del flecha

Canción del hermano fuego

Cara al sol

Centuria churruca

Centuria de cadetes

Centuria gran capitán

Centurias juveniles

Con nuestro emblema

Coplas de guerra

Covaleda

Covaleda I

Covaleda II

Cuatro de marzo

Cubre tu pecho

Curso de mandos

Décimo aniversario

Desde Rusia

Doncel

El alto de los leones

El camarada I

El camarada II

El dardo vivo de un quehacer

El día de mañana

En las calles de cualquier ciudad

En marcha unidos

Envío
Eran cuatro camaradas

España es mi canción

España, Franco y la cruz

Falanges de granada

Falanges de marruecos

Falanges juveniles de cadetes

Fidelidad

Flechas de castilla

Flechas y yugo de las J ONS

Garra hispánica

Gibraltar, gibraltar

Gloroia y honor a José

Antonio

Guarda tus penas

Himno a san Fernando

Himno de campamentos

Himno de combate

Himno de la aljaba Amanecer

Himno de la aljaba Carlos I

Himno de la bandera de

falange

Himno de la centuria Aguilas

doradas

Himno de la centuria

Alejandro Salazar

Himno de la centuria cid

campeador

Himno de la centuria J. M.

Guitarte

Himno de la centuria lepanto

Himno de la centuria Manuel

Hedilla

Himno de la centuria Plus

ultra

Himno de la centuria

Reconquista

Himno de la división azul

Himno de la escuadra Legión

de Honor

Himno de la escuwela de

espeleología de madrid

Himno de las jons de

valladolid

Himno del cículo Cardenal

Cisneros

Himno del círculo Tambor del

Bruch 


\section{Capítulo 6. Análisis musical del cancionero}

Himno del distrito de

chamberí

Himno del trabajo

Impulso imperial

I sabel y Fernando

J oven mando cursillista

Juventud española

Juventud estudiante

Juventudes de azul

Juventudes de la españa

heroica

Juventudes, juventudes

Juvnetud del SEU

La batalla del ebro

La centuria de castilla

La centuria Ruiz de Alda

La gloria del camino

Las J ONS

Lili Marlen

Los flechas

Luceros

Marcha de los aprendices

Marcha del flecha

Marchad

Marchando

Marcharás

Me gusta lo difícil

Mi camisa azul

Mi camisa vieja vestiré

Mi canción

Montañas nevadas

Nuestras escuadras jóvenes
Nuestro destino

Nuevo gibraltar

Nunca estaremos solos si

cantamos

Palabras limpias

Pasa la juventud

Pequeños arqueros

Por la españa imperial

Pregones de imperio

Prietas las filas

Primavera

Saludo a las juventudes de

Franco

Salve, mi españa

Ser español

Si cayeras, camarada

Si madrugan los arqueros

Si no puedes tú solo

Si un camarada falangista

Soy español

Surgirá el imperio

Tenemos un caudillo

Titán de españa

Un quehacer

Una españa mejor

Una vez oí una canción

Ünico capitán

Vale quien sirve

Ven con nosostros

Voces de imperio

Voluntarios de la división azul

\subsection{LA INTERPRETACIÓN DE LOS DATOS A TRAVÉS DE GRÁFICOS}

Como resultado del análisis individualizado de todas las canciones de estos cancioneros (2987 canciones, de las cuales 359 no contienen datos musicales (España es mi canción), se obtienen algunos datos significativos, que son más fáciles de interpretar de forma visual a través de gráficos Excell. 


\section{La educación musical en el franquismo}

\subsubsection{Los compases más utilizados}

Es evidente que hay compases que nos resultan más básicos o fáciles de utilizar.

En la actualidad, por ejemplo, en la música comercial estamos asistiendo a una predominancia casi fagocitante de los compases binarios. El primer compás que enseñamos desde el punto de vista didáctico es el binario $2 / 4$. Y es el compás más utilizado para las marchas e himnos - parte importante del cancionero de Frente de Juventudes,--

Los compases ternarios y de subdivisión ternaria, sin embargo, tienen una gran tradición en el folklore y también en la música clásica -donde uno de los elementos claves de la creación es la alternancia rítmica-.

En el análisis del corpus musical de los cancioneros del franquismo se aprecian los siguientes resultados:

$\begin{array}{lrrr}\text { N. DE CANCIONES } & \text { COMPÁS } & \text { \% DE PRESENCIA } & \\ 954 & 2 / 4 & 39,88 \% \\ 710 & 3 / 4 & 29,68 \% \\ 313 & 6 / 8 & 13,09 \% \\ 294 & 3 / 8 & 12,29 \% \\ 75 & 4 / 4 & 3,14 \% \\ 10 & 9 / 8 & 0,42 \% \\ 7 & 5 / 8 & 0,29 \% \\ 29 & \text { otros } & 1,21 \%\end{array}$

Es evidente la predominancia del compás de 2/ 4 (casi el 40\% del repertorio) se encuentran en este compás.

Sin embargo el siguiente compás binario importante, 4/4 apenas tiene presencia (sólo un 3\%).

Por el contrario, los compases ternarios básicos $\mathbf{3}$ / $\mathbf{4}$ y $\mathbf{3 / 8}$ tienen combinados incluso mayor presencia que el binario. 


\section{Capítulo 6. Análisis musical del cancionero}

Es decir, que se aprecia un interesante equilibrio entre los compases binarios y ternarios básicos.

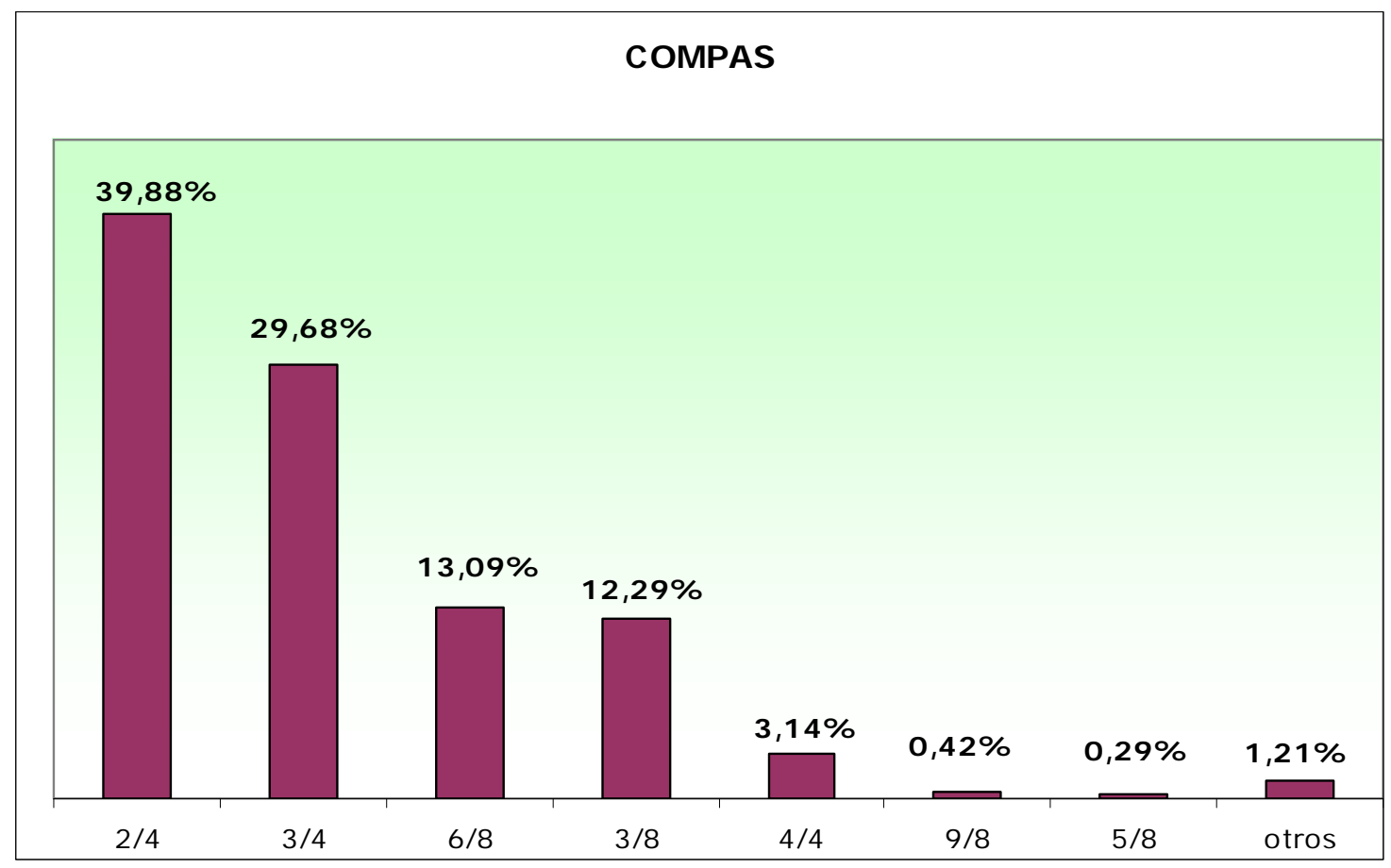

Mi hipótesis es que ello se debe a la gran presencia en los cancioneros de Sección Femenina de repertorio de origen folklórico, en el que los compases ternarios tienen una gran importancia.

La importante presencia del compás de $\mathbf{6 / 8}$ es significativa y se convierte en el tercer compás con más canciones.

Desde el punto de vista didáctico es interesante la selección mayoritaria de estos 4 tipos de compases - 2/4, $3 / 4,6 / 8$ y 3/8 - que serían los que mejor manejaban instructores y alumnos desde el punto de vista de la enseñanza del lenguaje musical. El resto son prácticamente irrelevantes.

\subsubsection{Intervalo inicial}

La interválica inicial de las canciones nos permite definir las preferencias de entonación en los incipits melódicos (memorizables) que son los primeros elementos para distinguir y aprender nuevos elementos del repertorio musical. 


\begin{tabular}{crlr}
$N^{\circ}$ DE CANCIONES & \multicolumn{2}{c}{ INTERVALO INICIAL } & \% DE PRESENCIA \\
& 703 & $2^{\mathrm{a}}$ & $26,75 \%$ \\
410 & $3^{\mathrm{a}}$ & $15,60 \%$ \\
447 & $4^{\mathrm{a}}$ & $17,01 \%$ \\
27 & $5^{\mathrm{a}}$ & $1,03 \%$ \\
28 & $6^{\mathrm{a}}$ & $1,07 \%$ \\
& 1 & $8^{\mathrm{a}}$ & $0,04 \%$ \\
& 1012 & Unísono & $38,51 \%$ \\
& 2628 & &
\end{tabular}

Es evidente una gran predominancia del unísono, es decir, la repetición del mismo sonido, que es evidentemente la fórmula más fácil de entonación.

La segunda fórmula preferida de entonación interválica es la utilización de los grados conjuntos (2ำ mayor y menor), según los esquemas de los esquemas y fórmulas de entonación (escalas) diatónicas, tanto modales como tonales

Y en tercer lugar, la fórmula de la $\mathbf{4} \mathbf{0}$ justa es el patrón favorito de los esquemas tonales (establece relaciones entre la dominante, la tónica y la subdominante). Y finalmente las terceras mayores y menores establecen el acorde que define la modalidad tonal (mayor o menor) en la entonación inicial y son el cuarto factor de entonación en imortancia.

\section{NTERVALO I NI CI AL}

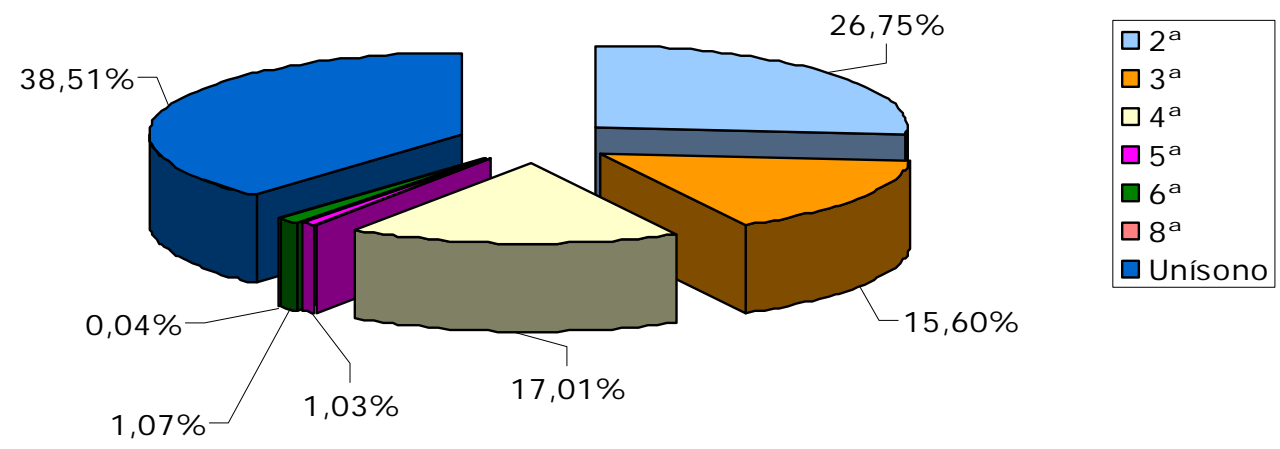




\section{Capítulo 6. Análisis musical del cancionero}

Los demás intervalos tienen una presencia insignificante, lo que implica realmente que no aportan elementos comprensibles o fácilmente reconocibles y que su dificultad de entonación melódica los hace descartables de un repertorio destinado a la mayoría de la población.

\subsubsection{Tipos de canción}

El tipo de canción que aparece mayoritariamente es muy diferente en los cancioneros de Sección Femenina y en los de Frente de Juventudes, lo que implica una selección del repertorio en ámbitos y centros de interés diferentes a la hora de enseñar contenidos de tipo ideológico

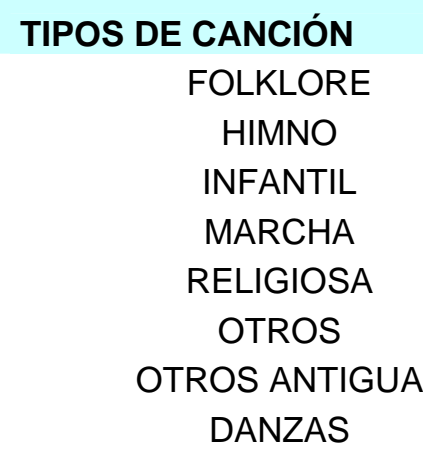

CANCIONEROS DE SECCIÓN FEMENINA
CANCIONEROS DE FRENTE DE JUVENTUDES

$27,2 \%$

$58,6 \%$

$1,6 \%$

$0,0 \%$

$8,4 \%$

$7,4 \%$

$1,7 \%$

$2,2 \%$

$0,3 \%$

$0,0 \%$

$0,1 \%$

$0,0 \%$

$9,8 \%$

$4,7 \%$

De los datos obtenidos se concluye que los centros de interés de Sección Femenina son el folklore, las danzas, las canciones infantiles y la religión.

Aunque la música religiosa parece en las cifras tener menor presencia que en el Frente de Juventudes, en realidad supone una gran cantidad de incorporación de música gregoriana - en latín, sin compás, modal, de difícil entonación -.

No obstante, queda claro que la principal intención de los repertorios recogidos por Sección Femenina es la difusión del folklore 


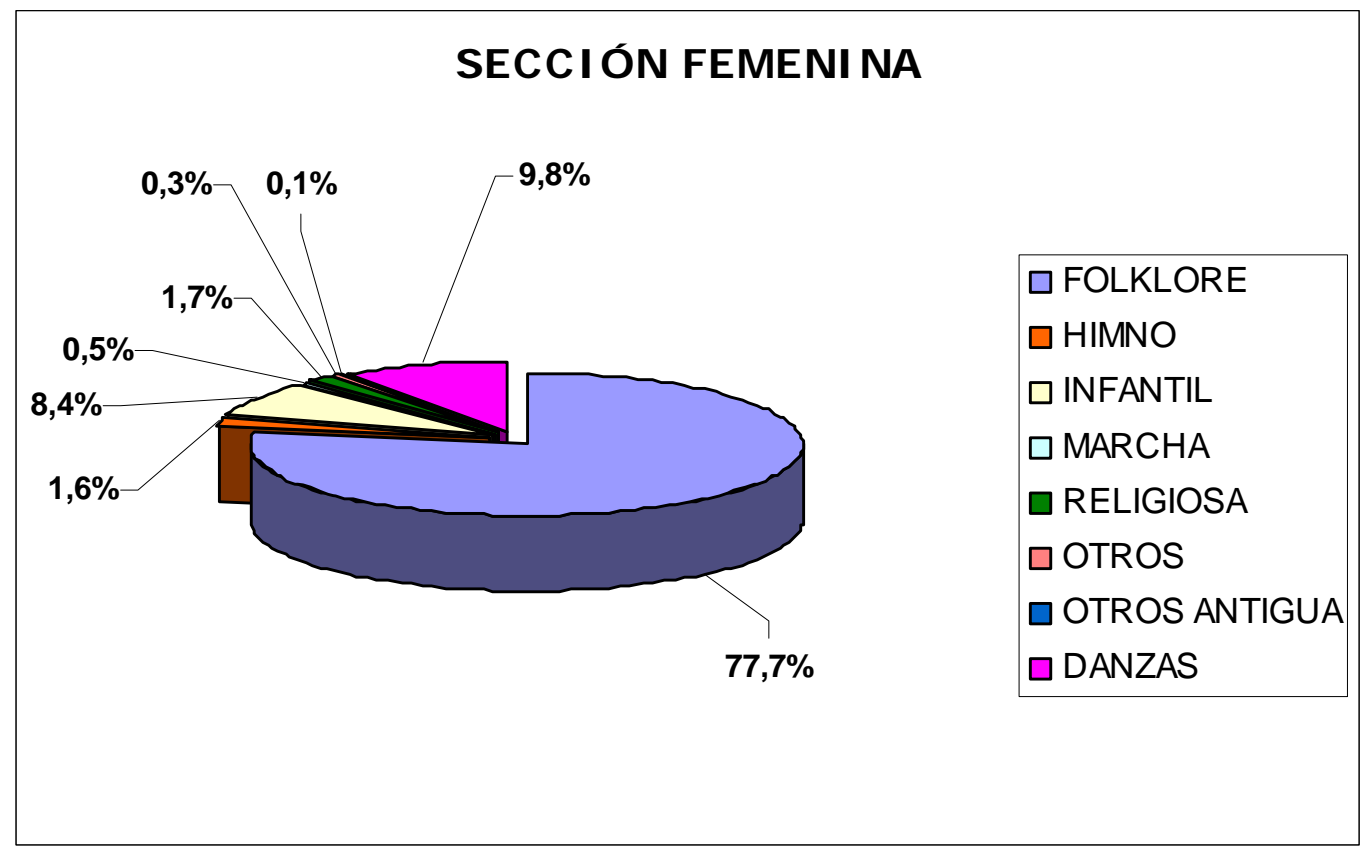

Sin embargo, los intereses de Frente de Juventudes son mayoritariamente los Himnos, secundariamente el folklore y las marchas.

La cifra de presencia de canciones de tipo religioso es engañosa y se debe a que el único cancionero importante con partituras de Frente de Juventudes fue confeccionado por un religioso (hermano marianista): Manuel Rodríguez. El resto de los cancioneros de Frente de Juventudes no contienen ninguna canción de tipo religioso - aún más, demuestran un profundo desinterés por el tema como un elemento ajeno y enojoso -, pero no aparecen contabilizados en la contabilidad analítica porque carecen de información musical.

Sobre la utilización del folklore en Frente de Juventudes, la intencionalidad es fundamentalmente el uso en actividades de tiempo libre y ocio, especialmente en torno al fuego de campamento, para despertar los sentimientos de integración en el grupo en los momentos de nostalgia - a diferencia de la difusión del folklore en Sección Femenina -.

En definitiva, la prioridad del repertorio de canciones de Frente de Juventudes es la transmisión ideológico-política y la afirmación del sentimiento colectivo grupal en las actividades de tiempo libre (las marchas y los himnos son elementos rítmicos básicos en las caminatas y desfiles) 


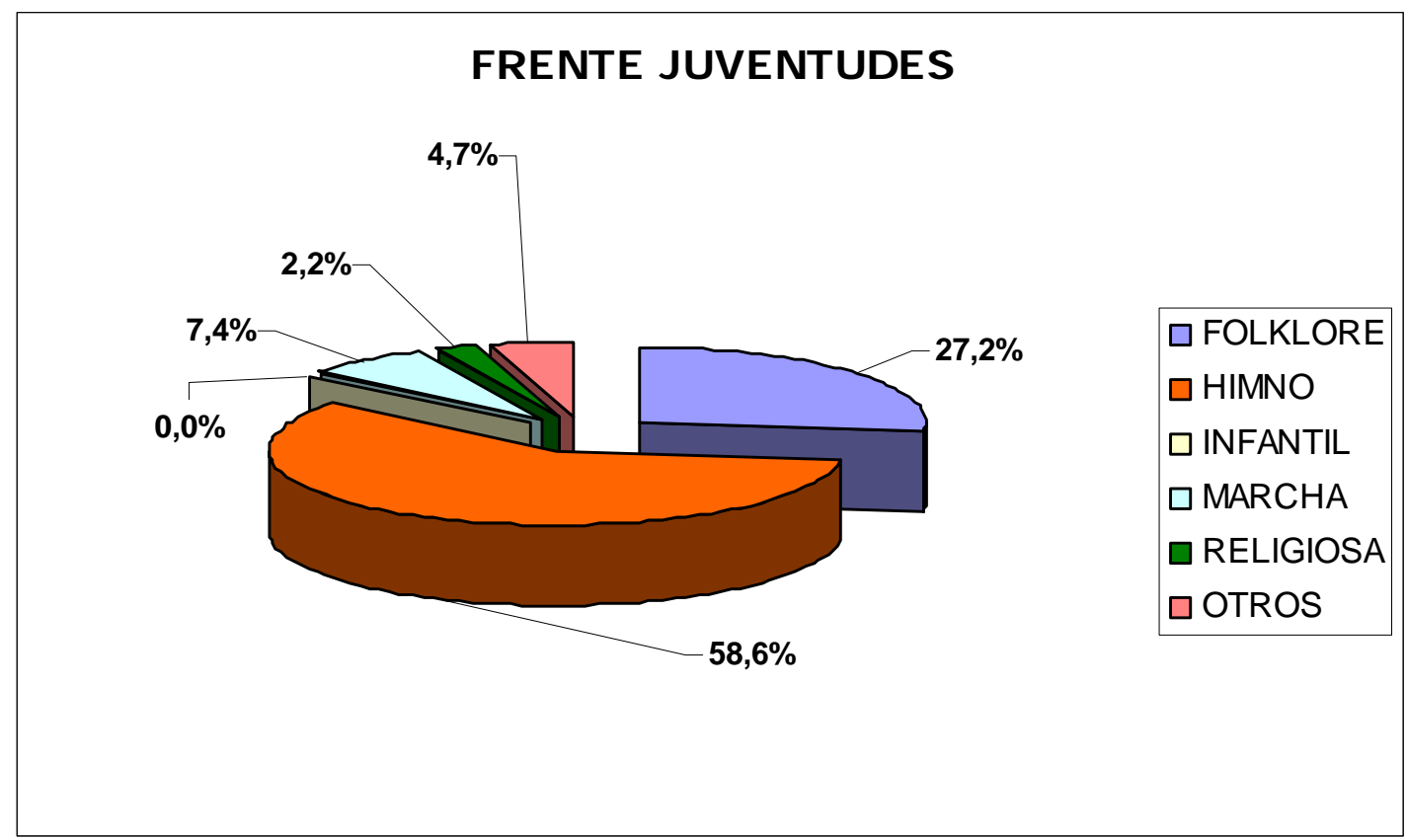

La distribución tipológica general de las canciones es la siguiente

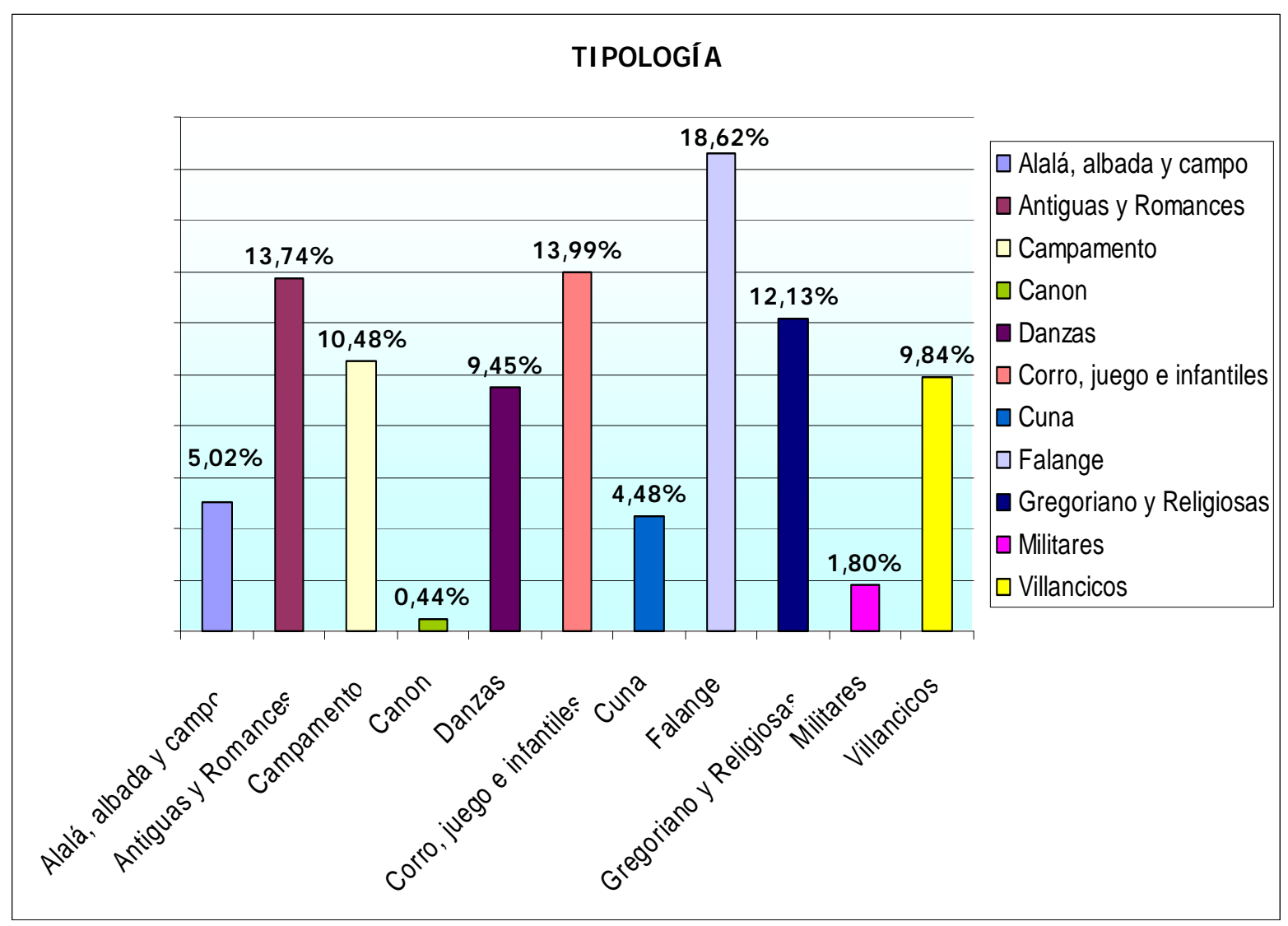




\section{La educación musical en el franquismo}

\subsubsection{El idioma y el origen regional de las canciones}

Tanto Sección Femenina como Frente de Juventudes se esfuerzan por divulgar una idea del país como un estado unido en el que participan todas las regiones españolas.

Frente a los nacionalismos en crecimiento durante el período republicano, la ideología falangista incita a la convivencia de todas las regiones con sus peculiaridades musicales y lingüísticas.

El repertorio de Sección Femenina es mayoritariamente folklórico y en él se aprecia la presencia y el respeto por las lenguas autóctonas como parte de la autenticidad de la recogida del material. No sólo es que las recojan en el idioma original, sino que además obligan a las niñas de todo el país a conocerlas y cantarlas en el idioma original. De hecho, toda una generación sabe canciones en gallego, catalán y vasco sin pertenecer a dichas regiones de origen.

Intentan que todos los ciudadanos conozcan un repertorio común de todo el estado como concebido como una unidad, con un reparto paritario de todas las regiones del país.

El caso del catalán afecta a las canciones procedentes de tres regiones: Valencia, Cataluña y Baleares.

En el caso de Valencia (Valencia, Alicante y Castellón) se puede apreciar una notable preferencia del catalán (casi el 75\%), y sin embargo es en relación a las otras dos regiones la que menos recogida en el idioma autóctona tiene.

$N^{\circ}$ DE CANCIONES VALENCIA

13 castellano

37 catalán
PROCENTAJES

$26,00 \%$

$74,00 \%$

Total 50 


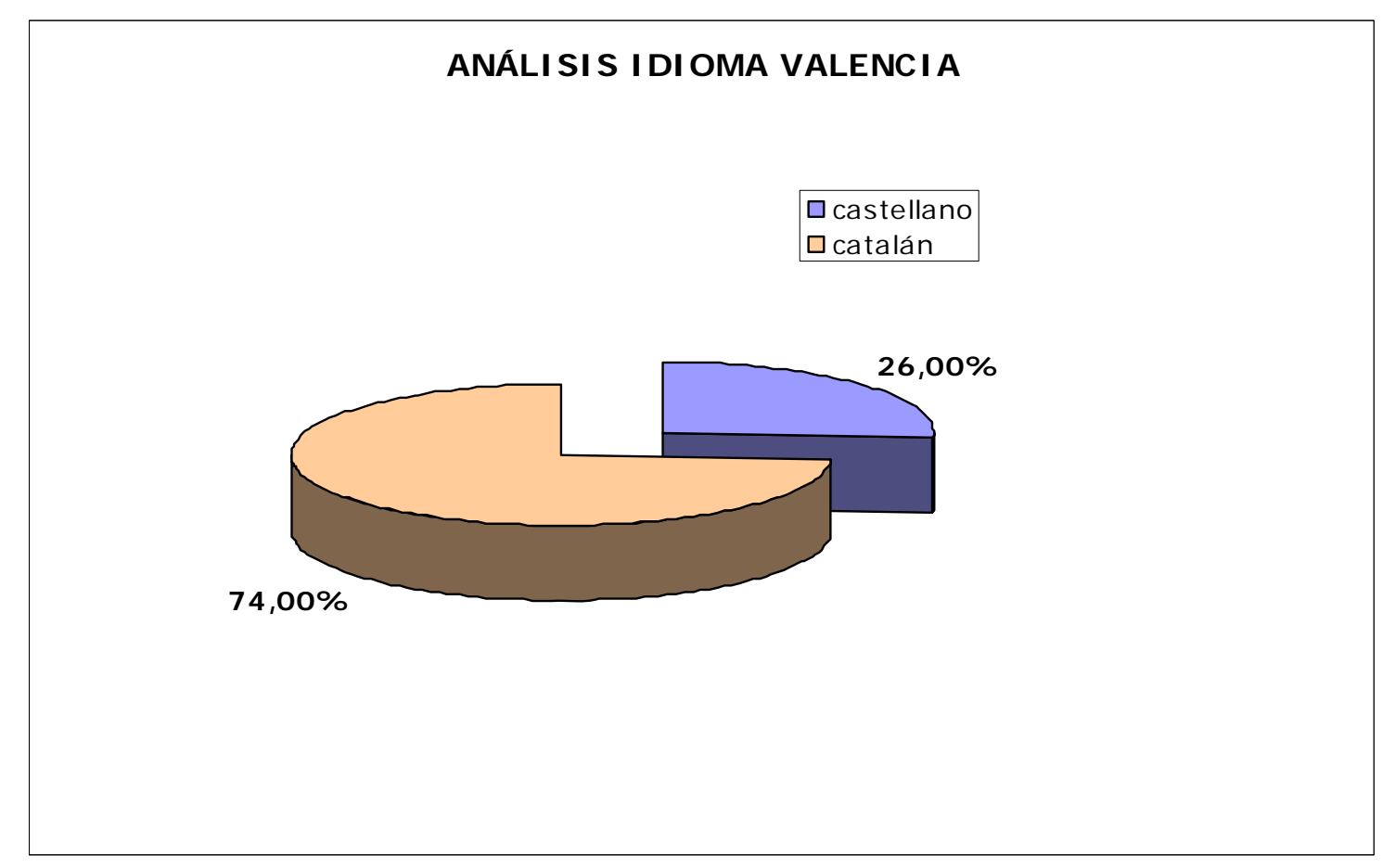

La zona de Cataluña (Barcelona, Gerona, Tarragona y Lérida) refleja una mayor presencia tanto en el número de canciones recogidas como en el porcentaje de uso del catalán (un 83\%)

$\mathbf{N}^{\circ}$ DE CANCIONES

\section{CATALUÑA}

15 castellano

77 catalán 92

Total.

\section{PROCENTAJES}

$16,30 \%$

$83,70 \%$ 


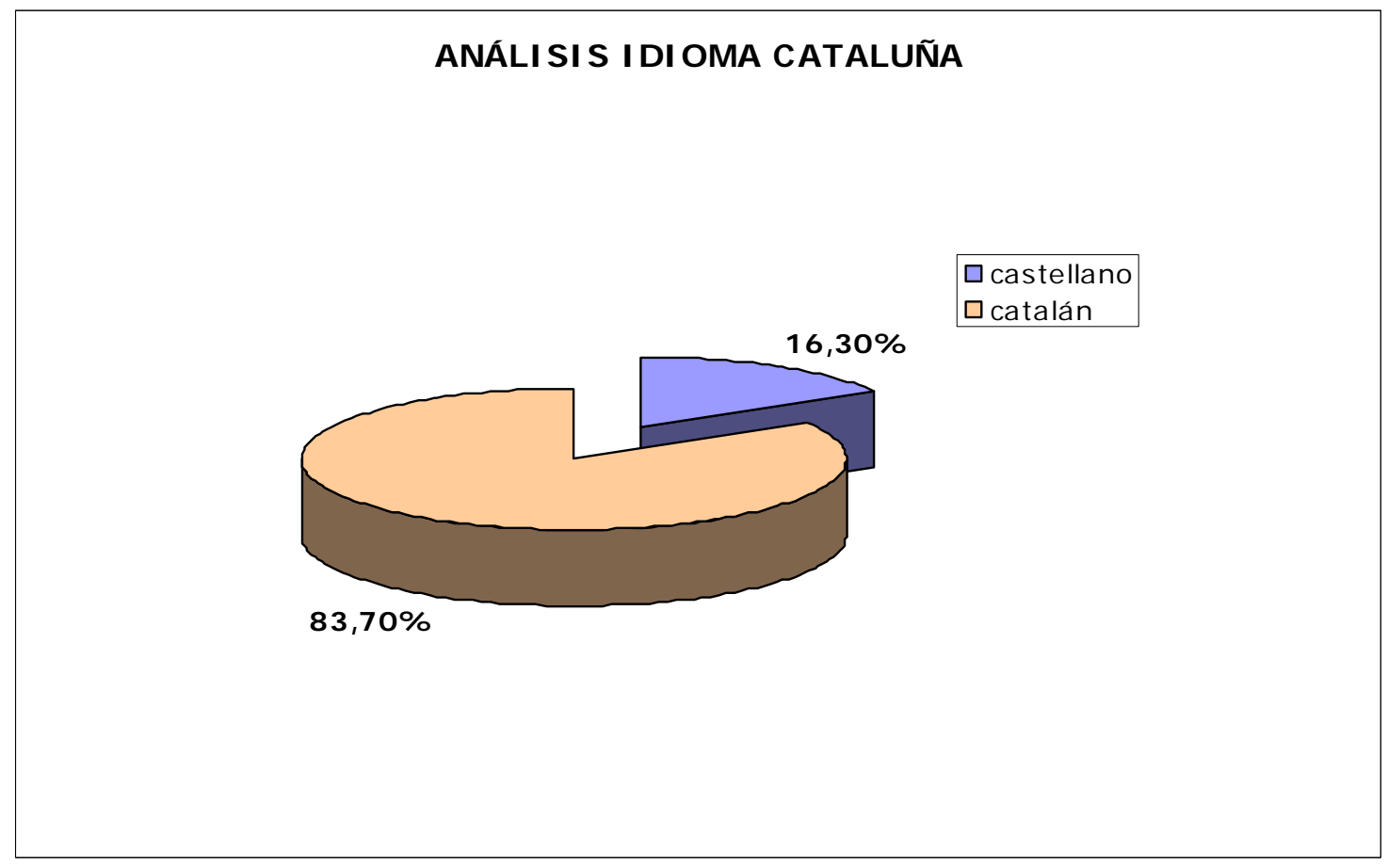

Las islas Baleares, por su menor extensión, son las que tienen menor número de canciones presentes en el cancionero, pero mantiene una alto porcentaje de ellas en el idioma original - probablemente de uso mayoritario y con menos contaminación folklórica de otras regiones debido al distanciamiento geográfico de la península (no había las facilidades de comunicación actuales, lo que provocaba cierto aislamiento)

\section{$N^{\circ}$ DE CANCIONES BALEARES}

15 Catalán

1 Castellano

2 instrumental 18

Total.

\section{PORCENTAJES}

$83,33 \%$

$5,56 \%$

$11,11 \%$ 


\section{Capítulo 6. Análisis musical del cancionero}

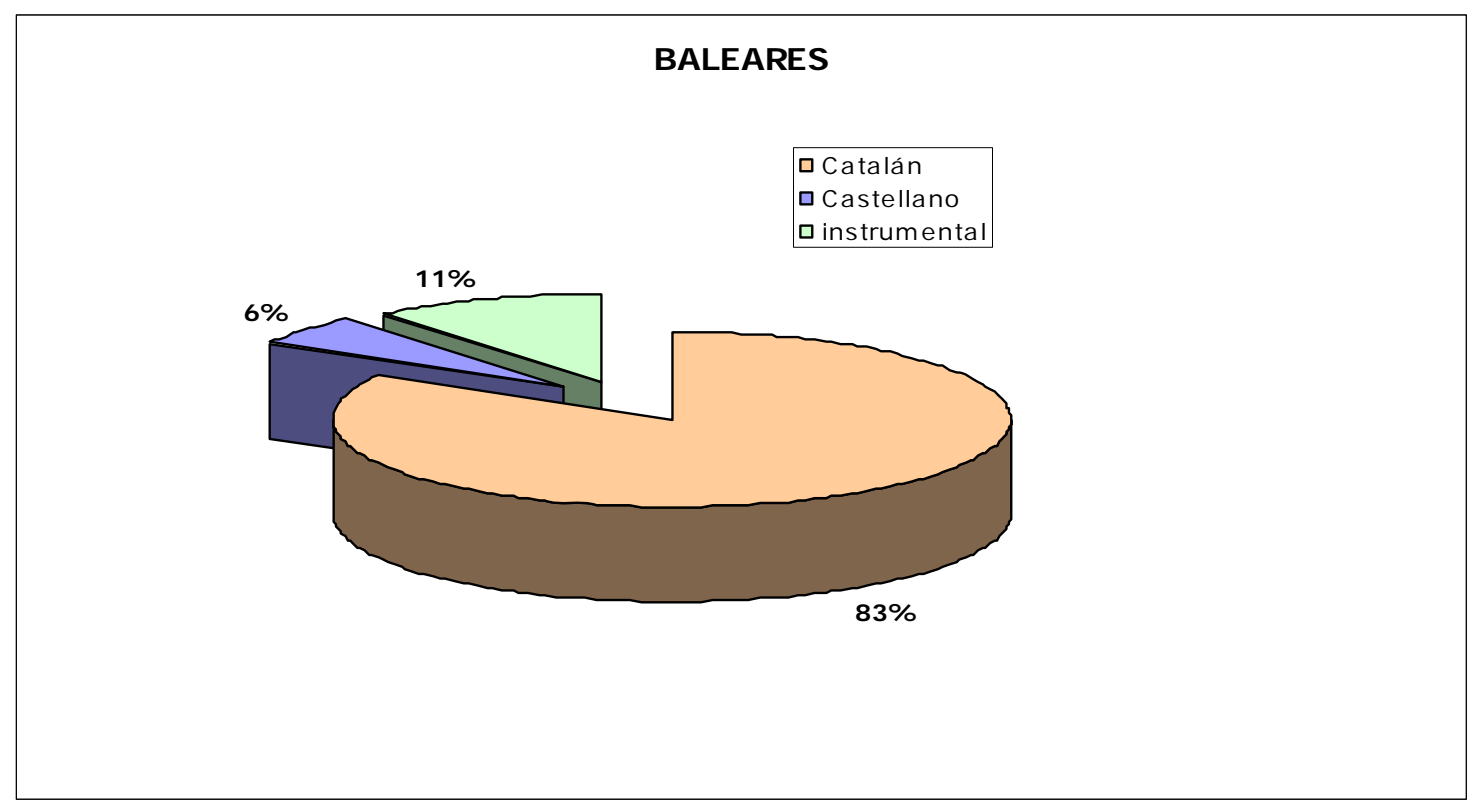

Otro caso singular es el uso del vasco o euskera, que a pesar de su evidente diferencia con respecto al resto de las lenguas del país, también aparece recogido en el repertorio. Su presencia, sin embargo, es mucho menor que la de las otras dos lenguas autóctonas (catalán y gallego). Hay que recordar que estas canciones eran cantadas en el idioma por las estudiantes de todas las demás regiones españolas. Y también que durante el franquismo, el euskera está en retroceso a las zonas rurales mientras las zonas urbanas industriales se desarrollan a base de emigrantes de otras zonas del país castellano parlantes. 


\section{ANÁLI SIS I DI OMA PAIS VASCO}

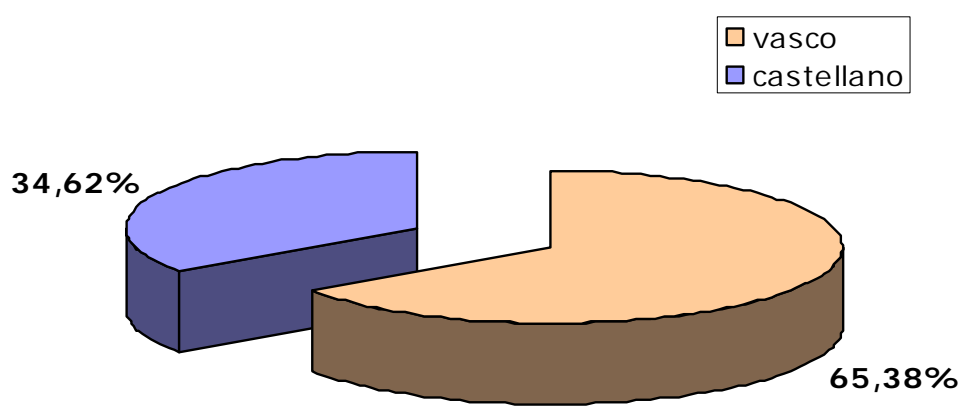

El gallego es el idioma más presente, después del castellano, en el cancionero. No sólo hay una gran presencia de canciones procedentes de Galicia (Orense, Pontevedra, Lugo, La Coruña), sino que prácticamente la totalidad de ellas están en el idioma original. Ello es debido probablemente a la ruralidad de esta región durante el franquismo y a una mayor tolerancia (es una lengua fácilmente comprensible por hiñas de otras regiones cercanas - Asturias, Zamora, León - y cercana en pronunciación y vocabulario al castellano).

\section{No DE CANCIONES GALICIA}

153 gallego

2 castellano

6 instrumental

\section{PORCENTAJES}

$95,03 \%$

$1,24 \%$

$3,73 \%$

Total. 


\section{ANÁLI SIS I DI OMA GALI CI A}

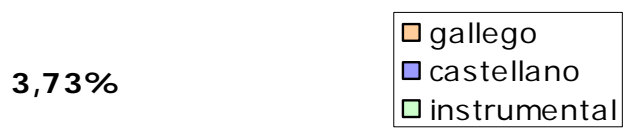

$1,24 \%$

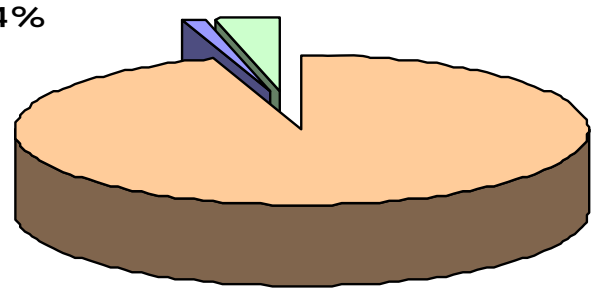

$95,03 \%$

En resumen, pese a las cuestiones ideológicas que en otros ámbitos especialmente en los niveles administrativo y educativo - impusieron el castellano como idioma único del estado, en el cancionero se muestra una gran tolerancia hacia las idiosincrasias lingüísticas en función de la preservación de la autenticidad del folklore

Aunque esta tendencia es más evidente en el repertorio recogido por Sección Femenina (donde la presencia del folklore es mayor), también se encuentra en los cancioneros de Frente de Juventudes.

\subsubsection{La importancia de las canciones}

La canción es el elemento fundamental de la educación musical en el franquismo.

La presencia de melodías instrumentales es muy inferior a la de canciones con texto. Algunas canciones tienen acompañamiento instrumental, pero también son una parte minoritaria del repertorio. 


\section{VOCAL / I NSTRUMENTAL}

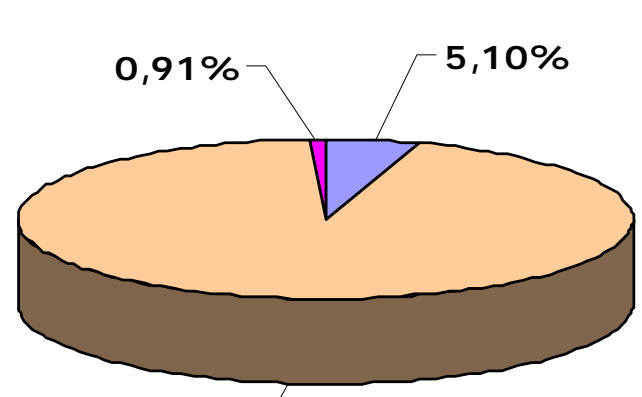

$\square$ Vocal Con Acompañamiento

$\square$ Vocal Sin Acompañamiento 口Instrumental

$93,99 \%$

En conclusión, que lo más importante para el cancionero es cantar.

La mayor parte del repertorio vocal es monódico, aunque aparecen versiones polifónicas a 2 voces y algunas armonizaciones a más voces, destinadas a los coros.

NÚMERO DE VOCES

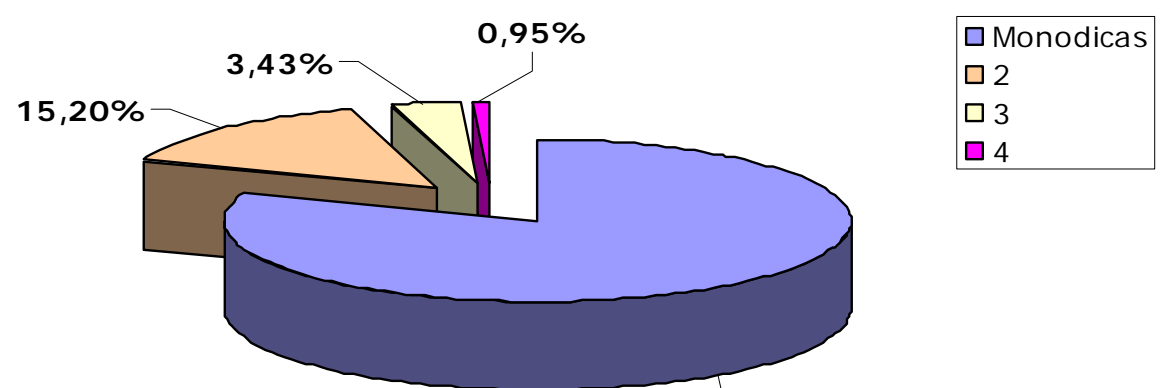

$80,42 \%$ 


\section{Capítulo 6. Análisis musical del cancionero}

De estos datos se desprende que la interpretación vocal fundamental es la canción monódica cantada individualmente 0 en grupo, aunque también se considera importante la interpretación en agrupaciones sencillas: coros monódicos o a dos voces.

En Mil canciones españoles aparece habitualmente el nombre de los autores de las armonizaciones a 2 y 3 voces de las canciones monódicas populares y es la principal fuente de las canciones polifónicas.

\subsubsection{Modalidad y tonalidad de las canciones}

Una gran parte de la música recogida en los cancioneros no se ajusta al sistema tonal, sino a las fórmulas de entonación modal (forma más antigua de organización de los patrones melódicos que pervive fundamentalmente en el folklore popular y en las melodías gregorianas)

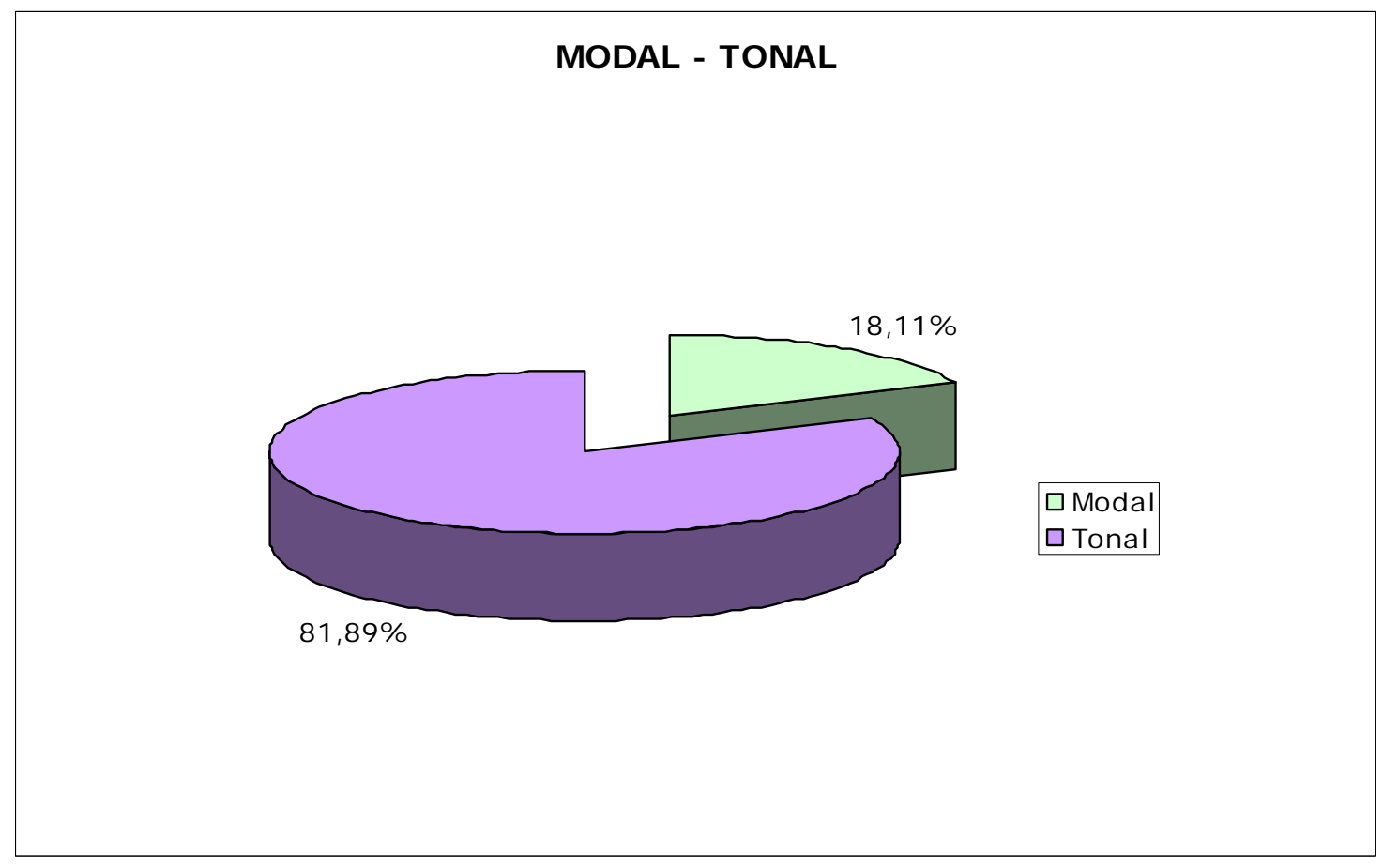

Dada la gran presencia de repertorio de origen folklórico y religioso en el cancionero de Sección Femenina, es lógico que aparezca mucha música modal no tonal. 


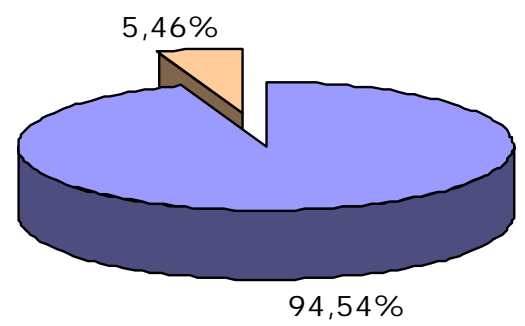

Por el contrario, la música modal que aparece en el Frente de Juventudes se refiere casi exclusivamente al repertorio religioso incluido en el Cancionero Juvnenil del hermano marianista Manuel Rodríguez.

En las canciones modales también se aprecia una gran diferencia según pertenezcan al folklore 0 al mundo religioso en las tónicas modales utilizadas

\section{FOLKLORE}

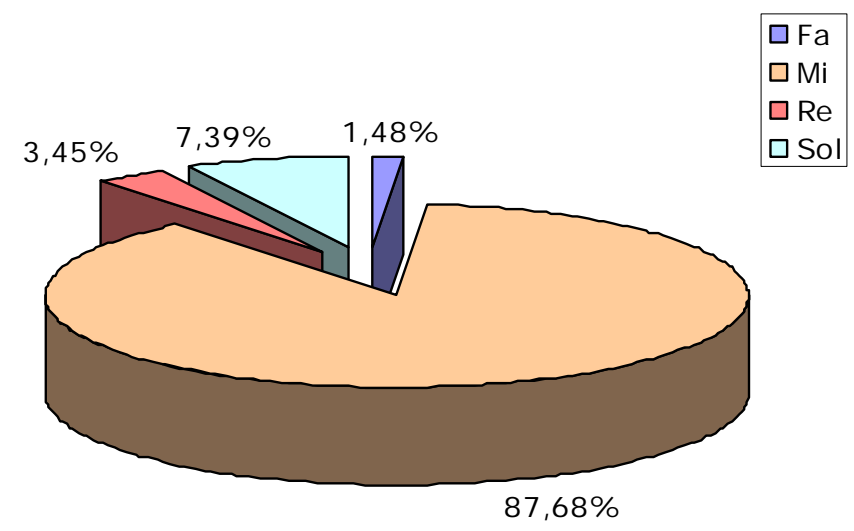




\section{Capítulo 6. Análisis musical del cancionero}

En el caso del repertorio folklórico, el modo fundamental utilizado - aunque en muchas ocasiones transportado - es del modo de mi.

\section{RELI GI OSA}

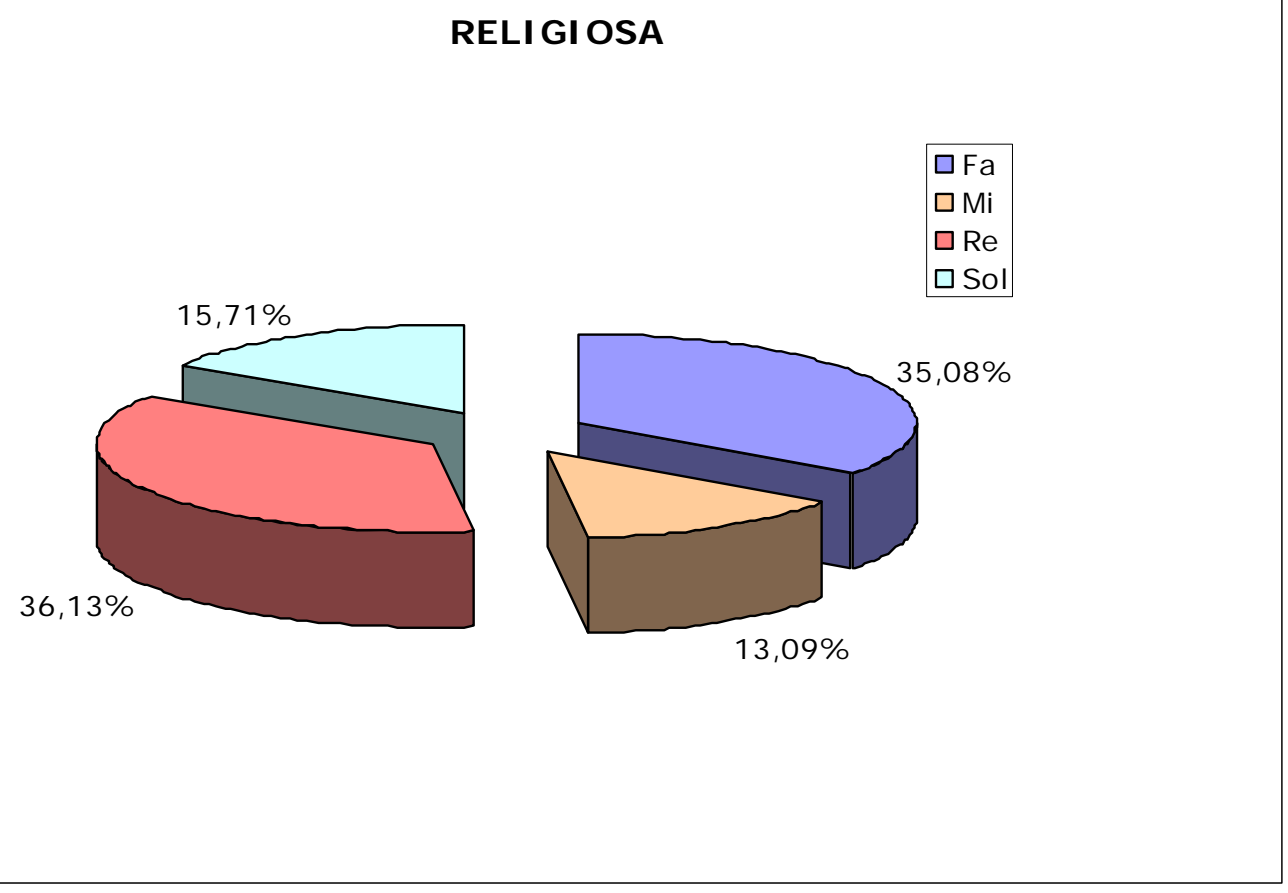

Sin embargo, en el repertorio gregoriano, se observa una mayor distribución, siendo prioritarios los modos de re y fa (origen de nuestros modos menor y mayor respectivamente), siendo el modo de mi minoritario.

\section{El repertorio tonal}

En cuanto a las canciones tonales, hay una clara preferencia por aquellas con un número menor de alteraciones, preferiblemente hasta tres sostenidos 0 bemoles. La mayor simplicidad a la hora de interpetar el repertorio en ciertos instrumentos, la comprensión de las tonalidades más sencillas y la subjetividad a la hora de juzgar la dificultad en la entonación al cantar con alteraciones, son algunas de las razones probables de esta selección de tonalidades. 


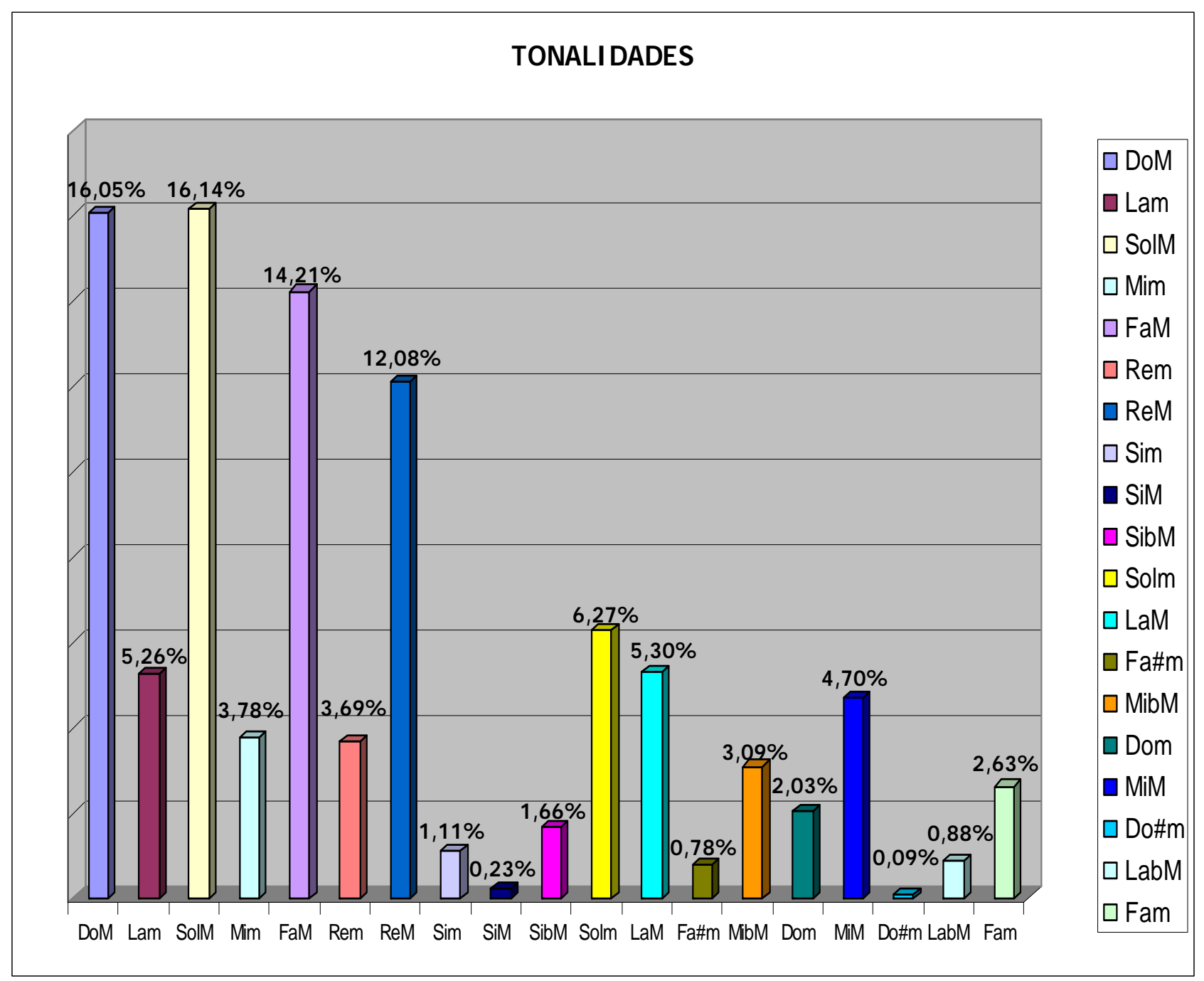

La mayor presencia del modo mayor es reflejo de la tonalización del repertorio.

Como era de esperar, Do Mayor (sin alteraciones) es la tonalidad favorita, junto con Fa Mayor (1 bemol) Sol Mayor (1 sostenido) y Re Mayor (2 sostenidos).

Sin embargo en el modo menor la tonalidad preferida es sol menor (2 bemoles), seguido por la menor (sin alteraciones), re menor ( 1 bemol) y mi menor (1 sostenido) 
Capítulo 6. Análisis musical del cancionero
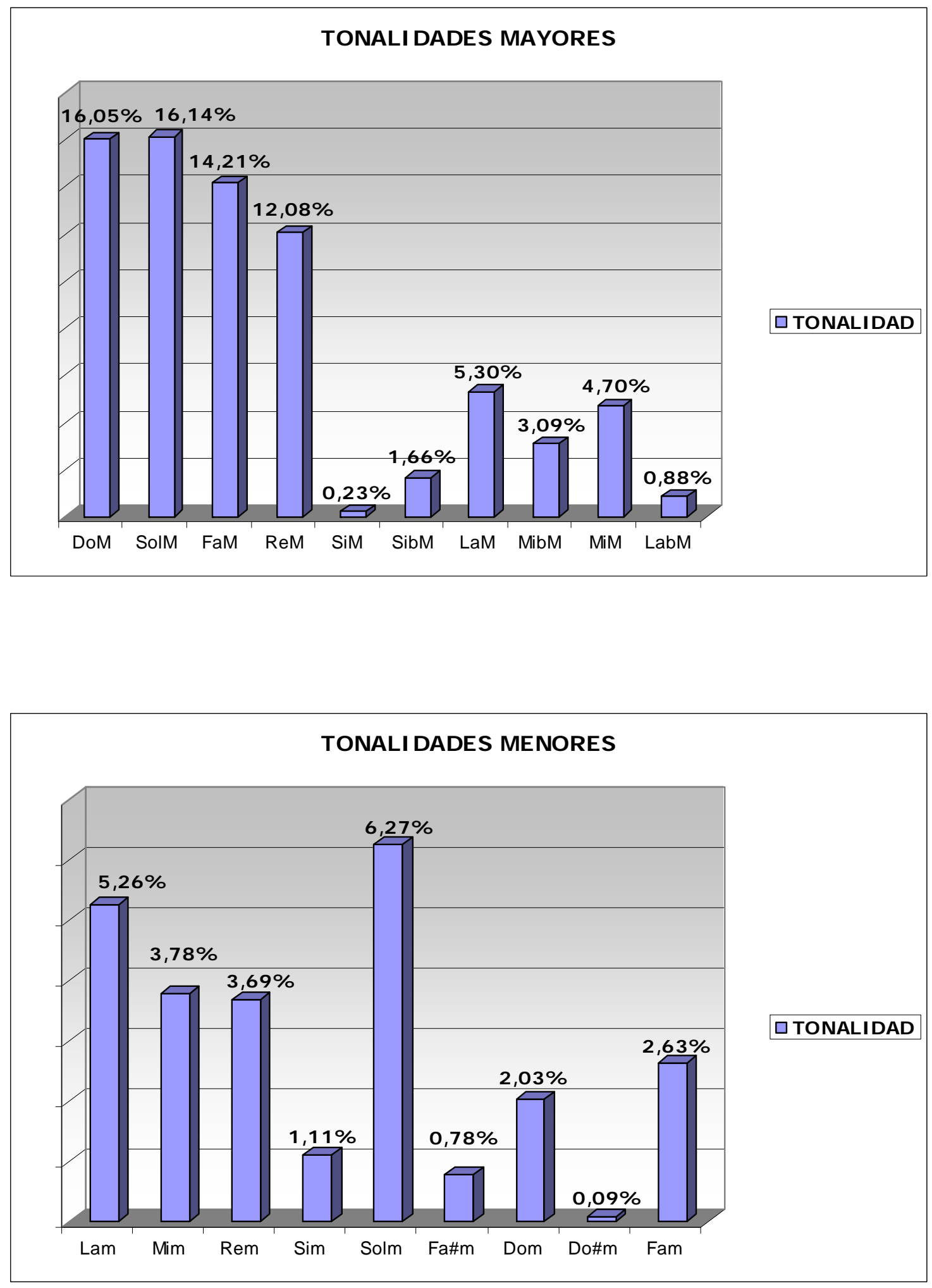


\section{La educación musical en el franquismo}

\subsection{Conclusiones del análisis}

A partir del análisis exhaustivo de las canciones recogidas en los materiales escolares y extraescolares del Frente de Juventudes y la Sección Femenina podemos llegar a una serie de conclusiones fundamentales.

1. Diferenciación en los repertorios de Sección Femenina y Frente de Juventudes, tanto en los contenidos como en los usos para actividades diversas

2. Importancia del folklore y conservación de algunos rasgos en función de la autenticidad (modalidad, respeto por las lenguas)

3. Intención de paridad en la distribución regional de las canciones

4. Pervivencia de la modalidad en el folklore y las canciones religiosas (gregoriano)

5. Importancia de la tonalidad en las canciones infantiles, modernas y en los himnos y marchas

6. Preponderancia de la canción como elemento fundamental de la educación musical

7. Preferencia por la interpretación monódica (aunque también aparecen canciones armonizadas para coros, fundamentalmente a dos y a tres voces)

8. Facilidad en el lenguaje musical: tonalidades con pocas alteraciones, interválica inicial sencilla, compases $2 / 4,3 / 4,3 / 8$ y 6/8

Todo ello nos lleva a la configuración de un repertorio grande en tamaño y diverso en contenidos, asequible para la formación previa de instructores y maestros (en principio), así como para la interpretación por parte de los niños y adolescentes. Es un cancionero asequible para toda la población, bien aprendido por medio de la imitación o bien a través de los conocimientos del lenguaje musical (no resulta imprescindible tener conocimientos profundos de música para su interpretación). 


\section{CAPÍTULO 7. CONCLUSIONES}

\subsection{Existió una educación musical organizada en los niveles educativos durante el franquismo}

De hecho, una parte importante de la investigación ha consistido en la localización de fondos documentales y el análisis de material musical de la época. La sistematización de ambas ha llevado a la catalogación de un fondo musical básico utilizado en los niveles escolares de la población española entre los años 1940 y 1975.

Entre los fondos documentales importantes destacan las normativas legales referentes a la presencia de la música en los ámbitos educativos a tres niveles:

- Educación primaria

- Educación secundaria

- Formación de maestros

\begin{tabular}{|l|l|}
\hline \multicolumn{2}{|l|}{ Normativa sobre educación musical en la Educación Primaria } \\
\hline Orden de 13 de marzo de 1941 & Regulación de las clases complementarias \\
\hline $\begin{array}{l}\text { Ley de Educación Primaria de 17 } \\
\text { de junio de } 1945\end{array}$ & $\begin{array}{l}\text { Capítulo IV: asignaturas complementarias } \\
\text { incluye Música y canto } \\
\text { Art. 38 asigna los cuestionarios de Canto y } \\
\text { música al Movimiento } \\
\text { Capítulo V: Actividades complementarias en } \\
\text { la escuela, art. 44 y 45 dedicados a la } \\
\text { formación extraescolar }\end{array}$ \\
\hline $\begin{array}{l}\text { Cuestionario de Enseñanza } \\
\text { Primaria. O.M. de 8 de julio de } \\
1965\end{array}$ & $\begin{array}{l}\text { Cinco sectores educativos: Técnicas de } \\
\text { expresión artística (dibujo, música y } \\
\text { canto y manualizaciones) A la educación } \\
\text { artística se le dedican 2 horas y media a la } \\
\text { semana y tiene presencia desde 1o hasta 8o }\end{array}$ \\
\hline
\end{tabular}




\begin{tabular}{|l|l|}
\hline & Curso \\
& $\begin{array}{l}\text { Los contenidos se basan en el canto e } \\
\text { interpretación de canciones, audiciones } \\
\text { musicales, principios básicos del solfeo y } \\
\text { coro a dos voces }\end{array}$ \\
\hline $\begin{array}{l}\text { Ley General de Educación de la } \\
\text { Reforma Educativa de 4 de } \\
\text { agosto de 1970 }\end{array}$ & $\begin{array}{l}\text { Se crea el área de expresión dinámica en } \\
\text { la que se incluyen música y educación } \\
\text { física. }\end{array}$ \\
\hline Decreto de 25 de mayo de 1972 & $\begin{array}{l}\text { Regula las titulaciones necesarias para } \\
\text { impartir el área de expresión dinámica en la } \\
\text { Segunda Etapa de EGB }\end{array}$ \\
\hline Orden de 4 de mayo de 1973 & $\begin{array}{l}\text { Cursillos de especialización para maestros } \\
\text { de Segunda Etapa de EGB. Modalidad: } \\
\text { Música y dramatiazación }\end{array}$ \\
\hline
\end{tabular}

\begin{tabular}{|c|c|}
\hline Normativa sobre educación & nusical en la Enseñanza Secundaria \\
\hline Orden de 30 de junio de 1941 & $\begin{array}{l}\text { Creación de las Escuelas de Hogar en los } \\
\text { Institutos Femeninos: entre las asignaturas a } \\
\text { impartir se encuentra la música }\end{array}$ \\
\hline $\begin{array}{l}\text { Ley de } 26 \text { de febrero de } 1953 \\
\text { sobre Ordenación de la } \\
\text { enseñanza Media }\end{array}$ & $\begin{array}{l}\text { Asignación de la docencia de las Escuelas del } \\
\text { Hogar (música y otras) a la Delegación } \\
\text { nacional de la Sección Femenina }\end{array}$ \\
\hline $\begin{array}{l}\text { Orden de } 3 \text { de noviembre de } \\
1953\end{array}$ & $\begin{array}{l}\text { Art. 44. Asignación de la docencia de las } \\
\text { Escuelas del hogar a Sección Femenina. } \\
\text { Art. 46. "La educación patriótica corresponde } \\
\text { al profesor de Formación del Espíritu } \\
\text { Nacional y habrá de abarcar (...) c.- Cantos } \\
\text { nacionales y patrióticos }\end{array}$ \\
\hline
\end{tabular}




\begin{tabular}{|l|l|}
\hline & $\begin{array}{l}\text { Art. 50. Fomento de la organización de coros, } \\
\text { orfeones, rondallas y cuadros de declamación } \\
\text { así como veladas artísticas y sesiones } \\
\text { musicales }\end{array}$ \\
\hline Orden de 21 de enero de 1954 & $\begin{array}{l}\text { Cuestionarios correspondientes a la música } \\
\text { que está presente en todos los cursos. } \\
\text { Incluyen nociones de solfeo, canto coral e } \\
\text { historia de la música. } \\
\text { No hace alusión a la separación entre } \\
\text { alumnos y alumnas, sino que aparece en las } \\
\text { materias comunes }\end{array}$ \\
\hline
\end{tabular}

\begin{tabular}{|l|l|}
\hline \multicolumn{2}{|l|}{ Normativa sobre educación musical del profesorado de primaria } \\
\hline Decreto de 10 de febrero de 1940 & Título de maestro-bachiller \\
\hline Orden de 14 de agosto de 1942 & $\begin{array}{l}\text { Se convalidan las titulaciones de } \\
\text { conservatorio por las asignaturas de } \\
\text { música }\end{array}$ \\
\hline $\begin{array}{l}\text { Orden de 24 de septiembre de } \\
1942\end{array}$ & $\begin{array}{l}\text { Asignaturas no del bachiller para obtener } \\
\text { el título de maestro: entre ellas música 1 } \\
\text { y } 2 \text { que deben cursar de forma libre ( o } \\
\text { haber convalidado por titulaciones de } \\
\text { conservatorio) }\end{array}$ \\
\hline $\begin{array}{l}\text { Orden de 27 de noviembre de } \\
1943\end{array}$ & $\begin{array}{l}\text { Reestructuración de los estudios de } \\
\text { Magisterio. 20 curso: música obligatorio, 2 } \\
\text { horas por semana }\end{array}$ \\
\hline Orden de 26 de octubre de 1944 & $\begin{array}{l}\text { Reestructuración de los estudios de } \\
\text { Magisterio: también en 3o curso: música } \\
\text { obligatoria, 2 horas por semana }\end{array}$ \\
\hline $\begin{array}{l}\text { Orden de 9 de octubre de 1945 o } \\
\text { “Plan profesional” }\end{array}$ & $\begin{array}{l}\text { La música está comprendida dentro de los } \\
\text { "cursos prácticos de especialización" en }\end{array}$ \\
\hline
\end{tabular}




\begin{tabular}{|c|c|}
\hline & $\begin{array}{l}\text { los que se incluyen idiomas, cantos } \\
\text { escolares, enseñanzas artísticas y } \\
\text { organizaciones postescolares } \\
\text { Cuestionario de Cantos escolares }\end{array}$ \\
\hline Orden de 14 de octubre de 1946 & $\begin{array}{l}\text { Aparece como parte de los "cursos } \\
\text { prácticos de especialización" pero } \\
\text { desglosada como música, con carácter } \\
\text { obligatorio para ambos sexos. }\end{array}$ \\
\hline Orden de 26 de octubre de 1946 & $\begin{array}{l}\text { Aparece música en los tres cursos, con } 2 \\
\text { horas semanales en } 10 \text { y } 1 \text { hora en } 20 \text { y } \\
\text { o respectivamente }\end{array}$ \\
\hline $\begin{array}{l}\text { Reglamento de las Escuelas de } \\
\text { Magisterio de } 7 \text { de julio de } 1950 \\
\text { ((BOE } 7 / 8 / 1950)\end{array}$ & $\begin{array}{l}\text { Se exige el bachillerato elemental. Se } \\
\text { imparte en } 20 \text { como Música, elementos } \\
\text { de solfeo y cantos religiosos, } \\
\text { patrióticos y escolares y } 30 \text { curso como } \\
\text { Música: cantos, con presencia de dos } \\
\text { horas semanales }\end{array}$ \\
\hline Orden de 10 de julio de 1951 & $\begin{array}{l}\text { Cuestionario de } 2^{\circ} \text { curso: Música, } \\
\text { elementos de solfeo y cantos religiosos, } \\
\text { patrióticos y escolares }\end{array}$ \\
\hline Orden de 20 de marzo de 1952 & Cuestionario de 3o curso: Música: cantos \\
\hline $\begin{array}{l}\text { Decreto de } 2 \text { de febrero de } 1967 \\
\text { (Plan de estudios) }\end{array}$ & $\begin{array}{l}2 \text { horas semanales en dos cursos. } \\
\text { Contempla los "Cursos de Capacitación de } \\
\text { tiempo libre" y las relaciones con las } \\
\text { Delegaciones y Servicios del Movimiento y } \\
\text { la Educación primaria. } \\
\text { Cuestionarios de Música } \mathbf{1} \text { y } \mathbf{2}\end{array}$ \\
\hline Resolución de 29 de julio de 1972 & $\begin{array}{l}\text { Contenido de los cursos para formar } \\
\text { profesores de Segunda Etapa de EGB }\end{array}$ \\
\hline Ordenes de 4 de mayo y 11 de & Convocatoria de cursos de especialización \\
\hline
\end{tabular}


Luego, desde el punto de vista legal, la educación musical está contemplada a lo largo del sistema educativo general desde los años 40.

La asignación de determinados contenidos educativos - entre ellos la música - a las Delegaciones Nacionales del Movimiento se produce desde la Ley General de Educación de 1945, lo que supone una doble asignación de cometidos y bastante confusión, ya que ello no supone la dotación inmediata de personal en todos los casos, especialmente en los centros educativos alejados de los centros urbanos. Los maestros siguen siendo los responsables finales de la formación obtenida por los alumnos, pero no parece que en realidad hubiera unos protocolos claros de reparto de trabajo y tareas establecidos y unificados.

Ello implica una gran disparidad de situaciones todas ellas posibles dentro del mismo marco legal:

- Maestros que impartían toda la docencia asignada a la Delegación del Frente de Juventudes o Sección Femenina, ya que todos tenían que haber superado el título de instructores elementales para conseguir el título de maestro

- Centros en los que además del maestro, otros instructores de las Delegaciones del Movimiento colaboraban en ciertas asignaturas. Esta colaboración era más evidente en Educación Física y Formación del Espíritu Nacional, pero las responsabilidades en cuanto a la educación musical quedan más diluidas.

- Centros en los que la totalidad de las materias asignadas a las Delegaciones del Movimiento tenían dotado profesorado especial a propuesta de Frente de Juventudes y Sección Femenina. Este caso se solía dar en los Institutos públicos de las capitales de provincia, pero en general, las dotaciones de personal eran escasas y se realizaban las 


\section{La educación musical en el franquismo}

asignaciones por prioridades. Los centros escolares de primaria estaban situados en segundo orden.

- Centros en los que había un gran rechazo al profesorado de las Delegaciones Nacionales del Movimiento, especialmente en los centros educativos privados de la iglesia, que prefieren forman a su propio personal (titulado a través de escuelas privadas de magisterio y a veces sin titulación) o contratar a personal ajeno con experiencia musical.

- Centros rurales y alejados de los núcleos urbanos, donde el maestro es el encargado de toda la docencia, aunque puede recurrir a las delegaciones locales del Movimiento. Tiene la obligación de colaborar en las actividades extraescolares organizadas por el Movimiento (como las cátedras ambulantes, la recogida de canciones y danzas para el fichero de Sección Femenina...)

La propia Ley de Educación de 1945 deja confusos los límites entre educación formal y educación no formal en lo que se refiere a las actividades de educación musical. No especifica la dedicación horaria en el sistema normalizado, pero contempla la posibilidad de realización de tareas en período extraescolar como parte del sistema: coros, rondallas, actividades de campamentos y albergues juveniles, conciertos.

Ello implica una gran complejidad a la hora de establecer cómo se realizaba la formación musical, ya que en muchos casos se realizaba en instalaciones ajenas y en actividades no controladas por el maestro: actividades de tiempo libre, grupos infantiles y juveniles de formación extraescolar, organizaciones juveniles del Movimiento.

No se realiza una programación de contenidos obligatorios ajustados a los diferentes cursos de la educación primaria hasta los Cuestionarios de 1965, por lo que éstos son desiguales, variados y sin progresión concreta.

La asignatura no tiene un carácter evaluable, sino más bien participativo y lúdico, con un pequeño porcentaje formativo hasta mediados de los años 60 . 
En un primer momento (años 40 y 50) se concentra en el canto de repertorios predeterminados políticamente y folklóricos. A partir de los cuestionarios de Enseñanza Media de 1954, aparecen explícitos contenidos de lenguaje musical e historia de la música, además del canto al unísono y en coro. Estos bloques de contenido se incorporan a la Educación Primaria en los cuestionarios de 1965. La Ley de Reforma Educativa de 1970 implica un gran cambio en los contenidos, vinculándolos a otras áreas como la dramatización y la educación física, así como la formación de profesorado especializado para impartirlos en la Segunda Etapa de la EGB, con arreglo a los nuevos principios pedagógicos y a la introducción de los métodos de educación musical europeos en nuestro país. La presencia de la Música en el BUP como asignatura evaluable es una innovación relevante en el currículo.

\subsection{Características básicas}

\subsubsection{La diferencia de género.}

Si hay algo que caracteriza la educación musical del período franquista es la diferenciación de género, es decir, la completa divergencia entre la educación musical de las niñas y de los niños.

Ciertamente, la educación escolar mixta no era una práctica habitual tampoco en los períodos anteriores, aunque la II República había intentando introducir cambios significativos en la instrucción pública y en la posibilidad de acceso de la mujer a la educación. No obstante, la coeducación era excepcional salvo en aquellos casos de necesidad extrema: escuelas unitarias donde el escaso número de alumnos no permitía que hubiera escuelas primarias femeninas y masculinas o centros urbanos con un único instituto de secundaria. Aun en estos casos, la mayoría de los alumnos era claramente masculina y en general, si se podía afrontar económicamente, la educación femenina se impartía a través de colegios e instituciones privadas, muchas de ellas de carácter religioso, o a través de los colegios menores de la Sección Femenina. Se trata de un hecho generalizado en todo el ámbito y aplicable a la totalidad del currículo escolar tanto en la educación primaria como secundaria. 


\section{La educación musical en el franquismo}

Pero, en el caso de la educación musical, dichas diferencias se hacen aún más patentes. Ello se debe a varias razones

a.- La asignación por la ley de educación de la enseñanza musical al Movimiento coincide con el Decreto de separación de Frente de Juventudes y Sección Femenina. Desde 1945 ambas instituciones funcionan separadamente y en el caso de la educación musical con criterios completamente divergentes tanto en los objetivos de aprendizaje como en los materiales educativos y los procedimientos didácticos. En realidad sólo colaboran, en el concurso nacional de villancicos escolares (de cuya laboriosa organización se encargaba Sección Femenina, pero que como incluía a los coros masculinos, tenía que contar con el visto bueno del J efe del Frente de Juventudes).

b.- La creación en los institutos de secundaria femeninos de las Escuelas de Hogar, entre cuyas materias figura la música, supone una diferenciación neta con respecto a los centros masculinos, en los que no hay legislación de cómo se debe afrontar la asignatura.

c.- La enorme disparidad a la hora de enfocar y seleccionar el repertorio que se enseña a uno y otro sexo. Los textos y sus contenidos son totalmente diferentes: mientras en los centros femeninos se presta especial atención a los contenidos de folklore, música religiosa e historia de la música, en los centros masculinos se aprecia el peso específico de la educación política y de transmisión ideológica.

d.- El personal que impartía la asignatura estaba vinculado a Sección Femenina en el caso de los centros femeninos (bien personal formado entre sus afiliadas, bien colaboradores músicos profesionales). El personal que impartía la asignatura vinculado a Frente de Juventudes rara vez se ocupaba de la educación musical en la presencia formal (dando prioridad a la Formación del Espíritu Nacional y a la Educación Física) y prefería la educación musical en los entornos no formales de carácter más lúdico (campamentos, excursiones, coros y rondallas). 


\section{Capítulo 7. Conclusiones}

e.- Los repertorios aprendidos, aunque con algunas canciones comunes (pocos himnos y algunas canciones populares del folklore) son fundamentalmente diferentes en función del género de los estudiantes.

f.- Por su parte, los colegios privados (mayoritariamente de tipo religioso) procuraban evitar la contratación de profesorado ajeno para impartir la asignatura de música y formaban en general a su propio profesorado, bien en las diferentes tendencias pedagógicas asociadas a la música litúrgica (el método Ward, la escolanía de Montserrat, la escolanía de El Escorial) o bien reservando esta docencia a profesores de las órdenes religiosas con formación musical previa (seminarios mayores y menores, formación de conservatorio etc.). La educación musical masculina parece tener un carácter de tipo más cultural en los colegios privados que en los centros públicos. La educación musical femenina tiene un carácter religioso mayor en los centros privados.

\subsubsection{La educación musical dentro de la educación formal y no formal}

En el caso de la educación musical se produce una gran confusión entre lo que hoy consideramos ámbitos de educación formal y no formal.

Esta confusión viene ya establecida en la propia redacción de la Ley de Educación de 1945, que contempla actividades escolares y extraescolares vinculadas a las enseñanzas impartidas por las instituciones vinculadas al Movimiento, entre las que se detallan específicamente actividades culturales (conciertos, coros y rondallas, audiciones) y actividades lúdico-formativas al aire libre (campamentos, actividades deportivas, excursiones) de carácter obligatorio para todos los alumnos vinculadas al currículo y al sistema escolar.

En muchos casos, especialmente en la educación masculina, la educación musical (sobre todo los Cantos patrióticos) parece estar estrechamente vinculada a este tipo de actividades (sobre todo en los campamentos) y a los actos públicos de carácter oficial con presencia de otros emblemas y signos: cantar el "Himno Nacional al izar la bandera, entonar el "Cara al Sol" en los 


\section{La educación musical en el franquismo}

actos oficiales, desfilar entonando himnos de diversa índole - militares y políticos -.

En el caso de la educación femenina, la orientación de la educación musical parece más vinculada al entorno familiar y a la propia formación. Como actividades colectivas se promueven sobre todo los coros y todo lo relacionado con la divulgación e investigación del folklore, dando mucha importancia a las danzas y los cantos populares y tradicionales. En el ámbito más cultural, está destinada a la mejora de la formación de la mujer en un plano más individualizado, con el fin de "desarrollar la sensibilidad". Los himnos se reservan prácticamente para los actos oficiales y sólo en parte de las actividades de campamentos, pero con una presencia muy minoritaria frente a la mucho mayor importancia de los repertorios folklóricos y religiosos.

Desde el principio, los colegios menores y las casas de flechas y margaritas contemplan como parte de las actividades juveniles la creación de coros y rondallas. En los centros masculinos abundan las formaciones de tipo pseudomilitar, con grupos instrumentales de cornetas y tambores y en los centros femeninos se crean numerosos grupos de coros y danzas en los que se integran hombres como parte de la formación instrumental y bailarines.

La formación musical queda pues compartida entre los dos ámbitos vinculados al sistema escolar, formal y no formal, pero no siempre quedan bien definidos los márgenes de las actividades a realizar entre uno y otro. La vinculación obligatoria de todo el profesorado primario al Movimiento (todos tenían que tener el título de Instructor Elemental para poder ejercer) hace que se entremezclen sus funciones y entornos cuando realizan sus actividades musicales. Tanto es así, que nunca queda del todo claro cuándo el material es evaluable y cuándo no, ni qué contenidos forman parte del currículo obligatorio y cuáles no. Esta disfunción queda patente en las publicaciones para maestras (Consigna) que entremezclan las actividades musicales para sus afiliadas de edades infantiles con las de la escuela sin distinguir qué elementos serán evaluables en uno y otro ámbito. 


\section{Capítulo 7. Conclusiones}

Así pues, la formación musical se confunde en muchas ocasiones con las actividades extraescolares o con la formación lúdica complementaria a nivel de educación primaria.

En el campo de la evaluación, parece que se siguen patrones de valoración actitudinal y de participación a la hora de evaluar los contenidos en lugar de programarlos desde el punto de vista técnico.

En el plano pedagógico, el aprendizaje es mayoritariamente memorístico e imitativo, más con la finalidad participativa global que en el nivel de crecimiento del conocimiento o de la expresión individual. Nunca está verdaderamente claro y programado cuáles van a ser las sesiones y los contenidos escolares y cuáles los extraescolares, con lo que se crea la sensación de ser una asignatura de carácter lúdico, complementario y frecuentemente vinculada a las actividades extraescolares, más que de ser una parte obligatoria del currículo.

Las orientaciones pedagógicas son diferentes con respecto a otras asignaturas con especial importancia de la consecución de objetivos de carácter más emocional que formativo ("que les guste, no hay que obligar a cantar")

En conclusión:

- NO se percibe la educación musical como una parte del currículum educativo en la enseñanza primaria

- Se confunde con las actividades extraescolares

- Se evalúa con criterios actitudinales y de participación y no conforme a la consecución de unos objetivos educativos propios

- Se parte de la idea de que hay "gente con cualidades musicales innatas" y no de la capacidad formativa y educativa para educar dichos valores

- El principal objetivo de la música en la educación no formal se ciñe a los valores para la relación grupal por medio del canto y de la danza colectivos. 


\section{La educación musical en el franquismo}

\section{3 ¿Quién impartió la educación musical}

La educación musical está muy estrechamente ligada a los procesos de formación recibidos por aquellas personas que la imparten, ya que su percepción de la actividad musical y la metodología aplicada varían enormemente según la propia experiencia en la aproximación a la interpretación musical.

En un primer momento podemos destacar que hay una gran cantidad de personas que impartieron conocimientos musicales sin estar suficientemente formados, por lo que transmitieron sus propias inseguridades en algunos aspectos importantes lo que instaló de forma colectiva algunas premisas poco educativas:

- La entonación es difícil

- Está ligada a cualidades innatas no educables

- El oído musical es una capacidad de unos pocos

- El lenguaje musical es un elemento de complicado aprendizaje

- No es útil ni necesario, es más fácil aprender las melodías por imitación

\subsubsection{Los maestros}

Los maestros y maestras recibían una formación específica de formación musical al estudiar su carrera en las Escuelas Normales y posteriormente ( con ley de Reforma educativa de 1970 en las Escuelas Universitarias de Formación del Profesorado).

Dicha formación se extendía a lo largo de dos cursos completos y era impartida por profesores que provenían a su vez de la formación profesional de los conservatorios como titulados superiores y que accedían a las plazas mediante concursos de oposición. El profesorado no numerario también tenía formación profesional musical. 
Los contenidos que estudiaban en las Escuelas normales los futuros maestros, según se puede colegir de las publicaciones específicas como la de Tratado de música para las Escuelas de Magisterio de Soler Palmer y Arnaudas Larrode o el Educación musical / y // de Matilde Murcia ya del período final, así como los cuestionarios de 1946, 1951 y 1952 $2^{253}$, demuestran una fuerte predominancia de los contenidos de lenguaje musical y solfeo: compases, tonalidades, dificultades rítmicas (síncopas, contratiempo) y de las canciones como principal recurso didáctico. Es una formación de gran carga teórica pero poco vinculada a la práctica escolar posterior y desprovista en la mayoría de los casos de nociones metodológicas para su aplicación en la escuela. Se trata más bien de una formación que permita a los maestros acceder al lenguaje musical y los repertorios recogidos en los cancioneros, pero no vinculada a la enseñanza de los rudimentos del lenguaje musical con los niños.

La formación del magisterio (que se convalida por la formación de carácter profesional de los conservatorios) se completa con indicaciones y aplicaciones prácticas en los cursillos organizados por el Frente de Juventudes y la Sección Femenina para maestros de carácter obligatorio, en los que hay una gran carga de repertorios seleccionados de canciones cuyo objetivo es interpretar y conocer (en muchos casos repitiendo por procedimientos memorísticos e imitativos).

A partir de finales de los años 60 se incorporan grandes novedades metodológicas en la enseñanza musical escolar: la interpretación con instrumentos de placas y flautas, los ejercicios rítmicos basados en el lenguaje y las palabras y la predominancia de canciones pedagógicas sobre las procedencias folklóricas e ideológicas (hasta entonces mayoritarias en los cancioneros). Se introducen también novedades metodológicas importantes, sobre todo difundidas a través de los cursillos de los incipientes Institutos de Ciencias de la Educación de las diferentes universidades, especialmente del método Orff en estos primeros años de la Educación General Básica. En la

\footnotetext{
${ }^{253}$ Cuestionarios publicados en las Órdenes Ministeriales de 9 de Octubre de 1946, 10 de julio de 1951 y 20 de marzo de 1952, respectivamente
} 


\section{La educación musical en el franquismo}

difusión de estas nuevas metodologías colaboran también activamente el profesorado de las nuevas Escuelas Universitarias del profesorado (hasta entonces Escuelas Normales del Magisterio) y la Sección Femenina.

\subsubsection{Los instructores del Frente de Juventudes}

En el marco de la enseñanza no reglada de los varones juega un papel determinante la actividad relacionada con la enseñanza musical llevada a cabo por los instructores del Frente de Juventudes.

Hay que tener en cuenta que muchas actividades escolares y extraescolares relacionadas con la actividad musical estaban vinculadas al Frente de Juventudes - como sección masculina del Movimiento - en el marco de la Ley de Educación de 1945.

Parte de la formación musical práctica de los maestros viene condicionada por la realización de los cursos de formación como instructores del Movimiento que tienen que cursar obligatoriamente para tomar posesión de sus plazas docentes. En este contexto es donde se realizan las prácticas de cantos escolares y patrióticos, así como toda la praxis vocal relacionada con las actividades físicas y de tiempo libre (marchas, campamentos, formación premilitar)

En estos cursos aprenden repertorios de canciones en contextos prácticos, realizan ejecuciones corales monódicas como acompañamiento a los desfiles y a las actividades de carácter ideológico principales, asocian canciones a las actividades de ocio colectivo y las utilizan en la dinámica de grupos como medio de expresión individual y aglutinante de los sentimientos del grupo.

También introducen grupos instrumentales, sobre todo de cornetas y tambores, pero también ligados al folklore como las rondallas.

Sin embargo, la expresión fundamental es el canto colectivo, casi siempre de carácter monódico y con gran peso de dos grandes géneros: las marchas e himnos y las canciones de campamento. 


\section{Capítulo 7. Conclusiones}

En definitiva: El objetivo principal de la música es la transmisión ideológica política y la afirmación del individuo dentro del grupo por medio de la afinidad y la manipulación sentimental. Se persigue una identificación afectiva con un cancionero de marcado carácter práctico: los aprendizajes se realizan de manera memorística y las interpretaciones son fundamentalmente colectivas.

No se hace la música por sí misma como un objeto artístico con buena interpretación, sino que se potencia la utilización de la música para fijar asociaciones de tipo ideológico. Se potencia el carácter rítmico de la música sobre el elemento melódico, al asociarlo al movimiento de la marcha y el desfile.

\subsubsection{Las profesoras de música de Sección Femenina}

Sección Femenina se ocupó de formar específicamente al personal que tenía que impartir las clases de música a escolares.

La importancia explícita y desglosada de la asignatura de música en las Escuelas del Hogar de Educación Secundaria, se muestra paralelamente en la intención de selección y dotación de su profesorado: contratación de profesionales colaboradores y programas de formación de sus instructoras.

Para cualificar a dicho personal de Secundaria se crea la Escuela Nacional de Música "Roger de Lauria" - un sueño largamente perseguido -, donde a partir de los años 60 se forma específicamente en pedagogía musical 110 profesoras especializadas en cómo enseñar música a los niños con las nuevas metodologías musicales (especialmente el método Orff). Al final del período franquista, Sección Femenina cuenta con 215 profesoras impartiendo la asignatura en diversos centros de enseñanza Secundaria por todo el país.

Además de este personal, la actividad de enseñanza musical se plasma en una gran cantidad de instructoras con conocimientos musicales obtenidos en conservatorios, que realizaban labores de todo tipo: difusión cultural musical, 


\section{La educación musical en el franquismo}

conferencias, conciertos sinfónicos para escolares, música escolar, coros y danzas, colaboración en tareas de recogida de folklore, etc.

La actividad musical de Sección Femenina es tan grande que necesita ser negociada a través de una Sección independiente de la Regiduría Central de Cultura. Se ocupa de actividades de formación, actividades de tiempo libre, organización de festivales, folklore, publicaciones, actividades en centros propios, programas de difusión musical, creación de bibliotecas y discotecas. Algunas de ellas obtienen un inmediato éxito popular a nivel nacional e internacional (los viajes de Coros y Danzas por el mundo) y otras son más discretas (cátedras ambulantes), pero todas tienen un gran eco en la sociedad y los grupos de población a los que afectan.

Las publicaciones de Sección Femenina referidas a la música obtienen gran difusión por todo el territorio nacional. La obligatoriedad de utilización de los repertorios contenidos en tres de ellas - Cancionero, Mil canciones españolas y la Revista Consigna - los convierten en auténticos best-sellers de la época.

Los ficheros de folklore - la niña mimada de los ojos de Josefa San Pelayo - y que incluyen tanto música como danzas, trajes, usos o tareas de artesanía, son uno de los grandes archivos documentales de una España en transformación al mundo moderno. En esta tarea colaboraron gran número de profesionales musicales (directores de banda, músicos e intérpretes, bailarines y coreógrafos,) y se plasma en publicaciones de colecciones de partituras, material discográfico y grabaciones cinematográficas.

Y esta difusión de la tradición musical se transfiere también a la educación escolar, a través de la selección de canciones y la unificación del repertorio

Atenta a las necesidades de adaptación a las innovaciones educativas, otorga becas y es la gran introductora a través de cursos con profesionales, a las nuevas metodologías de educación musical a partir de los años 1960 en todo el territorio. Está dispuesta a colaborar activamente con otras instituciones 


\section{Capítulo 7. Conclusiones}

emergentes como los Institutos de Ciencias de la Educación (ICEs) universitarios.

Realiza una enorme labor popular estable organizando concursos infantiles de villancicos, de coros y danzas regionales y de rondallas en todas las provincias y a nivel nacional.

Con una organización que abarca desde la presencia en las zonas rurales de pequeño tamaño hasta la centralizada burocracia de la Delegación nacional en Madrid, pasando por una logística jerarquizada provincial, es capaz de establecer relaciones desde las más pequeñas poblaciones hasta la difusión internacional de las producciones musicales autóctonas.

\subsection{Con qué material: las canciones y su análisis}

Las canciones son el material principal de la educación musical durante el franquismo: Todos los niños y niñas tienen que cantar.

La divergencia de género se plasma en la selección de repertorios diversos conforme a una diferencia de intencionalidad en las prioridades y objetivos educativos

Para Frente de Juventudes la prioridad es la transmisión política del ideario de Falange y en segundo término la conformidad dentro del colectivo grupal.

Para Sección Femenina la prioridad es la preservación del tradicionalismo, dando mayor importancia al folklore y la religiosidad, a la concepción de una España-nación en el que también tienen cabida las singularidades regionales.

Por ello, la selección del material que se muestra en los cancioneros de una y otra institución son fundamentalmente diferentes: 


\section{La educación musical en el franquismo}

Frente de Juventudes da mayor importancia a los himnos y marchas. $Y$ en todo caso a los mensajes transmitidos a través de las letras, por lo que son infrecuentes los cancioneros que incluyan melodías (partituras).

Sección Femenina promociona el aprendizaje del folklore de todas las partes del país respetando sus idiomas de origen (gallego, vasco y catalán) y crea un cancionero unificado desprovista de raiz. El resultado de la difusión de este cancionero (y de la obligatoriedad de su aprendizaje) es que dos generaciones de mujeres españolas conocen canciones de diversas raíces regionales que se interpretan como propias sin distinción, en varias lenguas. Detrás de todo ello existe una auténtica intencionalidad de configuración del pensamiento político de España-nación, que expresa la voluntad de Pilar Premio de Rivera en el prefacio del Cancionero

\footnotetext{
"Cuando los catalanes sepan cantar las canciones de Castilla, cuando en Castilla se conozcan también las sardanas y se toque el chistu, cuando del cante andaluz se entienda toda la profundidad y toda la filosofía que tiene - en vez de conocerlo a través de los tabladillos zarzueleros -, cuando las canciones de Galicia se canten en Levante, cuando se unan cincuenta o sesenta mil voces para cantar una misma canción, entonces habremos conseguido la unidad entre los hombres y las tierras de España"
}

Muchas de las canciones del folklore son modales, con una gran presencia del modo de mi. Y las tonalidades mayores ya tienen una presencia mayor que las de modo menor. Los compases más frecuentes con 2/4, 3 /4 y 6/8.

La mayoría de las canciones se interpretan de forma monódica y muy frecuentemente en coros.

La metodología de aprendizaje más habitual es la imitación y la repetición de modelos: el profesor canta la canción fragmentada en partes y los alumnos la repiten hasta la memorización completa. A veces también se desglosa la memorización de los textos (a los que se les da mucha importancia, especialmente en los contextos ideológicos). 


\section{Capítulo 7. Conclusiones}

La educación más técnica - como la enseñanza del lenguaje musical, el aprendizaje de instrumento) - y cultural - la historia de la música, la asistencia a conciertos sinfónicos didácticos, las conferencias, las audiciones comentadas de música clásica - adquiere una gran importancia a partir de los años 1960.

El cambio técnico que supone la difusión del método Orff (la prosodia lingüística para educación rítmica, la introducción de la dramatización y la expresión corporal combinables con la educación musical, la iniciación a los instrumentos melódicos y armónicos en agrupaciones escolares sencillas) a partir de los años 1960 y su generalización por la Ley de la Reforma Educativa de 1970 supone una revolución en la educación musical española que abre las puertas a la educación musical moderna que continúa en evolución hasta nuestros días.

En definitiva, educativamente hay dos etapas diferentes en la educación musical española: De 1945 a 1960 y a partir de 1960. Cambian los contenidos, cambia la metodología, cambia la percepción de su papel en la educación general (se convierte en asignatura obligatoria y evaluable del currículo con contenidos desglosados y profesorado específico)

\subsection{Nuevas hipótesis sobre las consecuencias de la educación musical recibidas durante el franquismo.}

Durante el franquismo - al igual que en los otros fascismos - hay una permanente interpretación musical de música y canciones. Toda la vida pública estaba rodeada de una parafernalia de la que la música formaba parte.

A pesar de ello, la mayoría de la gente no percibe que ello fuera una educación musical. ¿Por qué? Para responder a estas preguntas he elaborado las siguientes hipótesis sobre las consecuencias de la educación musical recibida durante el período franquista. 


\section{La educación musical en el franquismo}

1.- La imposición del repertorio trae como consecuencia el rechazo del mismo cuando las circunstancias políticas y sociales cambian. No se trató de un repertorio de canciones elegidas individualmente, sino de una selección impuesta dentro de un sistema ideológicamente totalitario.

A la muerte de Franco, España vive una gran transformación social e ideológica - "la transición democrática" -.

La música había sido utilizada por el Movimiento para conseguir fines ideológicos asociados emocionalmente: Con Falange (campamentos, desfiles, protocolo público), con el pensamiento tradicionalista (pervivencia del pasado y del folklore), religiosidad católica, la organización de España como un estado de regiones (frente a los resurgidos nacionalismos autonómicos), el paternalismo direccionista e impositivo (frente a la libertad de expresión de los cambios democráticos).

Por consiguiente, se produce un profundo rechazo a todo lo que se asocia al pasado inmediato, entre ello las canciones que se habían cantado. Se olvidan voluntariamente y se dejan de transmitir a la siguiente generación. Se inicia una nueva etapa con nuevas canciones, diferentes, que miran al futuro y no al pasado, a las influencias extranjeras y no al folklore nacional.

El mayor rechazo se produce hacia las canciones ideológicas; himno y marchas. Este repertorio se conserva sólo en los entornos políticos asociados con la extrema derecha y se cargan de un simbolismo de extrema significación política.

El folklore cae en desuso excepto para los intereses nacionalistas y la potenciación de las identidades autonómicas. Muchos de los nuevos cancioneros se nutren de las canciones recogidas por las entidades del franquismo, pero revisadas bajo unos parámetros de de utilización y difusión de la diversidad lingüística y bajo un concepto de identidad regional monotemática (no como el conglomerado de varias identidades regionales en la concepción de un estado mayor) 


\section{Capítulo 7. Conclusiones}

2.- La uniformidad del repertorio, aunque dividido en dos: masculino y femenino

Los repertorios libres se caracterizan por una gran diversidad en la que los criterios individuales de selección son condicionados por factores diversos y numerosos: gustos personales, melodías de referencia, origen, difusión, reafirmación de la individualidad y conformación del grupo socializado a pequeño nivel, familiaridad, cercanía y asequibilidad, acceso a los creadores 0 intérpretes (a través de música en vivo, conciertos y grabaciones), medios de comunicación y publicidad. En definitiva, cada persona conforma su repertorio a voluntad y los criterios son tan dispares que, aunque con elementos comunes, las elecciones realizadas son diferentes en cada individuo. Se caracterizan por la pluralidad.

En consecuencia, la generación educada durante el franquismo percibe como pobre en variedad el cancionero aprendido. Al mismo es necesario incorporar nuevas melodías y estilos musicales: extranjeros (jazz, pop, rock) y culturales (música clásica, flamenco, etnográficos).

3.- La difusión musical juega un importante papel en la introducción de las influencias internacionales y comerciales.

La incorporación de los medios de comunicación libres (durante el franquismo tanto la radio como la TVE eran controladas por el Movimiento y la censura) proporcionan un cambio radical a las posibilidades de acceso de la población general a nuevas formas musicales. Se crean cadenas de radio temáticas musicales y se conforma un nuevo y gran mercado condicionado por intereses comerciales de las empresas discográficas.

La capacidad de distribución y difusión de este nuevo mercado son inmensas y su crecimiento exponencial es una constante en las primeras décadas de la democracia. 


\section{La educación musical en el franquismo}

En España se pasó de no poder conseguir casi discos (grabaciones caras, pocas versiones disponibles, pocas tiendas dedicadas a la comercialización de música, pocos grupos de música moderna y clásica) a ser uno de los grandes negocios de mercado en apenas diez años.

La difusión que la televisión y la radio hicieron de las creaciones de los nuevos grupos musicales nacionales - más acordes con las tendencias anglosajonas e internacionales - configuró todo un nuevo tipo de repertorio que se incorporó como innovador frente al estatismo de los 40 años anteriores.

4.- La ideología política tan presente en el repertorio franquista es fuertemente rechazada.

Se prefieren temáticas asociadas a los sentimientos y la vida de los individuos, a sus deseos y ambiciones.

La pluralidad y la diversidad social se plasman en la vida creativa en toda su riqueza (por ejemplo "la movida madrileña" y su presentación de nuevas realidades: la homosexualidad, la liberación del subconsciente y el uso de las drogas, la transgresión y la provocación social como fórmula de la propia creación)

Tras una larga época de simbología política e imágenes predeterminadas (el camarada, la muerte, la patria, el valor, el honor) lo que busca la sociedad es la diversión y la realización aspiracional.

5.- La metodología de aprendizaje por imitación en lugar del aprendizaje del lenguaje musical hace que el repertorio adquirido se viva como una imposición y no como una selección.

Al privar a la mayoría de la población de la comprensión de la música como un lenguaje asequible - el solfeo era considerado desde el punto de vista profesionalizado y no desde un acercamiento sencillo - la gente no tiene la sensación de haber aprendido música por sí misma, sino de haber memorizado una serie de canciones. 


\section{Capítulo 7. Conclusiones}

Cuando dichas canciones dejan de ser útiles (la urbanización de la sociedad hace que el folklore ya no sea funcional) o ya no son políticamente correctas, dicho repertorio se deja de utilizar y revitalizar en la memoria. El aprendizaje memorístico se reafirma por la repetición de los elementos, que al dejar de ser renovados o repetidos se olvidan. Sólo se recuerdan cuando por algún motivo se escuchan y se interpretan en un entorno favorable y aceptado.

Tras el franquismo, muchas canciones dejan de ser interpretadas: las políticas ya no se repiten en público, las folklóricas ya no tienen funcionalidad (canciones de trabajo, nanas, aprendizaje tradicional, narración de historias). En realidad sólo perviven las canciones infantiles - de corro según la clasificación de Sección Femenina - y las que se utilizan en los juegos: para saltar a la cuerda, sorteos, juegos de palabras, juegos de pelota, juegos rítmicos, etc.

El repertorio se renueva con otras influencias que vienen a sustituir a las antiguas: internacionalidad, temas creados para los medios de comunicación (radio, televisión), comerciales... En una palabra: canciones modernas

6.- La interpretación grupal monódica que había sido la forma más habitual durante el franquismo cae en decadencia tras la muerte de Franco. Cada vez se considera se la práctica artística como una forma de expresión personal e individual. Se canta mucho menos en coro o en grupos grandes y mucho menos al unísono monódico.

7.- La educación musical en los conservatorios también estaba destinada a los aficionados y no específicamente hacia la profesionalización, lo que permitió hacerla compatible con otras dedicaciones. Se consideraba que las personas interesadas en adquirir una mejor educación musical podían obtenerla a través de estas instituciones. Pero no se garantiza la accesibilidad ni económica ni geográfica (hay pocos conservatorios y las clases particulares hay que pagarlas, gastos extras que la población en general no pudo permitirse hasta después de los años 1970). 


\section{La educación musical en el franquismo}

Se produce, por tanto una discriminación social en el acceso a la educación musical. Las clases más favorecidas son la burguesía con suficientes medios económicos y residentes en ciudades - no en el ámbito rural.

De hecho, una buena parte de la burguesía rural enviaba a sus hijas a centros escolares religiosos, donde además obtenían una educación musical básica como formación complementaria (canto coral, tocar el piano u otro instrumento melódico).ante la imposibilidad de tener acceso a los conservatorios como centros amateur.

8.- La falta de una programación de contenidos claros de educación musical a nivel escolar y la confusa asignación de la docencia tanto a las entidades educativas como a los organismos externos, hace que sea difícil realizar un seguimiento del cumplimiento de las tareas. La Inspección de Educación Primaria tampoco demuestra un gran interés en controlar la realización de las tareas musicales ya que también se realizan fuera de los entornos escolares y por organizaciones que no están sujetas a su supervisión.

La colaboración de los maestros y los instructores es una buena idea en abstracto, pero no están bien delimitados los límites entre las funciones de unos y otros, por lo que es mayor la probabilidad de que se produjeran desajustes por diversos motivos (negligencia, solapamiento de contenidos, rivalidad de competencias, repetición de materiales, enfrentamiento de técnicas y metodologías pedagógicas).

9.-La consideración de la música como una actividad fundamentalmente lúdica en lugar de una forma más de aprendizaje, hace que la consideración de la misma por parte de la comunidad social sufra un notable deterioro: no se considera como una asignatura más, no es evaluable, el objetivo principal es pasarlo bien en lugar de aprender (lo que no impide disfrutar durante el proceso de aprendizaje), no requiere disciplina ni se toma en serio.

En definitiva, se considera una "maría". 


\section{Capítulo 7. Conclusiones}

10.- Las actividades externas al entorno escolar tienen gran importancia en la educación musical.

Los concursos de villancicos, los conciertos sinfónicos, las conferencias, las exposiciones públicas, los campamentos, las marchas de senderismo en la naturaleza, los desfiles y las exhibiciones públicas de ejercicios rítmicos y gimnasia, son las formas principales de mostrar la actividad musical.

En muchas ocasiones lo importante no es aprender, sino "montar" piezas para el espectáculo o para amenizar la vida campamental.

11.- La interpretación musical sólo sigue normas de excelencia en los concursos y competiciones.

Pero en la vida escolar normal o en la vida campamental, se descuidan las pautas de tipo musical: corrección en la entonación, cuidada emisión vocal, buena dicción, perfección rítmica.. en función de otras prioridades: rapidez en el aprendizaje, no aburrir a los escolares, limitar la duración de los ensayos, no insistir en las correcciones

12.- La diferencia de tratamiento de la educación en género hace que la formación cultural musical sea preferencial para las mujeres. Las mujeres tienen que saber cantar para educar su sensibilidad, para acunar a sus hijos, para "adornar" y aportar un punto de belleza al entorno masculino.

La música que deben interpretar los hombres es premilitar (militar y paramilitar), recia, cargada de símbolos ideológicos... no un factor cultural ni culturizador, como en las mujeres.

Esta diferencia queda establecida en la consideración posterior de la música en la vida de los adultos. Las mujeres tienen más presencia en las actividades musicales: conciertos, coros, vida cultural.

Sin embargo la participación masculina no profesional en coros y otras formaciones musicales amateur es menor. 


\section{La educación musical en el franquismo}

Estas diferencias se reforzaron al practicar educaciones separadas y diferenciadas durante el período franquista y es de esperar que se diluyan con al coeducación .

También se aprecian grandes diferencias en las diferentes zonas del país: bandas y agrupaciones instrumentales numerosas en la zona de levante, agrupaciones vocales polifónicas en el norte. Ello se debe a la pervivencia de tradiciones desde épocas anteriores y a la existencia de interpretaciones populares colectivas.

13.- Se aprecia una gran diferencia en la forma de enfocar la educación musical llevada a cabo en Sección Femenina antes y después de los años 1960.

La primera etapa ha dejado tras de sí una generación formada en el folklore de todas las regiones.

La segunda etapa ha significado la iniciación de un camino hacia la nueva educación musical: lenguaje musical introducido en la escuela, conocimiento de un instrumento melódico sencillo, concepción cultural de la historia de la música, asistencia a conciertos y conferencias de temática musical, apreciación del patrimonio musical y participación en las iniciativas culturales vinculadas a la música y su difusión.

Una de las consecuencias significativas de esta mejora de la educación musical se plasma una generación más tarde en la enorme incorporación de los niños en la actualidad a los complementos de formación musicales: conservatorios, escuelas de música, danza y dramatización, jazz, grupos de música moderna y comercial. 


\section{Capítulo 7. Conclusiones}

\subsection{Propuestas de reflexión para el futuro}

1.- La introducción de nuevas metodologías pedagógicas para la enseñanza de la música en los años 1960 revolucionó la enseñanza musical en España. Ahora esas metodologías tienen una gran difusión y se aplican de forma habitual en la educación musical escolar.

Pero han pasado más de 30 años y es necesario dar difusión a nuevas metodologías y no conformarse con las ya instaladas. Hay que promover la investigación y la innovación educativa, también en el campo de la educación musical. Y para ello es necesario el soporte económico y la difusión institucional, como lo fue en el pasado.

2.- Una parte importante de los escolares y los padres siguen percibiendo la educación musical como una formación complementaria. Es necesario dotar de prestigio y normalidad a la enseñanza de la música a todos los niveles, profesionales y amateurs.

3.- La formación de profesorado con una buena preparación musical y que tengan seguridad en los diferentes elementos de la interpretación musical son fundamentales para crear una base educativa firme. Es necesario que los profesionales encargados de enseñar música a los niños y adolescentes tengan - además de buenos conocimientos teóricos - buenas prácticas musicales: seguridad en la entonación, conocimientos de dirección de agrupaciones vocales e instrumentales, capacidad para realizar instrumentaciones y armonizaciones de todo tipo de melodías, desarrollo de la expresividad y la creatividad, posibilidades para realizar buenos acompañamientos instrumentales e improvisaciones, conocimiento de los estilos musicales...

En la actualidad se imparte una especialidad del título de maestro en Educación Musical que en los nuevos planes de estudio se transforma en un itinerario formativo. 


\section{La educación musical en el franquismo}

4.- Es fundamental la continuidad y la progresión de dificultades de los contenidos y la buena programación a lo largo de todos los niveles educativos: infantil, primaria, secundaria, bachillerato, educación superior.

Es necesario distinguir entre los objetivos y contenidos de aprendizaje obligatorios en el sistema escolar general y aquellos otros de carácter complementario que serán aprendidos en otras instituciones tanto profesionales como amateurs

5.- Hay que ofrecer y garantizar las posibilidades de accesibilidad de la población general a la educación musical tanto amateur como profesionalizada.

6.- Es necesario regularizar las relaciones entre la educación artística profesionalizada y la educación general, de forma que permita compatibilizar ambos estudios. $Y$ en los niveles superiores, el reconocimiento de las titulaciones de alto nivel y la estructuración de los niveles de profesionalización son necesarios para la normalización laboral de las profesiones artísticas.

7.- Para asegurar la libertad de expresión y de elección de repertorios es necesario garantizar un buen conocimiento del lenguaje musical y la pluralidad de ejemplos musicales.

8.- La educación artística como forma de expresión es una asignatura naciente en el currículo educativo en España, y necesita dotaciones materiales y de innovación. La experimentación de nuevas metodologías, la aplicación de TICS especialmente diseñadas para el aprendizaje musical, la interculturalidad y la integración de las personas con otras necesidades, la interrelación con otros conocimientos y contenidos, son algunas de las líneas prioritarias. Y se tienen que abrir nuevas líneas de investigación para garantizar el dinamismo y la mejora continua de los resultados educativos de la educación musical.

9.- Sección Femenina a partir de 1970 abrió las puertas hacia una nueva de educar musicalmente a los niños. Ese trabajo sólo acaba de empezar. No 


\section{Capítulo 7. Conclusiones}

debemos ser conformistas, sino aprender que hay que experimentar constantemente para avanzar en la educación de las nuevas generaciones. 
La educación musical en el franquismo 


\section{CAPÍTULO 8. REFERENCIAS BIBLIOGRÁFICAS CITADAS}

ABELLA, R (1996) La vida cotidiana bajo el régimen de Franco. Madrid: Temas de Hoy

ABELLA, R. (1975) Por el imperio hacia Dios. Barcelona: Planeta

ABELLÁN, J.L. (1971) La cultura en España. Madrid: Cuadernos para el diálogo

AGULLÓ DÍAZ, M.C. (1993) La educación de la mujer durante el franquismo y su evolución en Valencia. Valencia: Servicio de publicaciones de la Universidad de Valencia

ALONSO MEDINA, J.A. y RODRÍGUEZ CRUZ, P.(1999) Evolución histórica de la formación musical de los maestros (1900-1967). En // Jornadas de historia local canaria: enseñanza y educación en Canarias., Boletín Millares Carlo, no 18

ALONSO MEDINA, J.A. (2002). “Cursos de formación musical para instructoras de la Sección Femenina" en El Guiniguada, no 11

ALVAREZ PUGA, E. (1969) Historia de la Falange. Barcelona: Dopesa

ARANGUREN, J.L. (1973) La juventud europea y otros ensayos. Barcelona

ARRIACA, J. (1967). Cancionero de Juventudes. Madrid: Doncel

BENERIA, L.(1977) Mujer, economía y patriarcado durante la España franquista. Barcelona: Anagrama

BENNER, C.H.(1974) Implications or social change for music education. En ISME Yearbook 11, 1974

BERICAT, E. (1998) La integración de los métodos cuantitativo y cualitativo en la investigación social. Barcelona: Ariel 
BERNSTEIN,B. (1981) Studien zur sprachlichen sozialisation .Frankfurt: Ullstein

BORDERÍAS MONDÉJAR, C. (1993) Entre líneas. Trabajo e identidad femenina en la España Contemporánea: La compañía Telefónica 1924-1980. Barcelona: Icaria Editorial

BORDIEU, P (1979) Distinction: A social critique of the judgement of taste. Cambridge, MA: Harvard University Press

BRUNER, J. (1997) La educación, puerta de la cultura. Madrid: Visor

CÁMARA VILLAR, G. (1984) Nacional-catolicismo y escuela. La socialización política del franquismo (1936-1951). Granada: Hesperia

CAMARA VILLAR, G (1984) El adoctrinamiento político en la escuela del franquismo: nacional-catolicismo y textos escolares, 1936-51. En Infancia y sociedad en España. Granada: Hesperia. (pp. 351 y ss).

CARBONELL, J. (1976) Cuatro décadas de educación franquista: Marco legal y política educativa. En Cuadernos de pedagogía, suplemento no3, (pp. 24-29).

CARREIRA, X.M. (1996) Contemporary music in Spain during the sixties. En Transgression as integration, publicación del congreso celebrado en Cascais (Portugal). También se puede encontrar, traducido al español en la red en http://www. mundoclasico.com/articulos

CASTELLET, J. M. et alt (1977). La cultura bajo el franquismo. Barcelona: Ediciones de bolsillo

CIERVA, R. de la (1978) Historia del franquismo. Barcelona: Planeta.

ClERVA, R. de la (1982) Francisco Franco. Biografía histórica. Barcelona: Planeta 
CIRICI PELLICER, A. (1977) La estética del franquismo. Barcelona: Gustavo Gili COLWELL, Richard y RICHARDSON, Carol (Eds.) (2002): The new handbook of resarch on music teaching and learning New York: Oxford University Press

COOLINS, R. (1971) Functional and conflict theoires of educational stratification. American Sociological Review, 36

COX, P.H.(1994) The professional socialization of Arkansas music teachers as musicians and educators, Tesis doctoral en la Universidad de North Texas, Denton.

CRUZ OROZCO, J. I. (2001) El yunque azul. Frente de Juventudes y sistema educativo. Madrid: Alianza

CHUECA RODRÍGUEZ, R. (1978) El boletín de los seminarios de formación del Frente de Juventudes en VARIOS: Las fuentes ideológicas de un régimen (España 1939-45). Zaragoza: Libros Pórtico

CHUECA RODRÍGUEZ, R (1983) El fascismo en los comienzos del régimen de Franco. Un estudio sobre FET-JONS. Madrid: Centro de Investigaciones Sociológicas

CHUECA RODRÍGUEZ, R (1987) Las juventudes falangistas. En STUDIA HISTORICA. Historia Contemporánea. Salamanca, vol V, 4 (1987), pag. 87-104

DíAZ, M (Coord) (2006) Introducción a la investigación en educación musical. Madrid: Enclave creativa

DíAZ VIANA, L (2007) Cancionero popular de la guerra civil española. Madrid: La esfera de los libros 
ELLWOOD ,S. (1984) Prietas las filas. Historia de la Falange Española 19331983. Barcelona: Grijalbo

ELLWOOD, S. (1987) Spanish fascism in the Franco Era: Falange Española de las JONS 1936-75. Basingstoke: MacMillan

ESCOLANO BENITO, A. (1989) Discurso ideológico, modernización técnica y pedagogía crítica durante el franquismo, en Revista Historia de la educación, no 8. Salamanca

ESCOLANO BENITO, A. (2002) La educación en la España contemporánea. Madrid: Biblioteca nueva

ESTEBAN MATEO, L. (1980) Evolución de los objetivos de formación de profesores. Concreción de un caso: Objetivos de formación magisterial durante el período bélico (1936-39). En La investigación pedagógica y la formación de profesores. Actas del VII Congreso Nacional de pedagogía. Madrid: Sociedad Española de pedagogía, Instituto San José de Calasanz del CSIC

FERNÁNDEZ ENGUITA, M. (1987) Reforma educativa, desigualdad social e inercia institucional. La enseñanza secundaria en España. Barcelona: Laia

FERNÁNDEZ SORIA, J.M. (1984) Educación y cultura en la guerra civil (España 1936-1939). Valencia: Nau llibres.

FERNÁNDEZ SORIA, J.M. (1984) Educación y cultura en la guerra civil (artículo) en Cuadernos de Educación comparada e historia de la educación", XII, Universidad de Valencia

FERNÁNDEZ SORIAL, J.M. (1988) educación, socialización y legitimación política (España 1931-1970). Valencia: Tirant lo Blanc 
FLECHA GARCÍA, C. (1989) Algunos aspectos sobre la mujer en la política educativa durante el régimen de Franco, en Revista Historia de la Educación, no 8. Salamanca

FONT, R.M. (1972). Metodología del ritmo musical, 1 y 2.Valladolid: Lex nova y (1980) Metodología del ritmo musical. El ritmo en la educación preescolar. Madrid: Ediciones paulinas

GALLEGO MÉNDEZ, M (1983). Mujer, falange y franquismo. Madrid: Taurus

GALLO, M. (1972) Historia de la España franquista. París: Ruedo Ibérico

GARDNER, H. (1997) Arte, mente y cerebro. Una aproximación cognitiva a la creatividad. Barcelona: Paidós

GEERTZ, C. (1989) La interpretación de las culturas (2º reimp.) Barcelona: Gedisa (Versión original en inglés: The interpretation of Cultures. Nueva York: Basic Books, 1973)

GIROUX, H (1981).: Ideology, culture and the process of schooling. Filadelfia: Temple University Press

GIROUX, H. (1991) Postmodernism, feminism, and cultural politics: Redrawing educational bounderies. Albany State University of New Cork Press

GONZÁLEZ GALLEGO, I. (1988). Falange y educación. Zaragoza, 1936-1940 . En Historia de la Educación, 7. pag (203-230)

GREEN, L. (1993) Music, gender and education: a report on some exploratory research. En British Journal or Music Education, 10, (pp. 219-254)

GREEN, L. (1994) Gender, musical meaning and education. En Philosophy of Music Education Review, 2,( pp. 99-105) 
GREEN, L. (1999) Research in the sociology of music education: some introductory comment. En Music Education Research, 1, (pp.159-170)

GREEN, L. (2001) Música, género y educación. Madrid: Alianza Editorial

HEMSY DE GAINZA, V. (2002) Didáctica de la música contemporánea en el aula. En Pedagogía musical. Dos décadas de pensamiento y acción educativa .Buenos Aires: Lumen

HEMSY DE GAINZA, V. (2004) La educación musical en el siglo XX. En Revista musical chilena, vol. 58, no 201, pag. 74-81. También en formato electróncio en http://www.scielo.cl

HERRERO SUAREZ, H. (2002) Educación no formal y adoctrinamiento infantil en la "España Azul". Flechas y Pelayos (1938-45). Tesis doctoral no publicada leída en la Universidad de Valladolid.

HERRERO SUÁREZ, H. (2007) Un yugo para los flechas. Educación no formal y adoctrinamiento infantil en Flechas y Pelayos .Lérida: Milenio

HERNÁNDEZ DÍ AZ, J. M. (1989) Franquismo y educación. Selección bibliográfica de trabajos publicados desde 1975 en Revista Historia de la Educación vol. 8. Salamanca.(pp. 335-342)

HUMPHREYS, J.T. (1997) Expanding the horizons of music education history and sociology. En Quarterly Journal of music teaching and learning, 7, pag. 519

IBÁÑEZ MARTÍN, J. (1981) Introducción al concepto de adoctrinamiento. En Revista Española de pedagogía, № 153 
JARABO JORDÁN, C. Los campamentos del Frente de Juventudes. Tesina de licenciatura. Barcelona: Universidad de Barcelona

JIMÉNEZ, E. (1981) La mujer en el Franquismo. Doctrina y acción de la Sección Femenina. En Tiempo de historia, 83.

JOUSSELIN, J. (1967) Al servicio de la juventud en $R / J, n^{\circ} 14$

KOCH, H.W. (1976) La juventud hitleriana. Madrid

LABAJ O, Joaquina.(1998) La educación musical de la sección femenina. En MANCHADO,M Música y mujeres: género y poder. Madrid: Horas y horas

LAMB, R. (1990) Possibilities or/for feminist music criticism in music education. En British Journal of Music Education, 10, (pp. 169-180). 1990

LAMB, R.(1994) Feminism as critique in philosophy of music education. En Philosophy of Music Education Review,2, (pp. 59-74)

LATORRE,, A., DEL RINCÓN, D. y ARNAL, J. (1996) Bases metodológicas de la investigación educativa. Barcelona: Graó

LEVI-STRAUSS, C (1995). Antropología estructural (2º reimp) Barcelona: Paidós (Versión original en francés: Anthropologie structurale. París: Plon, 1974

LÓPEZ CASANOVA, M.B. La música en el Magisterio de las Escuelas Normales y su proyección a la primera enseñanza desde 1837 a 1930. En Música y educación: Revista trimestral de pedagogía musical, año 15, no 49, 2002, pag 29-44

LORA TAMAYO, M (1974) Política educacional de una etapa 1962-1968. Madrid: Editora nacional 
LORING, T. (1993) Promoción político-social de la mujer durante los años del mandato de Franco. En VV.AA El legado de Franco. Burgos: Fundación nacional Francisco Franco

LUENGO SOJ O, A (1996) Sección Femenina. Actividad musical. Tesis doctoral no publicada leída en la Universidad de Barcelona

McCARTHY, M.(1996) Wheels within wheels: feminism, gender and multicultural music education, a response to Green and Lamb. En Critical reflections on music education: Proceedings of the second international symposium on the philosophy of music education, (pp. 264-272).Canadian Music Education Research Center, University of Toronto

MCCLARY, S.(1991) Feminine endings: music, gender and sexuality, Minneapolis: University of Minnesota Press

MANCHADO TORRES, M (1998). Música y mujeres: género y poder. Madrid: Horas y horas

MARTÍ, J. (1992) Hacia una antropología de la música. Anuario Musical 47,195225

MAYORDOMO, A. y FERNÁNDEZ SORIA, J.M. (1993) Vencer $y$ convencer. Educación y política. España 1936-1945. Valencia: Universitat de Valencia

MEDINA, E. Educación y sociedad: La lucha por la educación. En PUELLES BENÍTEZ, M. (1980) Educación e ideología en la España contemporánea (17671975). Barcelona: Labor

MERRIAM, A.P. (1964) The Anthropology of Music. Chicago: Northwestern University Press HARGREAVES, D.J. y NORTH, A.C. (Eds) (1997) The Social Psychology of Music. Oxford: Oxford University Press 
MENDIZÁBAL OSES, L. (1968) La política de Juventud: determinación de su concepto" En Revista de Estudios Políticos, no 162. Madrid

MONÉS I PUJ OL-BUSQUETS, J. (1981) L'escola a Catalunya sota el franquisme. Barcelona: Ediciones 62

MURSELL, J. (1943) Music in american schools. Nueva York: Silver Burdett Company

MURSELL, J.(1948) The psicology of music. Nueva Yourk: Norton and Co.

NAVARRO SALADRINAS, R. (1989) El franquismo, la escuela y el maestro (1936-1975), en Revista Historia de la educación, № 8. Salamanca

MAVARRO SALADRINAS, R. (1990) La enseñanza primaria durante el franquismo (1036-1975). Barcelona: PPU

ONIEVA, A. (1939) La nueva escuela española (Realización práctica) Valladolid: Librería Santaren

ORIOL, N (2005) La música en las enseñanzas de régimen general en España y su evolución en el siglo XX y comienzos del XXI. En Revista electrónica Europea de Música en la Educación LEEME. 16. Universidad de la Rioja y Rediris CSIC. http://musica.rediris.es. Parte de este artículo fue publicado como "La formación del profesorado de música en la Enseñanza General" en Revista Música y Educación, Año XII, no 37

ORTOlá noguera, A. (1994) El castillo de La Mota en medina del Campo. Valladolid: Junta de Castilla y León

OSSENBACH，G. (1996)Democratisation dan europanisation challenges to the Spanish Educational system since 1970, en BERNER D. y LENZEN, D. (eds) Education for the new Europe. Osford: Berghahn Books 
PALOP, P. (1976) Límites ideológicos de la pedagogía franquista. En Endecha pedagógica. Oviedo ( pp. 5-8).

PARRA CELAYA, M. (1989) La pedagogía del Frente de Juventudes. Tesis no publicada leída en la Universidad de Barcelona.

PARRA CELAYA, M. "Pedagogía de la canción". En España es mi canción en edición electrónica de la editorial Doncel. http://www.rumbos.net/cancionero

PASTOR, M.I. (1984). La educación femenina en la posguerra (1939-45) El caso de Mallorca. Madrid: Ministerio de Cultura

PAYNE, S. (1967). La España de Franco. Nueva Cork: Cromwell

PAYNE, S. (1987) The Franco Regime 1939-1975. Madison: University of Winconsin Press

PAYNE, S. (1993) Spain's first democracy: the Second Republic 1931-36. Madison: University of Wisconsin

PERIS LACASA, J. (1965) Música para niños. Madrid: Doncel

PEREZ MORENO, H.M. (2003) Educación y Sección Femenina en Huelva. La Cátedra Ambulante: una escuela rural de formación integral e intensiva (19561977). Tesis Doctoral no publicada de la Universidad de Huelva

PRESTON, P (1994), Franco, caudillo de España. Barcelona: Grijalbo

PRIMO DE RIVERA, P. (1938) Historia de la Sección Femenina. En la Revista Y, febrero y octubre de 1938

PRIMO DE RIVERA, P. (1983) Recuerdos de una vida. Madrid: Dyrsa

PUELLES BENÍTEZ, M. (1980) Educación e ideología en la España contemporánea (1767-1975). Barcelona: Labor 
RAMOS OLIVEIRA, A. - Historia de España, Tomo III. Mexico: Compañía General de ediciones

RICHMOND, K. (2004) Las mujeres en el fascismo español. La Sección femenina de la falange 1934-1959. Madrid: Alianza Ensayo

RIDEOUT, R.R. (2000) On the sociology of music education. School of music de la Universidad de Oklahoma.

RODRÍ GUEZ, M. (1947) Cancionero juvenil.

RUBIO LLORENTE, F. (1974) La política educativa. En La España de los años 70. Vol. III Madrid: Editorial Moneda y Crédito.

SABARIEGO, M. y BISQUERRA, R. (2004) El proceso de investigación. En BISQUERRA, R. (Coord.) Metodología de la Investigación Educativa. Madrid: La Muralla

SÁEZ MARÍN, J (1982) Asociacionismo juvenil en Europa hasta 1940. En De juventud, no 5 y también Asociacionismo juvenil en España hasta 1936-39. En De juventud, no 7

SÁEZ MARÍN, J. (1988) El Frente de Juventudes. Política de juventud en la España de la postguerra (1937-1960). Madrid: Siglo XXI

SANCHEZ LLAMAS, F.J. (1998) Las Cátedras ambulantes de la Sección Femenina en Málaga. Tesis doctoral no publicada leída en la Universidad de Málaga

SANZ BACHILLER, M. (1939) La mujer y la educación de los niños. Madrid: Ediciones del Auxilio Social, FET y de las JONS

SCRIBNER, S y COLE, M. Cognitive Consequences of formal and informal Education. En Science, 182,(pp. 553-559) 
SERRANO SUÑER, R. (1977) Entre el silencio y la propaganda. La historia como fue. Memorias. Barcelona: Planeta

SMALL, C.(1977) Music, society, education. Londres: Calder

SOLER PALMER, M. y ARNAUDAS LARRODE, M. Tratado de música para las escuelas del magisterio. Sevilla

SOPEÑA, Federico. (1964).Las dos enseñanzas de la música. En Páginas de la revista de educación, $\mathrm{n} \cong 39$

SUÁREZ FERNÁNDEZ, L (1992) Crónica de la Sección Femenina y su tiempo. Madrid: Asociación Nueva andadura

SUEIRO, D. y DÍAZ, B.(1986) Historia del franquismo. Madrid: Sarpe

TAMAMES, R. (1977) . La era de Franco. Madrid: Alianza Universidad

TANNEMBAUM, E (1975) La experiencia fascista: sociedad y cultura (19221945).Madrid: Alianza

TIANA FERRER, A (2000)El libro escolar, reflejo de intenciones políticas e influencias pedagógicas. Madrid: UNED

TORRES, M. (1938) La obra social del nuevo estado español Paris: Sorlot, Les amis de L'Espagne nouvelle

TOVAR, A. (1938) Nación, Unidad e imperio. En Orientaciones nacionales de la Enseñaza primaria. Burgos: Ministerio de Educación Nacional, Hijos de Santiago Rodríguez

TRILLA, J. (1986) La educación informal. Barcelona: PPU 
TRILLA, J. (1992) La educación no formal. Definición, conceptos básicos y ámbitos de aplicación. En SARRAMONA J. (Ed.) La educación no formal. CEAC, Barcelona, (pp. 9-50)

TRILLA J. et alt. (1993) La educación fuera de la escuela: ámbitos no formales y educación social. Barcelona: Ariel

TUÑóN DE LARA, M. (1977). Ideología y sociedad en la España contemporánea. Por un análisis del franquismo. Madrid: Edicusa

TUÑón DE LARA, M. y BIESCAS, J. A. (1980) Historia de España, tomo X. España bajo la dictadura franquista. Barcelona: Labor

VV.AA. DELEGACIÓN NACIONAL DE SECCIÓN FEMENINA de FET y de las JONS (1954) Normas relacionadas con el Departamento de música de la Regiduría Central de Cultura. Madrid: Servicio de Publicaciones. Industrias Gráficas Magerit

VV.AA. DELEGaión NACIONAL DE SECCIÓn FEMENINA. (1943) Cancionero. Madrid

VV.AA. DELEGACIÓN NACIONAL DE SECCIÓN FEMENINA. (1941 a 1976) Consigna, revista de Sección Femenina para maestras.

VV.AA. DELEGACIÓN NACIONAL DE SECCIÓN FEMENINA (1954) Canciones populares para escolares. Madrid

VV.AA. DELEGACIÓN NACIONAL DE SECCIÓN FEMENINA (1961) Música: Teoría de solfeo y canciones. Madrid

VV.AA. DELEGACIÓN NACIONAL DE SECCIÓN FEMENINA (1970) Cátedras ambulantes. Editorial Almena

VV.AA. (1978) Mil canciones españolas, vol. I y II. Madrid: Editorial Almena 
VV.AA. FET de las JONS (1939) La Sección Femenina: historia y organización.

Bilbao: Talleres Gráficos de J esús Alvarez

VV.AA. FET de las JONS (1943) Marchas y montañismo. madrid

VV.AA. FET de las JONS (1945) Cancionero falangista. Madrid

VV.AA. FET de las JONS (1948) Manual de campamentos. Madrid

VV.AA. FET de las JONS (1960) El Frente de Juventudes en la escuela. Valencia

VV.AA. HERMANDAD DONCEL (2000) España es mi canción. Edición electrónica en http://www.rumbos.net/cancionero/

VV.AA. Ley General de Educación y disposiciones complementarias. Textos legales del Ministerio de Educación y Ciencia

VV.AA. SINDICATO ESPAÑOL DEL MAGISTERIO (1939). Hacia una educación nacional. Salamanca

VEGA GIL, L (1989) Aproximación a la enseñanza secundaria durante el franquismo (1938-1967), en Revista Historia de la educación, № 8. Salamanca

VILA, I.(1998) Familia, escuela y comunidad. Barcelona: ICE

VYGOTSKI, L.S. (1979) El desarrollo de los procesos psicológicos superiores. Barcelona: Crítica

WALKER, J.C. y EVERS, C.W. (1988) The espistemological unity of educational research. En J.P. KEEVES (Ed, Educational Resarch, Methodology and Measurement: An Internacional Handbook (pp 28-36). Oxford:Pergamon

WHITE, H. G (1964). The professional role and status of the school music techer in American society. Tesis doctoral , Universidad de Kansas: Lawrence 



\section{INDICE}

La educación musical en el franquismo................................................................... 1

CAPÍTULO 1. INTRODUCCIÓN.......................................................................... 3

1.1 PRESENTACIÓN DEL TEMA ……………………………………………..... 3

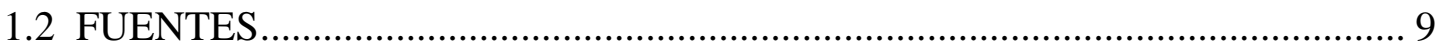

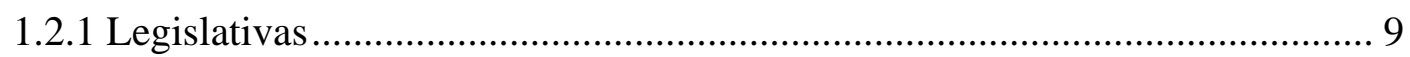

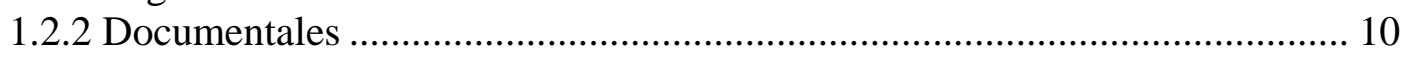

1.2.3 Publicaciones ...................................................................................... 12

1.2.4 Entrevistas y testimonios personales ............................................................. 15

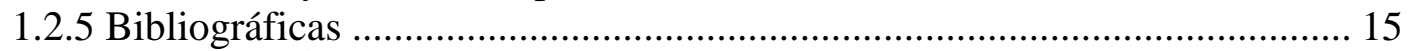

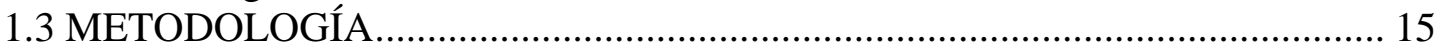

1.3.1 Bibliografía inicial................................................................................ 15

1.3.2 Herramientas metodológicas .................................................................... 18

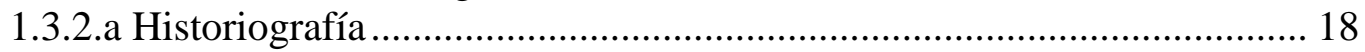

1.3.2.b Legales............................................................................................... 21

1.3.2.c Recensión, búsqueda y selección de documentación original de Falange

1.3.2.d El análisis musical del repertorio

1.3.2.e Percepción de la educación musical en la sociedad....................................... 22

1.4 ESTADO DE LA CUESTIÓN ………………………………………………..... 23

1.4.1 La investigación en educación musical .......................................................... 23

1.4.2 La formación de los músicos...................................................................... 26

1.4.3 La formación de los maestros....................................................................... 27

1.4.4 Sección Femenina y Frente de Juventudes ..................................................... 28

1.4.5 La educación no formal ............................................................................ 29

1.4.6 Conclusiones sobre el estado de la cuestión............................................... 32

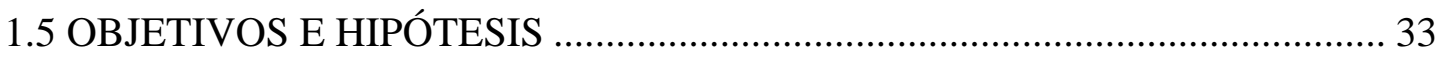

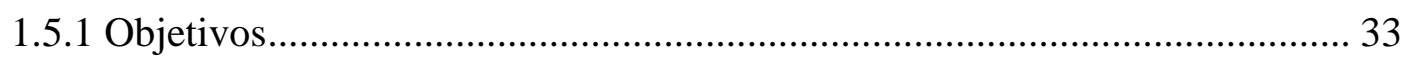

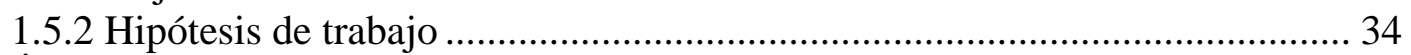

CAPÍTULO 2. EL MARCO LEGAL ....................................................................... 37

2.1 LOS CONSERVATORIOS............................................................................ 37

2.1.1 ¿Por qué hablar de los Conservatorios?........................................................... 37

2.1.2 Las leyes que afectan a los Conservatorios .................................................... 38

2.1.2.a Decreto de 15 de junio de 1942 ............................................................ 39

2.1.2.b Decreto de 10 de septiembre de 1966.................................................... 43

2.2 LAS LEYES DE EDUCACIÓN .................................................................... 47

2.2.1 La educación musical en las escuelas primarias............................................... 48

2.2.1.a. Hasta la ley de Educación Primaria de 1945 .......................................... 49

2.2.1.b. Ley de Educación Primaria. 17 de junio de 1945 (BOE 18 de julio).... 53

2.2.1.c. Ley General de Educación y financiamiento de la Reforma Educativa de

4 de agosto de 1970 (BOE 6 de agosto). ........................................................... 62

2.2.2 La educación no formal .............................................................................. 69

2.2.2.a La ley de Educación Primaria de 1945 y la educación no formal ........... 70

2.3 ESQUEMA RESUMEN DE LA LEGISLACIÓN SOBRE LA EDUCACIÓN MUSICAL DURANTE EL FRANQUISMO (1939-1975)....................................... 72

CAPÍTULO 3. LA FORMACIÓN MUSICAL DE LOS MAESTROS ..................... 75

3.1 LA FORMACIÓN EN LAS ESCUELAS NORMALES....................................... 75 
3.1.1 El marco legal de la formación de los maestros .......................................... 75

3.1.2 ¿Cuáles eran los contenidos musicales de la formación de los maestros? .... 81

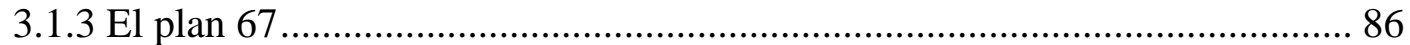

3.2 LA FORMACIÓN EN LAS ESCUELAS UNIVERSITARIAS DE

FORMACIÓN DEL PROFESORADO …............................................................. 91

3.3 EL PROFESORADO DE MÚSICA DE LAS ESCUELAS DE MAGISTERIO Y

ESCUELAS UNIVERSITARIAS DE FORMACIÓN DEL PROFESORADO ......... 94

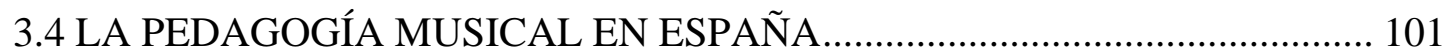

3.4.1 La pedagogía musical en España hasta los años 60 .................................. 102

3.4.2 La introducción de los métodos de pedagogía musical a partir de 1960 ..... 107

3.4.3 La pedagogía musical en España después de 1960 ................................... 113

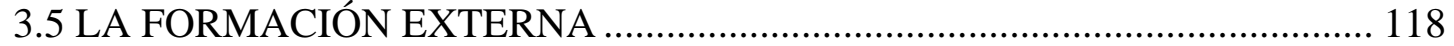

CAPÍTULO 4. MÚSICA E IDEOLOGÍA 1. EL FRENTE DE JUVENTUDES.. 125

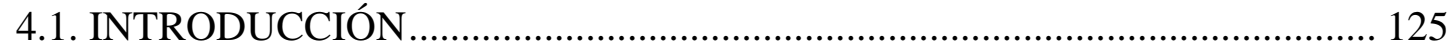

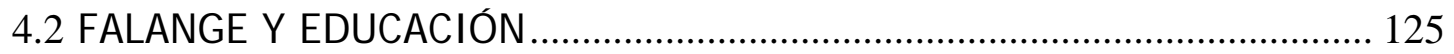

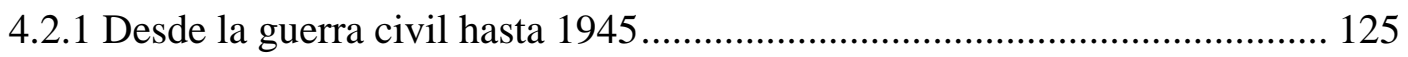

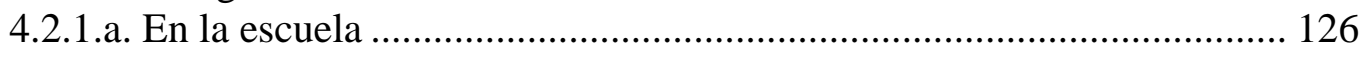

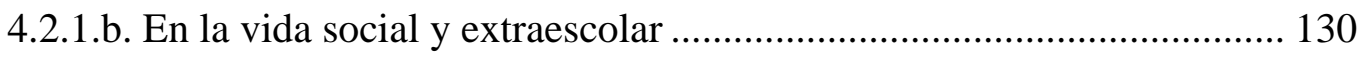

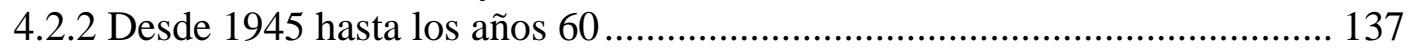

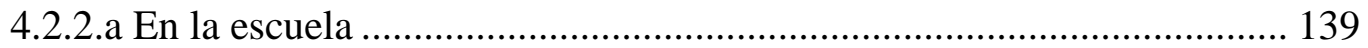

4.2.2.b En la vida social y extraescolar ........................................................ 140

4.2.2.c La separación de Sección Femenina y Frente de Juventudes ................ 141

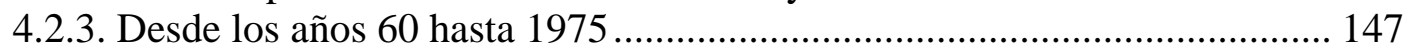

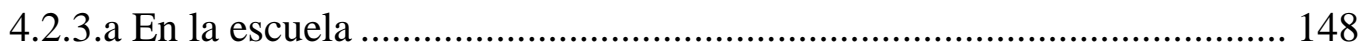

4.2.3.b En la vida social y extraescolar ........................................................ 152

4.3 FRENTE DE JUVENTUDES Y LA MÚSICA Frente de Juventudes y la música

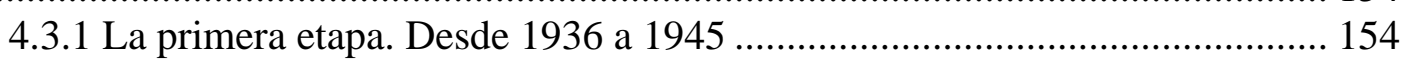

4.3.1.a La visión propagandística y premilitar de la sociedad civil.................. 154

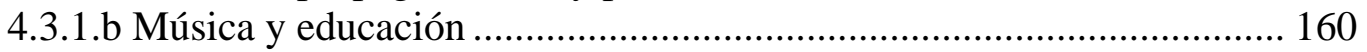

4.3.1.c El repertorio ........................................................................................... 165

4.3.1.d Algunas reflexiones sobre las canciones de la primera época.............. 187

4.3.2 La segunda etapa. Desde 1945 hasta 1960 ................................................ 192

4.3.2.a Los cursos para maestros y el espíritu de campamento .......................... 193

4.3.2.b Las escuelas del Patronato del Frente de Juventudes .......................... 197

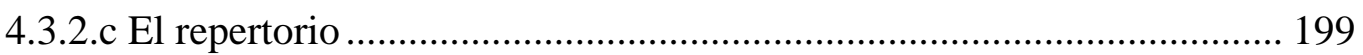

4.3.2.d Algunas reflexiones sobre esta etapa 1945-1960 ................................ 205

4.3.3 La tercera etapa. Desde 1960 ................................................................ 213

4.3.3.a Los cursos para la formación de maestros .......................................... 215

4.3.3.b La música y las juventudes de la OJE .............................................. 233

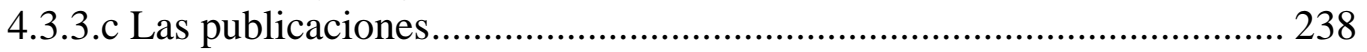

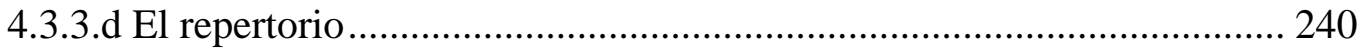

4.3.3.e Otras actividades............................................................................ 243

4.4.3.f. La colaboración entre Frente de Juventudes y Sección Femenina....... 247

CAPÍTULO 5. MÚSICA E IDEOLOGÍA 2.: LA SECCIÓN FEMENINA........... 251

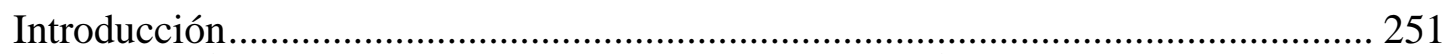

5.1 SECCIÓN FEMENINA Y SU CONTEXTO HISTÓRICO................................ 255

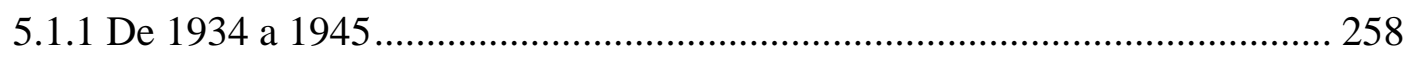

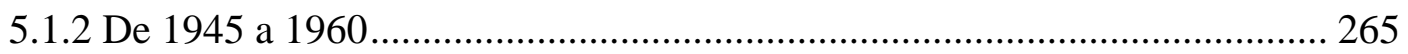

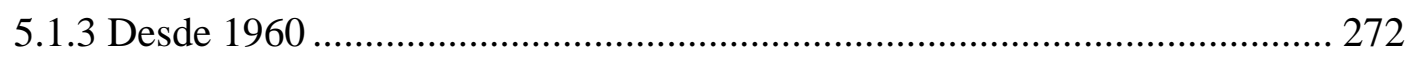


5.2.LA ESCTRUCTURA DE LA SECCIÓN FEMENINA .................................. 276

5.2.1 Organigrama de los órganos centrales de la Sección Femenina................... 276

5.3.2. Estructura de la Regiduría Central de Cultura de la Sección Femenina en su

relación con la música .......................................................................................... 282

5.2.3Funcionamiento interno de la Sección Femenina.......................................... 294

5.3.NORMATIVA DE MÚSICA DE LA REGIDURÍA CENTRAL DE CULTURA

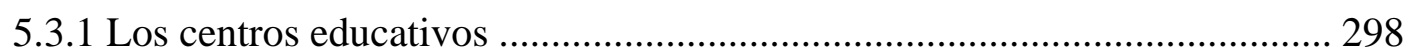

5.3.1.a Normativa para los Institutos de Bachillerato..................................... 299

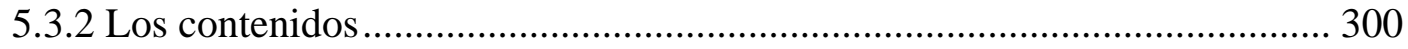

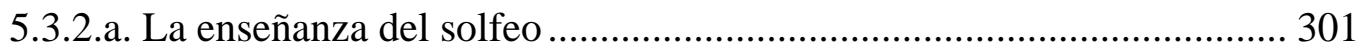

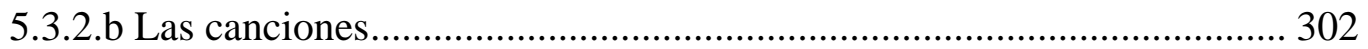

5.3.2.c Conferencias musicales e historia de la música.................................. 304

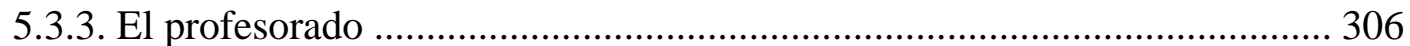

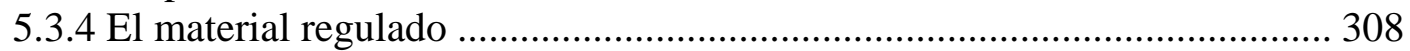

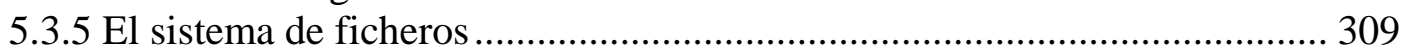

5.4 LA EDUCACIÓN MUSICAL NO FORMAL ................................................. 313

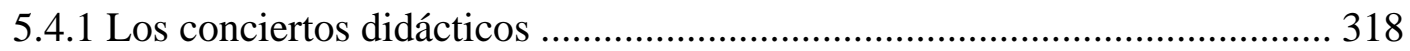

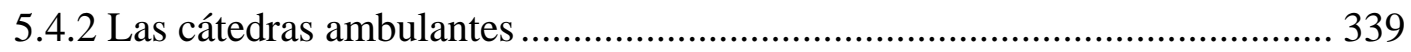

5.4.3 La formación interna de las afiliadas: el Servicio social y los Círculos Medina

348

5.5 LA FORMACIÓN DEL PROFESORADO ESPECIALIZADO DEMÚSICA . 364

5.5.1 El primer intento de creación de la Escuela nacional de Pedagogía musical

5.5.2 La Escuela nacional de música “Roger de Lauria” ................................... 374

5.5.3 La formación a través de cursos especializados de pedagogía musical ...... 398

5.6 EL PROFESORADO DE MÚSICA VINCULADO A LA SECCIÓN

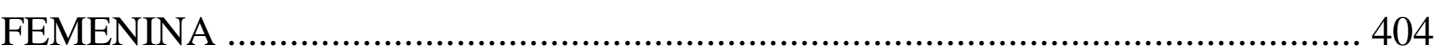

CAPÍTULO 6. ANÁLISIS MUSICAL DEL CANCIONERO ............................... 413

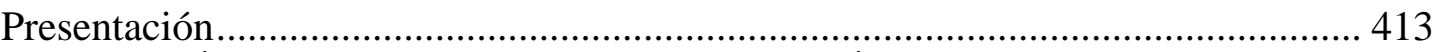

6.1 EL ANÁLISIS MUSICAL: LA ELABORACIÓN DE LAS FICHAS ............... 413

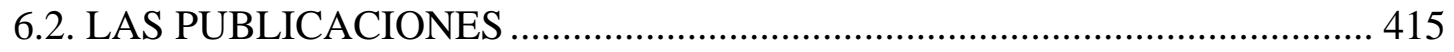

6.2.1. Las publicaciones de Sección Femenina ..................................................... 415

6.2.1.a Cancionero de Sección Femenina.................................................... 417

6.2.1.b Mil canciones españolas ..................................................................... 424

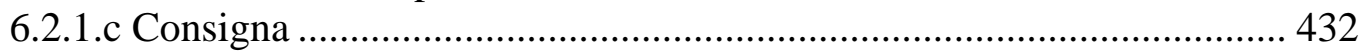

6.2.1.d Canciones populares para escolares ................................................. 447

6.2.1.e Música: Teoría del solfeo y canciones................................................. 449

6.2.2. Las publicaciones del Frente de Juventudes........................................... 451

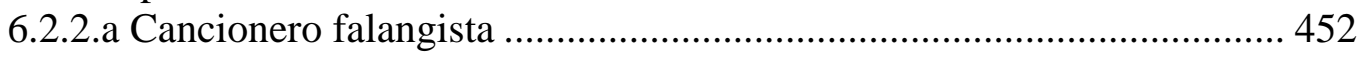

6.2.2.b El Frente de Juventudes en la escuela ................................................ 453

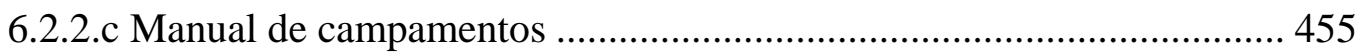

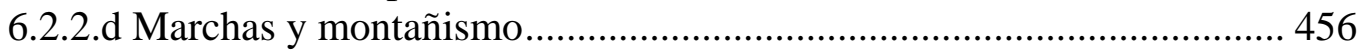

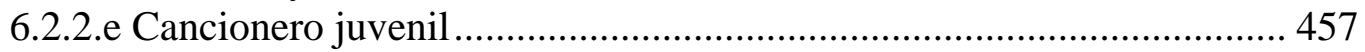

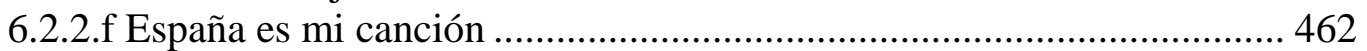

6.3 LA INTERPRETACIÓN DE LOS DATOS A TRAVÉS DE GRÁFICOS....... 465

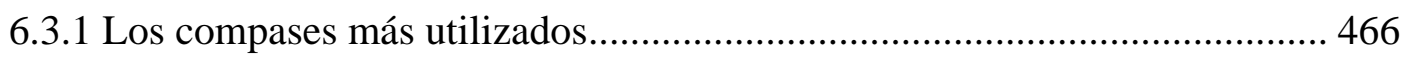

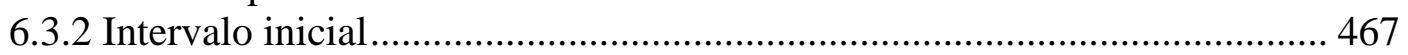

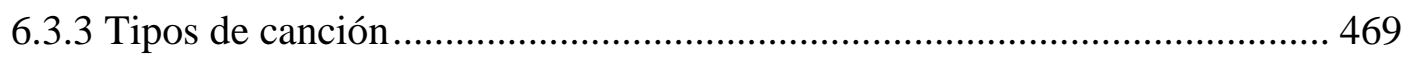

6.3.4 El idioma y el origen regional de las canciones ...................................... 472 
6.3.5 La importancia de las canciones

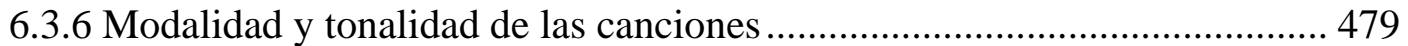

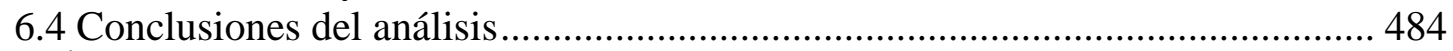

CAPÍTULO 7. CONCLUSIONES ......................................................................... 485

7.1 Existió una educación musical organizada en los niveles educativos durante el

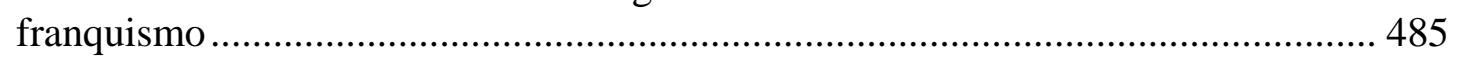

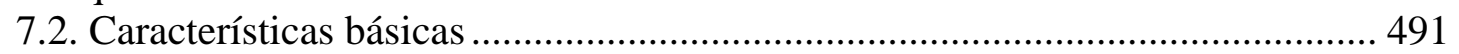

7.2.1. La diferencia de género. ....................................................................... 491

7.2.2. La educación musical dentro de la educación formal y no formal............. 493

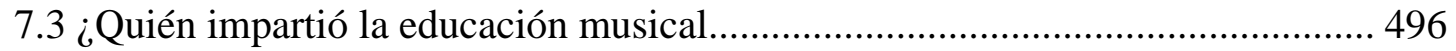

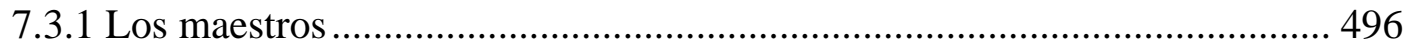

7.3.2 Los instructores del Frente de Juventudes.................................................. 498

7.3.3 Las profesoras de música de Sección Femenina ...................................... 499

7.4 Con qué material: las canciones y su análisis.................................................... 501

7.5. Nuevas hipótesis sobre las consecuencias de la educación musical recibidas

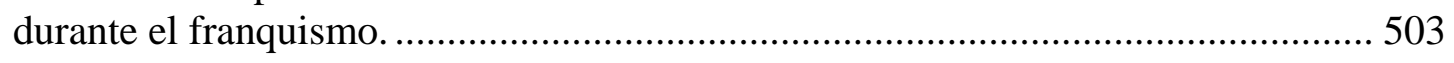

7.6 Propuestas de reflexión para el futuro ......................................................... 511

CAPÍTULO 8. REFERENCIAS BIBLIOGRÁFICAS CITADAS ......................... 515

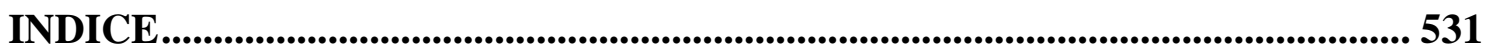

